Universidad deValladolid

PROGRAMA DE DOCTORADO EN INVESTIGACIÓN

TRANSDISCIPLINAR EN EDUCACIÓN

TESIS DOCTORAL:

\title{
LAS DIMENSIONES EMOCIONAL Y CREATIVA EN LA EDUCACIÓN PATRIMONIAL DESDE EL ÁMBITO DE LAS CCSS. EVALUACIÓN DE PROGRAMAS
}

Presentada por Carlos Munilla Garrido para optar al grado de Doctor por la Universidad de Valladolid

Dirigida por:

Olaia Fontal Merillas

Sofía Marín-Cepeda

Cosme J. Gómez Carrasco 


\section{Agradecimientos:}

A mis padres, por su ejemplo.

A mis hijos, por su paciencia en mis ausencias.

A Laura, por ofrecerme tiempo.

A mi hermano y a María José, por su ayuda incondicional.

A Santiago Martínez, por rescatarme para el mundo de la cultura y por su amistad.

A Olaia Fontal, Sofía Marín-Cepeda y Cosme Gómez, por acompañarme por el desierto y proporcionarme una salida. 
Índice

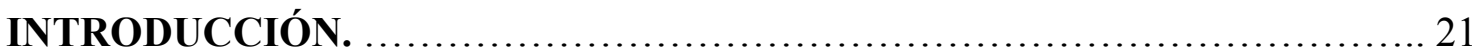

\section{CUERPO TEÓRICO}

CAPÍTULO 1. RELACIONES ENTRE PATRIMONIO Y EMOCIÓN. 29

1.1. La perspectiva internacional. 29

1.1.1. La Organización de las Naciones Unidas para la Educación, la Ciencia y la Cultura. ................................................................... 29

1.1.2 El Consejo de Europa. .................................................... 32

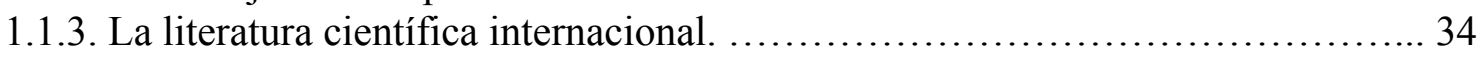

1.1.4. Programas de referencia internacional. .................................. 38

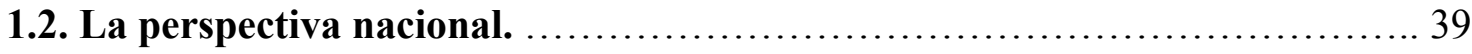

1.2.1 La legislación vigente en materia de Patrimonio. ............................... 39

1.2.2. El Instituto del Patrimonio Cultural de España y los Planes Nacionales. ......... 42

1.2.2.1. El Plan Nacional de Educación y Patrimonio. ............................... 44

1.2.2.2. El Plan Nacional para la Salvaguarda del Patrimonio Cultural Inmaterial. ... 45

1.2.3. La literatura científica nacional. ....................................... 46

CAPÍTULO 2. RELACIONES ENTRE PATRIMONIO Y CREATIVIDAD. .... 57

2.1. La perspectiva internacional. ..................................... 57

2.1.1. La Organización de las Naciones Unidas para la Educación, la Ciencia y la Cultura. .................................................................... 57

2.1.2. El Consejo de Europa. ................................................ 67

2.1.3. La literatura científica internacional. .................................... 72

2.1.4. Referentes internacionales. .......................................... 75

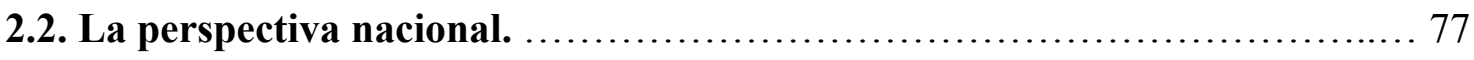

2.2.1. La legislación vigente en materia de Patrimonio. ......................... 77

2.2.2. El Instituto de Patrimonio Cultural de España y los Planes Nacionales. .......... 82

2.2.2.1. El Plan Nacional de Educación y Patrimonio. .............................. 82

2.2.2.2. El Plan Nacional para la salvaguarda del Patrimonio Cultural Inmaterial. ..... 83

2.2.3. La literatura científica nacional. ........................................ 84

CAPÍTULO 3. EMOCIONES Y CREATIVIDAD EN LA EDUCACIÓN PATRIMONIAL. ...................................................... 93

3.1. Las dimensiones emocional y creativa bajo la mirada de la educación patrimonial.

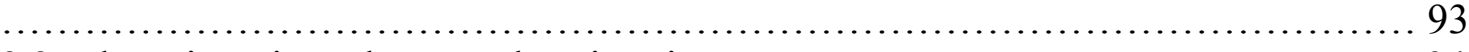

3.2. El patrimonio en la etapa de Primaria. ................................... 94 
3.3. El desarrollo emocional en la etapa de Primaria. ............................... 98

3.4. La creatividad en la etapa de Primaria. ................................... 101

3.5.El patrimonio, las emociones y la creatividad en la formación del profesorado de

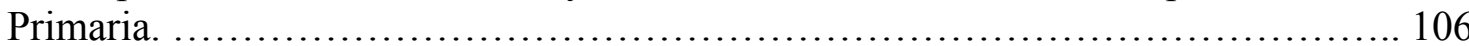

\section{CUERPO EMPÍRICO}

CAPÍTULO 4. DESCRIPCIÓN METODOLÓGICA. .......................... 119

4.1. Problema de investigación e hipótesis de partida. ............................ 119

4.2. Objetivos de la investigación. ............................................ 120

4.3. Fases de la investigación. ............................................ 120

4.4. Justificación de la elección y relevancia temática. ........................... 120

4.5. Diseño y enfoque de la investigación. ................................... 122

4.6. Participantes. ............................................................. 123

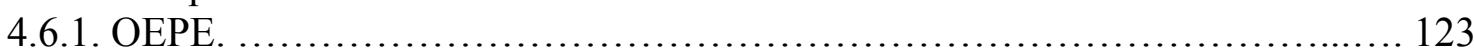

4.6.2. Base de datos OEPE. .................................................. 124

4.6.3. Variables. ............................................................... 125

4.6.4. Población y muestra. ................................................. 130

4.7. Instrumentos de recogida de información. ................................. 144

4.7.1. SAEPE-OEPE. ..................................................... 144

4.7.2. Q-Edutage. ............................................................ 146

4.8. Procedimiento y análisis de datos. ........................................ 147

CAPÍTULO 5. DESCRIPCIÓN Y ANÁLISIS DE DATOS. .................... 152

5.1. Análisis estadísticos descriptivos de variables sociodemográficas. ............... 153

5.2. Análisis estadísticos descriptivos de variables de resultado. ................... 157

5.3. Análisis de correlaciones. ................................................... 159

5.4. Análisis inferencial (ANOVA). ........................................ 160

\section{CUERPO CONCLUSIVO}

CAPÍTULO 6. CONCLUSIONES. ........................................... 229

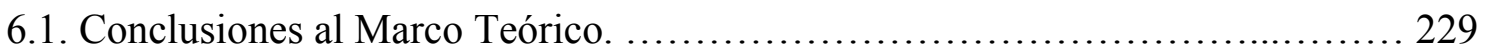

6.1.1. Patrimonio y emociones. ............................................ 229

6.1.2. Patrimonio y creatividad. ............................................ 232

6.1.3. Patrimonio, emociones y creatividad en la etapa de Primaria. ................ 236

6.2. Discusión y conclusiones al Marco Empírico................................... 237

6.2.1. Conclusiones del análisis descriptivo de variables y correlaciones. ............ 238

6.2.2. Conclusiones del análisis de varianza. ...................................... 240

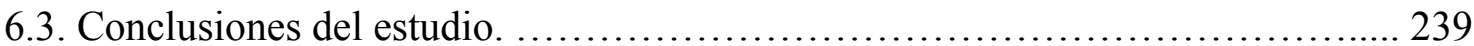

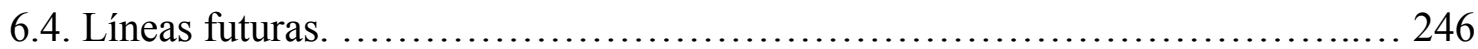

6.5. Limitaciones de la investigación. ....................................... 247

Bibliografía. ........................................................ 253 


\section{Índice de tablas}

Tabla 1. Referencias a Patrimonio y Emociones en los títulos de publicaciones en Wos y Scopus. ...................................................................... 34

Tabla 2. Menciones a las emociones en las Leyes Autonómicas. ...................... 39

Tabla 3. Referencias a Patrimonio y creatividad en títulos de publicaciones. ........... 73

Tabla 4. Menciones a la creatividad en las Leyes Autonómicas. ....................... 78

Tabla 5. Alusiones a Patrimonio, Emociones y Creatividad en la legislación vigente de

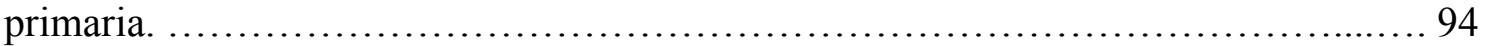

Tabla 6. Alusiones a Patrimonio en el R.D. 126/2014. Anexo 1. ....................... 94

Tabla 7. Alusiones a Patrimonio en el R.D. 126/2014. Anexo2. ....................... 95

Tabla 8. Alusiones a emociones en el R.D. 126/2014. Anexo1........................ 98

Tabla 9. Alusiones a emociones en el R.D. 126/2014. Anexo2. ....................... 99

Tabla 10. Alusiones a creatividad en el R.D. 126/2014. Anexo1. ..................... 102

Tabla 11. Alusiones a creatividad en el R.D. 126/2014. Anexo2. .................... 104

Tabla 12. Alusiones a Patrimonio, Emociones y Creatividad. ........................ 107

Tabla 13. Clasificación de las competencias creativas según los perfiles profesionales y

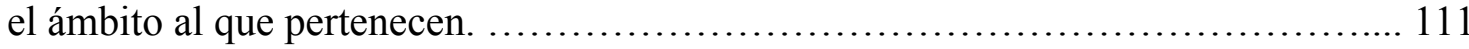

Tabla 14.Tabla de variables y subtipo de variables sociodemográficas. ............. 128

Tabla 15. Resultados de la búsqueda emocional. .............................. 131

Tabla 16. Resultados de la búsqueda creativa. ................................ 133

Tabla 17. Resultados de la búsqueda emocional y creativa. ....................... 143

Tabla 18. Frecuencias y porcentajes de cada tipo de entidad responsable. ............. 153

Tabla 19. Frecuencias y porcentajes de cada categoría de patrimonio. ............... 153

Tabla 20. Frecuencias y porcentajes de cada tipo de proyecto. ....................... 154

Tabla 21. Frecuencias y porcentajes del público al que se dirige. .................... 155

Tabla 22. Frecuencias y porcentajes del ámbito pedagógico. ........................ 156

Tabla 23. Frecuencias y porcentajes de los subtipos de la variable de Educación formal.

Tabla 24. Frecuencias y porcentajes totales de los subtipos de la variable de Educación formal que incluyen acciones en cada etapa de forma individual o asociados a otros. 157

Tabla 25. Estadísticos de variables de resultado. ................................ 157

Tabla 26. Matriz de correlaciones de Pearson. ....................................... 159

Tabla 27. Valores p de la tabla de correlación de Pearson. .......................... 159

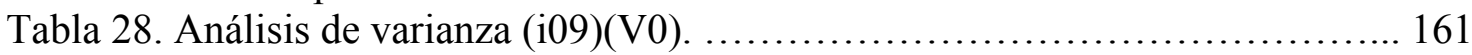

Tabla 29. Análisis de diferencias entre las categorías (i09) (V0). .................. 161

Tabla 30. Búsquedas / Tukey (HSD) / Análisis de las diferencias entre las categorías con un intervalo de confianza de 95\% (i09 obj)(V0). ........................... 161

Tabla 31. Análisis de varianza (i10)(V0). ..................................... 162

Tabla 32. Análisis de varianza (i11)(V0). .................................... 162

Tabla 33. Análisis de diferencias entre las categorías(V0). ..................... 163

Tabla 34. Búsquedas / Tukey (HSD) / Análisis de las diferencias entre las categorías con un intervalo de confianza de 95\% (i11 orienta)(V0). ......................... 163

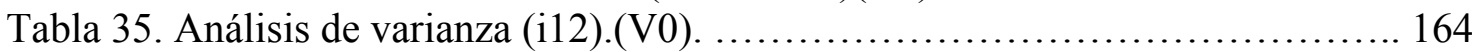

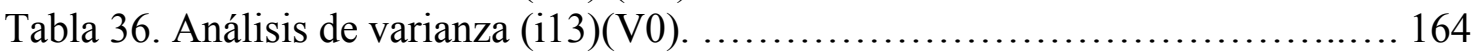

Tabla 37. Análisis de diferencias entre las categorías(V0). ....................... 164

Tabla 38. Búsquedas / Tukey (HSD) / Análisis de las diferencias entre las categorías con un intervalo de confianza de 95\% (i13 evaluación)(V0). ...................... 165

Tabla 39. Análisis de varianza (i14)(V0). ................................... 165 


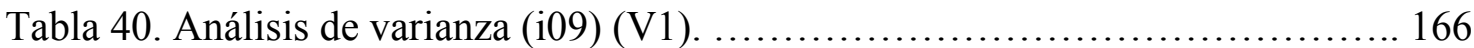

Tabla 41. Análisis de diferencias entre las categorías (V1). ........................ 166

Tabla 42. (Público- privado / Tukey (HSD) / Análisis de las diferencias entre las categorías con un intervalo de confianza de 95\% (i09 obj) (V1). .................... 166

Tabla 43. Análisis de varianza (i10) (V1) ........................................ 167

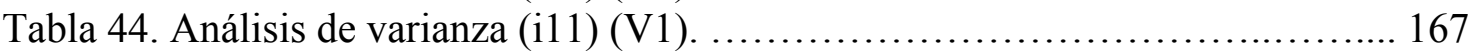

Tabla 45. Análisis de varianza (i12) (V1) ...................................... 168

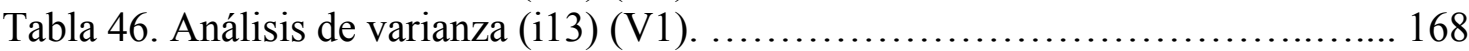

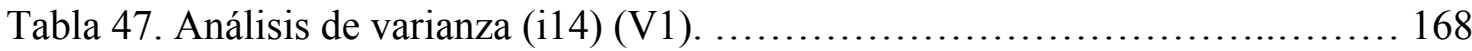

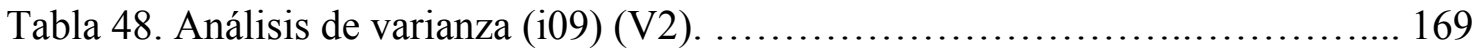

Tabla 49. Análisis de varianza (i10) (V2) . ................................. 170

Tabla 50. Análisis de varianza (i11) (V2) . .................................... 170

Tabla 51. Análisis de varianza (i12) (V2) . ................................... 170

Tabla 52. Análisis de varianza (i13) (V2). ...................................... 171

Tabla 53. Análisis de diferencias entre las categorías (V2) . ..................... 171

Tabla 54.Categoría de patrimonio / Tukey (HSD) / Análisis de las diferencias entre las

categorías con un intervalo de confianza de 95\% (i13 evaluación) (V2). ............. 171

Tabla 55. Análisis de varianza (i14) (V2) . ..................................... 174

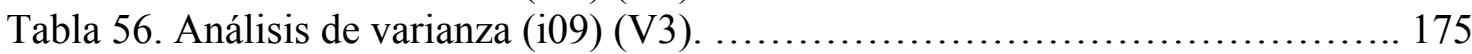

Tabla 57. Análisis de varianza (i10) (V3) . .................................. 175

Tabla 58. Análisis de diferencias entre las categorías. (V3). ...................... 175

Tabla 59. Tipo proyecto / Tukey (HSD) / Análisis de las diferencias entre las categorías con un intervalo de confianza de 95\% (i10 cont) (V3). ............................. 176

Tabla 60. Análisis de varianza (i11) (V3) ........................................... 179

Tabla 61. Análisis de varianza (i12) (V3) ..................................... 180

Tabla 62. Análisis de varianza (i13) (V3) . .................................... 180

Tabla 63. Análisis de varianza (i14) (V3) . .................................. 180

Tabla 64. Análisis de diferencias entre las categorías(V3) ........................ 181

Tabla 65. Tipo proyecto / Tukey (HSD) / Análisis de las diferencias entre las categorías con un intervalo de confianza de 95\% (i14 medición) (V3). ...................... 181

Tabla 66. Análisis de varianza (i09) (V4) ..................................... 185

Tabla 67. Análisis de diferencias entre las categorías (V4). ........................ 185

Tabla 68. Público al que se dirige / Tukey (HSD) / Análisis de las diferencias entre las categorías con un intervalo de confianza de 95\% (i09 obj) (V4). ..................... 186

Tabla 69. Análisis de varianza (i10) (V4) . ...................................... 188

Tabla 70. Análisis de diferencias entre las categorías (V4). ...................... 188

Tabla71.Público al que se dirige / Tukey (HSD) / Análisis de las diferencias entre las categorías con un intervalo de confianza de 95\% (i10 cont)(V4). .................. 189

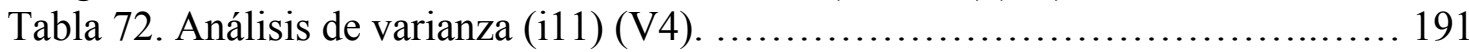

Tabla 73. Análisis de diferencias entre las categorías (V4). ....................... 191

Tabla 74.Público al que se dirige / Tukey (HSD) / Análisis de las diferencias entre las categorías con un intervalo de confianza de 95\% (i11 orienta) (V4). ................ 192

Tabla 75. Análisis de varianza (i12) (V4) . ..................................... 194

Tabla 76. Análisis de diferencias entre las categorías. (V4). ....................... 194

Tabla 77.Público al que se dirige / Tukey (HSD) / Análisis de las diferencias entre las categorías con un intervalo de confianza de 95\% (i12 recursos) (V4). ............... 194

Tabla 78. Análisis de varianza (i13) (V4). ........................................ 196

Tabla 79. Análisis de diferencias entre las categorías (V4) ....................... 197

Tabla 80.Público al que se dirige / Tukey (HSD) / Análisis de las diferencias entre las categorías con un intervalo de confianza de 95\% (i13 evaluación) (V4). ............. 197 


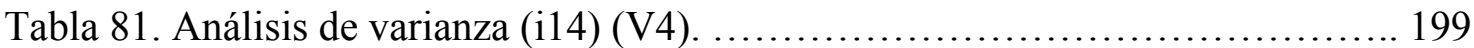

Tabla 82. Análisis de varianza (i09) (V5) ................................... 200

Tabla 83. Análisis de diferencias entre las categorías(V5). ...................... 200

Tabla 84. Ámbito pedagógico / Tukey (HSD) / Análisis de las diferencias entre las categorías con un intervalo de confianza de 95\% (i09 obj)(V5). .................... 201

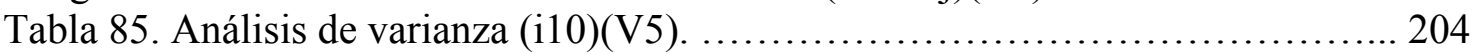

Tabla 86. Análisis de diferencias entre las categorías (V5) ...................... 205

Tabla 87.Ámbito pedagógico / Tukey (HSD) / Análisis de las diferencias entre las categorías con un intervalo de confianza de 95\% (i10 cont) (V5). ................. 205

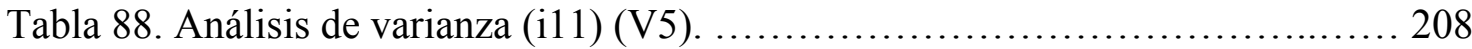

Tabla 89. Análisis de diferencias entre las categorías (V5). ....................... 209

Tabla 90.Ámbito pedagógico / Tukey (HSD) / Análisis de las diferencias entre las categorías con un intervalo de confianza de 95\% (i11 orienta) (V5). ................. 209

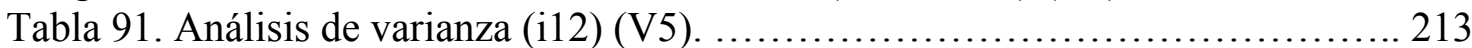

Tabla 92. Análisis de diferencias entre las categorías. (V5). ......................... 213

Tabla 93.Ámbito pedagógico / Tukey (HSD) / Análisis de las diferencias entre las categorías con un intervalo de confianza de 95\% (i12 recursos) (V5). ............... 214

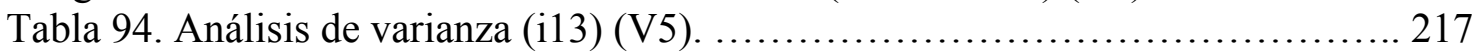

Tabla 95. Análisis de diferencias entre las categorías (V5). ...................... 218

Tabla 96.Ámbito pedagógico / Tukey (HSD) / Análisis de las diferencias entre las categorías con un intervalo de confianza de 95\% (i13 evaluación) (V5). ............. 218

Tabla 97. Análisis de varianza (i14) (V5) . ...................................... 221

Tabla 98. Resumen de significatividad ANOVA. .................................. 241

Tabla 99. Resumen de diferencias de medias entre categorías. ........................ 241 


\section{Índice de figuras}

Figura 1. Distribución de actividades del portal web. Fuente web OEP. ............ 124

Figura 2. Campos de búsqueda de la base de datos de OEPE. Fuente web OEPE. . . 124

Figura 3. Procedimiento secuencial de selección de programas. ................... 145

Figura 4. Tabla de estándares básicos. ...................................... 146

Figura 5. Tabla de estándares básicos. ..................................... 146

Figura 6. Box-plot de i01 contacto, i04 tipología e i05 bases. ...................... 158

Figura 7. Box-plot de i07anexos, i12 recursos e i13 evaluación. ..................... 158

Figura 8. Imágenes de la matriz de correlación y correlogramas. ................... 160

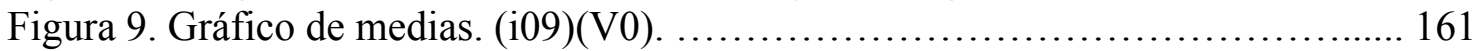

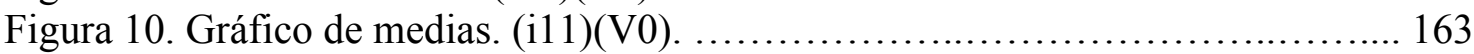





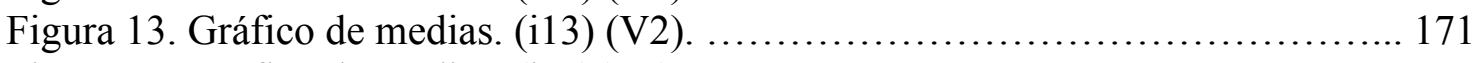

Figura 14. Gráfico de medias. (i10)(V3) . ................................... 175

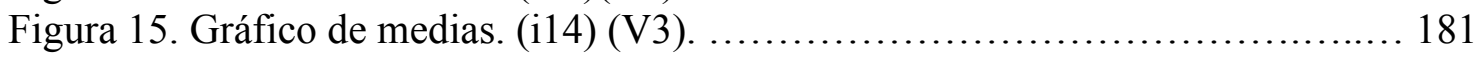

Figura 16. Gráfico de medias. (i09) (V4) . .................................... 185

Figura 17. Gráfico de medias. (i10)(V4) . .................................... 188

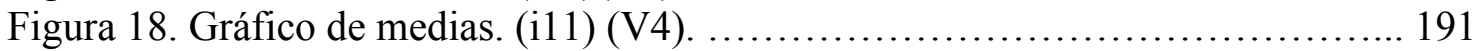

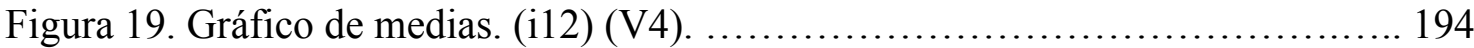

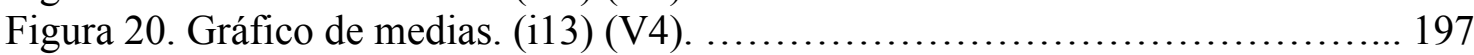

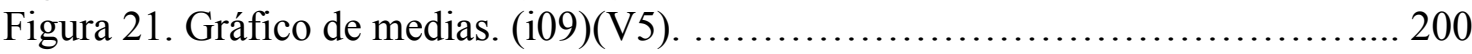

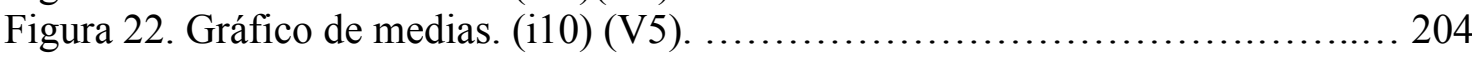

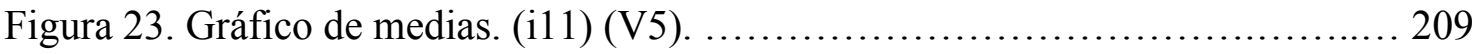

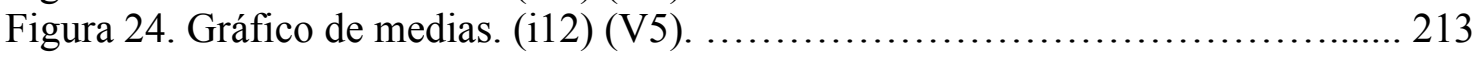

Figura 25. Gráfico de medias. (i13) (V5). ................................. 217 


\section{INTRODUCCIÓN}

La temática de esta tesis ha seguido un proceso de deriva lógico que zarpa del ámbito de la Historia y la Educación hasta atracar en el Patrimonio, las Emociones y la Creatividad. Un puerto dispar que ha sido construido a través de años de experiencia profesional en los campos educativos formal y no formal.

La idea que defendemos está basada en el convencimiento personal de que, uniendo los ejes de partida y los de arribo, se apareja el entramado básico de lo que puede conformar el desarrollo pleno, integral y humano de un niño, adolescente o incluso adulto, que accede al mundo social en el que vivimos. Se pretende que pueda afrontar ese reto con plenas garantías de contribuir a su mejora con arraigadas cualidades de pensamiento crítico, autonomía, sensibilidad, reflexión, paciencia, escucha, observación, creatividad, empatía, serenidad, trascendencia, respeto, intuición...y un profundo amor por la cultura, la ciencia y la naturaleza.

Debo reconocer que cuando comienza esta aventura, mi equipaje experiencial como docente e investigador era heterogéneo fruto de inquietudes muy diversas, aunque siempre circunscritas a la cultura. A lo largo de las reuniones de seguimiento del programa de doctorado, los profesores Fontal, Marín-Cepeda y Gómez me han ayudado a descubrir que todas las iniciativas desarrolladas a lo largo de mi vida profesional tenían un hilo conductor. Me han hecho ver que de forma natural y aún sin darme cuenta, había utilizado el patrimonio, la historia, la arqueología, la música o el arte, como vehículo educativo para ayudar a los alumnos a desarrollarse como personas plenas. A mediar en un conocimiento profundo de sí mismos, con capacidad para producir elementos nuevos, respetuosos con el pasado y el medio natural, en definitiva ciudadanos activos que buscan mejorar la sociedad.

Mi experiencia profesional en el quehacer educativo es la que me lleva a pensar que la belleza, la reflexión y creación, son elementos indispensables para conformar una personalidad sensible, empática e inquieta con la que afrontar los retos de la vida adulta. Por ello, esta tesis se fragua en trabajos de investigación-acción que la preceden así como estudios de Master y Fin de Grado centrados en esta misma temática.

Decía Fernando Savater (1996) que cuando una persona es culta menos dinero necesita para pasar un día feliz. En cambio cuanto menos cultura se posee, más derroche, más gasto, más pirotecnias, más ritos, por que no es fácil intentar amueblar el vacío. Según el autor, el interior de nuestra conciencia es tan infinito que, por más cosas que le echemos dentro, nunca se llena. Por ello, o bien vamos creando un fermento productivo, o si intentamos llenarlo de cosas exteriores, nunca será suficiente por que el pozo no tiene fondo.

De ahí esta búsqueda de la cultura como motor de la emoción y la creación tomadas como sustento ineludible de la historia de la humanidad.

Este trabajo analiza la presencia de Patrimonio, Emociones y Creatividad en los principales organismos nacionales e internacionales que trabajan con el patrimonio, así como en la documentación generada por ellos. De la misma forma se estudia la literatura científica y legislativa para conocer cual es a día de hoy la relación entre las tres variables señaladas.

Para ello realizamos un análisis del estado de la cuestión a escala internacional y nacional del tratamiento que se otorga a estas áreas de manera conjunta en dos organismos internacionales encargados de la definición y gestión del patrimonio, la Organización de las Naciones Unidas para la Educación, la Ciencia y la Cultura, y el Consejo de Europa. A nivel nacional exploraremos la legislación vigente en materia de 
patrimonio, tanto a nivel estatal como autonómico. La intención de ambas iniciativas es la de conocer qué referencias legislativas podrían sustentar nuestro objeto de estudio. En este sentido abordaremos también dentro de la ley educativa actual, el decreto de primaria con el objeto de buscar las posibles relaciones entre las alusiones existentes al patrimonio, con la creatividad o la emociones.

De la misma manera, y con el objeto de conocer que investigaciones se han realizado al respecto desde el ámbito científico, procederemos a una revisión de este tipo de publicaciones tanto a nivel nacional como internacional. Aplicamos para ello una metodología muy próxima a la desarrollada por Andre, Durksen y Volman (2016), quienes se apoyan en descriptores o indicadores clave para realizar un análisis comprensivo de la literatura científica.

Finalmente y con la intención de conocer como descansan todas las iniciativas anteriores en la práctica, accederemos a la base de datos del Observatorio de Educación Patrimonial de España (OEPE), para seleccionar aquellos programas de educación patrimonial que incluyen elementos emocionales y creativos, y evaluar la calidad de los mismos.

Así concretamos los objetivos generales y específicos de investigación de la siguiente manera:

- OG1: Establecer un estado de la cuestión en torno a la relación entre patrimonio, emociones y creatividad, a nivel legislativo y científico.

- OE1: Analizar la presencia de emociones y creatividad en la legislación patrimonial emanada de la UNESCO y el Consejo de Europa.

- OE2: Examinar las leyes de patrimonio estatales y autonómicas de España.

- OE3: Inspeccionar la ley educativa actual y el decreto de primaria.

- OE4: Explorar la literatura científica nacional e internacional al respecto.

- OG2: Analizar los programas patrimoniales inventariados en la base de datos de OEPE, para conocer la presencia de elementos emocionales y creativos dentro de ellos y valorar su calidad.

- OE1: Examinar los programas de educación patrimonial existentes en la base de datos de OEPE, para determinar cuales incluyen emociones y creatividad en sus propuestas.

- OE2: Analizar los programas de educación patrimonial inventariados en OEPE y que incluyen elementos emocionales y creativos.

- OE3: Evaluar los programas de educación patrimonial inventariados en la base de datos de OEPE que incluyen elementos emocionales.

- OE4: Evaluar los programas de educación patrimonial inventariados en la base de datos de OEPE que incluyen elementos creativos.

Se trata pues de una propuesta que persigue analizar la relación directa entre los ámbitos patrimonial, educativo, emocional y creativo. Para ello, comienza con una mirada a través de un zoom totalmente abierto, en un contexto macro a nivel internacional. Progresivamente va cerrando el objetivo, para terminar en un espacio micro, analizando propuestas concretas de trabajo a través de programas de educación patrimonial. 
CUERPO TEÓRICO 


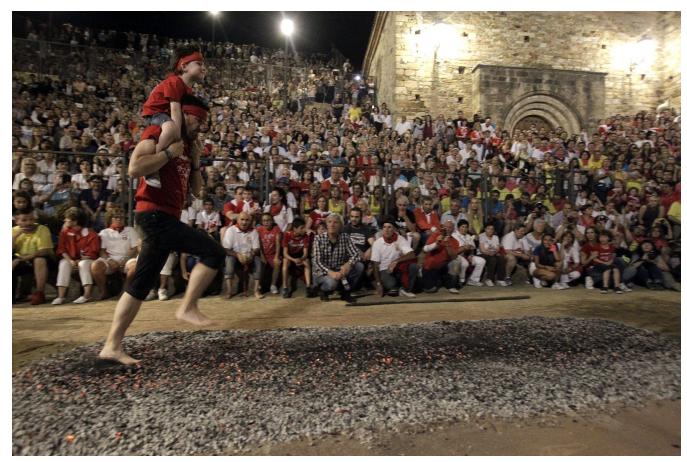

“...la competencia emocional está en función de las experiencias vitales que uno ha tenido...".

Rafael Visquerra






\section{CAPÍTULO 1. RELACIONES ENTRE PATRIMONIO Y EMOCIÓN.}

\subsection{La perspectiva internacional.}

A lo largo de este primer capítulo, vamos a analizar la relación entre el patrimonio y las emociones en el ámbito internacional desde la óptica educativa. Para ello, revisamos en primer lugar los espacios institucional y académico. Dentro del primero, atenderemos a la Organización de la Naciones Unidas para la Educación la Ciencia y la Cultura (UNESCO) y al Consejo de Europa. Posteriormente, revisaremos la literatura científica $\mathrm{y}$ finalmente, los que hemos considerado referentes internacionales por su grado de alcance e impacto.

\subsubsection{La Organización de las Naciones Unidas para la Educación, la Ciencia y la Cultura.}

Llevamos a cabo un análisis de las convenciones y tratados promulgados por la UNESCO en relación con el Patrimonio desde su fundación en 1945 hasta la actualidad. Partimos del descriptor de búsqueda "emociones", no obstante este análisis arroja un resultado no significativo, por lo que ampliamos los descriptores incorporando conceptos vinculados con lo emocional: "emoci" (emoción, emocionar, emocional...), y "sentim" (sentimiento, sentimental, etc.).

El primer hallazgo surge en la Conferencia General de la UNESCO ${ }^{1}$ del año 1956, en ella podemos encontrar la Recomendación que define los Principios Internacionales que deberían aplicarse a las excavaciones arqueológicas. En el apéndice 1, página 44 de la recomendación, se presenta como elemento más importante para la conservación del patrimonio, la estima que los pueblos puedan sentir por él. Para ello, se aboga por estimular sentimientos de afecto mediante acciones para el desarrollo de la ciencia y las relaciones internacionales de los estados miembros.

En el siguiente párrafo y dentro de la misma página, encontramos de nuevo una referencia a los sentimientos ligados al valor que la educación debe tener como medio para conocer los elementos patrimoniales para a través de ellos, facilitar la compresión entre los pueblos. Se hace hincapié en la contemplación y el conocimiento como puerta al espectro sentimental y emocional. Entendemos que por medio de una valoración de lo propio llegaremos a cultivar el respeto por lo ajeno o más lejano. Finalmente se aboga nuevamente por la colaboración internacional, para "la ejecución de la misión social" que corresponde a cada obra.

La palabra sentimiento aparece en alguna ocasión más dentro del apéndice 3 de educación, aparejada al sentimiento de solidaridad con la comunidad a la que se pertenece y a la educación, fundamentalmente en su aspecto moral (UNESCO, 1956).

En la Conferencia General de la $\mathrm{UNESCO}^{2}$, encontramos la Recomendación relativa a la Protección de la Belleza y del Carácter de los Lugares y Paisajes, donde se comprende la belleza como un motor de lo emocional, tanto en lo contemplativo como en lo creativo. Se enfoca fundamentalmente a la conservación y restauración del patrimonio material y natural, no obstante también encontramos líneas que abordan nuestro objeto de interés.

\footnotetext{
${ }^{1}$ Nueva Delhi (India) 5 de diciembre de 1956.

2 París (Francia) 9-12 de diciembre de 1962.
} 
Considerando que, por su belleza y carácter, la protección de paisajes y lugares definidos en la presente recomendación es necesaria para la vida del hombre, para el que son un poderoso regenerador físico, moral y espiritual y contribuyen a la vida artística y cultural de los pueblos como lo muestran muchos ejemplos universalmente conocidos (UNESCO, 1962, p.146).

En estas líneas podemos entrever la importancia de la belleza en el ámbito patrimonial más allá del valor estético de la misma, otorgándole un papel renovador en el interior de las personas que tiene relación con el objeto patrimonial a nivel moral y espiritual. Es decir, que otorga al patrimonio una función crucial para la integridad de las personas y su equilibrio anímico y psíquico.

En la Conferencia General de la UNESCO, la Ciencia y la Cultura (París, 19 de noviembre de 1968), podemos encontrar la Recomendación sobre Conservación de Bienes Culturales que la ejecución de Obras Públicas o Privadas.

Considerando que, en materia de preservación de bienes culturales, la garantía más segura está constituida por el respeto y vinculación que la propia población siente por estos bienes, y que los Estados Miembros pueden contribuir a fortalecer tales sentimientos por medio de medidas adecuadas. (UNESCO, 1968, p.148).

Esta recomendación en su página 148, apela directamente a la vinculación emocional con los elementos patrimoniales como la medida más eficaz para la preservación de los mismos, alentando a los estados miembros de la organización a fortalecer tales sentimientos mediante la adopción de las medidas adecuadas. Es una referencia que viene a reforzar la ya comentada del año 1956, aunque no encontramos en ninguna de las dos recomendaciones la concreción de esas "medidas adecuadas". Desde este trabajo, defendemos que la educación es la vía más adecuada para ello.

Se refrenda esta misma idea en la Convención, celebrada en París en 1970, para adoptar medidas que impidan la transferencia de propiedades ilícitas de Bienes Culturales, donde en su artículo 10, p.12, podemos leer que se alienta a esforzarse por medio de la educación, en crear y extender el aprecio por la valía de los bienes culturales.

En la Conferencia General de la UNESCO (Nairobi, de 26 de noviembre de 1976), encontramos la Recomendación relativa a la Salvaguarda de los Conjuntos Históricos o Tradicionales y su función en la vida contemporánea. Es aquí donde encontramos por primera vez el vocablo "emoción" ligado a estética.

Los conjuntos históricos y su medio, deberían ser protegidos activamente contra toda clase de deterioros, en especial los resultantes de un uso inapropiado, aditamentos parásitos y transformaciones abusivas $\mathrm{o}$ desprovistas de sensibilidad, que dañan su autenticidad, así como los provocados por cualquier forma de contaminación. Todas las obras de restauración que se emprendan, deberían basarse en principios científicos. Asimismo, debería prestarse especial atención a la armonía y a la emoción estética resultantes del encadenamiento o de los contrastes de los diferentes elementos que componen los conjuntos y que dan a cada uno de ellos, su carácter particular (UNESCO, 1976, p.142). 
Como podemos comprobar, ambas palabras son utilizadas formando un término único que unido a armonía, parece querer expresar la importancia que presentan los conjuntos históricos como generadores de sensaciones, debido a sus características envolventes. Esta particularidad unida a su habitual gran tamaño, puede provocar distintas emociones de manera más fácil. Por otro lado, se señala igualmente que la sucesión de elementos a observar y el contraste entre ellos, es una buena forma de acercarse al análisis estético de grandes conjuntos históricos. Asumimos esta afirmación y ampliamos la idea al análisis de varios objetos, independientemente del número de éstos. De esta forma, tanto la comparación como el contraste, son buenos aliados para el estudio de varios elementos.

En las actas de la Conferencia General de la UNESCO (París, 24 octubre al 28 de noviembre de 1978), encontramos, dentro de la Declaración sobre los Principios Fundamentales relativos a la contribución de los Medios de Comunicación de masas, al Fortalecimiento de la Paz y la Comprensión Internacional, a la promoción de los Derechos Humanos y la lucha contra el racismo, el apartheid y la incitación a la guerra, una referencia explícita a los sentimientos ligados a la identidad cultural, dentro del apartado de cultura y comunicación. Se invita al Director General a contribuir a que cada individuo y sociedad tomen conciencia de los valores particulares de la cultura del entorno que habitan, para de esta manera robustecer los sentimientos de valoración de la identidad cultural, entendiendo éstos como cruciales en el desarrollo social basado en el hombre (UNESCO, 1978).

Dentro de la Recomendación sobre la Salvaguarda y Protección de las imágenes en movimiento de la Conferencia General de la UNESCO de 1980, encontramos en uno de los principios rectores, una referencia a los sentimientos ligados al arte, la identidad cultural y el patrimonio espiritual. Se insta a los estados miembros a asegurar el acceso al arte de toda la población, mostrándose de acuerdo en que las disciplinas artísticas tienen la capacidad de manifestar las identidades culturales y espirituales de las distintas sociedades, favoreciendo la identidad de una comunidad humana (UNESCO, 1980).

Encontramos una referencia interesante en la Convención para la Salvaguarda del Patrimonio Inmaterial de la Conferencia General de la UNESCO en su 32 a reunión, celebrada en París del veintinueve de septiembre al diecisiete de octubre de 2003.

Se entiende por "patrimonio cultural inmaterial" los usos, representaciones, expresiones, conocimientos y técnicas, junto con los instrumentos, objetos, artefactos y espacios culturales que les son inherentes que las comunidades, los grupos y en algunos casos los individuos, reconozcan como parte integrante de su patrimonio cultural. Este patrimonio cultural inmaterial, que se transmite de generación en generación, es recreado constantemente por las comunidades y grupos en función de su entorno, su interacción con la naturaleza y su historia, infundiéndoles un sentimiento de identidad y continuidad $\mathrm{y}$ contribuyendo así, a promover el respeto de la diversidad cultural y la creatividad humana (UNESCO, 2003, p.2).

Se trata de una referencia de interés puesto que conecta emociones y creatividad. Más concretamente sentimientos y creatividad, se atribuye al sentimiento identitario la capacidad de promover la diversidad y por ende, la creatividad. Es una de las exiguas ocasiones a lo largo de la revisión emocional en que encontramos ambos términos de forma conjunta, con la intención de dotar a uno de ellos de la facultad de generar al otro. 
En la Recomendación sobre paisaje urbano de la Conferencia General del año 2011, encontramos también la palabra emoción relacionada con la importancia de la paz para el desarrollo de la sensación de pertenencia al plano local y mundial. Es una referencia con poca relevancia para nuestra temática, y se convierte en la última de las alusiones que hallamos en la revisión de la documentación patrimonial de la Organización de las Naciones Unidas.

Tras el análisis documental, vemos que la relevancia que se da a los sentimientos dentro de los más de treinta textos normativos relacionados con el patrimonio y publicados por la UNESCO desde 1948, no es muy extensa. Se alude a ellos en pocas ocasiones teniendo en cuenta el volumen de textos explorados, y solamente de forma ocasional, se aborda su valor para la formación personal.

\subsubsection{El Consejo de Europa.}

Analizamos a continuación los mismos parámetros señalados en el anterior apartado anterior, ahora en la escala continental. Para ello acudimos a EUR-Lex, un servicio de publicación en línea de la Unión Europea (UE) dotado de motor de búsqueda que permite acceder a su diario oficial, legislación, acuerdos internacionales, jurisprudencia, etc. Dentro de esta herramienta se ofrece una síntesis de la legislación agrupada en 32 temas, correspondientes a los diferentes ámbitos de actividad de la UE, de los cuales revisaremos Cultura y Educación.

En Cultura, creemos conveniente empezar por revisar el Tratado de Funcionamiento de la Unión Europea, que es el marco de referencia para las políticas culturales y programas de cultura que se desarrollan a día de hoy. En el Título XIII, artículo 167, se especifica el papel de la UE en el ámbito de la cultura, que consiste en completar, ayudar o coordinar las acciones de los países miembros, dando visibilidad al patrimonio cultural común de Europa. No obstante, este documento no presenta referencias emocionales directas.

Dentro de las políticas culturales revisamos los cuatro textos existentes: las conclusiones del Consejo sobre la promoción de la cultura y las relaciones internacionales de la Unión Europea, el reglamento relativo a la exportación de bienes culturales, las conclusiones del Consejo sobre el papel de la cultura en la cooperación para el desarrollo de la Unión Europea, y la comunicación al Parlamento y al Consejo hacia una estrategia de la Unión Europea para las relaciones culturales internacionales. Ninguno de ellos presenta tampoco alusiones a emociones o sentimientos.

Para encontrar las primeras referencias a nuestros conceptos de búsqueda, debemos ahondar en el apartado de programas culturales, que consta de siete iniciativas relativas a planteamientos locales centrados en las personas, capitales europeas de la cultura, planes de trabajo culturales, innovación, programa Europa Creativa, Europeana y el Sello de Patrimonio Europeo.

Dentro de ellos encontramos únicamente referencias a la potenciación de sentimientos de pertenencia a un espacio cultural común dentro de la diversidad, en tres de los documentos analizados y hasta en dos ocasiones, en las páginas 2 y 3 , en la Decisión relativa a las capitales europeas de la cultura de los años 2020 al 2033. Localizamos esta misma referencia, en términos similares en la página 23 del Reglamento por el que se establece el Programa Europa Creativa. Lo mismo sucede con la Decisión relativa al Sello de Patrimonio Europeo, aunque en esta ocasión encontramos en 4 referencias la palabra sentimiento haciendo especial hincapié en los jóvenes y el desarrollo económico.

Como vemos se trata de un resultado no significativo para nuestro objeto de estudio, ya que no se toman en cuenta las emociones desde el punto de vista de la investigación. 
Las referencias enumeradas están circunscritas al estímulo de los sentimientos hacia una cultura común europea y la valía de esas emociones para un crecimiento financiero.

Continuamos nuestro análisis documental examinando aquellos instrumentos legislativos relativos al ámbito educativo. Para ello, dado que los documentos a analizar no centran su temática en torno al patrimonio, cruzaremos las búsquedas relativas a emociones con las de patrimonio.

Tomamos como referencia el Tratado de Funcionamiento de la Unión Europea en sus artículos 165 y 166, donde se establece el papel de la educación, la formación y la política orientada hacia los jóvenes y el deporte como elementos imprescindibles para el crecimiento, el empleo, la cualificación y cohesión de la ciudadanía.

Comenzamos con el análisis del documento relativo al Espacio Europeo de Educación para 2015, localizado en la Comunicación para reforzar la identidad europea mediante la educación y la cultura. No localizamos ninguna referencia a las emociones en él, solamente algún testimonio sobre sentimientos, aunque en todo momento ligados al espíritu de pertenencia a la UE, tal y como anticipa el título de la comunicación. Sí localizamos varias referencias al patrimonio como motor para ese sentimiento de pertenencia a la Unión.

En la Recomendación sobre las competencias clave en el aprendizaje permanente, dentro de la definición de conciencia y expresiones culturales, podemos leer una alusión directa a las emociones y la utilidad de distintas artes para expresar éstas, siempre desde el punto de vista del artista y no tanto del observador. Así mismo, localizamos también referencias a la apreciación de la importancia de la expresión creativa de ideas, las experiencias y emociones a través de distintos medios, incluida la música, las artes escénicas, la literatura y las artes plásticas (Unión Europea, 2006).

Al hablar de competencias clave encontramos referencias a sentimientos y creatividad como competencias transversales a las 8 claves. Las competencias clave se consideran igualmente importantes, ya que cada una de ellas puede contribuir al éxito en la sociedad del conocimiento. Muchas de las competencias se solapan y entrelazan. Determinados aspectos esenciales en un ámbito, apoyan la competencia en otro. La competencia en las capacidades básicas fundamentales de la lengua, la lectura y la escritura, el cálculo y las tecnologías de la información y la comunicación (TIC), constituyen el fundamento esencial para el aprendizaje, mientras que todas las actividades de aprendizaje se sustentan en la capacidad de aprender a aprender. Hay una serie de temas que se aplican a lo largo del marco de referencia y que intervienen en las 8 competencias clave: el pensamiento crítico, la creatividad, la capacidad de iniciativa, la resolución de problemas, la evaluación del riesgo, la toma de decisiones y la gestión constructiva de los sentimientos (Unión Europea, 2006).

En este mismo documento y en la primera página, hallamos una referencia al patrimonio y la educación, donde se señala a esta última como elemento esencial para mantener y renovar el patrimonio. En las conclusiones sobre el fomento de la creatividad y la innovación en la educación y formación, descubrimos una referencia a la gestión constructiva de los sentimientos a través de las competencias clave, se abre una puerta a la utilidad del trabajo emocional de forma transversal a las competencias.

Finalmente en el anexo, página tres punto cuatro, de antecedentes políticos de las Conclusiones del Consejo y de los Representantes de los Estados miembros, reunidos en el seno del Consejo, de 22 de mayo de 2008, sobre el fomento de la creatividad y la innovación en la educación y la formación se plasma de nuevo literalmente, el párrafo sobre los temas que intervienen en las competencias y que acabamos de nombrar en la recomendación del año 2006. 
Como ya hemos mencionado anteriormente, la revisión legislativa europea del ámbito cultural arroja escasas referencias con relevancia para nuestros intereses de investigación. En cambio y pese al bajo número de referencias directas, entendemos que adquiere algo más de importancia en la revisión de origen educativo, donde se señala al patrimonio como esencial en la educación; a la gestión emocional como transversal en el proceso de adquisición de competencias; y a las artes como medio de expresión emocional. No obstante entendemos que todas las alusiones son muy generales como para generar propósitos concretos que contengan nuestros ámbitos objeto de estudio.

\subsubsection{La literatura científica internacional.}

Una vez analizadas las instituciones anteriores, acudimos a la literatura científica y realizamos una búsqueda en la escala internacional, a través de la Web of Science (WOS) y Scopus, en los idiomas inglés, francés, portugués y español (Tabla 1), cruzando los descriptores de búsqueda "patrimonio" y "emociones", en el campo de búsqueda relativo al título de las publicaciones.

Tabla 1. Referencias a Patrimonio y Emociones en los títulos de publicaciones en Wos y Scopus.

\begin{tabular}{|c|c|c|}
\hline IDIOMAS & WOS & SCOPUS \\
\hline Inglés & 29 & 39 \\
\hline Francés & 0 & 1 \\
\hline Portugués & 0 & 0 \\
\hline Castellano & 2 & 2 \\
\hline
\end{tabular}

Fuente: Propia

Las búsquedas en inglés en WOS y en Scopus, nos arrojan los mismos resultados para "heritage and feelings" con un total de 7 publicaciones que tienen en cuenta estos términos en sus títulos: "Feeling Half-Half? Exploring Relational Variation of TurkishHeritage Young Adults' Cultural Identity Compatibility and Conflict in Austria" (Vietze, Juang, Schachner, y Werneck, 2018), "Transgressive touch: Ruination, public feeling, and the sunday times heritage Project" (Jethro, 2017), "Affect, heritage, feeling" (Crouch, 2015), "The Effects of Language Brokering Frequency and Feelings on Mexican-Heritage Youth's Mental Health and Risky Behaviors" (Kam, 2011) y "How is the national past imagined? National sentimentality, true feeling and the "heritage film", 1980-1995" (Eley, 2008).

Profundizando en los trabajos localizados, descubrimos que los cinco artículos referidos anteriormente no presentan un enfoque educativo. Todos ellos inciden principalmente en afectos y sentimientos personales o de arraigo comunitario que pueden despertar las diferentes manifestaciones culturales.

Por el contrario, los dos restantes resultan interesantes para el objeto de nuestra investigación, ya que ponen la mirada en la importancia de las emociones en la experiencia patrimonial. Es el caso de "Nostalgic feelings: motivation, positive and negative emotions, and authenticity at heritage sites" (Prayag y Del Chiappa, 2021) donde se argumenta desde un punto de vista turístico, que emociones como la nostalgia pueden predecirse antes de las experiencias patrimoniales como puedan ser visitas a lugares arqueológicos o museos, teniendo en cuenta la motivación previa de los visitantes. Todo ello, independientemente de la procedencia de las visitas, donde no influye la cercanía física al lugar o la nacionalidad de los usuarios. Se afirma que las emociones suscitadas son mayores cuando ese lugar forma parte del patrimonio del 
visitante por su fama o interés hacia él, y no por formar parte de su entorno. Esto hace que podamos prever de antemano las reacciones emocionales de los visitantes, lo que según el artículo, presenta importantes implicaciones para la gestión de los espacios patrimoniales. El segundo de los trabajos al que hacemos referencia es: "Stories of feelings and things: intangible heritage from within the built heritage paradigm in the UK" (Djabarouti, 2020). El estudio investiga la relación entre elementos patrimoniales tangibles como son los edificios, y los relatos que estos construyen en las personas que interactúan con ellos. Los resultados del trabajo sugieren que la relación de las personas con el patrimonio tangible, va forjando un patrimonio inmaterial individual en cada uno de los visitantes, que a su vez genera la narrativa del edificio. Se crea así un efecto cíclico, que según las conclusiones del artículo, debería ser tenido en cuenta por los profesionales del patrimonio para hacerlos conscientes, no solo de su función como conservadores del patrimonio físico, sino también como narradores del patrimonio inmaterial.

Nos adentramos ahora en los resultados surgidos de la relación en los títulos de los términos "heritage and emotions". WOS nos reporta 24 artículos y Scopus 37, de los cuales 15 de ellos forman parte de ambos listados. Buena parte de los resultados presentan una temática investigadora que se circunscribe al ámbito del turismo presentando conclusiones sobre el papel de las emociones en las experiencias patrimoniales (Su, Hsu, 2013), (Ndlovu, 2015), (Benetti, Ozelame, Pereira y Tricarico, 2018), (Dominguez-Quintero, González-Rodriguez y Roldan, 2019), (Zhao, Wang y Ji, 2020), (Zheng, Liang y Ritchie, 2020), (Bull y De Angeli, 2020), (Hoare, 2020), (Oren, Shani y Polonia, 2021).

Encontramos un artículo interesante de la mano de De Leersnyder, Kim y Mesquita (2020), donde se investiga sobre la pervivencia de la cultura de origen de los emigrantes en el país de acogida. El estudio muestra que varía mucho la continuidad de elementos culturales, en función de la interacción que se tiene con otros compatriotas dentro del país de acogida. De la misma manera, la pervivencia del patrimonio inmaterial presenta mayor persistencia por la celebración de ritos o fiestas que también pueden realizarse en un contexto social.

Hallamos también algunas reflexiones interesantes en el artículo de Lucie Jagosova (2020), donde se incide en el beneficio que las visitas a museos pueden generar en el visitante a nivel cognitivo. Se desarrolla la idea de que, los aspectos psicológicos de la educación patrimonial no formal pueden generar estados como la relajación y la contemplación inducidos por las visitas a museos. Esta idea está en consonancia con algunos de los elementos que defendemos, como la utilización del patrimonio para generar rutinas de atención y análisis en la educación formal (Munilla, 2016).

Nos encontramos también con artículos que relacionan directamente el patrimonio con las tecnologías, como es el caso de "The practice and potential of heritage emotion research: an experimental mixed-methods approach to investigating affect and emotion in a historic house" (Hoare, 2020). El texto presenta un sistema de reconocimiento de emociones. El sistema filtra escenas de vídeo atendiendo a las respuestas emocionales grabadas y permite generar nuevos vídeos con el tipo de emoción elegido. El patrimonio cultural es el origen multimedia de las emociones y también el final ya que permite la narración de historias relativa a él. En un sentido similar de utilización conjunta de datos cualitativos y herramientas digitales, se sitúa otro artículo anterior del mismo autor (Hoare, 2018), donde ya presentaba un método para investigar la relación entre los espacios patrimoniales y la emociones de los visitantes, utilizando los datos personales de estos. 
Los buscadores nos muestran también una experiencia realizada en la ciudad de Milán donde a través de aplicaciones móviles en las visitas por la ciudad, se pretende acceder al universo emocional de los usuarios. Para ello se crean paisajes sonoros que acompañan el descubrimiento del paisaje urbano de la ciudad y su transformación histórica, utilizando como medio la experiencia narrativa de una novela. La investigación corre a cargo de Letizia Bolini e Irene Della Facia (2020).

Destacamos así mismo el trabajo: "Social emotions, heritage and recognition. The Struggle of Colina Stonemasons in Santiago, Chile" (2019), donde se analiza la relación entre la valoración del patrimonio y el reconocimiento comunitario. El artículo llega a la conclusión de que existen determinadas emociones sociales que son favorables o contrarias hacia elementos patrimoniales, dependiendo del colectivo social que sustenta esa cultura.

Queremos hacer mención también al artículo "Mapping authenticity: Cognition and emotion in public heritage" (Mock, 2018), donde se analiza la capacidad del método de mapeo afectivo para observar la interacción entre elementos tangibles e intangibles del pasado y el presente, en la búsqueda de la utilización del patrimonio como producto emergente multidisciplinar.

Otro texto interesante es "Moved by the tears of others: emotion networking in the heritage sphere" (Rana, Willemsen y Dibbits, 2017), que explora el término redes emocionales para referirse a las diferentes formas de apego que puede suscitar un elemento patrimonial al relacionarse con él. En esta línea de explorar los afectos o rechazos que puede generar un mismo objeto patrimonial a colectivos de realidades culturales diferentes, se sitúan también los artículos de Liebelt (2019), y Marchant y Nancarrow (2019).

Dentro del libro "Conservation Science in Cultural Heritage", volumen editado para la conferencia Internacional sobre "Patrimonio crítico en perspectivas transculturales", encontramos el artículo "Visitor Emotion, Affect and Registers of Engagement at Museums and Heritage Sites" (Smith, 2014). En él se realiza una disquisición sobre las diferentes maneras de acercarse al patrimonio y los museos para conocer como las personas manejan el pasado en el presente.

Encontramos algunos resultados más que contienen nuestros términos de búsqueda en el título, pero que presentan visiones excesivamente holísticas por un lado (KluczewskaWójcik, 2019), o con orientaciones hacia políticas culturales por otro (Tolia-Kelly, Waterton y Watson, 2016).

La búsqueda en francés arroja un resultado en Scopus: "Émotions patrimoniales: Quand le patrimoine devient l'affaire de tous" (Waty, 2016), donde se describe cómo el patrimonio cuando se ve amenazado, se convierte en un foco de compromiso social al sentir las personas que su identidad está implícitamente en peligro.

A la vista de los resultados, ampliamos la búsqueda en francés a las raíces de los términos señalados, localizando solamente publicaciones con enfoques psicológicos y/o neurocientíficos.

La búsqueda en Castellano nos depara dos hallazgos: "Recuperación de la memoria histórica de la lucha por la defensa del patrimonio en Cholula a través de las emociones" (Lauro, 2014) y "Turismo Vivencial en Zonas de Patrimonio: un análisis de las emociones a partir de los comentarios de Tripadvisor sobre la Carretera Transpantaneira-MT-Brasil" (Benetti, Ozelame, Pereira y Tricárico, 2018). El primero de ellos recupera la memoria histórica de la lucha por la defensa del territorio Cholulteca frente al proyecto expropiatorio, que pretendió construir un parque sobre una zona arqueológica en área protegida; el segundo analiza el valor de las redes sociales y 
los comentarios de los usuarios de las mismas sobre sus experiencias en un parque de Brasil.

No obtenemos resultados en ninguno de los dos buscadores para los términos en portugués. Por ello, ampliamos nuestra búsqueda a las raíces y extendemos los campos de búsqueda a "todos los campos", además de la utilización de la búsqueda avanzada con etiquetas de campo, operadores booleanos, paréntesis, etc. Pese a esta ampliación, no localizamos resultados.

La investigación en los buscadores mencionados nos ha proporcionado algunos otros resultados que, pese a no contener específicamente elementos emocionales en sus títulos, se presentan como escritos esenciales dentro del panorama de la educación patrimonial actual. Es el caso del libro "Handbook of Research on Citizenship and Heritage Education" (Delgado-Agarra y Cuenca-López, 2020), un manual que recoge aportaciones sobre educación para la ciudadanía y educación patrimonial de renombrados investigadores, que representan a más de veinticinco instituciones pertenecientes a diez países. El texto se estructura en tres secciones: una primera que acoge nueve capítulos con reflexiones teóricas sobre políticas educativas y currículum; una segunda donde se presentan hasta ocho investigaciones con temáticas dispares, como las concepciones de la ciudadanía o la historia por parte de docentes en formación, o la situación de la educación patrimonial en países como China o Chile, pasando por la didáctica de la historia y el patrimonio así como las aplicaciones de éste último a la memoria histórica; y una tercera y última parte donde se presentan seis experiencias didácticas de educación formal y no formal. Un total de veintitrés capítulos donde se exponen nuevas visiones metodológicas en la didáctica de las ciencias sociales, se aboga por una revisión de los currículums de éste área, se plasma la necesidad de formar personas que ejerzan una ciudadanía activa, se defiende el uso de nuevas tecnologías y redes sociales en entornos patrimoniales, y se señalan las relaciones entre educación para la ciudadanía y educación patrimonial, entre otras numerosas ideas desarrolladas a lo largo de 525 páginas. De entre todos los capítulos referidos, destacamos el de Fontal y Martínez (2020) por la amplitud de su mirada y la magnitud de su propuesta. En el texto las autoras proponen una red europea que investigue con visión continental sobre todos los aspectos que dan forma al entramado de la educación patrimonial, desde el más puramente teórico hasta llegar a su concreción en la práctica.

En este mismo texto, encontramos algunos otros capítulos que tiene cierta relación con nuestra investigación. Es el caso de "Conflictive Memory and Heritage Education in the Initial Training of Primary Teachers" (2020), donde se incluye la educación emocional dentro de la formación del profesorado de primaria en el ámbito de las ciencias sociales, a través del análisis de la memoria y el pasado. Posteriormente las actividades son llevadas al aula de primaria en el periodo de prácticas de los futuros profesores en los colegios.

Encontramos así mismo en el manual otros capítulos que narran experiencias con futuros docentes que resultan significativas de cara a su formación, y que por tanto revierten en la manera en que la educación patrimonial llega a la educación formal (Estepa-Giménez y Martín Cáceres, 2020), (Coma, Fuentes y Sánchez, 2020), (FerrerasListán, Pineda-Alfonso y Hunt-Gómez, 2020), (Gómez, López Facal y Castro, 2020), (Molina y Riquelme, 2020) 


\subsubsection{Programas de referencia internacional.}

Tras acometer las publicaciones de la UNESCO, el Consejo de Europa y artículos científicos en WOS y Scopus, abordamos a continuación los programas referentes por su alcance e impacto en el ámbito internacional.

Conviene destacar por su alcance, la labor del Instituto do Patrimonio Histórico e Artístico Nacional (IPHAN) de Brasil. Este instituto está vinculado al Ministerio de Ciudadanía, encargado de la conservación del Patrimonio Brasileño. Tiene como objetivo principal promover y proteger los bienes culturales del país. Dadas las dimensiones de Brasil, el instituto se subdivide en superintendencias o regiones, que abordan las peculiaridades culturales propias, organizándose en unidades especiales de las que dependen centros específicos. El IPHAN cuenta con un programa de educación patrimonial que persigue implementar la educación patrimonial en todas sus acciones institucionales, promoviendo políticas de reconocimiento, protección y promoción del patrimonio. $^{3}$

El instituto desarrolla dos acciones dirigidas a apoyar las estrategias del gobierno federal. Por un lado el programa Más Educación, que pretende promover la ampliación de la jornada escolar y la organización curricular de la misma, para introducir acciones de educación patrimonial en la enseñanza básica, y por otro lado el Programa Nacional de Extensión Universitaria (Proext), desarrollado en colaboración con diversas universidades, para estimular la participación de otros agentes capaces de asociarse a las políticas de reconocimiento, promoción y protección del patrimonio cultural brasileño.

El instituto no presenta ninguna iniciativa global que abarque el trabajo emocional directo con el patrimonio, aunque podemos encontrar algunas referencias puntuales. Dentro del gran número de publicaciones que edita, destacamos los cuadernos de educación patrimonial descargables en la página $w^{4} b^{4}, y$ entre ellos el número 5 dedicado a las políticas, relaciones de poder y acciones afirmativas. En este número encontramos el artículo "Dinâmica das emoções através da educação patrimonial pautada na arte/educação". El texto hace referencia a las acciones de arte llevadas a cabo en Pernambuco, que pretendían reflexionar sobre el potencial de las emociones y el amor en el descubrimiento de uno mismo, creando contextos relacionales con el patrimonio. Se trata de una iniciativa interesante que, no obstante, no tiene influencia en otras iniciativas a nivel estatal.

La UNESCO, a través de su Red de Escuelas Asociadas a la UNESCO, también es un referente en educación patrimonial. En el año 2018 en colaboración con la Comisión Europea puso en marcha varias iniciativas para trabajar el patrimonio a través de la red de escuelas, ofreciendo herramientas y orientaciones a los profesores, para incorporar el patrimonio cultural en las actividades curriculares y extracurriculares, con especial atención al patrimonio inmaterial, por medio de sesiones didácticas y juegos en línea. Todo ello se difunde a través de redes de profesores como Tinning, School Education Gateway o Euroclio, además de la web zona de aprendizaje de la UE. ${ }^{5}$ No obstante, esta red no presenta iniciativas directas sobre emociones, centrando su trabajo en el cambio climático y el desarrollo sostenible.

Para terminar, citamos el trabajo desarrollado por otras entidades internacionales que son referentes en el ámbito patrimonial mundial: el Consejo Internacional de Museos

\footnotetext{
${ }^{3}$ Información extraída de la web del IPHAN. http://portal.iphan.gov.br

${ }^{4}$ http://portal.iphan.gov.br/pagina/detalhes/617

${ }^{5}$ https://europa.eu/learning-corner/home_es
} 
(ICOM), Intangible Cultural Heritage \& Museums Proyect (IMP), dependiente del ICOM, International Council on Monuments and Sites (ICOMOS), y el International Centre for the Study of the Preservation and Restoration of Cultural Property (ICCROM). Pese a tratarse de instituciones y entidades de referencia internacional, no localizamos en sus iniciativas ninguna acción concreta en relación con nuestro ámbito de estudio.

\subsection{La perspectiva nacional.}

Analizamos en este apartado la presencia que tienen las emociones ${ }^{6}$ dentro del ámbito patrimonial en nuestro país. Para ello, revisamos la legislación vigente en materia de patrimonio, tanto nacional como autonómica. El análisis nos permite conocer las iniciativas que abordan nuestro tema de estudio en la escala nacional.

\subsubsection{La legislación vigente en materia de Patrimonio.}

A nivel nacional, consideramos la Ley de Patrimonio Histórico y la Ley de Patrimonio Inmaterial como referentes para el resto de leyes autonómicas. No obstante su revisión no aporta ningún resultado para nuestros criterios de búsqueda. Revisamos por tanto la presencia de los descriptores de búsqueda en las leyes autonómicas, atendiendo al orden cronológico de su aprobación (tabla 2).

Tabla 2. Menciones a las emociones en las Leyes Autonómicas

\begin{tabular}{|c|c|l|c|}
\hline Año & $\begin{array}{c}\text { Comunidad } \\
\text { autónoma }\end{array}$ & \multicolumn{1}{|c|}{ Ley } & $\begin{array}{c}\text { Número } \\
\text { de } \\
\text { referencias } \\
\text { emocional } \\
\text { es }\end{array}$ \\
\hline 1990 & Murcia & $\begin{array}{l}\text { Ley 4/1990, de 11 de abril, de medidas } \\
\text { de fomento del patrimonio histórico de la } \\
\text { Región de Murcia }\end{array}$ & 0 \\
\hline 1993 & Cataluña & $\begin{array}{l}\text { Ley 9/1993, de 30 de septiembre, del } \\
\text { Patrimonio Cultural Catalán }\end{array}$ & 0 \\
\hline 1998 & Valencia & $\begin{array}{l}\text { Ley 4/1998, de 11 de junio, del } \\
\text { Patrimonio Cultural Valenciano }\end{array}$ & 1 \\
\hline 1998 & Cantabria & $\begin{array}{l}\text { Ley 11/1998, de 13 de octubre, de } \\
\text { Patrimonio Cultural de Cantabria }\end{array}$ & 0 \\
\hline 1998 & Islas Baleares & $\begin{array}{l}\text { Ley 12/1998, de 21 de diciembre, del } \\
\text { Patrimonio Histórico de las Illes Balears }\end{array}$ & 0 \\
\hline 1999 & Aragón & $\begin{array}{l}\text { Ley 3/1999, de 10 de marzo, del } \\
\text { Patrimonio Cultural Aragonés }\end{array}$ & 1 \\
\hline 1999 & Canarias & $\begin{array}{l}\text { Ley 4/1999, de 15 de marzo, de } \\
\text { Patrimonio Histórico de Canarias }\end{array}$ & 0 \\
\hline 1999 & Extremadura & $\begin{array}{l}\text { Ley 2/1999, de 29 de marzo, de } \\
\text { Patrimonio Histórico y Cultural de } \\
\text { Extremadura }\end{array}$ & 0 \\
\hline 2001 & Asturias & $\begin{array}{l}\text { Ley 1/2001, de 6 de marzo, del } \\
\text { Patrimonio Cultural del Principado de }\end{array}$ & 0 \\
\hline
\end{tabular}

\footnotetext{
${ }^{6}$ Utilizaremos para la búsqueda las mismas raíces de la búsqueda internacional: "emoci” y "sentim”.
} 


\begin{tabular}{|c|c|c|c|}
\hline & & Asturias & \\
\hline 2002 & Castilla y León & $\begin{array}{l}\text { Ley } 12 / 2002, \text { de } 11 \text { de julio, de } \\
\text { Patrimonio Cultural de Castilla y León }\end{array}$ & 0 \\
\hline 2004 & La Rioja & $\begin{array}{l}\text { Ley } 7 / 2004, \text { de } 18 \text { de octubre, de } \\
\text { Patrimonio Cultural, Histórico y Artístico } \\
\text { de La Rioja }\end{array}$ & 0 \\
\hline 2005 & Navarra & $\begin{array}{l}\text { Ley Foral 14/2005, de } 22 \text { de noviembre, } \\
\text { del Patrimonio Cultural de Navarra }\end{array}$ & 0 \\
\hline 2007 & Murcia & $\begin{array}{l}\text { Ley 4/2007, de } 16 \text { de marzo, de } \\
\text { Patrimonio Cultural de la Comunidad } \\
\text { Autónoma de la Región de Murcia }\end{array}$ & 0 \\
\hline 2007 & Andalucía & $\begin{array}{l}\text { Ley 14/2007, de } 26 \text { de noviembre, del } \\
\text { Patrimonio Histórico de Andalucía }\end{array}$ & 1 \\
\hline 2013 & Castilla la Mancha & 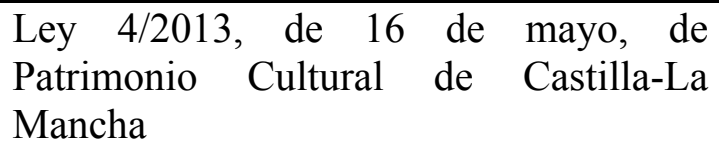 & 0 \\
\hline 2013 & Madrid & $\begin{array}{l}\text { Ley 3/2013, de } 18 \text { de junio, de } \\
\text { Patrimonio Histórico de la Comunidad de } \\
\text { Madrid }\end{array}$ & 0 \\
\hline 2016 & Galicia & $\begin{array}{l}\text { Ley 5/2016, de } 4 \text { de mayo, del } \\
\text { patrimonio cultural de Galicia }\end{array}$ & 2 \\
\hline 2019 & Islas Baleares & $\begin{array}{l}\text { Ley } 18 / 2019 \text {, de } 8 \text { de abril, de } \\
\text { salvaguardia del patrimonio cultural } \\
\text { inmaterial de las Illes Balears }\end{array}$ & 2 \\
\hline 2019 & País Vasco & $\begin{array}{l}\text { Ley } 6 / 2019 \text {, de } 9 \text { de mayo, de Patrimonio } \\
\text { Cultural Vasco }\end{array}$ & 2 \\
\hline
\end{tabular}

Fuente: Propia

En la Ley del Patrimonio Cultural Valenciano encontramos una alusión a la "utilización" del Monasterio de Santa María de la Valldigna, como elemento esencial para la unión sentimental de los valencianos (Ley de Patrimonio Cultural Valenciano, 1998, art. 104). Esta idea tiene su fundamento en el Estatuto de Autonomía de la Comunidad Valenciana del año 1982, en cuyo artículo 57 exclusivamente dedicado a este monumento, es catalogado como templo espiritual histórico y cultural del antiguo Reino de Valencia, así como símbolo de la grandeza del pueblo valenciano (Ley Orgánica 1/2006, de 10 de abril, de Reforma de Ley Orgánica 5/1982, de 1 de julio, de Estatuto de Autonomía de la Comunidad Valenciana).

Aragón hace alusión en el preámbulo de su ley al sentimiento de propiedad como elemento necesario para la conservación y apreciación del patrimonio. Es destacable que contrariamente a otras alusiones, en este caso se describe la manera de hacerlo, al afirmar que se puede conseguir mediante la información rigurosa y asequible. Entendemos que se refiere a la posibilidad de acercar el legado cultural a la mayor cantidad de gente posible, simplificando su explicación, pero sin perder por ello el rigor histórico. Incluso encontramos más concreción cuando se habla de adecuada formación e impulso de la participación ciudadana, lo que traducimos por educación y facilidad de acceso al patrimonio (Ley del Patrimonio Cultural Aragonés, 1999, preámbulo, p.8).

La Ley de la Comunidad Andaluza recoge una referencia en el preámbulo. Se presenta el sentimiento de aprecio hacia el Patrimonio, como clave para forjar una identidad colectiva, a la par que se enfatiza el impulso de un espíritu de ciudadanía respetuoso con 
el entorno cultural como motor de una mejor calidad de vida (Ley del Patrimonio Histórico de Andalucía, 2007, preámbulo, p.8).

Encontramos, en la Ley Gallega algunas referencias interesantes por el contexto en el cual se ubican:

Es justamente la idea de valor, la que determina la definición legal de bien cultural. El valor, como contenido de resonancia, no solo emocional o sentimental, sino directamente vinculado al devenir histórico del pueblo gallego en su caracterización pasada y en su apuesta de futuro, sobre la base material e inmaterial de lo que ya es, y en el horizonte de lo que quiere ser, en el campo de la civilización, entendida como concierto de las culturas y tradiciones (Ley del Patrimonio Cultural de Galicia, 2016, preámbulo, p.4).

Nos interesa esta mención porque la expresión "no solo emocional o sentimental" está atribuyendo al patrimonio este valor per sé. Quizá el otorgar de inicio a un bien cultural la capacidad emocional, pueda deberse al periplo que las leyes de patrimonio llevan desde la primera Ley de Patrimonio Histórico Español de1985, hasta la promulgación de la ley gallega en 2016. No podemos olvidar que es una de la últimas en ver la luz, por tanto los treinta y un años de leyes previas deben de tener reflejo en la sensibilización global de la ciudadanía del estado y por tanto, en la redacción de la ley. Sin embargo en el siguiente apartado del preámbulo, se achaca la supuesta falta de identificación de la ciudadanía y por ende falta de sentimiento de proximidad con el patrimonio, a la centralización de la gestión fruto de la especialización necesaria para su dictamen.

Las Islas Baleares dispone de 2 leyes de patrimonio: la Ley de Patrimonio Histórico, que no recoge ninguna mención relevante, y la Ley La Ley de Salvaguarda del Patrimonio Cultural Inmaterial de las Islas Baleares, donde encontramos las siguientes referencias:

Nos encontramos, por lo tanto, ante una visión temporal, de orientación retrospectiva -de mirada hacia el pasado-, que se materializa a través de la memoria y que prevé la recuperación de las manifestaciones desaparecidas. En cambio, el patrimonio cultural inmaterial, aunque prevé igualmente esta dimensión temporal, lo hace con una tendencia prospectiva -de mirada hacia el futuro-, con la pretensión de transmitirlas y legarlas a las generaciones futuras. Incorpora, además, el sentido de adaptación y recreación constante y, a través de su carácter vivo, interactúa con la naturaleza y su historia, y les infunde un sentimiento de identidad y continuidad (Ley de Salvaguarda del Patrimonio Cultural Inmaterial de la Islas Baleares, 2019, preámbulo, p.4).

Este patrimonio cultural inmaterial, que se transmite de generación en generación, lo recrean constantemente las comunidades, los grupos o las personas en función de su entorno, la interacción con la naturaleza y su historia, lo cual les infunde un sentimiento de identidad y continuidad y contribuye, por lo tanto, a promover el respeto a la diversidad cultural y a la creatividad humana (Ley de Salvaguarda del Patrimonio Cultural Inmaterial de la Islas Baleares, 2019, art. 2). 
Dos referencias interesantes. Ambas recogen elementos similares en torno al sentimiento de identidad, la segunda de ellas además, aúna en un mismo párrafo los conceptos de sentimiento y creatividad, atribuyendo al primero la capacidad de suscitar el segundo.

El patrimonio es una herramienta muy útil para la formación integral de la persona y el binomio emocional creativo resulta imprescindible para un desarrollo armónico de la personalidad. Esta idea, aunque en las citas se circunscribe al Patrimonio inmaterial, entendemos que se puede extrapolar a cualquier tipo de patrimonio. En este sentido nos parece interesante resaltar la referencia a continuidad histórica de la primera cita. La redacción ofrece a la creación patrimonial un hilo secuencial histórico, que justifica un sentimiento identitario nacido en la noche de los tiempos. Bajo esta perspectiva parece querer afirmarse que, cuanto más atrás históricamente nos remontamos en la búsqueda de señas culturales comunes, más objetividad tiene la defensa de una pertenencia sociocultural común. Es esta una propuesta a la que se recurre muy a menudo desde el punto de vista político, incluso para defender propuestas antagónicas. Cuanto más antiguo es el sustrato cultural de una sociedad, más legitimidad se le atribuye a la creación de un sentimiento identitario diferencial. Esta idea que presenta numerosos dilemas desde el punto de vista antropológico, sociológico o ético, es sin embargo utilizada de manera más o menos sutil a lo largo de varios de los documentos analizados hasta aquí desde el inicio del trabajo, incluyendo los organismos internacionales.

Este mismo artículo con una redacción muy similar lo encontramos en la Ley del Patrimonio Cultural Vasco del mismo año.

Como vemos, las comunidades de Murcia, Cataluña, Baleares, Canarias, Extremadura, Cantabria, Asturias, Castilla y León, La Rioja, Navarra, Castilla La Mancha y Madrid, no hacen ningún tipo de alusión a las emociones en sus leyes patrimoniales. Tan solo 6 leyes de las 19 revisadas (ya que Murcia y Baleares disponen de dos leyes patrimoniales), contienen alguna alusión.

Incluyendo las dos leyes estatales, las referencias se encuentran en menos del $24 \%$ de la legislación patrimonial, lo que se nos antoja escaso. Máxime cuando de los hallazgos anteriormente explicitados, la mayoría hacen referencia a la creación de un sentimiento identitario regional basado en el patrimonio, aunque sin apuntar en ningún caso la utilidad de éste para ayudar a los individuos a conocer o experimentar de forma consciente sus emociones, por medio de la referida conmoción emocional interior.

\subsubsection{El Instituto del Patrimonio Cultural de España y los Planes Nacionales.}

El Instituto del Patrimonio Cultural de España (IPCE) ${ }^{7}$, es una Subdirección General adscrita a la Dirección General de Bellas Artes del Ministerio de Cultura y Deporte. Su cometido es la investigación, conservación y restauración de los bienes que conforman el Patrimonio Cultural. Cumple así una tarea que emana del compromiso social de naturaleza constitucional, de la Administración General del Estado junto con el resto de las Administraciones Públicas para la preservación y enriquecimiento del Patrimonio Cultural.

El Real Decreto 817/2018, de 6 de julio, por el que se desarrolla la estructura orgánica básica del Ministerio de Cultura y Deporte, que modifica el Real Decreto 595/2018, de

\footnotetext{
${ }^{7}$ Información extraída de la página web del IPCE. https://ipce.culturaydeporte.gob.es/inicio.html
} 
22 de junio, por el que se establece la estructura orgánica básica de los departamentos ministeriales, confiere al IPCE las siguientes funciones:

- Elaboración y ejecución de planes para la conservación y restauración de los bienes muebles e inmuebles del patrimonio histórico, así como de los fondos que constituyen el patrimonio documental y bibliográfico y la cooperación con otras Administraciones públicas y entidades públicas o privadas para el desarrollo de dichos planes y su seguimiento.

- La promoción y fomento de los proyectos de investigación arqueológica española en el exterior.

- El archivo y sistematización de los trabajos realizados y de la documentación disponible sobre patrimonio histórico.

- La investigación y estudio sobre criterios, métodos y técnicas para la conservación y restauración del patrimonio histórico.

- La formación de técnicos y especialistas en conservación y restauración de los bienes inmuebles y muebles integrantes de dicho patrimonio.

Los planes nacionales de patrimonio cultural son instrumentos de gestión del patrimonio, compartidos por las diversas administraciones y con participación de otras entidades públicas o privadas. Su objetivo es el desarrollo de criterios y métodos compartidos y una programación coordinada de actividades, en función de las necesidades del patrimonio, que incluye actuaciones de protección, conservación, restauración, investigación, documentación, formación y difusión.

Los planes nacionales constituyen de esta forma una base informativa para tomar decisiones, estableciendo una metodología compartida de actuación y fijando prioridades en función de las necesidades del patrimonio, con el objetivo último de proteger y conservar los bienes culturales.

Los planes se agrupan en catorce temáticas:

- Plan Nacional de Catedrales.

- Plan Nacional de Abadías, Monasterios y Conventos.

- Plan Nacional de Arquitectura Defensiva.

- Plan Nacional de Patrimonio Industrial.

- Plan Nacional de Paisaje Cultural.

- Plan Nacional de Conservación del Patrimonio Cultural del siglo XX.

- Plan Nacional de Arquitectura Tradicional.

- Plan Nacional de Salvaguarda del Patrimonio Cultural Inmaterial.

- Plan Nacional de Investigación en conservación del Patrimonio Cultural.

- Plan Nacional de Conservación Preventiva, Plan Nacional de Conservación del Patrimonio Fotográfico.

- Plan Nacional de Educación y Patrimonio.

- Plan Nacional de Emergencias y Gestión de Riesgos en Patrimonio Cultural.

- Plan Nacional de Protección del Patrimonio Arqueológico Subacuático.

Por su relación con los objetivos de la investigación revisamos a continuación, el Plan Nacional de Educación y Patrimonio y el Plan Nacional para la Salvaguarda del Patrimonio Cultural Inmaterial. 


\subsubsection{El Plan Nacional de Educación y Patrimonio.}

Este es el documento, de todos los analizados hasta el momento, que más se acerca a la temática de nuestra investigación. Así lo podemos corroborar en el análisis de sus planteamientos:

Tanto el conocimiento como la comprensión o la valoración en ningún modo surgen de manera espontánea en el ser humano, sino que se adquieren a través de procesos educativos; se necesitan estrategias adecuadas que nos ayuden a conocer el Patrimonio, ya sea a partir de los sentidos, desde la emoción, desde el pensamiento o desde la propia actuación. Por lo mismo, las estrategias didácticas nos ayudan a comprender, nos animan a buscar el sentido, a otorgar los valores mediante procesos de investigación, experimentación, deducción, reflexión, etc. Todo ello nos indica que la forma de mediar es clave en el proceso de conocimiento, comprensión y puesta en valor del Patrimonio, por lo que requiere de un conocimiento técnico adecuado para poder ser efectiva, diversa, adaptada a cada contexto e individuo, en sus distintos niveles de competencia cognitiva, curricular, emocional, relacional, social, etc. Requiere, en definitiva, el conocimiento especializado de la didáctica del Patrimonio (Plan Nacional de Educación y Patrimonio, 2015, p. 17).

Una cita muy relevante para la temática de nuestro trabajo al afirmar que la comprensión y valoración del patrimonio se alcanzan a través de la educación, y que la intervención didáctica en ese proceso de aprendizaje es crucial. Destacamos así mismo, la alusión a las estrategias para conocer el patrimonio y las analizamos a continuación, teniendo en cuenta los modos de aproximación y relación con los conceptos emoción y patrimonio que orientan la investigación.

- A través de los sentidos. Esta estrategia resulta clave pues, es muy importante la toma de contacto con los elementos patrimoniales in situ, siempre que sea posible, fomentando la exploración sensorial.

- Desde la emoción. Comprendemos la emoción, en referencia a los sentimientos que es capaz de despertar en nosotros, dando por hecho que pueden ser positivos hacia ese elemento patrimonial o no. Lo interesante para nosotros es analizar o utilizar aquello que es capaz de despertar dentro de cada observador.

- Desde el pensamiento. Con un análisis pausado, riguroso, analítico y docto.

- Desde la propia actuación. Entendemos que es primordial el acceso al patrimonio en primera persona, vivenciándolo, independientemente de la disposición de mediadores o iniciativas de otro tipo, que faciliten el acceso al mismo.

Suscribimos la afirmación de que la mediación es clave y que por ello, requiere de un conocimiento técnico especializado para ser efectiva, no obstante dentro de la educación formal al menos, no se han dado pasos suficientes para capacitar a los docentes en este ámbito.

Encontramos otra cita interesante dentro del apartado de innovación en los recursos y herramientas para la interpretación del patrimonio, donde se describen los objetivos que garantizan la calidad de las líneas de actuación del plan. El primer objetivo es "potenciar los aspectos emocionales y sensoriales del Patrimonio, subrayando su valor simbólico e identitario" (Plan Nacional de Educación y Patrimonio, 2015, p. 28). 
Como hemos visto, el contenido emocional es el que, en ocasiones, acerca el patrimonio al ámbito identitario, otorgándole un sentido que trasciende las generaciones y mantiene inmutable a lo largo de ellas la valía de los elementos patrimoniales, más allá de su importancia artística o práctica.

\subsubsection{EI Plan Nacional para la Salvaguarda del Patrimonio Cultural Inmaterial.}

El Plan Nacional para la Salvaguarda del Patrimonio Cultural Inmaterial es uno de los que más se acerca al plano emocional e identitario del patrimonio. Por ello, desarrollamos a continuación un análisis pormenorizado del mismo.

El Patrimonio Cultural Inmaterial (PCI), es considerado parte de la identidad de individuos y comunidades, un elemento interiorizado en ellos y que lo diferencia de otros patrimonios (Plan Nacional para la Salvaguarda del Patrimonio Cultural Inmaterial, 2015).

Por tanto, una gran parte de las manifestaciones del PCI se caracteriza por usar el espacio, los límites y los recorridos, como un conjunto de códigos más al uso específico en relación a la celebración. Por otra parte, la mayoría de las emociones asociadas al PCI son generadas por evocaciones derivadas en relación al marco espacial y no sólo por las actividades desarrolladas en él (Plan Nacional para la Salvaguarda del Patrimonio Cultural Inmaterial, 2015, p11).

El elemento espacial cobra gran relevancia en el patrimonio inmaterial, ya que numerosas actividades y celebraciones tienen un marco espacial de referencia que, en ocasiones les da un significado especial. ${ }^{8}$

Además de los ámbitos espaciales, debemos también recordar que, en muchas ocasiones el PCI posee un soporte material que alcanza gran relevancia para su conservación, convirtiéndose en ocasiones en testimonio del sentimiento colectivo.

Por un lado, el objeto material se concibe como un soporte físico culturizado sobre el que descansan los significados y la información, que es lo que denominamos la cultura inmaterial, y por otro, lo inmaterial no existe mayoritariamente más que en función de referentes materiales. Consideramos al objeto material como producto cultural, testimonio y documento, nacido del sentimiento colectivo de una sociedad. Es, por tanto, receptor y transmisor de multitud de significados culturales (Plan Nacional para la Salvaguarda del Patrimonio Cultural Inmaterial, 2015, p10).

Por todo ello se entiende como clave en el Plan el refuerzo del sentimiento identitario para la conservación del patrimonio inmaterial, además de recalcar el esfuerzo que deben desarrollar las administraciones públicas para hacerlo posible a través de iniciativas que incidan directamente en la ciudadanía. El objetivo es hacer consciente a

\footnotetext{
${ }^{8}$ En este sentido podemos citar ejemplos de referencia como el Paso del Fuego, en San Pedro Manrique (Soria). El ritual se celebra cada 23 de junio coincidiendo con el solsticio de verano y siempre realizado en el mismo lugar, a los pies de la iglesia de la Virgen de la Peña. El espacio se ha convertido por la gran afluencia de público en un anfiteatro, pero desde tiempos inmemoriales ha sido utilizado para este mismo fin, a la par que han sido ocupados sus alrededores por diferentes culturas desde la prehistoria (Burillo, Burillo, Alfaro, 2014; Alfaro, 2018).
} 
la sociedad en general de la dimensión y valores que atesora el PCI (Plan Nacional para la Salvaguarda del Patrimonio Cultural Inmaterial, 2015, p26, p.35).

Como se evidencia en esta revisión de las alusiones a emociones y sentimientos, el PCI es el que más conexión presenta con este tipo de elementos personales, tanto individuales como colectivos, ya que están muy enraizados en la sociedad, en las fiestas y tradiciones que, en ocasiones, se consideran como la mejor representación de un colectivo.

\subsubsection{La literatura científica nacional.}

En la revisión de las bases de datos Web of Science (WOS) y Scopus, que se realizó en el análisis internacional al incluir búsquedas en castellano, comprobamos que afloraban pocos artículos de origen nacional. Incluimos aquí los tres resultados acontecidos en esta búsqueda. Comenzamos con "Patrimonio y emociones: estado de la cuestión desde las perspectivas nacional e internacional" (Munilla y Marín-Cepeda, 2020), donde como el propio título del artículo indica, se hace una revisión de la legislación nacional e internacional en materia de patrimonio buscando la inclusión de elementos emocionales en ella. Hallamos así mismo, un interesante artículo de Cuenca-López, Martín-Cáceres y Estepa (2020), donde se determinan elementos esenciales de buenas prácticas para el diseño de proyectos educativos que puedan interactuar con el patrimonio. Y por último, detallamos el artículo "Heritage identity, emotions and teaching of Experimental Sciences" (Vázquez-Bernal, Pérez y Jiménez-Pérez, 2020), donde se estudió por medio de un cuestionario, las predisposiciones emocionales positivas o negativas de los estudiantes de magisterio hacia las ciencias.

Con el objetivo de obtener una visión más amplia extendemos las búsquedas al portal bibliográfico Dialnet, la base de datos de tesis doctorales Teseo y el buscador especializado Google Académico, además de algunas búsquedas dirigidas a autores referentes, que abordan el tema en nuestro país. Para ello, utilizaremos como descriptores de búsqueda "patrimonio" y "emociones" conjuntamente en los títulos de los artículos.

En relación a los autores referentes en España en torno a emociones y patrimonio, nos centramos en Santacana $(2012 ; 2014 ; 2015 ; 2016 ; 2017 ; 2018)$, quien ha publicado diversos artículos referentes. Comenzamos destacando sus afirmaciones, quizá a día de hoy sobradamente admitidas, sobre la capacidad de emocionar que se atribuye a las artes pero que indudablemente también atesora el patrimonio.

Hay personas que desde una determinada posición erudita desprecian las emociones ligadas al patrimonio, cual si fueran manifestaciones espurias, irracionales y primitivas. Sin embargo, la capacidad emotiva del patrimonio es real, existe y no hay nada de malo en ello; ciertamente existen falsas razones para despreciar este universo emotivo de las personas. Al igual que el arte, que el teatro o el cine, el patrimonio puede emocionar (Santacana, 2012, p.140).

Encontramos otras claves interesantes en el artículo "El Patrimonio Cultural y el Sistema Emocional: un estado de la cuestión desde la didáctica", donde analiza la relación entre los factores emocionales y el patrimonio. El artículo presta atención a la correlación entre aprendizaje y motivación, entre aprendizaje y excitación emocional. Conviene subrayar la afirmación que señala al patrimonio como herramienta educativa, por su alto potencial de emotividad (Santacana y Martínez, 2018). Santacana insiste en 
esta idea de la importancia pedagógica en otro de sus trabajos, al referir que cuanto mayor sea la capacidad de emocionar del patrimonio, mayor es su valor didáctico (Santacana, 2014).

Localizamos más referencias a esta cuestión en el libro El patrimonio cultural inmaterial y su didáctica, coordinado por Santacana y Llonch (2015). En esta publicación resulta interesante el enfoque motivador de las emociones: "aquí hay una relación biyectiva mediante la cual las emociones estimulan la motivación y la motivación desencadena emociones; son dos caras de la misma moneda" (p.107).

Estamos ante planteamientos que entroncan directamente con las tesis que defendemos en esta investigación sobre el valor didáctico del patrimonio y su uso como herramienta pedagógica.

Conviene subrayar además, el trabajo emocional basado en objetos concretos como motores desencadenantes de emociones en Santacana y Llonch (2016) y Santacana (2017):

Quizás de todos los mensajes que los objetos pueden emitir, hay una gama de ellos que adquieren más importancia que otros: nos referimos a los mensajes de tipo emocional. El patrimonio más eficaz es el que posee la capacidad de emocionar. Ello nos obliga a reflexionar sobre las emociones que pueden transmitir los objetos "procedentes del pasado". Al margen de la capacidad o poder de emoción que tienen los objetos auténticos, hay otra capacidad que merece ser destacada: los objetos pueden ser desencadenantes de reflexiones de tipo lógico, surgidas en cadena y que simplemente hay que relacionarlas con el poder que tienen determinados objetos de hacernos pensar, de provocar ideas (Santacana y Llonch, 2016, p.19).

Cuando Santacana y Llonch hablan de objetos "procedentes del pasado" engloban en este término objetos arqueológicos, artísticos, instrumentales, arquitectónicos, etc., es decir, cualquier objeto susceptible de evocar emociones. Por lo tanto, hablamos de cualquier elemento material, todo aquello que desde su naturaleza tangible porta las cargas humanas de creadores, usuarios, admiradores, detractores, etc.

Otro de los autores referentes a desatacar es López Facal, desde la Universidad de Santiago de Compostela. El profesor diserta en torno a la utilización del patrimonio para la instrumentalización política y la necesidad de despertar la mirada crítica de la ciudadanía sobre ello. Afirma que lo patrimonial, cuando tiene un interés uniformizador de la identidad social, es de gran poder por que inmediatamente después de la valorización patrimonial, está la identificación emocional: "lo monumental funciona con un propósito persuasivo y lo emocional en un registro inmediato, más subjetivo, con el propósito de conducir al pueblo a un estado de éxtasis" (Castro y López, 2017, p. 52).

Siguiendo con el autor, en La comprensión del paisaje partiendo de las emociones, desarrolla un estudio de caso del IES OMilladoiro, que aborda la utilización de las emociones, el trabajo cooperativo o los contenidos multidisciplinares como modelo de integración y compromiso social. Persigue la búsqueda del cambio del paradigma en las aulas, pasando del modelo tradicional a otro más participativo en el que las emociones y la identificación con los lugares de origen de los alumnos son el eje vertebrador de la experiencia (Rivero, López, y López, 2017).

Resulta de interés el artículo que publica con Domínguez Almansa, titulado "Formación de Maestros y Educación Patrimonial", donde afirma que los maestros son capaces de 
desarrollar un modelo crítico del patrimonio, que incorpore la dimensión relacional y emocional en la construcción de identidades, aplicándolo a sus alumnos de primaria (Domínguez y López, 2017).

Una postura interesante la de López Facal, que pasa de la teoría a la práctica abarcando en ese tránsito, no solo la formación del profesorado, sino también acciones directas en las aulas donde adquieren valor tangible sus investigaciones.

Exploramos también las publicaciones desarrolladas por el grupo de investigación EPITEC de la Universidad de Huelva, que tiene entre sus objetivos la actualización teórica y la comunicación de la educación patrimonial y su papel en el tratamiento de la inteligencia emocional. ${ }^{9}$ Entre los artículos que podemos encontrar en su web destacamos "Educación Patrimonial e Inteligencia Emocional. Hablan los alumnos", donde se presentan los resultados de una investigación enmarcados en una tesis doctoral, que analiza qué se enseña de educación patrimonial en las clases de Ciencias Sociales. El caso de estudio demuestra, según los autores, la relación entre la educación patrimonial y la inteligencia emocional en la formación de ciudadanos críticos (Lucas y Estepa, 2017). Se muestra el patrimonio como la puerta para la conciencia emocional y el autoconocimiento: "a través del patrimonio, podemos ser conscientes de nuestro grado de conciencia emocional, lo que nos permitirá poder describirnos, saber quiénes somos y configurar nuestra identidad tanto personal como colectiva" (Lucas y Estepa, 2017, p.195). Entre las conclusiones del estudio, se establece que el total del alumnado encuestado atestiguaba que, a través del patrimonio, se había despertado en ellos actitudes como el entusiasmo o el compromiso: "finalmente, el total del alumnado afirma que la investigación sobre elementos patrimoniales despierta en ellos emociones y sentimientos positivos, como pueden ser el compromiso, el entusiasmo, la alegría, la motivación, la generosidad, etc." (Lucas y Estepa, 2017, p. 204).

Encontramos también algunos artículos desarrollados por otros investigadores del grupo, como Cuenca y Gómez, que está en total consonancia con nuestra propuesta, por la visión utilitaria del patrimonio como medio para otros fines educativos:

La educación emocional puede ayudarnos a trabajar el desarrollo global del alumnado promoviendo la construcción de ciudadanos capaces de convivir en nuestra sociedad respetando los derechos humanos y las libertades fundamentales, a través del conocimiento de las emociones y la regulación de las mismas (Gómez y Cuenca, 2015, p. 251).

El artículo describe una propuesta metodológica de trabajo para infantil o primaria, para analizar estrategias y recursos didácticos que ayuden a desarrollar las emociones a través de la Educación Patrimonial.

Continuamos con las búsquedas en bases de datos. Como criterio general de búsqueda, se tomará en consideración aquellos artículos que incluyen en su título de forma conjunta las palabras patrimonio y emociones. Analizamos seguidamente los resultados obtenidos en cada buscador y las características de los mismos.

En Google Scholar utilizamos la búsqueda avanzada para filtrar nuestros términos de búsqueda en los títulos y obtenemos 16 resultados. De todos ellos, uno aparece tres veces y nueve son citas sobre los mismos artículos reportados o sobre algunos ya referidos anteriormente de Santacana o Cuenca. Todo ello nos deja un total de cinco artículos que pasamos a referir.

\footnotetext{
${ }^{9} \mathrm{http}: / / \mathrm{www} \cdot$ proyectoepitec.es/?q=proyecto-objetivos
} 
El primero de ellos es un escrito de Ansiáin que conecta en su título la emoción y el patrimonio, en este caso inmaterial, a través de la narración de la iniciativa de un archivo oral navarro. El artículo describe el archivo, sus contenidos, diseño, trabajo científico y posibilidades de utilización:

También serviría para superar el abismo generacional y permitir el encuentro intergeneracional entre generaciones tradicionales $y$ generaciones marcadamente urbanas. Y, no menos importante, rescataría los valores tradicionales más adecuados para formar ciudadanos (vecindad, trabajo en grupo, educación de las emociones, valor de la superación y el esfuerzo, etc.) (Ansiáin, 2005, p. 14).

Como vemos, el autor relaciona el valor del patrimonio inmaterial y la educación emocional como elementos esenciales para formar ciudadanos, siempre y cuando, como podemos leer más adelante, estos elementos sean incluidos en los planes de estudio de forma transversal.

Seguidamente, encontramos otra publicación generada por investigadores de la Universidad Pública de Navarra en relación al patrimonio hablado y su relación con las emociones, en este caso referidas a la fraseología de tres emociones consideradas básicas: la alegría, la tristeza y el miedo y su conceptualización en el lenguaje castellano y euskera (Aznárez y Santazilia, 2016).

El tercer resultado nos lleva hasta un trabajo fin de grado de la Universidad de Granada, "El patrimonio cultural despierta nuestras emociones: un proyecto educativo para la educación infantil", donde Rusillo (2017), presenta un proyecto educativo para acercar el patrimonio cultural a los niños de tres años.

Dialnet nos reporta 131 resultados repartidos en 56 artículos de revista, 45 tesis, 25 artículos de libro y 5 libros. No obstante, al realizar una búsqueda avanzada nos encontramos que tan solo cuatro resultados integran los dos conceptos de búsqueda en el título, de ellos, tres ya han sido citados anteriormente en los resultados de Google y las referencias de autores considerados destacados. La nueva referencia, "Gestión del patrimonio emocional. Organizaciones emocionalmente sostenibles" (García 2004), como el propio título indica, aborda la gestión de las emociones desde el ámbito empresarial, lo cual no entra dentro de nuestro ámbito de estudio.

Al existir una enorme diferencia entre los resultados generales y aquellos que acogen los conceptos de búsqueda en el título, realizamos una revisión de los resúmenes de todos los hallazgos y citamos a continuación aquellos que tienen relación directa con nuestro objeto de estudio y consideramos más relevantes.

Comenzamos con "Emoción, oralidad e itinerarios didácticos: un estudio de caso en el grado en maestro de Educación Infantil", donde se reflexiona sobre el potencial educativo de los itinerarios didácticos, a la par que analiza la utilidad de la educación emocional en ellos. Se profundiza así mismo en el papel de las emociones, a la hora de generar un aprendizaje integral y crítico del entorno, en el diseño de itinerarios didácticos por parte de alumnos de magisterio para niños de Educación Infantil. El artículo presta especial atención a elementos como la empatía, el dolor, la alegría, el sufrimiento, el cariño, el autoconocimiento o la identificación (Fuertes, 2016).

Encontramos en esta publicación tres referencias a Álvarez, tomando lo emocional ligado a los museos pedagógicos. La autora afirma que "cualquier tipo de museo tiene un objetivo de provocación emocional" (Álvarez, 2007, p.17). Resulta de interés la afirmación de que, un museo debe atender a la formación integral de la persona y no 
solamente al aprendizaje. Como se ha señalado, al igual que el autor, abogamos en este estudio por una "utilización" del patrimonio para la formación integral de la persona:

Queremos entender que un museo pedagógico ha de preocuparse por equilibrar las dimensiones cognitiva y afectiva de la persona, pues claro está que hasta ahora, museos de índole diversa, no han hecho más que preocuparse por el conocimiento, sin asignarle la importancia que merecían el aprendizaje o educación de los sentimientos y de las emociones. Y, a la misma vez, queremos pensar que inconscientemente, se ha venido impidiendo la necesidad de la persona de satisfacer las funciones de autodesarrollo y mejora en el marco de una educación integral (Álvarez, 2007, p. 26).

Encontramos la misma línea argumentativa en otro artículo publicado algunos años más tarde donde además de insistir en la aportación que los museos pueden hacer a la educación emocional, se añade la transmisión de valores éticos y se presenta además la educación emocional en los museos, como alternativa a los paradigmas educativos del siglo XXI (Álvarez, 2017). Cabe destacar una alusión directa a la educación patrimonial y su valor en la mejora emocional en los museos: "repensar la educación patrimonial desde las emociones en escenarios museístico pedagógicos, representa un importante impulso y una sugestiva oportunidad para que la educación amplíe sus dominios más allá de lo cognitivo" (Álvarez, 2017, p. 24).

Finalmente localizamos un artículo de Arias (2017) donde se enfoca la utilidad del patrimonio hacia la integración social, por medio de la identidad que éste puede generar "emocionándonos podemos entenderlo desde una perspectiva integral y holística y utilizarlo como puente de enlace entre las personas" (Arias, 2017, p.313). En consonancia con la afirmación de Arias, entendemos que la emoción puede hacer que comprendamos la utilidad de determinados elementos patrimoniales y su poder educativo integral e integrador, tal y como se señala en el artículo.

Tras las búsquedas realizadas debemos destacar que, en el buscador de tesis doctorales Teseo, no encontramos ninguna referencia si, como habíamos señalado al principio de este apartado, filtramos los descriptores en los títulos. Encontramos hasta 106 referencias si realizamos el filtrado en el resumen, pero al revisar estos resultados no nos resultan válidos, ya el enfoque que presentan es de tipo turístico, publicitario, arquitectónico, etc. Este mismo problema temático se nos presenta en casi todos los resultados de Dialnet.

No obstante, entendemos que existe una genealogía de tesis doctorales sobre educación patrimonial que conforman un panorama investigador destacado en determinadas universidades españolas, y que podemos considerar referentes en este ámbito académico. Por ello pasamos a referir algunos de estos estudios desde el año 2010 hasta la actualidad.

Debemos comenzar en este sentido por destacar las tesis doctorales dependientes del Observatorio de Educación Patrimonial de España ${ }^{10}$. Es el caso de la tesis de Sofía Marín-Cepeda (2014), quien presenta una investigación sobre el análisis de programas de educación patrimonial, referentes en el trabajo con la diversidad de públicos con el objetivo de definir criterios y estándares de calidad, que determinen el éxito de la inclusión para definir un modelo educativo específico. Stella Maldonado (2015) centra

\footnotetext{
10 Se realiza una descripción más pormenorizada de este organismo y su trabajo en el marco empírico de esta investigación.
} 
sus investigaciones en la educación patrimonial y las redes sociales, analizando los procesos que van desde la comunicación hasta la educación desembocando y convergiendo en la construcción de los aprendizajes. "Memoria, identidad y comunidad: evaluación de programas de educación patrimonial en la Comunidad de Madrid" (2016) es el trabajo de Ana Sánchez quien realiza un análisis estadístico descriptivo de programas de educación patrimonial adscritos a la comunidad de Madrid y los evalúa determinando los estándares de calidad de los mismos. Ana Falcón realiza una investigación bajo el título "Pedagogía y performance en educación artística en la Enseñanza Secundaria Obligatoria" (2016), en ella se defiende el uso de la performance como metodología didáctica adaptada para la comprensión y el acercamiento hacia el arte contemporáneo para alumnos de secundaria. "Evaluación de programas en educación patrimonial. Indicadores de calidad a través del método SAEPEP-OEPE y su instrumento basado en estándares EBEB-OEPE" (2018). La investigación de Silvia García muestra la necesidad del diseño de herramientas de evaluación que permitan valorar programas de educación patrimonial, para lo que se valida la escala Q-Edutage. La valoración de programas muestra que estos, en un alto porcentaje, presentan deficiencias en su estructura didáctica o el diseño educativo. Se señala así mismo la necesidad de dar visibilidad a los proyectos como medio para mejorar su calidad. "La educación patrimonial inmaterial: análisis del currículo y evaluación de programas" (2019), tesis defendida por Marta Martínez, donde se realiza un análisis de la presencia del patrimonio cultural inmaterial dentro del currículo educativo y de los planes de estudio de magisterio. Así mismo, se realiza una evaluación de programas educativos sobre patrimonio inmaterial, extraídos del Observatorio de Educación Patrimonial de España.

Otra tesis en una línea de investigación similar, es la de Inmaculada Sánchez Macías (2019) donde se hace incidencia en la evaluación de aprendizajes de alumnos de secundaria y bachillerato, a la vez que se realiza una selección de programas idóneos de educación patrimonial. El OEPE presenta varios estudios más sobre la educación patrimonial conjugada con distintos enfoques educativos (Gómez-Redondo, 2013; García, 2013; Vicent, 2013; Gillate, 2014; Pérez, 2014; Coca, 2015 y De Castro, 2016).

Fuera del excelente trabajo realizado por este observatorio y sus investigadores, que ha quedado plasmado en las tesis anteriormente referidas, encontramos algunos otros ejemplos dignos de mención. Es el caso del trabajo de Carlos Teófilo López (2017), quien presenta un estudio de caso sobre cómo llevar la educación patrimonial a las escuelas. Se plantea una visión del patrimonio global e integradora, intentando vincular a los alumnos con el patrimonio y utilizando éste como medio de reflexión personal y profesional por parte del docente.

"La enseñanza del patrimonio y de la ciudadanía en las clases de ciencias sociales" (2018) realizada por Laura Lucas, que extrae de la investigación algunas conclusiones sobre el profesorado a tener en cuenta: los profesores no valoran su formación universitaria, están muy interesados de forma personal en el patrimonio, entienden su profesión como una forma de activismo social, utilizan para trabajar los elementos patrimoniales materiales creados por ellos mismos o actividades in situ, consideran la educación patrimonial como la mejor herramienta para trabajar el pensamiento crítico, la educación patrimonial debe der transversal.

Leticia Castro (2020), realiza una investigación para conocer la efectividad del programa Patrimonializarte, y medir si contribuye a la apropiación simbólica, sensibilización, identificación y conciencia del patrimonio cercano a los alumnos de infantil, primaria y secundaria. 
Encontramos además otras tesis doctorales que unen la educación patrimonial con campos tan dispares como el trastorno del espectro autista (Pablos, 2018), la realidad aumentada (Mendoza, 2019), la arqueología preventiva (Campos, 2019), la memoria oral (Aranguren, 2020), la gestión en música y danza (Gómez, 2020), o la diversidad afectivo-sexual (Fernández, 2021).

Con una visión conjunta de las publicaciones analizadas que abordan el patrimonio y las emociones conjuntamente, nos parece importante destacar el trabajo del OEPE y de EPITEC así como de forma particular el de algunos de sus investigadores, ya que engloban la mayor producción científica localizada en los campos que son objeto de interés para este capítulo de la investigación.

Podríamos suponer que el hecho de que los términos Patrimonio y Emociones no sean reflejados de forma explícita en un número mayor de títulos de artículos científicos, implica que estos temas no son centrales en los mismos y, por lo tanto, deducir que su importancia en ellos no es la esperada. Nos atrevemos a afirmar que el patrimonio es tenido muy en cuenta por cualquiera de los autores referidos desde el punto de vista educativo, y que como hemos visto se relaciona frecuentemente con las emociones de forma transversal, como elemento de valor formativo. No obstante echamos en falta, ya que ese era uno de los objetivos de nuestras búsquedas, experiencias educativas donde estos aspectos sean eje central educativo, o al menos cuerpos teóricos que guíen el diseño de una práctica concreta por parte de los educadores. 


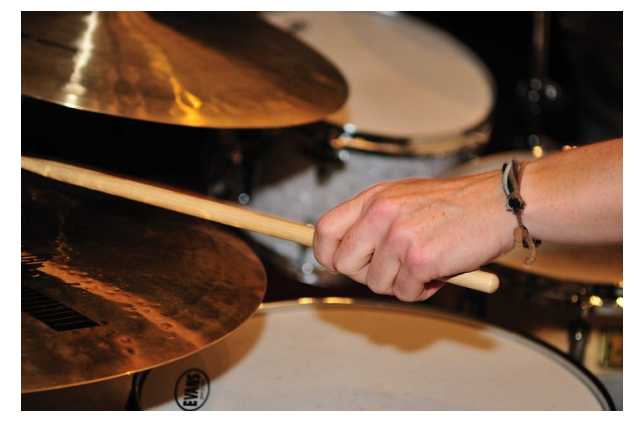

"Si no eres un artista eres un traidor a ti mismo y a la sociedad"

Richard de Marco.

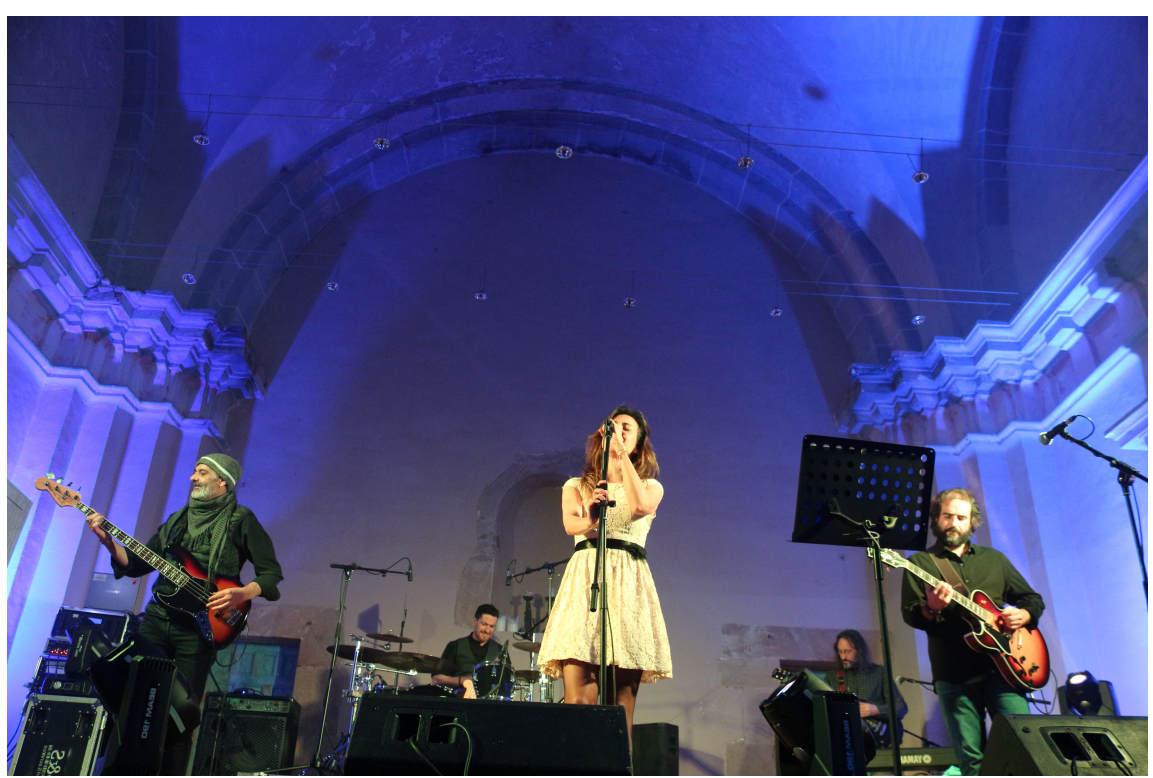




\section{CAPÍTULO 2. RELACIONES ENTRE PATRIMONIO Y CREATIVIDAD}

En el presente capítulo analizamos las referencias en torno a creatividad y patrimonio en los ámbitos nacional e internacional, aplicando los mismos criterios y ámbitos de análisis abordados en el capítulo anterior. Nos interesan de igual manera las referencias donde ambos conceptos aparezcan relacionados, y donde los dos términos se vinculen a objetivos comunes o aparezcan simultáneamente en iniciativas únicas.

\subsection{La perspectiva internacional.}

\subsubsection{La Organización de las Naciones Unidas para la Educación, la Ciencia y la Cultura}

La búsqueda del término creatividad, ofrece un bajo porcentaje de resultados, por lo que ampliamos los términos de búsqueda a conceptos que guardan relación con la creación. ${ }^{11}$ Encontramos la primera referencia a las creaciones en la Recomendación sobre los medios más eficaces para hacer los museos accesibles a todos. Una alusión a las "creaciones del espíritu" muy interesante, no solo por la manera de referirse a la creatividad sino también por la fecha en la que se produce, hace más de sesenta años. Al hablar de las creaciones del espíritu, podemos atisbar la intención de referirse a la creatividad per se, creatividad nacida de lo más profundo del ser humano como medio de expresión. Vemos que la organización toma en consideración las creaciones como valores culturales que tienen una gran influencia en el mundo, e insta al Director General a elaborar programas que desarrollen actividades culturales (UNESCO, 1958). Como referencia indirecta en la Conferencia General de París 1960, encontramos una mención a la creatividad humana referida a los monumentos históricos y la capacidad creadora de las gentes, algo que, según se plasma en la recomendación, debe quedar reflejado en la educación. Se asegura que los monumentos encarnan los más altos valores culturales heredados del pasado, son la marca tangible de la historia y el genio creador de los pueblos (UNESCO, 1960).

En la Recomendación relativa a la Protección de la Belleza y el Carácter de los Lugares y Paisajes (París 1962), dentro de la Recomendación II, relativa a la enseñanza técnica y profesional, podemos encontrar una referencia al esfuerzo creador. Se señala que en la enseñanza primaria se deben buscar los medios para infundir en los niños el gusto por la creación, apuntando que esta capacidad requiere de un esfuerzo. Entendemos como básico lo explicitado en este epígrafe, que por otra parte se ajusta perfectamente a los intereses que defendemos en nuestra investigación, referidos a la educación como elemento imprescindible para desarrollar las capacidades de observación y creación. Esperamos que algunas de las propuestas que se presentarán más adelante, puedan ser una referencia a la hora de dar contenido a los medios para engendrar esas facultades que acabamos de referir.

Todo sistema de educación primaria que revistiera un carácter principalmente general y no profesional, debería prever algún medio de infundir en los niños el gusto y el respeto del trabajo manual, acostumbrándoles a la observación y al esfuerzo creador, y despertando

\footnotetext{
${ }^{11}$ Se han analizado los resultados de las búsquedas de raíces terminológicas vinculadas con lo creativo: "crea" (crear, creación, creatividad...), "invent" (inventar, inventiva...)"ing” (ingenio, ingeniar...).
} 
en ellos una visión inteligente de los problemas prácticos del hogar y de la comunidad (UNESCO, 1962, p. 139).

En la 13 edición de la Declaración de la Conferencia General de la UNESCO, se aborda la eliminación del analfabetismo y se hace un llamamiento a las naciones en torno a 9 aspectos. En el cuarto podemos leer:

La finalidad primordial del desarrollo es liberar las energías creadoras y productivas de toda la humanidad. Este objetivo no puede lograrse en las tinieblas. No puede lograrse mientras la humanidad se halle dividida en dos grupos: los que poseen y los que están privados de los medios que la instrucción y la enseñanza proporcionan para enriquecer la vida y buscar nuevos caminos del saber, ni mientras no se libere al espíritu del hombre de la intolerancia, del recelo y del miedo, hijos de la ignorancia (UNESCO, 1964, p. 30).

De este modo, se da a entender que la creatividad existe de forma innata y que el desarrollo de la humanidad va ligado a su capacidad creadora y productiva, entendiendo esa producción como los elementos fruto de la creatividad. Todo ello debe hacerse por medio de la educación, es decir, la educación es parte importante del proceso creativo, entendemos que como base sobre la que se construye la creación y producción de elementos nuevos o mejorados.

En esta misma declaración, se relaciona nuevamente la facultad de crear con la educación, al presentar ésta última como la llave para acceder a la protección patrimonial, el acceso a las artes y la creación. Así invita al Director General a que prevea en el futuro programa que presenta el epígrafe, presupuesto y actividades formativas artísticas en la educación básica (UNESCO, 1964). Unas páginas más adelante se hace referencia nuevamente a la creación cultural, al aseverar que la UNESCO tradicionalmente se ha dedicado a la difusión de la cultura, aunque no se ha encargado de los problemas de la creación ni de ayudar a que se entienda el fenómeno cultural (UNESCO, 1964). Una declaración con varias e interesantes alusiones a la creación y la educación como elementos indispensables e indisolubles, para acometer el objetivo primordial que aborda de elimina el analfabetismo.

En la Conferencia General de París (1966), encontramos la invitación a los estados miembros a tomar las medidas adecuadas para estimular la creación. Se pretende la revitalización del mundo artístico acercándolo a la profesionalización, para lo que se propone la formación y la difusión de las creaciones (UNESCO, 1966). Así mismo, dentro de las resoluciones generales, en el artículo tres podemos leer: "la cooperación cultural internacional abarcará todas las esferas de las actividades intelectuales y creadoras en los campos de la educación, la ciencia y la cultura" (UNESCO, 1966, p. 88). Nos interesa esta referencia pues encontramos en un mismo párrafo referencias al intelecto (pensamiento), creación, educación, ciencia (investigación) y cultura. Son sin duda cinco términos clave para este trabajo.

La creación se muestra una vez más como elemento importante, al referirse a ella en dos ocasiones en la Recomendación sobre la conservación de bienes culturales que la ejecución de obras públicas o privadas puede poner en peligro (París, 1968). En la primera de ellas se señala la atención a la comisión, sobre la importancia de reforzar actividades que permitan a la juventud actividades creadoras, con especial atención a la estética (UNESCO, 1968). Es interesante la referencia a la formación estética, enfocada a conocer lo que vemos, analizarlo y valorarlo. En ocasiones ponemos énfasis en 
desarrollar la capacidad creadora, y ésta puede desplegarse también por medio del análisis y observación de lo existente, para a partir de ello desarrollarlo y modificarlo. Más adelante en los anexos se pide añadir el siguiente párrafo a las resoluciones de la recomendación.

Destacar el papel fundamental de la enseñanza de las bellas artes, que desarrolla, las aptitudes creadoras del individuo, incita a las masas a participar en la vida cultural de la comunidad, suscita nuevos tipos de personalidades creadoras y brinda a todos una vida más plena (UNESCO, 1968, p. 281).

Se trata de un párrafo en el que se destaca nuevamente el papel de la educación artística como elemento para el desarrollo de la creatividad. También en esta ocasión se le otorga la capacidad de incentivar la participación cultural comunitaria y de encontrar nuevas vías de creación cultural. Finalmente apunta el valor para una vida más plena, algo que, como ya se apunta en el prólogo, defendemos como verdad absoluta en este trabajo.

Antes de abandonar el tratado conviene abordar la afirmación localizada en la p. 303: "un delegado afirmó que el artista o creador moderno no debía ser considerado como una especie de paria social, porque su papel en la sociedad era muy importante". Podemos hacernos una idea de la situación de la cultura en el año 1968 cuando es necesario recordar tal cosa, pero además de ello, nos interesa el trato de sinónimo que se da a artista y creador moderno, dando cabida con este segundo término a todos los nuevos medios de expresión cultural.

Encontramos similares referencias a la creación artística y nuevas formas de creación, en las Actas de la Conferencia General de la 17 reunión celebrada en París en 1972 y, más concretamente, dentro de las Resoluciones del programa para 1973-1974 en el apartado de Ciencias Sociales, Humanidades y Cultura. Se insta a los estados miembros a estimular las nuevas formas de creación audiovisual, reorientando los festivales de arte y espectáculo hacia estos medios, facilitando la formación de artistas profesionales (UNESCO, 1972). Seguidamente, se pide al director general que continúe con los estudios técnicos y teóricos sobre las políticas y mecanismos de promoción artística incluyendo la evaluación de los mismos y los aspectos económicos que incluyen. Vemos que la resolución además de reclamar el estímulo creador, aborda también los elementos evaluativos y financieros que pudieran ser necesarios (UNESCO, 1972).

En las Resoluciones de la 19 reunión de Nairobi en 1976, ubicamos un número importante de referencias repartidas en diferentes apartados del documento.

Dentro de los objetivos del plan 1977-1982, en el artículo 3.6, podemos leer dos de ellas relativas nuevamente al estímulo de la creatividad (UNESCO, 1976). Más adelante, descubrimos el término capacidades creadoras, que resulta interesante por la alusión a la competencia creadora y que además, aparece asociada a otras expresiones también interesantes referidas a espíritu crítico, autoaprendizaje, reflexión o inquietud intelectual, máxime cuando se señala que todas ellas se deben mantener y estimular por medio de la escuela.

Orientar los programas escolares y de formación, en el sentido de mantener y estimular la curiosidad intelectual y de asignar un lugar más amplio, junto a la adquisición de conocimientos, al desarrollo de comportamientos autodidácticos, de un espíritu crítico, de actitudes reflexivas y de capacidades creadoras (UNESCO, 1976, p. 128). 
Resulta relevante la atribución a la educación, y más concretamente a la escuela, de la capacidad de conservación y fomento de la investigación, el estudio, el análisis o la creación, facultades tradicionalmente designadas a edades y etapas educativas más avanzadas.

En la Recomendación relativa a la Salvaguarda de los Conjuntos Históricos, podemos examinar cómo se considera a estos elementos arquitectónicos principios esenciales para la conservación de la cultura religiosa y social como poseedores tangibles de estos valores místicos de la sociedad, sin olvidar su valor urbanístico (UNESCO, 1976). Destacamos esta referencia a las creaciones, ya que por primera vez se habla de producciones más allá de lo cultural, al citar lo religioso y social como naturalezas que contienen también esa capacidad de desarrollar nuevos elementos.

En la Recomendación relativa a la participación y contribución de las masas populares en la vida cultural, encontramos gran número de alusiones a la creación, abarcando hasta ocho páginas distintas, con un total de 38 referencias entre las páginas 146 a la 153. Destacamos las más relevantes a continuación.

Nos topamos con dos menciones a las creaciones humanas como fruto de la interacción entre los hombres, por lo que se les otorga la condición de fenómeno social, que debe ser impulsor del progreso no solo económico sino también espiritual (UNESCO, 1976). La consideración de la cultura como parte crucial de la sociedad y un factor de progreso social e integral de las personas, enlaza con uno de los contenidos primordiales de nuestro trabajo: apostar por la cultura y la creación como elementos básicos en el desarrollo pleno de la persona.

Una página más adelante, hallamos referencias con un nuevo enfoque hacia la cultura. En este caso, se habla de la creación como medio de expresión personal que va más allá de la búsqueda o no de la belleza. Se trata de alumbrar elementos nuevos con la intención de liberar estados interiores sin afán artístico, pero sí creador.

Considerando que el acceso y la participación, que deben dar a todos y cada uno la posibilidad, no solamente de recibir, sino también de expresarse en todos los campos de la vida social, suponen la máxima libertad y tolerancia en la formación, la creación y la difusión culturales (UNESCO, 1976, p. 147).

Resulta interesante también la secuencia propuesta para acceder a la cultura: informarse, formarse, conocer, comprender y disfrutar. "Se entiende por acceso a la cultura, la posibilidad efectiva para todos, principalmente por medio de la creación de condiciones socioeconómicas, de informarse, formarse, conocer, comprender libremente y disfrutar de los valores y bienes culturales" (UNESCO, 1976, p. 148). Es cierto que las condiciones económicas pueden ser un elemento definitivo para algunos de los pasos de la secuencia, como el de la formación, y quizá no tanto para otros, como el disfrute si se dispone de una buena dosis de sensibilidad. No obstante, compartimos la idea como nos apunta el texto, de que aquello por lo que se debe de luchar es por crear las condiciones para que todo el mundo tenga la posibilidad efectiva de acceder a los acervos culturales. Destacamos, así mismo, un intento por acotar el contenido de la cultura por medio de todas las formas de creación individuales o grupales, incluyendo no solo la producción de objetos o ideas, si no también formas de vida. El concepto de cultura se amplía a todas las formas de creatividad y de expresión de los grupos o los individuos, ya sea en sus modos de vida o en sus actividades artísticas (UNESCO, 1976). 
Nos parece relevante la referencia al tiempo que precisa cualquier tipo de creación, pidiendo el espacio necesario en la vida de las personas, para posibilitar esas experiencias creadoras.

Crear condiciones en las que el trabajo y el reposo brinden, cada uno a su manera, ocasiones de creación cultural a todos los individuos, y establecer los regímenes de trabajo y de descanso, así como los regímenes del funcionamiento de las instituciones culturales para que la mayoría pueda acceder a la vida cultural y participar en ella (UNESCO, 1976, p. 151).

Para finalizar las alusiones en esta recomendación, encontramos nuevamente, aunque expresada de forma más clara y directa, una referencia a la creación no profesional y el respeto que merece como medio de expresión y desarrollo personal, sin fines profesionales o de intención artística (UNESCO, 1976).

En las Actas de la Conferencia General de la 20 reunión de París 1978, dentro del programa 1979-1980 y del apartado cultura y comunicación, encontramos que el objetivo 3.6. está dedicado plenamente a creatividad. Para su consecución, se basa en la estimulación de la creatividad artística e intelectual, para lo cual se enumeran las siguientes acciones y temas:

1. Autoriza al Director General a llevar a cabo actividades encaminadas a la consecución del objetivo 3.6 (Estimular la creatividad artística e intelectual), con relación a los siguientes temas: "La creación artística y su desarrollo en las sociedades tradicionales y en las industrializadas", "Desarrollo de los contactos e intercambios al servicio de la creación artística", "El arte y la educación permanente", "Promoción de la condición social del artista".

2. Invita al Director General a que, al llevar a cabo las citadas actividades:

a. Fomente la cooperación internacional en el campo artístico, en estrecha cooperación con los propios artistas y con sus organizaciones $\mathrm{y}$ asociaciones;

b. Estimule la participación de todas las categorías sociales en la creación artística;

c. Contribuya a promover las formas de arte tradicionales, en particular en los países en desarrollo, a la vez que preste todo el estímulo posible a las formas contemporáneas y a las investigaciones destinadas a conocer mejor el proceso de la creación, así como a un mayor conocimiento y aprecio del cometido del arte y de los artistas en la sociedad y, en particular, en todas las actividades de educación permanente que concurren al desarrollo armonioso del hombre y de la comunidad (UNESCO, 1978, p. 91).

Resulta interesante por lo recurrente en las actas de este año, la referencia distintiva a creatividad artística y creatividad intelectual, como elementos disímiles. Igualmente consideramos que otorgar al arte de manera individual la capacidad de generar procesos internos de creación, es una visión reduccionista, que se puede perfectamente extrapolar a producciones no artísticas.

Más adelante, en el apartado de Ciencias Sociales y Aplicaciones, encontramos un nuevo alegato a la creación, como nexo del pasado con el futuro, asegurando la pervivencia de las culturas de la humanidad. Se plasma la necesidad de mantener la identidad de los pueblos por medio de la conservación de su cultura, sin menoscabo de 
la modernización y desarrollo de sus señas de identidad para poder asegurar la supervivencia de las culturas. No hay mención, sin embargo, en este punto a la educación como un aliado eficaz para conseguirlo (UNESCO, 1978).

En las actas de la Conferencia General de la 21 reunión, en la preparación del plan 1984-1989, encontramos una referencia interesante abogando por el estudio de la creatividad. Nos parece destacable el interés de la organización por el estudio de los procesos cognitivos que permiten el acto creador, es la primera vez que tenemos referencia sobre ello y que la UNESCO va más allá de las creaciones y sus autores buscando el origen del proceso creativo.

Debería comprenderse y reforzarse la función del creador. En el plan deberían preverse medidas que pudieran servir de ayuda al creador y favorecer el estudio de la creatividad, y debería destacarse la importancia de medidas encaminadas a mejorar la condición del artista (UNESCO, 1980, p. 23).

Echamos en falta una vez asumida la importancia de conocer los procesos creativos, alguna iniciativa por parte de este organismo que incentive su estudio, publique sus conclusiones y facilite la aplicación de aquellos resultados que sean susceptibles de ser empleados en el mundo educativo, artístico, científico, etc.

En el programa para 1981-1986, dentro del apartado de cultura y comunicación encontramos nuevamente referencias a la investigación.

Estimular la creatividad artística e intelectual, prosiguiendo los estudios, los trabajos de investigación y la experimentación en el ámbito de la creación artística, y colaborando con la comunidad internacional de los artistas y con sus organizaciones profesionales, para impulsar los encuentros e intercambios, al servicio de la creación artística (UNESCO, 1980, p. 58).

Encontramos algunas indicaciones sobre como impulsar la investigación a través del intercambio de experiencias, por medio de encuentros de las organizaciones profesionales de artistas. Nos resulta una iniciativa interesante que, no obstante, se circunscribe únicamente al ámbito artístico, lo que no concuerda con el encabezamiento del apartado que incluye la creatividad intelectual, a la que posteriormente no se hace referencia.

En el anexo 1 dentro de las recomendaciones relativas a la condición del artista encontramos cuatro referencias consecutivas (UNESCO, 1980).

Destacamos la relativa a asegurar la libertad del artista y disfrutar de su arte, ensalzando así la figura del creador para desembocar finalmente en el papel que el arte debe jugar en el desarrollo de las naciones, y lo que nos parece más importante, su función para lograr una sociedad más humana y espiritualmente más rica. En la página siguiente, encontramos referencias incluso a las remuneraciones de los artistas, como medio para lograr ese reconocimiento social e influencia en la sociedad. Subrayamos así mismo la reseña al papel específico de la mujer, entendiendo que, si la relevancia social de los creadores en general no es alta, la del colectivo creador femenino lo es menos, y por ello es recordado expresamente. En este mismo sentido, localizamos referencias a la creatividad centrada específicamente en otros colectivos, como son los que se denomina como deficientes (UNESCO, 1980). El trabajo de la creatividad en personas con algún 
tipo de discapacidad intelectual es un buen medio de desarrollo de capacidades cognitivas.

En la Declaración de México sobre Políticas Culturales, de la Conferencia Mundial sobre Políticas culturales del año 1982, encontramos 2 alusiones a la creatividad. En la primera de ellas, se define el Patrimonio Cultural de un pueblo como el conjunto de las creaciones de sus miembros y éstas como el resultado de su creatividad (UNESCO, 1982). Nos parece interesante resaltar la alusión a "sabios", incluyendo en el espectro de los artistas a personas con grandes conocimiento en campos que no se consideran artísticos. En la segunda, encontramos referencias a la educación y a la formación integral de las personas.

Se requiere hoy una educación integral e innovadora que, no sólo informe y transmita, sino que forme y renueve, que permita a los educandos tomar conciencia de la realidad de su tiempo y de su medio, que favorezca el florecimiento de la personalidad, que forme en la autodisciplina, en el respeto a los demás y en la solidaridad social e internacional; una educación que capacite para la organización y para la productividad, para la producción de los bienes y servicios realmente necesarios, que inspire la renovación y estimule la creatividad (UNESCO, 1982, p. 4).

Nos parece oportuna la alusión a la educación integral, especificando que la formación no puede ser solamente transmisora de datos, efemérides o descubrimientos, sino que debe servir además para hacer florecer la personalidad o la solidaridad. Algo en lo que estamos muy de acuerdo y que, como hemos señalado, entendemos que se puede realizar de manera muy eficaz con la utilización del patrimonio como puente entre la cultura y los individuos.

En las actas de la 25 Reunión de París (1989), se recoge la Recomendación sobre la salvaguarda de la cultura tradicional y popular. Dentro del apartado de protección podemos leer:

La cultura tradicional popular, en la medida en que se plasma en manifestaciones de la creatividad intelectual individual o colectiva, merece una protección análoga a la que se otorga a las producciones intelectuales. Una protección de esta índole es indispensable para desarrollar, perpetuar y difundir en mayor medida este patrimonio, tanto en el país como en el extranjero, sin atentar contra los intereses legítimos (UNESCO, 1989, p. 257).

Es una referencia de especial interés ya que habla de creatividad intelectual individual o grupal, otorgando por tanto a los colectivos la capacidad de crear de forma social e intencional. Es evidente que la cultura tradicional tiene fuertes componentes grupales, no obstante en ocasiones, con el afán de perpetuar inamovibles las tradiciones, olvidamos que fueron creadas en algún momento y posiblemente evolucionaron por causa de modas, influencias tecnológicas, políticas o legislativas, y quizá en ocasiones también como fruto de interacciones de colectivos.

En las actas de la 31 reunión se incluye la Declaración universal sobre Diversidad Cultural, y en ella encontramos referencias interesantísimas para nuestro objeto de investigación ya que podemos leer referencias conjuntas a Patrimonio y Creatividad. 
Artículo 1 - La diversidad cultural, patrimonio común de la humanidad. La cultura adquiere formas diversas a través del tiempo y del espacio. Esta diversidad se manifiesta en la originalidad y la pluralidad de las identidades que caracterizan a los grupos y las sociedades que componen la humanidad. Fuente de intercambios, de innovación y de creatividad, la diversidad cultural es tan necesaria para el género humano como la diversidad biológica para los organismos vivos. En este sentido, constituye el patrimonio común de la humanidad y debe ser reconocida y consolidada en beneficio de las generaciones presentes y futuras (UNESCO, 2001, p. 73).

Artículo 7 - El patrimonio cultural, fuente de la creatividad. Toda creación tiene sus orígenes en las tradiciones culturales, pero se desarrolla plenamente en contacto con otras culturas. Ésta es la razón por la cual el patrimonio, en todas sus formas, debe ser preservado, realzado $\mathrm{y}$ transmitido a las generaciones futuras como testimonio de la experiencia y de las aspiraciones humanas, a fin de nutrir la creatividad en toda su diversidad e inspirar un verdadero dialogo entre las culturas (UNESCO, 2001, p. 74).

El primer artículo, en su título eleva a la categoría de patrimonio la diversidad cultural, explicando más adelante que la variedad es fruto de la creatividad nacida de la interacción entre los pueblos. Sin duda, una visión a tener en cuenta máxime cuando realiza el paralelismo con la diversidad biológica del planeta. Podemos por tanto pensar que la diversidad cultural elevada a patrimonio universal, puede considerarse la base del equilibrio creativo, mental y trascendente del género humano.

El artículo siete tiene la importancia de conjugar en su título patrimonio y creatividad, dándole al primero el origen del segundo. Sin duda nuestro mejor hallazgo hasta el momento, ya que concuerda con nuestra propuesta de trabajar la creatividad y las emociones por medio del patrimonio. Defendemos, al igual que lo hace este artículo, que la creación tiene su base en la tradición cultural y que por ello, el patrimonio como elemento universal nacido del hombre, puede y debe servir para estimular la inventiva, el ingenio y la sensibilidad creadora.

En la 32 reunión celebrada en Paris en el año 2003, existen distintas referencias a la creatividad relacionadas con los derechos de autor, el desarrollo y el respeto a la diversidad y el aprendizaje. No obstante, no nos aportan nada nuevo a las citas ya realizadas. Únicamente reseñamos entre ellas, la afirmación recogida en las resoluciones generales sobre fortalecimiento de las civilizaciones por medio del intercambio de ideas (UNESCO, 2003). Resulta interesante que se especifique distintos tipos de creatividad asociados a diferentes áreas, no solo físico-prácticas o tangibles, sino también de tipo espiritual o moral, entendiendo que la creatividad no solo se puede encauzar hacia lo material, sino también hacia elementos mentales que no necesariamente se deben plasmar de manera física.

En esta misma reunión encontramos la Convención para la Salvaguarda del Patrimonio Cultural Inmaterial, que para definir este tipo de patrimonio también se recurre a la creatividad humana como resultado de los sentimientos de identidad y continuidad.

Se entiende por "patrimonio cultural inmaterial" los usos, representaciones, expresiones, conocimientos y técnicas junto con los instrumentos, objetos, artefactos y espacios culturales que les son inherentes que las comunidades, los grupos y en algunos casos los 
individuos reconozcan como parte integrante de su patrimonio cultural. Este patrimonio cultural inmaterial, que se transmite de generación en generación, es recreado constantemente por las comunidades y grupos en función de su entorno, su interacción con la naturaleza y su historia, infundiéndoles un sentimiento de identidad $y$ continuidad $y$ contribuyendo así a promover el respeto de la diversidad cultural y la creatividad humana. A los efectos de la presente Convención, se tendrá en cuenta únicamente el patrimonio cultural inmaterial que sea compatible con los instrumentos internacionales de derechos humanos existentes y con los imperativos de respeto mutuo entre comunidades, grupos e individuos y de desarrollo sostenible (UNESCO, 2003, p. 3).

El patrimonio, tomado como elemento base para la creación de identidades, es algo recurrente en la UNESCO como hemos podido comprobar en nuestra revisión emocional del capítulo uno. En esta ocasión, insistiendo en la misma idea, se le otorga a la identidad la capacidad de contribuir al respeto por la diversidad cultural y la creatividad humana. Sin ánimo de contradecir a la Organización de Naciones, se nos antoja cuando menos aventurado afirmarlo de forma tajante, ya que la historia ha dejado suficientes muestras también de lo contrario. En distintos momentos históricos y por sociedades desiguales, se ha utilizado políticamente el sentimiento identitario para objetivos diametralmente opuestos al respeto por la cultura.

En la Convención sobre la protección y promoción de la diversidad de las expresiones culturales del año 2005 y revisando la edición de 2013 de textos fundamentales, hallamos numerosas referencias a creatividad. Analizamos cada una de ellas, que computan exactamente un total de once, y encontramos referencias enfocadas desde dos vertientes: por un lado, como cualidad humana resultado de la diversidad cultural de nuestra raza, y por otro, como producto fruto del fomento de políticas que protejan esa diversidad cultural. Una visión dicotómica que sin embrago tiene un sustrato recurrente en la UNESCO: la protección cultural-patrimonial, y su uso como motor económico.

En la 36 reunión, dentro de la Recomendación sobre el paisaje urbano histórico, se hace un llamamiento a la integración armónica de los cambios urbanos desde el respeto al patrimonio. Se toma como base la diversidad y creatividad culturales para, a partir del concepto de paisaje urbano, abogar por unas ordenaciones urbanísticas que tengan en cuenta los contextos históricos y culturales de cada región en sus planteamientos (UNESCO, 2011).

Encontramos interesante la referencia hallada en el resumen del debate de política general, cuando habla de la contribución de la UNESCO a la cultura de la paz.

Diálogo, solidaridad y creatividad: una perspectiva humanista para el siglo XXI. A pesar del contexto actual de crisis mundiales, hemos de mirar al futuro con optimismo y poner empeño en resolver los problemas mediante un auténtico diálogo. Las múltiples crisis son síntoma de que estamos asistiendo al surgimiento de un mundo nuevo, más interconectado, complejo y diverso. Los problemas han de encararse desde una perspectiva humanista basada en el respeto de los derechos humanos y la diversidad cultural, y en la práctica de la no violencia, la tolerancia y el diálogo. Sólo con una "brújula moral" de este tipo podrán tejerse lazos de solidaridad entre los pueblos y dentro de las sociedades, $\mathrm{y}$ crearse las condiciones de una paz y un desarrollo sostenible perdurables. El desafío consiste en ampliar el acervo común de valores y 
principios que unen a todos los seres humanos, conjurando al mismo tiempo las tendencias a la uniformidad. En ese sentido, el humanismo del siglo XXI deberá asentarse en una vasta concepción de la tolerancia, que no sólo abarque las relaciones sociales e interculturales, sino también la apertura a las ideas creativas, en los ámbitos de las actitudes éticas, los patrones de consumo, los modelos de empresa y las tecnologías innovadoras. Este humanismo basado en el diálogo, la solidaridad y la creatividad puede facilitar considerablemente la gestación de nuevas soluciones a los problemas actuales del mundo (UNESCO, 2011, p. 202).

Aquí se presenta la creatividad como base para incentivar un humanismo que presente nuevas soluciones a los problemas del mundo, a través del diálogo y la solidaridad. Una visión filantrópica del concepto de creatividad, que tiene más que ver con un deseo que con una fórmula para resolver las crisis mundiales tal y como encabeza el párrafo.

En la Recomendación relativa a la protección y promoción de los museos y colecciones, su diversidad y su función en la sociedad, podemos leer como se dota a los museos, y entendemos que a sus colecciones, de la capacidad de promover la creatividad. Defendemos la utilidad de las creaciones humanas como elemento base para construir a partir de ellos producciones de cualquier tipo, y dada la diversidad de temáticas que abracan los museos hoy en día, agradecemos que no se hable exclusivamente de museos de arte. Encontramos nuevamente referencias al bienestar espiritual de los ciudadanos, en este caso acompañadas de la mención al ocio y la industria cultural (UNESCO, 2015).

Dentro del apartado donde se detallan de las funciones esenciales de los museos, se tiene en cuenta la educación:

La educación es otra función primordial de los museos. Los museos imparten educación formal y no formal y aprendizaje a lo largo de toda la vida mediante la elaboración y transmisión de conocimientos $\mathrm{y}$ programas educativos y pedagógicos en asociación con otras instituciones docentes, en particular la escuela. Los programas educativos de los museos, contribuyen principalmente a la educación de diversos públicos en las disciplinas a las que pertenecen sus colecciones y en la vida cívica, y contribuyen a crear una mayor conciencia de la importancia de preservar el patrimonio y promover la creatividad. Además, los museos pueden proporcionar conocimientos y experiencias que permitan entender mejor las cuestiones sociales con ellos relacionadas (UNESCO, 2015, p. 17).

Amparamos la educación como la mejor vía para la conservación y también como una forma de cultivar la creatividad. Es cierto que los museos pueden ser una muy buena forma de trabajar la creatividad, tanto por la cantidad de estímulos que acogen como por la diversidad de los mismos. De la misma manera, las instituciones museísticas cada vez adquieren una mayor importancia para la difusión cultural, si tenemos en cuenta que los nuevos discursos expositivos tienen una clara vocación divulgadora y didáctica.

Como vemos, la UNESCO nos aporta bastantes y variadas referencias a la creatividad, mostrando que es una capacidad que se considera importante para el devenir de la humanidad. Así ha sido casi desde la fundación del organismo, ya que encontramos alusiones desde 1958 casi de forma ininterrumpida en todas las reuniones hasta nuestros días. 


\subsubsection{El Consejo de Europa.}

Como ya hemos realizado en el capítulo uno, para el análisis del ámbito europeo utilizaremos EUR-Lex, explorando los documentos de contenido patrimonial y educativo que contiene referencias al campo creativo. Comenzaremos igualmente por el Tratado de Funcionamiento de la Unión Europea.

En esta ocasión, el artículo 167 sí nos ofrece una referencia a la creación en su punto segundo aunque como ya nos ha ocurrido con la documentación de la UNESCO, tiene un cariz de acción productiva más que como una capacidad o habilidad creadora. De la misma forma las referencias en este tratado van a estar en su mayoría dirigidas a la creación artística y literaria, obviando en este epígrafe otros tipos de cultura o, al menos, no nombrándolos explícitamente como sería deseable (Unión Europea, 2007, p.89).

En la revisión de los documentos de temática cultural, encontramos referencias a la creatividad en dos títulos: Conclusiones del Consejo sobre la cultura en las relaciones exteriores de la UE, con énfasis en la cultura y en la cooperación para el desarrollo; y en las Conclusiones del Consejo y de los representantes de los Gobiernos de los Estados miembros, reunidos en el seno del Consejo, sobre la promoción de la diversidad cultural y el diálogo intercultural en las relaciones exteriores de la Unión Europea y de sus Estados miembros. En ambos documentos nos aparece en varias ocasiones la alusión a las industrias creativas, como motores de un desarrollo innovador y sostenible, así como de catalizadoras de la creación de empleo. Pese a la intención económica de los escritos, nos parece importante destacar la alusión a la "creación de capacidades", entendiéndola como fomento del desarrollo de la facultad creadora, tanto de las industrias culturales y creativas, como de los individuos de la Unión. De esta manera podemos leer (Unión Europea, 2015) "Apoyo al desarrollo estructurado y a largo plazo de los sectores cultural y creativo en los países asociados, sobre todo en términos de creación de capacidades, gobernanza cultural y sistemas de propiedad intelectual" (p. 42).

Nos resulta interesante el análisis de la Comunicación conjunta al Parlamento Europeo y al Consejo, por la gran cantidad de alusiones a la creatividad, un total de cuarenta y seis. Sin embargo, casi todas ellas están referidas a las industrias creativas como motor económico, y al programa Europa Creativa del que hablaremos más adelante. No obstante, destacamos el apartado de Principios rectores para la acción de la UE, donde podemos leer un enfoque de la creatividad como medio para construir las libertades fundamentales. Resulta atrayente la alusión explícita hacia la cultura, afirmando que no solo es arte y literatura, tal y como hemos defendido anteriormente, y describiendo otros ámbitos susceptibles de ser incluidos bajo el paraguas cultural, como son la educación, la investigación, la protección del patrimonio, las nuevas tecnologías o la artesanía. Destacamos el encontrar referencias directas al valor de la cultura "per se", como elemento capaz de proporcionar libertad individual, pero también de dotar de libertades colectivas a las sociedades que la ponen como eje social (Unión Europea, 2016).

A continuación, revisamos los documentos donde se recogen los programas de cultura tales como: Europeana, Sello de patrimonio europeo, Plan de trabajo en materia de cultura, Capitales europeas de la cultura y Planteamientos locales centrados en las personas del patrimonio cultural. En todos ellos encontramos numerosas referencias a contenidos creativos, aunque nuevamente todas ellas centradas en el valor que pudieran tener como motor de desarrollo económico, por lo que no hacemos mención específica a ninguna. 
En las Conclusiones del Consejo sobre pasarelas en el ámbito cultural y creativo para estimular la innovación, la sostenibilidad económica y la inclusión social, encontramos unos resultados de cincuenta y dos referencias sobre las industrias ya mencionadas. De entre ellas extraemos la siguiente cita que traemos aquí por aunar referencias creativas y educativas de los ámbitos formal, no formal e informal, circunstancia que nos parece importante ya que el fomento de las actitudes creativas dentro del ámbito patrimonial se debería hacer desde éstos tres caminos educativos.

El desarrollo de aptitudes creativas y de pensamiento crítico a lo largo de la educación formal y no formal y en el aprendizaje informal, permite a las personas responder mejor a las necesidades de una sociedad cada vez más diversa y basada en el conocimiento, así como de un mercado laboral exigente y en constante evolución (Unión Europea, 2015, p. 14).

La alusión a los tres tipos de aprendizaje nos parece relevante y esclarecedora del reparto de compromisos que hace la institución para conseguir los objetivos de desarrollo creativo. Entendemos, no obstante, que la alusión está en consonancia con el cariz económico de todos los documentos revisados hasta aquí, ya que la educación no formal e informal suele tener un sustento empresarial en muchos casos.

Queremos mencionar finalmente en este apartado de legislación cultural, el reglamento por el que se establece el Programa Europa Creativa en el que destacamos dos ideas:

Por un lado, el valor de la cultura como catalizador de la creatividad, entendiendo que el conocimiento es capaz de generar ideas, ingeniar soluciones o provocar invenciones, por lo que la educación adquiere un valor crucial en el desarrollo de capacidades que pueden llevar a la creación (Unión Europea, 2009).

Y por otro, el valor intrínseco de lo artístico junto a la labor que puede desarrollar como dinamizador e integrador social. Encontramos también aquí, como ocurre en algunos otros fragmentos, la palabra creatividad acompañando a la de innovación, algo que se asocia profusamente a lo tecnológico pero que puede tener indiscutiblemente también tintes interesantes en el plano social y cultural, como se señala a continuación.

El Programa debe tener en cuenta la naturaleza dual de la cultura y las actividades culturales reconociendo, por una parte, el valor intrínseco y artístico de la cultura y, por otra, el valor económico de estos sectores, incluida su contribución a la sociedad, en general, a la creatividad, la innovación y la integración social (Unión Europea, 2009, p. 3).

Entendemos tras la exploración realizada, que la mayoría de referencias que aparecen en la documentación de carácter cultural tienen un componente mercantil claro, con las excepciones al plano social y formativo que acabamos de referir.

Proseguimos la revisión documental con los textos de materia educativa. Al no ser instrumentos con una temática patrimonial ni cultural en origen, cruzaremos las búsquedas relativas a creatividad con las de patrimonio.

Esta documentación nos vuelve a remitir como título marco al Tratado de Funcionamiento de la Unión Europea, y como ocurrió con los términos emocionales, los artículos que atienden al ámbito educativo son los ya referidos 165 y 166.

Comenzamos el análisis del documento relativo al Espacio Europeo de Educación para 2015 que podemos encontrar en la Comunicación para reforzar la identidad europea mediante la educación y la cultura. Hallamos varias referencias creativas a lo largo del texto donde se establece una relación directa entre la diversidad cultural y la 
creatividad, dándole a la primera el origen de la segunda y vinculándolas a la vez con la innovación. Así mismo, hallamos alusiones una vez más al valor del patrimonio y la educación como medio de cohesión social. En este caso además, se apuesta por la diversidad cultural como una buena manera de estimular la creatividad, cuestión con la que estamos de acuerdo, ya que entendemos la variedad de estímulos como un importante motor creativo. Finalmente, suscribimos una mención más a la creatividad como germen de la innovación en cualquier campo, ampliando así el espectro de áreas susceptibles de trabajar la creatividad, más allá de lo artístico (Unión Europea, 2017).

Analizamos a continuación las Conclusiones del consejo sobre el papel de la educación infantil y primaria en el fomento de la creatividad, la innovación y la competencia digital. Encontramos aquí una reseña muy interesante para nuestro objeto de estudio, ya que destaca el papel del profesorado y el entorno como medio para desarrollar la creatividad. Una de las máximas que defendemos desde este estudio, es la importancia de las experiencias patrimoniales en primera persona, de ahí que nos parezca esencial el uso de los espacios como elementos esenciales en el aprendizaje, tal y como se refleja en el párrafo expuesto a continuación. Por otra parte una formación adecuada del profesorado en las áreas patrimonial y creativa es así mismo crucial, ya que éstos deberían ser los mediadores más eficaces entre el espacio patrimonial y el alumno creador, dentro de un contexto educativo formal.

Las Conclusiones del Consejo y de los Representantes de los Gobiernos de los Estados miembros, reunidos en el seno del Consejo, de 22 de mayo de 2008, sobre el fomento de la creatividad y la innovación en la educación y la formación, que destacaba en particular el papel crucial que desempeñan los profesores y el entorno de aprendizaje a la hora de alimentar y respaldar el potencial creativo de cada niño (Unión Europea, 2015, p. 17).

Siguiendo a Bolívar (2005), cuando analiza el Programa de desarrollo del conocimiento de la enseñanza de Shulman, entendemos que las didácticas específicas son cruciales para un buen desarrollo didáctico del profesorado de cualquier ámbito.

Señalamos otro hallazgo de la Conclusiones, como es la alusión a la cultura y la creatividad como competencias y motor del desarrollo intelectual, reconociendo dichas competencias como fuente de desarrollo sostenible de productos y servicios innovadores (Unión Europea, 2015). Encontramos destacable la aseveración del valor de la cultura y la creatividad, como elementos que fraguan un desarrollo intelectual palpable. No obstante, nuevamente encontramos el reconocimiento al valor de la creatividad como desarrollador de productos y servicios comerciales.

Vemos, así mismo, relevante la referencia a la utilidad del desarrollo creativo temprano, como elemento interesante para un mayor y mejor crecimiento de todo tipo de capacidades.

Fomentar la creatividad, la innovación y la competencia digital mediante la educación en los primeros años, (3) puede dar beneficios más adelante, al sentar las bases del aprendizaje posterior, al permitir que el conocimiento se desarrolle a un nivel mucho mayor y al mejorar en general la capacidad de cada niño de desarrollar un pensamiento creativo y crítico y hacerse ciudadano responsable de la Europa de mañana, capaz de hacer frente a los retos de un mundo cada vez más interconectado y globalizado (Unión Europea, 2015, p. 18). 
Compartiendo este punto de vista, defendemos así mismo la importancia de un estímulo permanente de lo creativo a lo largo de la vida. No tanto desde el plano económico o laboral, que quizá dependa de la ocupación de cada quien, si no desde el plano del desarrollo emocional y cultural. Algo a lo que deberíamos tender en nuestro proceso madurativo como un eje esencial de nuestro equilibrio interno, como individuos y también como seres sociales.

Encontramos también una alusión interesante desde el punto de vista educativo, sobre el papel de la pedagogía, los recursos y el entorno, como elementos a tener en cuenta para alimentar la creatividad. Se insta a la modernización de los planteamientos pedagógicos y todo el entorno formativo a través de la formación inicial y el desarrollo profesional de los docentes, entendiendo que son figuras clave para nutrir la creatividad de los niños con el ejemplo de su propia enseñanza (Unión Europea, 2015). El papel de los enseñantes como motor de todo tipo de desarrollos es mencionado habitualmente desde todo tipo de textos legislativos, así como la formación de éstos, que debería de capacitarles para el objetivo mencionado.

Más adelante hallamos una referencia a diferentes materias artísticas y a la fusión de ellas. Es esto último lo que nos llama la atención en este caso, ya que además de recalcar el término comprensión cultural, no referido al estudio quizá sino al disfrute desde el conocimiento, nos exhorta a explorar las posibilidades de las asociaciones creativas con diferentes artes (Unión Europea, 2015). Como ya hemos referido y siguiendo la línea de las Conclusiones, amparamos la utilización de la mayor cantidad posible de manifestaciones artísticas como medio de estimulación creativa a través del análisis y la experimentación de los elementos artísticos y patrimoniales.

Revisamos seguidamente la Comunicación sobre desarrollo escolar y docencia excelente, en busca de alusiones a la importancia de la formación del profesorado en materia de creatividad como elemento indispensable para desarrollar su trabajo de manera destacable, tal y como se alude en el título. No obstante, solamente encontramos la alusión a creatividad y pensamiento crítico, como competencias transversales a desarrollar por el alumnado sin concreción de cuál es el camino para conseguirlo (Unión Europea, 2017). Entendemos y apoyamos la importancia otorgada al desarrollo creativo, pero no comprendemos la ausencia de alusiones directas a la formación del profesorado en este ámbito, máxime cuando el epígrafe trata sobre docencia excelente. Para encontrar estas referencias, debemos analizar la Comunicación para mejorar la calidad del profesorado, en ella encontraremos menciones indirectas que nos emplazan a las competencias clave, las cuales son consideradas elementos esenciales que los profesores deben ayudar a desarrollar. De la misma manera, se insta a utilizar la creatividad para la colaboración entre instituciones donde trabajan los profesores (Unión Europea, 2007).

Finalmente, revisamos las Conclusiones sobre el fomento de la creatividad y la innovación en la educación y la formación. Evidentemente y como no podía ser de otra manera por el título, las referencias a creatividad son numerosas. No obstante, la asociación de creatividad y patrimonio no obtiene resultados. En cualquier caso y dada la materia del documento, entendemos interesante reflejar algunos elementos que resultan cercanos a nuestro objeto de estudio y que aportan ideas válidas en torno a la transversalidad, el profesorado, los centros educativos o la investigación.

- Transversalidad. Destacamos dos citas donde se recuerda que todos los niveles y materias de la educación pueden contribuir al desarrollo creativo (Unión Europea, 2008). Sin duda el estímulo de la creatividad puede y debe tener su origen en todas y cada una de las materias que a día de hoy componen la educación obligatoria e incluso la educación no formal. Si además abogamos por un enfoque transversal en su 
tratamiento, tanto interdisciplinar como inter etapa, podemos encontrar una excepcional fuente de estímulo para producir ideas, objetos o cualquier forma de arte.

- Profesorado. Señalamos dos textos donde se destaca la función de respaldo, ejemplo y ayuda de los docentes, como facilitadores del aprendizaje y potenciadores de la creatividad. Se exhorta a ayudar a los centros de formación del profesorado para que sean sensibles a los nuevos roles de los docentes y respondan a las demandas que esto genera en su formación (Unión Europea, 2008). Desde nuestra óptica como docentes, consideramos clave la aportación que el profesorado puede hacer como elemento estimulador del proceso creativo. Por ello, insistimos en la idea de que el docente no puede realizar esta labor de forma intuitiva, si no que precisa de una formación adecuada como certeza de éxito en el objetivo del desarrollo creativo.

- Centros educativos. Analizamos una referencia a los centros de formación del profesorado como responsables de dotar a los docentes de las competencias que exige la sociedad actual (Unión Europea, 2008). Resulta significativa la alusión a la formación continua del profesorado como la mejor manera de dotarlo de las competencias necesarias para ejercer su labor hoy en día, y clarificadora la omisión de los centros de formación inicial de los futuros docentes, las universidades. No encontramos ninguna mención directa a las facultades de educación, responsables de un período crucial de la instrucción de los docentes, especialmente cuando se alude como responsable de la creatividad y la innovación a un "entorno general" y a la clase dirigente.

- Investigación. Se señala a la exploración educativa como un medio de evaluar los resultados del aprendizaje competencial (Unión Europea, 2008). Nos resulta un párrafo interesante, ya que se intenta conformar un procedimiento de evaluación de los aprendizajes creativos e innovadores por medio del intercambio de datos de los investigadores en estos campos. Todo ello para procurar a los legisladores una base sólida en la que apoyar unas políticas educativas centradas en estos dos ámbitos.

Nos sorprende que, tras aludir a investigación, centros, profesorado y niveles, no se hable en ningún caso sobre materias o modos algo más concretos de desarrollar la tan nombrada creatividad, sobre todo al ser este un documento estrictamente dedicado a ello.

Finalmente, exponemos una alusión a la cultura y la ciencia en las conclusiones del Consejo.

Las conclusiones del Consejo Europeo de primavera de 2008, que consideraban que desarrollar plenamente el potencial de innovación y creatividad de los ciudadanos europeos sobre la base de la cultura y la excelencia científica europeas, constituye un factor fundamental para el crecimiento futuro (Unión Europea, 2008, p. 4).

Destacamos como novedosa la propuesta de la mejora de la creatividad tomando como base la cultura y la ciencia, primordialmente esta última, que no había tenido hasta aquí un papel destacado.

La revisión de la documentación europea de contenido educativo, plasma que no se vincula de manera directa el patrimonio con la creatividad, lo cual es significativo para nuestro objeto de investigación. La ausencia de referencias conjuntas en los ámbitos administrativos y legislativos, deja entrever que no se valoran como esenciales para el ámbito educativo, la presencia en él de la creatividad ligada al patrimonio.

Resuelto nuestro objetivo esencial, nos hemos centrado en extraer algunas otras referencias interesantes que vinculan al profesorado con la creatividad. Destacamos como ideas principales de las expuestas anteriormente, el desarrollo creativo a través de: 
la cohesión social, la diversidad cultural, el análisis y la experimentación artística. Así mismo, subrayamos el señalar a los profesores como vehículo esencial para el desarrollo creativo o la utilidad de la creatividad para el desarrollo intelectual. Nos admira que ciertos textos pretendan ofrecer argumentos a los redactores de las leyes para facilitar la inclusión de la creatividad en ellas, como si hubiera que justificar su presencia de modo especial. Fundamentalmente, por que se viene repitiendo a lo largo de distintos documentos la importancia de la creación en el desarrollo personal, psicológico, social, madurativo, etc. de las personas. Por el contrario sorprende que no se haga ningún esfuerzo para consignar un proceso de trabajo de la creatividad, tratando de concretar un método tangible de crecimiento creativo e innovador. Algo que a todas luces nos parece importante para que el anhelo del desarrollo creativo se plasme de manera tangible en el día a día escolar.

La revisión legislativa de este segundo capítulo, nos permite afirmar, dado el número de hallazgos referidos, que la importancia otorgada a la creatividad en el total de documentos analizados, es considerable. Sin embargo, debemos matizar que las referencias mayoritariamente atienden al uso del término desde un punto de vista económico, donde se le confiere a la creatividad la capacidad de regenerar los sectores económico y empresarial. Las citadas referencias económicas se producen con igual profusión en la documentación de los ámbitos cultural, patrimonial y educativo. Desde el punto de vista educativo, las alusiones al emprendimiento son continuas, y al hablar de desarrollo de capacidades casi todas ellas terminan con menciones a la innovación tecnológica y la creación de empleo. En el espectro cultural ocurre algo similar, hallamos innumerables referencias a la industria creativa y cultural como motor económico e identitario de países o regiones. En este sentido, asumimos que los propios objetivos de la UE tienen un importante componente económico. De los ocho objetivos fundamentales de la UE, tres tienen una clara visión económica, lo que da sentido a lo comentado anteriormente y quizá por ello, es inevitable que las referencias culturales o educativas estén enfocadas hacia este aspecto. ${ }^{12}$

Esta visión mercantilista se contrapone con la acepción del término que defendemos y el enfoque de utilidad del patrimonio que nos interesa. Esto es, el de conferir a la creatividad la facultad de desarrollarse a lo largo de toda la vida por medio de la educación y el estímulo de la misma, así como su capacidad para contribuir a un mejor desarrollo personal y social del individuo.

Para finalizar, reseñamos nuevamente como ya ocurrió en las conclusiones del capítulo anterior, que las referencias en este caso creativas, son muy generales como para tener una repercusión concreta en la población. No pueden hacerlo si no son el germen de programas concretos y tangibles o al menos el de políticas estables que los posibiliten.

\subsubsection{La literatura científica internacional.}

De la misma manera que en el apartado de emociones, realizamos una búsqueda de literatura científica a nivel internacional, a través de WOS y Scopus en los idiomas inglés, francés, portugués y español cruzando los conceptos de patrimonio, y en este caso creatividad, en el título de las publicaciones (tabla 3 ).

\footnotetext{
${ }^{12}$ https://europa.eu/european-union/about-eu/eu-in-brief es
} 
Tabla 3. Referencias a Patrimonio y creatividad en títulos de publicaciones

\begin{tabular}{|c|c|c|}
\hline & WOS & SCOPUS \\
\hline Inglés & 39 & 31 \\
\hline Francés & 0 & 0 \\
\hline Portugués & 0 & 0 \\
\hline Español & 0 & 0 \\
\hline
\end{tabular}

Fuente: Propia

Las búsquedas en inglés en Web of Science nos arrojan 39 resultados, una buena parte de ellos referidos a economía, tecnología o arquitectura como tema central, entre otros de arte, humanidades o antropología. En su mayor parte tocan la creatividad y el patrimonio como herramientas para el desarrollo económico o la evolución tecnológica. De todos ellos destacamos a continuación varios artículos, dada la importancia que otorgan sus investigaciones a la creatividad en relación con el patrimonio y desarrollo económico.

Comenzamos comentando el libro de Silvia Cerisola "Cultural Heritage, Creativity and Economic Development" (2019a) donde la autora diserta sobre el papel mediador que puede ejercer la creatividad entre el patrimonio y el desarrollo económico. El libro narra cómo debe ser el camino desde el patrimonio cultural al desarrollo económico, mediado por la creatividad. Tres capítulos describen este proceso: capítulo 5 "Del patrimonio cultural a la creatividad", capítulo 6 "De la creatividad al desarrollo económico", y capítulo 7 "Del patrimonio cultural al desarrollo pasando por la creatividad". Este manual ha sido ampliamente debatido y citado por otros autores y su propuesta se ha convertido en referente para las investigaciones de los últimos años.

Encontramos dos artículos más en los que participa la misma autora, que presentan al patrimonio de pequeñas localidades como fuente de creatividad para el desarrollo local. El primero de ellos (Capelo, Crisola y Perica, 2020), afirma que cuando el patrimonio tangible se combina con el inmaterial aumenta las posibilidades de desarrollo económico de los lugares que los albergan, de esta manera, ambos promueven la creatividad a través de elementos emocionales, impulsando así la innovación y el pensamiento crítico. No obstante, el estudio asume sus limitaciones principalmente por las dificultades para definir creatividad y por tanto, responder a la pregunta de investigación sobre si la creatividad tiene efecto en la economía surgida del patrimonio. El segundo de ellos "A new perspective on the cultural heritage-development nexus: the role of creativity" (Cerisola, 2019b), analiza la importancia de la cultura en el desarrollo económico de los territorios presentando un ejemplo práctico de ello. Introduce la idea de que no solamente el patrimonio cultural es el motor del turismo cultural, sino que además de él, podemos utilizar la creatividad como mediador entre ambos. Para ello, el artículo examina conceptual y empíricamente un modelo de actuación en algunas provincias italianas (NUTS3).

Teresa Cilona (2019) nos presenta la misma mirada económica en el uso del patrimonio, pero en esta ocasión se introduce el elemento del medio ambiente y el patrimonio natural, como complemento a la propuesta defendida por el resto de autores mencionados. Se centra el artículo en la experiencia realizada en la zona de Agriento (Italia), donde se puso en marcha una nueva forma de turismo basada en el disfrute del patrimonio cultural, etnográfico y natural de la comarca, primando las experiencias vivenciales y emocionales de los usuarios.

En el artículo titulado "Creativity and mediation in tourism and in heritage: approaches, stakeholders and issues" (Saidi, 2016), encontramos una temática antropológica que 
diserta sobre un nuevo modelo de la relación turismo-patrimonio. Se argumenta que existe un nuevo tipo de turista que no busca el turismo de masas ni de grandes iconos culturales, si no que persigue crear su propio viaje. Habla así mismo de las comunidades locales receptoras de este tipo de turismo. Se utilizan los términos ciudades creativas o localidades creativas, términos ya utilizados (Andersson, 2011), para atraer a este tipo de turismo.

Las búsquedas en inglés de Scopus arrojan un resultado de 31 artículos de los cuales 19 son coincidentes con los ya revisados en WOS. De los restantes, como nos ha ocurrido en el buscador anterior, la mayoría están relacionados con temáticas como negocios, gestión o contabilidad. Entre los que responden a nuestros intereses está "Intangible cultural heritage: Safeguarding for creativity" (Cominelli, 2012), el artículo se centra en el patrimonio inmaterial y su arraigo en territorios y comunidades, como elemento imprescindible para tener visiones creativas en torno a las sociedades y economía de las que parte ese patrimonio intangible. Presenta las prácticas, representaciones, expresiones, conocimientos o habilidades patrimoniales como fuente de creatividad o innovación.

Comentamos así mismo el artículo: "A Cultural Creativity Framework for the Sustainability of Intangible Cultural Heritage" (Tan, Lim, Tan y Kok, 2020). En él se presenta un estudio que pretende generar un modelo que permita preservar el patrimonio cultural inmaterial subyacente a Sitios de Patrimonio Mundial (WHS). Para ello se realizaron entrevistas y observaciones a usuarios de estos lugares, de donde se extraen algunos elementos básicos que pueden ayudar con carácter general, al objetivo de conservación señalado.

Hallamos una experiencia práctica muy interesante realizada en Al-Asha (Arabia Saudí), una ciudad con un rico patrimonio arquitectónico con altos valores artísticos. La investigación a través de una metodología experimental, emplea y adapta el potencial estético de la arquitectura tradicional de la ciudad para producir obras de arte en diseños decorativos y artesanía. Los investigadores (Kamel, Shahat y Al-Hashel, 2020), señalan que el patrimonio arquitectónico es una buena fuente de creatividad artística y recomienda estrechar lazos entre instituciones de patrimonio con facultades de bellas artes. Una postura que defendemos en este trabajo, la utilización del patrimonio como herramienta de trabajo emocional e inspiración creativa.

Prlic (2019) nos presenta una experiencia de cooperación entre diez museos etnográficos europeos, en la que se reflexiona sobre su futuro a tenor de los procesos de inmigración y globalización. Se investiga sobre los medios para colaborar con comunidades de artistitas y la búsqueda de otras posibilidades de acción, como los medios digitales. La acción busca nexos de unión entre los museos para debatir en torno a las identidades locales y transnacionales, poniendo énfasis en la inmigración y las comunidades de la diáspora. Se buscan soluciones creativas para generar ideas en torno a la supervivencia de los museos, teniendo en cuenta la situación actual de diversidad social.

Traemos seguidamente para su análisis, un artículo que, si bien presenta esencialmente la herramienta web eDIRICA destinada a la gestión del patrimonio cultural en Nigeria, hace hincapié en el problema de la visión turística en la gestión de lugares patrimoniales por encima de los fines educativos. Adetunji, Essien y Owolabi (2018), señalan que la educación patrimonial no está incluida en la escuela, ni formados en este ámbitos los maestros, destacando así mismo que la colaboración entre administraciones patrimoniales y educativas no existe en Nigeria.

No se encuentran resultados para las búsquedas en francés, portugués o castellano en ninguno de los dos buscadores. 
A tenor de los resultados, entendemos como escasos y en la mayoría de los casos poco relevantes los hallazgos realizados en torno a la relación del patrimonio y la creatividad. La generalidad de las coincidencias terminológicas no lo son posteriormente en las acepciones utilizadas, el término patrimonio es aplicado en su significación de herencia, $\mathrm{y}$ aunque la creatividad si se usa como nueva forma de entender o utilizar recursos patrimoniales, siempre se emplea en el contexto de generar nuevos recursos económicos y no didácticos.

\subsubsection{Referentes internacionales.}

Como referentes internacionales, analizamos las iniciativas de la Dirección General de Educación y Cultura de la Comisión Europea (DG EAC), la cual se ocupa de la educación, la formación, la juventud, el deporte, las lenguas y la cultura. El papel de la Unión en el ámbito de la cultura, como ya se ha señalado, se especifica en el artículo 167 del Tratado de Funcionamiento de la UE. Las actividades de la DG EAC en este sector se enmarcan dentro de la Agenda Europea para la Cultura, cuyo objetivo es dar mayor relevancia a la cultura. La DG EAC desarrolla políticas específicas y gestiona iniciativas, como Europa Creativa, en defensa del patrimonio cultural europeo.

Esta iniciativa es la que pretendemos analizar, ya que su nombre entronca directamente en el objeto de nuestra investigación. Para ello, dado que ya hemos comentado la documentación legal al respecto, indagamos sobre las iniciativas que se concretan en su página web. ${ }^{13}$

Del análisis de este recurso, se desprende que Europa Creativa es el programa marco de la UE para apoyar los sectores cultural y audiovisual, dando continuidad a lo que fue el programa "cultura y media". Cuenta con un presupuesto de 1.460 millones de euros para apoyar a lo que se denominan sectores cultural y creativo.

Dentro del subprograma de cultura, se incide principalmente en la cooperación transfronteriza, las plataformas, la creación de redes y la traducción literaria. La cooperación tiene como objetivo mejorar el acceso a las actividades culturales y creativas, así como promover la innovación y la creatividad apoyando proyectos que pueden ser interdisciplinarios. Las plataformas son de operadores culturales para publicitar a los nuevos artistas e impulsar un plan europeo de la labor cultural y artística. Se concede apoyo financiero a actividades como la movilidad de artistas, divulgación de obras, visibilidad de valores, etc. De la misma manera, se ofrece apoyo a las redes europeas para ayudar a los sectores cultural y creativo a funcionar en un contexto transnacional y aumentar su competitividad. Se ofrecen fondos para actividades que mejoren aptitudes y experiencias de trabajadores, fortalezcan organizaciones, creación de oportunidades profesionales, etc. Finalmente, se apoyan las iniciativas de traducción de obras literarias y de su promoción en los mercados de la UE, con objeto de facilitar el acceso a la literatura europea de calidad y aumentar el número de lectores.

En el subprograma media, se apoyan especialmente elementos como el cine, tv, desarrollo de videojuegos, apoyo a la distribución, desarrollo de la audiencia, acceso a los mercados, y formación para los profesionales de estos sectores.

Existe así mismo, un tercer subprograma llamado intersectorial, que se establece como instrumento de garantía para los dos sectores anteriores, el apoyo de políticas transnacionales y la red de oficinas de Europa Creativa.

\footnotetext{
${ }^{13}$ https://ec.europa.eu/programmes/creative-europe/index_es
} 
Tras la celebración durante el año 2018 del Año Europeo del Patrimonio Cultural, y para garantizar que su huella trascendía esa celebración, la Comisión Europea puso en marcha proyectos a largo plazo en torno a 10 temas, las llamadas "10 iniciativas europeas". Estas iniciativas correspondían a cuatro principios que definen la esencia del Año Europeo del Patrimonio Cultural 2018: compromiso, sostenibilidad, protección e innovación. Y son: Patrimonio compartido, Patrimonio en la escuela, La juventud con el Patrimonio, Patrimonio en transición, Turismo y Patrimonio, Apreciar el Patrimonio, Patrimonio en riesgo, Competencias asociadas al Patrimonio, Todo por el Patrimonio y Ciencia para el Patrimonio. ${ }^{14}$

Estas iniciativas pretendieron ofrecer un marco para aplicar un enfoque europeo, intersectorial e integrado al patrimonio cultural. Como podemos leer en la web, cada una de las diez iniciativas europeas agrupa una serie de actuaciones y proyectos que incluyen tanto iniciativas nuevas que se pusieron en marcha especialmente con motivo del Año Europeo, como iniciativas ya existentes que se revalorizaron y recibieron un nuevo impulso. Las iniciativas tratan los aspectos material, inmaterial y digital del patrimonio cultural y redundan en beneficio de diferentes grupos de destinatarios, desde los profesionales del ámbito del patrimonio cultural, hasta las comunidades locales, pasando por los jóvenes y los niños, los grupos a los que resulta más difícil acceder y el público general.

Analizamos en profundidad la iniciativa número dos, Patrimonio en la escuela, ya que tiene una relación directa con nuestro objeto de estudio. Está destinada principalmente a docentes, padres, comunidades locales y escolares entre 10 y 15 años. Consta de cuatro componentes: valorizar los proyectos de Erasmus+ sobre Patrimonio cultural y promover nuevas iniciativas, actividades de concienciación para escolares, actividades para niños en el marco de las jornadas europeas de patrimonio, y reforzar Europa a través de la educación y la cultura. El componente uno abarca acciones informativas y divulgativas de Erasmus $+\mathrm{y}$ eTwinning, una plataforma para centros escolares interesados en comunicarse, colaborar y desarrollar proyectos. Dentro del componente dos se llevan a cabo actividades de concienciación en dos niveles, por un lado la creación de herramientas para las escuelas centralizadas en eTwinning, School Education Gateway y Euroclio (Asociación Europea de Profesores de Historia); y por otro, la sensibilización acerca de la protección del patrimonio conjuntamente con la Red del Plan de escuelas asociadas de la UNESCO. El componente tres se desarrolló exclusivamente como parte de las Jornadas Europeas de Patrimonio, donde se organizó la "Semana de los Creadores de Patrimonio Europeo", con el fin de animar a los escolares a descubrir la dimensión europea del patrimonio local. Y finalmente, el componente cuatro donde el Comité Europeo de las Regiones organizó un debate sobre el tema de las ciudades y regiones como motores clave para el refuerzo de la identidad europea a través de la educación y la cultura.

Como vemos, se han diseñado un gran número de iniciativas educativo-patrimoniales que en algunos casos han trascendido el Año Europeo del Patrimonio Cultural y que gracias a las webs mencionadas, mantienen actualmente la comunicación entre docentes interesados en trabajar con el patrimonio. Sin embargo, no encontramos relación directa en ninguna de las iniciativas con la creatividad.

La Comisión Europea, dentro de su área de investigación e innovación, acoge una investigación sobre patrimonio cultural y creatividad en Europa ${ }^{15}$ que se circunscribe a

\footnotetext{
${ }^{14} \mathrm{https} / / / \mathrm{ec}$. europa.eu/culture/content/overview es

15 https://ec.europa.eu/info/research-and-innovation/research-area/social-sciences-andhumanities/europes-cultural-heritage-and-creativity_en\#briefs
} 
las iniciativas Horizonte $2020^{16}$. La iniciativa pone en marcha distintas acciones con el objetivo de: desarrollar herramientas y metodologías para preservar el patrimonio cultural tangible e inmaterial, proteger el patrimonio en peligro del tráfico ilícito, fomentar el acceso al patrimonio cultural a través de medios digitales, promover el turismo cultural para el desarrollo socioeconómico regional, y fortalecer la cooperación entre museos y sitios patrimoniales.

Al igual que nos ocurría en la revisión emocional, entidades internacionales que son referentes en el ámbito patrimonial mundial, como ICOM (Consejo Internacional de Museos), Intangible Cultural Heritage \& Museums Proyect IMP dependiente del ICOM, ICOMOS (International Council on Monuments and Sites), ICCROM (nternational Centre for the Study of the Preservation and Restoration of Cultural Property) no presentan acciones concretas en nuestro ámbito de estudio creativo.

\subsection{La perspectiva nacional.}

Analizaremos en este apartado la presencia que tiene la creatividad ${ }^{17}$ dentro del ámbito patrimonial en nuestro país. Para ello, revisaremos la legislación vigente en materia de patrimonio, tanto nacional como autonómica. Veremos si existe alguna iniciativa por parte del IPCE o referencias en los planes nacionales y para finalizar consideraremos la literatura científica.

\subsubsection{La legislación vigente en materia de patrimonio}

A nivel nacional, nuevamente consideraremos la Ley de Patrimonio Histórico y la Ley para la Salvaguarda del Patrimonio Cultural Inmaterial.

En la Ley de Patrimonio Histórico encontramos ocho referencias, de las que destacamos una en el preámbulo, y otra en el artículo sesenta y ocho.

El Patrimonio Histórico Español es el principal testigo de la contribución histórica de los españoles a la civilización universal y de su capacidad creativa contemporánea. La protección y el enriquecimiento de los bienes que lo integran, constituyen obligaciones fundamentales que vinculan a todos los poderes públicos, según el mandato que a los mismos dirige el artículo 46 de la norma constitucional (Ley de Patrimonio Histórico, 1985, preámbulo).

La referencia creativa del preámbulo hace alusión a la capacidad de creación de los españoles en la actualidad, dando al patrimonio el valor de germen de las creaciones contemporáneas. Sorprendentemente, se ha obviado el valor creativo de las personas que idearon esos elementos patrimoniales en su época. Parece algo rebuscado el otorgar un papel relevante al patrimonio como elemento inspirador de los creadores actuales, y negarle éste mismo papel a los creadores anteriores, como si el origen de las obras antiguas no tuviera componentes creativos y solamente el compendio de muchas de ellas a lo largo de los siglos, fuera constitutivo de generar la creatividad.

En el artículo sesenta y ocho, nos topamos con una referencia más de clara vinculación económica, en este caso importante, por su intención de sistematizar la aportación de recursos económicos del estado concretada en el 1\% del gasto en obra pública. Se liga así el desarrollo estructural del país al cultural. Un artículo algo confuso sin embargo,

16 https://ec.europa.eu/programmes/horizon2020/what-horizon-2020

${ }^{17}$ Utilizaremos las mismas raíces que anteriormente: "crea", "invent" e "ing". 
ya que, si bien por un lado deja claro su propósito al hablar de conservación y enriquecimiento del patrimonio, no lo hace tanto al referirse al fomento de la creatividad, cuya redacción resulta algo ambigua y ha dado cabida a interpretaciones dispares de los objetivos (Ley de Patrimonio Histórico, 1985, art. 68).

En la Ley para la Salvaguarda del Patrimonio Cultural Inmaterial encontramos una alusión de interés extraída de documentación de la UNESCO. La ya citada y comentada Declaración de México sobre Políticas Cultuales (UNESCO, 1982), donde se define el Patrimonio Cultural de un pueblo y la importancia de la creatividad como germen del mismo.

Otro jalón se encuentra en la relevante Conferencia Intergubernamental sobre Politicas Culturales, organizada por la UNESCO en México, en 1982. La aportación de este encuentro reside en que viene a realizar una labor de sistematización de las recomendaciones precedentes. En la Declaración aprobada por la Conferencia, referida a todos los ámbitos de la cultura, destaca que el patrimonio cultural lo integran «las obras materiales e inmateriales que expresan la creatividad de un pueblo», nombrando expresamente, entre otros bienes propios del patrimonio inmaterial, la lengua, los ritos, las creencias, la literatura y las obras de arte (Ley para la Salvaguarda del Patrimonio Cultural Inmaterial, 2015, preámbulo, p.10).

En este caso sí se alude directamente al patrimonio heredado como expresión de la creatividad de una sociedad, lo que se nos antoja como básico sin menoscabo de su referida importancia como base de nuevos impulsos creativos, como también hemos defendido.

Revisaremos a continuación la presencia de los descriptores de búsqueda en las leyes autonómicas por orden cronológico, exceptuando aquellas comunidades que posean más de una ley de patrimonio que comentaremos de manera conjunta (Tabla 4).

Tabla 4. Menciones a la creatividad en las Leyes Autonómicas

\begin{tabular}{|c|c|l|c|}
\hline Año & $\begin{array}{c}\text { Comunidad } \\
\text { autónoma }\end{array}$ & \multicolumn{1}{|c|}{ Ley } & $\begin{array}{c}\text { Número } \\
\text { de } \\
\text { referencias } \\
\text { creativas }\end{array}$ \\
\hline 1990 & Murcia & $\begin{array}{l}\text { Ley 4/1990, de 11 de abril, de medidas de } \\
\text { fomento del patrimonio histórico de la } \\
\text { Región de Murcia }\end{array}$ & 4 \\
\hline 1993 & Cataluña & $\begin{array}{l}\text { Ley 9/1993, de 30 de septiembre, del } \\
\text { Patrimonio Cultural Catalán }\end{array}$ & 1 \\
\hline 1998 & Valencia & $\begin{array}{l}\text { Ley 4/1998, de 11 de junio, del } \\
\text { Patrimonio Cultural Valenciano }\end{array}$ & 5 \\
\hline 1998 & Cantabria & $\begin{array}{l}\text { Ley 11/1998, de 13 de octubre, de } \\
\text { Patrimonio Cultural de Cantabria }\end{array}$ & 0 \\
\hline 1998 & Islas Baleares & $\begin{array}{l}\text { Ley 12/1998, de 21 de diciembre, del } \\
\text { Patrimonio Histórico de las Illes Balears }\end{array}$ & 4 \\
\hline 1999 & Aragón & $\begin{array}{l}\text { Ley 3/1999, de 10 de marzo, del } \\
\text { Patrimonio Cultural Aragonés }\end{array}$ & 6 \\
\hline 1999 & Canarias & $\begin{array}{l}\text { Ley 4/1999, de 15 de marzo, de } \\
\text { Patrimonio Histórico de Canarias }\end{array}$ & 0 \\
\hline
\end{tabular}




\begin{tabular}{|c|c|c|c|}
\hline 1999 & Extremadura & $\begin{array}{l}\text { Ley 2/1999, de } 29 \text { de marzo, de } \\
\text { Patrimonio Histórico y Cultural de } \\
\text { Extremadura }\end{array}$ & 3 \\
\hline 2001 & Asturias & $\begin{array}{l}\text { Ley 1/2001, de } 6 \text { de marzo, del } \\
\text { Patrimonio Cultural del Principado de } \\
\text { Asturias }\end{array}$ & 3 \\
\hline 2002 & Castilla y León & $\begin{array}{l}\text { Ley 12/2002, de } 11 \text { de julio, de } \\
\text { Patrimonio Cultural de Castilla y León }\end{array}$ & 0 \\
\hline 2004 & La Rioja & $\begin{array}{l}\text { Ley 7/2004, de } 18 \text { de octubre, de } \\
\text { Patrimonio Cultural, Histórico y Artístico } \\
\text { de La Rioja }\end{array}$ & 3 \\
\hline 2005 & Navarra & $\begin{array}{l}\text { Ley Foral } 14 / 2005 \text {, de } 22 \text { de noviembre, } \\
\text { del Patrimonio Cultural de Navarra }\end{array}$ & 1 \\
\hline 2007 & Murcia & $\begin{array}{l}\text { Ley 4/2007, de } 16 \text { de marzo, de } \\
\text { Patrimonio Cultural de la Comunidad } \\
\text { Autónoma de la Región de Murcia }\end{array}$ & 1 \\
\hline 2007 & Andalucía & $\begin{array}{l}\text { Ley 14/2007, de } 26 \text { de noviembre, del } \\
\text { Patrimonio Histórico de Andalucía }\end{array}$ & 1 \\
\hline 2013 & Castilla la Mancha & $\begin{array}{l}\text { Ley 4/2013, de } 16 \text { de } \begin{array}{l}\text { mayo, de } \\
\text { Patrimonio Cultural de } \\
\text { Mancha }\end{array} \\
\text { Castilla-La }\end{array}$ & 2 \\
\hline 2013 & Madrid & $\begin{array}{l}\text { Ley 3/2013, de } 18 \text { de junio, de } \\
\text { Patrimonio Histórico de la Comunidad de } \\
\text { Madrid }\end{array}$ & 0 \\
\hline 2016 & Galicia & $\begin{array}{l}\text { Ley } 5 / 2016 \text {, de } 4 \text { de mayo, del patrimonio } \\
\text { cultural de Galicia }\end{array}$ & 3 \\
\hline 2019 & Islas Baleares & $\begin{array}{l}\text { Ley } 18 / 2019 \text {, de } 8 \text { de abril, de } \\
\text { salvaguardia del patrimonio cultural } \\
\text { inmaterial de las Illes Balears }\end{array}$ & 3 \\
\hline 2019 & País Vasco & $\begin{array}{l}\text { Ley } 6 / 2019 \text {, de } 9 \text { de mayo, de Patrimonio } \\
\text { Cultural Vasco }\end{array}$ & 3 \\
\hline
\end{tabular}

Fuente: Propia

Murcia tiene en vigor dos leyes. Por un lado, la Ley de Patrimonio Cultural del año 2007, que no presenta más referencia que la contenida en la definición de sitio histórico en el artículo tres. Y por otro, la Ley de Patrimonio Histórico del año 1990 donde encontramos cuatro referencias a la creatividad, todas ellas con relación a los fondos destinados a fomentar la creatividad y provenientes de tantos por ciento de partidas de obras públicas o fondos complementarios transferidos. Como vemos, se trata de alusiones derivadas del citado artículo 68 de la Ley de Patrimonio Histórico.

En la Ley de Patrimonio Cultural Catalán, encontramos una sola referencia nuevamente centrada en el artículo 68 de la Ley de Patrimonio Histórico a través de la financiación de la conservación, restauración, excavación, adquisición de bienes o creación artística contemporánea a través el $1 \%$ de las partidas destinadas a obras públicas.

La Ley de Patrimonio Cultural Valenciano posee cinco referencias a la creación.

La primera de ellas en el artículo 1, donde se relatan todos los elementos que conforman el patrimonio cultural valenciano. Dentro de la enumeración de patrimonios encontramos la mención a "creaciones", sin especificar nada más al respecto. Seguidamente, nos topamos en la definición de sitio histórico en el artículo 26 donde se mencionan las creaciones culturales de valor histórico, etnológico o antropológico. En 
este mismo artículo y dentro de la referencia a bienes inmateriales, aparecen las creaciones como posibles bienes de interés cultural.

Finalmente, hallamos dos alusiones similares en los artículos 45 y 55 donde se habla de las creaciones como manifestaciones de la cultura y modos de vida tradicionales de los valencianos. Entendemos nuevamente que trata de menciones genéricas atribuibles a cualquier campo, no mencionado expresamente en el párrafo donde aparecen.

Todas estas referencias utilizan la palabra creación con la acepción de producción de elementos, más que con la de invención de algo novedoso. Por ello, no nos resultan relevantes para el estudio, más allá del número de alusiones ya que es la segunda ley que más contiene.

Islas Baleares es otra de las comunidades que posee dos leyes, como ya hemos señalado anteriormente, Ley de Patrimonio Histórico y Ley de Patrimonio Inmaterial. En la primera de ellas, encontramos de nuevo referencias a las creaciones en la definición de Lugar Histórico y dentro de las referencias al 1\% cultural de los presupuestos de obras públicas. La Ley de Salvaguardia del Patrimonio Cultural Inmaterial de las Islas Baleares acoge tres referencias a la creación, la primera de ellas recogida en el artículo dos, ha sido ya comentada en el capítulo uno por acoger los conceptos de estudio de creatividad y sentimiento. La segunda la encontramos en el artículo 5.

Los grupos o las entidades culturales sin ánimo de lucro, los forman las personas pertenecientes a una o varias comunidades que comparten conocimientos y técnicas específicas relacionados con la creación y la recreación del patrimonio cultural inmaterial, y que tienen entre sus objetivos el mantenimiento, la transmisión y otras medidas de salvaguarda de este patrimonio (La Ley de Salvaguardia del Patrimonio Cultural Inmaterial de las Islas Baleares, 1998, art.5).

Nos resulta interesante hallar conjuntamente los términos creación y recreación referidos a conocimientos y técnicas. Esta forma de redacción implica que las recreaciones de origen inmaterial requieren tanto de saberes específicos, como de sistemas o métodos técnicos que las convierten en algo que va más allá del mero espectáculo o atractivo turístico. Al final del artículo se vinculan ambas con el mantenimiento y la transmisión. Queremos entender que estas iniciativas aportan comportamientos creativos y actividades novedosas para el fin de la preservación.

Finalmente, encontramos el artículo 7 donde nuevamente el término creación aparece de forma genérica, acompañando a ámbitos, bienes o agentes que pudieran ser inventariados.

Aragón, en el preámbulo de su Ley del Patrimonio Cultural Aragonés, refiere la utilidad que el propio estatuto tiene para impulsar la creación. El objetivo descrito es el de conformar un marco jurídico que sirva de herramienta para posibilitar y dinamizar las creaciones presentes que constituyen el patrimonio de hoy y mañana, uniéndose al ya existente (Ley del Patrimonio Cultural Aragonés, 1999, preámbulo, p. 8).

La Ley de Patrimonio Histórico y Cultural de Extremadura recoge tres referencias de las que analizamos dos. Dentro del Artículo 1, se describe el objetivo de la Ley, la protección, conservación, engrandecimiento, difusión y estímulo del Patrimonio Histórico y Cultural con la misión de trasladarlo a las futuras generaciones, para que sirva de incentivo a la creatividad (Ley de patrimonio Histórico y Cultural de Extremadura, 1999, art.1). Para la siguiente referencia debemos ir hasta el artículo 83. 
La Junta de Extremadura promoverá ayudas, dentro de las previsiones presupuestarias, para la investigación, documentación, conservación, recuperación, restauración, difusión e incentivo de la creatividad artística de los bienes integrantes del Patrimonio Histórico y Cultural extremeño, que se concederán de acuerdo con los criterios de publicidad, concurrencia y objetividad (Ley de patrimonio Histórico y Cultural de Extremadura, 1999, art.83).

Consideramos cuando menos difusa la redacción de este artículo donde se habla de promover ayudas para la creatividad artística de los bienes patrimoniales. Se puede estimular la creatividad por medio del trabajo con un elemento patrimonial, sin embargo, tal y como está expresado, se confiere al patrimonio la posesión de la creatividad como una característica innata del elemento y no como objeto que la suscita. La Ley del Patrimonio Cultural de Galicia presenta varias alusiones de las que destacamos la extraída del preámbulo.

El estudio, la protección, la conservación, el acrecentamiento, la difusión y el fomento del patrimonio cultural son piedra angular del ejercicio de la dignidad colectiva y, por lo tanto, se plasman como el primer mandato legal, que no debe ser visto como limitación restrictiva, sino como participación de toda la sociedad en el cuidado de lo que ella misma ha creado y a lo que ella misma le pertenece. El patrimonio cultural se concibe, pues, como fundamento de cohesión social y desarrollo sostenible (Ley de Patrimonio Cultural de Galicia, 2016, preámbulo, p.4).

Nos interesa esta alusión colectiva a la sociedad como creadora y propietaria de los bienes patrimoniales, ya que es algo que defiende este estudio, la utilización de un bien colectivo y humano como es el Patrimonio para formar de manera integral a los futuros integrantes de la sociedad.

De las tres referencias localizadas en la Ley de Patrimonio Inmaterial de Baleares, examinamos la hallada en el artículo dos, ya que atribuye directamente al patrimonio y a la interacción con la naturaleza y la historia un valor para la creatividad humana. Estamos ante el mismo artículo ya comentado en el capítulo uno, al contener referencias a emociones y creatividad conjuntamente.

Este patrimonio cultural inmaterial, que se transmite de generación en generación, lo recrean constantemente las comunidades, los grupos o las personas en función de su entorno, la interacción con la naturaleza y su historia, lo cual les infunde un sentimiento de identidad y continuidad y contribuye, por lo tanto, a promover el respeto a la diversidad cultural y a la creatividad humana (Ley de Patrimonio Inmaterial de las Islas Baleares, 2019, art2).

Es destacable la alusión a la diversidad en las recreaciones emanada de las diferencias en el entorno, la relación con la naturaleza y la historia. En ocasiones se obvia la importancia de los componentes físicos en el desarrollo cultural de los pueblos, y lo que es también esencial, en la conservación de las tradiciones y elementos patrimoniales de que se componen.

Como ya hemos comentado también en el capítulo uno, este mismo artículo aparece con una redacción muy similar en la Ley de Patrimonio cultural Vasco del año 2019. 
Tan solo cuatro comunidades autónomas son las que no presentan ninguna referencia a la creatividad en sus leyes: Canarias, Cantabria, Castilla y León y Madrid.

No obstante, debemos considerar que muchas de las referencias plasmadas en la tabla 4 y correspondientes a comunidades autónomas distintas, están referidas a los mismos conceptos que se repiten una y otra vez de forma prácticamente igual, trasladados de las leyes estatales a las autonómicas. Es el caso de las definiciones de figuras patrimoniales como sitio histórico o patrimonio inmaterial, así como el 1\% cultural de los gastos en obra pública.

En cualquier caso, las referencias encontradas no tienen la intención de legislar directamente sobre la creatividad. Se hace referencia a los aspectos de la creación de forma accesoria, otorgando al patrimonio la capacidad de ayudar a su desarrollo. No obstante como venimos comentando, no se detalla la forma de hacerlo, si no que se acepta que los elementos patrimoniales poseen por si mismos la cualidad de despertar la capacidad creadora en los individuos.

\subsubsection{El Instituto del Patrimonio Cultural de España y los Planes Nacionales}

En el capítulo 1 se abordaron las funciones del IPCE y las acciones que realiza planificadas a través de los Planes Nacionales, por ello, en este caso pasamos directamente a considerar la presencia de la creatividad en ellos.

\subsubsection{EI Plan Nacional de Educación y Patrimonio.}

Hallamos la primera mención a la creación en las primeras páginas del documento. El plan presenta como conjunto educativo los ámbitos formal, no formal e informal, insistiendo en la necesidad de realizar programaciones e implementaciones conjuntas. Entendemos este planteamiento dentro de los objetivos generales de conservación o valoración, no obstante, y sin estar en contra de esta idea, pensamos que los tres ámbitos tienen objetivos particulares muy diferentes y esto hace que sea difícil conjugar propuestas que sean útiles a las tres esferas. Al hablar de los contextos donde el patrimonio se crea, entendemos como crucial el de la familia y quizá no tanto el de los medios de comunicación. Pensamos que existen otras entidades intermedias entre los núcleos familiares y la sociedad en general, como pueden ser grupos, asociaciones, comunidades o agrupaciones de distinto tipo que pueden jugar un papel fundamental como contextos donde también se crea, protege, transmite y pone en valor el patrimonio (Plan Nacional de Educación y Patrimonio, 2015, p. 5).

Encontramos la siguiente alusión dentro de las estrategias de comunicación social de la formación de gestores culturales. Se exhorta a cimentar las actividades culturales en el aprendizaje por descubrimiento, tanto individual como grupal, procurando fomentar en ellas la creatividad (Plan Nacional de Educación y Patrimonio, 2015, p. 35).

Hallar dos únicas referencias a la creatividad en un documento que aborda exclusivamente la visión educativa del patrimonio, nos da una idea de la importancia que se otorga a esta capacidad en el plan. Es evidente que no se considera relevante en ninguno de los apartados que incluye: objetivos, conceptos, aspectos metodológicos, líneas de actuación, difusión, etc. Pero destacamos por encima de todos los anteriores, que no tenga reflejo en cuestiones clave bajo nuestro punto de vista como son la investigación e innovación en didáctica del patrimonio, o formación de educadores, gestores e investigadores. Máxime cuando se hace alusión a aplicaciones didácticas, modelos educativos emergentes o recursos y herramientas para la interpretación, es decir el corpus pedagógico del plan. La falta de referencias en estos apartados 
didácticos contrasta, si nos atenemos al número de citas como venimos haciendo, con los de la educación formal. Como veremos más adelante, el análisis de la ley educativa vigente aprobada un año después de la redacción de este plan, tiene una presencia mucho mayor de referencias creativas, entendiendo por ello que, al menos desde la educación formal, se otorga un papel más crucial a la creatividad que el que le concede el Plan Nacional de Educación y Patrimonio.

\subsubsection{El Plan Nacional para la Salvaguarda del Patrimonio Cultural Inmaterial.}

Al analizar el Plan Nacional para la Salvaguarda del Patrimonio Cultural Inmaterial, nos encontramos con referencias a la creatividad en la propia definición de lo que es el PCI al referir que la recreación del mismo contribuye a la diversidad y la creatividad.

Se considera Patrimonio Cultural Inmaterial los usos, representaciones, expresiones, conocimientos y técnicas junto con los instrumentos, objetos, artefactos y espacios culturales que les son inherentes que las comunidades, los grupos y en algunos casos los individuos reconozcan como parte integrante de su patrimonio cultural. Este patrimonio cultural inmaterial, que se transmite de generación en generación, es recreado constantemente por las comunidades y grupos en función de su entorno, su interacción con la naturaleza y su historia, infundiéndoles un sentimiento de identidad y continuidad y contribuyendo así a promover el respeto de la diversidad cultural y la creatividad humana (Plan Nacional para la Salvaguarda del Patrimonio Cultural Inmaterial, 2015, p.7).

Secundamos la definición ya que, al recrear generación tras generación los elementos patrimoniales, estamos conservándolos. De la misma manera, la existencia del patrimonio inmaterial es fuente de creatividad, entendiéndola como un elemento que genera nuevas posibilidades partiendo de lo conocido, modificándolo, transformándolo, complementándolo, etc.

Algunas páginas más adelante, encontramos una referencia a la diversidad cultural y creatividad humana cuando se promueve por medio de la continuidad de las tradiciones. En este caso, se hace hincapié para ello, en la fusión de conocimientos y creencias con la naturaleza y la historia. Nos parece coherente la alusión a la importancia del entorno y la naturaleza, dado el valor que el PCI confiere a los espacios singulares donde se celebran ritos, ceremonias, celebraciones o fiestas (Plan Nacional para la Salvaguarda del Patrimonio Cultural Inmaterial, 2015).

Continuando con el análisis del documento, hallamos otra referencia sobre el contexto de las creaciones de nuestros antepasados.

Es evidente que la salvaguarda de este acervo cultural, se debe a una voluntad colectiva de autorreconocimiento sociocultural y de admiración por la creatividad y habilidad desarrolladas por generaciones anteriores a la hora de contribuir a la cultura. Ahora bien, si a este tipo de manifestaciones culturales no se le facilitan las vías para su salvaguarda y para su respeto, desaparecerán en breve, ya que muchas de las prácticas sociales como los conocimientos y vivencias son más vulnerables al no cumplir las funciones tradicionales que justificaban y estimulaban su perpetuación (Plan Nacional para la Salvaguarda del Patrimonio Cultural Inmaterial, 2015, p.16). 
Resulta interesante el reconocimiento a la creatividad de las generaciones anteriores, al hacer referencia al peligro que corren actualmente algunas manifestaciones culturales inmateriales debido a la uniformización cultural. El mismo argumento se exime sobre el riesgo de la predominancia cultural urbana sobre la rural. La primera, tiende a la homogenización del ocio, la moda, la creación e incluso de algunos sectores de la divulgación científica y artística. El mundo rural, donde generalmente se mantenían y conservaban una gran diversidad de manifestaciones culturales inmateriales, está desapareciendo con los últimos pobladores estables de las aldeas. Los descendientes de estos, defensores en los últimos tiempos de la cultura autóctona, tienen cada vez más difícil mantener el arraigo en sus hijos y todo ello aboca a la cultura rural a un final incierto en las próximas décadas.

Encontramos la última referencia a la creatividad en las premisas para la conservación de los soportes materiales del PCI, de los cuales hemos hablado en el apartado de emociones. Como vemos, se plantea la salvaguarda de los soportes materiales del Patrimonio Inmaterial ligada a su mantenimiento, de manera conjunta con la creatividad de sus portadores. Se explicita así mismo la posibilidad de un PCI vivo que pueda contener cambios o renovaciones a lo largo del tiempo, lo que realizado con corrección, puede ser así mismo constitutivo de creatividad y reflejo de la expresión de la nuevas sociedades que lo hagan subsistir (Plan Nacional para la Salvaguarda del Patrimonio Cultural Inmaterial, 2015, p. 41).

Descubrimos pocas referencias también en este Plan Nacional para la Salvaguarda del Patrimonio Cultural Inmaterial, que sin embargo dobla las del Plan Nacional de Educación y Patrimonio.

En cualquier caso, el número e importancia de las referencias halladas tanto en el IPCE como en los planes nacionales analizados, revela que no son suficientes para considerarlas como relevantes dentro de este estudio. Estimamos en consecuencia, que tanto la institución como los planes citados, no consideran que la creatividad sea una cualidad apreciable para la conservación o la difusión del patrimonio, de la misma manera que para la utilización del mismo en el desarrollo creativo de las personas.

\subsubsection{La literatura científica nacional.}

Procederemos a realizar la revisión de la literatura científica, de la misma forma que en el anterior apartado dedicado a este tipo de artículos en el que exploramos las emociones. Utilizaremos como lugares de búsqueda, el portal bibliográfico Dialnet, la base de datos de tesis doctorales Teseo y el buscador especializado Google Académico. En esta ocasión los descriptores de búsqueda serán patrimonio y creatividad utilizados conjuntamente en los títulos de los artículos.

Google Scholar en su búsqueda avanzada, nos ofrece veinticinco resultados. Diez son citas de textos que exponemos seguidamente y que aparecen de forma repetida. Seis hacen referencia a contextos empresariales, donde la creatividad se presenta como eje articulador de la industria turístico-patrimonial, en ningún caso se hace referencia al patrimonio como bien educativo, si no como producto turístico por lo que no los tomamos en consideración. De los restantes, tres están incluidos en el libro "Visiones transdisciplinares en torno a Patrimonio Creatividad y Poesía", este volumen junto con otros dos de temática similar componen una colección de didáctica que acometeremos en la búsqueda de Dialnet. De los restantes traemos hasta este estudio por su temática el trabajo "Creatividad y/o patrimonio: música culta vs. música popular". Se trata de un artículo en el que García (2009), alude al valor de la música folklórica o popular como 
elemento indispensable y habitualmente ligado a rituales religiosos y civiles por encima de la denominada música culta. Ahonda en este sentido sobre cómo esta distinción ha afectado a la creatividad y recreación de estos ritos. Sin duda, la música es un elemento indispensable en numerosas ceremonias que enmarcamos dentro del patrimonio inmaterial en el que cumple un papel muy importante desde el punto de vista motivacional, místico, de trance, etc. Debemos atender también a estos elementos musicales, no solamente como parte del patrimonio inmaterial, si no como un patrimonio en sí mismo que en ocasiones, por esa distinción estilística o de género a la que se refiere el autor, es considerado un patrimonio menor, incluso un arte menor. En ocasiones el fenómeno de la transmisión oral de este tipo de música a la que alude García, se toma como un condicionante que excluye automáticamente la creatividad y el rigor artístico, lo cual es sin duda un enorme error. No debemos olvidar que todas las artes han evolucionado en algún momento de la historia debido a la transmisión de maestros hacia aprendices. En el momento histórico en el que nos encontramos, las titulaciones derivadas de la enseñanza reglada han adquirido no solo un papel formativo, sino también de prestigio social, y han relegado al autoaprendizaje y la transmisión oral o personal, a un segundo y denostado plano.

Encontramos así mismo un trabajo fin de master vinculado a la Universidad de Zaragoza cuyo título entronca plenamente en nuestro ámbito de interés, "El patrimonio como cauce para la creatividad y la sensibilización" (Granel 2012). El trabajo consta de un estudio de investigación además de una propuesta de innovación sobre los estudios artísticos y el patrimonio. Se centra en el alumnado de secundaria y las actividades desarrolladas desde la escuela de arte de Teruel con el patrimonio de la ciudad. Nos resulta una actividad interesante, ya que parte del patrimonio cercano a los alumnos a los que va dirigido, buscando con ello un elemento identitario y motivacional. Por otro lado, tiene una base de observación del patrimonio y sensibilización por medio de esa mirada atenta que defendemos plenamente en este trabajo como extremadamente útil.

Finalmente Google nos aporta tres trabajos de américa latina, que no aparecieron en las búsquedas internacionales de WOS y Scopus y que por tanto reseñamos a continuación.

"Interpretación del patrimonio y creatividad" (Roma, Rosati, Gutiérrez y Maragliano, 2015). Está incluido dentro de las actas del segundo Congreso Internacional de Investigación y Docencia de la Creatividad celebrado en Argentina y aborda la utilidad de la interpretación del patrimonio para la solución creativa de problemas socioeconómicos, políticos, ambientales y culturales del territorio.

"Creatividad: un mecanismo de empoderamiento comunitario para la conservación del patrimonio" (Cordero, 2017). El artículo defiende cómo desde la creatividad es posible, no solo reforzar la identidad, sino también utilizarla como herramienta de empoderamiento comunitario para preservar el patrimonio.

"Creatividad e innovación educativa en museos y espacios patrimoniales" (Hayakawa 2018). Estamos ante un libro donde diversos profesionales del ámbito cultural en Chile debaten sobre la gestión de la cultura y los museos a nivel nacional y regional.

Abordamos ahora los resultados de Dialnet que alcanzan los 535 documentos. Entre ellos encontramos todos los aparecidos en Google Scholar que contienen los elementos de búsqueda en el título. Con este criterio de búsqueda no hayamos ninguno más, por lo que pasamos a referir aquellos que una vez analizado su resumen nos resultan relevantes para nuestro objeto de estudio.

Encontramos una referencia a patrimonio y creatividad por parte de Werner (2002) en un artículo donde se plantea la opción de territorio-museo, como producto turístico cultural integrado desde una visión creativa de la gestión del patrimonio, todo ello bajo el título "Territorio y gestión creativa del patrimonio cultural y natural". 
En el mismo sentido del trabajo anterior, localizamos artículos de carácter teóricocrítico referidos a la gestión creativa de ciudades (González Martínez, 2015) o sus centros históricos (González, 2016).

Encontramos una referencia interesante, por ser una propuesta de un programa de educación patrimonial, en la Comunidad Canaria bajo el título: "Patrimonio, Educación y ciudadanía creativa: el programa educación patrimonial". Se trata de un programa piloto que, impulsado desde la Consejería de Educación, Cultura y Deportes del Gobierno de Canarias, surge de la necesidad de atender la problemática en torno a la gestión y proyección social del Patrimonio Cultural de Canarias. Nos parece interesante principalmente por la interdisciplinariedad con que se planteó en su momento, abarcando contenidos matemáticos, lingüísticos o físicos. Como nos comenta Sanjo en su artículo, "el Patrimonio es utilizado como un recurso educativo para mejorar la formación de los estudiantes, impartiendo a partir de él conocimientos de otras disciplinas" (Sanjo, 2004, p. 296). Debemos así mismo señalar, que la perspectiva creativa no está enfocada directamente con la didáctica de las actividades, si no a lo novedoso de la propuesta global del centro.

Así mismo, hallamos varias referencias más basadas en la creatividad y la música (García, 2007; Dios, 2008), donde la perspectiva de los textos es eminentemente musical dando por hecho el componente creativo de la música, tanto de manera implícita como explícita, pero no ahondando en sus componentes o utilidades para la creación si no aludiendo a ella como elemento intrínseco a la música.

En la revisión emocional ya nos encontramos con Álvarez y sus referencias a los museos pedagógicos como medio de trabajo en la educación emocional. En este caso, el autor aúna museos pedagógicos y creatividad al coordinar un libro con artículos en torno a ello. No obstante, debemos apuntar que, así como las conexiones entre los museos pedagógicos y las emociones quedan sobradamente demostradas en los trabajos ya referidos, en el caso de los museos y la creatividad, el enfoque no nos queda tan claro. Si bien es cierto que aparece en el título "Los museos pedagógicos en España. Entre la memoria y la creatividad" y que parece referirse a la innovación en el enfoque de los discursos expositivos y actividades que se desarrollan, esta palabra no vuelve aparecer en los títulos de ningunos de los capítulos que componen el volumen. Para poder entender la función que se otorga a la creatividad en el libro debemos poner atención al prólogo de Alejandro Mayordomo.

El lector podrá comprobar enseguida que este libro tiene detrás muchas historias, que es producto de un extraordinario esfuerzo de muchas personas y mucho tiempo (...) Y digo esto, no solo por el volumen ahora publicado, sino por todo cuanto le ha precedido, por el largo y coral trabajo que fue necesario para ir componiendo esta red de recuperación, estudio y exposición de nuestro patrimonio histórico-educativo. Contiene y expresa motivos, razón, creatividad, emoción, pasado y presente y futuro (Álvarez, 2016, p. 13).

Entendemos quizá, que se trata la creatividad de forma genérica al proyecto global, tanto del libro como de la creación de la Sociedad Española para el Estudio del Patrimonio Histórico-Educativo (SEPHE). Unas páginas más adelante, el propio Álvarez en la presentación del libro nos parafrasea dos veces el título del mismo al hablar de la necesidad de dar a conocer en nuestro país los diversos museos de educación. Esas son exclusivamente las referencias encontradas sobre creatividad (Álvarez, 2016). Pensamos por tanto, como hemos apuntado al comienzo, que se enfoca 
la creatividad de forma genérica y transversal al proceso de modernización de los museos pedagógicos. Podemos decir que se tiene en cuenta, pero sin concreción tangible en el enfoque didáctico de los museos a nivel expositivo y de actividades desarrolladas en los mismos.

Más resultados de búsqueda para ámbitos que no nos aportan nada nuevo para nuestro estudio como es el de la gestión patrimonial (Padró, 2003) basado en la búsqueda de nuevas fórmulas de gestión de elementos patrimoniales, o el de los derechos autor (Riera, 2016; Oliver, 2019) donde se aborda la creación y no la creatividad.

Localizamos también una tesis doctoral interesante (Martínez, 2017) por el planteamiento de la misma, ya que se propone el arte como hilo conductor de toda la educación de un centro.

Con el objetivo principal de contribuir a la optimización de una educación integral e innovadora en la escuela, se investiga la posibilidad, a modo de propuesta educativa, de generar un proyecto en un centro escolar, con el Arte como elemento generador y gestor de dicho proyecto. Este proyecto aspira a coordinar de manera interdisciplinar diferentes actividades del centro, teniendo como finalidad fomentar la multidisciplina, la creatividad, la cultura, la interdisciplina y la experimentación; todo ello haciendo uso del Arte como mediador en el aprendizaje. Relacionándolo con diferentes áreas de conocimiento, se utilizará el Arte para profundizar tanto en las asignaturas formales del currículum, como en otras áreas igualmente importantes en el aprendizaje escolar, como son las emociones o los valores, y de esta manera generar una red cultural en todo el entorno escolar; utilizando siempre el Arte como guía para conocer y aprehender (Martínez, 2017, p.15).

Al proponer el arte como eje vertebrador de todo un proyecto de centro, pone la educación artística y cultural en el centro del sistema educativo. Es una iniciativa atractiva por el enfoque y los objetivos que persigue, aunque obvia una gran parte del patrimonio ya que solamente incluye el arte. Sin embargo, se acerca mucho a nuestras propuestas al tratar de forma trascendente tanto la creatividad como la formación integral del alumnado. Podemos hallar una iniciativa similar en el "Proyecto Espora" descrito en la web de Proyecto IGNIS ${ }^{18}$ desarrollado entre el Colegio Nuestra Señora del Pilar (Escolapios, Soria) con el Museo Thyssen Bornemisza, donde se utilizaban diferentes obras del museo para trabajar contenidos curriculares de infantil, primaria, secundaria y bachillerato. El proyecto perseguía completar el ideal de perfil de salida de los alumnos en el ámbito patrimonial, aportándoles tanto conocimientos artísticos concretos, como actitudes de respeto, valoración y disfrute del arte. Por otro lado, también tenía como objetivo desarrollar la sensibilidad y estimular la creatividad. Para ello se crearon un conjunto actividades secuenciadas a lo largo de las cuatro etapas con las que cuenta el centro, donde tenían cabida enfoques diferentes del arte utilizado como vehículo didáctico para trabajar contenidos de matemáticas, geografía e historia, lengua, filosofía, química, artística, etc.

Previamente al inicio de la búsqueda científica conocíamos algunas publicaciones que se han ocupado del patrimonio y la creatividad de forma conjunta. Destacamos tres: "Patrimonio y Creatividad. Miradas educativas", "Visiones transdisciplinares en torno a

\footnotetext{
${ }^{18} \mathrm{https}$ //proyectoignis.es/investigacion/proyecto-espora/
} 
Patrimonio, Creatividad y Poesía" y "Patrimonio, Creatividad y Teatro. Territorios comunes". Estos volúmenes acogen diferentes iniciativas de educación formal y no formal que incluyen la creatividad, la poesía y el teatro siempre bajo el paraguas educativo y patrimonial. Extraemos algunos capítulos como es el que firman Maldonado y Marañón (2017) en el que encontramos afirmaciones interesantes para nuestro objeto de estudio.

Por eso creemos firmemente en la necesidad de utilizar las diferentes técnicas creativas, no sólo para transmitir, difundir y generar procesos educativos y de aprendizaje, sino también para investigar y generar comunidad, tanto con personas directamente vinculadas con el estudio, gestión y dinamización de elementos patrimoniales, como con aquellos otros agentes, no directamente vinculados, que viven de una $u$ otra forma los patrimonios (Maldonado y Marañón, 2017, p 238).

Nos interesa la mención a las técnicas creativas como elementos de dinamización patrimonial. Al hablar de técnicas, las autoras van más allá que la mayoría de los artículos analizados donde se utiliza la palabra creatividad como sinónimo de novedoso. Así ocurre con la gestión del patrimonio, donde se buscan incansablemente nuevas formas de dinamizar elementos patrimoniales y no utilizar éstos para otros fines por medio de técnicas creativas como aquí nos apuntan Maldonado y Marañón. Es una alusión a un corpus técnico-didáctico que podría guiar de manera concreta un trabajo creativo, algo que venimos defendiendo en estas líneas, una concreción de procesos de trabajo para estimular la creatividad.

Nos resulta muy interesante así mismo, la siguiente referencia donde se ligan creatividad y emociones.

Además, la creatividad, al ser un elemento intrínseco al ser humano (aunque éste no lo sepa o lo valore como tal), está ligada a otros elementos constituyentes como pueden ser las emociones, la cognición, las ideas, los sentimientos; por tanto, todas estas ligazones que nos construyen, ayudan a dar vida a las acciones que en base a la actitud creativa se quieran desarrollar (Maldonado y Marañón, 2017, p 244).

Se trata de dos elementos que, inequívocamente, son constituyentes de lo humano y por tanto útiles para dar vida a cualquier acción que pretendamos iniciar bien individual, colectiva, con objetivos artísticos, instrumentales, utilitarios, etc.

En esta misma línea de trabajo encontramos las afirmaciones de Díez (2018) quien asevera que no es posible ser creativo sin un estado emocional adecuado. Ahonda en estas afirmaciones a lo largo del capítulo "Trance y proceso creativo" que forma parte del segundo de los textos referidos, relatando que existen estados emocionales que impiden la creatividad y otros que la favorecen. Declara así mismo que: "Estos estados creativos y esta capacidad de sintonizar con ellos es algo que puede en gran medida enseñarse y entrenarse" (Díez, 2018, p. 215). Lo que nos da pie para afirmar que debemos entrenar las capacidades creativas como un medio de desarrollo personal y no solo artístico. Este es uno de los pilares de nuestra propuesta educativa, la utilización de los elementos patrimoniales como herramienta y base del desarrollo creativo a la par que emocional.

Concluimos que ambos conceptos, tanto patrimonio como creatividad, tienen una producción literaria importante tomados como disciplinas únicas. En cambio, cuando 
cruzamos los conceptos y buscamos coincidencias que traten los dos ámbitos de forma conjunta, las referencias son mínimas.

Las búsquedas en Teseo arrojan resultados interesantes al examinar los términos en el título. Sí encontramos registros cuando filtramos en el resumen, aunque los consideramos irrelevantes para nuestro estudio, con las excepciones ya citadas por la temática que abordan: restauración, derechos de autor o protección jurídica del patrimonio.

Tanto en Google Académico en la búsqueda general, como en Dialnet en la mayoría de resultados, las referencias a creatividad dentro del ámbito patrimonial, vienen dadas por la búsqueda de nuevas fórmulas de gestión turística de los espacios.

Al hablar de patrimonio artístico, la creatividad se toma como intrínseca a todo lo relacionado con la creación, obviando la necesidad de su desarrollo ya que, aunque se considera punto de partida para cimentar nuevas obras, se le presupone de manera natural al creador.

Todo ello nos hace pensar que el tratamiento de ambos conceptos de forma paralela, utilizando uno como motor del otro, no ha sido tenido en cuenta por iniciativas que lo propongan de forma sistemática dentro de la educación. Por tanto, así como ocurre con patrimonio y emociones, se nos presenta un campo de acción educativo tan yermo como interesante.

A tenor de los resultados, entendemos como escasos y poco relevantes los hallazgos realizados en torno a la relación del patrimonio y la creatividad. La mayoría de las coincidencias terminológicas no lo son posteriormente en las acepciones utilizadas, el término patrimonio es aplicado en su significación de herencia, y aunque la creatividad si se usa como nueva forma de entender o utilizar recursos patrimoniales, siempre se emplea en el contexto de generar nuevos recursos económicos y no didácticos. 


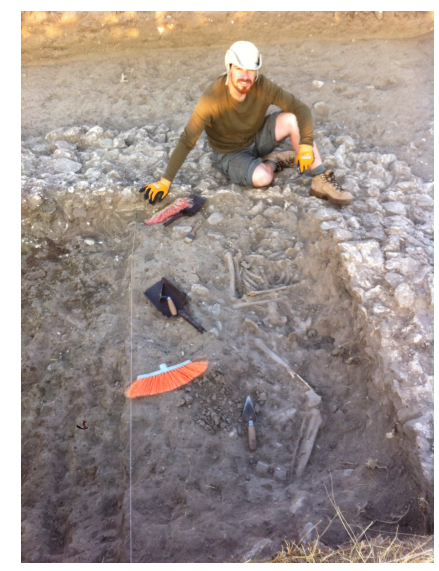

“...cuando el acento se sitúa en el sujeto que aprende, considerando además sus necesidades culturales, parece importante, desde los objetivos de la educación, conocer el presente cultural para poder llegar a comprenderlo..."

Olaia Fontal

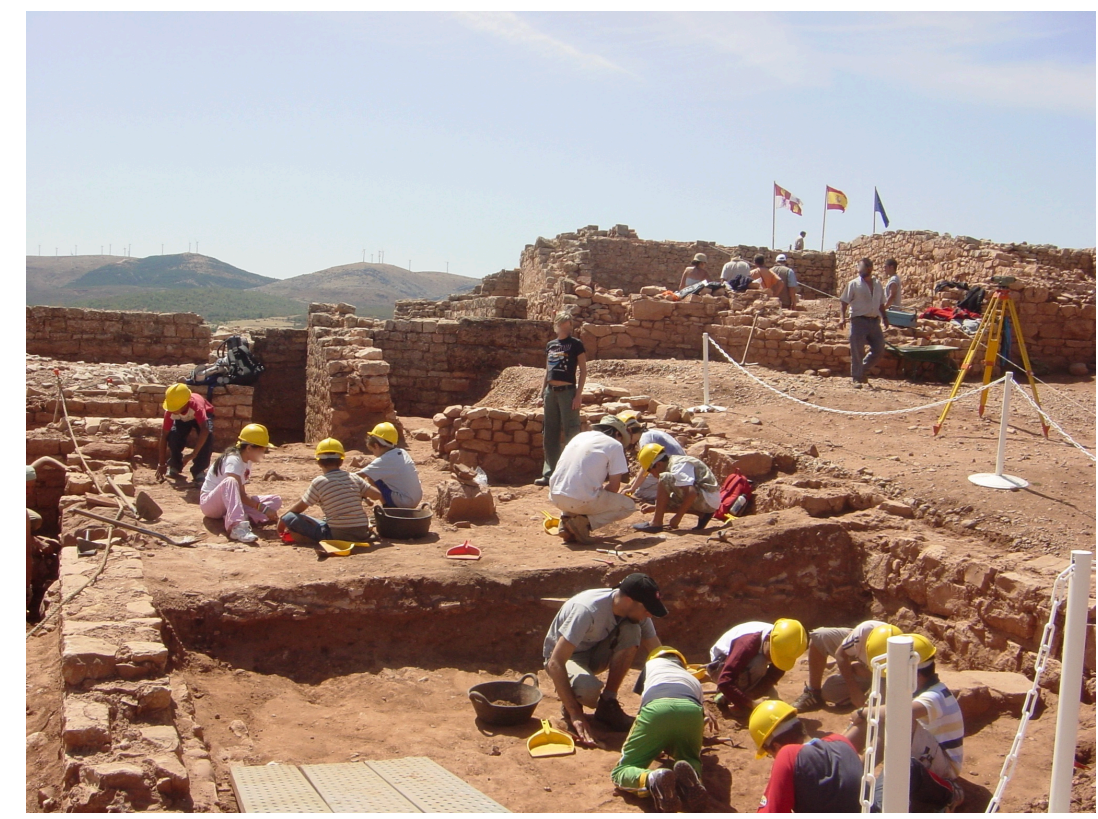




\title{
CAPÍTULO 3. EMOCIONES Y CREATIVIDAD EN LA EDUCACIÓN PATRIMONIAL
}

\author{
3.1. Las dimensiones emocional y creativa bajo la mirada de la educación \\ patrimonial.
}

En una primera aproximación previa a este estudio de los términos que circunscriben esta investigación: patrimonio, emociones y creatividad, ya se evidenció que no se obtenían resultados relevantes en cuanto a iniciativas que los tomaran en consideración de forma paralela. Por ello, no se integraron los tres ámbitos de forma conjunta en las búsquedas de esta tesis y se organizaron éstas emparejando patrimonio y emociones por un lado, y patrimonio y creatividad por otro, tal y como se evidencia en los capítulos uno y dos. Corroboramos ahora que no existen referencias relevantes para nuestros intereses que tomen de forma ligada los tres ámbitos, tras analizar la producción científica, legislativa e institucional por medio de los buscadores referidos en los capítulos anteriores.

En este punto del tercer capítulo, pretendemos explorar los territorios comunes que pudieran existir entre las tres disciplinas, siempre bajo el paraguas de la educación patrimonial, fundamentando el porqué de nuestra insistencia en tratarlos de manera ligada y con un horizonte de mejora en la formación personal del alumnado.

Nuestra propuesta y objetivo de investigación nace del análisis de resultados de varias iniciativas anteriores que se circunscriben a los ámbitos patrimonial, histórico, arqueológico, artístico, didáctico y sensorial (Munilla, 2007, 2012, 2013, 2014, 2016, 2017, 2018; Munilla y Martínez, 2005, 2006; Martínez, Aldecoa y Munilla, 2011; Martínez y Munilla, 2017; Munilla y Marín-Cepeda, 2020). Estas experiencias previas conforman un continuo evolutivo de investigación-acción que reafirma paso a paso, la idea inicial de que la cultura es la mejor herramienta para formar ciudadanos. Ese camino ya andado está conformado por acciones tales como: análisis de la presencia del patrimonio en libros de texto de primaria; propuestas de dinamización de museos; didáctica del patrimonio arqueológico; experiencias con el arte como eje central de propuestas curriculares en infantil, primaria, secundaria y bachillerato; acceso al arte a través de los sentidos; presentación de proyectos curriculares con el patrimonio como eje vertebrador; publicaciones científicas; organización y dirección de congresos temáticos al respecto; creación de un aula específica de patrimonio en un centro de primaria donde se ha experimentado con los tres ámbitos de estudio; edición de cuadernos didácticos, etc. Un análisis detenido de estas experiencias, nos lleva finalmente a proponer a modo de síntesis la utilización del patrimonio, las emociones y la creatividad como tres elementos clave para la formación de ciudadanos libres, sensibles, racionales, creativos y empáticos. Personas que vivan su existencia de forma plena participando en la vida social de forma constructiva.

"Heritage Thinking" (Munilla, 2017), es el nombre con el que hemos concretado la propuesta de trabajo. Da nombre a una manera de entender y enfocar la educación. No es una metodología ni una corriente didáctica, no es una innovación educativa ni una teoría del aprendizaje, no nace de la neuroeducación ni se basa en la tecnología, aunque quizá tenga algo de cada una de ellas. Es un término nacido de la acción educativa, del ensayo-error, de la práctica. Engloba una forma de hacer en la educación integral de la persona. Formación emocional, cultural y creativa basada en las producciones humanas, tanto instrumentales como ornamentales o artísticas. Parte de lo existente para construir lo presente, aunque evidentemente tiene su objetivo en el futuro, el de la sociedad 
formada en su parte activa por las personas que se educan hoy. Hunde sus cimientos en la historia del hombre a través de las creaciones del mismo, la evolución tecnológica, instrumental, artística y cotidiana de la humanidad: el Patrimonio. Estos componentes creativos dan sentido a la evolución humana desde el plano externo e interno del individuo. Tiene por tanto varios pilares motores como son el patrimonio, la creatividad y las emociones. Aunque desembocan en elementos didácticos esenciales: el pensamiento metacognitivo, el trabajo colaborativo y el aprendizaje activo y vivencial.

Este sería el marco, tanto a nivel conceptual como de análisis previo, de los contextos metodológico-prácticos que se proponen como elementos de trabajo para profesionales de la educación.

\subsection{El patrimonio en la etapa de Primaria}

Seguidamente pretendemos analizar la presencia que el patrimonio tiene en la ley educativa vigente, la Ley Orgánica 8/2013, de 9 de diciembre, para la mejora de la calidad educativa (LOMCE), y su concreción en primaria a través del Real Decreto 126/2014, de 28 de febrero, por el que se establece el currículo básico de la Educación Primaria (tabla 5).

Tabla 5. Alusiones a Patrimonio, Emociones y Creatividad en la legislación vigente de primaria

\begin{tabular}{|l|c|c|c|}
\hline Textos legislativos & Patrimonio & Emociones & Creatividad \\
\hline $\begin{array}{l}\text { LOMCE: Ley } \\
\text { orgánica } 8 / 2013\end{array}$ & 0 & 1 & 3 \\
\hline $\begin{array}{l}\text { Real decreto } \\
126 / 2014\end{array}$ & 16 & 14 & 35 \\
\hline
\end{tabular}

Fuente: Propia

Como vemos en la tabla 5, la LOMCE no guarda ninguna referencia al Patrimonio y debemos buscar en el Real Decreto de Primaria para encontrar alusiones directas. No obstante debemos señalar, que todas ellas aparecen en los anexos y que por lo tanto no existe referencia alguna en los artículos y disposiciones que conforman el Decreto. Esto significa que no se nombra el patrimonio ni en los objetivos generales de la educación primaria, ni en los procesos de aprendizaje, ni en los elementos transversales de la etapa. Todo ello nos informa de que el Patrimonio no es tenido en cuenta en la estructura básica del diseño de la etapa, al no tener presencia en el corpus metodológico y didáctico de la misma.

En los citados anexos, hallamos dieciséis referencias, ocho en el anexo 1 donde se recogen las asignaturas troncales y otros ocho en el anexo 2 de asignaturas específicas.

Tabla 6. Alusiones a Patrimonio en el R.D. 126/2014. Anexo 1.

\begin{tabular}{|l|c|c|c|c|c|}
\hline $\begin{array}{l}\text { Asignaturas } \\
\text { troncales }\end{array}$ & $\begin{array}{c}\text { Descripción } \\
\text { del área }\end{array}$ & $\begin{array}{c}\text { Bloque de } \\
\text { contenidos }\end{array}$ & Contenidos & Criterios & Estándares \\
\hline $\begin{array}{l}\text { Ciencias de la } \\
\text { Naturaleza }\end{array}$ & 0 & - & 0 & 0 & 0 \\
\hline Ciencias Sociales & 2 & $\begin{array}{c}\text { 4-Las huellas } \\
\text { del tiempo }\end{array}$ & 1 & 1 & 3 \\
\hline $\begin{array}{l}\text { Lengua } \\
\text { Castellana y y } \\
\text { Literatura }\end{array}$ & 0 & $\begin{array}{c}\text { 4- } \\
\text { Conocimiento } \\
\text { de la lengua }\end{array}$ & 1 & 0 & 0 \\
\hline
\end{tabular}




\begin{tabular}{|l|l|l|l|l|l|}
\hline Matemáticas & 0 & - & 0 & 0 & 0 \\
\hline $\begin{array}{l}\text { Primera Lengua } \\
\text { Extranjera }\end{array}$ & 0 & - & 0 & 0 & 0 \\
\hline
\end{tabular}

Fuente: Propia

Como vemos en la tabla 6, de las ocho referencias extraídas entre las asignaturas troncales, las dos primeras menciones nos aparecen dentro de la descripción del área de Ciencias Sociales. En este apartado B del anexo se refiere la importancia de desarrollar la curiosidad por conocer los entramados sociales y culturales de nuestros antepasados a través de la Historia y el Patrimonio, así como la capacidad de valorar ambas cosas (Real Decreto 126/2014, p. 22).

Las cinco siguientes referencias se encuentran en la tabla de contenidos, criterios y estándares de Ciencias Sociales dentro del bloque cuatro denominado "Las huellas del tiempo". Se reparten en un contenido, un criterio y tres estándares. El contenido "Nuestro patrimonio histórico y cultural", se desglosa en un criterio enfocado a desarrollar la curiosidad por el pasado, y el cuidado y conservación de los elementos tangibles fruto del mismo. El criterio se concreta en estos dos estándares:

4.1. Identifica, valora y respeta el patrimonio natural, histórico, cultural y artístico y asume las responsabilidades que supone su conservación y mejora.

4.2. Respeta los restos históricos y los valora como un patrimonio que debemos legar y reconoce el valor que el patrimonio arqueológico monumental nos aporta para el conocimiento del pasado (Real Decreto 126/2014, p. 26).

Parece lógico que el área de Ciencias Sociales aporte el mayor número de referencias al abarcar diferentes tipos de patrimonio. Podemos apreciar que, desde la descripción del área hasta los dos estándares finales, se produce un proceso de concreción de los objetivos del área que descansa finalmente en una concepción individual de los mismos al estar redactados como estándares de aprendizaje. Pensamos que la finalidad inicial se resume de forma seria al nombrar de forma explícita los patrimonios natural, histórico, cultural, artístico, arqueológico y monumental, insistiendo en su identificación valoración y respeto.

Destacamos además que, como vemos en los estándares citados, se hace referencia al patrimonio natural, aunque el área de Ciencias Naturales no presente menciones al mismo.

\begin{tabular}{|l|c|c|c|c|c|}
\hline $\begin{array}{l}\text { Asignaturas } \\
\text { Específicas }\end{array}$ & $\begin{array}{c}\text { Descripción } \\
\text { del área }\end{array}$ & $\begin{array}{c}\text { Bloque de } \\
\text { contenidos }\end{array}$ & Contenidos & Criterios & Estándares \\
\hline $\begin{array}{l}\text { Educación } \\
\text { Artística }\end{array}$ & 1 & - & - & - & - \\
\hline $\begin{array}{l}\text { A) Educación } \\
\text { Plástica }\end{array}$ & - & $\begin{array}{c}\text { 2- Expresión } \\
\text { Artística }\end{array}$ & - & 2 & 2 \\
\hline $\begin{array}{l}\text { B)Educación } \\
\text { Musical }\end{array}$ & - & 1- Escucha & - & 1 & 0 \\
\hline $\begin{array}{l}\text { B)Educación } \\
\text { Musical }\end{array}$ & - & $\begin{array}{c}\text { 3-La música, el } \\
\text { movimiento y }\end{array}$ & - & 1 & 1 \\
\hline
\end{tabular}




\begin{tabular}{|l|c|c|c|c|c|}
\hline & & la danza & & & \\
\hline Educación Física & 0 & - & 0 & 0 & 0 \\
\hline $\begin{array}{l}\text { Segunda Lengua } \\
\text { Extrajera }\end{array}$ & 0 & - & - & 0 & 0 \\
\hline $\begin{array}{l}\text { Valores Sociales y } \\
\text { Cívicos }\end{array}$ & 0 & - & - & 0 & 0 \\
\hline
\end{tabular}

Como podemos apreciar en la tabla 6, el área de Lengua Castellana y Literatura presenta un contenido que alude a la riqueza lingüística de nuestro territorio, enunciando esta como reflejo del patrimonio histórico y cultural (Real Decreto 126/2014, p. 32).

Tabla 7. Alusiones a Patrimonio en el R.D. 126/2014. Anexo2.

Fuente: Propia

En el anexo 2 de asignaturas específicas, encontramos igualmente ocho referencias Patrimoniales, todas ellas en el área de Educación Artística. Como vemos en la tabla 7, la primera alusión aparece en la descripción del área, cuando se afirma que el conocimiento plástico y musical permite un mejor disfrute del patrimonio cultural y artístico. El texto nos refiere que el saber en estas áreas, ayuda a valorar y respetar las aportaciones que se han ido haciendo al patrimonio a lo largo de la historia (Real Decreto 126/2014, p. 46).

En la parte correspondiente a las tablas de criterios y estándares del área de Artística, dentro de la materia de Educación Plástica, encontramos cuatro alusiones consignadas en el bloque de contenidos número dos denominado "Expresión artística". Se reparten equitativamente entre criterios y estándares. Concretamente el criterio número seis acoge dos menciones al patrimonio artístico y cultural, al plasmar la necesidad de conocerlo, respetarlo y valorarlo. Como es habitual el infinitivo de este criterio se transforma en la tercera persona del presente de indicativo para enunciar los estándares de aprendizaje, concretando su intención y destacando especialmente el interés por aquellas manifestaciones declaradas patrimonio de la humanidad.

6.1. Reconoce, respeta y valora las manifestaciones artísticas más importantes del patrimonio cultural y artístico español, especialmente aquellas que han sido declaradas patrimonio de la humanidad (Real Decreto 126/2014, p. 47).

En la materia de Educación Musical hallamos tres referencias. En el bloque uno de "Escucha", el criterio tres nos habla de la importancia de conocer obras variadas por medio de audiciones y representaciones como medio de mantenimiento y difusión (Real Decreto 126/2014, p. 48). Dentro del bloque tres "La música, el movimiento y la danza", encontramos dos referencias. La primera en un criterio que habla de adquirir capacidades expresivas y creativas por medio de la expresión corporal y la danza, y la segunda en un estándar que valora el conocimiento de danzas de distintas épocas y lugares (Real Decreto 126/2014, 48).

Como hemos visto, existen varias referencias al patrimonio en el decreto de primaria. Podemos afirmar también, que constan algunas otras reseñas no explícitas en varios de los contenidos, criterios de evaluación y estándares, que se muestran de manera asociada a los referidos o que amplían la cobertura que el decreto da al patrimonio sin necesidad de nombrarlo directamente. En cualquier caso, aun no pudiendo afirmar que sea escasa su presencia, sí debemos señalar que no parece relevante la importancia que se le otorga. Las áreas donde aparece son espacios más que previsibles y aun así, las 
referencias las consideramos poco concretas. Parece evidente que las Ciencias Sociales deben reflejar el patrimonio histórico, inmaterial, cultural, artístico, etc. No obstante, en muchos casos, ni siquiera se nombran de forma específica todos ellos y se deja al "cultural" un universo indefinido de patrimonios. El área de lengua, como parece lógico, se circunscribe al patrimonio lingüístico y, el área de artística con música al comprendido por sus campos.

Dado nuestro objeto de investigación, echamos en falta la presencia del patrimonio en el contexto de valores sociales y cívicos. Como hemos apuntado nos parece una buena herramienta de socialización y educación ciudadana por lo que pensamos que podría ser un instrumento eficaz dentro de los objetivos de esta materia. En cualquier caso, el patrimonio no aparece reflejado en los objetivos generales de la etapa de primaria, mientras sí que forma parte de los objetivos generales de secundaria y bachillerato (Reyes y Méndez, 2017).

Somos conscientes, no obstante, de que la verdadera riqueza de la utilización del patrimonio a nivel curricular, depende en gran medida de la concreción de este decreto en las programaciones de aula y libros de texto. Ferreras y Jiménez (2013) en un artículo anterior a la LOMCE concluyen:

Entre los resultados obtenidos, podemos determinar que la visión que se transmite del patrimonio en los libros es muy simple, afincada generalmente en un nivel básico de complejidad. No aparecen apenas elementos vinculados al patrimonio científico-tecnológico, ni por supuesto se abordan desde una perspectiva holística que integre todas las manifestaciones patrimoniales, perspectiva que se correspondería con nuestro nivel de referencia (p. 609).

Reyes y Méndez (2017) refrendan la idea de inconcreción que referimos en un artículo que analiza la educación patrimonial en la LOMCE, y denuncian así mismo la ausencia del patrimonio en la formación en valores, tal y como hemos destacado anteriormente:

(...) la presencia del Patrimonio Histórico y Cultural tanto en la normativa educativa como en su reflejo en los manuales escolares, ha sido constante. Aunque no por ser tan insistente ha tenido resultados efectivos. Generalmente se ha introducido en la enseñanza de las ciencias sociales como ilustración, barniz cultural o como contenido desde una perspectiva memorística (conocer). En estos casos se obvia la formación en actitudes (valorar, respetar, conservar) y procedimientos (aprender a aprender) (p.126).

Cuenca, Estepa y Martín (2017), afirman que los libros de texto poseen una visión excepcional, monumental y unidisciplinar al analizar los libros de texto de las enseñanzas obligatorias. En lo referido exclusivamente a primaria, señalan que solo excepcionalmente encontramos una visión simbólico-identitaria y siempre asociada al patrimonio histórico artístico.

En nuestra opinión basada en la experiencia docente con diferentes leyes educativas, más de veinte años dedicados a la educación primaria impartiendo casi todas las áreas del currículo, más de una década impartiendo en exclusividad Ciencias Sociales, la utilización durante todo este tiempo del patrimonio como elemento transversal, la realización de trabajos académicos de investigación al respecto (Munilla, 2012), experiencia como profesor en varias facultades de educación, y habiendo sido formador 
de profesores en activo a nivel nacional e internacional, nos atrevemos a concluir que la importancia del patrimonio ha ido en aumento con el paso de los años, tanto en las leyes educativas como en los libros de textos de primaria. No obstante, tanto en unas como en otros, la ampliación de referencias en los textos no se ha desarrollado de forma análoga a su introducción real dentro de las aulas. Esta se ha limitado, en el mejor de los casos, a experiencias puntuales y de enfoque conceptual con el patrimonio cultural y en menor medida el inmaterial. Esto pudiera ser achacable a una deficiente formación del profesorado en este campo que hace que los maestros no tengan una base didáctica sólida para diseñar actividades patrimoniales, o al no reconocimiento de nuestro campo como un área esencial en la formación de los alumnos.

\subsection{El desarrollo emocional en la etapa de Primaria.}

Analizamos a continuación las referencias emocionales en los dos documentos legislativos referidos.

En la LOMCE, como vemos en la tabla 5, encontramos una sola reseña en el apartado uno del artículo 71, haciendo alusión al desarrollo emocional del alumnado. Se determina que recae en las administraciones educativas la responsabilidad de poner los medios necesarios para que todos los alumnos se desarrollen de forma personal, intelectual, social y emocional (Ley Orgánica 8/2013, p. 97895).

El Real Decreto 126/2014, recoge 14 alusiones emocionales, la primera de ellas en el preámbulo y trece en los anexos.

La recogida en la introducción nos informa de que el RD se basa en la potenciación del aprendizaje por competencias en línea con la Recomendación 2006/962/EC, del Parlamento Europeo y del Consejo, de 18 de diciembre de 2006. La propuesta es la de renovar la práctica docente y el proceso de enseñanza aprendizaje, integrando las competencias en los elementos curriculares. Se presenta la competencia como una combinación de habilidades prácticas, conocimientos, motivación, valores éticos, actitudes, emociones, y otros componentes sociales y de comportamiento, que se movilizan conjuntamente para lograr una acción eficaz (Real Decreto 126/2014, p.3). El elemento emocional se plasma como un componente social y de comportamiento que junto a otras habilidades, deben ayudar a facilitar el conocimiento en la práctica participando socialmente.

Tabla 8. Alusiones a emociones en el R.D. 126/2014. Anexo1.

\begin{tabular}{|l|c|c|c|c|c|}
\hline $\begin{array}{l}\text { Asignaturas } \\
\text { troncales }\end{array}$ & $\begin{array}{c}\text { Descripción } \\
\text { del área }\end{array}$ & $\begin{array}{c}\text { Bloque de } \\
\text { contenidos }\end{array}$ & Contenidos & Criterios & Estándares \\
\hline $\begin{array}{l}\text { Ciencias de la } \\
\text { Naturaleza }\end{array}$ & 1 & $\begin{array}{c}\text { 2-El ser } \\
\text { humano y la } \\
\text { salud }\end{array}$ & 0 & 0 & 1 \\
\hline Ciencias Sociales & 0 & - & 0 & 0 & 0 \\
\hline $\begin{array}{l}\text { Lengua } \\
\begin{array}{l}\text { Lastellana } \quad y \\
\text { Literatura }\end{array}\end{array}$ & $\begin{array}{c}1- \\
\text { Comunicación } \\
\text { oral hablar y } \\
\text { escuchar }\end{array}$ & 0 & 0 & 2 \\
\hline Matemáticas & 1 & - & 0 & 0 & 0 \\
\hline $\begin{array}{l}\text { Primera Lengua } \\
\text { Extranjera }\end{array}$ & 0 & - & 0 & 0 & 0 \\
\hline
\end{tabular}

Fuente: Propia 
Las referencias halladas en los anexos, se distribuyen como podemos observar en las tablas 8 y 9, cinco en el anexo uno de asignaturas troncales y ocho en el anexo dos de asignaturas específicas.

En el anexo uno, al describir la asignatura de Ciencias de la Naturaleza se nos expone que el currículo básico se ha diseñado teniendo en cuenta el desarrollo emocional y cognitivo de las edades que comprenden primaria (Real Decreto 126/2014, p. 17). Este mismo párrafo lo encontraremos también más adelante, al presentar el área de Matemáticas. Al acercarnos a la tabla de contenidos, criterios y estándares de Ciencias Naturales tenemos otra referencia en el estándar 3.8 que exponemos a continuación:

3.8. Identifica emociones y sentimientos propios, de sus compañeros y de los adultos manifestando conductas empáticas (Real Decreto 126/2014, p. 19).

El estándar aborda el conocimiento de las emociones propias y ajenas. Si analizamos los contenidos, el criterio del que procede este estándar 3.8 y el resto de estándares que lo completan, vemos que se atienden las emociones de forma paralela con la salud corporal y mental, la toma de decisiones y la conducta. Todo ello relacionado con la estabilidad emocional, como medio de relación satisfactorio con los iguales.

Las dos siguientes referencias las encontramos en el área de Lengua Castellana y Literatura, dentro del bloque 1 "Comunicación oral: hablar y escuchar". El estándar 1.1 nos presenta el empleo de la lengua oral como un medio de expresión de sentimientos y emociones. El 1.3 por su parte se centra en la escucha y respeto por los sentimientos de los compañeros (Real Decreto 126/2014, p.29).

Para finalizar las alusiones emocionales en el anexo uno, debemos ir hasta la descripción del área de Matemáticas que reproduce, como ya hemos señalado, el mismo párrafo ya comentado de la descripción del Área de ciencias Naturales.

Tabla 9. Alusiones a emociones en el R.D. 126/2014. Anexo2.

\begin{tabular}{|c|c|c|c|c|c|}
\hline $\begin{array}{l}\text { Asignaturas } \\
\text { Específicas }\end{array}$ & $\begin{array}{l}\text { Descripción } \\
\text { del área }\end{array}$ & $\begin{array}{l}\text { Bloque de } \\
\text { contenidos }\end{array}$ & Contenidos & Criterios & Estándares \\
\hline $\begin{array}{l}\text { Educación } \\
\text { Artística }\end{array}$ & 0 & - & - & - & - \\
\hline $\begin{array}{l}\text { A) Educación } \\
\text { Plástica }\end{array}$ & - & & - & 0 & 0 \\
\hline $\begin{array}{l}\text { B)Educación } \\
\text { Musical }\end{array}$ & - & $\begin{array}{c}\text { 3-La música, el } \\
\text { movimiento y la } \\
\text { danza }\end{array}$ & - & 0 & 1 \\
\hline Educación Física & 0 & - & - & 1 & 0 \\
\hline $\begin{array}{l}\text { Segunda Lengua } \\
\text { Extrajera }\end{array}$ & 0 & - & - & 0 & 0 \\
\hline $\begin{array}{l}\text { Valores Sociales } \\
\text { y Cívicos }\end{array}$ & 0 & $\begin{array}{l}\text { 1-La identidad } \\
\text { y la dignidad de } \\
\text { la persona }\end{array}$ & - & 1 & 1 \\
\hline- & & $\begin{array}{c}\text { 2-La } \\
\text { compresión y el } \\
\text { respeto en las } \\
\text { relaciones } \\
\text { interpersonales }\end{array}$ & - & 1 & 2 \\
\hline- & & 3-La & - & - & 1 \\
\hline
\end{tabular}




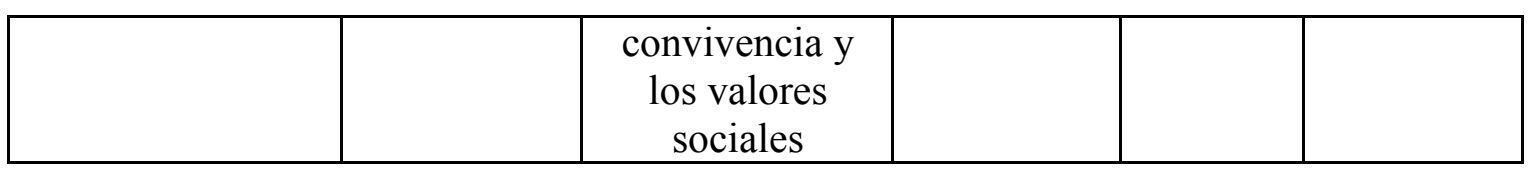

Fuente: Propia

Como refleja la tabla 9 el anexo dos acoge ocho referencias.

La primera de ellas, la encontramos en el área de Educación Artística, dentro de la materia de Educación Musical, en el bloque tres "La música, el movimiento y la danza". La referencia se plasma en un estándar que evalúa la capacidad de los alumnos para expresar sentimientos y emociones a través del propio cuerpo, y como forma de interacción social (Real Decreto 126/2014, p.48). Esta misma idea de expresión emocional por medio del cuerpo la encontramos en el área de Educación Física. El criterio 2 nos habla de los recursos expresivos del cuerpo y el movimiento, asociados a la estética, la creatividad y la comunicación de sensaciones, emociones e ideas (Real Decreto 126/2014, p. 51). Consideramos interesantes estas alusiones de ambas áreas, ya que están referidas a un medio de expresión emocional que suele quedar en el olvido, como es el cuerpo. Utilizamos diariamente las expresiones faciales o las manos como un apoyo a la comunicación oral, pero de manera más bien inconsciente. Por el contrario, la utilización del cuerpo como medio de expresión intencional sigue siendo minoritaria quizá porque nos expone de manera muy evidente a los demás. Su inclusión en este Real Decreto de manera explícita y recogido además por dos áreas diferentes, nos parece muy acertado y está en consonancia con algunas propuestas y experiencias que hemos realizado previamente a este trabajo y que están recogidas en el proyecto IGNIS $^{19}$ y algunas publicaciones (Munilla, 2016).

Las últimas seis alusiones las hallamos en el área de Valores Sociales y Cívicos. Dentro del bloque uno "La identidad y la dignidad de la persona", aparecen dos de ellas en el criterio número cinco y su estándar correspondiente. En ellos se habla de la necesidad de estructurar un pensamiento efectivo e independiente empleando las emociones de forma positiva, para lo que es necesario, tal y como se explicita, un adecuado reconocimiento e identificación de las emociones que nos permitirá además enfrentar la vida de manera positiva y cooperativa (Real Decreto 126/2014, p. 56).

En el bloque dos "La compresión y el respeto en las relaciones interpersonales", encontramos tres alusiones en un criterio y dos estándares. El primero tiene relación con la ya citada expresión corporal, dado que nos habla de la necesidad de expresar las emociones de forma coordinada con el lenguaje verbal y no verbal. Los estándares por su parte, inciden en la expresión clara de sentimientos y emociones, así como en el establecimiento de relaciones emocionales amistosas (Real Decreto 126/2014, p. 56).

En el bloque tres "La convivencia y los valores sociales", hallamos la última alusión centrada en el análisis emocional ajeno, como forma de empatizar y buscar soluciones a los problemas, siendo sensible a los diferentes puntos de vista de las partes en conflicto (Real Decreto 126/2014, p.57).

Como vemos la mayoría de referencias del área de Valores Sociales y Cívicos, agrupan su interés en el establecimiento de relaciones sociales basadas en componentes emocionales sanos y duraderos, utilizando para ello los recursos verbales y corporales.

Comprobamos por tanto, que la ley contiene una sola referencia de carácter muy general, si bien deja claro que son las comunidades autónomas a través de sus decretos de concreción de la misma, quienes tiene la responsabilidad de poner los medios

19 https://proyectoignis.es/educacion-formal/ 
necesarios para un correcto desarrollo emocional de los alumnos. Tanto con la mención, como con la dirección de aplicación, se deja clara la importancia que se le otorga y además se dota de autonomía a las administraciones competentes para concretar las medidas que ayuden desarrollar las capacidades emocionales.

Es significativa la presencia de las emociones en el decreto de primaria, sobre todo si la consideramos en relación con documentos similares anteriores. Ruiz y Corchuelo (2015) realizan una aproximación a la educación emocional analizando el marco legislativo, desde la Ley General de Educación de 1970 hasta la LOMCE. En su análisis determinan que si bien es un componente educativo que ha estado presente en la educación, ha formado parte de lo que se ha llamado el currículo oculto, y progresivamente a lo largo de los años y las leyes ha ido tomando una relevancia más plena hasta llegar a la ley actual, donde como hemos visto aparece reflejado en varias ocasiones de manera explícita.

Las emociones, su reconocimiento, manifestación y encauzamiento, se consideran a día de hoy un elemento clave para un desarrollo adecuado de la personalidad, y por ello es esencial trabajarlos en las aulas a través de la inteligencia emocional (Bisquerra, 2003).

Al igual que hemos apuntado en el apartado anterior sobre Patrimonio, la cuestión está en cómo se plasman todas estas intenciones en las aulas, si ocurre de manera programada e ineludible, o solamente es una recomendación que depende de la buena voluntad de los maestros. No obstante podemos decir que existen varios programas desde hace algunos años que han optado seriamente por el trabajo emocional, y han abierto un camino a editoriales y profesionales educativos (Ozáez, 2015; Soler, Aparicio, Díaz, Escolano y Rodríguez 2016).

\subsection{La creatividad en la etapa de Primaria.}

Examinamos finalmente las referencias creativas en los mismos documentos legislativos descritos, LOMCE y R.D. 126/2014. Como podemos observar en la tabla cinco, la creatividad es de los términos analizados en la LOMCE, la que más menciones presenta con un total de tres. Esto nos da una idea de la importancia que la ley otorga a este elemento, al menos en comparación con los otros dos investigados.

La primera referencia la podemos ver en el apartado cuatro del preámbulo, donde se alude a la creatividad como una competencia transversal que debe proyectarse a lo largo de toda la vida. Se califican las habilidades cognitivas como insuficientes si no están acompañadas de competencias como pensamiento crítico, gestión de la diversidad, capacidad de comunicar, confianza individual, entusiasmo, constancia, aceptación del cambio o creatividad (Ley Orgánica 8/2013, p. 97860).

En el apartado dos del artículo dieciséis, nos topamos con la aseveración de que la educación primaria no solo debe formar en lo académico, sino también de manera integral y para ello se nombra la creatividad como un elemento que puede ayudar a ese tipo de formación (Ley Orgánica 8/2013, p 97870). Este artículo viene a concretar la referencia del prólogo ya que desglosa lo que anteriormente había calificado como habilidades cognitivas al nombrar: expresión y comprensión oral, lectura, escritura, cálculo, adquisición de nociones básicas de la cultura, además de los hábitos de convivencia, estudio y trabajo. Estos se complementarían con el sentido artístico, la creatividad y la afectividad, con el fin de garantizar una formación integral que contribuya al pleno desarrollo de la personalidad de los alumnos. Es decir, formación académica y desarrollo personal.

Nos interesa finalmente, una última alusión en el artículo diecisiete, donde dentro del párrafo $b$ podemos leer: 
b) Desarrollar hábitos de trabajo individual y de equipo, de esfuerzo y de responsabilidad en el estudio, así como actitudes de confianza en sí mismo, sentido crítico, iniciativa personal, curiosidad, interés y creatividad en el aprendizaje, y espíritu emprendedor (Ley Orgánica 8/2013, p.97870).

Como vemos, se habla de creatividad en el aprendizaje. No nos queda claro si se refiere a ser creativos en la manera en que se aprende poniendo por tanto el foco en el sujeto que asimila, o por el contrario, en el que facilita los aprendizajes e incluso el propio legislador. Entendemos que al referirse al desarrollo de una capacidad, se traslada esta responsabilidad al docente, aunque tal y como se redacta la acción de aprender es inequívocamente responsabilidad del aprendiz.

Comenzamos ahora con la revisión del Decreto de primaria, donde encontraremos hasta treinta y cinco referencias como hemos recogido en la tabla 5.

La primera de ellas aparece en el artículo seis, que recoge los principios generales de la educación primaria. En este artículo se enumeran los aprendizajes que debe realizar un alumno a lo largo de la etapa. Junto a elementos curriculares encontramos otros de desarrollo de habilidades personales, dentro de éstos nos aparece la creatividad paralelamente a otros como afectividad o sentido artístico (Real Decreto 126/2014, p. 7). Estamos ante un fragmento muy similar y por tanto, quizá extraído del ya citado artículo dieciséis de la LOMCE. Es un párrafo interesante para nosotros por la alusión a la formación integral de los alumnos, incluyendo en ella la creatividad y la afectividad como medios indispensables para un pleno desarrollo de la personalidad.

En el artículo siete donde se recogen los objetivos de la educación primaria, se habla de desarrollar capacidades que les permitan conocer, adquirir o desarrollar diferentes valores normas o competencias. Entre ellas, encontramos nuevamente la capacidad creativa, con idéntica redacción al párrafo referido a creatividad en el aprendizaje, del que ya hemos hablado al revisar la LOMCE.

El artículo 10.4 nos habla del espíritu emprendedor, destacando como habilidades para desarrollarlo la creatividad o la autonomía. Este tipo de alusiones están muy en consonancia con los enfoques empresariales que hemos podido analizar en la documentación europea o incluso de la UNESCO (Real Decreto 126/2014, p.10).

Tabla 10. Alusiones a creatividad en el R.D. 126/2014. Anexo1.

\begin{tabular}{|l|c|c|c|c|c|}
\hline $\begin{array}{l}\text { Asignaturas } \\
\text { troncales }\end{array}$ & $\begin{array}{c}\text { Descripción } \\
\text { del área }\end{array}$ & $\begin{array}{c}\text { Bloque de } \\
\text { contenidos }\end{array}$ & Contenidos & Criterios & Estándares \\
\hline $\begin{array}{l}\text { Ciencias de la } \\
\text { Naturaleza }\end{array}$ & 0 & $\begin{array}{c}\text { 2-El ser } \\
\text { humano y la } \\
\text { salud }\end{array}$ & 0 & 0 & 1 \\
\hline Ciencias Sociales & 1 & $\begin{array}{c}\text { 1- Contenidos } \\
\text { comunes }\end{array}$ & 0 & 1 & 1 \\
\hline- & - & $\begin{array}{c}3-\text { Vivir en } \\
\text { sociedad }\end{array}$ & 0 & 0 & 1 \\
\hline $\begin{array}{l}\text { Lengua } \\
\text { Literatura }\end{array}$ & y & $\begin{array}{c}1- \\
\text { Comunicación } \\
\text { oral: hablar y } \\
\text { escuchar }\end{array}$ & 1 & 1 & 1 \\
\hline- & - & $\begin{array}{c}3- \\
\text { Comunicación }\end{array}$ & 0 & 2 & 1 \\
\hline
\end{tabular}




\begin{tabular}{|c|c|c|c|c|c|}
\hline & & escrita: escribir & & & \\
\hline- & - & $\begin{array}{c}\text { 5-Educación } \\
\text { literaria }\end{array}$ & 1 & 1 & 0 \\
\hline Matemáticas & 0 & - & 0 & 0 & 0 \\
\hline $\begin{array}{l}\text { Primera Lengua } \\
\text { Extranjera }\end{array}$ & 0 & - & 0 & 0 & 0 \\
\hline
\end{tabular}

Fuente: Propia

Continuando con el análisis del decreto, llegamos hasta el anexo uno que recoge las asignaturas troncales. Dentro de ellas, podemos confirmar referencias en las asignaturas de Ciencias Naturales, Ciencias Sociales y Lengua Castellana y Literatura, la cuales pasamos a detallar (Tabla 10).

La referencia de Ciencias Naturales nos aparece en los estándares del bloque dos "El ser humano y la salud". El estándar valora la capacidad de planificar autónoma y creativamente las actividades de ocio y tiempo libre (Real Decreto 126/2014, p. 19). Sin ser esta una capacidad cercana a nuestro objeto de estudio, entendemos que hace referencia a que los alumnos sean competentes para elegir opciones de ocio fuera de lo habitual, quizá explorando opciones menos convencionales que las que habitualmente se les ofrecen y que uniformizan en exceso el tiempo libre.

Al acercarnos al área de Ciencias Sociales, recogemos la primera referencia en la presentación de la asignatura, cuando se enumeran las actitudes y hábitos que fomenta el área. El párrafo transcribe buena parte del ya plasmado artículo diecisiete de la LOMCE (Real Decreto 126/2014, p.22).

A continuación, y dentro de la misma asignatura, encontramos dos referencias en el bloque uno de "Contenidos comunes". En el criterio 9 las alusiones están ligadas al espíritu emprendedor, aprovechando la información y las ideas para generar propuestas innovadoras. El estándar 9.1 habla sobre las actitudes personales, entre las que incluye la creatividad y nuevamente el espíritu emprendedor (Real Decreto 126/2014, p.23). Dentro del bloque tres "Vivir en sociedad", el estándar 13.1 vuelve a insistir sobre el desarrollo de la creatividad y la capacidad de valorar el emprendimiento (Real Decreto 126/2014, p.25). Pensamos que quizá la insistencia en hacer confluir emprendimiento y creatividad en tantas ocasiones es algo forzada, dando la sensación de que la palabra creatividad se utiliza como un aderezo que mejora cualquier contenido al que se asocia.

A continuación nos aparecen nuevas referencias en el área de Lengua Castellana y Literatura. Encontramos tres en la presentación, coligando la creatividad a la comprensión e interpretación de textos como medio para desarrollar el pensamiento crítico, la producción escrita y posibilidades expresivas (Real Decreto 126/2014, p. 27 , 28).

Seguidamente, tenemos que continuar hasta los diferentes bloques temáticos para encontrar las referencias restantes. En el bloque uno, "Comunicación oral: hablar y escuchar", podemos ver referencias en contenido, criterio y estándar. El contenido está dirigido a la creación de textos literarios en prosa o verso de manera creativa. En el caso del criterio y el estándar se trata la memorización y reproducción posterior dejando a la creatividad la función de renovar las estrategias de comunicación oral. Señalamos como interesante la alusión que vemos en el contenido, a la valoración del sentido estético de cuentos, poemas, adivinanzas, canciones y teatro. A nuestro parecer resulta necesario trabajar en la etapa de primaria el desarrollo de la capacidad de análisis y crítica estética, bien desde la creación literaria o desde cualquier otro tipo de creación cultural, por lo que echamos en falta una alusión más generalizada a otros campos artísticos (Real Decreto 126/2014, p. 29). 
A continuación debemos saltar hasta el bloque tres "Comunicación escrita: escribir" para encontrar las siguientes tres referencias, dos de ellas en los criterios cinco y siete y una más en el estándar 1.3.

5. Buscar una mejora progresiva en el uso de la lengua, explorando cauces que desarrollen la sensibilidad, la creatividad y la estética.

7. Llevar a cabo el plan de escritura que dé respuesta a una planificación sistemática de mejora de la eficacia escritora y fomente la creatividad.

1.3. Escribe diferentes tipos de textos adecuando el lenguaje a las características del género, siguiendo modelos, encaminados a desarrollar su capacidad creativa en la escritura (Real Decreto 126/2014, p. 31).

Nos interesan las alusiones al desarrollo de la capacidad creativa que vemos en los párrafos anteriores. No obstante, prestamos especial atención al criterio cinco, sobre todo a la exploración de elementos que nos puedan llevar a ser creativos, y al criterio siete en la alusión a una planificación sistemática para fomentar la creatividad escrita. Estas dos referencias, al hacer alusión a métodos o elementos que favorecen la creatividad, están en la línea de aportar técnicas que desarrollen la capacidad que analizamos y van más allá de lo visto hasta ahora que una simple mención creativa que acompaña a otras destrezas principales.

Finalizamos el análisis del área de Lengua con el bloque cinco de "Educación literaria", donde encontramos un contenido y su criterio asociado. Ambos tienen una redacción similar entre ellos y muy parecida a la referencia ya comentada en el bloque uno sobre estética (Real Decreto 126/2014, p.32).

Tabla 11. Alusiones a creatividad en el R.D. 126/2014. Anexo2.

\begin{tabular}{|c|c|c|c|c|c|}
\hline $\begin{array}{l}\text { Asignaturas } \\
\text { Específicas }\end{array}$ & $\begin{array}{l}\text { Descripción } \\
\text { del área }\end{array}$ & $\begin{array}{l}\text { Bloque de } \\
\text { contenidos }\end{array}$ & Contenidos & Criterios & Estándares \\
\hline $\begin{array}{l}\text { Educación } \\
\text { Artística }\end{array}$ & 2 & - & - & - & - \\
\hline $\begin{array}{l}\text { A) Educación } \\
\text { Plástica }\end{array}$ & - & $\begin{array}{c}\text { 2- Expresión } \\
\text { artística }\end{array}$ & - & 2 & 1 \\
\hline $\begin{array}{l}\text { B)Educación } \\
\text { Musical }\end{array}$ & - & $\begin{array}{l}\text { 3-La música, el } \\
\text { movimiento y la } \\
\text { danza }\end{array}$ & - & 1 & - \\
\hline Educación Física & 1 & - & - & 1 & 1 \\
\hline $\begin{array}{l}\text { Segunda Lengua } \\
\text { Extrajera }\end{array}$ & 0 & - & - & 0 & 0 \\
\hline $\begin{array}{l}\text { Valores Sociales } \\
\text { y Cívicos }\end{array}$ & 0 & $\begin{array}{l}\text { 1-La identidad } \\
\text { y la dignidad de } \\
\text { la persona }\end{array}$ & - & 0 & 2 \\
\hline- & & $\begin{array}{c}2-\mathrm{La} \\
\text { compresión y el } \\
\text { respeto en las } \\
\text { relaciones } \\
\text { interpersonales } \\
\end{array}$ & - & 0 & 3 \\
\hline- & & $\begin{array}{c}\text { 3-La } \\
\text { convivencia y } \\
\text { los valores } \\
\text { sociales }\end{array}$ & - & - & 3 \\
\hline
\end{tabular}


En el análisis del anexo dos de asignaturas específicas, podemos encontrar referencias en las áreas de Educación Artística, Educación física, y Valores Sociales y Cívicos que es la que más alusiones creativas acoge, como vemos en la tabla 11.

En las asignaturas de educación artística encontramos las dos primeras referencias en la presentación del área. La primera abarca en sus finalidades los dos ámbitos que acoge la Artística: Plástica y Música, y está referida al conocimiento, entendimiento e investigación de ambos lenguajes como medio de desarrollo. La segunda de las alusiones tiene un objetivo más práctico, ya que especifica los bloques en que se divide la Educación Musical, enunciando que el tercero de ellos es el dedicado a las capacidades expresivas y creativas (Real Decreto 126/2014, p.46).

En la tabla de contenidos encontramos tres referencias dentro del bloque dos de "Expresión Artística". Se distribuyen en dos criterios y un estándar. Todos ellos aluden a las pautas del proceso creativo. Estamos ante uno de los pocos casos en que se trata la creatividad como un continuo evolutivo, se alude a sistematizar ordenadamente la producción plástica, no se habla de creatividad sino de creación. Experimentar, reconocer, diferenciar, elegir, organizar, conocer, intercambiar, desarrollar, compartir, son algunos de los verbos que guían el proceso, según la secuencia del área. Apoyamos esta visión progresiva de la experiencia creadora y también el hecho de que en esta etapa se plantee lo experiencial como una necesidad (Real Decreto 126/2014, p. 47).

Dentro de la Educación Musical debemos adentrarnos hasta el bloque tres: "Música, Movimiento y Danza" para encontrar una referencia en el criterio uno, donde se alude a capacidades y no a procesos. La redacción da a entender que la adquisición de capacidades expresivas y creativas se produce porque estas son innatas a la danza y expresión corporal y se adquieren al practicarlas. Entendemos que ambas técnicas son una buena herramienta expresiva, pero el simple hecho de practicarlas no aporta per se la capacidad expresiva o creativa, si no que más bien son un cauce por el que podemos expresarnos y crear, pero no una capacidad.

Adquirir capacidades expresivas y creativas que ofrecen la expresión corporal y la danza, valorando su aportación al patrimonio y disfrutando de su interpretación como una forma de interacción social (Real Decreto $126 / 2014$, p. 48).

Dentro del área de Educación Física, encontramos referencias al tratar la expresión corporal dentro de las cinco situaciones motrices en que se desglosa el área. La acción motriz de índole artística o de expresión se describe como de carácter estético y comunicativo. Los diferentes registros de expresión corporal, oral, danza o musical son la base de las acciones creativas y comunicativas. Esta misma idea se concreta en el criterio 2 y el estándar 13.2. ampliando la utilidad comunicativa a sensaciones, emociones o ideas (Real Decreto 126/2014, p.49, 51).

Finalizamos la revisión del decreto con el análisis del área de Valores Sociales y Cívicos donde encontramos el mayor número de alusiones. La creatividad tiene representación en los tres bloques temáticos en los que se divide el área. Bloque uno, "La identidad y dignidad de la persona", donde se relaciona la creatividad con los recursos personales a la hora de actuar en contextos sociales (Real Decreto 126/2014, 56). Bloque dos, "La comprensión y el respeto en las relaciones interpersonales", que agrupa la creatividad con la expresión y descripción adecuada de cuestiones relacionales (Real Decreto 126/2014, p. 56). Y el bloque tres, "La convivencia y los valores 
sociales" donde podemos ver hasta tres alusiones en los estándares, 19.3, 22.3 y 25.2, y que aluden a competencias personales para la vida en sociedad, en relación a los impuestos, la contaminación y la publicidad (Real Decreto 126/2014, p 58).

El enfoque que se da a la creatividad queda claro cuando en la ley se afirma que debe tratarse como un eje transversal. De esta manera se traslada la responsabilidad de su trabajo a todas las áreas.

En el decreto, aunque se alude numerosas veces a la creatividad, en ningún caso se señalan estrategias para desarrollarla. Simplemente se pide que se cree, se produzca, se analice, etc. de forma creativa, pero no se señalan ni estrategias ni contextos educativos concretos. En numerosas ocasiones se alude al proceso creativo en el sentido de línea de creación, como sinónimo de producción y no como innovación. Es decir, se habla de construir cosas y no de hacerlo de forma diferente, sorpresiva o inhabitual. Entendemos que se habla de creación y no de creatividad.

Admitimos que quizá en las presentaciones de las materias o los contenidos no esté recogido el proceso de trabajo, pero los criterios y estándares si deberían concretar cómo desarrollar y adquirir competencias creativas. Estamos de acuerdo como señala Navarro (2008), que enseñar creatividad en la escuela es complicado por la propia estructura del sistema educativo o la propia escuela. Sin olvidar la problemática de los tres elementos decisivos para su desarrollo: los maestros y su formación; el contexto y los espacios; y el alumnado y su predisposición. De la Torre $(2006,2007)$ entiende más fácil el trabajo creativo al afirmar que la creatividad se fomenta realizando actividades creativas, es decir, poniendo a los alumnos en la tesitura de crear o buscar soluciones. Pensamos que este enfoque, sin más formación específica, deja la responsabilidad nuevamente en el interés de los maestros por hacerlo posible. Por ello, si como se desprende del reciente análisis legislativo admitimos la importancia de la creatividad, entendemos que se debe sistematizar su desarrollo en el aula.

Con una mirada panorámica reparamos en que el tratamiento de los tres elementos analizados, patrimonio, emociones y creatividad es similar. Se entiende que son elementos que se deben trabajar, se aluden genéricamente en varias ocasiones y se introducen en varias áreas como centros de interés que deberían ser tenidos en cuenta a la hora de diseñar las programaciones de aula. Es esta una manera de introducir elementos en el currículo, en la que toda la responsabilidad se traslada al profesorado o a las editoriales, incluso en este segundo caso, finalmente también corresponde al profesor la decisión última de su aplicación. De esta manera, deberíamos preguntarnos si las facultades de educación tienen en cuenta esta exigencia sobre los docentes a la hora de diseñar sus grados y por ende, si sus egresados titulan suficientemente preparados para afrontar este reto.

\subsection{El patrimonio, las emociones y la creatividad en la formación del profesorado de Primaria.}

Para estudiar la presencia que nuestros tres ámbitos de estudio tienen en la formación del profesorado, analizaremos dos textos que consideramos esenciales en el sentido que nos ocupa. Por un lado, la Ley Orgánica 6/2001, de 21 de diciembre, de Universidades (LOU) y, por otro lado, el Libro Blanco del Título de Grado en Magisterio de la Agencia Nacional de Evaluación de la Calidad y la Acreditación (ANECA). 
Tabla 12. Alusiones a Patrimonio, Emociones y Creatividad

\begin{tabular}{|l|c|c|c|}
\hline Textos analizados & Patrimonio & Emociones & Creatividad \\
\hline LOU: Ley 6/2001 & $0(8)$ & 0 & 0 \\
\hline $\begin{array}{l}\text { Libro blanco } \\
\text { ANECA. Volumen }\end{array}$ & 0 & 7 & 43 \\
1. & & & \\
\hline $\begin{array}{l}\text { Libro blanco } \\
\text { ANECA. Volumen }\end{array}$ & $0(1)$ & 2 & \\
2. & & & \\
\hline
\end{tabular}

Fuente: Propia

Como vemos en la tabla 12, no encontramos ninguna referencia a emociones o creatividad en la LOU. Sí podemos hallar varias sobre patrimonio, no obstante estas están referidas al patrimonio material con que cuentan las universidades, es decir patrimonio arquitectónico, mobiliario, bibliotecario, etc. pero en ningún caso existen referencias a la utilidad del patrimonio como elemento formativo.

Ello nos lleva al análisis del libro blanco de ANECA que está editado en dos volúmenes. Estos textos recogen propuestas para el diseño de los títulos de grado adaptados al Espacio Europeo de Educación Superior (EEES). En el documento se analizan cuestiones como la situación de los estudios de Magisterio en Europa, el modelo de estudios europeos, plazas ofertadas y demanda del título, estudios de inserción laboral de los titulados, perfiles profesionales, competencias transversales del docente, competencias específicas de formación profesional y disciplinar, clasificación de las competencias en relación con los perfiles o especialidades, valoración de las competencias, contraste de las competencias con experiencia académica y profesional, objetivos del título, estructura del título, distribución de contenidos y asignación de créditos europeos, entre otras.

El análisis de las referencias de ambos textos, nos informa de que no existe alusión alguna al patrimonio en ellos. Dada esta ausencia tan extrema, entendemos que no se concibe, ni a nivel nacional ni europeo, que el patrimonio sea un componente apreciable en la formación del profesorado. Gozález-Monfort (2011) nos informa en este sentido, a la vez que señala que el ámbito sociohistórico y natural debería ser el espacio que articulara el trabajo patrimonial. Fontal (2016) por el contrario, propone subsanar este vacío desde el área universitaria de Didáctica de la Expresión Plástica, indicando que existe una línea de investigación al respecto que llevan adelante varias universidades españolas como la Universidad Complutense de Madrid, la Universidad de Barcelona, la Universidad de Girona, la Universidad de Granada, la Universidad de Valencia y la Universidad de Valladolid, a través de tesis doctorales y proyectos $\mathrm{I}+\mathrm{D}+\mathrm{i}$.

Encontramos un trabajo clarificador al respecto de la mano de Fontal, IbáñezEchevarría, Martínez y Ribero (2017) quienes, a la vista de las numerosas referencias al patrimonio en el currículo de primaria, analizan si esta presencia tiene un reflejo directo en la formación de los maestros. Los autores concluyen que no es así y achacan esta discordancia al desfase en el currículo en el momento de diseñar los planes de estudio de los maestros (Fontal, et al 2017).

Como nos indican los diferentes trabajos de investigación citados y pese a no estar recogido en el libro blanco correspondiente, el patrimonio sí que forma parte de algunos planes de estudio de facultades de educación, pero en ningún caso con una relevancia en consonancia a la que se le otorga en el decreto de primaria. Esto origina que haya un vacío en el ámbito patrimonial entre la formación con que los profesores cuentan al 
terminar su carrera de magisterio y las competencias que el currículo les exige cuando comienzan a trabajar.

Pasamos seguidamente a analizar la presencia de las emociones en el libro blanco. Como podemos observar en la tabla 12, encontramos siete referencias en el primer volumen y dos en el segundo.

Al examinar las del volumen uno, vemos que todas las referencias hacen alusión a la "Capacidad de relación y de comunicación, así como de equilibrio emocional en las variadas circunstancias de la actividad profesional", esta facultad es valorada por los académicos encuestados en el informe, atendiendo a lo que se estipula como competencia común a todos los maestros. Posteriormente, se hacen las mismas apreciaciones desde las especialidades de Educación Infantil, Lengua Extranjera, Educación Física y Necesidades Educativas Especiales (Libro Blanco título de Grado de Magisterio. Volumen 1, 2004, pp. 90-214).

En lo que respecta al segundo volumen donde se recogen los anexos, encontramos las dos referencias en el estudio de Grados de Magisterio de Europa. Aquí se analizan las estructuras de los sistemas educativos de escolarización obligatoria, las competencias clave y la formación inicial del profesorado de veinticinco países de la Unión Europea. De todos ellos solamente dos, Luxemburgo y Finlandia, incluyen una referencia emocional cada uno dentro de la descripción de las competencias clave en la educación general obligatoria. Luxemburgo lo hace con la siguiente redacción: "El área de las capacidades y destrezas técnicas básicas: la enseñanza preescolar favorece notablemente el desarrollo de la expresión emocional y el uso de la lengua en los niños, junto con la coordinación corporal y muscular y los reflejos" (Libro Blanco título de Grado de Magisterio. Volumen 2, 2004, p. 79). Finlandia lo incluye dentro de las materias obligatorias y las competencias que éstas deben ayudar a desarrollar: "música y arte (crecimiento emocional y moral, destrezas sociales, conocimientos culturales)" (Libro Blanco título de Grado de Magisterio. Volumen 2, 2004, p. 117).

Como vemos, cada país incluye la referencia emocional dentro de un apartado diferente: competencias clave, capacidades técnicas básicas y materias obligatorias. De esta manera el tratamiento de las emociones tiene un peso diferente según donde incide su ubicación. Cabe subrayar que no existan referencias al ámbito emocional dentro de la relación de competencias transversales o genéricas. Éstas se consideran como esenciales en los maestros y se distribuyen en instrumentales, personales o sistémicas. Quizá, en nuestra opinión, dentro de cualquiera de las dos últimas tendría un acomodo claro.

Podemos encontrar una explicación a la escasez de alusiones emocionales en el perfil profesional tan tradicional que dibujan las competencias descritas en el informe, y que contrasta con la vocación innovadora del propio estudio. El objetivo del mismo es analizar la situación de las enseñanzas del grado de maestro a nivel europeo, para realizar una propuesta de mejora y adecuación al Espacio Europeo de Educación Superior. Sin embargo, los resultados del estudio muestran que las características que se consideran esenciales en un buen maestro, responden a una visión clásica del mismo, y no se incluye en ellas casi ningún rasgo de las competencias que se le exigen ya en este momento a un docente en activo.

Así pues, y en definitiva, quizás lo más destacado de todo resulte la visión más bien anclada en el rol convencional del maestro: alguien que se expresa bien en su lengua, que organiza y planifica su trabajo y que, esto sí, reconoce la multiculturalidad; alguien, al mismo tiempo, para el que una lengua extranjera (excepto para los de ese perfil) y las nuevas tecnologías suponen una formación necesaria pero poco valorada frente a 
otras competencias; y alguien para quien la mayor parte de las propuestas de innovación educativa recogidas por la literatura de los últimos años permanecen al fin en un segundo plano. La prevalencia de esta perspectiva tradicional predominante ha supuesto una sorpresa, en la medida que las expectativas de los miembros del grupo de trabajo se enmarcaban en la dirección contraria, y también un motivo de preocupación de cara a la resistencia al cambio del modelo formativo que se propone desde estas páginas (Libro Blanco título de Grado de Magisterio. Volumen 1, 2004, p. 86)

Dentro de la descripción de objetivos del informe, cuando se enumeran las nuevas exigencias en el proceso formativo de maestros, no encontramos ni una sola referencia a las capacidades emocionales a desarrollar. $\mathrm{Ni}$ en los docentes propiamente, ni tampoco en el desarrollo de sus habilidades para propiciarlo en sus futuros alumnos (Libro Blanco título de Grado de Magisterio. Volumen 1, 2004,pp. 94-95).

Nos parece significativo no encontrar alusiones al ámbito emocional en unas líneas tan cruciales, donde se recogen las figuras clave de lo que es el diseño de los actuales títulos de grado. Con todo ello, podríamos concluir que la presencia del ámbito emocional en las facultades de educación desde el primer nivel de concreción de sus contenidos en las carreras de magisterio resultaría insuficiente.

Examinamos, finalmente, las 63 referencias a la creatividad señaladas en la tabla 12 y que se incluyen en el Libro Blanco del Título de Grado en Magisterio que estamos analizando. Comenzamos rastreando las 43 del volumen 1.

La primera mención la encontramos en los estudios de inserción laboral de los graduados, dentro de las conclusiones de las universidades españolas, donde podemos ver que los encuestados entienden que el estímulo de la creatividad es esencial.

Así mismo, y en relación con la formación inicial, los encuestados destacan la importancia de la expresión oral y escrita como muy útiles para el trabajo. Algo parecido ocurre en la formación para estimular la creatividad, la gestión, las competencias instrumentales, la toma de decisiones y el liderazgo (Libro Blanco título de Grado de Magisterio. Volumen 1, 2004, p. 70).

Resulta significativo que se hable de "formación para estimular la creatividad". Como hemos comprobado a lo largo de este estudio, es infrecuente encontrar menciones donde se afirme que el estímulo de la creatividad puede tener una base didáctica, es decir que se puede aprender a estimular la creatividad. Esta reseña da a entender que existen recursos pedagógicos o didácticos que los profesionales deben adquirir para estimular convenientemente la creatividad, lo que sin duda apoyamos firmemente.

Posteriormente, la mayoría de las referencias, hasta un total de 38, están incluidas en las competencias de los profesores. Las encontramos repartidas de la siguiente manera: competencias transversales 3, competencias específicas 14, y perfiles profesionales 21 .

En las tres menciones de las competencias transversales o genéricas, se incluye la creatividad como una competencia exclusiva dentro del grupo de sistémicas. La primera referencia la encontramos dentro de las observaciones que realizan los académicos consultados. Teniendo en cuenta que la tasación máxima es cuatro, vemos que la creatividad es una de las más altamente valoradas por este colectivo, situándose la media por encima de tres en todos los perfiles profesionales, excepto en lengua extranjera con 2,88 (2004, p. 84). 
La siguiente referencia la encontramos en el análisis que el propio libro hace de las respuestas estadísticas sobre las competencias genéricas, donde podemos ver que la creatividad se sitúa entre el segundo grupo de las tres mejor valoradas, junto con el trabajo en equipo y las relaciones interpersonales (Libro Blanco título de Grado de Magisterio. Volumen 1, 2004, p.85).

La última de las referencias en las competencias genéricas aparece cuando en el análisis, al establecer diferencias entre los perfiles, se destaca que la creatividad es la mejor valorada por todos los perfiles, excepto por el de lenguas extranjeras (2004, p.86). Como vemos son tres alusiones a un mismo resultado estadístico, aunque éste es analizado por diferentes agentes: los académicos en primer lugar, la valoración de los redactores del libro blanco y la comparación de ese resultado entre las diferentes especialidades de magisterio.

A continuación, entramos en las referencias incluidas en las competencias específicas que se encuentran desglosadas del siguiente modo teniendo en cuenta los perfiles profesionales donde han sido valoradas.

En el perfil de Educación Infantil, dentro de las competencias profesionales saber hacer, encontramos: "Ser capaz de diseñar, aplicar y evaluar actividades y materiales que fomenten la creatividad infantil", "Ser capaz de diseñar actividades de aprendizaje de nuevas formas de expresión plástica a partir de materiales diversos con el fin de potenciar la creatividad" (2004, p.94). Estas dos alusiones se vuelven a repetir algo más adelante cuando se presenta una clasificación de valoración por parte de los académicos. En este ranking la competencia más valorada tiene una puntuación de 3,58. Las competencias referidas a creatividad, y por el orden mencionado, tienen unas valoraciones de 2,87 y 2,73 respectivamente (2004, p.96). Así en Educación Infantil, la creatividad tomada como sistémica y transversal ocupa la cuarta posición, las otras dos competencias específicas ya enunciadas más arriba ocupan los lugares 53 y 60 sobre un total de 76 (2004, pp.120, 123, 124).

Dentro del perfil de Primaria, en Lengua 1 podemos leer: "Tomar conciencia del papel del conocimiento metalingüístico y diseñar actividades para el desarrollo de los procesos de autocontrol y creatividad específicas de formación disciplinar $\mathrm{y}$ profesional". Y en Lengua 2 se plasma: "Ser capaz de usar los recursos audiovisuales y las nuevas tecnologías aplicadas a la enseñanza de las lenguas, de un modo creativo (Libro Blanco título de Grado de Magisterio. Volumen 1, 2004, pp.98-99). Dentro de la especialidad de Geografía e Historia habla de la capacidad de reconocer en las situaciones sociales y personales cotidianas, oportunidades para desarrollar actitudes positivas y creativas en los niños (Libro Blanco título de Grado de Magisterio. Volumen 1, 2004, pp.104-105). Al llegar a la Educación Artística, se incide en la facultad de desplegar habilidades y recursos para orientar y solucionar los problemas de tipo expresivo, estético y creativo que el alumnado requiera o pueda plantear (Libro Blanco título de Grado de Magisterio. Volumen 1, 2004, pp.106-107). Y finalmente, en Educación Física se hace hincapié en relacionar la actividad física con las distintas áreas que configuran el currículo de infantil y primaria, incidiendo en el desarrollo de la creatividad y las distintas manifestaciones expresivo-comunicativas (Libro Blanco título de Grado de Magisterio. Volumen 1, 2004, p.110).

Como vemos, en la mayoría de los casos encontramos dos alusiones por área, la primera de ellas corresponde con la valoración que se le otorga para ayudar a alcanzar los objetivos del área y la segunda, cuando se establece como una competencia docente.

Finalmente, se analizan las 21 referencias relativas a los perfiles profesionales. En este apartado se clasifican todas las competencias transversales o genéricas y las específicas. Concretamente se contabilizan 149 competencias en total, valoradas para cada perfil 
profesional y ordenadas por la puntuación media otorgada por los académicos. Esta puntuación les asigna un número ordinal al que hacemos alusión en la tabla 13.

De esta manera, reflejamos en la tabla la posición en la que quedan las competencias con alusiones creativas (que detallamos a continuación) con respecto al total de las 149 referidas en el documento, y asociadas al ámbito y especialidad al que hace referencia la competencia creativa.

Las competencias con alusiones a la creatividad en cada perfil profesional son: dentro de Lengua 1: Tomar conciencia del papel del conocimiento metalingüístico y diseñar actividades para el desarrollo de los procesos de autocontrol y creatividad (2004, pp. 135, 147, 159, 172). En Lengua 2: Ser capaz de usar los recursos audiovisuales y las nuevas tecnologías aplicadas a la enseñanza de las lenguas, de un modo creativo (2004, pp. 136, 160, 173). En Geografía e Historia: Reconocer en las situaciones sociales y personales cotidianas oportunidades para desarrollar actitudes positivas y creativas en los niños (2004, pp. 131, 144, 156, 168). En Artística: Ser capaz de desplegar habilidades y recursos para orientar y solucionar los problemas de tipo expresivo, estético y creativo que el alumnado requiera o pueda plantear (2004, pp. 128, 141, 153, 165). En Educación Física: Relacionar la actividad física con las distintas áreas que configuran el currículo de infantil y primaria, incidiendo en el desarrollo de la creatividad y las distintas manifestaciones expresivo comunicativas (2004, pp. 125, 145). En Creatividad: Transversal, sistémica (2004, pp. 134, 144, 152, 166).

Tabla 13. Clasificación de las competencias creativas según los perfiles profesionales y el ámbito al que pertenecen.

\begin{tabular}{|l|c|c|c|c|}
\hline $\begin{array}{c}\text { Ámbito al que } \\
\text { pertenece la } \\
\text { competencia } \\
\text { creativa }\end{array}$ & $\begin{array}{c}\text { Puesto } \\
\text { otorgado a la } \\
\text { competencia } \\
\text { creativa desde } \\
\text { el perfil de } \\
\text { Lengua } \\
\text { Extranjera }\end{array}$ & $\begin{array}{c}\text { Puesto } \\
\text { otorgado a la } \\
\text { competencia } \\
\text { creativa desde } \\
\text { el perfil de } \\
\text { Educación } \\
\text { Física }\end{array}$ & $\begin{array}{c}\text { Puesto } \\
\text { otorgado a la } \\
\text { competencia } \\
\text { creativa desde } \\
\text { el perfil de } \\
\text { Educación } \\
\text { Artística }\end{array}$ & $\begin{array}{c}\text { Puesto otorgado } \\
\text { a la competencia } \\
\text { creativa desde el } \\
\text { perfil de } \\
\text { Necesidades } \\
\text { Educativas } \\
\text { Específicas }\end{array}$ \\
\hline Lengua 1 & 107 & 114 & 112 & 113 \\
\hline Lengua 2 & 132 & 131 & 130 & 131 \\
\hline $\begin{array}{l}\text { Geografía } \\
\text { Historia }\end{array}$ & 64 & 67 & 67 & 71 \\
\hline E. Artística & 30 & 30 & 33 & - \\
\hline E. Física & - & 93 & 22 & 40 \\
\hline $\begin{array}{l}\text { Creatividad } \\
\text { Transversal }\end{array}$ & 102 & 70 & & - \\
\hline
\end{tabular}

Fuente: Propia

El análisis de la tabla 13 nos aporta algunas conclusiones interesantes. Observamos que a la competencia artística se le otorga el mayor valor desde todos los perfiles profesionales, no bajando del lugar 33. Por el contrario, la competencia física solamente es tenida en cuenta por su propio perfil profesional. Nos parece muy destacable el resultado de Geografía e Historia estando sus valores entre 64 y 71, lo que le confiere una importancia reseñable comparada con el resto, y en franca competencia incluso con la creatividad transversal. Es un resultado que está muy en consonancia con la propuesta 
de trabajo de este estudio, donde defendemos que la historia puede ser un excelente punto de partida para trabajar la creatividad desde un área concreta.

Entendemos, a tenor de lo visto, que desde cualquier perfil profesional de primaria la creatividad es muy tenida en cuenta, pero que no obstante, se deja el peso de su desarrollo al ámbito artístico. Esto lo podemos afirmar tanto por el resultado del área en si, como por el de la creatividad tomada como eje transversal, donde se alcanza la valoración más alta subiendo hasta el puesto 20.

En consecuencia podemos declarar que son significativas tanto el número de referencias creativas, como la importancia que se otorga a las mismas desde las diferentes visiones que alberga este volumen 1 de la actividad y formación de los docentes de Infantil y Primaria

Continuando con el análisis del Volumen 2, las ocho primeras referencias a la creatividad las encontramos en los estudios de grado de Europa. Los países donde se incluyen estas competencias en sus diseños de grado son: Bélgica (tres referencias), Chipre, Austria, Polonia, Portugal, Eslovenia y Finlandia.

Las siguientes referencias nos aparecen dentro de los estudios de inserción profesional de Maestros de las universidades. Así hay menciones a ellos en las universidades de Cataluña, donde los maestros valoran especialmente la formación destinada a desarrollar la creatividad (2004, pp. 297, 304, 318). La formación para estimular la creatividad ha puntuado en los maestros $(4,6)$ por encima de la media del área, al igual que en la valoración de su utilidad $(5,4)(2004$, p. 299).

Las siguientes referencias aparecen en las encuestas de opinión a maestros, directores e inspectores. En ellas, se señala como punto débil la falta de creatividad (2004, p. 345) por ello, se insiste posteriormente en la potenciación y fomento de la misma (2004, pp. 386, 393).

De esta manera, llegamos a la última referencia contenida en el acta de la reunión del pleno de representantes de las universidades, más concretamente en la propuesta de distribución de créditos ECTS a los bloques de materias por competencias. Se incluye la creatividad en el bloque 6 de materias que ayudan a conseguir competencias específicas comunes orientadas al área de "Expresión Artística y Creatividad" (2004, p. 407). Como vemos, se hace referencia a artística y creatividad como un área conjunta, fusionándolas bajo un mismo término y materia educativa. Queda patente nuevamente la importancia que se otorga a la educación artística como elemento de desarrollo creativo, inclusive asociándola a la creatividad, para crear una unidad que no hace otra cosa que otorgarle toda la responsabilidad de su desarrollo. Este enfoque nos parece a todas luces insuficiente, ya que la creatividad, como hemos defendido, se puede desarrollar desde múltiples ámbitos debido a que se aplica en cualquier terreno de la vida cotidiana.

Como podemos apreciar, el número de referencias a la creatividad en el Libro Blanco del Título de Grado de Magisterio es numeroso. Sin embargo, debemos aclarar que en varios casos, tal y como ha quedado reflejado, se refiere a la misma competencia analizada desde distintos puntos de vista. En otras ocasiones es el mismo dato repetido al plasmar el tanto por ciento de las veces que se le ha elegido y posteriormente, colocarlo en el ranking de respuestas más nombradas.

En cualquier caso, deducimos que es muy significativa la atención prestada a la creatividad tomada como competencia, que aparece en todos los perfiles de maestro que se detallan, tanto de Infantil como de las distintas disciplinas de Primaria.

Como ya hemos señalado en los datos específicos, parece que desde los distintos perfiles se decantan mayoritariamente por la Educación Artística, como el área que más puede aportar en su desarrollo, algo en lo que no estamos muy de acuerdo, ya que entendemos que contextos como la resolución de problemas, creación literaria, 
construcción de máquinas, creación de maquetas en Ciencias Naturales o Ciencias Sociales, coreografías, diseño de circuitos en Educación Física, etc. son tan propicios para el desarrollo creativo, como lo puedan ser artística o música.

Si reflexionamos con perspectiva sobre las referencias encontradas en el Libro Blanco con respecto a los tres ámbitos de estudio, Patrimonio, Emociones y Creatividad, es evidente como ya nos apuntaba la tabla doce, que el número de alusiones creativas es mucho mayor que el referido a Patrimonio o Emociones. Esto nos indica que la importancia que se le otorga a la creatividad es mayúscula, máxime cuando se alude a ella en competencias, inserción laboral, objetivos, estructura general del título, etc.

Quizá esta tendencia se podría extrapolar al resto de documentación analizada en todo el marco teórico. Desde el prisma educativo, la creatividad es quizá, el elemento al que más importancia se otorga. Esto pudiera ser debido a que a priori, se le entiende más provecho para una utilización transversal en el currículo, y por tanto más facilidad se le presume para una concreción en el aula a través de diferentes áreas. 
CUERPO EMPÍRICO 


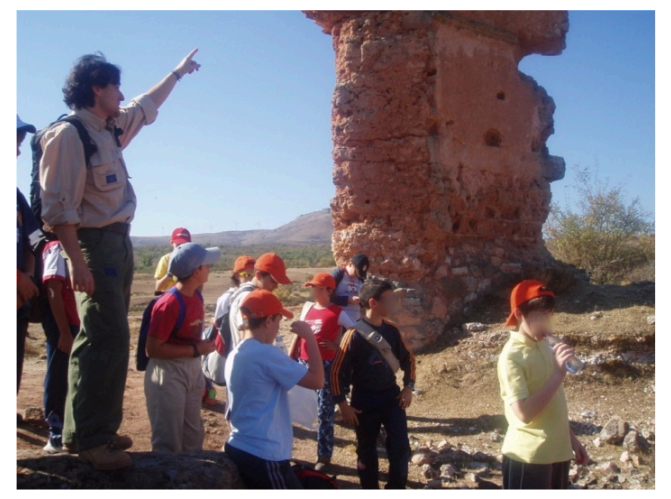

"La docencia es una profesión emocionalmente apasionante, profundamente ética e intelectualmente exigente, cuya complejidad solamente es vivida por quienes solemos poner el cuerpo y el alma en el aula."

M. Fullan y A. Hargreaves

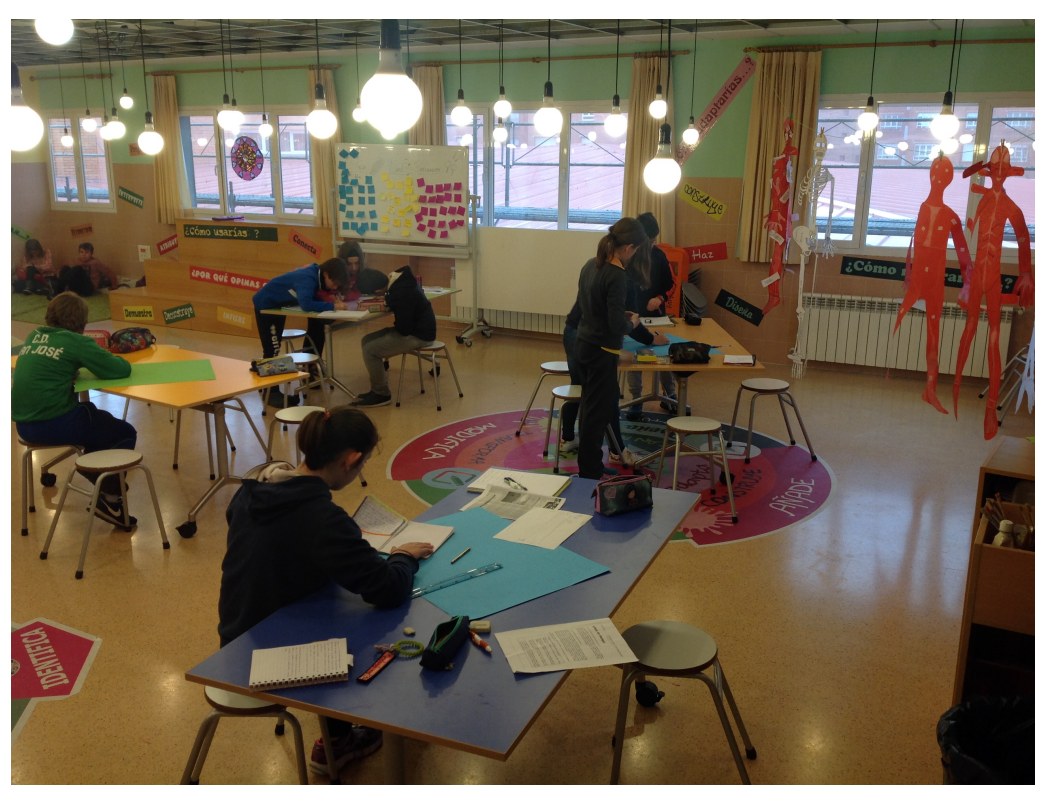




\section{CAPITULO 4. DESCRIPCIÓN METODOLÓGICA}

La presente investigación, analiza la presencia de los ámbitos emocional y creativo en el entorno patrimonial. Para ello en el cuerpo teórico, se revisa la presencia de alusiones emocionales y creativas en la documentación de carácter patrimonial de instituciones internacionales, como la UNESCO o el Consejo de Europa, sin olvidar otros organismos o iniciativas que consideramos referentes. De la misma manera, se revisan las menciones a las familias de palabras de los conceptos mencionados en la literatura científica.

En el ámbito nacional, se tienen en cuenta los mismos objetivos analizando la legislación vigente en materia de patrimonio, los Planes Nacionales, el IPCE y la literatura científica estatal.

El apartado teórico finaliza con la revisión de los mismos conceptos para el entorno de la educación formal en la etapa de primaria y las facultades de educación.

De esta manera se pretende plasmar un estado de la cuestión del que partir para realizar una evaluación de programas con estas temáticas circunscrito a la base de datos del OEPE.

\subsection{Problema de investigación e hipótesis de partida.}

El análisis documental realizado en el marco teórico de la investigación, permite confirmar la presencia de elementos emocionales y creativos en textos de temática patrimonial a nivel legislativo y científico. A lo largo de los últimos años de este siglo se han producido un notable número de publicaciones sobre educación patrimonial (Fontal e Ibáñez, 2017), que ha permitido que la investigación en este campo se haya desarrollado rápidamente. En este sentido la educación patrimonial se nos presenta como una herramienta muy eficaz para la formación plena de la persona (Apaydin, 2018). Así y teniendo en cuenta que el trabajo con el patrimonio puede ayudar al desarrollo dela inteligencia emocional (Cuenca y Estepa, 2017) (López, 2010), y que la creatividad no es una cualidad inmutable y puede ser desarrollada (De Bono, 2008, 2010, 2016, 2018), planteamos el uso de los elementos patrimoniales como recurso para el desarrollo de las habilidades creativas y emocionales (Munilla, 2017).

Partiendo de que la infancia es la etapa crucial en la que se pueden trabajar mejor ambas destrezas, tanto la creatividad (Gardner, 2002), como la inteligencia emocional (Bisquerra, Pérez y García, 2015; Bisquerra, 2009), debemos volver nuestra mirada a las facultades de educación.

Se apunta por tanto la necesidad de que los futuros docentes y profesionales del patrimonio sean formados convenientemente para trabajar en este ámbito (Castro y López-Facal, 2019; Conde y Armas, 2019), lo que según el estudio de Fontal, GarcíaCeballos y Aso (2020), no se ha conseguido.

Por ello creemos esencial analizar el último eslabón de la cadena educativa, aquel que incide directamente en el público final, los programas de educación. De ahí que pretendamos conocer y evaluarla presencia de emociones y creatividad en los programas de educación patrimonial, así como la calidad de aquellos que las incluyen.

Presentamos por tanto, los objetivos que tratamos de alcanzar con la presente investigación. 


\subsection{Objetivos de la investigación}

Objetivo general de la investigación:

OG1 - Analizar los programas patrimoniales inventariados en la base de datos de OEPE, para conocer la presencia de elementos emocionales y creativos dentro de ellos y valorar su calidad.

Objetivos específicos de la investigación:

- OE1- Examinar los programas de educación patrimonial existentes en la base de datos de OEPE, para determinar cuales incluyen emociones y creatividad en sus propuestas.

- OE2- Analizar los programas de educación patrimonial inventariados en OEPE y que incluyen elementos emocionales y creativos.

- OE3- Evaluar los programas de educación patrimonial inventariados en la base de datos de OEPE que incluyen elementos emocionales.

- OE4- Evaluar los programas de educación patrimonial inventariados en la base de datos de OEPE que incluyen elementos creativos.

\subsection{Fases de la investigación}

Con el propósito de dar respuesta a los objetivos planteados, se estructura la investigación en las siguientes fases:

- F1: Localización de programas educativos inventariados en OEPE que contengan iniciativas de trabajo en el ámbito de las emociones y la creatividad.

- F2: Evaluación de los programas localizados.

- F3: Discusión, conclusiones, limitaciones y futuras líneas de investigación.

\subsection{Justificación de la elección y relevancia temática.}

La importancia otorgada al patrimonio cultural a escala internacional queda patente en distintos organismos desde el siglo pasado. Un paso clave a nivel de conservación y sensibilización lo realiza la UNESCO en la Convención del Patrimonio Mundial celebrada en Paris en 1972, donde se constatan las amenazas al patrimonio cultural y natural, considerando la importancia que tiene para todos los pueblos la conservación de esos bienes únicos e irreemplazables, por lo que se determina como indispensable adoptar para ello nuevas disposiciones convencionales que establezcan un sistema eficaz de protección colectiva del patrimonio cultural y natural de valor excepcional organizada de una manera permanente, y según métodos científicos y modernos. Una de las acciones que derivan de esta convención es la creación de la Lista del Patrimonio Mundial, como elemento de protección por parte de los estados hacia los elementos patrimoniales que acceden a este inventario mundial.

A partir de estas y otras iniciativas, se produce un desarrollo del ámbito patrimonial que da como resultado el nacimiento o impulso de disciplinas paralelas, como pueden ser la 
conservación patrimonial, la gestión patrimonial o la mediación patrimonial. Todo ello desemboca en uso social del patrimonio que genera entre otras cosas, la parición de nuestra disciplina, la educación patrimonial.

Tanto la utilización del término educación patrimonial (Colom, 1998; Fontal, 2003), como el corpus científico alrededor de la materia (Fontal e Ibañez-Etxebarría, 2017), muestran un estimable desarrollo de la misma en nuestro país, tanto en el plano formal (Fontal, Ibáñez-Etxeberria, Martínez-Rodríguez, y Rivero, 2017), como en el no formal o informal (Fontal, y Juanola, 2015). No obstante estimamos que no en la misma proporción, ya que el plano no formal y principalmente los museos, han puesto en marcha iniciativas muy destacables al respecto (Calaf, Fontal, Valle, 2007; Fontal 2003).

Las emociones tal y como apunta Goleman (1996), hacen referencia no solo a un sentimiento sino también a los pensamientos, los estados psicológicos y biológicos, así como a las acciones derivadas de ellos. Las emociones abarcan un compendio de elementos tal, que se hace difícil definirlos con palabras, no obstante nadie duda de su importancia para un desarrollo armónico de la persona. Asíy dentro de la psicología se produce a lo largo del siglo veinte un desarrollo de diferentes corrientes de investigación que persiguen aunar cognición y emoción (Sevdalis, Petrides y Harvey, 2007) y que desembocanen el constructo de inteligencia emocional (Salovey y Mayer, 1990). En décadas sucesivas y bajo éste termino, se han desarrollado diferentes modelos de inteligencia emocional (Salovey y Mayer, 1990; Goleman 1996; Petrides y Furnham, 2001; Zeidner, Matthews, Roberts y MacCann, 2003; Mikolajczak, 2009). En cualquier caso el citado libro "Inteligencia Emocional" de Goleman, se convierte en un verdadero éxito y esto hace que tenga una influencia mayúscula en diversos campos. En el ámbito educativo el epígrafe "La escolarización de las emociones" (Goleman, 1995) es un punto de partida para el traslado del interés emocional a las aulas.

En nuestro país la atención a las emociones desde la docencia y el espectro académico, se hace a través del término educación emocional que concreta muy bien Rafael Bisquerra (2009, p.158) cuando habla de "un proceso educativo permanente para desarrollar las emociones, como una parte esencial del progreso humano". Esta línea de atención a la educación emocional dentro de la educación formal, considera que el periodo de seis a doce años, que es el que nosotros proponemos como etapa de trabajo emocional por medio del patrimonio, es crucial para el desarrollo de la personalidad y por ello, considera que la educación reglada debe atender no solo los aspectos cognitivos, sino también afectivos (Renom, 2003). Como hemos podido ver en el marco teórico de este estudio, la atención a las emociones queda ya reflejada en la ley educativa analizada con más o menos peso. Por ello, independientemente de la concreción de las alusiones, su inclusión en el texto da cabida formal a la línea de intervención educativa a la que aludimos en este trabajo.

En cuanto a la creatividad, conocemos que desde finales del XIX ya existen algunos intentos de abordar su estudio (Galton, 1868), posteriormente entrados ya en el siglo $\mathrm{XX}$, van apareciendo trabajos metódicos principalmente dentro del campo de la psicología (Buss, 2011). Paralelamente se suceden diferentes y numerosos intentos por concretar el término (Esquivias, 2004), aunque podemos decir que muchos de ellos incluyen algunos parámetros comunes como las referencias a crear elementos nuevos, producir ideas novedosas, combinar componentes o solucionar problemas. La preocupación por la creatividad dentro del ámbito académico, se desarrolla en estos mismos años como nos muestra Guilford (1968) cuando la pone en un primer plano, al afirmar que su estímulo por medio de la educación, puede ayudar a resolver problemas de ámbito social a nivel global. Más recientemente divulgadores cercanos al ámbito 
educativo, han formulado sus propuestas de innovación pedagógica teniendo en cuenta la creatividad, es el caso de Gardner (1995, 1998, 2002) o De Bono (2008, 2010, 2016, 2018). No podemos obviar acercamientos interesantes desde el campo no formal, como el trabajo de Ferreira (2016) "Criatividade nos Museus". En lengua castellana han aparecido distintas investigaciones que pretenden acercar la teoría al aula a través de propuestas prácticas o que sientan las bases de la práctica, es el caso de Ballester, Ferrándiz y López (2003), Fuentes y Torbay(2004) o De la torre (2006), aunque nos interesan especialmente por coincidir con nuestra propuesta para primaria, concreciones como las de López y Navarro (2010) o Lanza (2012). Sin duda todas ellas tienen cabida en el currículo formal por las alusiones a la creatividad de la ley educativa analizada y también comentadas en el marco teórico.

Para encontrar iniciativas que tengan en cuenta, tal y como nosotros defendemos, los tres ámbitos objeto de investigación de forma conjunta: patrimonio, creatividad y emociones, debemos acudir a las iniciativas de la Universidad de Valladolid y más concretamente a la Facultad de Educación del Campus Duques de Soria, donde se organiza desde hace varias ediciones el Congreso Internacional Educación, Patrimonio y Creatividad cuya producción científica aborda estas áreas (De la Fuente y Munilla 2017, 2018 y 2019). ${ }^{20}$

Pretendemos por ello analizar los programas existentes en la base de datos de OEPE que utilicen alguno de los parámetros nombrados en sus iniciativas. La evaluación de programas en educación patrimonial presenta una sólida producción científica al respecto que avala nuestra apuesta por la misma(Marín-Cepeda, 2014; García-Ceballos y Fontal, 2016; Maldonado, 2016;Martínez-Rodríguez y Fontal, 2016;Masachs, Maroto y Berciano, 2017;García-Caballos, 2018).

Teniendo en cuenta lo descrito en esta justificación, encontramos no obstante algunas carencias. En el marco teórico se contextualizan las tres áreas de estudio atendiendo a la documentación patrimonial a nivel internacional, europeo y nacional, en base a las raíces terminológicas emoci- y creat-, además de las leyes de patrimonio autonómicas, planes nacionales, LOMCE y libro blanco del grado de magisterio (Fontal, IbáñezEtxeberria, Cuenca y Martín-Cáceres, 2015). Todo ello proporciona un extenso paisaje de la situación actual objeto de estudio, proporcionándonos una visión clara de la escasez de propuestas patrimoniales que trabajan emociones y creatividad, tanto en el plano formal, como no formal o informal. Dentro de las ausencias mencionadas, destacamos que la educación formal, pese a incluir en la LOMCE referencias a patrimonio, emociones y creatividad, no presenta iniciativas concretas y conjuntas para su desarrollo. Si tenemos en cuenta la idoneidad que la etapa de primaria nos manifiesta por la fase de desarrollo madurativo en la que se encuentran los alumnos que abarca (Renom, 2003), se podrían utilizar de forma inmejorable los elementos descritos para la formación integral de la persona.

\subsection{Diseño y enfoque de investigación.}

Entendemos que para alcanzar nuestros objetivos de investigación, debemos analizar de forma transversal (Boniolo, Dalle \& Elbert, 2005) el momento en el que se encuentra actualmente el tratamiento de los elementos emocionales y creativos, desde el punto de vista del patrimonio, como así se plasma en el marco teórico del estudio. La

\footnotetext{
20 http://epac.es
} 
investigación se concreta en un enfoque cuantitativo y evaluativo de los programas, y un análisis correlacional de las variables.

Estamos ante una investigación que persigue además del análisis y la medición, la utilización de los resultados para una mejora de la realidad educativa (Alcina, 2004; McMillan \& Schumacher, 2005; Stenhouse, 2007) entorno a los elementos que la definen, aunque circunscrita principalmente al ámbito de las ciencias sociales (González Monfort 2006 ; Cazau, 2006).

Para la realización del estudio cuantitativo, no tomaremos una muestra aleatoria de programas si no que recurriremos a los programas inventariados en la base de datos del Observatorio de Educación Patrimonial de España, al considerar que este proyecto recoge las iniciativas más interesantes de educación patrimonial, estando vinculado con el Plan Nacional de Educación y Patrimonio, y el Ministerio de Economía y Competitividad a través de distintos proyecto $\mathrm{I}+\mathrm{D}+\mathrm{i}$.

\subsection{Participantes.}

\subsubsection{OEPE}

El Observatorio de Educación Patrimonial de España es, tal y como podemos leer en su web $^{21}$, una sucesión de proyectos desarrollados a partir del año 2010 y que llegan hasta la actualidad. El primero de ellos "Observatorio de Educación Patrimonial en España. Análisis Integral del estado de la Educación Patrimonial en España” (Ref. EDU200909679) tiene el objetivo de evaluar e inventariar los diferentes programas del ámbito nacional e internacional que trabajan la educación patrimonial. El segundo denominado "La educación en España: consolidación, evaluación de programas e internacionalización del OEPE" (Ref. EDU2012-37212), incide en el ámbito internacional y en la selección de programas inventariados para realizar una evaluación basada en estándares. El tercero bajo el nombre "Evaluación de los aprendizajes en programas de Educación Patrimonial centrados en los procesos de sensibilización, valorización y socialización del patrimonio cultural" (Ref. EDU 2015/65716-C2-1-R) persigue identificar y analizar los métodos efectivos para la consecución de los procesos de patrimonialización que se concretan en la sensibilización, valorización y socialización del patrimonio cultural. Y el cuarto "Modelos de aprendizaje en entornos digitales de Educación Patrimonial" (PID2019-106539RB-100) que pretende profundizar sobre la enseñanza-aprendizaje del patrimonio en contextos digitales.

Buena parte de la actividad del proyecto se sintetiza en su web. Se presentan dos vertientes, por un lado una parte pública donde se dan a conocer el proyecto y sus acciones, y por otra una base de datos para uso de sus investigadores, donde se inventarían los programas.

$21_{\text {http://www.oepe.es/ }}$ 
Figura 1. Distribución de actividades del portal web. Fuente web OEPE

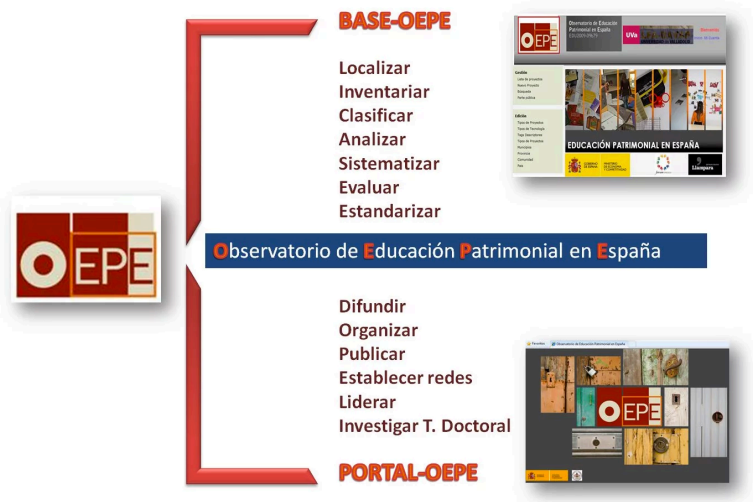

Fuente:http://www.oepe.es/

No obstante como señala Fontal (2016), el objetivo principal del OEPE es localizar, discriminar, inventariar, analizar y evaluar programas de educación patrimonial.

Como vemos el espectro de trabajo del proyecto es amplio y sistemático, lo que avala que podamos recurrir a él y más concretamente a su base de datos, como la mejor fuente para localizar las iniciativas más relevantes de educación patrimonial y analizar nuestros centros de interés emocionales y creativos en ellos.

\subsubsection{Base de datos OEPE}

Según informa la propia web, la base OEPE permite localizar programas de educación patrimonial a partir de 23 criterios de selección y 14 de exclusión, convenientemente definidos y desarrollados. Estos programas son inventariados mediante una ficha de recogida de datos y un anexo documental que se estructura en 5 secciones: identificación y localización, descripción, datos del diseño educativo, relación con otras fichas y anexo documental. Estas secciones a su vez, se subdividen en otros apartados hasta completar un total de 42 campos.

Figura 2. Campos de búsqueda de la base de datos de OEPE. Fuente web OEPE.

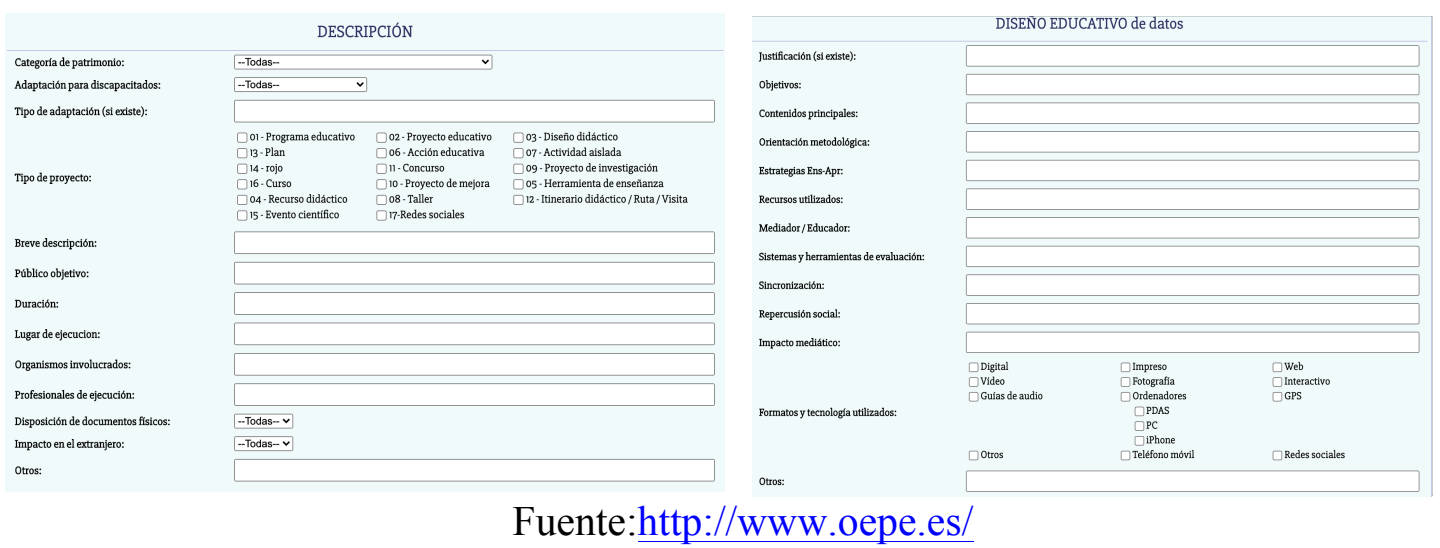

Actualmente la base tiene inventariados 2221 programas, ordenados en 16 tipologías en función de su naturaleza educativa y 18 categorías en base a su naturaleza patrimonial. 
Remitiéndonos al campo de búsqueda, el motor de la base nos aporta datos concretos que requiera el investigador, atendiendo a los parámetros que hayamos seleccionado en los campos de búsqueda.

\subsubsection{Variables}

Las variables independientes o sociodemográficas están determinadas por los campos de búsqueda estandarizados de la base de datos de OEPE (Figura 2).

La totalidad de campos de búsqueda que presenta la base es de cuarenta, aunque algunos de ellos presentan subdivisiones, que aportan una información más concreta en estos aspectos. Se distribuyen y ordenan de la siguiente forma:

\section{A- Localización \\ Entidad responsable \\ País \\ Comunidad autónoma \\ Provincia \\ Localidad \\ Dirección postal \\ Teléfonos de contacto \\ Personas responsables \\ Email \\ Dirección web \\ Investigador \\ Otros}

B- Descripción

Categoría de patrimonio

Adaptación a discapacitados

Tipo de adaptación

Tipo de proyecto

Programas educativo

Proyecto educativo

Diseño didáctico

Plan

Acción educativa

Actividad aislada

Red

Concurso

Proyecto de investigación

Curso

Proyecto de mejora

Herramienta didáctica

Recurso didáctico

Taller

Itinerario didáctico/ruta/visita

Evento científico

Redes Sociales

Breve descripción

Público al que se dirige

Tiempo de duración 
Lugar de ejecución

Organismos implicados

Profesionales encargados de la ejecución

Disposición de documentos físicos

Repercusión en el extranjero

Otros

C- Datos del diseño educativo

Justificación

Objetivos

Contenidos principales

Orientación metodológica

Estrategias de enseñanza aprendizaje

Recursos empleados

Mediador/Educador

Sistemas y herramientas de evaluación

Temporalización

Repercusión social

Repercusión mediática

Digital

Impreso

Web

Vídeo

Fotografía

Interactivos

Audio guías

Ordenadores

GPS

D- Otros

Dadas las características de nuestra investigación atenderemos a las siguientes variables (Tabla 14):

- Categoría de búsqueda (V0). Compuesta por tres subtipos correspondientes con los conceptos de búsqueda realizados en la base de datos de OEPE. Emociones, creatividad y emociones+creatividad.

- Tipo de entidad responsable (V1). Tomaremos en consideración tres tipos de ámbitos: público, privado y mixto. El público, referido principalmente a instituciones $\mathrm{u}$ organismos dependientes de la administración pública, tanto estatal como regional o local. El sector privado, comprendiendo entidades no sostenidas con fondos públicos o dependientes de estas. Y ámbito mixto, principalmente referido a proyectos o iniciativas que se desarrollan con fondos provenientes de entidades publicas y privadas al mismo tiempo.

- Categoría de patrimonio (V2). Estas categorías son las mismas que se utilizan en la base de datos de OEPE.

- Tipo de proyecto (V3). Las diferentes tipologías de proyectos también están extraídas de las utilizadas en la base de datos de OEPE

- Público al que se dirige (V4). Dividimos esta variable en: infantil, juvenil, sénior, tercera edad y todos los públicos. Infantil, consideramos dentro de ella los individuos comprendidos entre 0 y 16 años, la etapa de educación obligatoria. Juvenil, comprendida por personas entre los 16 y los 22 años, la considerada en España educación no obligatoria: bachillerato y estudios 
universitarios. Sénior, 22 a 65 años, es decir, sujetos susceptibles de ser población activa. Tercera edad, población de 65 en adelante. Todos los públicos, es decir aquellas propuestas que están dirigidas a la población general sin concreción en una determinada franja de edad. Y finalmente, colectivos específicos para aquellas propuestas que, independientemente de la edad, tiene sus objetivos fijados en algún tipo de población definida.

- Ámbito pedagógico (V5). Esta variable la dividimos en tres subtipos: educación informal, educación no formal y educación formal. Siguiendo a Touriñan (1996) entendemos por educación informal (V5.2) aquella actividad que no está organizada ni sistematizada, teniendo en cuenta que, aun pudiendo ser una actividad intencional, su intencionalidad no es exclusivamente educativa (Castillejo, 1981, p.52). La educación informal quedaría definida como el proceso de adquisición y el conjunto de actitudes, destrezas y competencias educativas adquiridas por medio de estímulos no directamente educativos (Touriñán, 1983). La educación no formal (V5.1) es el proceso de adquisición y el conjunto de competencias, destrezas y actitudes educativas adquiridas con estímulos directamente educativos, en actividades no conformadas por el sistema escolar. "La educación formal es el proceso de adquisición y el conjunto de competencias, destrezas y actitudes educativas adquiridas con estímulos directamente educativos en actividades conformadas por el sistema escolar" (Touriñan, 1996, p. 76). Teniendo en cuenta lo expuesto, dividimos la educación formal en las etapas educativas obligatorias y no obligatorias existentes en nuestro país ${ }^{22}$; así mismo, concretamos las edades para poder utilizar esas franjas de edad para actividades de países con un sistema educativo no coincidente con el nuestro: Infantil de cero a tres años (V5.3), primaria de seis a doce años (V5.4), secundaria de doce a dieciséis años (V5.5), bachillerato de dieciséis a dieciocho años (V5.6), y formación universitaria de dieciocho a veintidós años (V5.7), sin perder de vista que cualquier adulto tiene acceso a esta formación.

Estas variables recogidas en la tabla 14, son las que consideramos esenciales para la valoración y contraste de los diferentes programas seleccionados.

En ellas añadimos a las seleccionadas de las estandarizadas de la base OEPE, otra variable tenida en cuenta en la investigación que, si bien no se explicita en la base como campo individual, sí que se puede conformar extrayendo la información de los datos contenidos en cada programa inventariado. Nos estamos refiriendo al ámbito pedagógico al que va dirigido el proyecto (V5). De esta forma, podremos prestar especial atención en la valoración a las iniciativas que incluyen educación primaria, variable relevante por los motivos ya señalados en esta investigación.

\footnotetext{
${ }^{22}$ Cuando se han analizado programas de otros países donde la denominación de las etapas educativas no coincide con las de España, se han incluido en las denominaciones utilizadas en este trabajo atendiendo a las coincidencias de las franjas de edad de cada una de ellas.
} 
Tabla 14. Tabla de variables y subtipo de variables sociodemográficas.

\begin{tabular}{|c|c|c|c|c|c|}
\hline Variable & $\begin{array}{l}\text { Variable } 1 . \\
\text { Tipo de } \\
\text { entidad } \\
\text { responsable }\end{array}$ & $\begin{array}{l}\text { Variable } 2 . \\
\text { Categoría } \\
\text { patrimonio }\end{array}$ & $\begin{array}{l}\text { Variable } 3 . \\
\text { Tipo de } \\
\text { proyecto }\end{array}$ & $\begin{array}{l}\text { Variable } \\
\text { 4. } \\
\text { Público al } \\
\text { que se } \\
\text { dirige }\end{array}$ & $\begin{array}{l}\text { Variable } 5 . \\
\text { Ámbito } \\
\text { pedagógico }\end{array}$ \\
\hline $\begin{array}{l}\text { Subtipo } \\
\text { de } \\
\text { variables }\end{array}$ & $\begin{array}{l}\text { V1.1.Públic } \\
\text { o } \\
\text { V1.2.Privad } \\
\text { o } \\
\text { V1.3.Mixto }\end{array}$ & $\begin{array}{l}\text { V2.1. } \\
\text { Conjuntos: } \\
\text { Construcciones } \\
\text { aisladas. } \\
\text { V2.2. } \\
\text { Conjuntos: } \\
\text { Construcciones } \\
\text { reunidas. } \\
\text { V2.3. } \\
\text { Lugares: } \\
\text { Arqueológicos. } \\
\text { V2.4. } \\
\text { Lugares: } \\
\text { Especiales. } \\
\text { V2. 5. } \\
\text { Lugares: } \\
\text { Creados por el } \\
\text { hombre. } \\
\text { V2. 6. } \\
\text { Lugares: } \\
\text { Creados por el } \\
\text { hombre y la } \\
\text { naturaleza } \\
\text { V2.7. } \\
\text { Monumentos: } \\
\text { Inscripción en } \\
\text { cavernas } \\
\text { V2.8. } \\
\text { Monumentos: } \\
\text { Obra pictórica } \\
\text { V2.9. } \\
\text { Monumentos: } \\
\text { Arqueología } \\
\\
\text { V2.10. }\end{array}$ & $\begin{array}{l}\text { V3.1. } \\
\text { Programa } \\
\text { educativo } \\
\text { V3.2. } \\
\text { Proyecto } \\
\text { educativo } \\
\text { V3.3. } \\
\text { Diseño } \\
\text { didáctico } \\
\text { V3.4. } \\
\text { Recurso } \\
\text { didáctico } \\
\text { V3.5. } \\
\text { Herramienta } \\
\text { didáctica } \\
\text { V3.6. } \\
\text { Acción } \\
\text { educativa } \\
\text { V3.7. } \\
\text { Actividad } \\
\text { aislada } \\
\text { V3.8. Taller } \\
\text { V3.12. } \\
\text { Proyecto de } \\
\text { investigació } \\
\text { n } \\
\text { V3.11. } \\
\text { Proyecto de } \\
\text { mejora } \\
\\
\text { Concurso } \\
\text { Ve. }\end{array}$ & $\begin{array}{l}\text { V4.1. } \\
\text { Infantil } \\
\text { V4.2. } \\
\text { Juvenil } \\
\text { V4.3. } \\
\text { Sénior } \\
\text { V4.4. } \\
\text { Tercera } \\
\text { edad } \\
\text { V4. 5. } \\
\text { Todos los } \\
\text { públicos } \\
\text { V4.6. } \\
\text { Colectivos } \\
\text { específico } \\
\text { s }\end{array}$ & $\begin{array}{l}\text { V5.1. } \\
\text { Educación } \\
\text { no formal } \\
\text { V5.2. } \\
\text { Educación } \\
\text { informal } \\
\text { V5.3. } \\
\text { Educación } \\
\text { formal: } \\
\text { Infantil } \\
\text { V5.4. } \\
\text { Educación } \\
\text { formal: } \\
\text { Primaria. } \\
\text { V5.5. } \\
\text { Educación } \\
\text { formal: } \\
\text { Secundaria } \\
\text { V5.6. } \\
\text { Educación } \\
\text { formal: } \\
\text { Bachillerato } \\
\text { V5.7. } \\
\text { Educación } \\
\text { formal: } \\
\text { Universidad }\end{array}$ \\
\hline
\end{tabular}




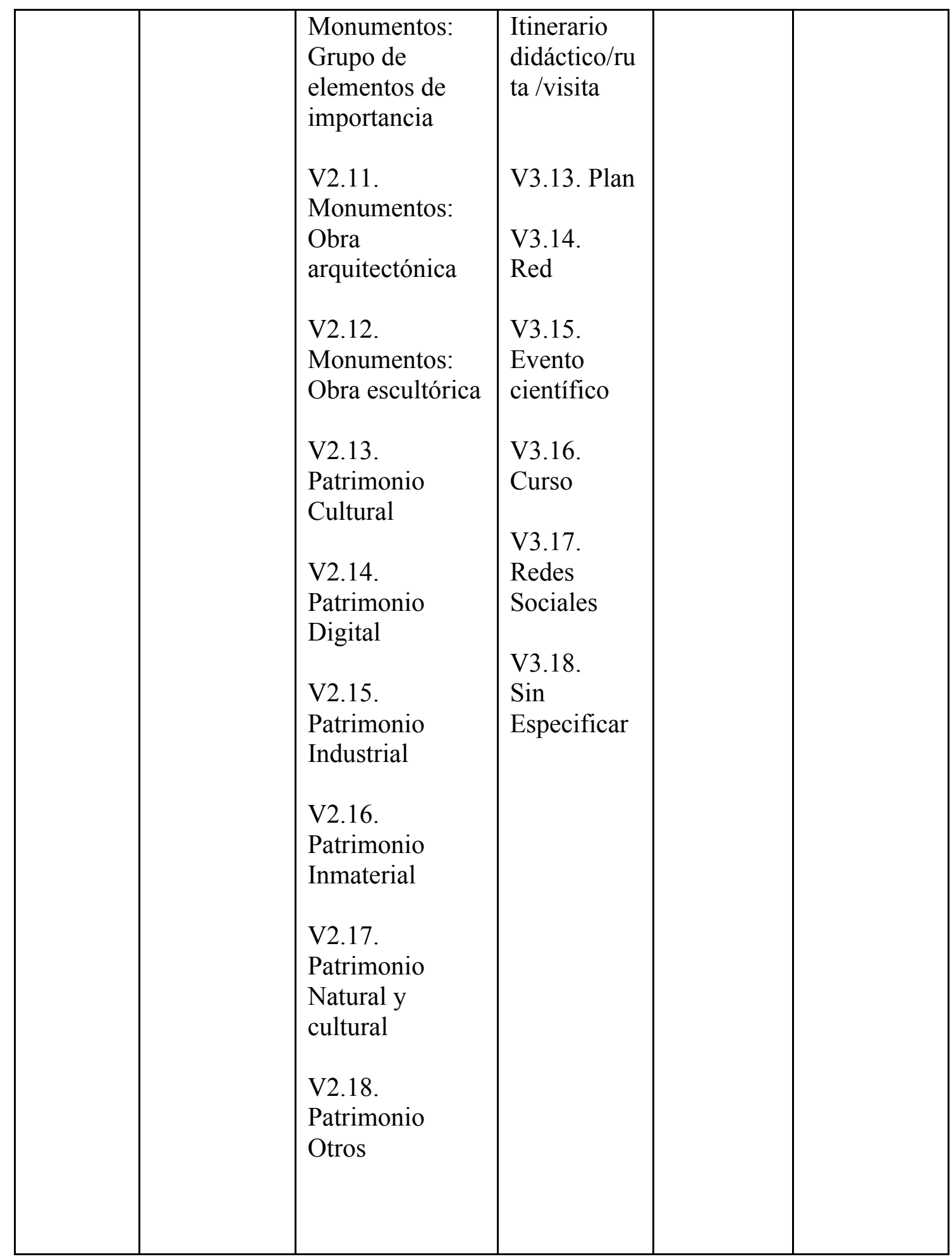

Fuente: Propia

Las variables dependientes o variables de resultados están así mismo determinadas por los catorce ítems de la escala de valoración de SAEPE-OEPE, agrupados en el ámbito de la calidad de la información y el grado de concreción del diseño.

A - Calidad de la información sobre el programa (metadatos)

1- Datos de contacto con la dirección y/o de diseño, planificación e implementación. 
2- Descriptores que definen el programa.

3- Concepción holística del patrimonio en su naturaleza (material e inmaterial) y en sus cualidades (arqueológico, histórico, documental, artístico...).

4- Especificación del tipo/tipología del proyecto desarrollado (programa educativo, proyecto educativo, diseño educativo, acción educativa, actividad aislada, etc.).

5- Descripción de las bases, principios y criterios sobre los se establece el programa

6- Concreción al público que va dirigido.

7- Incorporación de anexos documentales (memoria, imágenes, vídeos, materiales

didácticos empleados, etc.).

B - Grado de concreción del diseño

8- Justificación del proyecto.

9- Descripción de los objetivos a lograr en el desarrollo del programa.

10- Presentación de contenidos abordados en el programa.

11- Orientación metodológica y estrategias de enseñanza-aprendizaje.

12- Definición de recursos, formatos, soportes y tecnología empleada.

13- Determinación de los sistemas o herramientas de evaluación.

14- Medición del impacto y repercusión de la propuesta.

\subsubsection{Población y muestra}

La población de la que parte el estudio son los 2221 programas inventariados en la base de datos del OEPE.

La búsqueda de acciones de interés para nuestra investigación se realiza a través del campo de búsqueda general que permite una exploración ágil, ya que admite filtrar a través de la raíz de las palabras utilizando un asterisco tras ella. Así rastreamos partiendo de las raíces emoci* y creat*. Desechamos en el campo de palabras creativo la raíz crea*, ya que nos incluye numerosos elementos que no nos interesan al estar utilizado el verbo crear, no como un proceso creativo, si no de construcción, instauración, organización, etc.

De esta forma obtenemos los siguientes resultados: con la raíz emoci*57 programas, con la raíz creati*220 programas (el resultado nos reporta un programa repetido que eliminamos) y con la suma emoci*+creati* 262 (eliminamos nuevamente el programa repetido que aparece igualmente en este resultado).

La búsqueda cruzada de los términos emociones más creatividad, no filtra solamente los programas que trabajan ambos conceptos conjuntamente, sino que suma también los resultados de las búsquedas anteriores. Por ello, si sumamos los resultados de las búsquedas individuales $57+220=277$, y le restamos el resultado de la búsqueda cruzada, la incidencia de programas que trabajan ambos conceptos paralelamente es de quince 277-262=15. Esta cifra se ha corroborado revisando el total de proyectos y examinando el número de programas del listado de emociones que se repetían en creatividad (15) e igualmente cuantos de creatividad se repetían en emociones (15). Los resultados como vemos son iguales, asimismo concuerdan también los nombres de los programas al examinarlos uno por uno. Por ello, eliminamos estos programas de la búsquedas individuales ya que en nuestro análisis valoraremos tres tipos iniciativas: las que trabajan exclusivamente emociones, las que trabajan exclusivamente creatividad y las que trabajan ambas cosas a la vez.

Una vez extraídos estos quince programas de los listados individuales, los números totales quedan de la siguiente manera: el total de programas es de 262; 42 de ellos 
trabajan únicamente emociones (tabla 15), resultando por tanto un $16,031 \%$ del total que abarcamos; 205 trabajan singularmente creatividad (tabla 16) siendo un 78,244\%; y 15 trabajan conjuntamente emociones y creatividad (Tabla 17), lo que constituye un $5,725 \%$ del total que estudiaremos.

Enumeramos a continuación el total de programas que analizaremos organizados por búsquedas (Tablas 15, 16 y 17).

Tabla 15. Resultados de la búsqueda emocional.

\begin{tabular}{|c|c|c|c|}
\hline \multicolumn{4}{|c|}{ Búsqueda: emoci* } \\
\hline \multicolumn{4}{|c|}{ Número de programas:42 } \\
\hline $\mathrm{n}^{\mathrm{o}}$ & Título & Entidad responsable & País \\
\hline $\mathrm{P} 1$ & "Cabanyal Portes Obertes" & Plataforma Salvem el Cabanyal & España \\
\hline $\mathrm{P} 2$ & "Fet a má" & Plataforma Salvem el Cabanyal & España \\
\hline P3 & $\begin{array}{l}\text { "Educar para conservar y } \\
\text { restaurar" }\end{array}$ & Colegio & España \\
\hline $\mathrm{P} 4$ & Acuarela como soporte social & $\begin{array}{l}\text { Museo Nacional de la Acuarela } \\
\text { "Alfredo Guati Rojo" }\end{array}$ & México \\
\hline P5 & $\begin{array}{l}\text { Artesanías de ayer y de hoy. } \\
\text { Muestra de artesanías: } \\
\text { sociedad rural de Río Cuarto }\end{array}$ & $\begin{array}{l}\text { Hogar escuela María Benita Arias } \\
\text { (Argentina) }\end{array}$ & Argentina \\
\hline P6 & $\begin{array}{l}\text { Asignatura Patrimonio } \\
\text { Cultural. Hogar escuela María } \\
\text { Benita Arias (Argentina) }\end{array}$ & $\begin{array}{l}\text { Hogar escuela María Benita Arias } \\
\text { (Argentina) }\end{array}$ & Argentina \\
\hline P7 & $\begin{array}{l}\text { Banco de prácticas } \\
\text { significativas en educación } \\
\text { artística }\end{array}$ & educaconartistica.org & España \\
\hline P8 & Conoce tu patrimonio & Ayuntamioento de Cáceres & España \\
\hline P9 & De mi escuela para mi ciudad & $\begin{array}{l}\text { Ayuntamiento de Segovia, Junta } \\
\text { de Castilla y León, Escuela } \\
\text { universitaria de magisterio, } \\
\text { Ministerio de Medio Ambiente }\end{array}$ & España \\
\hline P10 & $\begin{array}{l}\text { École et cinéma (escuela y } \\
\text { cine) }\end{array}$ & Les enfants du cinéma & Francia \\
\hline P11 & $\begin{array}{l}\text { El camino de Santiago en } \\
\text { Educación Infantil }\end{array}$ & $\begin{array}{l}\text { Grupo de trabajo El camino de } \\
\text { Santiago: Ed. infantil CFIE de } \\
\text { burgos }\end{array}$ & España \\
\hline P12 & $\begin{array}{l}\text { El patrimonio, parte viva de la } \\
\text { ciudad educadora. Una } \\
\text { propuesta didáctica }\end{array}$ & $\begin{array}{l}\text { Universidad de Córdoba, IES } \\
\text { Grupo Cántico }\end{array}$ & Argentina \\
\hline $\mathrm{P} 13$ & Entre castaños y brezos & Instituto la Vaguada & España \\
\hline P14 & Feria de oficios & $\begin{array}{l}\text { Ayuntamiento de Villanueva de } \\
\text { Duero }\end{array}$ & España \\
\hline $\mathrm{P} 15$ & Festival Tarraco Viva & Ayuntamiento de Tarragona & España \\
\hline P16 & $\begin{array}{l}\text { Guia 13: Determinantes } \\
\text { culturales en nuestra } \\
\text { personalidad }\end{array}$ & Mineduc/UNESCO & $\begin{array}{l}\text { América } \\
\text { Latina }\end{array}$ \\
\hline P17 & History of emotions & $\begin{array}{l}\text { Australian research council center } \\
\text { of excellent for History of } \\
\text { emotions. }\end{array}$ & $\begin{array}{l}\text { Desconoci } \\
\text { do }\end{array}$ \\
\hline
\end{tabular}




\begin{tabular}{|c|c|c|c|}
\hline P18 & $\begin{array}{l}\text { JORNADAS DE } \\
\text { INTERCAMBIO DE } \\
\text { EXPERIENCIAS Y } \\
\text { EVALUACIÓN DEL } \\
\text { PROYECTO IMSERSO- } \\
\text { PROGRESS }\end{array}$ & $\begin{array}{l}\text { Escuela de Vixoi, CRA de } \\
\text { Bergondo }\end{array}$ & España \\
\hline E19 & $\begin{array}{l}\text { Kit pedagógico de la } \\
\text { asociación VMF }\end{array}$ & Vieilles Maisons Françaises & Francia \\
\hline P20 & La naturaleza de la Alhambra. & $\begin{array}{l}\text { Patronato de la Alhambra y el } \\
\text { Generalife. }\end{array}$ & España \\
\hline $\mathrm{P} 21$ & Lapurdi: emoción al natural & $\begin{array}{l}\text { Centro de Patrimonio Cultural del } \\
\text { Gobierno Vasco }\end{array}$ & España \\
\hline P22 & $\begin{array}{l}\text { Le patrimoine, toute une } \\
\text { histoire ! (El patrimonio, toda } \\
\text { una historia) }\end{array}$ & Vieilles Maisons Françaises & Francia \\
\hline $\mathrm{P} 23$ & $\begin{array}{l}\text { Les petits artistes de la } \\
\text { mémoire (Los pequeños } \\
\text { artistas de la memoria) }\end{array}$ & $\begin{array}{l}\text { Office national des anciens } \\
\text { combattants et victimes de guerre }\end{array}$ & Francia \\
\hline $\mathrm{P} 24$ & $\begin{array}{l}\text { Mapa emocional de Villavieja } \\
\text { de Lozoya }\end{array}$ & $\begin{array}{l}\text { Ayuntamiento Villavieja del } \\
\text { Lozoya }\end{array}$ & España \\
\hline $\mathrm{P} 25$ & MuMo (El museo móvil) & Les Amis du MuMo (asociación) & Francia \\
\hline $\mathrm{P} 26$ & Orihuela ciudad educadora & Casa Museo de Miguel Hernández & España \\
\hline $\mathrm{P} 27$ & Paisajes & $\begin{array}{l}\text { Museo Nacional Centro de Arte } \\
\text { Reina Sofía }\end{array}$ & España \\
\hline P28 & $\begin{array}{l}\text { Plan de igualdad, sexo y } \\
\text { patrimonio }\end{array}$ & $\begin{array}{l}\text { IES Nuevo Condesa, Santos Isasa } \\
\text { y colegio colegio Malmuerta }\end{array}$ & Argentina \\
\hline P29 & Plan Proxecta & Xunta de Galicia & España \\
\hline P30 & Ponte nas ondas & Universidad de Vigo & España \\
\hline P31 & \begin{tabular}{|l|} 
Programa de Educación \\
Artística, Cultura y Ciudadanía \\
\end{tabular} & educaconartistica.org & España \\
\hline P32 & \begin{tabular}{|l|} 
Programa Educativo de la \\
Pinacoteca de Sao Paulo \\
\end{tabular} & $\begin{array}{l}\text { Centro de Acción para la } \\
\text { Educación (NAE) de la Pinacoteca }\end{array}$ & \begin{tabular}{|l} 
Desconoci \\
do
\end{tabular} \\
\hline P33 & Proyecto Touché & l'Institut Català de Paleontologia & España \\
\hline P34 & $\begin{array}{l}\text { Red de Formación Inicial para } \\
\text { el patrimonio cultural digital }\end{array}$ & $\begin{array}{l}\text { Becas Marie Curie financia la } \\
\text { unión Europea }\end{array}$ & España \\
\hline P35 & \begin{tabular}{|l} 
Ruta de los Tres Templos (GR- \\
$120)$
\end{tabular} & Debagoieneko Mankomunitatea & España \\
\hline P36 & Sculpteurs de parole & $\begin{array}{l}\text { Académie des Sciences, des Arts } \\
\text { et des Belles lettres de Caen y } \\
\text { Musée de Normandie }\end{array}$ & Francia \\
\hline P37 & $\begin{array}{l}\text { Sensory Friendly Autism } \\
\text { Acceptance Disco }\end{array}$ & The Andy Warhol Museum & \begin{tabular}{|l} 
Estados \\
Unidos \\
\end{tabular} \\
\hline P38 & the Oak of finland & Junta Nacional de Educación. & $\begin{array}{l}\text { Desconoci } \\
\text { do } \\
\end{array}$ \\
\hline P39 & $\begin{array}{l}\text { Unidad didáctica: todos para } \\
\text { uno y uno para todos }\end{array}$ & $\begin{array}{l}\text { CEIP Las esperanzas, (San pedro } \\
\text { del Pinatar- Murcia) }\end{array}$ & España \\
\hline $\mathrm{P} 40$ & $\begin{array}{l}\text { Visita al museo de Bellas Artes } \\
\text { de Río Cuarto. }\end{array}$ & $\begin{array}{l}\text { Hogar escuela María Benita Arias } \\
\text { (Argentina) }\end{array}$ & Argentina \\
\hline $\mathrm{P} 41$ & Visita Guiada al MUME & Programa Indika, Consorci del & España \\
\hline
\end{tabular}




\begin{tabular}{|l|l|l|l|}
\hline & & Museu Memorial de l'Exili & \\
\hline P42 & Vivir y sentir el patrimonio. & Junta de Andalucía. Conserjería de & \\
& $17-18$ & Educación. & España \\
\hline
\end{tabular}

Fuente: Propia

Tabla 16. Resultados de la búsqueda creativa.

\begin{tabular}{|c|c|c|c|}
\hline \multicolumn{4}{|c|}{ Búsqueda: creati* } \\
\hline \multicolumn{4}{|c|}{ Número de elementos: 205} \\
\hline $\mathrm{n}^{\mathrm{o}}$ & Título & Entidad responsable & País \\
\hline P43 & $\begin{array}{l}\text { "I-treasures. Capturing the } \\
\text { intangible" }\end{array}$ & $\begin{array}{l}\text { Proyecto Integrado (PI) del séptimo } \\
\text { Marco de la Unión Europea "TIC } \\
\text { para el Acceso a los Recursos } \\
\text { Culturales 'Programa }\end{array}$ & $\begin{array}{l}\text { Estados } \\
\text { Unidos }\end{array}$ \\
\hline P44 & $\begin{array}{l}\text { ¿Leemos?. Un cuento sobre } \\
\text { la guerra de sucesión. }\end{array}$ & $\begin{array}{l}\text { la Direcció General de Recerca de } \\
\text { la Generalitat de Catalunya }\end{array}$ & España \\
\hline P45 & $\begin{array}{l}\text { Reactivación de la } \\
\text { transmisión entre } \\
\text { generaciones del canto } \\
\text { polifónico tradicional en } \\
\text { Georgia. }\end{array}$ & UNESCO & Georgia \\
\hline P46 & $\begin{array}{l}\text { Campaña trienal para } \\
\text { fomentar el interés por el } \\
\text { patrimonio vivo de Colombia }\end{array}$ & UNESCO & Colombia \\
\hline P47 & $\begin{array}{l}\text { Cinco años y aprendiendo de } \\
\text { la prehistoria. }\end{array}$ & $\begin{array}{l}\text { Camp d'Aprenentatge de la } \\
\text { Noguera }\end{array}$ & España \\
\hline P48 & $\begin{array}{l}\text { Proyecto Re-habita Fábrica, } \\
\text { Portalegre } 2015 .\end{array}$ & $\begin{array}{l}\text { La Fundación Robinson } \\
\text { (Portalegre). Fundación Antonio } \\
\text { Gala para Jóvenes Creadores. }\end{array}$ & Desconocido \\
\hline $\mathrm{P} 49$ & The art boulevard & Proyecto Convivir en el Arte. & Portugal \\
\hline P50 & Taller de mosaico Nolla. & ARAE Patrimonio y Restauración. & España \\
\hline P51 & "En un taller de la Mancha" & $\begin{array}{l}\text { Educación y Patrimonio, S.L. } \\
\text { Proyectos Culturales. }\end{array}$ & España \\
\hline P52 & A cidade precisa de praias $* *$ & $\begin{array}{l}\text { FUNARTE Fundación Nacional de } \\
\text { las Artes }\end{array}$ & $\begin{array}{l}\text { América } \\
\text { Latina }\end{array}$ \\
\hline P53 & ABCinema & $\begin{array}{l}\text { Creative Europe - MEDIA } \\
\text { subprograma }\end{array}$ & Desconocido \\
\hline P54 & $\begin{array}{l}\text { Access AK, Creative } \\
\text { Connection, Please Touch, } \\
\text { Art Sende-Actions }\end{array}$ & Allbright-Knox Art Gallery & $\begin{array}{l}\text { Estados } \\
\text { Unidos }\end{array}$ \\
\hline P55 & Acción-Edición & & España \\
\hline P56 & Adopt a monument & & Desconocido \\
\hline P57 & Alas y Raíces & Secretaría de Cultura & México \\
\hline P58 & $\begin{array}{l}\text { Alfenim, o doce sabor do } \\
\text { Patrimônio }\end{array}$ & $\begin{array}{l}\text { Universidad Federal de Paraíba y } \\
\text { Escola Municipal Maria do Carmo } \\
\text { Pedrosa Mendes }\end{array}$ & $\begin{array}{l}\text { América } \\
\text { Latina }\end{array}$ \\
\hline P59 & $\begin{array}{l}\text { Anglo Saxons. Heritage } \\
\text { Education }\end{array}$ & WarwickShire County Council & Reino Unido \\
\hline P60 & $\begin{array}{l}\text { App Cuadros Vivos Museo } \\
\text { Thyssen }\end{array}$ & Museo Thyssen-Bornemisza & España \\
\hline
\end{tabular}




\begin{tabular}{|c|c|c|c|}
\hline P61 & App Dantzan! & $\begin{array}{l}\text { Euskal Herriko Ikastolak - } \\
\text { Ikastolas de Euskal Herria }\end{array}$ & España \\
\hline P62 & App Euskal Herrian ihesi & Argia & España \\
\hline P63 & $\begin{array}{l}\text { App Explorar el arte rupestre. } \\
\text { La cueva del Chufin y su } \\
\text { entorno entorno hace } 17.000 \\
\text { años }\end{array}$ & $\begin{array}{l}\text { Saja Nansa Asociación de } \\
\text { desarrollo rural }\end{array}$ & España \\
\hline P64 & App Herrizki & Artez Euskara Fundazioa & España \\
\hline P65 & App Islas de Nubla & Museo Thyssen-Bornemisza & España \\
\hline P66 & App Modernisme & Reus Gaudi Center & España \\
\hline P67 & $\begin{array}{l}\text { App Ruta de las Villas } \\
\text { Romanas }\end{array}$ & Red de Villas romanas & España \\
\hline P68 & $\begin{array}{l}\text { App Second Canvas Museo } \\
\text { del Prado }\end{array}$ & museo del prado & España \\
\hline P69 & App Terrassa + & $\begin{array}{l}\text { mnactec (museu ciencia y } \\
\text { tecnologia de la tecnica de } \\
\text { Catalunya. Ajuntamient de Terrassa }\end{array}$ & España \\
\hline P70 & App Visit Gipuzkoa & $\begin{array}{l}\text { Departamento de Cultura } \\
\text { (Diputación Foral de Gipuzkoa) }\end{array}$ & España \\
\hline P71 & App Zurrumurru & Cartamundi Digital & España \\
\hline P72 & $\begin{array}{l}\text { Apprendisti Ciceroni: } \\
\text { Cultural Heritage Education } \\
\text { Programme. }\end{array}$ & & Desconocido \\
\hline P73 & \begin{tabular}{|l|} 
Aprovechamiento del entorno \\
geográfico y del patrimonio
\end{tabular} & $\begin{array}{l}\text { Gabinete Pedagógico de Bellas } \\
\text { Artes de Málaga }\end{array}$ & España \\
\hline P74 & $\begin{array}{l}\text { Arqueología somos todos a } \\
\text { pie de calle. Transferencia } 1.0\end{array}$ & $\begin{array}{l}\text { Grupo de investigación Sísifu } \\
\text { (UCO) }\end{array}$ & España \\
\hline P75 & $\begin{array}{l}\text { Arqueología somos todos: } \\
\text { reinventando el futuro }\end{array}$ & $\begin{array}{l}\text { Ministerio de Economía y } \\
\text { Competitividad a través de la } \\
\text { Fundación Española para la ciencia } \\
\text { y la tecnología (FECYT). Grupo de } \\
\text { Investigación Sísifo de la } \\
\text { Universidad de Córdoba }\end{array}$ & España \\
\hline $\mathrm{P} 76$ & Art Corner & & Desconocido \\
\hline P77 & Arte para todos & $\begin{array}{l}\text { Museo Patio Herreriano de Arte } \\
\text { Contemporáneo Español }\end{array}$ & España \\
\hline P78 & Así se siente mi barrio & Centro de la Imagen & México \\
\hline P79 & AulaDcine, 2017-2018 & $\begin{array}{l}\text { Junta de Andalucía, Consejería de } \\
\text { Educación }\end{array}$ & España \\
\hline P80 & $\begin{array}{l}\text { Autism Awareness Family } \\
\text { Celebratios }\end{array}$ & Dallas Museum of Art & $\begin{array}{l}\text { Estados } \\
\text { Unidos }\end{array}$ \\
\hline P81 & $\begin{array}{l}\text { Blog de Verónica Quiles } \\
\text { sobre Educación y } \\
\text { Patrimonio }\end{array}$ & Veronica Quiles & España \\
\hline $\mathrm{P} 82$ & Cambiando de protagonistas & Museo de historia de Catalunya. & España \\
\hline P83 & $\begin{array}{l}\text { Carpeta pedagógica } \\
\text { Trabajemos el Patrimonio } \\
\text { Cultural y Natural del Perú }\end{array}$ & Ministerio de Educación de Perú & Perú \\
\hline P84 & Casa de la memoria de & Casa de la memoria & América \\
\hline
\end{tabular}




\begin{tabular}{|c|c|c|c|}
\hline & Paranapiacaba & & Latina \\
\hline P85 & Ceuta Historia y Patrimonio. & $\begin{array}{l}\text { Consejería de educación cultura y } \\
\text { mujer }\end{array}$ & España \\
\hline P86 & $\begin{array}{l}\text { Ceuta te enseña. Proyecto } \\
\text { Ciudades Educadoras }\end{array}$ & $\begin{array}{l}\text { Consejería de Educación y Cultura, } \\
\text { Ciudad Autónoma de Ceuta }\end{array}$ & España \\
\hline P87 & $\begin{array}{l}\text { CHIJERÉ: luchando contra la } \\
\text { erosión y el olvido. Proyecto } \\
\text { de estudio patrimonial }\end{array}$ & IES Poeta García Cabrera & Desconocido \\
\hline P88 & Club Discovery & Creative Discovery Museum & \begin{tabular}{|l|} 
Estados \\
Unidos \\
\end{tabular} \\
\hline P89 & $\begin{array}{l}\text { Community Arts \& Heritage } \\
\text { Education Project }\end{array}$ & $\begin{array}{l}\text { Asociación/fundación CAHEP, } \\
\text { Gobierno de Ontario. }\end{array}$ & Canadá \\
\hline P90 & $\begin{array}{l}\text { Concurso de cómics Las } \\
\text { aventuras de Patrimonito }\end{array}$ & $\begin{array}{l}\text { Escuelas asociadas de la UNESCO, } \\
\text { RedPEA UNESCO España }\end{array}$ & España \\
\hline P91 & Concurso de Cruces de Mayo & $\begin{array}{l}\text { Consejería de Educación Cultura y } \\
\text { Mujer }\end{array}$ & España \\
\hline P92 & $\begin{array}{l}\text { Concurso de guión gráfico y } \\
\text { Patrimonito }\end{array}$ & MEC & España \\
\hline P93 & $\begin{array}{l}\text { Concurso de producción de } \\
\text { videos }\end{array}$ & OCPM & Desconocido \\
\hline P94 & $\begin{array}{l}\text { Concurso la increíble bitácora } \\
\text { de cuarentena }\end{array}$ & $\begin{array}{l}\text { Instituto Cultural de Aguascalientes } \\
\text { (ICA) }\end{array}$ & México \\
\hline P95 & $\begin{array}{l}\text { Concurso Patrimonio Cultural } \\
\text { en el Aula }\end{array}$ & Ministerio de Educación de Perú & Perú \\
\hline P96 & $\begin{array}{l}\text { Congreso Internacional de } \\
\text { Educación: Patrimonio y } \\
\text { Creatividad }\end{array}$ & Universidad de Valladolid & España \\
\hline P97 & $\begin{array}{l}\text { Construyendo el patrimonio } \\
\text { de Boiro }\end{array}$ & Isabel Cobas Fernández & España \\
\hline P98 & $\begin{array}{l}\text { Córdoba en la historia. } \\
\text { Arqueología, turismo y } \\
\text { nuevas tecnologías }\end{array}$ & $\begin{array}{l}\text { Grupo de investigación Sísifu } \\
\text { (UCO) }\end{array}$ & España \\
\hline P99 & $\begin{array}{l}\text { Créations en cours } \\
\text { (Creaciones en proceso) }\end{array}$ & Ateliers Médicis & Francia \\
\hline P100 & Creative Connections & Orlando Museum of Art & \begin{tabular}{|l|} 
Estados \\
Unidos \\
\end{tabular} \\
\hline P101 & CULTURA a la ROMANA & Diputación de Palencia & España \\
\hline $\mathrm{P} 102$ & Cultura Comunitaria & Secretaría de Cultura & México \\
\hline P103 & $\begin{array}{l}\text { Culture and Learning. Creatin } \\
\text { arts and Heritage Education } \\
\text { Projects }\end{array}$ & Heritage Lottery Fund & Reino Unido \\
\hline P104 & $\begin{array}{l}\text { Culture(s) de demain } \\
\text { (Cultura(s) del mañana) }\end{array}$ & Le Bal - La Fabrique du Regard & Francia \\
\hline P105 & $\begin{array}{l}\text { Curso de verano Turismo y } \\
\text { patrimonio industrial Un } \\
\text { recurso en tiempos de crisis } \\
\text { (a la búsqueda de soluciones } \\
\text { innovadoras) }\end{array}$ & Universidad Autónoma de Madrid & España \\
\hline $\mathrm{P} 106$ & Curso en Didáctica del & UNED & España \\
\hline
\end{tabular}




\begin{tabular}{|c|c|c|c|}
\hline & Patrimonio Cultural & & \\
\hline P107 & $\begin{array}{l}\text { De las escuelas de calle al } \\
\text { museo }\end{array}$ & $\begin{array}{l}\text { Museo de Arte e Historia de } \\
\text { Zarautz }\end{array}$ & España \\
\hline P108 & Debajo del Sombrero & Asociación Debajo del Sombrero & España \\
\hline P109 & Dinbilidanbala & $\begin{array}{l}\text { Servicio de patrimonio histórico, } \\
\text { Departamento de cultura, deporte y } \\
\text { juventud del Gobierno de Navarra }\end{array}$ & España \\
\hline P110 & \begin{tabular}{|l} 
Educación Patrimonial Los \\
Vilos
\end{tabular} & & Chile \\
\hline P111 & $\begin{array}{l}\text { Educación Patrimonial. } \\
\text { Propuestas creativas desde el } \\
\text { espacio educativo }\end{array}$ & Gobierno de Canarias & España \\
\hline P112 & $\begin{array}{l}\text { Educar ciudadanos } \\
\text { democráticos a partir del } \\
\text { Patrimonio en Ciencias } \\
\text { Sociales. I.E.S. Castillo de } \\
\text { Luna (La Puebla de Cazalla, } \\
\text { Sevilla) }\end{array}$ & $\begin{array}{l}\text { I.E.S. Castillo de Luna (La Puebla } \\
\text { de Cazalla, Sevilla) }\end{array}$ & España \\
\hline P113 & $\begin{array}{l}\text { El camino de Santiago para } \\
\text { personas con discapacidad } \\
\text { intelectual }\end{array}$ & La Caixa y ASPANIAS Burgos & España \\
\hline P114 & $\begin{array}{l}\text { El día de las Lenguas } \\
\text { Maternas }\end{array}$ & $\begin{array}{l}\text { Fundación premio convivencia y } \\
\text { Consejería de Educación, Cultura y } \\
\text { Mujer de Ceuta }\end{array}$ & España \\
\hline P115 & $\begin{array}{l}\text { El ferrocarril económico de } \\
\text { Valladolid a medina de } \\
\text { Rioseco (VI), Cuaderno de } \\
\text { Tecnología, Máquina de } \\
\text { vapor del tren económico } \\
\text { Valladolid-Medina de } \\
\text { Rioseco } \\
\end{array}$ & $\begin{array}{l}\text { Junta de Castilla y León, IES } \\
\text { Campos y Torozos }\end{array}$ & España \\
\hline P116 & $\begin{array}{l}\text { El kit: Patrimonio Mundial en } \\
\text { Manos de los Jóvenes }\end{array}$ & $\begin{array}{l}\text { Dirigido por el Centro del } \\
\text { Patrimonio Mundial de la UNESCO } \\
\text { (WHC) en coordinación con el Plan } \\
\text { de Escuelas Asociadas de la } \\
\text { UNESCO (PEA) y en estrecha } \\
\text { cooperación con las Oficinas fuera } \\
\text { de la Sede, las Comisiones } \\
\text { Nacionales para la UNESCO y } \\
\text { otras partes inte }\end{array}$ & Francia \\
\hline P117 & $\begin{array}{l}\text { El patrimonio cultural como } \\
\text { factor de desarrollo social y } \\
\text { económico }\end{array}$ & $\begin{array}{l}\text { Dirección de Patrimonio Cultural, } \\
\text { Departamento de Cultura, Gobierno } \\
\text { Vasco-Eusko Jaurlaritza }\end{array}$ & España \\
\hline P118 & $\begin{array}{l}\text { El patrimonio cultural en } \\
\text { manos jóvenes, propuestas } \\
\text { creativas del espacio } \\
\text { educativo }\end{array}$ & $\begin{array}{l}\text { Programa Juventud, Educación } \\
\text { Patrimonial y Recuperación } \\
\text { Ambiental que impulsan las } \\
\text { concejalías de Juventud y } \\
\text { Medioambiente, Educación y } \\
\text { Cultura del Ayuntamiento de }\end{array}$ & Desconocido \\
\hline
\end{tabular}




\begin{tabular}{|c|c|c|c|}
\hline & & $\begin{array}{l}\text { Arrecife y la Consejería de } \\
\text { Educación y Cultura del Cabildo de } \\
\text { Lanzarote }\end{array}$ & \\
\hline P119 & $\begin{array}{l}\text { El patrimonio cultural en } \\
\text { nuestras manos }\end{array}$ & $\begin{array}{l}\text { Coordinación Nacional de } \\
\text { Patrimonio Cultural y Turismo }\end{array}$ & México \\
\hline $\mathrm{P} 120$ & El pescante de Vallehermoso & IES Poeta García Cabrera & España \\
\hline P121 & $\begin{array}{l}\text { El secreto de los almirantes: } \\
\text { Iglesia de San Andrés y el } \\
\text { rollo de Aguilar de Campos. }\end{array}$ & IES Diego de Praves & España \\
\hline $\mathrm{P} 122$ & $\begin{array}{l}\text { Elección de los } 10 \text { Tesoros } \\
\text { del Patrimonio Cultural } \\
\text { Inmaterial de España } \\
\end{array}$ & $\begin{array}{l}\text { IBOCC The International bureau of } \\
\text { cultural capitals }\end{array}$ & Desconocido \\
\hline P123 & $\begin{array}{l}\text { Érase una vez... una provincia } \\
\text { de cuento }\end{array}$ & $\begin{array}{l}\text { Area de Programas educativos de la } \\
\text { provincia de Zamora, CFIE } \\
\text { Benavente y CFIE de Zamora. }\end{array}$ & España \\
\hline $\mathrm{P} 124$ & Ersilia & Le Bal & Francia \\
\hline P125 & $\begin{array}{l}\text { Escuela de Iniciación } \\
\text { Artística Asociada al INBAL } \\
\text { Categoría Infantíl }\end{array}$ & Centro Cultural los Arquitos & México \\
\hline P126 & $\begin{array}{l}\text { Escuela de Iniciación } \\
\text { Artística Asociada al INBAL } \\
\text { Categoría Juvenil }\end{array}$ & Centro Cultural los Arquitos & México \\
\hline P127 & $\begin{array}{l}\text { Escuelas de verano, Área de } \\
\text { Cultura de la Comarca de La } \\
\text { Hoya de Huesca }\end{array}$ & $\begin{array}{l}\text { Área de Cultura de la Comarca de } \\
\text { La Hoya de Huesca }\end{array}$ & España \\
\hline P128 & $\begin{array}{l}\text { Espías y Espionaje en el } \\
\text { Siglo de Oro Español }\end{array}$ & $\begin{array}{l}\text { Archivo General de Simancas, } \\
\text { Asociación Cultural "El Calabacín } \\
\text { Errante" }\end{array}$ & España \\
\hline P129 & $\begin{array}{l}\text { Experiencia didáctica Museo } \\
\text { de Minerales Andrés del } \\
\text { Castillo. }\end{array}$ & $\begin{array}{l}\text { Museo de Minerales Andrés del } \\
\text { Castillo. }\end{array}$ & Perú \\
\hline P130 & $\begin{array}{l}\text { Experiencia Fotográfica } \\
\text { Internacional de los } \\
\text { Monumentos (EFIM) }\end{array}$ & $\begin{array}{l}\text { Generalitat de Catalunya, } \\
\text { Departament de Cultura, Direcció } \\
\text { General del Patrimoni Cultural, } \\
\text { Àrea de Suport Tècnic }\end{array}$ & España \\
\hline P131 & $\begin{array}{l}\text { Festival de arquitectura } \\
\text { infantil }\end{array}$ & & España \\
\hline P132 & Formando el futuro & $\begin{array}{l}\text { Grupo de investigación Sísifu } \\
\text { (UCO)-FECYT }\end{array}$ & España \\
\hline P133 & Fundación Arte Viva & $\begin{array}{l}\text { Fundación Arte Viva, Arte Viva } \\
\text { Europa }\end{array}$ & España \\
\hline $\mathrm{P} 134$ & $\begin{array}{l}\text { Gestión y salvaguardia del } \\
\text { patrimonio cultural inmaterial } \\
\text { en el mediterráneo }\end{array}$ & $\begin{array}{l}\text { Instituto Europeo del Mediterráneo } \\
\text { y Fundación Dieta Mediterránea }\end{array}$ & España \\
\hline $\mathrm{P} 135$ & $\begin{array}{l}\text { Guía 02: Festival de la } \\
\text { Canción }\end{array}$ & Mineduc/ UNESCO & $\begin{array}{l}\text { América } \\
\text { Latina }\end{array}$ \\
\hline P136 & $\begin{array}{l}\text { Guía 12: Nuestra fiesta } \\
\text { popular }\end{array}$ & Mineduc/UNESCO & $\begin{array}{l}\text { América } \\
\text { Latina }\end{array}$ \\
\hline $\mathrm{P} 137$ & Guía 15: Mi entorno, mi & Mineduc/UNESCO & América \\
\hline
\end{tabular}




\begin{tabular}{|c|c|c|c|}
\hline & patrimonio & & Latina \\
\hline P138 & $\begin{array}{l}\text { Guía 18: Nominación de un } \\
\text { sitio a la lista nacional de } \\
\text { patrimonio }\end{array}$ & Mineduc/UNESCO & $\begin{array}{l}\text { América } \\
\text { Latina }\end{array}$ \\
\hline P139 & $\begin{array}{l}\text { Guía de actividades } \\
\text { patrimoniales Re-creo mi } \\
\text { identidad }\end{array}$ & Mineduc/UNESCO & $\begin{array}{l}\text { América } \\
\text { Latina } \\
\end{array}$ \\
\hline P140 & $\begin{array}{l}\text { Guia didáctica aprender a ver } \\
\text { arquitectura }\end{array}$ & Consejería de Cultura & España \\
\hline P141 & $\begin{array}{l}\text { Guia Metodológica } \\
\text { Patrimonio Nacional de la } \\
\text { Nación } \\
\end{array}$ & Instituto Nacional de Cultura & Perú \\
\hline P142 & $\begin{array}{l}\text { Hackathon del Patrimonio } \\
\text { Cultural del Centro Histórico }\end{array}$ & Autoridad del Centro Histórico & México \\
\hline P143 & Historia de un Ovillo de Lana & $\begin{array}{l}\text { Archivo de la Real Chancillería de } \\
\text { Valladolid }\end{array}$ & España \\
\hline P144 & $\begin{array}{l}\text { I Concurso de Fotografía } \\
\text { Ciudades Patrimonio en las } \\
\text { Redes Sociales }\end{array}$ & $\begin{array}{l}\text { Grupo Ciudades Patrimonio de la } \\
\text { Humanidad }\end{array}$ & España \\
\hline P145 & $\begin{array}{l}\text { I Concurso Fotográfico } \\
\text { "Ciudades Patrimonio y } \\
\text { Naturaleza" en las RRSS. }\end{array}$ & $\begin{array}{l}\text { Grupo CIudades patrimonio de la } \\
\text { Humanidad de España }\end{array}$ & España \\
\hline P146 & $\begin{array}{l}\text { II Congreso Internacional } \\
\text { Ciudades Creativas }\end{array}$ & $\begin{array}{l}\text { Facultad de Ciencias de la } \\
\text { Información de la Universidad } \\
\text { Complutense de Madrid y la } \\
\text { Asociación Científica Icono14 }\end{array}$ & España \\
\hline P147 & \begin{tabular}{|l|} 
III Foro Juvenil \\
Iberoamericano de \\
Patrimonio Mundial \\
\end{tabular} & $\begin{array}{l}\text { Patrimonio Joven, Ministerio de } \\
\text { Cultura de España }\end{array}$ & España \\
\hline P148 & INCEPTION & Universidad de Ferrara, Italia & Desconocido \\
\hline P149 & $\begin{array}{l}\text { Innovate Heritage. } \\
\text { Conversation between Arts\& } \\
\text { heritage }\end{array}$ & Innovate heritage & online \\
\hline $\mathrm{P} 150$ & Integrarte & Fundación Arte Viva & España \\
\hline P151 & $\begin{array}{l}\text { IV Jornadas Ciudades } \\
\text { Creativas }\end{array}$ & $\begin{array}{l}\text { Fundación Creanta, Ayuntamiento } \\
\text { de Madrid }\end{array}$ & España \\
\hline P152 & $\begin{array}{l}\text { JM France (Juventudes } \\
\text { musicales en Francia) }\end{array}$ & JM France & Francia \\
\hline P153 & $\begin{array}{l}\text { Jornadas de Valorización y } \\
\text { Dinamización del Patrimonio } \\
\text { Ibérico }\end{array}$ & Diputación de Jaén & España \\
\hline P154 & \begin{tabular}{|l|} 
Jornadas sobre Patrimonio \\
Histórico-Artístico \\
\end{tabular} & Eusko Ikaskuntza & España \\
\hline P155 & Kit Joven Diversidades & $\begin{array}{l}\text { UNESCO Etxea y la Cátedra } \\
\text { UNESCO en Políticas Culturales y } \\
\text { Cooperación de la Universidad de } \\
\text { Gerona }\end{array}$ & España \\
\hline P156 & $\begin{array}{l}\text { Kit pédagogique Série } \\
\text { graphique }\end{array}$ & $\begin{array}{l}\text { Cnap (Centro nacional de artes } \\
\text { plásticas) }\end{array}$ & Francia \\
\hline
\end{tabular}




\begin{tabular}{|c|c|c|c|}
\hline P157 & $\begin{array}{l}\text { La Conservación y } \\
\text { Recuperación del Patrimonio } \\
\text { Cultural como materia } \\
\text { optativa para el Segundo } \\
\text { Ciclo de la Enseñanza } \\
\text { Obligatoria }\end{array}$ & & Desconocido \\
\hline P158 & $\begin{array}{l}\text { La fotografía comparativa, un } \\
\text { recurso educativo para la } \\
\text { difusión del patrimonio } \\
\text { fotográfico }\end{array}$ & Universidad de las Islas Baleares & España \\
\hline P159 & $\begin{array}{l}\text { La Mezquita-Catedral de } \\
\text { Córdoba }\end{array}$ & $\begin{array}{l}\text { Gabinetes Pedagógicos de Bellas } \\
\text { Artes }\end{array}$ & Argentina \\
\hline \begin{tabular}{|l|}
$\mathrm{P} 160$ \\
\end{tabular} & La voz de los sin voz & UNESCO & Argentina \\
\hline P161 & $\begin{array}{l}\text { La webquest como recurso } \\
\text { educativo de ciencias sociales } \\
\text { en Primaria }\end{array}$ & C.P. Francesc Candela & España \\
\hline P162 & $\begin{array}{l}\text { Las imágenes cuentan cosas. } \\
\text { El retablo del mar }\end{array}$ & $\begin{array}{l}\text { Fundación Municipal del Cultura } \\
\text { (Ayto. de Gijón) }\end{array}$ & España \\
\hline P163 & $\begin{array}{l}\text { Le Créa, centro de creación } \\
\text { vocal y escénica }\end{array}$ & Le Créa & Francia \\
\hline P164 & $\begin{array}{l}\text { Les Ateliers de la création } \\
\text { (Los talleres creativos) }\end{array}$ & $\begin{array}{l}\text { Ircam (Instituto de investigación y } \\
\text { creación acústica musical) }\end{array}$ & Francia \\
\hline P165 & $\begin{array}{l}\text { Les Fabriques à musique } \\
\text { (fábricas de música) }\end{array}$ & SACEM & Francia \\
\hline P166 & Levadura & $\begin{array}{l}\text { Matadero Madrid y la Asociación } \\
\text { Pedagogías Invisibles }\end{array}$ & España \\
\hline P167 & Licenciatura en Restauración & $\begin{array}{l}\text { Escuela Nacional de Conservación, } \\
\text { Restauración y Museografía. }\end{array}$ & México \\
\hline P168 & Los domingos del Laredo & Escuela de Tiempo Libre EALA & España \\
\hline P169 & Los nueve secretos & Fundación del Patrimonio Historico & España \\
\hline $\mathrm{P} 170$ & Manos a la opera & Auditorio de Barañain & España \\
\hline P171 & $\begin{array}{l}\text { méxico, cultura para la } \\
\text { armonia }\end{array}$ & $\begin{array}{l}\text { Dirección General de Culturas } \\
\text { Populares, Indígenas y Urbanas }\end{array}$ & México \\
\hline P172 & $\begin{array}{l}\text { Mi Ciudad, Nuestro } \\
\text { Patrimonio Mundial, } \\
\text { Concurso internacional de } \\
\text { producción de videos } \\
\end{array}$ & $\begin{array}{l}\text { Organización de las ciudades del } \\
\text { patrimonio mundial }\end{array}$ & Desconocido \\
\hline P173 & $\begin{array}{l}\text { Miradas Jóvenes en la gestión } \\
\text { cultural }\end{array}$ & $\begin{array}{l}\text { Educ'Art S.L. servicios educativos } \\
\text { y culturales }\end{array}$ & España \\
\hline $\mathrm{P} 174$ & Museo e l'Autismo & Museo Tattile Statale Omero & Italia \\
\hline P175 & $\begin{array}{l}\text { Museos y memoria. Imaginar } \\
\text { y crear. Kit didáctico. }\end{array}$ & ICOM & España \\
\hline P176 & Música en el Kiosko & Escuela de Tiempo Libre EALA & España \\
\hline P177 & $\begin{array}{l}\text { Musica tradicional de } \\
\text { Andalucía }\end{array}$ & $\begin{array}{l}\text { Centro de Documentación Musical } \\
\text { de Andalucía }\end{array}$ & España \\
\hline P178 & Net-Heritage & $\begin{array}{l}\text { Italian Ministry for Cultural } \\
\text { Heritage and Activities v. del } \\
\text { Collegio Romano }\end{array}$ & Italia \\
\hline $\mathrm{P} 179$ & nexus & Nexus & Reino Unido \\
\hline
\end{tabular}




\begin{tabular}{|c|c|c|c|}
\hline P180 & $\begin{array}{l}\text { NMAC-Educa } \\
\text { (programación) }\end{array}$ & Fundación NMAC & España \\
\hline P181 & $\begin{array}{l}\text { Nuevas estrategias para } \\
\text { salvar el Patrimonio Cultural }\end{array}$ & $\begin{array}{l}\text { Laboratorio de Fotogrametría, } \\
\text { Universidad de Valladolid }\end{array}$ & España \\
\hline P182 & Para além da história & $\begin{array}{l}\text { Centro Cultural de Vila Flor- } \\
\text { Guimarães }\end{array}$ & Portugal \\
\hline P183 & Pasaporte del arte & Instituto Nacional de Bellas Artes & México \\
\hline P184 & PASOS & $\begin{array}{l}\text { Unidad de patrimonio, } \\
\text { Ayuntamiento de Viña del Mar }\end{array}$ & Chile \\
\hline P185 & $\begin{array}{l}\text { Patrimonio a la plaza: volver } \\
\text { a las plazas de mercado }\end{array}$ & $\begin{array}{l}\text { Instituto Distrital de Patrimonio } \\
\text { Cultural, sector cultura, recreación } \\
\text { y deporte }\end{array}$ & Colombia \\
\hline P186 & $\begin{array}{l}\text { Patrimonio y creación } \\
\text { contemporánea. De Las } \\
\text { Huelgas... al CAB } \\
\end{array}$ & $\begin{array}{l}\text { CAB de Burgos (Centro de Arte } \\
\text { Caja de Burgos) }\end{array}$ & España \\
\hline P187 & $\begin{array}{l}\text { People \& Heritage Una } \\
\text { galería visual sobre las } \\
\text { personas y la interacción de } \\
\text { arte público }\end{array}$ & $\begin{array}{l}\text { Universidad Cardenal Cisneros } \\
\text { Colegio, Alcalá de Henares, } \\
\text { España, y de la Facultad de } \\
\text { Educación de la Universidad de } \\
\text { Laponia, Rovaniemi, Finlandia }\end{array}$ & España \\
\hline P188 & Picasso i el procés creatiu & Museo Picasso & España \\
\hline P189 & Plan Estratégico de $\mathrm{HC}$ & $\begin{array}{l}\text { Consejo de Patrimonio de Victoria, } \\
\text { Australia }\end{array}$ & España \\
\hline P190 & Plan Nacional del Buen Vivir & Gobierno de Ecuador & $\begin{array}{l}\text { América } \\
\text { Latina }\end{array}$ \\
\hline P191 & Premios CreArte & Ministerio de Cultura & España \\
\hline P192 & \begin{tabular}{|l|} 
Premios Unión Europea de \\
Patrimonio Cultural 2011 \\
\end{tabular} & UE & España \\
\hline P193 & Programa "Aula Patrimonio" & $\begin{array}{l}\text { Grupo de Ciudades Patrimonio de } \\
\text { la Humanidad de España }\end{array}$ & España \\
\hline P194 & $\begin{array}{l}\text { Programa de Estímulo a la } \\
\text { Creación y al Desarrollo } \\
\text { Artístico (PECDA) }\end{array}$ & $\begin{array}{l}\text { Secretaría de Cultura del Gobierno } \\
\text { Federal, por conducto de la } \\
\text { Dirección General de Vinculación } \\
\text { Cultural, y los gobiernos estatales a } \\
\text { través de sus instituciones } \\
\text { responsables de cultura (ICGE) }\end{array}$ & México \\
\hline P195 & \begin{tabular}{|l|} 
Programa de la Unión \\
Europea para los sectores \\
cultural y creativo (2014- \\
$2020)$ \\
\end{tabular} & European Commission & Desconocido \\
\hline P196 & $\begin{array}{l}\text { Programa de promoción de la } \\
\text { identidad y creatividad } \\
\text { cultural en Iberoamérica }\end{array}$ & $\begin{array}{l}\text { Centro Cultural de España en } \\
\text { México }\end{array}$ & México \\
\hline P197 & $\begin{array}{l}\text { Programa del Creative } \\
\text { Growth Art Center } \\
\end{array}$ & Creative Growth Art Center & \begin{tabular}{|l|} 
Estados \\
Unidos \\
\end{tabular} \\
\hline P198 & $\begin{array}{l}\text { Programa educativo Hospital } \\
\text { de los Venerables }\end{array}$ & Fundación Focus Abengoa. & España \\
\hline P199 & $\begin{array}{l}\text { Programa educativo } \\
\text { Sembrando color }\end{array}$ & Fundación Granada Educa & España \\
\hline
\end{tabular}




\begin{tabular}{|c|c|c|c|}
\hline P200 & $\begin{array}{l}\text { Programas de Educación } \\
\text { Artística del Ircam }\end{array}$ & $\begin{array}{l}\text { Ircam (Instituto de investigación y } \\
\text { creación acústica musical) }\end{array}$ & Francia \\
\hline P201 & $\begin{array}{l}\text { Programas del Centro cultural } \\
\text { de España en México }\end{array}$ & $\begin{array}{l}\text { Agencia Española de Cooperación } \\
\text { Internacional para el Desarrollo, } \\
\text { Centro cultural de España en } \\
\text { México }\end{array}$ & Desconocido \\
\hline P202 & Projet Résonances & $\begin{array}{l}\text { association d'artiste SONAR y le } \\
\text { musée de Vieux-la-Romaine }\end{array}$ & Francia \\
\hline P203 & $\begin{array}{l}\text { Proyecto APLEX, Asociación } \\
\text { estudio y divulgación del } \\
\text { patrimonio lingüístico } \\
\text { extremeño }\end{array}$ & Junta de Extremadura & España \\
\hline P204 & $\begin{array}{l}\text { Proyecto Baetica. Proyecto } \\
\text { educativo Andaluz }\end{array}$ & $\begin{array}{l}\text { Junta de Andalucía, Consejería de } \\
\text { Educación }\end{array}$ & España \\
\hline P205 & \begin{tabular}{|l|} 
Proyecto bit:LAV, \\
Laboratorio de \\
Experimentación de Arte \\
Digital y Cultura Abierta \\
\end{tabular} & $\begin{array}{l}\text { Laboratorio de las Artes de } \\
\text { Valladolid (LAVA) } \\
\end{array}$ & España \\
\hline P206 & $\begin{array}{l}\text { Proyecto Ciudades Creativas } \\
\text { Tierras de imaginario }\end{array}$ & $\begin{array}{l}\text { Unión EUropea, Barakaldo, } \\
\text { Tournefeuille }\end{array}$ & España \\
\hline P207 & $\begin{array}{l}\text { Proyecto de innovación } \\
\text { educativa: empretic me } \\
\text { gust@ la naturaleza }\end{array}$ & $\begin{array}{l}\text { DGIEE (Consejería de Educación, } \\
\text { Valladolid). Area de Programas } \\
\text { Educativos. CFIE de Benavente }\end{array}$ & España \\
\hline P208 & $\begin{array}{l}\text { Proyecto educativo Dieta } \\
\text { meditteránea }\end{array}$ & Fundación dieta mediterránea & España \\
\hline P209 & Proyecto ESPORA & $\begin{array}{l}\text { El colegio concertado Nuestra } \\
\text { Señora del Pilar (Escolapios) de } \\
\text { Soria y el Museo Thyssen- } \\
\text { Bornemisza }\end{array}$ & España \\
\hline P210 & Proyecto PACMyC & $\begin{array}{l}\text { Secretaría de Cultura del Gobierno } \\
\text { de la República Mexicana }\end{array}$ & México \\
\hline P211 & $\begin{array}{l}\text { Proyecto Reflexionart- } \\
\text { Tutorias de arte }\end{array}$ & $\begin{array}{l}\text { grupo de trabajo de Lenguajes } \\
\text { Artísticos del Consejo de } \\
\text { Coordinació Pedagògica de } \\
\text { Barcelona. }\end{array}$ & España \\
\hline $\mathrm{P} 212$ & Remise en jeu & INRAP y La Criée & Francia \\
\hline P213 & $\begin{array}{l}\text { Roy Lichtenstein de principio } \\
\text { a fin }\end{array}$ & Fundación Juan March & España \\
\hline P214 & $\begin{array}{l}\text { San Carlos visita tu } \\
\text { comunidad }\end{array}$ & Museo Nacional de San Carlos & México \\
\hline $\mathrm{P} 215$ & Saturday Morning Stripes & Children's Museum of Arts & Desconocido \\
\hline P216 & $\begin{array}{l}\text { Segundas Jornadas Arte }+\mathrm{i} \\
\text { Industria }\end{array}$ & $\begin{array}{l}\text { Fundación de los Trabajadores de la } \\
\text { Siderurgia Integral }\end{array}$ & España \\
\hline P217 & $\begin{array}{l}\text { SEME@: Sharing European } \\
\text { Memories at School } \\
\text { (Compartiendo memorias } \\
\text { europeas en la escuela) } \\
\end{array}$ & Sociedad de Ciencias Aranzadi & España \\
\hline P218 & $\begin{array}{l}\text { Seminario Patrimonio } \\
\text { Etnológico }\end{array}$ & $\begin{array}{l}\text { Comisión de Elaboración de } \\
\text { Unidades Didácticas de la }\end{array}$ & España \\
\hline
\end{tabular}




\begin{tabular}{|c|c|c|c|}
\hline & & $\begin{array}{l}\text { Asociación de Gaiteros de Aragón } \\
\text { (A.G.A.) }\end{array}$ & \\
\hline P219 & $\begin{array}{l}\text { SEMUGA servicios } \\
\text { educativos de museos y } \\
\text { galerías }\end{array}$ & $\begin{array}{l}\text { Instituto Cultural de Aguascalientes } \\
\text { (ICA) }\end{array}$ & México \\
\hline P220 & $\begin{array}{l}\text { Slam à l'école (Slam en la } \\
\text { escuela) }\end{array}$ & $\begin{array}{l}\text { la Ligue Slam de France y la } \\
\text { asociación APPUI }\end{array}$ & Francia \\
\hline P221 & Soinu mapa (Mapa sonoro) & $\begin{array}{l}\text { Departamento sonoro del Centro de } \\
\text { Arte Contemporáneo Arteleku, } \\
\text { Audiolab }\end{array}$ & España \\
\hline P222 & Taller de la experiencia & $\begin{array}{l}\text { Centro Social de Personas Mayores } \\
\text { de Puerto de Mazarrón } \\
\end{array}$ & España \\
\hline P223 & $\begin{array}{l}\text { Taller didáctico virtual sobre } \\
\text { el escultor valenciano Andreu } \\
\text { Alfaro }\end{array}$ & $\begin{array}{l}\text { IVAM Instituto Valenciano de Arte } \\
\text { Moderno. Generalitat. }\end{array}$ & España \\
\hline P224 & $\begin{array}{l}\text { Talleres de ocio } \\
\text { intergeneracional e inclusivo: } \\
\text { Por una casa para todos } \\
\end{array}$ & $\begin{array}{l}\text { La Casa Encendida, de Obra Social } \\
\text { Caja Madrid, desde el Área de } \\
\text { Solidaridad. }\end{array}$ & España \\
\hline P225 & Talleres didácticos del IVAM & $\begin{array}{l}\text { IVAM Instituto Valenciano de Arte } \\
\text { Moderno }\end{array}$ & España \\
\hline P226 & $\begin{array}{l}\text { Talleres en "Escuela de Artes } \\
\text { y oficios de Vitoria-Gasteiz". }\end{array}$ & $\begin{array}{l}\text { Escuela de Artes y oficios de } \\
\text { Victoria Gasteiz }\end{array}$ & España \\
\hline P227 & $\begin{array}{l}\text { The Friendship Workshop for } \\
\text { Families Affected by Autism }\end{array}$ & Queens Museum of Art & Desconocido \\
\hline P228 & Tradición oral en las aulas & & España \\
\hline P229 & Turismo raro & $\begin{array}{l}\text { Unofficial tourism y otros } \\
\text { colectivos implicados }\end{array}$ & España \\
\hline $\mathrm{P} 230$ & Un mar de historias ** & $\begin{array}{l}\text { Concejalía de Cultura y Educación } \\
\text { de Almuñécar }\end{array}$ & España \\
\hline $\mathrm{P} 231$ & UNESCOEtxea & UNESCO & España \\
\hline P232 & $\begin{array}{l}\text { Unidad didáctica de bailes } \\
\text { tradicionales de Murcia }\end{array}$ & & España \\
\hline P233 & Unidad didáctica el carnaval & $\begin{array}{l}\text { Comisión de Elaboración de } \\
\text { Unidades Didácticas de la } \\
\text { Asociación de Gaiteros de Aragón } \\
\text { (A.G.A.) }\end{array}$ & España \\
\hline P234 & Unidad didáctica el verano & $\begin{array}{l}\text { Comisión de Elaboración de } \\
\text { Unidades Didácticas de la } \\
\text { Asociación de Gaiteros de Aragón } \\
\text { (A.G.A.) }\end{array}$ & España \\
\hline P235 & $\begin{array}{l}\text { Unidad didáctica la cultura } \\
\text { andaluza }\end{array}$ & CSIF Sector de Enseñanza & España \\
\hline P236 & Unidad didáctica La Navidad & $\begin{array}{l}\text { Comisión de Elaboración de } \\
\text { Unidades Didácticas de la } \\
\text { Asociación de Gaiteros de Aragón } \\
\text { (A.G.A.) }\end{array}$ & España \\
\hline P237 & $\begin{array}{l}\text { Vamos a descubrir el castillo } \\
\text { de Gala y Dalí. }\end{array}$ & Fundación Gala-Dalí & España \\
\hline $\mathrm{P} 238$ & Vidas imperfectas 2.0 & Safa Grial & España \\
\hline
\end{tabular}




\begin{tabular}{|c|c|c|c|}
\hline P239 & $\begin{array}{l}\text { Vidas imperfectas, un trabajo } \\
\text { de reflexión en torno a la obra } \\
\text { fotográfica de Gregory } \\
\text { Crewdson } \\
\end{array}$ & Centro Grial & España \\
\hline P240 & $\begin{array}{l}\text { Vigías de nuestro patrimonio } \\
\text { cultural }\end{array}$ & Gobierno de Colombia & Colombia \\
\hline P241 & $\begin{array}{l}\text { Vigías del Patrimonio } \\
\text { Cultural }\end{array}$ & $\begin{array}{l}\text { Coordinación Nacional de } \\
\text { Patrimonio Cultural y Turismo }\end{array}$ & México \\
\hline P242 & $\begin{array}{l}\text { VII Congreso Las } \\
\text { rentabilidades económicas y } \\
\text { sociales de los patrimonios } \\
\text { culturales y los museos }\end{array}$ & Museo Oiasso & España \\
\hline P243 & $\begin{array}{l}\text { Visitas y talleres } \\
\text { intergeneracionales: 'Lo } \\
\text { creativo a través de lo } \\
\text { cotidiano' }\end{array}$ & $\begin{array}{l}\text { Dirección General de Bellas Artes } \\
\text { Comunidad de Madrid. }\end{array}$ & España \\
\hline P244 & $\begin{array}{l}\text { Vivir y sentir el flamenco. } \\
17-18\end{array}$ & $\begin{array}{l}\text { Junta de Andalucía. Conserjería de } \\
\text { Educación. }\end{array}$ & España \\
\hline P245 & \begin{tabular}{|l|} 
Voluntariado Cultural \\
Segovia 2016 \\
\end{tabular} & Ayuntamiento de Segovia & España \\
\hline P246 & $\begin{array}{l}\text { WebQuest sobre el castillo de } \\
\text { Crevillent }\end{array}$ & C. P. Francesc Candela & España \\
\hline P247 & $\begin{array}{l}\text { ZAWP Bilbao (Zorrotzaurre } \\
\text { Art Working Progress) }\end{array}$ & ZAWP Bilbao & España \\
\hline
\end{tabular}

Fuente: Propia

Tabla 17. Resultados de la búsqueda emocional y creativa.

\begin{tabular}{|c|c|c|c|}
\hline \multicolumn{4}{|c|}{ Búsqueda: creati+emoci* } \\
\hline \multicolumn{4}{|c|}{ Número de elementos: 15} \\
\hline $\mathrm{n}^{\mathrm{o}}$ & Título & Entidad responsable & País \\
\hline P248 & $\begin{array}{l}\text { "La cultura de la India en } \\
\text { las Aulas de la Merced" }\end{array}$ & IES La Merced & España \\
\hline P249 & $\begin{array}{l}\text { ¿A qué jugaban mis } \\
\text { abuelos? }\end{array}$ & Universidad de Valencia & España \\
\hline $\mathrm{P} 250$ & $\begin{array}{l}\text { Catas artísticas: } \\
\text { Enocultura y patrimonio } \\
\text { en Rioja Alavesa }\end{array}$ & $\begin{array}{l}\text { Cuadrilla de Laguardia-Rioja } \\
\text { Alavesa }\end{array}$ & España \\
\hline $\mathrm{P} 251$ & $\begin{array}{l}\text { Cuadernos de Teseo, } \\
\text { Taller de Laberintos } \\
\text { interiores }\end{array}$ & Estudio Rossana Zaera & Web \\
\hline $\mathrm{P} 252$ & $\begin{array}{l}\text { Diálogo: vivir el } \\
\text { Patrimonio }\end{array}$ & Diálogo: vivir el Patrimonio & España \\
\hline $\mathrm{P} 253$ & $\begin{array}{l}\text { Experiencia pedagógica } \\
\text { didáctica de valoración del } \\
\text { patrimonio cultural con } \\
\text { orientación proyectual }\end{array}$ & Universidad de Palermo & Argentina \\
\hline $\mathrm{P} 254$ & Huellas de la ciudad & $\begin{array}{l}\text { Área Comunicación Audiovisual y } \\
\text { Publicidad (Facultad Ciencias } \\
\text { Sociales, Jurídicas y de la }\end{array}$ & España \\
\hline
\end{tabular}




\begin{tabular}{|c|c|c|c|}
\hline & & $\begin{array}{l}\text { Comunicación de la Universidad de } \\
\text { Valladolid, Museo Esteban Vicente }\end{array}$ & \\
\hline $\mathrm{P} 255$ & $\begin{array}{l}\text { Memoria de la industria, } \\
\text { memoria del mar }\end{array}$ & Xunta de Galicia & España \\
\hline P256 & $\begin{array}{l}\text { Memorias de nuestra } \\
\text { infancia: los niños de la } \\
\text { guerra }\end{array}$ & $\begin{array}{l}\text { Actividad financiada por la } \\
\text { convocatoria de proyectos del IN3 } \\
2002 \text {. }\end{array}$ & España \\
\hline P257 & $\begin{array}{l}\text { Patrimonio artístico de } \\
\text { Andalucía }\end{array}$ & $\begin{array}{l}\text { Gabinetes Pedagógicos de Bellas } \\
\text { Artes }\end{array}$ & España \\
\hline P258 & Rainbow Artists & $\begin{array}{l}\text { Museum of Contemporary Art } \\
\text { (MOCA) }\end{array}$ & Desconocido \\
\hline P259 & REHARQ & $\begin{array}{l}\text { Archivo de la Real Chancillería de } \\
\text { Valladolid y el Archivo General de } \\
\text { Indias. }\end{array}$ & España \\
\hline P260 & Sabores Viajeros & $\begin{array}{l}\text { Archivo de la Real Chancillería de } \\
\text { Valladolid y Museo de las Ferias de } \\
\text { Medina Del Campo }\end{array}$ & España \\
\hline P261 & $\begin{array}{l}\text { Simón Ruíz- Comercio en } \\
\text { clave de Pasión }\end{array}$ & $\begin{array}{l}\text { Archivo General de Simancas, } \\
\text { Asociación Cultural "El Calabacín } \\
\text { Errante" }\end{array}$ & España \\
\hline $\mathrm{P} 262$ & Vacaciones en el Castillo & & España \\
\hline
\end{tabular}

Fuente: Propia

\subsection{Instrumentos de recogida de información.}

El primer instrumento de recogida de datos utilizado nos lo proporciona la base OEPE donde, una vez filtrados los programas que incluyen los elementos que conforman la evaluación, tenemos la posibilidad de descargar los datos deseados en una hoja Excel con la que realizamos el reporte de datos permitiendo relaciones de frecuencias. Posteriormente el siguiente instrumento utilizado será el que corresponde con la tabla de dimensiones y estándares básicos (figura 5)que utilizaremos para la evaluación de la calidad de los programas.

\subsubsection{SAEPE-OEPE.}

El método SAEPE-OEPE es un método secuencial de análisis y evaluación de programas de educación patrimonial (Fontal, 2016b). Se fundamenta en una evaluación basada en estándares atendiendo al enfoque teórico, las metas, la calidad del diseño, la planificación de las actuaciones, el grado de cumplimiento, la implementación, la utilidad de los resultados y los impactos generados por el proyecto.

El método se estructura en ocho fases a través de un sistema de filtros secuenciados, cada uno coligado a un determinado instrumentos de evaluación (Fontal y Juanola, 2015).

1- La primera de ellas está dedicada a la búsqueda y localización de programas por distintos medios web, congresos o revisiones bibliográficas.

2- La segunda fase está dedicada a analizar, por medio de criterios de inclusión y exclusión, cuales de aquellos programas localizados deben ser inventariados en la base de datos. 
3- La tercera fase reúne la información de los programas seleccionados distribuida en los cuarenta y dos campos de registro divididos en: identificación, localización, descripción del proyecto, diseño educativo y anexo documental.

4- La cuarta fase tiene como objeto realizar un análisis descriptivo de los datos inventariados a través de su adscripción a la categoría de programa, la localización, adaptaciones, objetivos, metodologías, etc.

5- La quinta fase es un proceso evaluativo atendiendo a catorce estándares básicos repartidos en dos dimensiones: Calidad de la información sobre el programa y grado de concreción del diseño educativo.

6- La sexta fase es nuevamente una evaluación, en este caso con veintiocho estándares extendidos, ordenados en cuatro dimensiones: calidad del diseño del programa, calidad de la implementación, calidad de los resultados y grado de difusión de los programas y sus resultados.

7- La séptima fase, al igual que la siguiente, consiste en un estudio pormenorizado de los programas con mejores resultados por medio estudio de casos únicos o múltiples.

8- En la fase octava se realiza un estudio de aprendizajes.

Figura 3. Procedimiento secuencial de selección de programas.

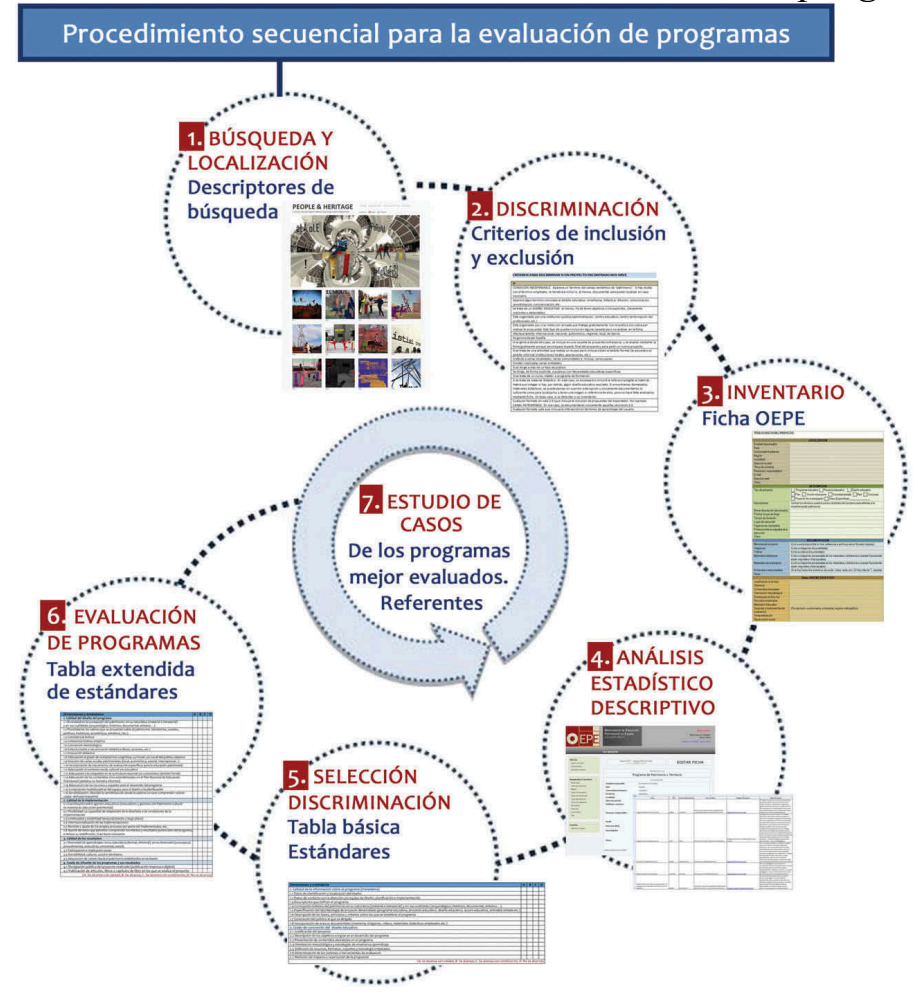

Fuente: (Fontal 2015).

En nuestro caso al tomar como población de la muestra los programas ya inventariados en la base de datos, utilizaremos las herramientas de evaluación descritas en la fase cinco para valorar los programas que hayamos seleccionado por su relación con elementos emocionales y creativos. Por ello pasamos a describir de manera pormenorizada esta herramienta.

Los estándares básicos han sido definidos a partir de tres análisis estadísticos en los que se analizaban programas de la base de OEPE, $n=350, n=644$ y $n=1.120$. Se incluyen 
además criterios sobre aspectos metodológicos derivados del Plan Nacional de Educación y Patrimonio. Los estándares se agrupan en dimensiones desarrollando cada una de ellas y concretándose en rúbricas de evaluación. Estos se distribuyen en dos grupos, uno de quince tipos, considerados estándares básicos y otro de veintiocho, considerados estándares extendidos. Ambos gruposse recogen en tablas (Figuras 5 y 6 ) para plasmar la recogida de información.

Figura 4. Tabla de estándares básicos.

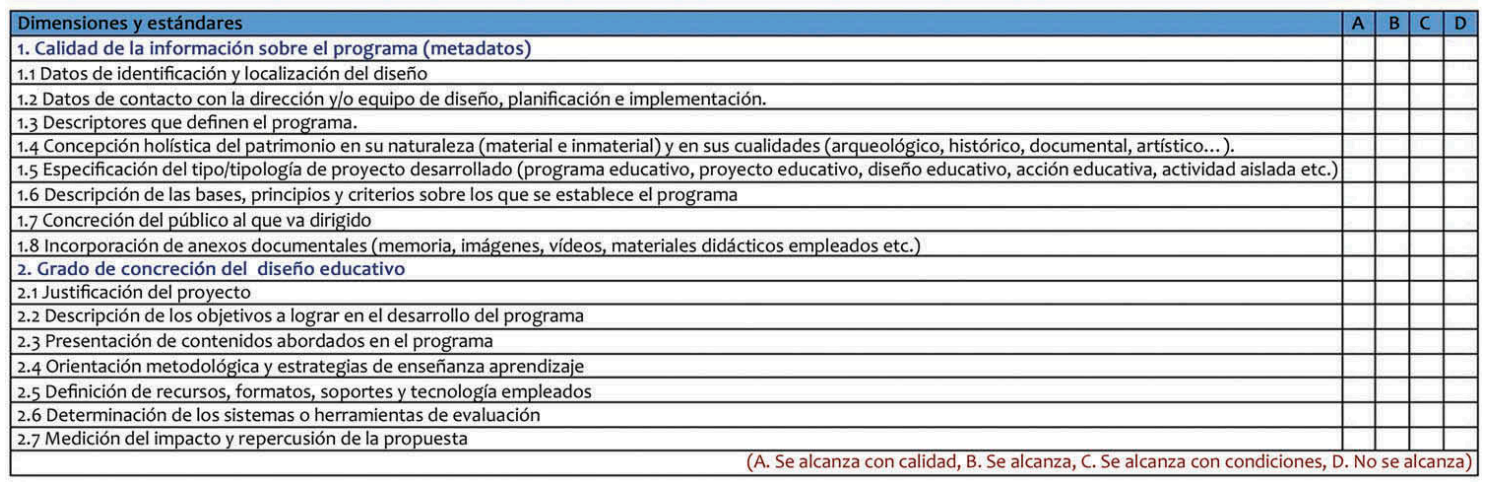

Fuente:(Fontal 2015)

Figura 5. Tabla de estándares básicos.

\begin{tabular}{|c|c|c|c|c|}
\hline Dimensiones y estándares & A & B & 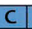 & $\mathrm{D}$ \\
\hline 1. Calidad del diseño del programa & & & & \\
\hline $\begin{array}{l}1.1 \text { Diversidad en la concepción del patrimonio: en su naturaleza (material e inmaterial) } \\
\text { y en sus cualidades (arqueológico, histórico, documental, artístico...). }\end{array}$ & & & & \\
\hline $\begin{array}{l}1.2 \text { Pluralidad de los valores que se proyectan sobre el patrimonio: identitarios, sociales, } \\
\text { políticos, históricos, económicos, emotivos, etc.). }\end{array}$ & & & & \\
\hline 1.3 Consistencia teórica & & & & \\
\hline 1.4 Coherencia teórico-empírica & & & & \\
\hline 1.5 Concreción metodológica & & & & \\
\hline 1.6 Estructuración y secuenciación didáctica (fases, acciones, etc.) & & & & \\
\hline 1.7 Innovación didáctica & & & & \\
\hline 1.8 Adecuación al grado de competencia congnitiva, curricular y/o social del público objetivo & & & & \\
\hline 1.9 Inclusión de varias escalas patrimoniales (local, autonómica, estatal, internacional...) & & & & \\
\hline 1.10 Incorporación de mecanismos de evaluación específicos para la educación patrimonial & & & & \\
\hline 1.11 Adecuación al contexto social, cultural y/o educativo & & & & \\
\hline 1.12 Adecuación a lo estipulado en el currículum nacional y/o autonómico (ámbito fomal) & & & & \\
\hline $\begin{array}{l}\text { 1.13 Adecuación de los contenidos a los estandarizados en el Plan Nacional de Educación } \\
\text { Patrimonial (ámbitos no formal e informal) }\end{array}$ & & & & \\
\hline 1.14 Adecuación de los recursos y soportes para el desarrollo del programa & & & & \\
\hline 1.15 Composición multidisciplinar del equipo para el diseño y la planificación & & & & \\
\hline $\begin{array}{l}\text { 1.16 Sensibilización: Abordan la sensibilización desde la cadena conocer-comprender-valorar- } \\
\text { cuidar- disfrutar-transmitir }\end{array}$ & & & & \\
\hline 2. Calidad de la implementación & & & & \\
\hline $\begin{array}{l}2.1 \text { Coordinación entre agentes educativos (educadores y gestores del Patrimonio Cultural } \\
\text { en materia de educación patrimonial) }\end{array}$ & & & & \\
\hline $\begin{array}{l}\text { 2.2 Flexibilidad: La capacidad de adaptación de lo diseñado a las condiciones de la } \\
\text { implementación }\end{array}$ & & & & \\
\hline 2.3 Continuidad y estabilidad temporal (medio y largo plazo) & & & & \\
\hline 2.4 Internacionalización de las implementaciones & & & & \\
\hline 2.5 Revisión y ajuste de los propios procesos por parte del implementador, etc. & & & & \\
\hline $\begin{array}{l}\text { 2.6 Aporte de datos que permitan comprender los efectos y resultados potenciales del programa, } \\
\text { e incluso su redefinición, si así fuese necesario. }\end{array}$ & & & & \\
\hline 3. Calidad de los resultados & & & & \\
\hline $\begin{array}{l}\text { 3.1 Diversidad de aprendizajes: en su naturaleza (formal, informal), en su dimensión (conceptual, } \\
\text { procedimental, actitudinal, emocional, social). }\end{array}$ & & & & \\
\hline 3.2 Participación e implicación social & & & & \\
\hline 3.4 Rentabilidad: cultural, social e identitaria. & & & & \\
\hline 3.5 Adquisición de valores hacia el patrimonio establecidos en el diseño & & & & \\
\hline 4. Grado de difusión de los programas y sus resultados & & & & \\
\hline 4.1 Divulgación pública del proyecto realizado (publicación impresa o digital) & & & & \\
\hline 4.2 Publicación de artículos, libros o capítulos de libro en los que se analice el p & & & & \\
\hline
\end{tabular}

Fuente: (Fontal 2015).

\subsubsection{Q-Edutage.}

Los estándares básicos fueron concebidos en su momento como una escala cualitativa (Fontal 2015). De esta forma surge una rúbrica donde se detallan los criterios básicos de un buen programa patrimonial que atiende en su diseño a la institución que lo genera, su diseño didáctico o el tipo de programa. Posteriormente se pasó a una escala ordinal 
cuantitativa generando la escala Q-Edutage (Fontal, García, Arias y Arias, 2018) que es la que nosotros utilizaremos y que pasamos por tanto a describir.

La escala Q-Edutage, según Fontal et al. (2018), nace con el objeto de crear un instrumento para la evaluación de la calidad de programas de educación patrimonial que mantenga un equilibrio adecuado entre precisión y brevedad, y que pueda ser utilizado tanto en solitario como en apoyo a sistemas de evaluación más amplios. La escala se diseñó en tres pasos:

1-Identificación, mediante la revisión de la literatura relevante de los principales indicadores básicos de calidad de los programas de educación patrimonial.

2-Selección de los indicadores con mayores garantías de validez de contenido, mediante un estudio de jueces expertos.

3-La calibración y construcción de la versión final del instrumento, mediante procedimientos enmarcados en la Teoría de la Respuesta al Ítem (TRI).

Los baremos de puntación de la prueba presentan una calidad razonablemente alta (con una deviación típica por encima de la media tal y como nos indican Fontal, García, Aris y Arias (2018), donde para las puntuaciones de la escala final, primero se estiman las puntuaciones esperadas a posteriori, y después se transforman en una escala con media 100 y desviación típica 15.

El resultado es una escala unidimensional, con indicadores que representan aspectos y facetas de la calidad variados y no redundantes. Posee un grado de fiabilidad elevado, alcanzando su precisión máxima en un rango de calidad comprendido entre zonas bajas (aproximadamente -1 desviaciones típicas) y muy altas (aproximadamente +2 desviaciones típicas). No presenta un efecto techo relevante, dado que es capaz de discriminar con elevada precisión entre varios niveles de la variable (i.e., muy bajo, bajo, medio, alto y muy alto), permitiendo una adecuada clasificación de los programas de acuerdo a su calidad. Las puntuaciones obtenidas tras su aplicación se consideran independientes del evaluador dada la estabilidad de las propiedades de medida una vez comparadas con las respuestas de tres observadores independientes.

Por ello, y apoyando las conclusiones de Fontal et al. (2018), consideramos que la escala Q-Edutage contribuye a una planificación educativa rigurosa, facilitando la investigación evaluativa en educación patrimonial, la evaluación de la calidad de proyectos y la extracción de información de los mismos. Por todo ello la adoptamos como herramienta evaluativa para nuestra investigación.

\subsection{Procedimiento y análisis de datos.}

Los datos obtenidos fueron tratados con el software de análisis estadístico XLSTAL v.2020 para el análisis estadístico de los ítems señalados anteriormente. Utilizaremos principalmente tres tipos de estudios: análisis descriptivo, correlaciones y análisis inferencial.

El análisis estadístico descriptivo nos permitirá conocer las frecuencias, rangos, medianas, varianzas, desviaciones típicas de las variables y cuartiles que se representarán en gráficos box-plot.

Las correlaciones nos permitirán conocer la relación y proporcionalidad entre las variables estadísticas tomadas de dos en dos. En nuestro caso utilizaremos el coeficiente de correlación de Pearson, un índice que usaremos para medir el grado de correlación de nuestras variables numéricas continuas.

Finalmente realizaremos un análisis inferencial para intentar obtener conclusiones basándonos en las informaciones numéricas. 
Usaremos el modelo ANOVA (Análisis de varianza) que nos permite comparar medias cuando tenemos más de dos grupos como es nuestro caso. El nivel de confianza se sitúa en el $95 \%$ y el resultado se considera estadísticamente significativo cuando el valor $p$ de la tabla ANOVA es menor de $0,05(\mathrm{p}<0,05)$. Cuando esto ocurre podemos afirmar con una confianza del 95\%, que al menos la media de uno de los grupos es suficientemente distinta a la media de alguno de los otros grupos, como para afirmar que hay medias estadísticamente significativas entre ellos.

Cuando esto ocurre debemos identificar entre que grupos de los comparados existen esas diferencias, para ello utilizamos pruebas post-hoc. En nuestro caso dado que la muestra general se considera homogénea y la cantidad de elementos de cada grupo es diferente, utilizaremos la prueba Tukey. 


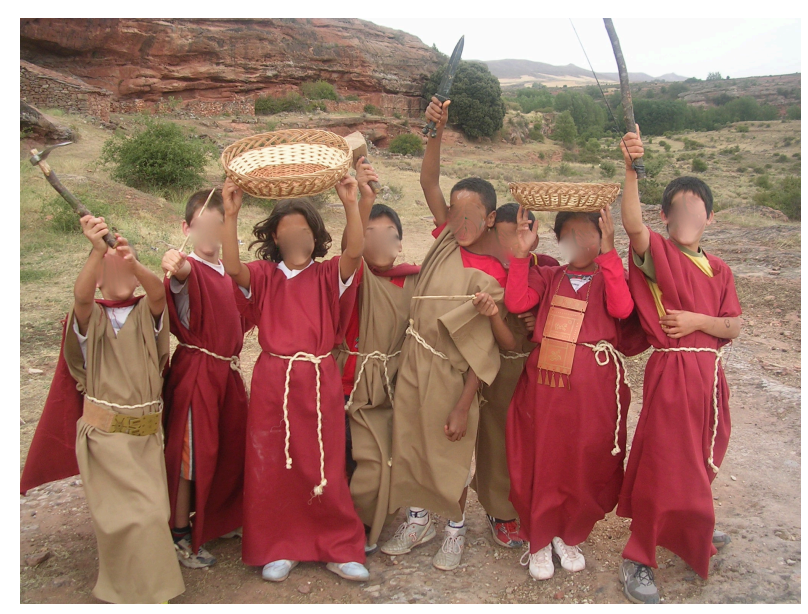

“...no se puede entender la naturaleza de la inteligencia y del pensamiento fuera del contexto de la cultura..."

Robert Stemberg.

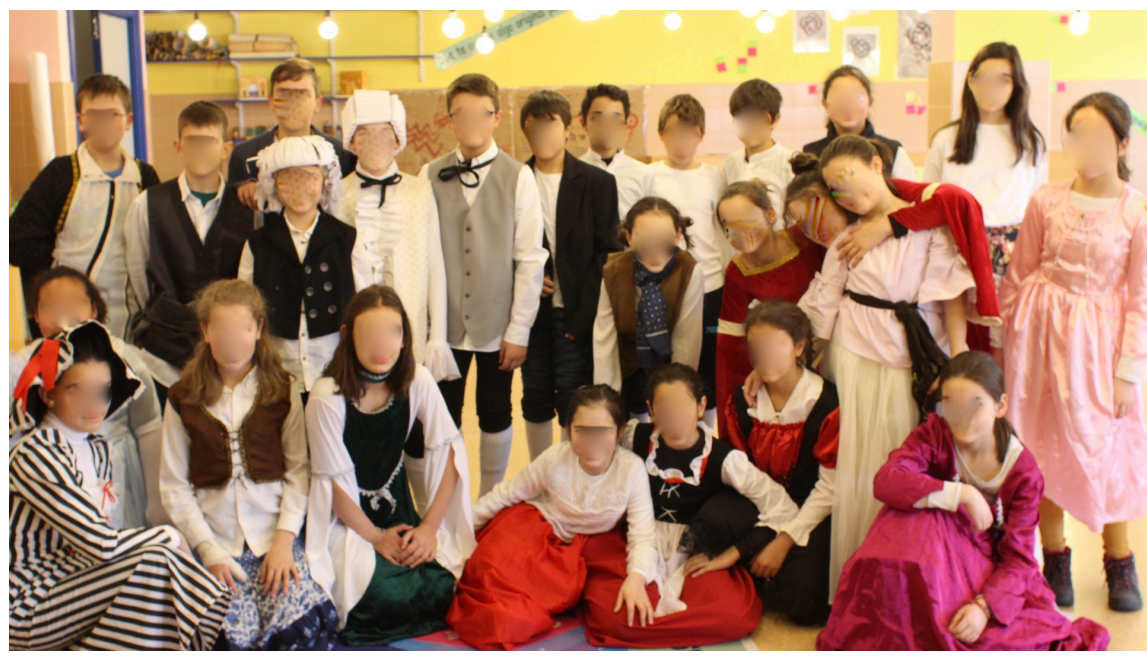




\section{CAPÍTULO 5. DESCRIPCIÓN Y ANÁLISIS DE DATOS.}

\subsection{Análisis estadísticos descriptivos de variables sociodemográficas.}

Comenzamos el análisis de resultados analizando qué tipos de entidad responsable es la que más trabaja con elementos emocionales y creativos (V1), qué categorías de patrimonio de las establecidas en la variable dos son las que abordan nuestros elementos de investigación (V2), qué importancia se les otorga según los tipos de proyecto establecidos en la variable tres (V3), para qué tipo de públicos mayoritarios se diseñan programas con las temáticas analizadas (V4) y en qué ámbito pedagógico tienen más representación nuestros dos ámbitos (V5).

En la tabla 18 correspondiente a la variable uno (V1), podemos observar que las entidades públicas son las que abordan con mayor asiduidad el trabajo emocional y creativo $(n=177 ; 67,56 \%)$. Si a este porcentaje le sumamos aquellas iniciativas que reciben en parte aportaciones públicas y que incluimos en el subtipo de variable mixta $(n=48 ; 18,32 \%)$, nos situamos en un porcentaje por encima del $85 \%$ de programas que con financiación pública total o parcial consideran nuestros ámbitos de estudio.

Tabla 18. Frecuencias y porcentajes de cada tipo de entidad responsable.

\begin{tabular}{|l|c|c|}
\hline \multicolumn{3}{|c|}{ TIPO DE ENTIDAD RESPONSABLE. V1 } \\
\hline Subtipo de variable & Frecuencia & Porcentaje \\
\hline Público & 177 & $67,557 \%$ \\
\hline Privado & 37 & $14,122 \%$ \\
\hline Mixto & 48 & $18,321 \%$ \\
\hline Total & 262 & $100 \%$ \\
\hline
\end{tabular}

Fuente: Propia

En la tabla 19 correspondiente a la variable V2, podemos observar que es el patrimonio cultural el que destaca muy por encima del resto de los diecisiete subtipos de variable analizados $(\mathrm{n}=103 ; 39,31 \%)$, casi doblando la frecuencia del patrimonio inmaterial que es el que presenta el segundo mayor porcentaje $(n=57 ; 21,75 \%)$. Resalta el dato el hecho de que ninguno de los demás subtipos sobrepase el $6 \%$ con la excepción de "otros" $(\mathrm{n}=49 ; 18,7 \%)$ que como es lógico, aglutina el resto de categorías de patrimonio no explicitadas dentro de las 18 que se presentan en esta variable. Destacamos así mismo que tres tipologías no incluyen ningún programa que trate las emociones o la creatividad, concretamente las relativas a "conjuntos construcciones aisladas", "conjuntos construcciones reunidas" y "monumentos inscripción en cavernas".

Tabla 19. Frecuencias y porcentajes de cada categoría de patrimonio.

\begin{tabular}{|l|c|c|}
\hline \multicolumn{2}{|c|}{ CATEGORÍA DE PATRIMONIO. V2 } \\
\hline Subtipo de variable & Frecuencia & Porcentaje \\
\hline $\begin{array}{l}\text { C. Construcciones } \\
\text { aisladas }\end{array}$ & 0 & $0 \%$ \\
\hline $\begin{array}{l}\text { C. Construcciones } \\
\text { reunidas }\end{array}$ & 0 & $0 \%$ \\
\hline L. arqueológicos & 4 & $1,527 \%$ \\
\hline L. especiales & 1 & $0,382 \%$ \\
\hline L. creados por el hombre & 7 & $2,672 \%$ \\
\hline
\end{tabular}




\begin{tabular}{|l|c|c|}
\hline $\begin{array}{l}\text { L. creados por el hombre } \\
\text { y la naturaleza }\end{array}$ & 2 & $0,763 \%$ \\
\hline M.inscripción en cavernas & 0 & $0 \%$ \\
\hline M. obra pictórica & 3 & $1,145 \%$ \\
\hline M. arqueología & 5 & $1,908 \%$ \\
\hline $\begin{array}{l}\text { M. grupo de elementos de } \\
\text { importancia }\end{array}$ & 0 & $0 \%$ \\
\hline M. obra arquitectónica & 8 & $3,053 \%$ \\
\hline M. obra escultórica & 1 & $0,382 \%$ \\
\hline Patrimonio cultural & 103 & $39,313 \%$ \\
\hline Patrimonio digital & 4 & $1,527 \%$ \\
\hline Patrimonio industrial & 3 & $1,145 \%$ \\
\hline Patrimonio inmaterial & 57 & $21,756 \%$ \\
\hline $\begin{array}{l}\text { Patrimonio natural } \\
\text { cultural }\end{array}$ & 15 & $5,725 \%$ \\
\hline Patrimonio otros & 49 & $18,702 \%$ \\
\hline Total & 262 & $100 \%$ \\
\hline
\end{tabular}

Fuente: Propia

La variable tres (Tabla 20) aglutina nuevamente otras 18 subvariables en las que encontramos como tipos de proyecto con mayor frecuencia los programas educativos en primer lugar $(n=67 ; 25,57 \%)$, los proyectos educativos a continuación $(n=37 ; 14,12 \%)$ y los recursos didácticos en tercer lugar $(n=31 ; 11,83 \%)$. En este caso el subtipo que presenta ausencias de frecuencia es el de redes sociales. De la misma manera vuelve a tener una incidencia considerable el subtipo "sin especificar" $(n=24 ; 9,16 \%)$, donde se incluyen aquellos programas que no se incluyen en ninguna de las tipologías que recoge la variable analizada (V3) o que son de difícil definición.

Tabla 20. Frecuencias y porcentajes de cada tipo de proyecto.

\begin{tabular}{|l|c|c|}
\hline \multicolumn{3}{|c|}{ TIPO DE PROYECTO. V3 } \\
\hline Subtipo de variable & Frecuencia & Porcentaje \\
\hline Programa educativo & 67 & $25,573 \%$ \\
\hline Proyecto educativo & 37 & $14,122 \%$ \\
\hline Diseño didáctico & 17 & $6,489 \%$ \\
\hline Recurso didáctico & 31 & $11,832 \%$ \\
\hline Herramienta didáctica & 6 & $2,290 \%$ \\
\hline Acción educativa & 14 & $5,344 \%$ \\
\hline Acción aislada & 2 & $0,763 \%$ \\
\hline Taller & 14 & $5,344 \%$ \\
\hline Proyecto de investigación & 10 & $3,817 \%$ \\
\hline Proyecto de mejora & 2 & $0,763 \%$ \\
\hline Concurso & 15 & $5,725 \%$ \\
\hline Itinerario didáctico & 5 & $1,908 \%$ \\
\hline Plan & 4 & $1,527 \%$ \\
\hline Red & 4 & $1,527 \%$ \\
\hline Evento científico & 5 & $1,908 \%$ \\
\hline Curso & 5 & $1,908 \%$ \\
\hline Redes sociales & 0 & $0 \%$ \\
\hline
\end{tabular}




\begin{tabular}{|l|c|c|}
\hline Sin Especificar & 24 & $9,160 \%$ \\
\hline Total & 262 & $100 \%$ \\
\hline
\end{tabular}

Fuente: Propia

Dentro de la variable cuatro, se analizan las edades del publico al que se dirigen las propuestas. En este caso las hemos distribuido en trece categorías (Tabla 21), seis analizadas individualmente por grupos de edad: infantil, juvenil, sénior, tercera edad, todos los públicos y colectivos específicos; y otras siete categorías que agrupan las anteriores en conjuntos de dos o tres elementos.

Al analizar las categorías individuales, observamos que las mayores frecuencias (a excepción de todos los públicos) aparecen en las edades más tempranas: infantil $(n=63$; $24,046 \%)$ y juvenil $(n=37 ; 14,504 \%)$. En el polo opuesto, tenemos las actividades dirigidas a la tercera edad exclusivamente que no acogen ninguna iniciativa. Resultan destacables aquellos programas destinados a todos los públicos $(n=84 ; 32,061 \%)$, lo que supone el mayor tanto por ciento del análisis de la variable, señalando que existe un interés creciente por diseñar propuestas que abarquen cualquier grupo de edad.

Examinando las categorías agrupadas observamos que el grupo infantil-juvenil, seguido por juvenil-sénior, son los que presentan un mayor porcentaje apoyando los resultados ya comentados anteriormente en las categorías individuales. Destacamos que en estas categorías sí que se recogen acciones hacia la tercera edad, emparejadas con todos los grupos de edad, infantil, juvenil y sénior.

Si tomamos en consideración los números resultantes de asociar los programas dirigidos individualmente a un grupo de edad y a éste asociado a otros, encontramos que el grupo de edad de infantil acogería 91 propuestas, juvenil 76, sénior 34 y tercera edad 3. Así el grupo de edad al que más iniciativas patrimoniales creativas-emocionales se le dirige es al comprendido entre los 0 y 16 años, infantil. Tras él, los programas dirigidos a todos los públicos, seguidamente la franja de edad juvenil de 16 a 22 años con 76 programas. En cuarto lugar la franja sénior de 22 a 65 con 34, y finalmente, la tercera edad con 3.

Tabla 21. Frecuencias y porcentajes del público al que se dirige

\begin{tabular}{|l|c|c|c|}
\hline \multicolumn{5}{|c|}{ PUBLICO AL QUE SE DIRIGE. V4 } \\
\hline Subtipo de variable & Categorías & Frecuencia & Porcentaje \\
\hline Infantil & 1 & 63 & $24,046 \%$ \\
\hline Juvenil & 2 & 38 & $14,504 \%$ \\
\hline Sénior & 3 & 20 & $7,634 \%$ \\
\hline Tercera edad & 4 & 0 & $0 \%$ \\
\hline Todos los públicos & 5 & 84 & $32,061 \%$ \\
\hline $\begin{array}{l}\text { Colectivos } \\
\text { específicos }\end{array}$ & 6 & 16 & $6,107 \%$ \\
\hline Infantil y juvenil & $1-2$ & 25 & $9,542 \%$ \\
\hline $\begin{array}{l}\text { Infantil y tercera } \\
\text { edad }\end{array}$ & $1-4$ & 1 & $0,382 \%$ \\
\hline $\begin{array}{l}\text { Infantil y colectivos } \\
\text { específicos }\end{array}$ & $1-6$ & 1 & 0,382 \\
\hline $\begin{array}{l}\text { Infantil, juvenil y } \\
\text { sénior }\end{array}$ & $1-2-3$ & 1 & 0,382 \\
\hline Juvenil y sénior & $2-3$ & 11 & 0,198 \\
\hline $\begin{array}{l}\text { Juvenil, sénior y } \\
\text { tercera edad }\end{array}$ & $2-3-4$ & 1 & \\
\hline
\end{tabular}




\begin{tabular}{|l|c|c|c|}
\hline Sénior y tercera edad & $3-4$ & 1 & 0,382 \\
\hline Total & 13 & 262 & $100 \%$ \\
\hline
\end{tabular}

Fuente: Propia

El análisis de la variable cinco, (V5) evidencia que tanto la educación patrimonial formal, como la no formal, prestan una importante atención a los elemento creativoemocionales $(n=105 ; 40,076 \%)$. La suma de los porcentajes de ambos ámbitos se sitúa por encima el $80 \%$ (Tabla 22 ) de los programas analizados.

A continuación ponemos el foco en la educación formal, ya que es uno de los centros de interés de este estudio. En la tabla 23 observamos que el análisis de los programas y las etapas educativas a las que estos se dirigen nos lleva a determinar 14 categorías: 5 individuales, correspondientes a los distintos periodos en que se divide la educación en nuestro país y 9 más, donde se distribuyen los programas que se dirigen a más de una etapa. Atendiendo a esta disposición, encontramos que es la universidad la que posee una frecuencia mayor $(n=25 ; 9,542 \%)$, seguida por los programas destinados a la Educación Secundaria Obligatoria $(\mathrm{n}=19 ; 7,252 \%)$.

En el lado opuesto de las frecuencias se sitúan los programas destinados a todas las etapas educativas conjuntamente, categoría $3,4,5,6$, y 7 ( $\mathrm{n}=1 ; 0,382 \%)$.

Si tomamos en consideración las frecuencias y porcentajes totales de los subtipos de la variable de Educación Formal, que incluyen acciones en cada etapa tomados de forma individual o asociados a otros (Tabla 24), observamos que arroja resultados bastante homogéneos entre todos los subtipos de variable. Profundizando en el análisis, podemos apreciar que la etapa con mayor porcentaje de proyectos es la de secundaria $(n=45$; $26,627 \%)$, seguida por la de primaria( $\mathrm{n}=41 ; 24,260 \%)$ siendo ambas las que aglutinan un porcentaje ligeramente superior al 50\%. Las etapas de infantil, bachillerato y universidad se sitúan todas en un porcentaje alrededor del $28 \%$.

Tabla 22. Frecuencias y porcentajes del ámbito pedagógico.

\begin{tabular}{|l|c|c|}
\hline \multicolumn{3}{|c|}{ ÁMBITO PEDAGÓGICO. V5 } \\
\hline Subtipo de variable & Frecuencia & Porcentaje \\
\hline Educación no formal & 105 & $40,076 \%$ \\
\hline Educación informal & 52 & $19,847 \%$ \\
\hline Educación formal & 105 & $40,076 \%$ \\
\hline Total & 262 & $100 \%$ \\
\hline
\end{tabular}

Fuente: Propia

Tabla 23. Frecuencias y porcentajes de los subtipos de la variable de Educación formal

\begin{tabular}{|l|c|c|c|c|}
\hline \multicolumn{4}{|c|}{ ÁMBITO PEDAGOGICO. V.5 } \\
\hline \multicolumn{4}{|c|}{ Análisis del subtipo de variable de Educación formal } \\
\hline Subtipo de variable & Categoría & Frecuencia & $\begin{array}{c}\text { Porcentaje } \\
\text { sobre } \\
\text { Educación } \\
\text { Formal }\end{array}$ & $\begin{array}{c}\text { Porcentaje } \\
\text { sobre el total }\end{array}$ \\
\hline EI & 3 & 5 & $4,762 \%$ & $1,908 \%$ \\
\hline EI y EPO & $3-4$ & 9 & $8,571 \%$ & $3,435 \%$ \\
\hline EI, EPO, ESO ESO, Bachillerato & $3-4-5$ & 2 & $1,905 \%$ & $0,763 \%$ \\
\hline $\begin{array}{l}\text { EI, EPO, ESO, Bachillerato, } \\
\text { Universidad }\end{array}$ & $3-4-5-6-7$ & 10 & $9,524 \%$ & $3,816 \%$ \\
\hline
\end{tabular}




\begin{tabular}{|l|c|c|c|c|}
\hline EPO & 4 & 12 & $11,429 \%$ & $4,580 \%$ \\
\hline EPO y ESO & $4-5$ & 5 & $4,762 \%$ & $1,908 \%$ \\
\hline EPO, ESO, Bachillerato & $4-5-6$ & 2 & $1,905 \%$ & $0,764 \%$ \\
\hline ESO & 5 & 19 & $18,095 \%$ & $7,252 \%$ \\
\hline ESO y Bachillerato & $5-6$ & 5 & $4,762 \%$ & $1,908 \%$ \\
\hline $\begin{array}{l}\text { ESO, Bachillerato y } \\
\text { Universidad }\end{array}$ & $5-6-7$ & 1 & $0,952 \%$ & $0,382 \%$ \\
\hline Bachillerato & 6 & 8 & $7,619 \%$ & $3,053 \%$ \\
\hline Bachillerato y Universidad & $6-7$ & 1 & $0,952 \%$ & $0,382 \%$ \\
\hline Universidad & 7 & 25 & $23,810 \%$ & $9,542 \%$ \\
\hline Total & 14 & 105 & $100,000 \%$ & $40,076 \%$ \\
\hline
\end{tabular}

Fuente: Propia

Tabla 24. Frecuencias y porcentajes totales de los subtipos de la variable de Educación formal que incluyen acciones en cada etapa de forma individual o asociados a otros.

\begin{tabular}{|l|c|c|}
\hline \multicolumn{3}{|c|}{ ÁMBITO PEDAGÓGICO. V5 } \\
\hline \multicolumn{3}{|c|}{ Total de proyectos que se dirigen a cada etapa individualmente o asociados a otra } \\
etapa
\end{tabular}

Fuente: Propia

\subsection{Análisis estadísticos descriptivos de variables de resultado.}

La evaluación realizada sobre las variables de resultado a través de la Escala QEdutage, desprende unos resultados con una valoración baja de los programas de educación patrimonial que incluyen elementos emocionales-creativos. Tal y como podemos observar en la tabla 25 , solamente un ítem tiene una valoración por encima de 3 puntos de media y solo dos consiguen una valoración entre 2,5 puntos y 3 . Once de los catorce ítems tiene una puntuación igual o por debajo de 2,5 y una mediana de 2 o 1 lo que nos informa de que no alcanzan la calidad suficiente, o lo hacen con condiciones.

Tabla 25. Estadísticos de variables de resultado.

\begin{tabular}{|c|c|c|c|c|c|c|c|c|c|c|c|c|c|c|}
\hline Estadístico & i01 Contacto & $\begin{array}{c}\text { i02 } \\
\text { descriptores } \\
\end{array}$ & $\begin{array}{c}\text { i03 } \\
\text { patrimonio } \\
\end{array}$ & i04 tipología & i05 bases & i06publico & i07 Anexos & $\begin{array}{c}\text { i08 } \\
\text { justificacion } \\
\end{array}$ & i09 obj & i10 cont & i11 orienta & i12 recursos & $\begin{array}{c}\text { i13 } \\
\text { evaluación } \\
\end{array}$ & i14 medición \\
\hline No. de observ & 262 & 262 & 262 & 262 & 262 & 262 & 262 & 262 & 262 & 262 & 262 & 262 & 262 & 262 \\
\hline Mínimo & 2,000 & 1,000 & 1,000 & 1,000 & 1,000 & 1,000 & 1,000 & 1,000 & 1,000 & 1,000 & 1,000 & 1,000 & 1,000 & 1,000 \\
\hline Máximo & 4,000 & 4,000 & 4,000 & 44,000 & 4,000 & 4,000 & 4,000 & 4,000 & 4,000 & 4,000 & 4,000 & 4,000 & 4,000 & 4,000 \\
\hline Frec. del míniı & 129 & 131 & 22 & 24 & 16 & 68 & 240 & 153 & 87 & 124 & 156 & 176 & 229 & 56 \\
\hline Frec. del máxi & 82 & 11 & 39 & 1 & 36 & 30 & 2 & 13 & 23 & 15 & 12 & 18 & 11 & 3 \\
\hline Rango & 2,000 & 3,000 & 3,000 & 43,000 & 3,000 & 3,000 & 3,000 & 3,000 & 3,000 & 3,000 & 3,000 & 3,000 & 3,000 & 3,000 \\
\hline $1^{\circ}$ Cuartil & 2,000 & 1,000 & 2,000 & 4,000 & 2,000 & 1,000 & 1,000 & 1,000 & 1,000 & 1,000 & 1,000 & 1,000 & 1,000 & 2,000 \\
\hline Mediana & 3,000 & 1,500 & 2,000 & 4,000 & 3,000 & 2,000 & 1,000 & 1,000 & 2,000 & 2,000 & 1,000 & 1,000 & 1,000 & 2,000 \\
\hline $3^{\circ}$ Cuartil & 4,000 & 2,000 & 3,000 & 4,000 & 3,000 & 3,000 & 1,000 & 2,000 & 3,000 & 3,000 & 2,000 & 2,000 & 1,000 & 2,000 \\
\hline Media & 2,821 & 1,748 & 2,500 & 3,878 & 2,634 & 2,351 & 1,111 & 1,653 & 2,061 & 1,847 & 1,584 & 1,550 & 1,279 & 1,858 \\
\hline Varianza $(n)$ & 0,773 & 0,769 & 0,716 & 6,916 & 0,629 & 0,976 & 0,167 & 0,799 & 0,897 & 0,885 & 0,693 & 0,828 & 0,590 & 0,290 \\
\hline Desviación típ & 0,879 & 0,877 & 0,846 & 2,630 & 0,793 & 0,988 & 0,409 & 0,894 & 0,947 & 0,941 & 0,833 & 0,910 & 0,768 & 0,539 \\
\hline Desviación típ & 0,881 & 0,878 & 0,848 & 2,635 & 0,795 & 0,990 & 0,410 & 0,896 & 0,949 & 0,943 & 0,834 & 0,912 & 0,770 & 0,540 \\
\hline
\end{tabular}

Fuente: Propia

Los tres ítems con más valoración son el 1, 4 y 5. Estos ítems, entran dentro de los que se consideran metadatos y que forman parte de la información del programa. El ítem i01 
está referido a los datos de contacto con la dirección y/o equipo de diseño, planificación e implementación; i04 está referido a la especificación de la tipología de proyecto desarrollado; y el ítem i05 a la descripción de las bases, principios y criterios sobre los que se establece el programa.

Como podemos ver en la figura 6, el rango intercuartílico (Q1-Q3) se sitúa entre 3,5 y 4 en el ítem 4, y entre 2,5 y 3 en los ítems 1 y 5 . Por lo tanto, la mayor parte de estos programas alcanzaron el nivel de calidad exigido en estos ítems de identificación.

Figura 6. Box-plot de i01contacto, i04 tipología e i05 bases.

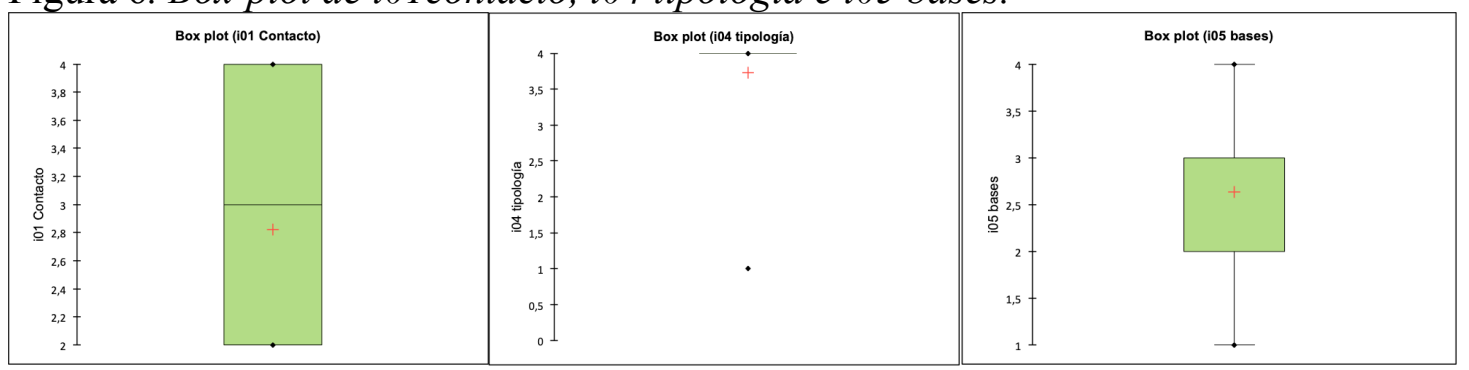

Fuente: Propia

Los tres ítems con menor valoración son el 7, 12 y 13. El primero de ellos forma parte como los anteriores, de los ítems de la calidad de la información de los programas, i07 incorporación de anexos documentales; y los dos últimos pertenecen al grupos de ítems del grado de concreción del diseño educativo, i012 definición de recursos formatos, soportes y tecnologías empleados, e i013 determinación de los sistemas o herramientas de evaluación.

Como podemos apreciar en la figura 7, los rangos intercuartílicos de la valoración de estos programas se sitúan todos entre 1 y 2 , en el caso de los ítems i07 e i13 por debajo de $1,5 \mathrm{y}$ en el de 112 ligeramente por encima de 1,5. En este caso estas puntuaciones nos informan de que, la mayor parte de estos programas no cumplieron con los criterios de calidad o lo hicieron con condiciones.

Señalamos así mismo, que todos los ítems correspondientes a la concreción del diseño educativo, aquellos que se sitúan entre el 8 y el 14 (justificación, objetivos, contenidos, orientaciones, recursos, evaluación y medición), tiene una media inferior a 2 (con la excepción no significativa por su puntuación del número $9, \mathrm{x}=2,061$ ) y una media de 2 o 1 . A tenor de los resultados entendemos que muy pocos cumplen con los criterios de calidad exigibles en su diseño didáctico.

Figura 7. Box-plot de i07anexos, i12 recursos e i13 evaluación.

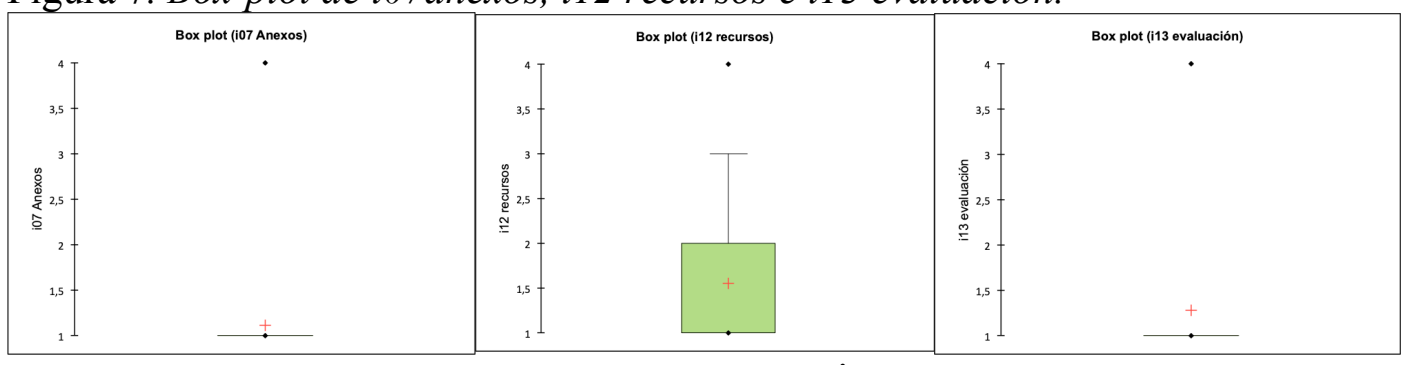

Fuente: Propia 


\subsection{Análisis de correlaciones.}

Tabla 26. Matriz de correlaciones de Pearson.

\begin{tabular}{|c|c|c|c|c|c|c|c|c|c|c|c|c|c|c|}
\hline Variables & i01 Contacto & $\begin{array}{c}\text { i02 } \\
\text { descriptores }\end{array}$ & $\begin{array}{c}\text { i03 } \\
\text { patrimonio }\end{array}$ & i04 tipología & i05 bases & io6publico & i07 Anexos & $\begin{array}{c}\text { i08 } \\
\text { justificacion }\end{array}$ & i09 obj & i10 cont & i11 orienta & i12 recursos & $\begin{array}{c}13 \\
\text { evaluación }\end{array}$ & i14 medición \\
\hline i01 Contacto & 1 & $-0,064$ & 0,049 & $-0,041$ & 0,075 & 0,121 & 0,002 & 0,149 & 0,219 & 0,115 & 0,044 & 0,138 & 0,108 & 0,278 \\
\hline i02 descriptor & $-0,064$ & 1 & 0,751 & $-0,025$ & $-0,067$ & 0,195 & 0,131 & 0,142 & 0,014 & 0,009 & 0,071 & $-0,023$ & 0,110 & 0,062 \\
\hline i03 patrimonis & 0,049 & 0,751 & 1 & $-0,072$ & 0,114 & 0,119 & 0,105 & 0,109 & $-0,033$ & $-0,005$ & $-0,068$ & $-0,104$ & 0,126 & 0,147 \\
\hline i04 tipología & $-0,041$ & $-0,025$ & $-0,072$ & 1 & 0,010 & 0,003 & 0,013 & $-0,025$ & $-0,058$ & $-0,078$ & 0,024 & 0,006 & 0,017 & $-0,064$ \\
\hline 105 bases & 0,075 & $-0,067$ & 0,114 & 0,010 & 1 & $-0,148$ & $-0,110$ & $-0,142$ & $-0,097$ & $-0,147$ & $-0,225$ & $-0,266$ & 0,030 & 0,175 \\
\hline i06publico & 0,121 & 0,195 & 0,119 & 0,003 & $-0,148$ & 1 & 0,178 & 0,225 & 0,157 & 0,115 & 0,303 & 0,206 & 0,193 & 0,051 \\
\hline i07 Anexos & 0,002 & 0,131 & 0,105 & 0,013 & $-0,110$ & 0,178 & 1 & 0,063 & 0,101 & 0,113 & 0,046 & 0,072 & 0,035 & 0,019 \\
\hline i08 justificacic & 0,149 & 0,142 & 0,109 & $-0,025$ & $-0,142$ & 0,225 & 0,063 & 1 & 0,422 & 0,318 & 0,339 & 0,277 & 0,263 & 0,034 \\
\hline i09 obj & 0,219 & 0,014 & $-0,033$ & $-0,058$ & $-0,097$ & 0,157 & 0,101 & 0,422 & 1 & 0,370 & 0,386 & 0,240 & 0,270 & 0,071 \\
\hline i10 cont & 0,115 & 0,009 & $-0,005$ & $-0,078$ & $-0,147$ & 0,115 & 0,113 & 0,318 & 0,370 & 1 & 0,270 & 0,281 & 0,291 & $-0,064$ \\
\hline i11 orienta & 0,044 & 0,071 & $-0,068$ & 0,024 & $-0,225$ & 0,303 & 0,046 & 0,339 & 0,386 & 0,270 & 1 & 0,357 & 0,306 & $-0,088$ \\
\hline i12 recursos & 0,138 & $-0,023$ & $-0,104$ & 0,006 & $-0,266$ & 0,206 & 0,072 & 0,277 & 0,240 & 0,281 & 0,357 & 1 & 0,180 & $-0,192$ \\
\hline ¡13 evaluaciór & 0,108 & 0,110 & 0,126 & 0,017 & 0,030 & 0,193 & 0,035 & 0,263 & 0,270 & 0,291 & 0,306 & 0,180 & 1 & $-0,024$ \\
\hline ¡14 medición & 0,278 & 0,062 & 0,147 & $-0,064$ & 0,175 & 0,051 & 0,019 & 0,034 & 0,071 & $-0,064$ & $-0,088$ & $-0,192$ & 024 & 1 \\
\hline
\end{tabular}

Fuente: Propia

Tabla 27. Valores p de la tabla de correlación de Pearson.

\begin{tabular}{|c|c|c|c|c|c|c|c|c|c|c|c|c|c|c|}
\hline Variables & i01 Contacto & $\begin{array}{c}\text { i02 } \\
\text { descriptores }\end{array}$ & $\begin{array}{c}103 \\
\text { patrimonio }\end{array}$ & i04 tipología & i05 bases & i06publico & i07 Anexos & $\begin{array}{c}\text { i08 } \\
\text { justificacion }\end{array}$ & i09 obj & ¡10 cont & i11 orienta & i12 recursos & $\begin{array}{c}\text { i13 } \\
\text { evaluación }\end{array}$ & i14 medición \\
\hline i01 Contacto & 0 & 0,305 & 0,432 & 0,510 & 0,224 & 0,051 & 0,972 & 0,016 & 0,000 & 0,064 & 0,478 & 0,026 & 0,081 & $<0,0001$ \\
\hline i02 descriptor & 0,305 & 0 & $<0,0001$ & 0,688 & 0,281 & 0,002 & 0,034 & 0,022 & 0,822 & 0,886 & 0,253 & 0,716 & 0,076 & 0,318 \\
\hline i03 patrimonis & 0,432 & $<0,0001$ & 0 & 0,245 & 0,066 & 0,055 & 0,090 & 0,080 & 0,591 & 0,938 & 0,275 & 0,093 & 0,041 & 0,017 \\
\hline i04 tipología & 0,510 & 0,688 & 0,245 & 0 & 0,876 & 0,958 & 0,839 & 0,693 & 0,347 & 0,205 & 0,701 & 0,927 & 0,786 & 0,306 \\
\hline i05 bases & 0,224 & 0,281 & 0,066 & 0,876 & 0 & 0,017 & 0,075 & 0,022 & 0,116 & 0,018 & 0,000 & $<0,0001$ & 0,632 & 0,005 \\
\hline io6publico & 0,051 & 0,002 & 0,055 & 0,958 & 0,017 & 0 & 0,004 & 0,000 & 0,011 & 0,063 & $<0,0001$ & 0,001 & 0,002 & 0,415 \\
\hline io7 Anexos & 0,972 & 0,034 & 0,090 & 0,839 & 0,075 & 0,004 & 0 & 0,306 & 0,103 & 0,067 & 0,463 & 0,242 & 0,568 & 0,756 \\
\hline i08 justificacic & 0,016 & 0,022 & 0,080 & 0,693 & 0,022 & 0,000 & 0,306 & 0 & $<0,0001$ & $<0,0001$ & $<0,0001$ & $<0,0001$ & $<0,0001$ & 0,587 \\
\hline i09 obj & 0,000 & 0,822 & 0,591 & 0,347 & 0,116 & 0,011 & 0,103 & $<0,0001$ & 0 & $<0,0001$ & $<0,0001$ & $<0,0001$ & $<0,0001$ & 0,255 \\
\hline i10 cont & 0,064 & 0,886 & 0,938 & 0,205 & 0,018 & 0,063 & 0,067 & $<0,0001$ & $<0,0001$ & 0 & $<0,0001$ & $<0,0001$ & $<0,0001$ & 0,299 \\
\hline i11 orienta & 0,478 & 0,253 & 0,275 & 0,701 & 0,000 & $<0,0001$ & 0,463 & $<0,0001$ & $<0,0001$ & $<0,0001$ & 0 & $<0,0001$ & $<0,0001$ & 0,156 \\
\hline i12 recursos & 0,026 & 0,716 & 0,093 & 0,927 & $<0,0001$ & 0,001 & 0,242 & $<0,0001$ & $<0,0001$ & $<0,0001$ & $<0,0001$ & 0 & 0,004 & 0,002 \\
\hline i13 evaluaciór & 0,081 & 0,076 & 0,041 & 0,786 & 0,632 & 0,002 & 0,568 & $<0,0001$ & $<0,0001$ & $<0,0001$ & $<0,0001$ & 0,004 & 0 & 0,693 \\
\hline 4 medición & $<0,0001$ & 0,318 & 0,017 & 0,306 & 0,005 & 0,415 & 0,756 & 0,587 & 0,255 & 0,299 & 0,156 & 0,002 & 0,693 & 0 \\
\hline
\end{tabular}

Fuente: Propia

Los coeficientes de correlación de Pearson estadísticamente significativos, es decir que se pueden considerar distintos a 0 , aparecen en negrita en la tabla 26. Son aquellos que, tras realizar un adecuado contraste de hipótesis, presentan un valor $\mathrm{p}$ correspondiente, una probabilidad de ser iguales a 0 , menor que $0,05(\mathrm{p}<0,05)$. Los valores $\mathrm{p}$ están recogidos en la tabla 27 donde podemos apreciar en negrita aquellos que son menores que 0,05 .

El menor valor, despreciando el signo, del coeficiente de correlación para ser considerado estadísticamente significativo es de 0,126 , hallado entre las variables i03 e i13. Resulta entendible que, a la hora de enunciar los descriptores de un programa no se haga excesivo hincapié en las herramientas de evaluación, ya que es un elemento muy concreto del mismo que tiene una mejor cabida en la descripción del diseño educativo.

El mayor coeficiente de correlación es de 0,751 entre las variables i02 e i03. En este caso, parece claro que son dos variables afines dedicadas ambas a plasmar a grandes rasgos la temática del programa, describiendo sus objetivos y el tipo de patrimonio que trabajan, por lo que parece entendible que tenga puntuaciones similares.

Al analizar las variables distintas, encontramos que 39 de las 91 parejas posibles presentan correlaciones significativas, lo que supone el $42,86 \%$ del total. De estas 39 , 33 presentan un coeficiente de correlación positivo, indicador de una correlación directa, lo que representa un porcentaje del $84,61 \%$ sobre las 39 correlaciones significativas y $36,26 \%$ sobre el total. Así mismo, 6 presentan un coeficiente de correlación negativo, indicador de una correlación indirecta, lo que se plasma numéricamente en un 5,38\% de las 39 correlaciones citadas y un 6,59\% sobre el total.

Esta información se resume en la figura 8 . En verde encontramos aquellas correlaciones que son directas y en rojo las indirectas. A mayor intensidad de color, mayor correlación. El negro indica que no hay correlación significativa. 
Teniendo en cuenta el cifrado de colores, observamos que hay una uniformidad destacable entre las variables i09, i10, i11, i12 e i13, creando un cuadrado amplio que da una idea clara de la relación entre estas variables, todas ellas pertenecientes a la concreción y descripción del diseño educativo de los programas.

Figura 8. Imágenes de la matriz de correlación y correlogramas.



Fuente: Propia

\subsection{Análisis inferencial (ANOVA).}

Para los análisis de varianza hemos seleccionado los ítems sobre el grado de concreción del diseño educativo (i08-i14), (despreciando el ítem i08 justificación del proyecto) debido a que, además de circunscribirse de manera más clara al interés de la investigación, presentan en conjunto unos altos coeficientes de correlación tal y como acabamos de comentar y se evidencia en el matriz de correlación (figura 8) y en las correlaciones de Pearson de las tablas 26 y 27.

Compararemos las seis variables de resultado que acabamos de referir con cada una de las seis variables sociodemográficas.

Todos los datos estadísticos obtenidos pueden consultarse en los anexos de la investigación. Para nuestro objeto de estudio, nos centraremos en los análisis de varianza, las medias y las diferencias entre categorías.

\subsubsection{ANOVA-Búsquedas. (V0)}

Los criterios de búsqueda nos determinaron tres categorías: categoría 1 para los programas que incluyen elementos emocionales, categoría 2 para los programas que tienen en cuenta elementos creativos y finalmente categoría 3 para aquellos que toman en consideración ambos aspectos. Los valores porcentuales de cada resultado sobre el total de las búsquedas, ya han sido referidos anteriormente.

\subsubsection{Análisis de la variable i09.(V0). Descripción de los objetivos a lograr en el desarrollo de programas.}

Realizamos el análisis sobre si existen diferencias significativas en la descripción de los objetivos de los programas con respecto las tres categorías que incluyen: emociones, creatividad y ambas. 
Tabla 28. Análisis de varianza (i09) (V0).

\begin{tabular}{llllll}
\hline Fuente & GL & $\begin{array}{l}\text { Suma de Cuadrados } \\
\text { cuadrados }\end{array}$ & medios & F & Pr F \\
\hline Modelo & 2 & 5,394 & 2,697 & 3,042 & $\mathbf{0 , 0 4 9}$ \\
$\begin{array}{l}\text { Error } \\
\text { Total }\end{array}$ & 259 & 229,629 & 0,887 & & \\
corregido & 261 & 235,023 & & \\
\hline \multicolumn{5}{c}{ Fuente: Propia }
\end{tabular}

Dado el valor $\mathrm{p}$ asociado al estadístico $\mathrm{F}$ calculado en la tabla ANOVA, y dado el nivel de significación del $5 \%$, existen diferencias estadísticamente significativas en la variable i09.

Figura 9. Gráfico de medias. (i09)(V0)

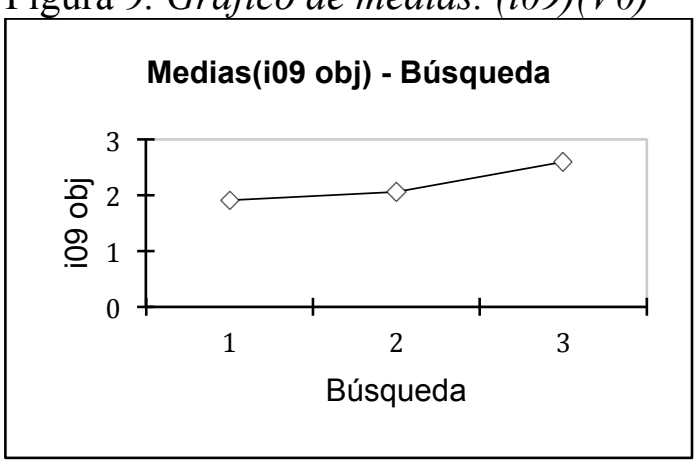

Fuente: Propia

Tabla 29. Análisis de diferencias entre las categorías (i09) (V0)

\begin{tabular}{lllllll}
\hline Categoría & Medias LS & $\begin{array}{l}\text { Error } \\
\text { estándar }\end{array}$ & $\begin{array}{l}\text { Límite } \\
\text { inferior } \\
(95 \%)\end{array}$ & $\begin{array}{l}\text { Límite } \\
\text { superior } \\
(95 \%)\end{array}$ & Grupos & \\
\hline 3 & 2,600 & 0,243 & 2,121 & 3,079 & $\mathrm{~A}$ & \\
2 & 2,054 & 0,066 & 1,924 & 2,183 & $\mathrm{~A}$ & $\mathrm{~B}$ \\
1 & 1,905 & 0,145 & 1,619 & 2,191 & & $\mathrm{~B}$ \\
\hline
\end{tabular}

Fuente: Propia

Tabla 30. Búsquedas / Tukey (HSD) / Análisis de las diferencias entre las categorías con un intervalo de confianza de $95 \%$ (i09 obj)(V0)

\begin{tabular}{llllll}
\hline Contraste & Diferencia & $\begin{array}{l}\text { Diferencia } \\
\text { estandarizada }\end{array}$ & $\begin{array}{l}\text { Valor } \\
\text { crítico }\end{array}$ & Pr $>$ Dif & Significativo \\
\hline 3 vs 1 & 0,695 & 2,455 & 2,357 & $\mathbf{0 , 0 3 9}$ & Sí \\
3 vs 2 & 0,546 & 2,169 & 2,357 & 0,078 & No \\
2 vs 1 & 0,149 & 0,934 & 2,357 & 0,620 & No \\
\hline
\end{tabular}

Valor crítico del d de

Tukey:

3,334

Fuente: Propia

Como podemos apreciar en el gráfico de medias y la tabla de diferencias de medias, la categoría 3 tiene una media significativamente mayor que la categoría 1. Así mismo, también podemos observar que su media está por encima de la categoría 2. La categoría de proyectos que tienen en cuenta tanto emociones como creatividad (categoría 
3),resulta significativa con respecto a los que solo contienen elementos emocionales (categoría 1).

Al contrastar los pares, vemos que 3 vs 1 resulta estadísticamente significativo $(p=0,039)$. Señalamos así mismo, que el contraste de la categoría 3 vs 2 ,pese a no resultar significativo, presenta unos valores cercanos a $0,05(p=0,078)$. En cambio los valores de comparativa de las categorías 2 vs 1 se presentan muy lejanos a 0,05 $(\mathrm{p}=0,620)$.

La media más alta de la categoría 3, y por tanto su significatividad en Tukey, podría ser debida a que en la descripción de objetivos de los programas que contienen dos elementos (creatividad y emociones), se desglose un mayor número de objetivos al acometer los de cada elemento tomado por separado, y también al hacerlo de forma conjunta. Por ello, quizá la amplitud temática exija un grado de concreción mayor que pudiera traducirse en la significatividad encontrada.

\subsubsection{Análisis de la variable i10 (V0) Presentación de contenidos abordados en el programa.}

Realizamos el análisis de la valoración de los contenidos de los programas con respecto a las tres categoría de la variable de búsquedas.

Tabla 31. Análisis de varianza (i10) (V0)

\begin{tabular}{llllll}
\hline Fuente & GL & $\begin{array}{l}\text { Suma de Cuadrados } \\
\text { cuadrados }\end{array}$ & F & Pr $>$ F \\
\hline $\begin{array}{l}\text { Modelo } \\
\text { Error }\end{array}$ & 2 & 5,279 & 2,639 & 3,017 & 0,051 \\
$\begin{array}{l}\text { Total } \\
\text { corregido }\end{array}$ & 259 & 226,614 & 0,875 & & \\
\hline
\end{tabular}

Fuente: Propia

Los resultados indican que no existen diferencias estadísticamente significativas $[F(2,261)=3,017 ; \mathrm{p}=0,051]$ a la hora de comparar las medias de las tres categorías.

\subsubsection{Análisis de la variable i11.(V0) Orientación metodológica y estrategias de enseñanza aprendizaje.}

Analizamos ahora la calidad de los programas, en cuanto a la descripción de sus metodologías y las estrategias utilizadas para la enseñanza aprendizaje, estudiando las medias con respecto a las tres categorías citadas.

Tabla 32. Análisis de varianza (i11)(V0)

\begin{tabular}{|c|c|c|c|c|c|}
\hline Fuente & GL & $\begin{array}{l}\text { Suma de } \\
\text { cuadrados }\end{array}$ & $\begin{array}{l}\text { Cuadrados } \\
\text { medios }\end{array}$ & $\mathrm{F}$ & $\operatorname{Pr}>F$ \\
\hline Modelo & 2 & 8,939 & 4,469 & 6,702 & 0,001 \\
\hline Error & 259 & 172,714 & 0,667 & & \\
\hline $\begin{array}{l}\text { Total } \\
\text { corregido }\end{array}$ & 261 & 181,653 & & & \\
\hline
\end{tabular}

Fuente: Propia 
Dado el valor $\mathrm{p}$ asociado al estadístico $\mathrm{F}$ calculado en la tabla ANOVA, y dado el nivel de significación del 5\%, existen diferencias estadísticamente significativas en la variable i11.

Figura 10. Gráfico de medias. (i11)(V0)



Fuente: Propia

Tabla 33. Análisis de diferencias entre las categorías(V0).

\begin{tabular}{lllllll}
\hline Categoría & Medias LS & $\begin{array}{l}\text { Error } \\
\text { estándar }\end{array}$ & $\begin{array}{l}\text { Límite } \\
\text { inferior } \\
(95 \%)\end{array}$ & $\begin{array}{l}\text { Límite } \\
\text { superior } \\
(95 \%)\end{array}$ & Grupos & \\
\hline 3 & 2,333 & 0,211 & 1,918 & 2,749 & A & B \\
1 & 1,548 & 0,126 & 1,299 & 1,796 & & B \\
2 & 1,537 & 0,057 & 1,424 & 1,649 & & B \\
\hline
\end{tabular}

Fuente: Propia

Tabla 34. Búsquedas / Tukey (HSD) / Análisis de las diferencias entre las categorías con un intervalo de confianza de 95\% (ill orienta)(V0).

\begin{tabular}{llllll}
\hline Contraste & Diferencia & $\begin{array}{l}\text { Diferencia } \\
\text { estandarizada }\end{array}$ & $\begin{array}{l}\text { Valor } \\
\text { crítico }\end{array}$ & $\operatorname{Pr}>$ Dif & Significativo \\
\hline 3 vs 2 & 0,797 & 3,648 & 2,357 & $\mathbf{0 , 0 0 1}$ & Sí \\
3 vs 1 & 0,786 & 3,199 & 2,357 & $\mathbf{0 , 0 0 4}$ & Sí \\
1 vs 2 & 0,011 & 0,080 & 2,357 & 0,996 & No \\
\hline \multicolumn{7}{l}{ Valor crítico del d de Tukey: } & 3,334 & &
\end{tabular}

Fuente: Propia

La categoría tres, programas con elementos emocionales y creativos, presenta una media superior $(2,333)$ a las categorías uno y dos que presentan medias muy similares.

Resultan estadísticamente significativos los contrastes 3 vs $2(0,001)$ y 3 vs $1(0,004)$, nuevamente al comparar la categoría tres con las otras dos categorías resultan significativos estos pares, por lo que esta categoría presenta diferencias con respecto a la orientación metodológica y las estrategias de enseñanza aprendizaje.

\subsubsection{Análisis de la variable i12 (V0). Definición de recursos, formatos, soportes, y tecnología empleados}

Estudiamos a continuación la calidad de los programas en la exposición de los recursos que emplean, así como los soportes en que se encuentran éstos comparándolos con las temáticas emocionales, creativas y ambas a la vez. 
Tabla 35. Análisis de varianza (i12).(V0)

\begin{tabular}{|c|c|c|c|c|c|}
\hline Fuente & GL & $\begin{array}{l}\text { Suma de } \\
\text { cuadrados }\end{array}$ & $\begin{array}{l}\text { Cuadrados } \\
\text { medios }\end{array}$ & $\mathrm{F}$ & $\operatorname{Pr}>F$ \\
\hline Modelo & 2 & 4,297 & 2,149 & 2,618 & 0,075 \\
\hline Error & 259 & 212,558 & 0,821 & & \\
\hline $\begin{array}{l}\text { Total } \\
\text { corregido }\end{array}$ & 261 & 216,855 & & & \\
\hline
\end{tabular}

Fuente: Propia

Los resultados indican que no existen diferencias estadísticamente significativas $[\mathrm{F}(2,261)=2,618 ; \mathrm{p}=0,075]$ a la hora de comparar las medias de las tres categorías.

\subsubsection{Análisis de la variable i13(V0). Determinación de los sistemas o herramientas de evaluación.}

Abordamos seguidamente el análisis de las herramientas de evaluación que utilizan los programas que contienen alguna de las tres categorías estudiadas.

Tabla 36. Análisis de varianza (i13)(V0)

\begin{tabular}{llllll}
\hline Fuente & GL & \multicolumn{2}{c}{$\begin{array}{l}\text { Suma de Cuadrados } \\
\text { cuadrados }\end{array}$} & medios & Pr $>$ F \\
\hline Modelo & 2 & 8,556 & 4,278 & 7,583 & $\mathbf{0 , 0 0 1}$ \\
$\begin{array}{l}\text { Error } \\
\text { Total } \\
\text { corregido }\end{array}$ & 259 & 146,105 & 0,564 & & \\
\hline
\end{tabular}

Fuente: Propia

Dado el valor $\mathrm{p}$ asociado al estadístico $\mathrm{F}$ calculado en la tabla ANOVA, y dado el nivel de significación del 5\%, existen diferencias estadísticamente significativas en la variable i13.

Figura 11. Gráfico de medias. (i13)(V0)

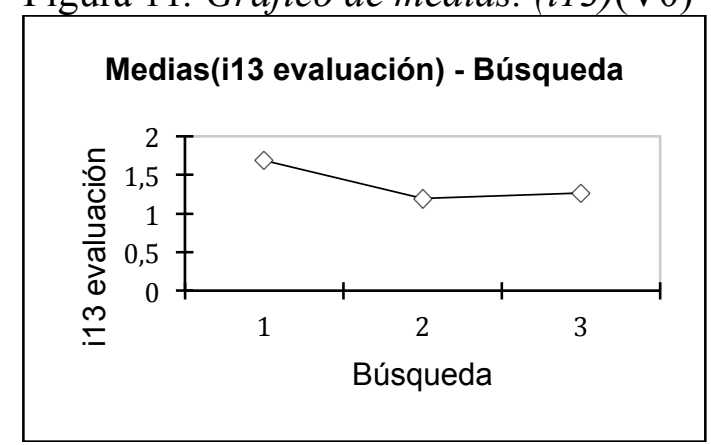

Fuente: Propia

Tabla 37. Análisis de diferencias entre las categorías(V0)

\begin{tabular}{lllllll}
\hline Categoría & Medias LS & $\begin{array}{l}\text { Error } \\
\text { estándar }\end{array}$ & $\begin{array}{l}\text { Límite } \\
\text { inferior } \\
(95 \%)\end{array}$ & $\begin{array}{l}\text { Límite } \\
\text { superior } \\
(95 \%)\end{array}$ & Grupos & \\
\hline 1 & 1,690 & 0,116 & 1,462 & 1,919 & A & \\
3 & 1,267 & 0,194 & 0,885 & 1,649 & A & B
\end{tabular}


Fuente: Propia

Tabla 38. Búsquedas / Tukey (HSD) / Análisis de las diferencias entre las categorías con un intervalo de confianza de 95\% (i13 evaluación)(V0)

\begin{tabular}{llllll}
\hline Contraste & Diferencia & $\begin{array}{l}\text { Diferencia } \\
\text { estandarizada }\end{array}$ & $\begin{array}{l}\text { Valor } \\
\text { crítico }\end{array}$ & Pr $>$ Dif & Significativo \\
\hline 1 vs 2 & 0,495 & 3,894 & 2,357 & $\mathbf{0 , 0 0 0}$ & Sí \\
1 vs 3 & 0,424 & 1,876 & 2,357 & 0,148 & No \\
3 vs 2 & 0,072 & 0,356 & 2,357 & 0,933 & No \\
\hline
\end{tabular}

Valor crítico del d de Tukey:

3,334

Fuente: Propia

La categoría uno $(1,690)$ presenta una media mayor que las categorías dos $(1,195)$ y tres $(1,267)$.

Observamos que el contrate 1 vs 2 tiene una media significativamente mayor $(p=0,00)$ que los otros dos pares examinados.

Entendemos que las herramientas de evaluación tienen un diseño específico enfocado a comprobar individualmente la consecución de cada objetivo por separado. Esto puede resultar un hándicap para programas que atienden a más de un criterio de evaluación (categoría tres),complicando la metodología evaluativa.

\subsubsection{Análisis de la variable i14(V0). Medición del impacto y repercusión de la propuesta.}

Finalmente observamos la comparativa de medias de las medición de las repercusiones de los programas con las tres categorías a estudio en la variable de búsquedas (V0).

Tabla 39. Análisis de varianza (i14)(V0)

\begin{tabular}{llllll}
\hline Fuente & GL & \multicolumn{2}{l}{$\begin{array}{l}\text { Suma de Cuadrados } \\
\text { cuadrados }\end{array}$} & medios & Pr $>$ F \\
\hline Modelo & 2 & 0,040 & 0,020 & 0,069 & 0,934 \\
\hline & & & & & \\
$\begin{array}{l}\text { Error } \\
\begin{array}{l}\text { Total } \\
\text { corregido }\end{array}\end{array}$ & 259 & 75,715 & 0,292 & & \\
\hline
\end{tabular}

Fuente: Propia

Los resultados indican que no existen diferencias estadísticamente significativas $[\mathrm{F}(2,261)=0,069 ; \mathrm{p}=0,934]$ a la hora de comparar las medias de las tres categorías.

\subsubsection{ANOVA - Público/privado (V1).}

Nos adentramos ahora en el análisis de los tipos de organismos que promueven los programas extraídos de OEPE. Nos surgen así tres categorías: programas que provienen de organismos públicos, programas fomentados por organismos privados y programas que tienen organización mixta publica-privada. 


\subsubsection{Análisis de la variable i09 (V1). Descripción de los objetivos a lograr en el desarrollo de programas.}

Analizamos si existen diferencias significativas en la descripción de los objetivos de los programas con respecto a la promoción pública, privada o mixta de los mismos.

Tabla 40. Análisis de varianza (i09) (V1)

\begin{tabular}{|c|c|c|c|c|c|}
\hline Fuente & GL & $\begin{array}{l}\text { Suma de } \\
\text { cuadrados }\end{array}$ & $\begin{array}{l}\text { Cuadrados } \\
\text { medios }\end{array}$ & $\mathrm{F}$ & $\operatorname{Pr}>F$ \\
\hline Modelo & 2 & 10,135 & 5,068 & 5,836 & 0,003 \\
\hline Error & 259 & 224,888 & 0,868 & & \\
\hline $\begin{array}{l}\text { Total } \\
\text { corregido }\end{array}$ & 261 & 235,023 & & & \\
\hline
\end{tabular}

Fuente: Propia

Dado el valor $\mathrm{p}$ asociado al estadístico $\mathrm{F}$ calculado en la tabla ANOVA, y dado el nivel de significación del 5\%, existen diferencias estadísticamente significativas en la variable i09.

Figura 12. Gráfico de medias. (i09) (V1)

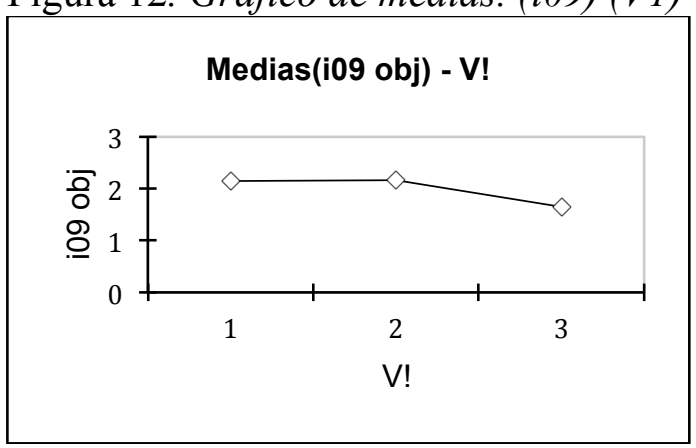

Fuente: Propia

Tabla 41. Análisis de diferencias entre las categorías (V1)

\begin{tabular}{lllllll}
\hline Categoría & Medias LS & $\begin{array}{l}\text { Error } \\
\text { estándar }\end{array}$ & $\begin{array}{l}\text { Límite } \\
\text { inferior } \\
(95 \%)\end{array}$ & $\begin{array}{l}\text { Límite } \\
\text { superior } \\
(95 \%)\end{array}$ & Grupos & \\
\hline 2 & 2,162 & 0,153 & 1,861 & 2,464 & A & \\
1 & 2,153 & 0,070 & 2,015 & 2,290 & A & B \\
3 & 1,646 & 0,134 & 1,381 & 1,911 & & B \\
\hline
\end{tabular}

Fuente: Propia

Tabla 42. (Público- privado / Tukey (HSD) / Análisis de las diferencias entre las categorías con un intervalo de confianza de 95\% (i09 obj) (V1)

\begin{tabular}{llllll}
\hline Contraste & Diferencia & $\begin{array}{l}\text { Diferencia } \\
\text { estandarizada }\end{array}$ & $\begin{array}{l}\text { Valor } \\
\text { crítico }\end{array}$ & Pr $>$ Dif & Significativo \\
\hline 2 vs 3 & 0,516 & 2,533 & 2,357 & $\mathbf{0 , 0 3 2}$ & Sí \\
2 vs 1 & 0,010 & 0,057 & 2,357 & 0,998 & No \\
1 vs 3 & 0,507 & 3,342 & 2,357 & $\mathbf{0 , 0 0 3}$ & Sí \\
\hline
\end{tabular}


Como podemos apreciar en el gráfico de medias (Figura 12), las categorías uno $(2,153)$ y dos $(2,162)$ poseen medias significativamente mayores que las de la categoría tres $(1,646)$. A su vez, observamos que las categorías uno y dos poseen una media similar.

Al analizar los contrastes (Tabla 48), vemos que los pares 2 vs 3 , y 1 vs 3 son estadísticamente significativos, $\mathrm{p}=0,032$ para el primero y $\mathrm{p}=0,003$ para el segundo de ellos. Advertimos por tanto, que la comparación de programas con financiación pública y privada (2 vs 1) en cuanto a sus objetivos, no presentan diferencias significativas, y en cambio si lo hace con respecto a los programas con financiación mixta.

\subsubsection{Análisis de la variable i10(V1). Presentación de contenidos abordados en el programa.}

Analizamos los contenidos de los programas atendiendo a la institución que los promueve.

Tabla 43. Análisis de varianza (i10) (V1)

\begin{tabular}{llllll}
\hline \multirow{2}{*}{ Fuente } & \multirow{2}{*}{ GL } & $\begin{array}{l}\text { Suma de } \\
\text { cuadrados }\end{array}$ & medios & F & Pr $>$ F \\
\hline $\begin{array}{l}\text { Modelo } \\
\text { Error }\end{array}$ & 2 & 0,580 & 0,290 & 0,325 & 0,723 \\
$\begin{array}{l}\text { Total } \\
\text { corregido }\end{array}$ & 259 & 231,313 & 0,893 & & \\
\hline
\end{tabular}

Fuente: Propia

Los resultados indican que no existen diferencias estadísticamente significativas $[\mathrm{F}(2,261)=0,325 ; \mathrm{p}=0,723]$ a la hora de comparar las medias de las categorías.

\subsubsection{Análisis de la variable i11(V1). Orientación metodológica y estrategias de enseñanza aprendizaje.}

Revisamos los resultados estadísticos de metodología y estrategias de enseñanza aprendizaje con respecto al tipo de entidad que promueve los programas

Tabla 44. Análisis de varianza (i11) (V1)

\begin{tabular}{llllll}
\hline Fuente & GL & \multicolumn{2}{c}{$\begin{array}{l}\text { Suma de Cuadrados } \\
\text { cuadrados }\end{array}$} & medios & Fr $>$ F \\
\hline Modelo & 2 & 0,365 & 0,182 & 0,261 & 0,771 \\
$\begin{array}{l}\text { Error } \\
\text { Total }\end{array}$ & 259 & 181,288 & 0,700 & & \\
corregido & 261 & 181,653 & & & \\
\hline
\end{tabular}

Fuente: Propia

Los resultados indican que no existen diferencias estadísticamente significativas $[\mathrm{F}(2,261)=0,261 ; \mathrm{p}=0,771]$ a la hora de comparar las medias de las categorías.

5.4.2.4. Análisis de la variable i12(V1). Definición de recursos, formatos, soportes, y tecnología empleados. 
Comparamos las medias de la concreción de recursos de los programas con respecto a las entidades que los financian.

Tabla 45. Análisis de varianza (i12) (V1)

\begin{tabular}{|c|c|c|c|c|c|}
\hline Fuente & GL & $\begin{array}{l}\text { Suma de } \\
\text { cuadrados }\end{array}$ & $\begin{array}{l}\text { Cuadrados } \\
\text { medios }\end{array}$ & $\mathrm{F}$ & $\operatorname{Pr}>F$ \\
\hline Modelo & 2 & 4,501 & 2,251 & 2,745 & 0,066 \\
\hline Error & 259 & 212,354 & 0,820 & & \\
\hline $\begin{array}{l}\text { Total } \\
\text { corregido }\end{array}$ & 261 & 216,855 & & & \\
\hline
\end{tabular}

Fuente: Propia

Los resultados indican que no existen diferencias estadísticamente significativas $[F(2,261)=2,745 ; \mathrm{p}=0,066]$ a la hora de comparar las medias de las tres categorías.

\subsubsection{Análisis de la variable i13 (V1).Determinación de los sistemas o herramientas de evaluación.}

Estudiamos la valoración de los instrumentos de evaluación de los programas analizados con respecto a los organismos que los promueven.

Tabla 46. Análisis de varianza (i13) (V1)

\begin{tabular}{llllll}
\hline Fuente & GL & $\begin{array}{l}\text { Suma de Cuadrados } \\
\text { cuadrados }\end{array}$ & medios & F & \multirow{2}{*}{ Pr } \\
\hline Modelo & 2 & 2,345 & 1,173 & 1,994 & 0,138 \\
$\begin{array}{l}\text { Error } \\
\text { Total }\end{array}$ & 259 & 152,315 & 0,588 & & \\
corregido & 261 & 154,660 & & & \\
\hline
\end{tabular}

Fuente: Propia

Los resultados indican que no existen diferencias estadísticamente significativas $[\mathrm{F}(2,261)=1,994 ; \mathrm{p}=0,138]$ a la hora de comparar las medias de las tres categorías.

\subsubsection{Análisis de la variable i14 (V1).Medición del impacto y repercusión de la propuesta}

Repasamos las valoraciones sobre la repercusión de los programas atendiendo al organismo que las impulsa.

Tabla 47. Análisis de varianza (i14) (V1)

\begin{tabular}{llllll}
\hline Fuente & GL & \multicolumn{2}{l}{$\begin{array}{l}\text { Suma de Cuadrados } \\
\text { cuadrados }\end{array}$} & medios & Pr $>$ F \\
\hline Modelo & 2 & 0,713 & 0,356 & 1,230 & 0,294 \\
$\begin{array}{l}\text { Error } \\
\text { Total }\end{array}$ & 259 & 75,042 & 0,290 & & \\
corregido & 261 & 75,755 & & & \\
\hline
\end{tabular}

Fuente: Propia 
Los resultados indican que no existen diferencias estadísticamente significativas $[\mathrm{F}(2,261)=1,230 ; \mathrm{p}=0,294]$ a la hora de comparar las medias de las categorías.

\subsubsection{ANOVA- Categoría de patrimonio (V2).}

Nos adentramos en el análisis de los resultados para la variable sociodemográfica V2 referida a las categorías de patrimonio. Esta variable incluye dieciocho categorías, entre ellas, hay cuatro que no están representadas en los programas seleccionados por lo que no aparecen en los resultados estadísticos, son las correspondientes a construcciones aisladas (categoría 1), construcciones reunidas (categoría 2), inscripciones en cavernas (categoría 7) y grupo de elementos de importancia (categoría 10).

Por tanto, las categorías que se incluyen en el estudio son: 3-lugares arqueológicos, 4lugares especiales, 5-lugares especiales creados por el hombre, 6- lugares especiales creados por el hombre y la naturaleza, 8-monumento obra pictórica, 9- monumento obra arqueológica, 11-monumentos obra arquitectónica, 12-monumento obra escultórica, 13patrimonio cultural, 14-patrimonio digital, 15-patrimonio industrial, 16-patrimonio inmaterial, 17-patrimonio natural y cultural, 18-otros patrimonios.

\subsubsection{Análisis de la variable i09 (V2). Descripción de los objetivos a lograr en el desarrollo de programas.}

Analizamos la existencia de diferencias significativas en las descripciones de los programas de las catorce categorías incluidas en el estudio.

Tabla 48. Análisis de varianza (i09) (V2)

\begin{tabular}{|c|c|c|c|c|c|}
\hline Fuente & GL & $\begin{array}{l}\text { Suma de } \\
\text { cuadrados }\end{array}$ & $\begin{array}{l}\text { Cuadrados } \\
\text { medios }\end{array}$ & $\mathrm{F}$ & $\operatorname{Pr}>F$ \\
\hline Modelo & 13 & 11,594 & 0,892 & 0,990 & 0,462 \\
\hline Error & 248 & 223,429 & 0,901 & & \\
\hline $\begin{array}{l}\text { Total } \\
\text { corregido }\end{array}$ & 261 & 235,023 & & & \\
\hline
\end{tabular}

Fuente: Propia

Los resultados indican que no existen diferencias estadísticamente significativas $[\mathrm{F}(13,261)=0,990 ; \mathrm{p}=0,462]$ a la hora de comparar las medias de las categorías.

\subsubsection{Análisis de la variable i10 (V2). Presentación de contenidos abordados en el programa.}

Escrutamos la variable de resultado que analiza la presentación de los contenidos con respecto a las catorce categorías de la variable sociodemográfica del tipo de patrimonio.

Tabla 49. Análisis de varianza (i10) (V2)

\begin{tabular}{|c|c|c|c|c|c|}
\hline Fuente & GL & $\begin{array}{l}\text { Suma de } \\
\text { cuadrados }\end{array}$ & $\begin{array}{l}\text { Cuadrados } \\
\text { medios }\end{array}$ & $\mathrm{F}$ & $\operatorname{Pr}>F$ \\
\hline Modelo & 13 & 11,412 & 0,878 & 0,987 & 0,464 \\
\hline Error & 248 & 220,481 & 0,889 & & \\
\hline $\begin{array}{l}\text { Total } \\
\text { corregido }\end{array}$ & 261 & 231,893 & & & \\
\hline
\end{tabular}


Los resultados indican que no existen diferencias estadísticamente significativas $[\mathrm{F}(13,261)=0,987 ; \mathrm{p}=0,464]$ a la hora de comparar las medias de las categorías.

\subsubsection{Análisis de la variable i11(V2). Orientación metodológica y estrategias de enseñanza aprendizaje.}

Inspeccionamos seguidamente la metodología y estrategias de enseñanza aprendizaje de las categorías de la variable sociodemográfica del tipo de patrimonio.

Tabla 50. Análisis de varianza (i11) (V2)

\begin{tabular}{|c|c|c|c|c|c|}
\hline Fuente & GL & $\begin{array}{l}\text { Suma de } \\
\text { cuadrados }\end{array}$ & $\begin{array}{l}\text { Cuadrados } \\
\text { medios }\end{array}$ & $F$ & $\operatorname{Pr}>\mathrm{F}$ \\
\hline Modelo & 13 & 11,148 & 0,858 & 1,247 & 0,246 \\
\hline Error & 248 & 170,505 & 0,688 & & \\
\hline $\begin{array}{l}\text { Total } \\
\text { corregido }\end{array}$ & 261 & 181,653 & & & \\
\hline
\end{tabular}

Fuente: Propia

Los resultados indican que no existen diferencias estadísticamente significativas $[\mathrm{F}(13,261)=1,247 ; \mathrm{p}=0,246]$ a la hora de comparar las medias de las categorías.

\subsubsection{Análisis de la variable i12 (V2).Definición de recursos, formatos, soportes, y tecnología empleados}

Estudiamos la valoración de los recursos, los formatos de estos, así como los soportes y tecnologías que se emplean en los programas seleccionados atendiendo a las categorías de la variable sociodemográfica V2.

Tabla 51. Análisis de varianza (i12) (V2)

\begin{tabular}{|c|c|c|c|c|c|}
\hline Fuente & GL & $\begin{array}{l}\text { Suma de } \\
\text { cuadrados }\end{array}$ & $\begin{array}{l}\text { Cuadrados } \\
\text { medios }\end{array}$ & $\mathrm{F}$ & $\operatorname{Pr}>F$ \\
\hline Modelo & 13 & 6,208 & 0,478 & 0,562 & 0,883 \\
\hline Error & 248 & 210,647 & 0,849 & & \\
\hline $\begin{array}{l}\text { Total } \\
\text { corregido }\end{array}$ & 261 & 216,855 & & & \\
\hline
\end{tabular}

Fuente: Propia

Los resultados indican que no existen diferencias estadísticamente significativas $[\mathrm{F}(13,261)=0,562 ; \mathrm{p}=0,883]$ a la hora de comparar las medias de las categorías.

\subsubsection{Análisis de la variable i13 (V2).Determinación de los sistemas o herramientas de evaluación.}

Observamos seguidamente, los resultados de las valoraciones de las herramientas evaluativas descritas en los programas según si estos están fomentados por entidades públicas, privadas o mixtas. 
Tabla 52. Análisis de varianza (i13) (V2)

\begin{tabular}{llllll}
\hline Fuente & GL & $\begin{array}{l}\text { Suma de Cuadrados } \\
\text { cuadrados }\end{array}$ & medios & Pr $>$ F \\
\hline Modelo & 13 & 16,108 & 1,239 & 2,218 & $\mathbf{0 , 0 0 9}$ \\
$\begin{array}{l}\text { Error } \\
\text { Total }\end{array}$ & 248 & 138,552 & 0,559 & & \\
corregido & 261 & 154,660 & & & \\
\hline
\end{tabular}

Fuente: Propia

Dado el valor $\mathrm{p}$ asociado al estadístico $\mathrm{F}$ calculado en la tabla ANOVA, y dado el nivel de significación del $5 \%$, existen diferencias estadísticamente significativas en la variable i13.

Figura 13. Gráfico de medias. (i13) (V2)

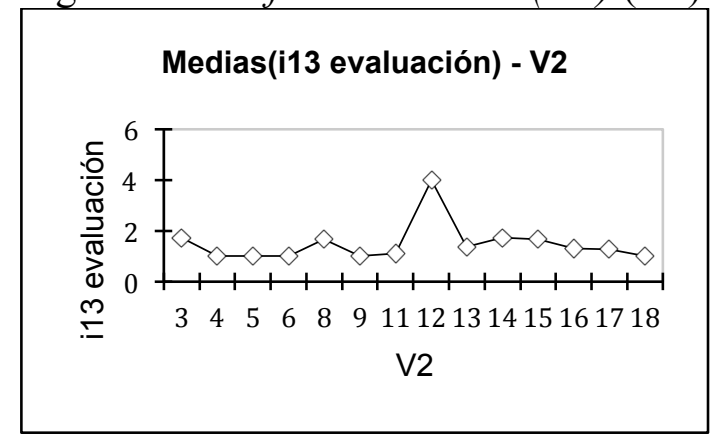

Fuente: Propia

Tabla 53. Análisis de diferencias entre las categorías (V2)

\begin{tabular}{lllllll}
\hline Categoría & Medias LS & $\begin{array}{l}\text { Error } \\
\text { estándar }\end{array}$ & $\begin{array}{l}\text { Límite } \\
\text { inferior } \\
(95 \%)\end{array}$ & $\begin{array}{l}\text { Límite } \\
\text { superior } \\
(95 \%)\end{array}$ & Grupos & \\
\hline 12 & 4,000 & 0,747 & 2,528 & 5,472 & A & \\
3 & 1,750 & 0,374 & 1,014 & 2,486 & & B \\
14 & 1,750 & 0,374 & 1,014 & 2,486 & $\mathrm{~B}$ \\
8 & 1,667 & 0,432 & 0,817 & 2,517 & $\mathrm{~B}$ \\
15 & 1,667 & 0,432 & 0,817 & 2,517 & $\mathrm{~B}$ \\
13 & 1,369 & 0,074 & 1,224 & 1,514 & $\mathrm{~B}$ \\
16 & 1,298 & 0,099 & 1,103 & 1,493 & $\mathrm{~B}$ \\
17 & 1,267 & 0,193 & 0,887 & 1,647 & $\mathrm{~B}$ \\
11 & 1,125 & 0,264 & 0,605 & 1,645 & $\mathrm{~B}$ \\
4 & 1,000 & 0,747 & $-0,472$ & 2,472 & $\mathrm{~B}$ \\
5 & 1,000 & 0,283 & 0,444 & 1,556 & $\mathrm{~B}$ \\
6 & 1,000 & 0,529 & $-0,041$ & 2,041 & $\mathrm{~B}$ \\
9 & 1,000 & 0,334 & 0,342 & 1,658 & $\mathrm{~B}$ \\
18 & 1,000 & 0,107 & 0,790 & 1,210 & \\
\hline
\end{tabular}

Fuente: Propia

Tabla 54.Categoría de patrimonio / Tukey (HSD) / Análisis de las diferencias entre las categorías con un intervalo de confianza de 95\% (i13 evaluación) (V2) 


\begin{tabular}{|c|c|c|c|c|c|}
\hline Contraste & Diferencia & $\begin{array}{l}\text { Diferencia } \\
\text { estandarizada }\end{array}$ & $\begin{array}{l}\text { Valor } \\
\text { crítico }\end{array}$ & $\operatorname{Pr}>$ Dif & Significativo \\
\hline 12 vs 4 & 3,000 & 5,152 & 3,387 & $<0,0001$ & Sí \\
\hline 12 vs 5 & 3,000 & 5,152 & 3,387 & $<0,0001$ & Sí \\
\hline 12 vs 6 & 3,000 & 5,152 & 3,387 & $<0,0001$ & Sí \\
\hline 12 vs 9 & 3,000 & 5,152 & 3,387 & $<0,0001$ & Sí \\
\hline 12 vs 18 & 3,000 & 5,152 & 3,387 & $<0,0001$ & Sí \\
\hline 12 vs 11 & 2,875 & 4,937 & 3,387 & $\mathbf{0 , 0 0 0}$ & Sí \\
\hline 12 vs 17 & 2,733 & 4,694 & 3,387 & $\mathbf{0 , 0 0 0}$ & Sí \\
\hline 12 vs 16 & 2,702 & 4,640 & 3,387 & $\mathbf{0 , 0 0 0}$ & Sí \\
\hline 12 vs 13 & 2,631 & 4,518 & 3,387 & 0,001 & Sí \\
\hline 12 vs 8 & 2,333 & 4,007 & 3,387 & 0,006 & Sí \\
\hline 12 vs 15 & 2,333 & 4,007 & 3,387 & 0,006 & Sí \\
\hline 12 vs 3 & 2,250 & 3,864 & 3,387 & $\mathbf{0 , 0 1 0}$ & Sí \\
\hline 12 vs 14 & 2,250 & 3,864 & 3,387 & 0,010 & Sí \\
\hline 14 vs 4 & 0,750 & 1,288 & 3,387 & 0,991 & No \\
\hline 14 vs 5 & 0,750 & 1,288 & 3,387 & 0,991 & No \\
\hline 14 vs 6 & 0,750 & 1,288 & 3,387 & 0,991 & No \\
\hline 14 vs 9 & 0,750 & 1,288 & 3,387 & 0,991 & No \\
\hline 14 vs 18 & 0,750 & 1,288 & 3,387 & 0,991 & No \\
\hline 14 vs 11 & 0,625 & 1,073 & 3,387 & 0,998 & No \\
\hline 14 vs 17 & 0,483 & 0,830 & 3,387 & 1,000 & No \\
\hline 14 vs 16 & 0,452 & 0,776 & 3,387 & 1,000 & No \\
\hline 14 vs 13 & 0,381 & 0,654 & 3,387 & 1,000 & No \\
\hline 14 vs 8 & 0,083 & 0,143 & 3,387 & 1,000 & No \\
\hline 14 vs 15 & 0,083 & 0,143 & 3,387 & 1,000 & No \\
\hline 14 vs 3 & 0,000 & 0,000 & 3,387 & 1,000 & No \\
\hline 3 vs 4 & 0,750 & 1,288 & 3,387 & 0,991 & No \\
\hline 3 vs 5 & 0,750 & 1,288 & 3,387 & 0,991 & No \\
\hline 3 vs 6 & 0,750 & 1,288 & 3,387 & 0,991 & No \\
\hline 3 vs 9 & 0,750 & 1,288 & 3,387 & 0,991 & No \\
\hline 3 vs 18 & 0,750 & 1,288 & 3,387 & 0,991 & No \\
\hline 3 vs 11 & 0,625 & 1,073 & 3,387 & 0,998 & No \\
\hline 3 vs 17 & 0,483 & 0,830 & 3,387 & 1,000 & No \\
\hline 3 vs 16 & 0,452 & 0,776 & 3,387 & 1,000 & No \\
\hline 3 vs 13 & 0,381 & 0,654 & 3,387 & 1,000 & No \\
\hline 3 vs 8 & 0,083 & 0,143 & 3,387 & 1,000 & No \\
\hline 3 vs 15 & 0,083 & 0,143 & 3,387 & 1,000 & No \\
\hline 15 vs 4 & 0,667 & 1,145 & 3,387 & 0,997 & No \\
\hline 15 vs 5 & 0,667 & 1,145 & 3,387 & 0,997 & No \\
\hline 15 vs 6 & 0,667 & 1,145 & 3,387 & 0,997 & No \\
\hline 15 vs 9 & 0,667 & 1,145 & 3,387 & 0,997 & No \\
\hline 15 vs 18 & 0,667 & 1,145 & 3,387 & 0,997 & No \\
\hline 15 vs 11 & 0,542 & 0,930 & 3,387 & 1,000 & No \\
\hline 15 vs 17 & 0,400 & 0,687 & 3,387 & 1,000 & No \\
\hline 15 vs 16 & 0,368 & 0,633 & 3,387 & 1,000 & No \\
\hline
\end{tabular}




\begin{tabular}{|c|c|c|c|c|}
\hline 15 vs 13 & 0,298 & 0,511 & 3,387 & 1,000 \\
\hline 15 vs 8 & 0,000 & 0,000 & 3,387 & 1,000 \\
\hline 8 vs 4 & 0,667 & 1,145 & 3,387 & 0,997 \\
\hline 8 vs 5 & 0,667 & 1,145 & 3,387 & 0,997 \\
\hline 8 vs 6 & 0,667 & 1,145 & 3,387 & 0,997 \\
\hline 8 vs 9 & 0,667 & 1,145 & 3,387 & 0,997 \\
\hline 8 vs 18 & 0,667 & 1,145 & 3,387 & 0,997 \\
\hline 8 vs 11 & 0,542 & 0,930 & 3,387 & 1,000 \\
\hline 8 vs 17 & 0,400 & 0,687 & 3,387 & 1,000 \\
\hline 8 vs 16 & 0,368 & 0,633 & 3,387 & 1,000 \\
\hline 8 vs 13 & 0,298 & 0,511 & 3,387 & 1,000 \\
\hline 13 vs 4 & 0,369 & 0,634 & 3,387 & 1,000 \\
\hline 13 vs 5 & 0,369 & 0,634 & 3,387 & 1,000 \\
\hline 13 vs 6 & 0,369 & 0,634 & 3,387 & 1,000 \\
\hline 13 vs 9 & 0,369 & 0,634 & 3,387 & 1,000 \\
\hline 13 vs 18 & 0,369 & 0,634 & 3,387 & 1,000 \\
\hline 13 vs 11 & 0,244 & 0,419 & 3,387 & 1,000 \\
\hline 13 vs 17 & 0,102 & 0,176 & 3,387 & 1,000 \\
\hline 13 vs 16 & 0,071 & 0,121 & 3,387 & 1,000 \\
\hline 16 vs 4 & 0,298 & 0,512 & 3,387 & 1,000 \\
\hline 16 vs 5 & 0,298 & 0,512 & 3,387 & 1,000 \\
\hline 16 vs 6 & 0,298 & 0,512 & 3,387 & 1,000 \\
\hline 16 vs 9 & 0,298 & 0,512 & 3,387 & 1,000 \\
\hline 16 vs 18 & 0,298 & 0,512 & 3,387 & 1,000 \\
\hline 16 vs 11 & 0,173 & 0,298 & 3,387 & 1,000 \\
\hline 16 vs 17 & 0,032 & 0,054 & 3,387 & 1,000 \\
\hline 17 vs 4 & 0,267 & 0,458 & 3,387 & 1,000 \\
\hline 17 vs 5 & 0,267 & 0,458 & 3,387 & 1,000 \\
\hline 17 vs 6 & 0,267 & 0,458 & 3,387 & 1,000 \\
\hline 17 vs 9 & 0,267 & 0,458 & 3,387 & 1,000 \\
\hline 17 vs 18 & 0,267 & 0,458 & 3,387 & 1,000 \\
\hline 17 vs 11 & 0,142 & 0,243 & 3,387 & 1,000 \\
\hline 11 vs 4 & 0,125 & 0,215 & 3,387 & 1,000 \\
\hline 11 vs 5 & 0,125 & 0,215 & 3,387 & 1,000 \\
\hline 11 vs 6 & 0,125 & 0,215 & 3,387 & 1,000 \\
\hline 11 vs 9 & 0,125 & 0,215 & 3,387 & 1,000 \\
\hline 11 vs 18 & 0,125 & 0,215 & 3,387 & 1,000 \\
\hline 18 vs 4 & 0,000 & 0,000 & 3,387 & 1,000 \\
\hline 18 vs 5 & 0,000 & 0,000 & 3,387 & 1,000 \\
\hline 18 vs 6 & 0,000 & 0,000 & 3,387 & 1,000 \\
\hline 18 vs 9 & 0,000 & 0,000 & 3,387 & 1,000 \\
\hline 9 vs 4 & 0,000 & 0,000 & 3,387 & 1,000 \\
\hline 9 vs 5 & 0,000 & 0,000 & 3,387 & 1,000 \\
\hline 9 vs 6 & 0,000 & 0,000 & 3,387 & 1,000 \\
\hline $6 \mathrm{vs} 4$ & 0,000 & 0,000 & 3,387 & 1,000 \\
\hline 6 vs 5 & 0,000 & 0,000 & 3,387 & 1,000 \\
\hline
\end{tabular}




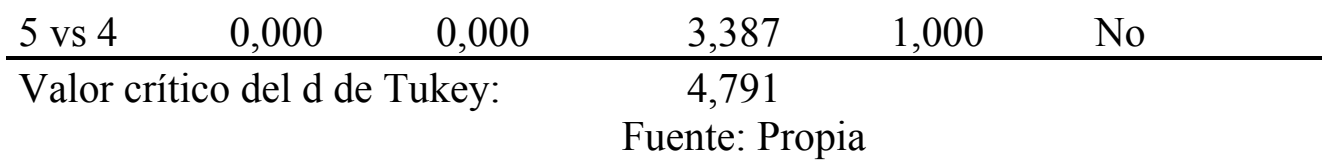

Al analizar el gráfico de medias (Figura 13) vemos que resulta muy significativa la categoría 12 alcanzando un valor de 4,000.

En el contraste de categorías la doce resulta significativa con respecto a las categorías 3 , $4,5,6,8,9,11,13,14,15,16,17,18$. Es decir todas excepto ella misma, ya que como hemos comentado las categorías y 1,2 , 7, y 10 no nos han reportado ejemplos de programas de este tipo en la muestra analizada.

Las mayores diferencias $(3,000)$ se establecen con las categorías $4,5,6,9$ y 18 . Y las menores $(2,250)$ con las categorías 3 y 14.

\subsubsection{Análisis de la variable i14 (V2). Medición del impacto y repercusión de la propuesta}

Revisamos finalmente la repercusión de los programas con respecto al tipo de patrimonio con el que trabajan.

Tabla 55. Análisis de varianza (i14) (V2)

\begin{tabular}{|c|c|c|c|c|c|}
\hline Fuente & GL & $\begin{array}{l}\text { Suma de } \\
\text { cuadrados }\end{array}$ & $\begin{array}{l}\text { Cuadrados } \\
\text { medios }\end{array}$ & $\mathrm{F}$ & $\operatorname{Pr}>F$ \\
\hline Modelo & 13 & 5,005 & 0,385 & 1,350 & 0,185 \\
\hline Error & 248 & 70,749 & 0,285 & & \\
\hline $\begin{array}{l}\text { Total } \\
\text { corregido }\end{array}$ & 261 & 75,755 & & & \\
\hline
\end{tabular}

Fuente: Propia

Los resultados indican que no existen diferencias estadísticamente significativas $[\mathrm{F}(13,261)=1,350 ; \mathrm{p}=0,185]$ a la hora de comparar las medias de las categorías.

\subsubsection{ANOVA - Tipo proyecto (V3).}

La variable (V3) hace referencia al tipo de proyecto patrimonial. Esta variable contiene 18 categorías de las que nuestra muestra incluye 17, excluyendo "redes sociales" que no está representada en nuestros programas. Las categoría incluidas son: 1-programa educativo, 2-proyecto educativo, 3-diseño didáctico, 4-recurso didáctico, 5- herramienta didáctica, 6-acción educativa, 7-actividad aislada, 8-taller, 9-proyecto de investigación, 10-proyecto de mejora, 11-concurso, 12-itinerario didáctico/ruta/visita, 13-plan, 14-red, 15-evento científico, 16-curso, 18-otros.

\subsubsection{Análisis de la variable i09 (V3). Descripción de los objetivos a lograr en el desarrollo de programas.}

Revisamos a continuación si existen diferencias significativas en la descripción de los objetivos de los programas atendiendo a su tipología. 
Tabla 56. Análisis de varianza (i09) (V3)

\begin{tabular}{|c|c|c|c|c|c|}
\hline Fuente & GL & $\begin{array}{l}\text { Suma de } \\
\text { cuadrados }\end{array}$ & $\begin{array}{l}\text { Cuadrados } \\
\text { medios }\end{array}$ & $\mathrm{F}$ & $\operatorname{Pr}>F$ \\
\hline Modelo & 16 & 17,634 & 1,102 & 1,242 & 0,236 \\
\hline Error & 245 & 217,389 & 0,887 & & \\
\hline $\begin{array}{l}\text { Total } \\
\text { corregido }\end{array}$ & 261 & 235,023 & & & \\
\hline
\end{tabular}

Fuente: Propia

Los resultados indican que no existen diferencias estadísticamente significativas $[\mathrm{F}(16,261)=1,242 ; \mathrm{p}=0,236]$ a la hora de comparar las medias de las categorías.

\subsubsection{Análisis de la variable i10 (V3). Presentación de contenidos abordados en el} programa.

Observamos en este apartado si existen diferencias estadísticamente significativas entre las categorías de la variable V3 con respecto a la presentación de sus contenidos.

Tabla 57. Análisis de varianza (i10) (V3)

\begin{tabular}{|c|c|c|c|c|c|}
\hline Fuente & GL & $\begin{array}{l}\text { Suma de } \\
\text { cuadrados }\end{array}$ & $\begin{array}{l}\text { Cuadrados } \\
\text { medios }\end{array}$ & $\mathrm{F}$ & $\operatorname{Pr}>F$ \\
\hline Modelo & 16 & 27,407 & 1,713 & 2,052 & 0,011 \\
\hline Error & 245 & 204,486 & 0,835 & & \\
\hline $\begin{array}{l}\text { Total } \\
\text { corregido }\end{array}$ & 261 & 231,893 & & & \\
\hline
\end{tabular}

Fuente: Propia

Dado el valor $\mathrm{p}$ asociado al estadístico $\mathrm{F}$ calculado en la tabla ANOVA, y dado el nivel de significación del 5\%, existen diferencias estadísticamente significativas en la variable i10.

Figura 14. Gráfico de medias. (i10)(V3)

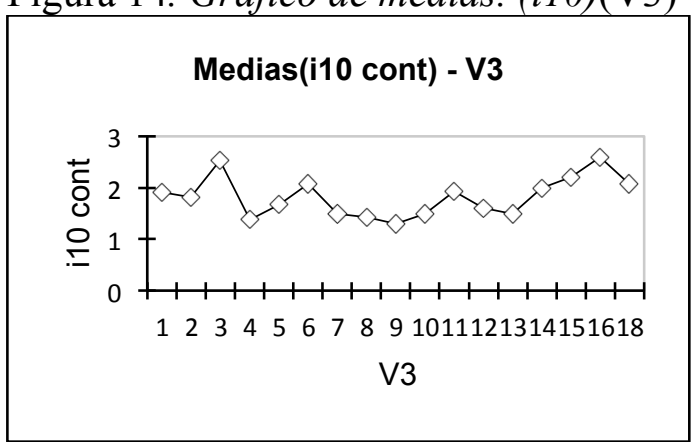

Fuente: Propia

Tabla 58. Análisis de diferencias entre las categorías. (V3)

\begin{tabular}{llllll}
\hline Categoría & Medias LS & $\begin{array}{l}\text { Error } \\
\text { estándar }\end{array}$ & $\begin{array}{l}\text { Límite } \\
\text { inferior } \\
(95 \%)\end{array}$ & $\begin{array}{l}\text { Límite } \\
\text { superior } \\
(95 \%)\end{array}$ & Grupos \\
\hline 16 & 2,600 & 0,409 & 1,795 & 3,405 & A \\
3 & 2,529 & 0,222 & 2,093 & 2,966 & A
\end{tabular}




\begin{tabular}{llllll}
15 & 2,200 & 0,409 & 1,395 & 3,005 & $\mathrm{~A}$ \\
18 & 2,083 & 0,186 & 1,716 & 2,451 & $\mathrm{~A}$ \\
6 & 2,071 & 0,244 & 1,590 & 2,552 & $\mathrm{~A}$ \\
14 & 2,000 & 0,457 & 1,100 & 2,900 & $\mathrm{~A}$ \\
11 & 1,933 & 0,236 & 1,469 & 2,398 & $\mathrm{~A}$ \\
1 & 1,910 & 0,112 & 1,691 & 2,130 & $\mathrm{~A}$ \\
2 & 1,811 & 0,150 & 1,515 & 2,107 & $\mathrm{~A}$ \\
5 & 1,667 & 0,373 & 0,932 & 2,401 & $\mathrm{~A}$ \\
12 & 1,600 & 0,409 & 0,795 & 2,405 & $\mathrm{~A}$ \\
7 & 1,500 & 0,646 & 0,228 & 2,772 & $\mathrm{~A}$ \\
10 & 1,500 & 0,646 & 0,228 & 2,772 & $\mathrm{~A}$ \\
13 & 1,500 & 0,457 & 0,600 & 2,400 & $\mathrm{~A}$ \\
8 & 1,429 & 0,244 & 0,948 & 1,910 & $\mathrm{~A}$ \\
4 & 1,387 & 0,164 & 1,064 & 1,710 & $\mathrm{~A}$ \\
9 & 1,300 & 0,289 & 0,731 & 1,869 & $\mathrm{~A}$ \\
\hline
\end{tabular}

Tabla 59. Tipo proyecto / Tukey (HSD) / Análisis de las diferencias entre las categorías con un intervalo de confianza de $95 \%$ (i10 cont) (V3)

\begin{tabular}{llllll}
\hline Contraste & Diferencia & $\begin{array}{l}\text { Diferencia } \\
\text { estandarizada }\end{array}$ & $\begin{array}{l}\text { Valor } \\
\text { crítico }\end{array}$ & Pr $>$ Dif & Significativo \\
\hline 16 vs 9 & 1,300 & 2,501 & 3,495 & 0,504 & No \\
16 vs 4 & 1,213 & 2,334 & 3,495 & 0,630 & No \\
16 vs 8 & 1,171 & 2,254 & 3,495 & 0,688 & No \\
16 vs 7 & 1,100 & 2,116 & 3,495 & 0,780 & No \\
16 vs 10 & 1,100 & 2,116 & 3,495 & 0,780 & No \\
16 vs 13 & 1,100 & 2,116 & 3,495 & 0,780 & No \\
16 vs 12 & 1,000 & 1,924 & 3,495 & 0,883 & No \\
16 vs 5 & 0,933 & 1,796 & 3,495 & 0,931 & No \\
16 vs 2 & 0,789 & 1,518 & 3,495 & 0,985 & No \\
16 vs 1 & 0,690 & 1,327 & 3,495 & 0,996 & No \\
16 vs 11 & 0,667 & 1,283 & 3,495 & 0,997 & No \\
16 vs 14 & 0,600 & 1,154 & 3,495 & 0,999 & No \\
16 vs 6 & 0,529 & 1,017 & 3,495 & 1,000 & No \\
16 vs 18 & 0,517 & 0,994 & 3,495 & 1,000 & No \\
16 vs 15 & 0,400 & 0,770 & 3,495 & 1,000 & No \\
16 vs 3 & 0,071 & 0,136 & 3,495 & 1,000 & No \\
3 vs 9 & 1,229 & 2,365 & 3,495 & 0,606 & No \\
3 vs 4 & 1,142 & 2,198 & 3,495 & 0,727 & No \\
3 vs 8 & 1,101 & 2,118 & 3,495 & 0,779 & No \\
3 vs 7 & 1,029 & 1,981 & 3,495 & 0,856 & No \\
3 vs 10 & 1,029 & 1,981 & 3,495 & 0,856 & No \\
3 vs 13 & 1,029 & 1,981 & 3,495 & 0,856 & No \\
3 vs 12 & 0,929 & 1,788 & 3,495 & 0,933 & No \\
3 vs 5 & 0,863 & 1,660 & 3,495 & 0,964 & No \\
3 vs 2 & 0,719 & 1,383 & 3,495 & 0,994 & No
\end{tabular}




\begin{tabular}{|c|c|c|c|c|}
\hline 3 vs 1 & 0,619 & 1,191 & 3,495 & 0,999 \\
\hline 3 vs 11 & 0,596 & 1,147 & 3,495 & 0,999 \\
\hline 3 vs 14 & 0,529 & 1,019 & 3,495 & 1,000 \\
\hline 3 vs 6 & 0,458 & 0,881 & 3,495 & 1,000 \\
\hline 3 vs 18 & 0,446 & 0,858 & 3,495 & 1,000 \\
\hline 3 vs 15 & 0,329 & 0,634 & 3,495 & 1,000 \\
\hline 15 vs 9 & 0,900 & 1,732 & 3,495 & 0,949 \\
\hline 15 vs 4 & 0,813 & 1,564 & 3,495 & 0,980 \\
\hline 15 vs 8 & 0,771 & 1,484 & 3,495 & 0,988 \\
\hline 15 vs 13 & 0,700 & 1,347 & 3,495 & 0,996 \\
\hline 15 vs 7 & 0,700 & 1,347 & 3,495 & 0,996 \\
\hline 15 vs 10 & 0,700 & 1,347 & 3,495 & 0,996 \\
\hline 15 vs 12 & 0,600 & 1,154 & 3,495 & 0,999 \\
\hline 15 vs 5 & 0,533 & 1,026 & 3,495 & 1,000 \\
\hline 15 vs 2 & 0,389 & 0,749 & 3,495 & 1,000 \\
\hline 15 vs 1 & 0,290 & 0,557 & 3,495 & 1,000 \\
\hline 15 vs 11 & 0,267 & 0,513 & 3,495 & 1,000 \\
\hline 15 vs 14 & 0,200 & 0,385 & 3,495 & 1,000 \\
\hline 15 vs 6 & 0,129 & 0,247 & 3,495 & 1,000 \\
\hline 15 vs 18 & 0,117 & 0,224 & 3,495 & 1,000 \\
\hline 18 vs 9 & 0,783 & 1,507 & 3,495 & 0,986 \\
\hline 18 vs 4 & 0,696 & 1,340 & 3,495 & 0,996 \\
\hline 18 vs 8 & 0,655 & 1,260 & 3,495 & 0,998 \\
\hline 18 vs 13 & 0,583 & 1,122 & 3,495 & 0,999 \\
\hline 18 vs 7 & 0,583 & 1,122 & 3,495 & 0,999 \\
\hline 18 vs 10 & 0,583 & 1,122 & 3,495 & 0,999 \\
\hline 18 vs 12 & 0,483 & 0,930 & 3,495 & 1,000 \\
\hline 18 vs 5 & 0,417 & 0,802 & 3,495 & 1,000 \\
\hline 18 vs 2 & 0,273 & 0,524 & 3,495 & 1,000 \\
\hline 18 vs 1 & 0,173 & 0,333 & 3,495 & 1,000 \\
\hline 18 vs 11 & 0,150 & 0,289 & 3,495 & 1,000 \\
\hline 18 vs 14 & 0,083 & 0,160 & 3,495 & 1,000 \\
\hline 18 vs 6 & 0,012 & 0,023 & 3,495 & 1,000 \\
\hline 6 vs 9 & 0,771 & 1,484 & 3,495 & 0,988 \\
\hline 6 vs 4 & 0,684 & 1,317 & 3,495 & 0,997 \\
\hline 6 vs 8 & 0,643 & 1,237 & 3,495 & 0,998 \\
\hline 6 vs 13 & 0,571 & 1,099 & 3,495 & 1,000 \\
\hline 6 vs 7 & 0,571 & 1,099 & 3,495 & 1,000 \\
\hline 6 vs 10 & 0,571 & 1,099 & 3,495 & 1,000 \\
\hline 6 vs 12 & 0,471 & 0,907 & 3,495 & 1,000 \\
\hline 6 vs 5 & 0,405 & 0,779 & 3,495 & 1,000 \\
\hline 6 vs 2 & 0,261 & 0,501 & 3,495 & 1,000 \\
\hline 6 vs 1 & 0,161 & 0,310 & 3,495 & 1,000 \\
\hline 6 vs 11 & 0,138 & 0,266 & 3,495 & 1,000 \\
\hline 6 vs 14 & 0,071 & 0,137 & 3,495 & 1,000 \\
\hline 14 vs 9 & 0,700 & 1,347 & 3,495 & 0,996 \\
\hline
\end{tabular}




\begin{tabular}{|c|c|c|c|c|}
\hline 14 vs 4 & 0,613 & 1,179 & 3,495 & 0,999 \\
\hline 14 vs 8 & 0,571 & 1,099 & 3,495 & 1,000 \\
\hline 14 vs 13 & 0,500 & 0,962 & 3,495 & 1,000 \\
\hline 14 vs 7 & 0,500 & 0,962 & 3,495 & 1,000 \\
\hline 14 vs 10 & 0,500 & 0,962 & 3,495 & 1,000 \\
\hline 14 vs 12 & 0,400 & 0,770 & 3,495 & 1,000 \\
\hline 14 vs 5 & 0,333 & 0,641 & 3,495 & 1,000 \\
\hline 14 vs 2 & 0,189 & 0,364 & 3,495 & 1,000 \\
\hline 14 vs 1 & 0,090 & 0,172 & 3,495 & 1,000 \\
\hline 14 vs 11 & 0,067 & 0,128 & 3,495 & 1,000 \\
\hline 11 vs 9 & 0,633 & 1,219 & 3,495 & 0,999 \\
\hline 11 vs 4 & 0,546 & 1,051 & 3,495 & 1,000 \\
\hline 11 vs 8 & 0,505 & 0,971 & 3,495 & 1,000 \\
\hline $11 \mathrm{vs} 13$ & 0,433 & 0,834 & 3,495 & 1,000 \\
\hline 11 vs 7 & 0,433 & 0,834 & 3,495 & 1,000 \\
\hline 11 vs 10 & 0,433 & 0,834 & 3,495 & 1,000 \\
\hline 11 vs 12 & 0,333 & 0,641 & 3,495 & 1,000 \\
\hline 11 vs 5 & 0,267 & 0,513 & 3,495 & 1,000 \\
\hline 11 vs 2 & 0,123 & 0,236 & 3,495 & 1,000 \\
\hline 11 vs 1 & 0,023 & 0,044 & 3,495 & 1,000 \\
\hline 1 vs 9 & 0,610 & 1,175 & 3,495 & 0,999 \\
\hline 1 vs 4 & 0,523 & 1,007 & 3,495 & 1,000 \\
\hline $1 \mathrm{vs} 8$ & 0,482 & 0,927 & 3,495 & 1,000 \\
\hline 1 vs 13 & 0,410 & 0,790 & 3,495 & 1,000 \\
\hline $1 \mathrm{vs} 7$ & 0,410 & 0,790 & 3,495 & 1,000 \\
\hline 1 vs 10 & 0,410 & 0,790 & 3,495 & 1,000 \\
\hline 1 vs 12 & 0,310 & 0,597 & 3,495 & 1,000 \\
\hline 1 vs 5 & 0,244 & 0,469 & 3,495 & 1,000 \\
\hline 1 vs 2 & 0,100 & 0,192 & 3,495 & 1,000 \\
\hline 2 vs 9 & 0,511 & 0,983 & 3,495 & 1,000 \\
\hline 2 vs 4 & 0,424 & 0,815 & 3,495 & 1,000 \\
\hline 2 vs 8 & 0,382 & 0,735 & 3,495 & 1,000 \\
\hline 2 vs 13 & 0,311 & 0,598 & 3,495 & 1,000 \\
\hline 2 vs 7 & 0,311 & 0,598 & 3,495 & 1,000 \\
\hline 2 vs 10 & 0,311 & 0,598 & 3,495 & 1,000 \\
\hline 2 vs 12 & 0,211 & 0,406 & 3,495 & 1,000 \\
\hline 2 vs 5 & 0,144 & 0,277 & 3,495 & 1,000 \\
\hline 5 vs 9 & 0,367 & 0,705 & 3,495 & 1,000 \\
\hline 5 vs 4 & 0,280 & 0,538 & 3,495 & 1,000 \\
\hline 5 vs 8 & 0,238 & 0,458 & 3,495 & 1,000 \\
\hline 5 vs 13 & 0,167 & 0,321 & 3,495 & 1,000 \\
\hline 5 vs 7 & 0,167 & 0,321 & 3,495 & 1,000 \\
\hline 5 vs 10 & 0,167 & 0,321 & 3,495 & 1,000 \\
\hline 5 vs 12 & 0,067 & 0,128 & 3,495 & 1,000 \\
\hline 12 vs 9 & 0,300 & 0,577 & 3,495 & 1,000 \\
\hline 12 vs 4 & 0,213 & 0,410 & 3,495 & 1,000 \\
\hline
\end{tabular}




\begin{tabular}{llllll}
12 vs 8 & 0,171 & 0,330 & 3,495 & 1,000 & No \\
12 vs 13 & 0,100 & 0,192 & 3,495 & 1,000 & No \\
12 vs 7 & 0,100 & 0,192 & 3,495 & 1,000 & No \\
12 vs 10 & 0,100 & 0,192 & 3,495 & 1,000 & No \\
13 vs 9 & 0,200 & 0,385 & 3,495 & 1,000 & No \\
13 vs 4 & 0,113 & 0,217 & 3,495 & 1,000 & No \\
13 vs 8 & 0,071 & 0,137 & 3,495 & 1,000 & No \\
13 vs 7 & 0,000 & 0,000 & 3,495 & 1,000 & No \\
13 vs 10 & 0,000 & 0,000 & 3,495 & 1,000 & No \\
10 vs 9 & 0,200 & 0,385 & 3,495 & 1,000 & No \\
10 vs 4 & 0,113 & 0,217 & 3,495 & 1,000 & No \\
10 vs 8 & 0,071 & 0,137 & 3,495 & 1,000 & No \\
10 vs 7 & 0,000 & 0,000 & 3,495 & 1,000 & No \\
7 vs 9 & 0,200 & 0,385 & 3,495 & 1,000 & No \\
7 vs 4 & 0,113 & 0,217 & 3,495 & 1,000 & No \\
7 vs 8 & 0,071 & 0,137 & 3,495 & 1,000 & No \\
8 vs 9 & 0,129 & 0,247 & 3,495 & 1,000 & No \\
8 vs 4 & 0,041 & 0,080 & 3,495 & 1,000 & No \\
4 vs 9 & 0,087 & 0,168 & 3,495 & 1,000 & No \\
\hline Valor crítico del d de Tukey: & 4,943 & & \\
& & Fuente: Propia &
\end{tabular}

En la gráfica de medias, observamos que la categoría que presenta un valor más alto es la $16(2,600)$ y la de menor valor es la categoría $9(1,300)$.

El análisis de los contrastes entre categorías no presenta diferencias estadísticamente significativas entre ninguno de los pares.

\subsubsection{Análisis de la variable i11 (V3). Orientación metodológica y estrategias de enseñanza aprendizaje.}

Entramos en el análisis de diferencias del tipo de proyecto con respecto a la metodología utilizada.

Tabla 60. Análisis de varianza (i11) (V3)

\begin{tabular}{llllll}
\hline Fuente & GL & \multicolumn{2}{l}{$\begin{array}{l}\text { Suma de Cuadrados } \\
\text { cuadrados }\end{array}$} & medios & Pr $>$ F \\
\hline Modelo & 16 & 12,577 & 0,786 & 1,139 & 0,320 \\
Error & 245 & 169,076 & 0,690 & \\
Total & & & \\
corregido & 261 & 181,653 & \\
\hline \multicolumn{5}{c}{ Fuente: Propia }
\end{tabular}

Los resultados indican que no existen diferencias estadísticamente significativas $[F(16,261)=1,139 ; p=0,320]$ a la hora de comparar las medias de las categorías.

\footnotetext{
5.4.4.4. Análisis de la variable i12 (V3). Definición de recursos, formatos, soportes, y tecnología empleados
} 
Realizamos el análisis sobre si existen diferencias significativas en los recursos empleados con respecto las diecisiete categorías de la variable V3.

Tabla 61. Análisis de varianza (i12) (V3)

\begin{tabular}{|c|c|c|c|c|c|}
\hline Fuente & GL & $\begin{array}{l}\text { Suma de } \\
\text { cuadrados }\end{array}$ & $\begin{array}{l}\text { Cuadrados } \\
\text { medios }\end{array}$ & $\mathrm{F}$ & $\operatorname{Pr}>F$ \\
\hline Modelo & 16 & 20,506 & 1,282 & 1,599 & 0,069 \\
\hline Error & 245 & 196,349 & 0,801 & & \\
\hline $\begin{array}{l}\text { Total } \\
\text { corregido }\end{array}$ & 261 & 216,855 & & & \\
\hline
\end{tabular}

Fuente: Propia

Los resultados indican que no existen diferencias estadísticamente significativas $[\mathrm{F}(16,261)=1,599 ; \mathrm{p}=0,069]$ a la hora de comparar las medias de las categorías.

\subsubsection{Análisis de la variable i13 (V3). Determinación de los sistemas o herramientas de evaluación.}

Continuamos con el análisis de diferencias en este caso entre las diecisiete categorías de la variable tipo de proyecto atendiendo al las herramientas de evaluación que incluyen los programas.

Tabla 62. Análisis de varianza (i13) (V3).

\begin{tabular}{|c|c|c|c|c|c|}
\hline Fuente & GL & $\begin{array}{l}\text { Suma de } \\
\text { cuadrados }\end{array}$ & $\begin{array}{l}\text { Cuadrados } \\
\text { medios }\end{array}$ & $\mathrm{F}$ & $\operatorname{Pr}>F$ \\
\hline Modelo & 16 & 14,679 & 0,917 & 1,606 & 0,068 \\
\hline Error & 245 & 139,982 & 0,571 & & \\
\hline $\begin{array}{l}\text { Total } \\
\text { corregido }\end{array}$ & 261 & 154,660 & & & \\
\hline
\end{tabular}

Fuente: Propia

Los resultados indican que no existen diferencias estadísticamente significativas $[\mathrm{F}(16,261)=1,606 ; \mathrm{p}=0,068]$ a la hora de comparar las medias de las categorías.

\subsubsection{Análisis de la variable i14 (V3). Medición del impacto y repercusión de la propuesta}

Finalizamos el análisis de diferencias de las categorías de la variable V3 en este caso atendiendo a la repercusión de los programas analizados.

Tabla 63. Análisis de varianza (i14) (V3)

\begin{tabular}{|c|c|c|c|c|c|}
\hline Fuente & GL & $\begin{array}{l}\text { Suma de } \\
\text { cuadrados }\end{array}$ & $\begin{array}{l}\text { Cuadrados } \\
\text { medios }\end{array}$ & $\mathrm{F}$ & $\operatorname{Pr}>\mathrm{F}$ \\
\hline Modelo & 16 & 8,504 & 0,531 & 1,936 & 0,018 \\
\hline Error & 245 & 67,251 & 0,274 & & \\
\hline $\begin{array}{l}\text { Total } \\
\text { corregido }\end{array}$ & 261 & 75,755 & & & \\
\hline
\end{tabular}

Fuente: Propia 
Dado el valor $\mathrm{p}$ asociado al estadístico $\mathrm{F}$ calculado en la tabla ANOVA, y dado el nivel de significación del 5\%, existen diferencias estadísticamente significativas en la variable i14.

Figura 15. Gráfico de medias. (i14) (V3)

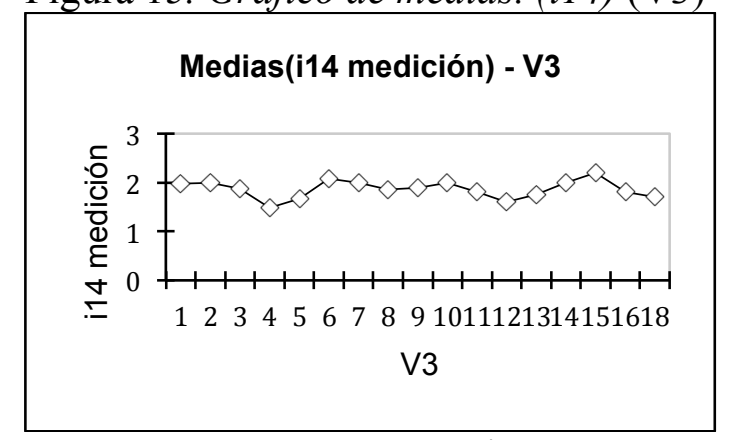

Fuente: Propia

Tabla 64. Análisis de diferencias entre las categorías(V3)

\begin{tabular}{llllll}
\hline Categoría & Medias LS & $\begin{array}{l}\text { Error } \\
\text { estándar }\end{array}$ & $\begin{array}{l}\text { Límite } \\
\text { inferior } \\
(95 \%)\end{array}$ & $\begin{array}{l}\text { Límite } \\
\text { superior } \\
(95 \%)\end{array}$ & Grupos \\
\hline 15 & 2,200 & 0,234 & 1,738 & 2,662 & $\mathrm{~A}$ \\
6 & 2,071 & 0,140 & 1,796 & 2,347 & $\mathrm{~A}$ \\
7 & 2,000 & 0,370 & 1,270 & 2,730 & $\mathrm{~A}$ \\
10 & 2,000 & 0,370 & 1,270 & 2,730 & $\mathrm{~A}$ \\
14 & 2,000 & 0,262 & 1,484 & 2,516 & $\mathrm{~A}$ \\
2 & 1,996 & 0,086 & 1,827 & 2,166 & $\mathrm{~A}$ \\
1 & 1,970 & 0,064 & 1,844 & 2,096 & $\mathrm{~A}$ \\
9 & 1,900 & 0,166 & 1,574 & 2,226 & $\mathrm{~A}$ \\
3 & 1,882 & 0,127 & 1,632 & 2,133 & $\mathrm{~A}$ \\
8 & 1,857 & 0,140 & 1,581 & 2,133 & $\mathrm{~A}$ \\
11 & 1,800 & 0,135 & 1,534 & 2,066 & $\mathrm{~A}$ \\
16 & 1,800 & 0,234 & 1,338 & 2,262 & $\mathrm{~A}$ \\
13 & 1,750 & 0,262 & 1,234 & 2,266 & $\mathrm{~A}$ \\
18 & 1,708 & 0,107 & 1,498 & 1,919 & $\mathrm{~A}$ \\
5 & 1,667 & 0,214 & 1,245 & 2,088 & $\mathrm{~A}$ \\
12 & 1,600 & 0,234 & 1,138 & 2,062 & $\mathrm{~A}$ \\
4 & 1,484 & 0,094 & 1,299 & 1,669 & $\mathrm{~A}$ \\
\hline
\end{tabular}

Fuente: Propia

Tabla 65. Tipo proyecto / Tukey (HSD) / Análisis de las diferencias entre las categorías con un intervalo de confianza de 95\% (i14 medición) (V3)

\begin{tabular}{llllll}
\hline Contraste & Diferencia & $\begin{array}{l}\text { Diferencia } \\
\text { estandarizada }\end{array}$ & $\begin{array}{l}\text { Valor } \\
\text { crítico }\end{array}$ & $\operatorname{Pr}>$ Dif & Significativo \\
\hline 15 vs 4 & 0,716 & 2,403 & 3,495 & 0,578 & No \\
15 vs 12 & 0,600 & 2,013 & 3,495 & 0,839 & No \\
15 vs 5 & 0,533 & 1,789 & 3,495 & 0,933 & No \\
15 vs 18 & 0,492 & 1,650 & 3,495 & 0,966 & No \\
15 vs 13 & 0,450 & 1,510 & 3,495 & 0,986 & No \\
15 vs 16 & 0,400 & 1,342 & 3,495 & 0,996 & No
\end{tabular}




\begin{tabular}{|c|c|c|c|c|}
\hline 15 vs 11 & 0,400 & 1,342 & 3,495 & 0,996 \\
\hline 15 vs 8 & 0,343 & 1,150 & 3,495 & 0,999 \\
\hline 15 vs 3 & 0,318 & 1,066 & 3,495 & 1,000 \\
\hline 15 vs 9 & 0,300 & 1,007 & 3,495 & 1,000 \\
\hline 15 vs 1 & 0,230 & 0,771 & 3,495 & 1,000 \\
\hline 15 vs 2 & 0,204 & 0,684 & 3,495 & 1,000 \\
\hline 15 vs 7 & 0,200 & 0,671 & 3,495 & 1,000 \\
\hline 15 vs 10 & 0,200 & 0,671 & 3,495 & 1,000 \\
\hline 15 vs 14 & 0,200 & 0,671 & 3,495 & 1,000 \\
\hline 15 vs 6 & 0,129 & 0,431 & 3,495 & 1,000 \\
\hline 6 vs 4 & 0,588 & 1,971 & 3,495 & 0,861 \\
\hline 6 vs 12 & 0,471 & 1,582 & 3,495 & 0,977 \\
\hline 6 vs 5 & 0,405 & 1,358 & 3,495 & 0,995 \\
\hline 6 vs 18 & 0,363 & 1,218 & 3,495 & 0,999 \\
\hline 6 vs 13 & 0,321 & 1,078 & 3,495 & 1,000 \\
\hline 6 vs 16 & 0,271 & 0,911 & 3,495 & 1,000 \\
\hline 6 vs 11 & 0,271 & 0,911 & 3,495 & 1,000 \\
\hline 6 vs 8 & 0,214 & 0,719 & 3,495 & 1,000 \\
\hline 6 vs 3 & 0,189 & 0,634 & 3,495 & 1,000 \\
\hline 6 vs 9 & 0,171 & 0,575 & 3,495 & 1,000 \\
\hline 6 vs 1 & 0,101 & 0,340 & 3,495 & 1,000 \\
\hline 6 vs 2 & 0,075 & 0,253 & 3,495 & 1,000 \\
\hline 6 vs 7 & 0,071 & 0,240 & 3,495 & 1,000 \\
\hline 6 vs 10 & 0,071 & 0,240 & 3,495 & 1,000 \\
\hline 6 vs 14 & 0,071 & 0,240 & 3,495 & 1,000 \\
\hline 14 vs 4 & 0,516 & 1,732 & 3,495 & 0,949 \\
\hline 14 vs 12 & 0,400 & 1,342 & 3,495 & 0,996 \\
\hline 14 vs 5 & 0,333 & 1,118 & 3,495 & 1,000 \\
\hline 14 vs 18 & 0,292 & 0,979 & 3,495 & 1,000 \\
\hline 14 vs 13 & 0,250 & 0,839 & 3,495 & 1,000 \\
\hline 14 vs 16 & 0,200 & 0,671 & 3,495 & 1,000 \\
\hline 14 vs 11 & 0,200 & 0,671 & 3,495 & 1,000 \\
\hline 14 vs 8 & 0,143 & 0,479 & 3,495 & 1,000 \\
\hline 14 vs 3 & 0,118 & 0,395 & 3,495 & 1,000 \\
\hline 14 vs 9 & 0,100 & 0,336 & 3,495 & 1,000 \\
\hline 14 vs 1 & 0,030 & 0,100 & 3,495 & 1,000 \\
\hline 14 vs 2 & 0,004 & 0,013 & 3,495 & 1,000 \\
\hline 14 vs 7 & 0,000 & 0,000 & 3,495 & 1,000 \\
\hline 14 vs 10 & 0,000 & 0,000 & 3,495 & 1,000 \\
\hline 10 vs 4 & 0,516 & 1,732 & 3,495 & 0,949 \\
\hline 10 vs 12 & 0,400 & 1,342 & 3,495 & 0,996 \\
\hline 10 vs 5 & 0,333 & 1,118 & 3,495 & 1,000 \\
\hline 10 vs 18 & 0,292 & 0,979 & 3,495 & 1,000 \\
\hline 10 vs 13 & 0,250 & 0,839 & 3,495 & 1,000 \\
\hline 10 vs 16 & 0,200 & 0,671 & 3,495 & 1,000 \\
\hline 10 vs 11 & 0,200 & 0,671 & 3,495 & 1,000 \\
\hline
\end{tabular}




\begin{tabular}{|c|c|c|c|c|}
\hline 10 vs 8 & 0,143 & 0,479 & 3,495 & 1,000 \\
\hline 10 vs 3 & 0,118 & 0,395 & 3,495 & 1,000 \\
\hline 10 vs 9 & 0,100 & 0,336 & 3,495 & 1,000 \\
\hline 10 vs 1 & 0,030 & 0,100 & 3,495 & 1,000 \\
\hline 10 vs 2 & 0,004 & 0,013 & 3,495 & 1,000 \\
\hline 10 vs 7 & 0,000 & 0,000 & 3,495 & 1,000 \\
\hline 7 vs 4 & 0,516 & 1,732 & 3,495 & 0,949 \\
\hline 7 vs 12 & 0,400 & 1,342 & 3,495 & 0,996 \\
\hline 7 vs 5 & 0,333 & 1,118 & 3,495 & 1,000 \\
\hline 7 vs 18 & 0,292 & 0,979 & 3,495 & 1,000 \\
\hline 7 vs 13 & 0,250 & 0,839 & 3,495 & 1,000 \\
\hline 7 vs 16 & 0,200 & 0,671 & 3,495 & 1,000 \\
\hline 7 vs 11 & 0,200 & 0,671 & 3,495 & 1,000 \\
\hline 7 vs 8 & 0,143 & 0,479 & 3,495 & 1,000 \\
\hline 7 vs 3 & 0,118 & 0,395 & 3,495 & 1,000 \\
\hline 7 vs 9 & 0,100 & 0,336 & 3,495 & 1,000 \\
\hline 7 vs 1 & 0,030 & 0,100 & 3,495 & 1,000 \\
\hline 7 vs 2 & 0,004 & 0,013 & 3,495 & 1,000 \\
\hline 2 vs 4 & 0,512 & 1,719 & 3,495 & 0,952 \\
\hline 2 vs 12 & 0,396 & 1,329 & 3,495 & 0,996 \\
\hline 2 vs 5 & 0,330 & 1,106 & 3,495 & 1,000 \\
\hline 2 vs 18 & 0,288 & 0,966 & 3,495 & 1,000 \\
\hline 2 vs 13 & 0,246 & 0,826 & 3,495 & 1,000 \\
\hline 2 vs 16 & 0,196 & 0,658 & 3,495 & 1,000 \\
\hline 2 vs 11 & 0,196 & 0,658 & 3,495 & 1,000 \\
\hline 2 vs 8 & 0,139 & 0,466 & 3,495 & 1,000 \\
\hline 2 vs 3 & 0,114 & 0,382 & 3,495 & 1,000 \\
\hline 2 vs 9 & 0,096 & 0,323 & 3,495 & 1,000 \\
\hline $2 \mathrm{vs} 1$ & 0,026 & 0,087 & 3,495 & 1,000 \\
\hline 1 vs 4 & 0,486 & 1,632 & 3,495 & 0,970 \\
\hline $1 \mathrm{vs} 12$ & 0,370 & 1,242 & 3,495 & 0,998 \\
\hline 1 vs 5 & 0,303 & 1,018 & 3,495 & 1,000 \\
\hline $1 \mathrm{vs} 18$ & 0,262 & 0,878 & 3,495 & 1,000 \\
\hline 1 vs 13 & 0,220 & 0,739 & 3,495 & 1,000 \\
\hline $1 \mathrm{vs} 16$ & 0,170 & 0,571 & 3,495 & 1,000 \\
\hline $1 \mathrm{vs} 11$ & 0,170 & 0,571 & 3,495 & 1,000 \\
\hline 1 vs 8 & 0,113 & 0,379 & 3,495 & 1,000 \\
\hline 1 vs 3 & 0,088 & 0,295 & 3,495 & 1,000 \\
\hline $1 \mathrm{vs} 9$ & 0,070 & 0,235 & 3,495 & 1,000 \\
\hline 9 vs 4 & 0,416 & 1,396 & 3,495 & 0,994 \\
\hline 9 vs 12 & 0,300 & 1,007 & 3,495 & 1,000 \\
\hline 9 vs 5 & 0,233 & 0,783 & 3,495 & 1,000 \\
\hline 9 vs 18 & 0,192 & 0,643 & 3,495 & 1,000 \\
\hline 9 vs 13 & 0,150 & 0,503 & 3,495 & 1,000 \\
\hline 9 vs 16 & 0,100 & 0,336 & 3,495 & 1,000 \\
\hline 9 vs 11 & 0,100 & 0,336 & 3,495 & 1,000 \\
\hline
\end{tabular}




\begin{tabular}{|c|c|c|c|c|c|}
\hline 9 vs 8 & 0,043 & 0,144 & 3,495 & 1,000 & No \\
\hline 9 vs 3 & 0,018 & 0,059 & 3,495 & 1,000 & No \\
\hline 3 vs 4 & 0,398 & 1,337 & 3,495 & 0,996 & No \\
\hline 3 vs 12 & 0,282 & 0,947 & 3,495 & 1,000 & No \\
\hline 3 vs 5 & 0,216 & 0,724 & 3,495 & 1,000 & No \\
\hline 3 vs 18 & 0,174 & 0,584 & 3,495 & 1,000 & No \\
\hline 3 vs 13 & 0,132 & 0,444 & 3,495 & 1,000 & No \\
\hline 3 vs 16 & 0,082 & 0,276 & 3,495 & 1,000 & No \\
\hline 3 vs 11 & 0,082 & 0,276 & 3,495 & 1,000 & No \\
\hline 3 vs 8 & 0,025 & 0,085 & 3,495 & 1,000 & No \\
\hline 8 vs 4 & 0,373 & 1,252 & 3,495 & 0,998 & No \\
\hline 8 vs 12 & 0,257 & 0,863 & 3,495 & 1,000 & No \\
\hline 8 vs 5 & 0,190 & 0,639 & 3,495 & 1,000 & No \\
\hline 8 vs 18 & 0,149 & 0,499 & 3,495 & 1,000 & No \\
\hline 8 vs 13 & 0,107 & 0,359 & 3,495 & 1,000 & No \\
\hline 8 vs 16 & 0,057 & 0,192 & 3,495 & 1,000 & No \\
\hline 8 vs 11 & 0,057 & 0,192 & 3,495 & 1,000 & No \\
\hline 11 vs 4 & 0,316 & 1,061 & 3,495 & 1,000 & No \\
\hline 11 vs 12 & 0,200 & 0,671 & 3,495 & 1,000 & No \\
\hline 11 vs 5 & 0,133 & 0,447 & 3,495 & 1,000 & No \\
\hline 11 vs 18 & 0,092 & 0,308 & 3,495 & 1,000 & No \\
\hline 11 vs 13 & 0,050 & 0,168 & 3,495 & 1,000 & No \\
\hline 11 vs 16 & 0,000 & 0,000 & 3,495 & 1,000 & No \\
\hline 16 vs 4 & 0,316 & 1,061 & 3,495 & 1,000 & No \\
\hline 16 vs 12 & 0,200 & 0,671 & 3,495 & 1,000 & No \\
\hline 16 vs 5 & 0,133 & 0,447 & 3,495 & 1,000 & No \\
\hline 16 vs 18 & 0,092 & 0,308 & 3,495 & 1,000 & No \\
\hline 16 vs 13 & 0,050 & 0,168 & 3,495 & 1,000 & No \\
\hline 13 vs 4 & 0,266 & 0,893 & 3,495 & 1,000 & No \\
\hline 13 vs 12 & 0,150 & 0,503 & 3,495 & 1,000 & No \\
\hline 13 vs 5 & 0,083 & 0,280 & 3,495 & 1,000 & No \\
\hline 13 vs 18 & 0,042 & 0,140 & 3,495 & 1,000 & No \\
\hline 18 vs 4 & 0,224 & 0,753 & 3,495 & 1,000 & No \\
\hline 18 vs 12 & 0,108 & 0,363 & 3,495 & 1,000 & No \\
\hline 18 vs 5 & 0,042 & 0,140 & 3,495 & 1,000 & No \\
\hline 5 vs 4 & 0,183 & 0,613 & 3,495 & 1,000 & No \\
\hline 5 vs 12 & 0,067 & 0,224 & 3,495 & 1,000 & No \\
\hline 12 vs 4 & 0,116 & 0,390 & 3,495 & 1,000 & No \\
\hline
\end{tabular}

Las medias de las diferentes categorías se sitúan en este caso más cercanas, siendo el mayor valor el de la categoría $15(2,200)$ y el menor el de la categoría $4(1,484)$.

En el análisis de diferencias entre los pares no encontramos ninguno con resultados estadísticamente significativos. 


\subsubsection{ANOVA-Público al que se dirige (V4).}

La variable V4 analiza el tipo de público al que están dirigidos los programas analizados. Esta variable contiene seis categorías: 1- infantil, 2- juvenil, 3- sénior, 4tercera edad, 5-todos los públicos, 6-colectivos específicos.

\subsubsection{Análisis de la variable i09(V4). Descripción de los objetivos a lograr en el desarrollo de programas.}

Estudiamos si existen diferencias estadísticamente significativas en los objetivos de los programas con respecto al tipo de público al que están dirigidos.

Tabla 66. Análisis de varianza (i09) (V4)

\begin{tabular}{|c|c|c|c|c|c|}
\hline Fuente & GL & $\begin{array}{l}\text { Suma de } \\
\text { cuadrados }\end{array}$ & $\begin{array}{l}\text { Cuadrados } \\
\text { medios }\end{array}$ & $\mathrm{F}$ & $\operatorname{Pr}>F$ \\
\hline Modelo & 11 & 31.197 & 2.836 & 3.484 & 0.000 \\
\hline Error & 249 & 202.696 & 0.814 & & \\
\hline $\begin{array}{l}\text { Total } \\
\text { corregido }\end{array}$ & 260 & 233.893 & & & \\
\hline
\end{tabular}

Fuente: Propia

Dado el valor $\mathrm{p}$ asociado al estadístico $\mathrm{F}$ calculado en la tabla ANOVA, y dado el nivel de significación del 5\%, existen diferencias estadísticamente significativas en la variable i09.

Figura 16. Gráfico de medias. (i09) (V4)

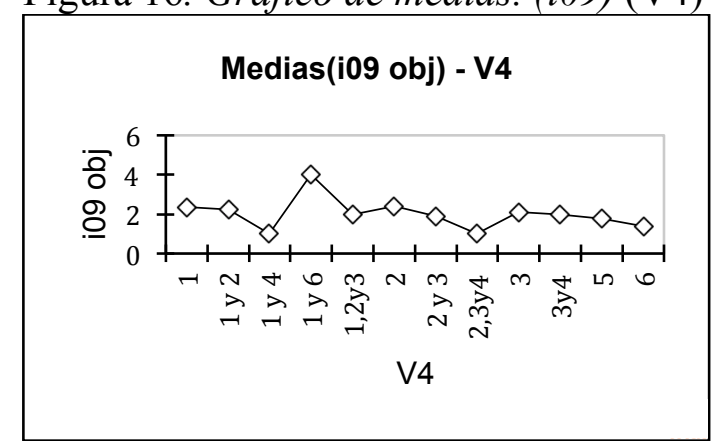

Fuente: Propia

Tabla 67. Análisis de diferencias entre las categorías (V4)

\begin{tabular}{lllllll}
\hline Categoría & Medias LS & $\begin{array}{l}\text { Error } \\
\text { estándar }\end{array}$ & $\begin{array}{l}\text { Límite } \\
\text { inferior } \\
(95 \%)\end{array}$ & $\begin{array}{l}\text { Límite } \\
\text { superior } \\
(95 \%)\end{array}$ & Grupos & \\
\hline 1 y 6 & 4.000 & 0.902 & 2.223 & 5.777 & $\mathrm{~A}$ & \\
2 & 2.421 & 0.146 & 2.133 & 2.709 & $\mathrm{~A}$ & $\mathrm{~B}$ \\
1 & 2.349 & 0.114 & 2.125 & 2.573 & $\mathrm{~A}$ & $\mathrm{~B}$ \\
1 у 2 & 2.240 & 0.180 & 1.885 & 2.595 & $\mathrm{~A}$ & $\mathrm{~B}$ \\
3 & 2.100 & 0.202 & 1.703 & 2.497 & $\mathrm{~A}$ & $\mathrm{~B}$ \\
1,2 y3 & 2.000 & 0.902 & 0.223 & 3.777 & $\mathrm{~A}$ & $\mathrm{~B}$ \\
3у4 & 2.000 & 0.902 & 0.223 & 3.777 & $\mathrm{~A}$ & $\mathrm{~B}$
\end{tabular}




\begin{tabular}{lllllll}
2 у 3 & 1.909 & 0.272 & 1.373 & 2.445 & $\mathrm{~A}$ & $\mathrm{~B}$ \\
5 & 1.783 & 0.099 & 1.588 & 1.978 & $\mathrm{~A}$ & $\mathrm{~B}$ \\
6 & 1.375 & 0.226 & 0.931 & 1.819 & $\mathrm{~A}$ & $\mathrm{~B}$ \\
1 у 4 & 1.000 & 0.902 & -0.777 & 2.777 & & $\mathrm{~B}$ \\
2,3 y4 & 1.000 & 0.902 & -0.777 & 2.777 & & $\mathrm{~B}$ \\
\hline
\end{tabular}

Fuente: Propia

Tabla 68. Público al que se dirige / Tukey (HSD) / Análisis de las diferencias entre las categorías con un intervalo de confianza de 95\% (i09 obj) (V4)

\begin{tabular}{|c|c|c|c|c|c|}
\hline Contraste & Diferencia & $\begin{array}{c}\text { Diferencia } \\
\text { estandarizad } \\
\mathrm{a}\end{array}$ & $\begin{array}{l}\text { Valor } \\
\text { crítico }\end{array}$ & $\operatorname{Pr}>$ Dif & $\begin{array}{c}\text { Significativ } \\
0\end{array}$ \\
\hline 1 y 6 vs 1 y 4 & 3.000 & 3.539 & 3.299 & 0.024 & $\mathrm{Si}$ \\
\hline 1 y 6 vs $2,3 y 4$ & 3.000 & 3.539 & 3.299 & 0.024 & $\mathrm{Si}$ \\
\hline 1 y 6 vs 6 & 2.625 & 3.096 & 3.299 & 0.089 & No \\
\hline 1 y 6 vs 5 & 2.217 & 2.615 & 3.299 & 0.277 & No \\
\hline 1 y 6 vs 2 y 3 & 2.091 & 2.466 & 3.299 & 0.366 & No \\
\hline 1 y 6 vs $1,2 y 3$ & 2.000 & 2.359 & 3.299 & 0.438 & No \\
\hline 1 y 6 vs $3 y 4$ & 2.000 & 2.359 & 3.299 & 0.438 & No \\
\hline 1 y 6 vs 3 & 1.900 & 2.241 & 3.299 & 0.522 & No \\
\hline 1 y 6 vs 1 y 2 & 1.760 & 2.076 & 3.299 & 0.640 & No \\
\hline 1 y 6 vs 1 & 1.651 & 1.947 & 3.299 & 0.728 & No \\
\hline 1 y 6 vs 2 & 1.579 & 1.862 & 3.299 & 0.781 & No \\
\hline 2 vs 1 y 4 & 1.421 & 1.676 & 3.299 & 0.877 & No \\
\hline 2 vs $2,3 y 4$ & 1.421 & 1.676 & 3.299 & 0.877 & No \\
\hline 2 vs 6 & 1.046 & 1.234 & 3.299 & 0.986 & No \\
\hline 2 vs 5 & 0.638 & 0.752 & 3.299 & 1.000 & No \\
\hline 2 vs 2 y 3 & 0.512 & 0.604 & 3.299 & 1.000 & No \\
\hline 2 vs $1,2 y 3$ & 0.421 & 0.497 & 3.299 & 1.000 & No \\
\hline 2 vs $3 y 4$ & 0.421 & 0.497 & 3.299 & 1.000 & No \\
\hline 2 vs 3 & 0.321 & 0.379 & 3.299 & 1.000 & No \\
\hline 2 vs 1 y 2 & 0.181 & 0.214 & 3.299 & 1.000 & No \\
\hline 2 vs 1 & 0.072 & 0.085 & 3.299 & 1.000 & No \\
\hline 1 vs 1 y 4 & 1.349 & 1.591 & 3.299 & 0.911 & No \\
\hline 1 vs $2,3 y 4$ & 1.349 & 1.591 & 3.299 & 0.911 & No \\
\hline 1 vs 6 & 0.974 & 1.149 & 3.299 & 0.992 & No \\
\hline 1 vs 5 & 0.566 & 0.668 & 3.299 & 1.000 & No \\
\hline 1 vs 2 y 3 & 0.440 & 0.519 & 3.299 & 1.000 & No \\
\hline 1 vs $1,2 y 3$ & 0.349 & 0.412 & 3.299 & 1.000 & No \\
\hline 1 vs $3 y 4$ & 0.349 & 0.412 & 3.299 & 1.000 & No \\
\hline 1 vs 3 & 0.249 & 0.294 & 3.299 & 1.000 & No \\
\hline 1 vs 1 y 2 & 0.109 & 0.129 & 3.299 & 1.000 & No \\
\hline 1 y 2 vs 1 y 4 & 1.240 & 1.463 & 3.299 & 0.949 & No \\
\hline
\end{tabular}




\begin{tabular}{|c|c|c|c|c|c|}
\hline 1 y 2 vs $2,3 y 4$ & 1.240 & 1.463 & 3.299 & 0.949 & No \\
\hline 1 y 2 vs 6 & 0.865 & 1.020 & 3.299 & 0.997 & No \\
\hline 1 y 2 vs 5 & 0.457 & 0.539 & 3.299 & 1.000 & No \\
\hline 1 y 2 vs 2 y 3 & 0.331 & 0.390 & 3.299 & 1.000 & No \\
\hline 1 y 2 vs 1,2 y3 & 0.240 & 0.283 & 3.299 & 1.000 & No \\
\hline 1 y 2 vs 3y4 & 0.240 & 0.283 & 3.299 & 1.000 & No \\
\hline 1 y 2 vs 3 & 0.140 & 0.165 & 3.299 & 1.000 & No \\
\hline 3 vs 1 y 4 & 1.100 & 1.297 & 3.299 & 0.979 & No \\
\hline 3 vs $2,3 y 4$ & 1.100 & 1.297 & 3.299 & 0.979 & No \\
\hline 3 vs 6 & 0.725 & 0.855 & 3.299 & 0.999 & No \\
\hline 3 vs 5 & 0.317 & 0.374 & 3.299 & 1.000 & No \\
\hline 3 vs 2 y 3 & 0.191 & 0.225 & 3.299 & 1.000 & No \\
\hline 3 vs $1,2 y 3$ & 0.100 & 0.118 & 3.299 & 1.000 & No \\
\hline 3 vs $3 y 4$ & 0.100 & 0.118 & 3.299 & 1.000 & No \\
\hline $3 y 4$ vs 1 y 4 & 1.000 & 1.180 & 3.299 & 0.990 & No \\
\hline $3 y 4$ vs 2,3y4 & 1.000 & 1.180 & 3.299 & 0.990 & No \\
\hline $3 y 4$ vs 6 & 0.625 & 0.737 & 3.299 & 1.000 & No \\
\hline $3 y 4$ vs 5 & 0.217 & 0.256 & 3.299 & 1.000 & No \\
\hline $3 y 4$ vs 2 y 3 & 0.091 & 0.107 & 3.299 & 1.000 & No \\
\hline $3 y 4$ vs $1,2 y 3$ & 0.000 & 0.000 & 3.299 & 1.000 & No \\
\hline 1,2 y3 vs 1 y 4 & 1.000 & 1.180 & 3.299 & 0.990 & No \\
\hline $1,2 y 3$ vs $2,3 y 4$ & 1.000 & 1.180 & 3.299 & 0.990 & No \\
\hline $1,2 y 3$ vs 6 & 0.625 & 0.737 & 3.299 & 1.000 & No \\
\hline $1,2 y 3$ vs 5 & 0.217 & 0.256 & 3.299 & 1.000 & No \\
\hline 1,2 y3 vs 2 y 3 & 0.091 & 0.107 & 3.299 & 1.000 & No \\
\hline 2 y 3 vs 1 y 4 & 0.909 & 1.072 & 3.299 & 0.996 & No \\
\hline 2 y 3 vs 2,3 y 4 & 0.909 & 1.072 & 3.299 & 0.996 & No \\
\hline 2 y 3 vs 6 & 0.534 & 0.630 & 3.299 & 1.000 & No \\
\hline 2 y 3 vs 5 & 0.126 & 0.149 & 3.299 & 1.000 & No \\
\hline 5 vs 1 y 4 & 0.783 & 0.924 & 3.299 & 0.999 & No \\
\hline 5 vs $2,3 y 4$ & 0.783 & 0.924 & 3.299 & 0.999 & No \\
\hline 5 vs 6 & 0.408 & 0.481 & 3.299 & 1.000 & No \\
\hline 6 vs 1 y 4 & 0.375 & 0.442 & 3.299 & 1.000 & No \\
\hline 6 vs $2,3 y 4$ & 0.375 & 0.442 & 3.299 & 1.000 & No \\
\hline $2,3 y 4$ vs 1 y 4 & 0.000 & 0.000 & 3.299 & 1.000 & No \\
\hline
\end{tabular}

Fuente: Propia

Como podemos apreciar en el grafico de medias (Figura 16), la categoría 1 y 6 posee una media significativamente mayor que el resto. Así mismo las categorías 1 y 4 ; y 2,3 y 4 son las que presentan las medias más bajas. A su vez el resto de categorías poseen medias similares situándose entre los valores 2,5 y 1 . 
Al analizar los contrastes (Tabla 68), vemos que el par 1 y 6 vs 1 y 4 son

estadísticamente significativos, $\mathrm{p}=0,025$. Así como el par 1 y 6 vs 2,3 y 4, $\mathrm{p}=0,025$.

5.4.5.2. Análisis de la variable i10 (V4). Presentación de contenidos abordados en el programa.

Estudiamos si existen diferencias estadísticamente significativas en los contenidos de los programas con respecto al tipo de público al que están dirigidos.

Tabla 69. Análisis de varianza (i10) (V4)

\begin{tabular}{|c|c|c|c|c|c|}
\hline Fuente & GL & $\begin{array}{l}\text { Suma de } \\
\text { cuadrados }\end{array}$ & $\begin{array}{l}\text { Cuadrados } \\
\text { medios }\end{array}$ & $\mathrm{F}$ & $\operatorname{Pr}>\mathrm{F}$ \\
\hline Modelo & 11 & 28.665 & 2.606 & 3.204 & 0.000 \\
\hline Error & 249 & 202.507 & 0.813 & & \\
\hline $\begin{array}{l}\text { Total } \\
\text { corregido }\end{array}$ & 260 & 231.172 & & & \\
\hline
\end{tabular}

Fuente: Propia

Dado el valor $\mathrm{p}$ asociado al estadístico $\mathrm{F}$ calculado en la tabla ANOVA, y dado el nivel de significación del 5\%, existen diferencias estadísticamente significativas en la variable $\mathrm{i} 10$.

Figura 17. Gráfico de medias. (i10)(V4)

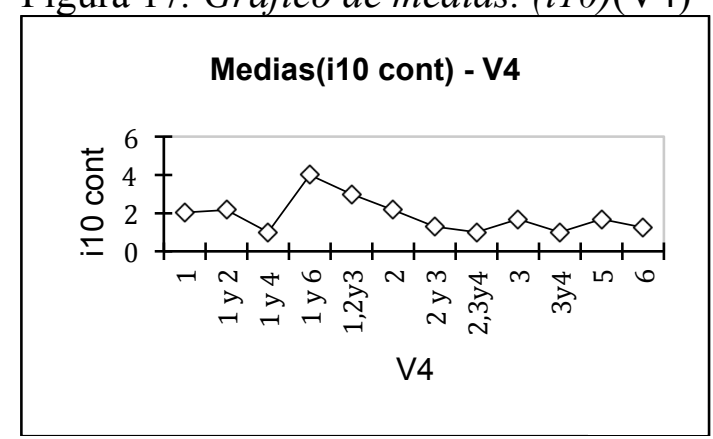

Fuente: Propia

Tabla 70. Análisis de diferencias entre las categorías (V4)

\begin{tabular}{lllllll}
\hline Categoría & Medias LS & $\begin{array}{l}\text { Error } \\
\text { estándar }\end{array}$ & $\begin{array}{l}\text { Límite } \\
\text { inferior } \\
(95 \%)\end{array}$ & Límite & Grupos & \\
\hline 1 y 6 & 4.000 & 0.902 & 2.224 & 5.776 & $\mathrm{~A}$ & \\
1,2 y3 & 3.000 & 0.902 & 1.224 & 4.776 & $\mathrm{~A}$ & $\mathrm{~B}$ \\
1 y 2 & 2.160 & 0.180 & 1.805 & 2.515 & $\mathrm{~A}$ & $\mathrm{~B}$ \\
2 & 2.158 & 0.146 & 1.870 & 2.446 & $\mathrm{~A}$ & $\mathrm{~B}$ \\
1 & 2.048 & 0.114 & 1.824 & 2.271 & $\mathrm{~A}$ & $\mathrm{~B}$ \\
3 & 1.700 & 0.202 & 1.303 & 2.097 & $\mathrm{~A}$ & $\mathrm{~B}$ \\
5 & 1.687 & 0.099 & 1.492 & 1.882 & $\mathrm{~A}$ & $\mathrm{~B}$ \\
2 y 3 & 1.273 & 0.272 & 0.737 & 1.808 & $\mathrm{~A}$ & $\mathrm{~B}$ \\
6 & 1.250 & 0.225 & 0.806 & 1.694 & $\mathrm{~A}$ & $\mathrm{~B}$ \\
1 y 4 & 1.000 & 0.902 & -0.776 & 2.776 & & $\mathrm{~B}$ \\
2,3 y4 & 1.000 & 0.902 & -0.776 & 2.776 & & $\mathrm{~B}$
\end{tabular}


Fuente: Propia

Tabla71.Público al que se dirige / Tukey (HSD) / Análisis de las diferencias entre las categorías con un intervalo de confianza de 95\% (i10 cont)(V4).

\begin{tabular}{|c|c|c|c|c|c|}
\hline Contraste & Diferencia & $\begin{array}{l}\text { Diferencia } \\
\text { estandarizada }\end{array}$ & $\begin{array}{l}\text { Valor } \\
\text { crítico }\end{array}$ & $\operatorname{Pr}>$ Dif & Significativo \\
\hline 1 y 6 vs 1 y 4 & 3.000 & 2.352 & 3.299 & 0.024 & Yes \\
\hline 1 y 6 vs $2,3 y 4$ & 3.000 & 2.352 & 3.299 & 0.024 & Yes \\
\hline 1 y 6 vs 3y4 & 3.000 & 2.352 & 3.299 & 0.024 & Yes \\
\hline 1 y 6 vs 6 & 2.750 & 2.958 & 3.299 & 0.059 & No \\
\hline 1 y 6 vs 2 y 3 & 2.727 & 2.895 & 3.299 & 0.063 & No \\
\hline 1 y 6 vs 5 & 2.313 & 2.550 & 3.299 & 0.218 & No \\
\hline 1 y 6 vs 3 & 2.300 & 2.489 & 3.299 & 0.226 & No \\
\hline 1 y 6 vs 1 & 1.952 & 2.148 & 3.299 & 0.477 & No \\
\hline 1 y 6 vs 2 & 1.842 & 2.016 & 3.299 & 0.570 & No \\
\hline 1 y 6 vs 1 y 2 & 1.840 & 2.001 & 3.299 & 0.572 & No \\
\hline 1 y 6 vs 1,2 y3 & 1.000 & 0.784 & 3.299 & 0.990 & No \\
\hline $1,2 y 3$ vs 1 y 4 & 2.000 & 1.568 & 3.299 & 0.437 & No \\
\hline $1,2 y 3$ vs $2,3 y 4$ & 2.000 & 1.568 & 3.299 & 0.437 & No \\
\hline $1,2 y 3$ vs 3y4 & 2.000 & 1.568 & 3.299 & 0.437 & No \\
\hline $1,2 y 3$ vs 6 & 1.750 & 1.883 & 3.299 & 0.648 & No \\
\hline $1,2 y 3$ vs 2 y 3 & 1.727 & 1.834 & 3.299 & 0.667 & No \\
\hline $1,2 y 3$ vs 5 & 1.313 & 1.448 & 3.299 & 0.925 & No \\
\hline $1,2 y 3$ vs 3 & 1.300 & 1.407 & 3.299 & 0.930 & No \\
\hline $1,2 y 3$ vs 1 & 0.952 & 1.048 & 3.299 & 0.993 & No \\
\hline $1,2 y 3$ vs 2 & 0.842 & 0.922 & 3.299 & 0.998 & No \\
\hline 1,2 y 3 vs 1 y 2 & 0.840 & 0.913 & 3.299 & 0.998 & No \\
\hline 1 y 2 vs 1 y 4 & 1.160 & 1.261 & 3.299 & 0.968 & No \\
\hline 1 y 2 vs $2,3 y 4$ & 1.160 & 1.261 & 3.299 & 0.968 & No \\
\hline 1 y 2 vs $3 y 4$ & 1.160 & 1.261 & 3.299 & 0.968 & No \\
\hline 1 y 2 vs 6 & 0.910 & 3.152 & 3.299 & 0.996 & No \\
\hline 1 y 2 vs 2 y 3 & 0.887 & 2.719 & 3.299 & 0.996 & No \\
\hline 1 y 2 vs 5 & 0.473 & 2.300 & 3.299 & 1.000 & No \\
\hline 1 y 2 vs 3 & 0.460 & 1.700 & 3.299 & 1.000 & No \\
\hline 1 y 2 vs 1 & 0.112 & 0.527 & 3.299 & 1.000 & No \\
\hline 1 y 2 vs 2 & 0.002 & 0.009 & 3.299 & 1.000 & No \\
\hline 2 vs 1 y 4 & 1.158 & 1.267 & 3.299 & 0.969 & No \\
\hline 2 vs $2,3 y 4$ & 1.158 & 1.267 & 3.299 & 0.969 & No \\
\hline 2 vs 3y4 & 1.158 & 1.267 & 3.299 & 0.969 & No \\
\hline 2 vs 6 & 0.908 & 3.378 & 3.299 & 0.996 & No \\
\hline 2 vs 2 y 3 & 0.885 & 2.867 & 3.299 & 0.996 & No \\
\hline 2 vs 5 & 0.471 & 2.667 & 3.299 & 1.000 & No \\
\hline
\end{tabular}




\begin{tabular}{|c|c|c|c|c|c|}
\hline 2 vs 3 & 0.458 & 1.838 & 3.299 & 1.000 & No \\
\hline 2 vs 1 & 0.110 & 0.595 & 3.299 & 1.000 & No \\
\hline 1 vs 1 y 4 & 1.048 & 1.153 & 3.299 & 0.986 & No \\
\hline 1 vs $2,3 y 4$ & 1.048 & 1.153 & 3.299 & 0.986 & No \\
\hline 1 vs $3 y 4$ & 1.048 & 1.153 & 3.299 & 0.986 & No \\
\hline 1 vs 6 & 0.798 & 3.159 & 3.299 & 0.999 & No \\
\hline 1 vs 2 y 3 & 0.775 & 2.629 & 3.299 & 0.999 & No \\
\hline 1 vs 5 & 0.361 & 2.395 & 3.299 & 1.000 & No \\
\hline 1 vs 3 & 0.348 & 1.502 & 3.299 & 1.000 & No \\
\hline 3 vs 1 y 4 & 0.700 & 0.758 & 3.299 & 1.000 & No \\
\hline 3 vs $2,3 y 4$ & 0.700 & 0.758 & 3.299 & 1.000 & No \\
\hline 3 vs $3 y 4$ & 0.700 & 0.758 & 3.299 & 1.000 & No \\
\hline 3 vs 6 & 0.450 & 1.488 & 3.299 & 1.000 & No \\
\hline 3 vs 2 y 3 & 0.427 & 1.262 & 3.299 & 1.000 & No \\
\hline 3 vs 5 & 0.013 & 0.059 & 3.299 & 1.000 & No \\
\hline 5 vs 1 y 4 & 0.687 & 0.757 & 3.299 & 1.000 & No \\
\hline 5 vs $2,3 y 4$ & 0.687 & 0.757 & 3.299 & 1.000 & No \\
\hline 5 vs $3 y 4$ & 0.687 & 0.757 & 3.299 & 1.000 & No \\
\hline 5 vs 6 & 0.437 & 1.774 & 3.299 & 1.000 & No \\
\hline 5 vs 2 y 3 & 0.414 & 1.431 & 3.299 & 1.000 & No \\
\hline 2 y 3 vs 1 y 4 & 0.273 & 0.290 & 3.299 & 1.000 & No \\
\hline 2 y 3 vs 2,3y4 & 0.273 & 0.290 & 3.299 & 1.000 & No \\
\hline 2 y 3 vs $3 y 4$ & 0.273 & 0.290 & 3.299 & 1.000 & No \\
\hline 2 y 3 vs 6 & 0.023 & 0.064 & 3.299 & 1.000 & No \\
\hline 6 vs 1 y 4 & 0.250 & 0.269 & 3.299 & 1.000 & No \\
\hline 6 vs $2,3 y 4$ & 0.250 & 0.269 & 3.299 & 1.000 & No \\
\hline 6 vs $3 y 4$ & 0.250 & 0.269 & 3.299 & 1.000 & No \\
\hline $3 y 4$ vs 1 y 4 & 0.000 & 0.000 & 3.299 & 1.000 & No \\
\hline $3 y 4$ vs $2,3 y 4$ & 0.000 & 0.000 & 3.299 & 1.000 & No \\
\hline $2,3 y 4$ vs 1 y 4 & 0.000 & 0.000 & 3.299 & 1.000 & No \\
\hline
\end{tabular}

Fuente: Propia

Como podemos apreciar en el grafico de medias (Figura 17), la categoría 1 y 6 posee una media mayor que el resto $(4,000)$. En segundo lugar encontramos la categoría 1, 2 y 3 , con un valor de 3,000. El resto de categorías se sitúan entre los valores 2,200 y 1,000 .

Al analizar los contrastes (Tabla 71), vemos que los pares 1 y 6 vs 1 y 4 ; 1 y 6 vs 2,3 y 4; y 1 y 6 vs 3 y 4 resultan estadísticamente significativos, siendo para todos ellos $\mathrm{p}=0,025$.

5.4.5.3. Análisis de la variable i11 (V4). Orientación metodológica y estrategias de enseñanza aprendizaje. 
Estudiamos si existen diferencias estadísticamente significativas en la metodología de los programas con respecto al tipo de público al que están dirigidos.

Tabla 72. Análisis de varianza (i11) (V4)

\begin{tabular}{|c|c|c|c|c|c|}
\hline Fuente & GL & $\begin{array}{l}\text { Suma de } \\
\text { cuadrados }\end{array}$ & $\begin{array}{l}\text { Cuadrados } \\
\text { medios }\end{array}$ & $\mathrm{F}$ & $\operatorname{Pr}>F$ \\
\hline Modelo & 11 & 24.634 & 2.239 & 3.559 & 0.000 \\
\hline Error & 249 & 156.676 & 0.629 & & \\
\hline $\begin{array}{l}\text { Total } \\
\text { corregido }\end{array}$ & 260 & 181.310 & & & \\
\hline
\end{tabular}

Fuente: Propia

Dado el valor $\mathrm{p}$ asociado al estadístico $\mathrm{F}$ calculado en la tabla ANOVA, y dado el nivel de significación del 5\%, existen diferencias estadísticamente significativas en la variable $\mathrm{i} 11$.

Figura 18. Gráfico de medias. (i11) (V4)

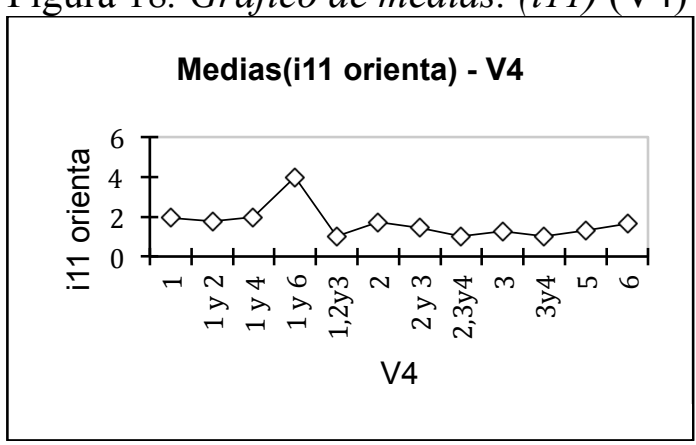

Fuente: Propia

Tabla 73. Análisis de diferencias entre las categorías (V4)

\begin{tabular}{lllllll}
\hline Categoría & Medias LS & $\begin{array}{l}\text { Error } \\
\text { estándar }\end{array}$ & $\begin{array}{l}\text { Límite } \\
\text { inferior } \\
(95 \%)\end{array}$ & $\begin{array}{l}\text { Límite } \\
\text { superior } \\
(95 \%)\end{array}$ & Grupos & \\
\hline 1 y 6 & 4.000 & 0.793 & 2.438 & 5.562 & $\mathrm{~A}$ & \\
1 y 4 & 2.000 & 0.793 & 0.438 & 3.562 & $\mathrm{~A}$ & $\mathrm{~B}$ \\
1 & 1.921 & 0.100 & 1.724 & 2.117 & $\mathrm{~A}$ & $\mathrm{~B}$ \\
1 y 2 & 1.760 & 0.159 & 1.448 & 2.072 & $\mathrm{~A}$ & $\mathrm{~B}$ \\
2 & 1.711 & 0.129 & 1.457 & 1.964 & $\mathrm{~A}$ & $\mathrm{~B}$ \\
6 & 1.625 & 0.198 & 1.234 & 2.016 & $\mathrm{~A}$ & $\mathrm{~B}$ \\
2 y 3 & 1.455 & 0.239 & 0.983 & 1.926 & & $\mathrm{~B}$ \\
5 & 1.301 & 0.087 & 1.130 & 1.473 & & $\mathrm{~B}$ \\
3 & 1.250 & 0.177 & 0.901 & 1.599 & & $\mathrm{~B}$ \\
1,2 y3 & 1.000 & 0.793 & -0.562 & 2.562 & & $\mathrm{~B}$ \\
2,3 y4 & 1.000 & 0.793 & -0.562 & 2.562 & & $\mathrm{~B}$ \\
3у4 & 1.000 & 0.793 & -0.562 & 2.562 & & $\mathrm{~B}$ \\
\hline
\end{tabular}

Fuente: Propia 
Tabla 74.Público al que se dirige / Tukey (HSD) / Análisis de las diferencias entre las categorías con un intervalo de confianza de 95\% (i11 orienta) (V4).

\begin{tabular}{|c|c|c|c|c|c|}
\hline Contraste & Diferencia & $\begin{array}{c}\text { Diferencia } \\
\text { estandarizada }\end{array}$ & $\begin{array}{l}\text { Valor } \\
\text { crítico }\end{array}$ & $\operatorname{Pr}>$ Dif & Significativo \\
\hline 1 y 6 vs 1,2 y3 & 3.000 & 4.025 & 3.299 & 0.004 & Sí \\
\hline 1 y 6 vs $2,3 y 4$ & 3.000 & 4.025 & 3.299 & 0.004 & Sí \\
\hline 1 y 6 vs $3 y 4$ & 3.000 & 4.025 & 3.299 & 0.004 & Sí \\
\hline 1 y 6 vs 3 & 2.750 & 3.689 & 3.299 & 0.014 & Sí \\
\hline 1 y 6 vs 5 & 2.699 & 3.621 & 3.299 & 0.018 & Sí \\
\hline 1 y 6 vs 2 y 3 & 2.545 & 3.415 & 3.299 & 0.035 & Sí \\
\hline 1 y 6 vs 6 & 2.375 & 3.186 & 3.299 & 0.069 & No \\
\hline 1 y 6 vs 2 & 2.289 & 3.072 & 3.299 & 0.095 & No \\
\hline 1 y 6 vs 1 y 2 & 2.240 & 3.005 & 3.299 & 0.113 & No \\
\hline 1 y 6 vs 1 & 2.079 & 2.790 & 3.299 & 0.191 & No \\
\hline 1 y 6 vs 1 y 4 & 2.000 & 2.683 & 3.299 & 0.241 & No \\
\hline 1 y 4 vs 1,2 y3 & 1.000 & 1.342 & 3.299 & 0.973 & No \\
\hline 1 y 4 vs $2,3 y 4$ & 1.000 & 1.342 & 3.299 & 0.973 & No \\
\hline 1 y 4 vs $3 y 4$ & 1.000 & 1.342 & 3.299 & 0.973 & No \\
\hline 1 y 4 vs 3 & 0.750 & 1.006 & 3.299 & 0.997 & No \\
\hline 1 y 4 vs 5 & 0.699 & 0.938 & 3.299 & 0.999 & No \\
\hline 1 y 4 vs 2 y 3 & 0.545 & 0.732 & 3.299 & 1.000 & No \\
\hline 1 y 4 vs 6 & 0.375 & 0.503 & 3.299 & 1.000 & No \\
\hline 1 y 4 vs 2 & 0.289 & 0.388 & 3.299 & 1.000 & No \\
\hline 1 y 4 vs 1 y 2 & 0.240 & 0.322 & 3.299 & 1.000 & No \\
\hline 1 y 4 vs 1 & 0.079 & 0.106 & 3.299 & 1.000 & No \\
\hline 1 vs $1,2 y 3$ & 0.921 & 1.235 & 3.299 & 0.986 & No \\
\hline 1 vs $2,3 y 4$ & 0.921 & 1.235 & 3.299 & 0.986 & No \\
\hline 1 vs $3 y 4$ & 0.921 & 1.235 & 3.299 & 0.986 & No \\
\hline 1 vs 3 & 0.671 & 0.900 & 3.299 & 0.999 & No \\
\hline 1 vs 5 & 0.619 & 0.831 & 3.299 & 1.000 & No \\
\hline 1 vs 2 y 3 & 0.466 & 0.625 & 3.299 & 1.000 & No \\
\hline 1 vs 6 & 0.296 & 0.397 & 3.299 & 1.000 & No \\
\hline 1 vs 2 & 0.210 & 0.282 & 3.299 & 1.000 & No \\
\hline 1 vs 1 y 2 & 0.161 & 0.216 & 3.299 & 1.000 & No \\
\hline 1 y 2 vs 1,2 y 3 & 0.760 & 1.020 & 3.299 & 0.997 & No \\
\hline 1 y 2 vs $2,3 y 4$ & 0.760 & 1.020 & 3.299 & 0.997 & No \\
\hline 1 y 2 vs $3 y 4$ & 0.760 & 1.020 & 3.299 & 0.997 & No \\
\hline 1 y 2 vs 3 & 0.510 & 0.684 & 3.299 & 1.000 & No \\
\hline 1 y 2 vs 5 & 0.459 & 0.616 & 3.299 & 1.000 & No \\
\hline 1 y 2 vs 2 y 3 & 0.305 & 0.410 & 3.299 & 1.000 & No \\
\hline 1 y 2 vs 6 & 0.135 & 0.181 & 3.299 & 1.000 & No \\
\hline
\end{tabular}




\begin{tabular}{|c|c|c|c|c|c|}
\hline 1 y 2 vs 2 & 0.049 & 0.066 & 3.299 & 1.000 & No \\
\hline 2 vs $1,2 y 3$ & 0.711 & 0.953 & 3.299 & 0.998 & No \\
\hline 2 vs $2,3 y 4$ & 0.711 & 0.953 & 3.299 & 0.998 & No \\
\hline 2 vs $3 y 4$ & 0.711 & 0.953 & 3.299 & 0.998 & No \\
\hline 2 vs 3 & 0.461 & 0.618 & 3.299 & 1.000 & No \\
\hline 2 vs 5 & 0.409 & 0.549 & 3.299 & 1.000 & No \\
\hline 2 vs 2 y 3 & 0.256 & 0.343 & 3.299 & 1.000 & No \\
\hline 2 vs 6 & 0.086 & 0.115 & 3.299 & 1.000 & No \\
\hline 6 vs $1,2 y 3$ & 0.625 & 0.839 & 3.299 & 1.000 & No \\
\hline 6 vs 2,3y4 & 0.625 & 0.839 & 3.299 & 1.000 & No \\
\hline 6 vs $3 y 4$ & 0.625 & 0.839 & 3.299 & 1.000 & No \\
\hline 6 vs 3 & 0.375 & 0.503 & 3.299 & 1.000 & No \\
\hline 6 vs 5 & 0.324 & 0.434 & 3.299 & 1.000 & No \\
\hline 6 vs 2 y 3 & 0.170 & 0.229 & 3.299 & 1.000 & No \\
\hline 2 y 3 vs 1,2 y3 & 0.455 & 0.610 & 3.299 & 1.000 & No \\
\hline 2 y 3 vs $2,3 y 4$ & 0.455 & 0.610 & 3.299 & 1.000 & No \\
\hline 2 y 3 vs $3 y 4$ & 0.455 & 0.610 & 3.299 & 1.000 & No \\
\hline 2 y 3 vs 3 & 0.205 & 0.274 & 3.299 & 1.000 & No \\
\hline 2 y 3 vs 5 & 0.153 & 0.206 & 3.299 & 1.000 & No \\
\hline 5 vs $1,2 y 3$ & 0.301 & 0.404 & 3.299 & 1.000 & No \\
\hline 5 vs 2,3y4 & 0.301 & 0.404 & 3.299 & 1.000 & No \\
\hline 5 vs $3 y 4$ & 0.301 & 0.404 & 3.299 & 1.000 & No \\
\hline 5 vs 3 & 0.051 & 0.069 & 3.299 & 1.000 & No \\
\hline 3 vs $1,2 y 3$ & 0.250 & 0.335 & 3.299 & 1.000 & No \\
\hline 3 vs 2,3y4 & 0.250 & 0.335 & 3.299 & 1.000 & No \\
\hline 3 vs $3 y 4$ & 0.250 & 0.335 & 3.299 & 1.000 & No \\
\hline $3 y 4$ vs 1,2y3 & 0.000 & 0.000 & 3.299 & 1.000 & No \\
\hline $3 y 4$ vs $2,3 y 4$ & 0.000 & 0.000 & 3.299 & 1.000 & No \\
\hline $2,3 y 4$ vs $1,2 y 3$ & 0.000 & 0.000 & 3.299 & 1.000 & No \\
\hline \multicolumn{3}{|c|}{ Valor crítico del d de Tukey: } & 4.666 & & \\
\hline
\end{tabular}

Como podemos apreciar en el grafico de medias (Figura 18), la categoría 1 y 6 posee una media significativamente mayor que el resto. El resto de categorías se sitúan entre los valores 2,000 y 1,000 .

Al analizar los contrastes (Tabla 71), vemos que los pares 1 y 6 vs 1 , y $3 ; 1$ y 6 vs 2,3 y $4 ; 1$ y 6 vs 3 y 4 ; 1 y 6 vs $3 ; 1$ y 6 vs 5 ; y1 y 6 vs 3 son estadísticamente significativos.

5.4.5.4. Análisis de la variable i12(V4). Definición de recursos, formatos, soportes, y tecnología empleados.

Estudiamos si existen diferencias estadísticamente significativas en los recursos de los programas con respecto al tipo de público al que están dirigidos. 
Tabla 75. Análisis de varianza (i12) (V4)

\begin{tabular}{|c|c|c|c|c|c|}
\hline Fuente & GL & $\begin{array}{l}\text { Suma de } \\
\text { cuadrados }\end{array}$ & $\begin{array}{l}\text { Cuadrados } \\
\text { medios }\end{array}$ & $\mathrm{F}$ & $\operatorname{Pr}>F$ \\
\hline Modelo & 11 & 30.112 & 2.737 & 3.656 & $<0.0001$ \\
\hline Error & 249 & 186.440 & 0.749 & & \\
\hline $\begin{array}{l}\text { Total } \\
\text { corregido }\end{array}$ & 260 & 216.552 & & & \\
\hline
\end{tabular}

Fuente: Propia

Dado el valor $\mathrm{p}$ asociado al estadístico $\mathrm{F}$ calculado en la tabla ANOVA, y dado el nivel de significación del 5\%, existen diferencias estadísticamente significativas en la variable i12.

Figura 19. Gráfico de medias. (i12) (V4)

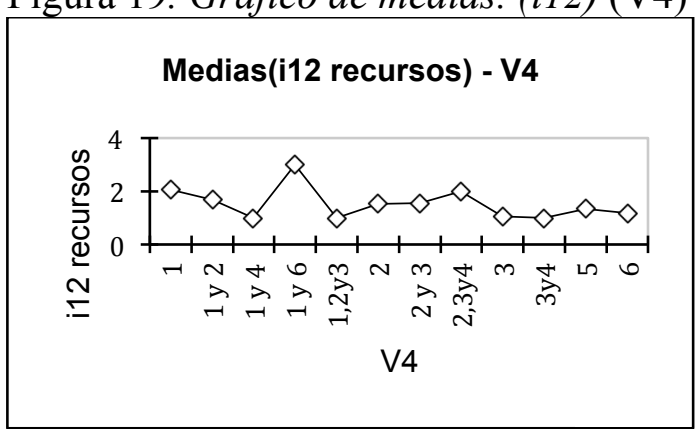

Fuente: Propia

Tabla 76. Análisis de diferencias entre las categorías. (V4)

\begin{tabular}{llllll}
\hline Categoría & Medias LS & $\begin{array}{l}\text { Error } \\
\text { estándar }\end{array}$ & $\begin{array}{l}\text { Límite } \\
\text { inferior } \\
(95 \%)\end{array}$ & $\begin{array}{l}\text { Límite } \\
\text { superior } \\
(95 \%)\end{array}$ & Grupos \\
\hline 1 y 6 & 3.000 & 0.865 & 1.296 & 4.704 & $\mathrm{~A}$ \\
1 & 2.048 & 0.109 & 1.833 & 2.262 & $\mathrm{~A}$ \\
2,3 y4 & 2.000 & 0.865 & 0.296 & 3.704 & $\mathrm{~A}$ \\
1 y 2 & 1.680 & 0.173 & 1.339 & 2.021 & $\mathrm{~A}$ \\
2 y 3 & 1.545 & 0.261 & 1.032 & 2.059 & $\mathrm{~A}$ \\
2 & 1.526 & 0.140 & 1.250 & 1.803 & $\mathrm{~A}$ \\
5 & 1.337 & 0.095 & 1.150 & 1.524 & $\mathrm{~A}$ \\
6 & 1.188 & 0.216 & 0.761 & 1.614 & $\mathrm{~A}$ \\
3 & 1.050 & 0.193 & 0.669 & 1.431 & $\mathrm{~A}$ \\
1 y 4 & 1.000 & 0.865 & -0.704 & 2.704 & $\mathrm{~A}$ \\
1,2 y3 & 1.000 & 0.865 & -0.704 & 2.704 & $\mathrm{~A}$ \\
3y4 & 1.000 & 0.865 & -0.704 & 2.704 & $\mathrm{~A}$ \\
\hline \multicolumn{5}{c}{ Fuente: Propia } &
\end{tabular}

Tabla 77.Público al que se dirige / Tukey (HSD) / Análisis de las diferencias entre las categorías con un intervalo de confianza de 95\% (i12 recursos) (V4). 


\begin{tabular}{|c|c|c|c|c|c|}
\hline Contraste & Diferencia & $\begin{array}{c}\text { Diferencia } \\
\text { estandarizada }\end{array}$ & $\begin{array}{l}\text { Valor } \\
\text { crítico }\end{array}$ & $\operatorname{Pr}>$ Dif & Significativo \\
\hline 1 y 6 vs 1 y 4 & 2.000 & 2.460 & 3.299 & 0.370 & No \\
\hline 1 y 6 vs $1,2 y 3$ & 2.000 & 2.460 & 3.299 & 0.370 & No \\
\hline 1 y 6 vs $3 y 4$ & 2.000 & 2.460 & 3.299 & 0.370 & No \\
\hline 1 y 6 vs 3 & 1.950 & 2.398 & 3.299 & 0.411 & No \\
\hline 1 y 6 vs 6 & 1.813 & 2.229 & 3.299 & 0.530 & No \\
\hline 1 y 6 vs 5 & 1.663 & 2.045 & 3.299 & 0.662 & No \\
\hline 1 y 6 vs 2 & 1.474 & 1.812 & 3.299 & 0.810 & No \\
\hline 1 y 6 vs 2 y 3 & 1.455 & 1.789 & 3.299 & 0.823 & No \\
\hline 1 y 6 vs 1 y 2 & 1.320 & 1.623 & 3.299 & 0.899 & No \\
\hline 1 y 6 vs $2,3 y 4$ & 1.000 & 1.230 & 3.299 & 0.986 & No \\
\hline 1 y 6 vs 1 & 0.952 & 1.171 & 3.299 & 0.991 & No \\
\hline 1 vs 1 y 4 & 1.048 & 1.288 & 3.299 & 0.980 & No \\
\hline 1 vs $1,2 y 3$ & 1.048 & 1.288 & 3.299 & 0.980 & No \\
\hline 1 vs $3 y 4$ & 1.048 & 1.288 & 3.299 & 0.980 & No \\
\hline 1 vs 3 & 0.998 & 1.227 & 3.299 & 0.986 & No \\
\hline 1 vs 6 & 0.860 & 1.058 & 3.299 & 0.996 & No \\
\hline 1 vs 5 & 0.710 & 0.874 & 3.299 & 0.999 & No \\
\hline 1 vs 2 & 0.521 & 0.641 & 3.299 & 1.000 & No \\
\hline 1 vs 2 y 3 & 0.502 & 0.618 & 3.299 & 1.000 & No \\
\hline 1 vs 1 y 2 & 0.368 & 0.452 & 3.299 & 1.000 & No \\
\hline 1 vs $2,3 y 4$ & 0.048 & 0.059 & 3.299 & 1.000 & No \\
\hline $2,3 y 4$ vs 1 y 4 & 1.000 & 1.230 & 3.299 & 0.986 & No \\
\hline $2,3 y 4$ vs $1,2 y 3$ & 1.000 & 1.230 & 3.299 & 0.986 & No \\
\hline 2,3y4 vs 3y4 & 1.000 & 1.230 & 3.299 & 0.986 & No \\
\hline $2,3 y 4$ vs 3 & 0.950 & 1.168 & 3.299 & 0.991 & No \\
\hline $2,3 y 4$ vs 6 & 0.812 & 0.999 & 3.299 & 0.998 & No \\
\hline $2,3 y 4$ vs 5 & 0.663 & 0.815 & 3.299 & 1.000 & No \\
\hline $2,3 y 4$ vs 2 & 0.474 & 0.583 & 3.299 & 1.000 & No \\
\hline $2,3 y 4$ vs 2 y 3 & 0.455 & 0.559 & 3.299 & 1.000 & No \\
\hline $2,3 y 4$ vs 1 y 2 & 0.320 & 0.394 & 3.299 & 1.000 & No \\
\hline 1 y 2 vs 1 y 4 & 0.680 & 0.836 & 3.299 & 1.000 & No \\
\hline 1 y 2 vs 1,2 y3 & 0.680 & 0.836 & 3.299 & 1.000 & No \\
\hline 1 y 2 vs $3 y 4$ & 0.680 & 0.836 & 3.299 & 1.000 & No \\
\hline 1 y 2 vs 3 & 0.630 & 0.775 & 3.299 & 1.000 & No \\
\hline 1 y 2 vs 6 & 0.492 & 0.606 & 3.299 & 1.000 & No \\
\hline 1 y 2 vs 5 & 0.343 & 0.421 & 3.299 & 1.000 & No \\
\hline 1 y 2 vs 2 & 0.154 & 0.189 & 3.299 & 1.000 & No \\
\hline 1 y 2 vs 2 y 3 & 0.135 & 0.165 & 3.299 & 1.000 & No \\
\hline 2 y 3 vs 1 y 4 & 0.545 & 0.671 & 3.299 & 1.000 & No \\
\hline 2 y 3 vs 1,2 y3 & 0.545 & 0.671 & 3.299 & 1.000 & No \\
\hline 2 y 3 vs $3 y 4$ & 0.545 & 0.671 & 3.299 & 1.000 & No \\
\hline
\end{tabular}




\begin{tabular}{llllll}
2 y 3 vs 3 & 0.495 & 0.609 & 3.299 & 1.000 & No \\
2 y 3 vs 6 & 0.358 & 0.440 & 3.299 & 1.000 & No \\
2 y 3 vs 5 & 0.208 & 0.256 & 3.299 & 1.000 & No \\
2 y 3 vs 2 & 0.019 & 0.024 & 3.299 & 1.000 & No \\
2 vs 1 y 4 & 0.526 & 0.647 & 3.299 & 1.000 & No \\
2 vs 1,2 y3 & 0.526 & 0.647 & 3.299 & 1.000 & No \\
2 vs 3y4 & 0.526 & 0.647 & 3.299 & 1.000 & No \\
2 vs 3 & 0.476 & 0.586 & 3.299 & 1.000 & No \\
2 vs 6 & 0.339 & 0.417 & 3.299 & 1.000 & No \\
2 vs 5 & 0.189 & 0.232 & 3.299 & 1.000 & No \\
5 vs 1 y 4 & 0.337 & 0.415 & 3.299 & 1.000 & No \\
5 vs 1,2 y3 & 0.337 & 0.415 & 3.299 & 1.000 & No \\
5 vs 3y4 & 0.337 & 0.415 & 3.299 & 1.000 & No \\
5 vs 3 & 0.287 & 0.353 & 3.299 & 1.000 & No \\
5 vs 6 & 0.150 & 0.184 & 3.299 & 1.000 & No \\
6 vs 1 y 4 & 0.188 & 0.231 & 3.299 & 1.000 & No \\
6 vs 1,2 y3 & 0.188 & 0.231 & 3.299 & 1.000 & No \\
6 vs 3y4 & 0.188 & 0.231 & 3.299 & 1.000 & No \\
6 vs 3 & 0.138 & 0.169 & 3.299 & 1.000 & No \\
3 vs 1 y 4 & 0.050 & 0.061 & 3.299 & 1.000 & No \\
3 vs 1,2 y3 & 0.050 & 0.061 & 3.299 & 1.000 & No \\
3 vs 3y4 & 0.050 & 0.061 & 3.299 & 1.000 & No \\
3 y4 vs 1 y 4 & 0.000 & 0.000 & 3.299 & 1.000 & No \\
3 y4 vs 1,2 y3 & 0.000 & 0.000 & 3.299 & 1.000 & No \\
1,2 y3 vs 1 y 4 & 0.000 & 0.000 & 3.299 & 1.000 & No \\
\hline Valor crítico del d de Tukey: & & 4.666 & &
\end{tabular}

Fuente: Propia

Como podemos apreciar en el grafico de medias, la categoría 1 y 6 posee la media más alta 3,000, seguida por la categoría 1 y 2 que presenta un valor de 2,333. Así mismo las categorías 1 y $4 ; 1,2,3$; y 3, 4 son las que presentala medias más baja $(1,000)$.

Al analizar los contrastes observamos que ninguno de ellos resulta estadísticamente significativo.

5.4.5.5. Análisis de la variable i13(V4). Determinación de los sistemas o herramientas de evaluación.

Estudiamos si existen diferencias estadísticamente significativas en la evaluación de los programas con respecto al tipo de público al que están dirigidos.

Tabla 78. Análisis de varianza (i13) (V4)

\begin{tabular}{|c|c|c|c|c|c|}
\hline Fuente & GL & $\begin{array}{l}\text { Suma de } \\
\text { cuadrados }\end{array}$ & $\begin{array}{l}\text { Cuadrados } \\
\text { medios }\end{array}$ & $\mathrm{F}$ & $\operatorname{Pr}>F$ \\
\hline Modelo & 11 & 16.557 & 1.505 & 2.715 & 0.003 \\
\hline Error & 249 & 138.025 & 0.554 & & \\
\hline
\end{tabular}


Total

corregido $\quad 260 \quad 154.582$

Fuente: Propia

Dado el valor $\mathrm{p}$ asociado al estadístico $\mathrm{F}$ calculado en la tabla ANOVA, y dado el nivel de significación del 5\%, existen diferencias estadísticamente significativas en la variable i13.

Figura 20. Gráfico de medias. (i13) (V4)

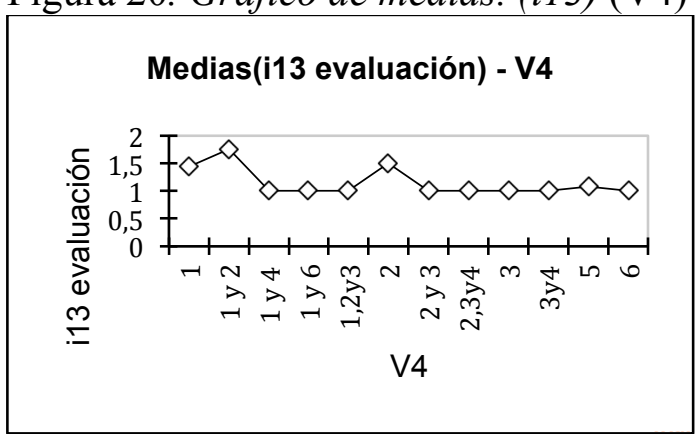

Fuente: Propia

Tabla 79. Análisis de diferencias entre las categorías (V4)

\begin{tabular}{llllll}
\hline Categoría & Medias LS & $\begin{array}{l}\text { Error } \\
\text { estándar }\end{array}$ & $\begin{array}{l}\text { Límite } \\
\text { inferior } \\
(95 \%)\end{array}$ & $\begin{array}{l}\text { Límite } \\
\text { superior } \\
(95 \%)\end{array}$ & Grupos \\
\hline 1 y 2 & 1.760 & 0.149 & 1.467 & 2.053 & $\mathrm{~A}$ \\
2 & 1.500 & 0.121 & 1.262 & 1.738 & $\mathrm{~A}$ \\
1 & 1.444 & 0.094 & 1.260 & 1.629 & $\mathrm{~A}$ \\
5 & 1.084 & 0.082 & 0.923 & 1.245 & $\mathrm{~A}$ \\
1 y 4 & 1.000 & 0.745 & -0.466 & 2.466 & $\mathrm{~A}$ \\
1 y 6 & 1.000 & 0.745 & -0.466 & 2.466 & $\mathrm{~A}$ \\
1,2 y3 & 1.000 & 0.745 & -0.466 & 2.466 & $\mathrm{~A}$ \\
2 y 3 & 1.000 & 0.224 & 0.558 & 1.442 & $\mathrm{~A}$ \\
2,3 y4 & 1.000 & 0.745 & -0.466 & 2.466 & $\mathrm{~A}$ \\
3 & 1.000 & 0.166 & 0.672 & 1.328 & $\mathrm{~A}$ \\
3 y4 & 1.000 & 0.745 & -0.466 & 2.466 & $\mathrm{~A}$ \\
6 & 1.000 & 0.186 & 0.633 & 1.367 & $\mathrm{~A}$ \\
\hline
\end{tabular}

Fuente: Propia

Tabla 80.Público al que se dirige / Tukey (HSD) / Análisis de las diferencias entre las categorías con un intervalo de confianza de 95\% (i13 evaluación) (V4).

\begin{tabular}{lrrrrc}
\hline \multicolumn{1}{c}{ Contraste } & Diferencia & $\begin{array}{c}\text { Diferencia } \\
\text { estandarizada }\end{array}$ & $\begin{array}{c}\text { Valor } \\
\text { crítico }\end{array}$ & Pr $>$ Dif & Significativo \\
\hline 1 y 2 vs 1 y 4 & 0.760 & 1.086 & 3.299 & 0.995 & No \\
1 y 2 vs 1 y 6 & 0.760 & 1.086 & 3.299 & 0.995 & No \\
1 y 2 vs 1,2y3 & 0.760 & 1.086 & 3.299 & 0.995 & No \\
1 y 2 vs 2 y 3 & 0.760 & 1.086 & 3.299 & 0.995 & No \\
1 y 2 vs 2,3y4 & 0.760 & 1.086 & 3.299 & 0.995 & No
\end{tabular}




\begin{tabular}{|c|c|c|c|c|}
\hline 1 y 2 vs 3 & 0.760 & 1.086 & 3.299 & 0.995 \\
\hline 1 y 2 vs $3 y 4$ & 0.760 & 1.086 & 3.299 & 0.995 \\
\hline 1 y 2 vs 6 & 0.760 & 1.086 & 3.299 & 0.995 \\
\hline 1 y 2 vs 5 & 0.676 & 0.966 & 3.299 & 0.998 \\
\hline 1 y 2 vs 1 & 0.316 & 0.451 & 3.299 & 1.000 \\
\hline 1 y 2 vs 2 & 0.260 & 0.372 & 3.299 & 1.000 \\
\hline 2 vs 1 y 4 & 0.500 & 0.715 & 3.299 & 1.000 \\
\hline 2 vs 1 y 6 & 0.500 & 0.715 & 3.299 & 1.000 \\
\hline 2 vs $1,2 y 3$ & 0.500 & 0.715 & 3.299 & 1.000 \\
\hline 2 vs 2 y 3 & 0.500 & 0.715 & 3.299 & 1.000 \\
\hline 2 vs $2,3 y 4$ & 0.500 & 0.715 & 3.299 & 1.000 \\
\hline 2 vs 3 & 0.500 & 0.715 & 3.299 & 1.000 \\
\hline 2 vs $3 y 4$ & 0.500 & 0.715 & 3.299 & 1.000 \\
\hline 2 vs 6 & 0.500 & 0.715 & 3.299 & 1.000 \\
\hline 2 vs 5 & 0.416 & 0.594 & 3.299 & 1.000 \\
\hline 2 vs 1 & 0.056 & 0.079 & 3.299 & 1.000 \\
\hline 1 vs 1 y 4 & 0.444 & 0.635 & 3.299 & 1.000 \\
\hline 1 vs 1 y 6 & 0.444 & 0.635 & 3.299 & 1.000 \\
\hline 1 vs $1,2 y 3$ & 0.444 & 0.635 & 3.299 & 1.000 \\
\hline 1 vs 2 y 3 & 0.444 & 0.635 & 3.299 & 1.000 \\
\hline 1 vs $2,3 y 4$ & 0.444 & 0.635 & 3.299 & 1.000 \\
\hline 1 vs 3 & 0.444 & 0.635 & 3.299 & 1.000 \\
\hline 1 vs $3 y 4$ & 0.444 & 0.635 & 3.299 & 1.000 \\
\hline 1 vs 6 & 0.444 & 0.635 & 3.299 & 1.000 \\
\hline 1 vs 5 & 0.360 & 0.515 & 3.299 & 1.000 \\
\hline 5 vs 1 y 4 & 0.084 & 0.121 & 3.299 & 1.000 \\
\hline 5 vs 1 y 6 & 0.084 & 0.121 & 3.299 & 1.000 \\
\hline 5 vs $1,2 y 3$ & 0.084 & 0.121 & 3.299 & 1.000 \\
\hline 5 vs 2 y 3 & 0.084 & 0.121 & 3.299 & 1.000 \\
\hline 5 vs $2,3 y 4$ & 0.084 & 0.121 & 3.299 & 1.000 \\
\hline 5 vs 3 & 0.084 & 0.121 & 3.299 & 1.000 \\
\hline 5 vs $3 y 4$ & 0.084 & 0.121 & 3.299 & 1.000 \\
\hline 5 vs 6 & 0.084 & 0.121 & 3.299 & 1.000 \\
\hline 6 vs 1 y 4 & 0.000 & 0.000 & 3.299 & 1.000 \\
\hline 6 vs 1 y 6 & 0.000 & 0.000 & 3.299 & 1.000 \\
\hline 6 vs $1,2 y 3$ & 0.000 & 0.000 & 3.299 & 1.000 \\
\hline 6 vs 2 y 3 & 0.000 & 0.000 & 3.299 & 1.000 \\
\hline 6 vs 2,3y4 & 0.000 & 0.000 & 3.299 & 1.000 \\
\hline 6 vs 3 & 0.000 & 0.000 & 3.299 & 1.000 \\
\hline 6 vs $3 y 4$ & 0.000 & 0.000 & 3.299 & 1.000 \\
\hline $3 y 4$ vs 1 y 4 & 0.000 & 0.000 & 3.299 & 1.000 \\
\hline $3 y 4$ vs 1 y 6 & 0.000 & 0.000 & 3.299 & 1.000 \\
\hline $3 y 4$ vs $1,2 y 3$ & 0.000 & 0.000 & 3.299 & 1.000 \\
\hline $3 y 4$ vs 2 y 3 & 0.000 & 0.000 & 3.299 & 1.000 \\
\hline
\end{tabular}




\begin{tabular}{|c|c|c|c|c|c|}
\hline $3 y 4$ vs 2,3y4 & 0.000 & 0.000 & 3.299 & 1.000 & No \\
\hline $3 y 4$ vs 3 & 0.000 & 0.000 & 3.299 & 1.000 & No \\
\hline 3 vs 1 y 4 & 0.000 & 0.000 & 3.299 & 1.000 & No \\
\hline 3 vs 1 y 6 & 0.000 & 0.000 & 3.299 & 1.000 & No \\
\hline 3 vs $1,2 y 3$ & 0.000 & 0.000 & 3.299 & 1.000 & No \\
\hline 3 vs 2 y 3 & 0.000 & 0.000 & 3.299 & 1.000 & No \\
\hline 3 vs $2,3 y 4$ & 0.000 & 0.000 & 3.299 & 1.000 & No \\
\hline $2,3 y 4$ vs 1 y 4 & 0.000 & 0.000 & 3.299 & 1.000 & No \\
\hline $2,3 y 4$ vs 1 y 6 & 0.000 & 0.000 & 3.299 & 1.000 & No \\
\hline $2,3 y 4$ vs $1,2 y 3$ & 0.000 & 0.000 & 3.299 & 1.000 & No \\
\hline $2,3 y 4$ vs 2 y 3 & 0.000 & 0.000 & 3.299 & 1.000 & No \\
\hline 2 y 3 vs 1 y 4 & 0.000 & 0.000 & 3.299 & 1.000 & No \\
\hline 2 y 3 vs 1 y 6 & 0.000 & 0.000 & 3.299 & 1.000 & No \\
\hline 2 y 3 vs 1,2 y3 & 0.000 & 0.000 & 3.299 & 1.000 & No \\
\hline $1,2 y 3$ vs 1 y 4 & 0.000 & 0.000 & 3.299 & 1.000 & No \\
\hline 1,2 y3 vs 1 y 6 & 0.000 & 0.000 & 3.299 & 1.000 & No \\
\hline 1 y 6 vs 1 y 4 & 0.000 & 0.000 & 3.299 & 1.000 & No \\
\hline
\end{tabular}

Fuente: Propia

Como podemos apreciar en el grafico de medias, la categoría 1 y 2 posee la media más alta 1,773. El valor 1,000 lo presentan el resto de categorías exceptuando la 1; la 2; y la 5 .

Al analizar los contrastes observamos que ninguno de ellos resulta estadísticamente significativo.

5.4.5.6. Análisis de la variable i14(V4). Medición del impacto y repercusión de la propuesta.

Estudiamos si existen diferencias estadísticamente significativas en el impacto de los programas con respecto al tipo de público al que están dirigidos.

Tabla 81. Análisis de varianza (i14) (V4)

\begin{tabular}{|c|c|c|c|c|c|}
\hline Fuente & GL & $\begin{array}{l}\text { Suma de } \\
\text { cuadrados }\end{array}$ & $\begin{array}{l}\text { Cuadrados } \\
\text { medios }\end{array}$ & $\mathrm{F}$ & $\operatorname{Pr}>F$ \\
\hline Modelo & 11 & 4.089 & 0.372 & 1.292 & 0.229 \\
\hline Error & 249 & 71.666 & 0.288 & & \\
\hline $\begin{array}{l}\text { Total } \\
\text { corregido }\end{array}$ & 260 & 75.755 & & & \\
\hline
\end{tabular}

Fuente: Propia

Los resultados indican que no existen diferencias estadísticamente significativas $[\mathrm{F}(12,261)=1,189 ; \mathrm{p}=0,291]$ a la hora de comparar las medias de las categorías. 


\subsubsection{ANOVA- Ámbito pedagógico (V5).}

La variable V5 hace referencia al ámbito pedagógico al que se dirige el programa. Esta variable comprende siete categorías: 1- educación no formal, 2- educación informal, 3educación formal, infantil, 4-educación formal, primaria, 5-educación formal, secundaria, 6-educación formal, bachillerato, y 7-educación formal, universidad.

\subsubsection{Análisis de la variable i09 (V5). Descripción de los objetivos a lograr en el desarrollo de programas.}

Estudiamos si existen diferencias significativas en la descripción de los objetivos de los programas atendiendo al ámbito pedagógico al que están destinados.

Tabla 82. Análisis de varianza (i09) (V5)

\begin{tabular}{llllll}
\hline \multirow{2}{*}{ Fuente } & GL & $\begin{array}{l}\text { Suma de } \\
\text { cuadrados }\end{array}$ & medios & F & Pr $>$ F \\
\hline Modelo & 15 & 31,966 & 2,131 & 2,586 & $\mathbf{0 , 0 0 1}$ \\
$\begin{array}{l}\text { Error } \\
\text { Total }\end{array}$ & 245 & 201,927 & 0,824 & & \\
corregido & 260 & 233,893 & & & \\
\hline
\end{tabular}

Fuente: Propia

Dado el valor $\mathrm{p}$ asociado al estadístico $\mathrm{F}$ calculado en la tabla ANOVA, y dado el nivel de significación del 5\%, existen diferencias estadísticamente significativas en la variable i09.

Figura 21. Gráfico de medias. (i09)(V5)

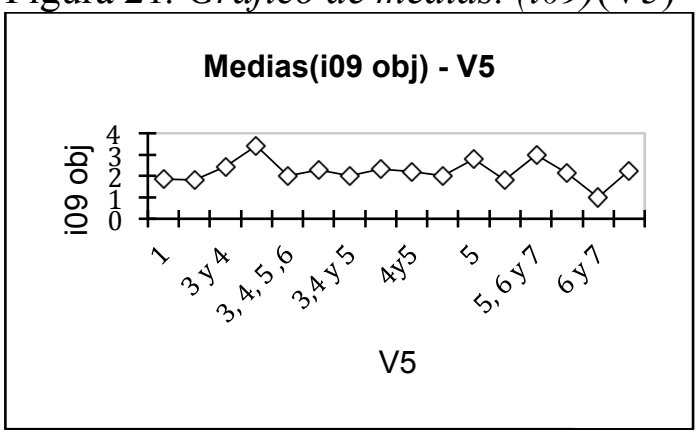

Fuente: Propia

Tabla 83. Análisis de diferencias entre las categorías(V5).

\begin{tabular}{llllll}
\hline Categoría & Medias LS & $\begin{array}{l}\text { Error } \\
\text { estándar }\end{array}$ & $\begin{array}{l}\text { Límite } \\
\text { inferior } \\
(95 \%)\end{array}$ & $\begin{array}{l}\text { Límite } \\
\text { superior } \\
(95 \%)\end{array}$ & Grupos \\
\hline 3 & 3,400 & 0,406 & 2,600 & 4,200 & $\mathrm{~A}$ \\
5,6 y 7 & 3,000 & 0,908 & 1,212 & 4,788 & $\mathrm{~A}$ \\
5 & 2,789 & 0,208 & 2,379 & 3,200 & $\mathrm{~A}$ \\
3 y 4 & 2,444 & 0,303 & 1,848 & 3,041 & $\mathrm{~A}$ \\
4 & 2,333 & 0,262 & 1,817 & 2,850 & $\mathrm{~A}$ \\
$3,4,5,6$ & 2,300 & 0,287 & 1,735 & 2,865 & $\mathrm{~A}$
\end{tabular}




\begin{tabular}{llllll}
7 & 2,240 & 0,182 & 1,882 & 2,598 & $\mathrm{~A}$ \\
4 y5 & 2,200 & 0,406 & 1,400 & 3,000 & $\mathrm{~A}$ \\
6 & 2,125 & 0,321 & 1,493 & 2,757 & $\mathrm{~A}$ \\
$3,4,5,6$ y & & & & & \\
7 & 2,000 & 0,908 & 0,212 & 3,788 & $\mathrm{~A}$ \\
3,4 у 5 & 2,000 & 0,642 & 0,736 & 3,264 & $\mathrm{~A}$ \\
4,5 y 6 & 2,000 & 0,642 & 0,736 & 3,264 & $\mathrm{~A}$ \\
1 & 1,867 & 0,089 & 1,692 & 2,041 & $\mathrm{~A}$ \\
2 & 1,824 & 0,127 & 1,573 & 2,074 & $\mathrm{~A}$ \\
5 y 6 & 1,800 & 0,406 & 1,000 & 2,600 & $\mathrm{~A}$ \\
6 y 7 & 1,000 & 0,908 & $-0,788$ & 2,788 & $\mathrm{~A}$ \\
\hline
\end{tabular}

Fuente: Propia

Tabla 84.Ámbito pedagógico / Tukey (HSD) / Análisis de las diferencias entre las categorías con un intervalo de confianza de 95\% (i09 obj)(V5)

\begin{tabular}{|c|c|c|c|c|c|}
\hline Contraste & Diferencia & $\begin{array}{c}\text { Diferencia } \\
\text { estandarizad } \\
\text { a }\end{array}$ & $\begin{array}{l}\text { Valor } \\
\text { crítico }\end{array}$ & $\operatorname{Pr}>$ Dif & Significativo \\
\hline 3 vs 6 y 7 & 2,400 & 3,298 & 3,462 & 0,081 & No \\
\hline 3 vs 5 y 6 & 1,600 & 2,198 & 3,462 & 0,697 & No \\
\hline 3 vs 2 & 1,576 & 2,166 & 3,462 & 0,720 & No \\
\hline 3 vs 1 & 1,533 & 2,107 & 3,462 & 0,759 & No \\
\hline 3 vs $3,4,5,6$ y 7 & 1,400 & 1,924 & 3,462 & 0,863 & No \\
\hline 3 vs 3,4 y 5 & 1,400 & 1,924 & 3,462 & 0,863 & No \\
\hline 3 vs 4,5 y 6 & 1,400 & 1,924 & 3,462 & 0,863 & No \\
\hline 3 vs 6 & 1,275 & 1,752 & 3,462 & 0,930 & No \\
\hline 3 vs $4 y 5$ & 1,200 & 1,649 & 3,462 & 0,957 & No \\
\hline 3 vs 7 & 1,160 & 1,594 & 3,462 & 0,968 & No \\
\hline 3 vs $3,4,5,6$ & 1,100 & 1,511 & 3,462 & 0,980 & No \\
\hline 3 vs 4 & 1,067 & 1,466 & 3,462 & 0,985 & No \\
\hline 3 vs 3 y 4 & 0,956 & 1,313 & 3,462 & 0,995 & No \\
\hline 3 vs 5 & 0,611 & 0,839 & 3,462 & 1,000 & No \\
\hline 3 vs 5,6 y 7 & 0,400 & 0,550 & 3,462 & 1,000 & No \\
\hline 5,6 y 7 vs 6 y 7 & 2,000 & 2,748 & 3,462 & 0,307 & No \\
\hline 5,6 y 7 vs 5 y 6 & 1,200 & 1,649 & 3,462 & 0,957 & No \\
\hline 5,6 y 7 vs 2 & 1,176 & 1,617 & 3,462 & 0,964 & No \\
\hline 5,6 y 7 vs 1 & 1,133 & 1,557 & 3,462 & 0,974 & No \\
\hline 5,6 y 7 vs 3,4 y 5 & 1,000 & 1,374 & 3,462 & 0,992 & No \\
\hline 5,6 y 7 vs 4,5 y 6 & 1,000 & 1,374 & 3,462 & 0,992 & No \\
\hline \multicolumn{6}{|l|}{5,6 y 7 vs $3,4,5,6$} \\
\hline y 7 & 1,000 & 1,374 & 3,462 & 0,992 & No \\
\hline 5,6 y 7 vs 6 & 0,875 & 1,202 & 3,462 & 0,998 & No \\
\hline 5,6 y 7 vs $4 y 5$ & 0,800 & 1,099 & 3,462 & 0,999 & No \\
\hline 5,6 y 7 vs 7 & 0,760 & 1,044 & 3,462 & 1,000 & No \\
\hline 5,6 y 7 vs $3,4,5,6$ & 0,700 & 0,962 & 3,462 & 1,000 & No \\
\hline
\end{tabular}




\begin{tabular}{|c|c|c|c|c|}
\hline 5,6 y 7 vs 4 & 0,667 & 0,916 & 3,462 & 1,000 \\
\hline 5,6 y 7 vs 3 y 4 & 0,556 & 0,763 & 3,462 & 1,000 \\
\hline 5,6 y 7 vs 5 & 0,211 & 0,289 & 3,462 & 1,000 \\
\hline 5 vs 6 y 7 & 1,789 & 2,459 & 3,462 & 0,506 \\
\hline 5 vs 5 y 6 & 0,989 & 1,360 & 3,462 & 0,993 \\
\hline 5 vs 2 & 0,966 & 1,327 & 3,462 & 0,995 \\
\hline 5 vs 1 & 0,923 & 1,268 & 3,462 & 0,997 \\
\hline 5 vs $3,4,5,6$ y 7 & 0,789 & 1,085 & 3,462 & 0,999 \\
\hline 5 vs 3,4 y 5 & 0,789 & 1,085 & 3,462 & 0,999 \\
\hline 5 vs 4,5 y 6 & 0,789 & 1,085 & 3,462 & 0,999 \\
\hline 5 vs 6 & 0,664 & 0,913 & 3,462 & 1,000 \\
\hline 5 vs $4 y 5$ & 0,589 & 0,810 & 3,462 & 1,000 \\
\hline 5 vs 7 & 0,549 & 0,755 & 3,462 & 1,000 \\
\hline 5 vs $3,4,5,6$ & 0,489 & 0,673 & 3,462 & 1,000 \\
\hline 5 vs 4 & 0,456 & 0,627 & 3,462 & 1,000 \\
\hline 5 vs 3 y 4 & 0,345 & 0,474 & 3,462 & 1,000 \\
\hline 3 y 4 vs 6 y 7 & 1,444 & 1,985 & 3,462 & 0,831 \\
\hline 3 y 4 vs 5 y 6 & 0,644 & 0,885 & 3,462 & 1,000 \\
\hline 3 y 4 vs 2 & 0,621 & 0,853 & 3,462 & 1,000 \\
\hline 3 y 4 vs 1 & 0,578 & 0,794 & 3,462 & 1,000 \\
\hline 3 y 4 vs $3,4,5,6$ y 7 & 0,444 & 0,611 & 3,462 & 1,000 \\
\hline 3 y 4 vs 3,4 y 5 & 0,444 & 0,611 & 3,462 & 1,000 \\
\hline 3 y 4 vs 4,5 y 6 & 0,444 & 0,611 & 3,462 & 1,000 \\
\hline 3 y 4 vs 6 & 0,319 & 0,439 & 3,462 & 1,000 \\
\hline 3 y 4 vs $4 y 5$ & 0,244 & 0,336 & 3,462 & 1,000 \\
\hline 3 y 4 vs 7 & 0,204 & 0,281 & 3,462 & 1,000 \\
\hline 3 y 4 vs $3,4,5,6$ & 0,144 & 0,198 & 3,462 & 1,000 \\
\hline 3 y 4 vs 4 & 0,111 & 0,153 & 3,462 & 1,000 \\
\hline 4 vs 6 y 7 & 1,333 & 1,832 & 3,462 & 0,902 \\
\hline 4 vs 5 y 6 & 0,533 & 0,733 & 3,462 & 1,000 \\
\hline 4 vs 2 & 0,510 & 0,700 & 3,462 & 1,000 \\
\hline 4 vs 1 & 0,467 & 0,641 & 3,462 & 1,000 \\
\hline 4 vs 3,4 y 5 & 0,333 & 0,458 & 3,462 & 1,000 \\
\hline 4 vs 4,5 y 6 & 0,333 & 0,458 & 3,462 & 1,000 \\
\hline 4 vs $3,4,5,6$ y 7 & 0,333 & 0,458 & 3,462 & 1,000 \\
\hline 4 vs 6 & 0,208 & 0,286 & 3,462 & 1,000 \\
\hline 4 vs $4 y 5$ & 0,133 & 0,183 & 3,462 & 1,000 \\
\hline 4 vs 7 & 0,093 & 0,128 & 3,462 & 1,000 \\
\hline 4 vs $3,4,5,6$ & 0,033 & 0,046 & 3,462 & 1,000 \\
\hline $3,4,5,6$ vs 6 y 7 & 1,300 & 1,786 & 3,462 & 0,919 \\
\hline $3,4,5,6$ vs 5 y 6 & 0,500 & 0,687 & 3,462 & 1,000 \\
\hline $3,4,5,6$ vs 2 & 0,476 & 0,655 & 3,462 & 1,000 \\
\hline $3,4,5,6$ vs 1 & 0,433 & 0,595 & 3,462 & 1,000 \\
\hline
\end{tabular}




\begin{tabular}{|c|c|c|c|c|c|}
\hline $3,4,5,6$ vs 3,4 y 5 & 0,300 & 0,412 & 3,462 & 1,000 & No \\
\hline $3,4,5,6$ vs 4,5 y 6 & 0,300 & 0,412 & 3,462 & 1,000 & No \\
\hline \multicolumn{5}{|l|}{$3,4,5,6$ vs $3,4,5,6$} & \\
\hline y 7 & 0,300 & 0,412 & 3,462 & 1,000 & No \\
\hline $3,4,5,6$ vs 6 & 0,175 & 0,240 & 3,462 & 1,000 & No \\
\hline $3,4,5,6$ vs $4 y 5$ & 0,100 & 0,137 & 3,462 & 1,000 & No \\
\hline $3,4,5,6$ vs 7 & 0,060 & 0,082 & 3,462 & 1,000 & No \\
\hline 7 vs 6 y 7 & 1,240 & 1,704 & 3,462 & 0,944 & No \\
\hline 7 vs 5 y 6 & 0,440 & 0,605 & 3,462 & 1,000 & No \\
\hline 7 vs 2 & 0,416 & 0,572 & 3,462 & 1,000 & No \\
\hline 7 vs 1 & 0,373 & 0,513 & 3,462 & 1,000 & No \\
\hline 7 vs 3,4 y 5 & 0,240 & 0,330 & 3,462 & 1,000 & No \\
\hline 7 vs 4,5 y 6 & 0,240 & 0,330 & 3,462 & 1,000 & No \\
\hline 7 vs $3,4,5,6$ y 7 & 0,240 & 0,330 & 3,462 & 1,000 & No \\
\hline 7 vs 6 & 0,115 & 0,158 & 3,462 & 1,000 & No \\
\hline 7 vs $4 y 5$ & 0,040 & 0,055 & 3,462 & 1,000 & No \\
\hline $4 y 5$ vs 6 y 7 & 1,200 & 1,649 & 3,462 & 0,957 & No \\
\hline $4 y 5$ vs 5 y 6 & 0,400 & 0,550 & 3,462 & 1,000 & No \\
\hline $4 y 5$ vs 2 & 0,376 & 0,517 & 3,462 & 1,000 & No \\
\hline $4 y 5$ vs 1 & 0,333 & 0,458 & 3,462 & 1,000 & No \\
\hline $4 y 5$ vs 3,4 y 5 & 0,200 & 0,275 & 3,462 & 1,000 & No \\
\hline $4 y 5$ vs 4,5 y 6 & 0,200 & 0,275 & 3,462 & 1,000 & No \\
\hline $4 y 5$ vs $3,4,5,6$ y 7 & 0,200 & 0,275 & 3,462 & 1,000 & No \\
\hline $4 y 5$ vs 6 & 0,075 & 0,103 & 3,462 & 1,000 & No \\
\hline 6 vs 6 y 7 & 1,125 & 1,546 & 3,462 & 0,976 & No \\
\hline 6 vs 5 y 6 & 0,325 & 0,447 & 3,462 & 1,000 & No \\
\hline 6 vs 2 & 0,301 & 0,414 & 3,462 & 1,000 & No \\
\hline 6 vs 1 & 0,258 & 0,355 & 3,462 & 1,000 & No \\
\hline 6 vs 3,4 y 5 & 0,125 & 0,172 & 3,462 & 1,000 & No \\
\hline 6 vs 4,5 y 6 & 0,125 & 0,172 & 3,462 & 1,000 & No \\
\hline 6 vs $3,4,5,6$ y 7 & 0,125 & 0,172 & 3,462 & 1,000 & No \\
\hline 4,5 y 6 vs 6 y 7 & 1,000 & 1,374 & 3,462 & 0,992 & No \\
\hline 4,5 y 6 vs 5 y 6 & 0,200 & 0,275 & 3,462 & 1,000 & No \\
\hline 4,5 y 6 vs 2 & 0,176 & 0,242 & 3,462 & 1,000 & No \\
\hline 4,5 y 6 vs 1 & 0,133 & 0,183 & 3,462 & 1,000 & No \\
\hline \multicolumn{5}{|l|}{4,5 y 6 vs $3,4,5,6$} & \\
\hline y 7 & 0,000 & 0,000 & 3,462 & 1,000 & No \\
\hline 4,5 y 6 vs 3,4 y 5 & 0,000 & 0,000 & 3,462 & 1,000 & No \\
\hline 3,4 y 5 vs 6 y 7 & 1,000 & 1,374 & 3,462 & 0,992 & No \\
\hline 3,4 y 5 vs 5 y 6 & 0,200 & 0,275 & 3,462 & 1,000 & No \\
\hline 3,4 y 5 vs 2 & 0,176 & 0,242 & 3,462 & 1,000 & No \\
\hline 3,4 y 5 vs 1 & 0,133 & 0,183 & 3,462 & 1,000 & No \\
\hline \multicolumn{5}{|l|}{3,4 y 5 vs $3,4,5,6$ y } & \\
\hline 7 & 0,000 & 0,000 & 3,462 & 1,000 & No \\
\hline
\end{tabular}




\begin{tabular}{llllll}
$3,4,5,6$ y 7 vs 6 y 7 & 1,000 & 1,374 & 3,462 & 0,992 & No \\
$3,4,5,6$ y 7 vs 5 y 6 & 0,200 & 0,275 & 3,462 & 1,000 & No \\
$3,4,5,6$ y 7 vs 2 & 0,176 & 0,242 & 3,462 & 1,000 & No \\
$3,4,5,6$ y 7 vs 1 & 0,133 & 0,183 & 3,462 & 1,000 & No \\
1 vs 6 y 7 & 0,867 & 1,191 & 3,462 & 0,998 & No \\
1 vs 5 y 6 & 0,067 & 0,092 & 3,462 & 1,000 & No \\
1 vs 2 & 0,043 & 0,059 & 3,462 & 1,000 & No \\
2 vs 6 y 7 & 0,824 & 1,132 & 3,462 & 0,999 & No \\
2 vs 5 y 6 & 0,024 & 0,032 & 3,462 & 1,000 & No \\
5 y 6 vs 6 y 7 & 0,800 & 1,099 & 3,462 & 0,999 & No \\
\hline Valor crítico del d de Tukey: & & 4,896 & &
\end{tabular}

Fuente: Propia

Como podemos apreciar en la gráfica de medias, todas las categorías se sitúan entre los valores 3,400 (para la categoría 3), y 1,000 (para la categoría 6 y 7).

El análisis del contrate de pares no nos reporta ningún resultado estadísticamente significativo.

\subsubsection{Análisis de la variable i10 (V5). Presentación de contenidos abordados en el programa.}

Analizamos si existen diferencias significativas en la descripción de los contenidos de los programas atendiendo al ámbito pedagógico al que están destinados.

Tabla 85. Análisis de varianza (i10)(V5)

\begin{tabular}{|c|c|c|c|c|c|}
\hline Fuente & GL & $\begin{array}{l}\text { Suma de } \\
\text { cuadrados }\end{array}$ & $\begin{array}{l}\text { Cuadrados } \\
\text { medios }\end{array}$ & $\mathrm{F}$ & $\operatorname{Pr}>F$ \\
\hline Modelo & 15 & 29,257 & 1,950 & 2,367 & 0,003 \\
\hline Error & 245 & 201,916 & 0,824 & & \\
\hline $\begin{array}{l}\text { Total } \\
\text { corregido }\end{array}$ & 260 & 231,172 & & & \\
\hline
\end{tabular}

Fuente: Propia

Dado el valor $\mathrm{p}$ asociado al estadístico $\mathrm{F}$ calculado en la tabla ANOVA, y dado el nivel de significación del 5\%, existen diferencias estadísticamente significativas en la variable i10.

Figura 22. Gráfico de medias. (i10) (V5)

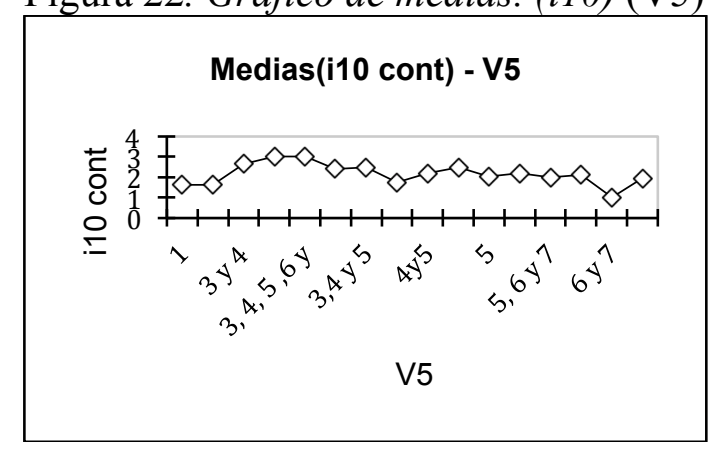


Fuente: Propia

Tabla 86. Análisis de diferencias entre las categorías (V5)

\begin{tabular}{llllll}
\hline Categoría & Medias LS & $\begin{array}{l}\text { Error } \\
\text { estándar }\end{array}$ & $\begin{array}{l}\text { Límite } \\
\text { inferior } \\
(95 \%)\end{array}$ & $\begin{array}{l}\text { Límite } \\
\text { superior } \\
(95 \%)\end{array}$ & Grupos \\
\hline 3 & 3,000 & 0,406 & 2,200 & 3,800 & $\mathrm{~A}$ \\
$3,4,5,6$ y & & & & & \\
7 & 3,000 & 0,908 & 1,212 & 4,788 & $\mathrm{~A}$ \\
3 y 4 & 2,667 & 0,303 & 2,071 & 3,263 & $\mathrm{~A}$ \\
3,4 y 5 & 2,500 & 0,642 & 1,236 & 3,764 & $\mathrm{~A}$ \\
4,5 y 6 & 2,500 & 0,642 & 1,236 & 3,764 & $\mathrm{~A}$ \\
$3,4,5,6$ & 2,400 & 0,287 & 1,835 & 2,965 & $\mathrm{~A}$ \\
4 55 & 2,200 & 0,406 & 1,400 & 3,000 & $\mathrm{~A}$ \\
5 y 6 & 2,200 & 0,406 & 1,400 & 3,000 & $\mathrm{~A}$ \\
6 & 2,125 & 0,321 & 1,493 & 2,757 & $\mathrm{~A}$ \\
5 & 2,053 & 0,208 & 1,642 & 2,463 & $\mathrm{~A}$ \\
5,6 y 7 & 2,000 & 0,908 & 0,212 & 3,788 & $\mathrm{~A}$ \\
7 & 1,960 & 0,182 & 1,602 & 2,318 & $\mathrm{~A}$ \\
4 & 1,750 & 0,262 & 1,234 & 2,266 & $\mathrm{~A}$ \\
1 & 1,648 & 0,089 & 1,473 & 1,822 & $\mathrm{~A}$ \\
2 & 1,627 & 0,127 & 1,377 & 1,878 & $\mathrm{~A}$ \\
6 y 7 & 1,000 & 0,908 & $-0,788$ & 2,788 & $\mathrm{~A}$ \\
\hline
\end{tabular}

Fuente: Propia

Tabla 87. Ámbito pedagógico / Tukey (HSD) / Análisis de las diferencias entre las categorías con un intervalo de confianza de 95\% (i10 cont) (V5)

\begin{tabular}{lrrrrl}
\hline \multicolumn{1}{c}{ Contraste } & Diferencia & $\begin{array}{c}\text { Diferencia } \\
\text { estandarizada }\end{array}$ & $\begin{array}{r}\text { Valor } \\
\text { crítico }\end{array}$ & Pr > Dif & Significativo \\
\hline $3,4,5,6$ y 7 vs 6 y 7 & 2,000 & 1,558 & 3,462 & 0,974 & No \\
$3,4,5,6$ y 7 vs 2 & 1,373 & 1,497 & 3,462 & 0,982 & No \\
$3,4,5,6$ y 7 vs 1 & 1,352 & 1,483 & 3,462 & 0,984 & No \\
$3,4,5,6$ y 7 vs 4 & 1,250 & 1,323 & 3,462 & 0,995 & No \\
$3,4,5,6$ y 7 vs 7 & 1,040 & 1,123 & 3,462 & 0,999 & No \\
$3,4,5,6$ y 7 vs 5,6 & & & & & \\
y 7 & 1,000 & 0,779 & 3,462 & 1,000 & No \\
$3,4,5,6$ y 7 vs 5 & 0,947 & 1,017 & 3,462 & 1,000 & No \\
$3,4,5,6$ y 7 vs 6 & 0,875 & 0,909 & 3,462 & 1,000 & No \\
$3,4,5,6$ y 7 vs 4 y 5 & 0,800 & 0,804 & 3,462 & 1,000 & No \\
$3,4,5,6$ y 7 vs 5 y 6 & 0,800 & 0,804 & 3,462 & 1,000 & No \\
$3,4,5,6$ y 7 vs & & & & & No \\
$3,4,5,6$ & 0,600 & 0,630 & 3,462 & 1,000 & \\
$3,4,5,6$ y 7 vs 3,4 y & & & & & No \\
5 & 0,500 & 0,450 & 3,462 & 1,000 & No \\
$3,4,5,6$ y 7 vs 4,5 & 0,500 & 0,450 & 3,462 & 1,000 &
\end{tabular}




\begin{tabular}{|c|c|c|c|c|c|}
\hline $3,4,5,6$ y 7 vs 3 y 4 & 0,333 & 0,348 & 3,462 & 1,000 & No \\
\hline $3,4,5,6$ y 7 vs 3 & 0,000 & 0,000 & 3,462 & 1,000 & No \\
\hline 3 vs 6 y 7 & 2,000 & 2,011 & 3,462 & 0,817 & No \\
\hline 3 vs 2 & 1,373 & 3,226 & 3,462 & 0,099 & No \\
\hline 3 vs 1 & 1,352 & 3,254 & 3,462 & 0,092 & No \\
\hline 3 vs 4 & 1,250 & 2,587 & 3,462 & 0,413 & No \\
\hline 3 vs 7 & 1,040 & 2,338 & 3,462 & 0,596 & No \\
\hline 3 vs 5,6 y 7 & 1,000 & 1,006 & 3,462 & 1,000 & No \\
\hline 3 vs 5 & 0,947 & 2,076 & 3,462 & 0,778 & No \\
\hline 3 vs 6 & 0,875 & 1,691 & 3,462 & 0,948 & No \\
\hline 3 vs $4 y 5$ & 0,800 & 1,393 & 3,462 & 0,991 & No \\
\hline 3 vs 5 y 6 & 0,800 & 1,393 & 3,462 & 0,991 & No \\
\hline 3 vs $3,4,5,6$ & 0,600 & 1,207 & 3,462 & 0,998 & No \\
\hline 3 vs 3,4 y 5 & 0,500 & 0,658 & 3,462 & 1,000 & No \\
\hline 3 vs 4,5 y 6 & 0,500 & 0,658 & 3,462 & 1,000 & No \\
\hline 3 vs 3 y 4 & 0,333 & 0,658 & 3,462 & 1,000 & No \\
\hline 3 y 4 vs 6 y 7 & 1,667 & 1,742 & 3,462 & 0,933 & No \\
\hline 3 y 4 vs 2 & 1,039 & 3,166 & 3,462 & 0,116 & No \\
\hline 3 y 4 vs 1 & 1,019 & 3,232 & 3,462 & 0,097 & No \\
\hline 3 y 4 vs 4 & 0,917 & 2,290 & 3,462 & 0,632 & No \\
\hline 3 y 4 vs 7 & 0,707 & 2,002 & 3,462 & 0,822 & No \\
\hline 3 y 4 vs 5,6 y 7 & 0,667 & 0,697 & 3,462 & 1,000 & No \\
\hline 3 y 4 vs 5 & 0,614 & 1,672 & 3,462 & 0,952 & No \\
\hline 3 y 4 vs 6 & 0,542 & 1,228 & 3,462 & 0,998 & No \\
\hline 3 y 4 vs $4 y 5$ & 0,467 & 0,922 & 3,462 & 1,000 & No \\
\hline 3 y 4 vs 5 y 6 & 0,467 & 0,922 & 3,462 & 1,000 & No \\
\hline 3 y 4 vs $3,4,5,6$ & 0,267 & 0,639 & 3,462 & 1,000 & No \\
\hline 3 y 4 vs 3,4 y 5 & 0,167 & 0,235 & 3,462 & 1,000 & No \\
\hline 3 y 4 vs 4,5 y 6 & 0,167 & 0,235 & 3,462 & 1,000 & No \\
\hline 4,5 y 6 vs 6 y 7 & 1,500 & 1,349 & 3,462 & 0,994 & No \\
\hline 4,5 y 6 vs 2 & 0,873 & 1,333 & 3,462 & 0,994 & No \\
\hline 4,5 y 6 vs 1 & 0,852 & 1,315 & 3,462 & 0,995 & No \\
\hline 4,5 y 6 vs 4 & 0,750 & 1,082 & 3,462 & 0,999 & No \\
\hline 4,5 y 6 vs 7 & 0,540 & 0,809 & 3,462 & 1,000 & No \\
\hline 4,5 y 6 vs 5,6 y 7 & 0,500 & 0,450 & 3,462 & 1,000 & No \\
\hline 4,5 y 6 vs 5 & 0,447 & 0,663 & 3,462 & 1,000 & No \\
\hline 4,5 y 6 vs 6 & 0,375 & 0,523 & 3,462 & 1,000 & No \\
\hline 4,5 y 6 vs $4 y 5$ & 0,300 & 0,395 & 3,462 & 1,000 & No \\
\hline 4,5 y 6 vs 5 y 6 & 0,300 & 0,395 & 3,462 & 1,000 & No \\
\hline 4,5 y 6 vs $3,4,5,6$ & 0,100 & 0,142 & 3,462 & 1,000 & No \\
\hline 4,5 y 6 vs 3,4 y 5 & 0,000 & 0,000 & 3,462 & 1,000 & No \\
\hline 3,4 y 5 vs 6 y 7 & 1,500 & 1,349 & 3,462 & 0,994 & No \\
\hline
\end{tabular}




\begin{tabular}{|c|c|c|c|c|}
\hline 3,4 y 5 vs 2 & 0,873 & 1,333 & 3,462 & 0,994 \\
\hline 3,4 y 5 vs 1 & 0,852 & 1,315 & 3,462 & 0,995 \\
\hline 3,4 y 5 vs 4 & 0,750 & 1,082 & 3,462 & 0,999 \\
\hline 3,4 y 5 vs 7 & 0,540 & 0,809 & 3,462 & 1,000 \\
\hline 3,4 y 5 vs 5,6 y 7 & 0,500 & 0,450 & 3,462 & 1,000 \\
\hline 3,4 y 5 vs 5 & 0,447 & 0,663 & 3,462 & 1,000 \\
\hline 3,4 y 5 vs 6 & 0,375 & 0,523 & 3,462 & 1,000 \\
\hline 3,4 y 5 vs 4 y 5 & 0,300 & 0,395 & 3,462 & 1,000 \\
\hline 3,4 y 5 vs 5 y 6 & 0,300 & 0,395 & 3,462 & 1,000 \\
\hline 3,4 y 5 vs $3,4,5,6$ & 0,100 & 0,142 & 3,462 & 1,000 \\
\hline $3,4,5,6$ vs 6 y 7 & 1,400 & 1,470 & 3,462 & 0,985 \\
\hline $3,4,5,6$ vs 2 & 0,773 & 2,461 & 3,462 & 0,504 \\
\hline $3,4,5,6$ vs 1 & 0,752 & 2,504 & 3,462 & 0,472 \\
\hline $3,4,5,6$ vs 4 & 0,650 & 1,672 & 3,462 & 0,952 \\
\hline $3,4,5,6$ vs 7 & 0,440 & 1,295 & 3,462 & 0,996 \\
\hline $3,4,5,6$ vs 5,6 y 7 & 0,400 & 0,420 & 3,462 & 1,000 \\
\hline $3,4,5,6$ vs 5 & 0,347 & 0,979 & 3,462 & 1,000 \\
\hline $3,4,5,6$ vs 6 & 0,275 & 0,639 & 3,462 & 1,000 \\
\hline $3,4,5,6$ vs 4 y 5 & 0,200 & 0,402 & 3,462 & 1,000 \\
\hline $3,4,5,6$ vs 5 y 6 & 0,200 & 0,402 & 3,462 & 1,000 \\
\hline 5 y 6 vs 6 y 7 & 1,200 & 1,207 & 3,462 & 0,998 \\
\hline 5 y 6 vs 2 & 0,573 & 1,346 & 3,462 & 0,994 \\
\hline 5 y 6 vs 1 & 0,552 & 1,329 & 3,462 & 0,994 \\
\hline 5 y 6 vs 4 & 0,450 & 0,931 & 3,462 & 1,000 \\
\hline 5 y 6 vs 7 & 0,240 & 0,540 & 3,462 & 1,000 \\
\hline 5 y 6 vs 5,6 y 7 & 0,200 & 0,201 & 3,462 & 1,000 \\
\hline 5 y 6 vs 5 & 0,147 & 0,323 & 3,462 & 1,000 \\
\hline 5 y 6 vs 6 & 0,075 & 0,145 & 3,462 & 1,000 \\
\hline 5 y 6 vs $4 y 5$ & 0,000 & 0,000 & 3,462 & 1,000 \\
\hline $4 y 5$ vs 6 y 7 & 1,200 & 1,207 & 3,462 & 0,998 \\
\hline $4 y 5$ vs 2 & 0,573 & 1,346 & 3,462 & 0,994 \\
\hline $4 y 5$ vs 1 & 0,552 & 1,329 & 3,462 & 0,994 \\
\hline $4 y 5$ vs 4 & 0,450 & 0,931 & 3,462 & 1,000 \\
\hline $4 y 5$ vs 7 & 0,240 & 0,540 & 3,462 & 1,000 \\
\hline $4 y 5$ vs 5,6 y 7 & 0,200 & 0,201 & 3,462 & 1,000 \\
\hline $4 y 5$ vs 5 & 0,147 & 0,323 & 3,462 & 1,000 \\
\hline $4 y 5$ vs 6 & 0,075 & 0,145 & 3,462 & 1,000 \\
\hline 6 vs 6 y 7 & 1,125 & 1,168 & 3,462 & 0,999 \\
\hline 6 vs 2 & 0,498 & 1,441 & 3,462 & 0,987 \\
\hline 6 vs 1 & 0,477 & 1,434 & 3,462 & 0,988 \\
\hline 6 vs 4 & 0,375 & 0,905 & 3,462 & 1,000 \\
\hline 6 vs 7 & 0,165 & 0,447 & 3,462 & 1,000 \\
\hline 6 vs 5,6 y 7 & 0,125 & 0,130 & 3,462 & 1,000 \\
\hline
\end{tabular}




\begin{tabular}{llllll}
6 vs 5 & 0,072 & 0,189 & 3,462 & 1,000 & No \\
5 vs 6 y 7 & 1,053 & 1,130 & 3,462 & 0,999 & No \\
5 vs 2 & 0,425 & 1,743 & 3,462 & 0,933 & No \\
5 vs 1 & 0,405 & 1,789 & 3,462 & 0,918 & No \\
5 vs 4 & 0,303 & 0,904 & 3,462 & 1,000 & No \\
5 vs 7 & 0,093 & 0,335 & 3,462 & 1,000 & No \\
5 vs 5,6 y 7 & 0,053 & 0,057 & 3,462 & 1,000 & No \\
5,6 y 7 vs 6 y 7 & 1,000 & 0,779 & 3,462 & 1,000 & No \\
5,6 y 7 vs 2 & 0,373 & 0,406 & 3,462 & 1,000 & No \\
5,6 y 7 vs 1 & 0,352 & 0,386 & 3,462 & 1,000 & No \\
5,6 y 7 vs 4 & 0,250 & 0,265 & 3,462 & 1,000 & No \\
5,6 y 7 vs 7 & 0,040 & 0,043 & 3,462 & 1,000 & No \\
7 vs 6 y 7 & 0,960 & 1,037 & 3,462 & 1,000 & No \\
7 vs 2 & 0,333 & 1,500 & 3,462 & 0,982 & No \\
7 vs 1 & 0,312 & 1,546 & 3,462 & 0,976 & No \\
7 vs 4 & 0,210 & 0,659 & 3,462 & 1,000 & No \\
4 vs 6 y 7 & 0,750 & 0,794 & 3,462 & 1,000 & No \\
4 vs 2 & 0,123 & 0,421 & 3,462 & 1,000 & No \\
4 vs 1 & 0,102 & 0,370 & 3,462 & 1,000 & No \\
1 vs 6 y 7 & 0,648 & 0,710 & 3,462 & 1,000 & No \\
1 vs 2 & 0,020 & 0,130 & 3,462 & 1,000 & No \\
2 vs 6 y 7 & 0,627 & 0,684 & 3,462 & 1,000 & No \\
\hline Valor crítico del d de Tukey: & & 4,896 & &
\end{tabular}

Fuente: Propia

Como podemos apreciar en la gráfica de medias, las categorías que presentan unos valores más altos $(3,000)$ son la categoría 3 , la categoría $3,4,5,6,7$, y 1 categoría 4, 5 ,6. En los valores opuestos $(1,000)$ se sitúa la categoría 6, 7.

El análisis del contrate de pares no nos reporta ningún resultado estadísticamente significativo.

5.4.6.3. Análisis de la variable i11 (V5). Orientación metodológica y estrategias de enseñanza aprendizaje.

Observamos si existen diferencias significativas en la metodología de los programas atendiendo al ámbito pedagógico al que están destinados.

Tabla 88. Análisis de varianza (i11) (V5)

\begin{tabular}{llllll}
\hline Fuente & GL & $\begin{array}{l}\text { Suma de } \\
\text { cuadrados }\end{array}$ & medios & F & Pr $>$ F \\
\hline Modelo & 15 & 27,446 & 1,830 & 2,914 & $\mathbf{0 , 0 0 0}$ \\
$\begin{array}{l}\text { Error } \\
\text { Total }\end{array}$ & 245 & 153,864 & 0,628 & & \\
corregido & 260 & 181,310 & & & \\
\hline
\end{tabular}

Fuente: Propia 
Dado el valor $\mathrm{p}$ asociado al estadístico $\mathrm{F}$ calculado en la tabla ANOVA, y dado el nivel de significación del 5\%, existen diferencias estadísticamente significativas en la variable i11,

Figura 23, Gráfico de medias, (i11) (V5)

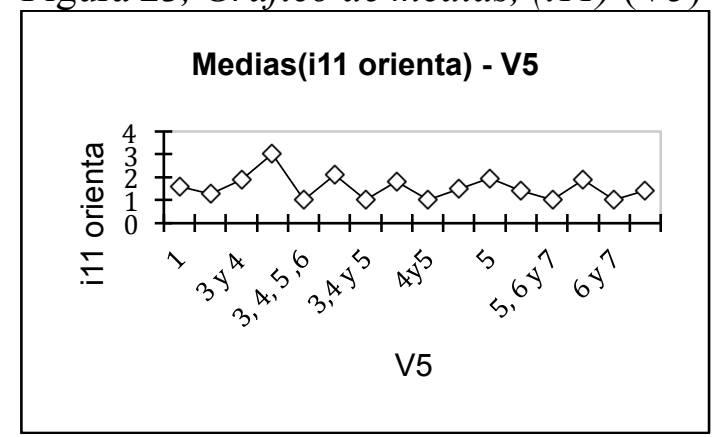

Fuente: Propia

Tabla 89. Análisis de diferencias entre las categorías (V5)

\begin{tabular}{llllll}
\hline Categoría & Medias LS & $\begin{array}{l}\text { Error } \\
\text { estándar }\end{array}$ & $\begin{array}{l}\text { Límite } \\
\text { inferior } \\
(95 \%)\end{array}$ & $\begin{array}{l}\text { Límite } \\
\text { superior } \\
(95 \%)\end{array}$ & Grupos \\
\hline 3 & 3,000 & 0,354 & 2,302 & 3,698 & $\mathrm{~A}$ \\
$3,4,5,6$ & 2,100 & 0,251 & 1,606 & 2,594 & $\mathrm{~A}$ \\
5 & 1,947 & 0,182 & 1,589 & 2,305 & $\mathrm{~A}$ \\
3 y 4 & 1,889 & 0,264 & 1,369 & 2,409 & $\mathrm{~A}$ \\
6 & 1,875 & 0,280 & 1,323 & 2,427 & $\mathrm{~A}$ \\
4 & 1,833 & 0,229 & 1,383 & 2,284 & $\mathrm{~A}$ \\
1 & 1,600 & 0,077 & 1,448 & 1,752 & $\mathrm{~A}$ \\
4,5 y 6 & 1,500 & 0,560 & 0,396 & 2,604 & $\mathrm{~A}$ \\
5 y 6 & 1,400 & 0,354 & 0,702 & 2,098 & $\mathrm{~A}$ \\
7 & 1,400 & 0,158 & 1,088 & 1,712 & $\mathrm{~A}$ \\
2 & 1,255 & 0,111 & 1,036 & 1,473 & $\mathrm{~A}$ \\
$3,4,5,6$ y & & & & & \\
7 & 1,000 & 0,792 & $-0,561$ & 2,561 & $\mathrm{~A}$ \\
5,6 y 7 & 1,000 & 0,792 & $-0,561$ & 2,561 & $\mathrm{~A}$ \\
6 y 7 & 1,000 & 0,792 & $-0,561$ & 2,561 & $\mathrm{~A}$ \\
3,4 y 5 & 1,000 & 0,560 & $-0,104$ & 2,104 & $\mathrm{~A}$ \\
4 y5 & 1,000 & 0,354 & 0,302 & 1,698 & $\mathrm{~A}$ \\
\hline & & & Fuente: Propia &
\end{tabular}

Tabla 90,Ámbito pedagógico / Tukey (HSD) / Análisis de las diferencias entre las categorías con un intervalo de confianza de 95\% (ill orienta) (V5),

\begin{tabular}{lrrrrr}
\hline \multicolumn{1}{c}{ Contraste } & Diferencia & $\begin{array}{c}\text { Diferencia } \\
\text { estandarizada }\end{array}$ & $\begin{array}{c}\text { Valor } \\
\text { crítico }\end{array}$ & Pr >Dif & Significativo \\
\hline 3 vs 3,4 y 5 & 2,000 & 3,148 & 3,462 & 0,122 & No \\
3 vs 4y5 & 2,000 & 3,148 & 3,462 & 0,122 & No \\
3 vs 3, 4, 5,6 y 7 & 2,000 & 3,148 & 3,462 & 0,122 & No
\end{tabular}




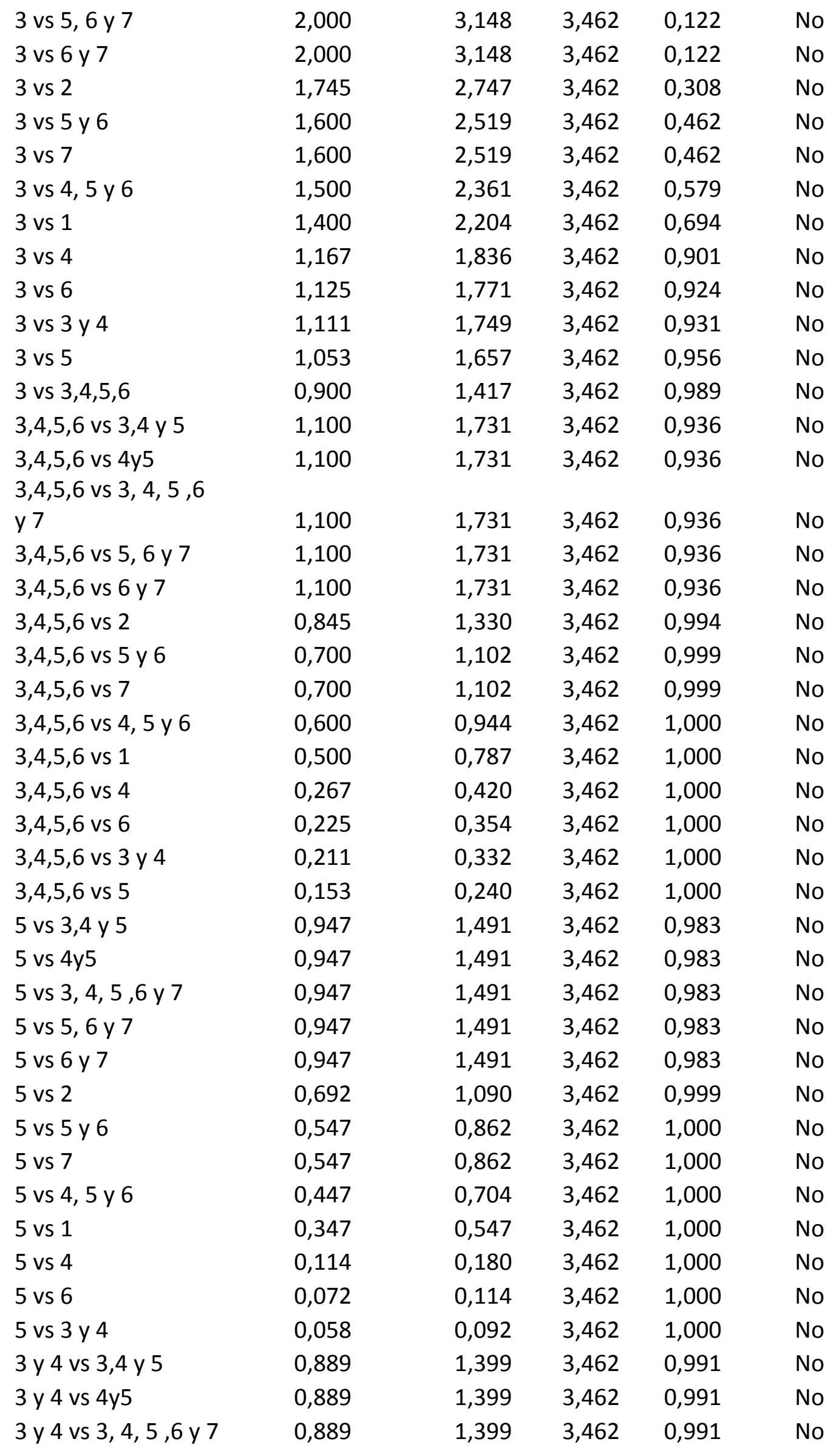




\begin{tabular}{|c|c|c|c|c|}
\hline 3 y 4 vs 5,6 y 7 & 0,889 & 1,399 & 3,462 & 0,991 \\
\hline 3 y 4 vs 6 y 7 & 0,889 & 1,399 & 3,462 & 0,991 \\
\hline 3 y 4 vs 2 & 0,634 & 0,998 & 3,462 & 1,000 \\
\hline 3 y 4 vs 5 y 6 & 0,489 & 0,770 & 3,462 & 1,000 \\
\hline 3 y 4 vs 7 & 0,489 & 0,770 & 3,462 & 1,000 \\
\hline 3 y 4 vs 4,5 y 6 & 0,389 & 0,612 & 3,462 & 1,000 \\
\hline 3 y 4 vs 1 & 0,289 & 0,455 & 3,462 & 1,000 \\
\hline 3 y 4 vs 4 & 0,056 & 0,087 & 3,462 & 1,000 \\
\hline 3 y 4 vs 6 & 0,014 & 0,022 & 3,462 & 1,000 \\
\hline 6 vs 3,4 y 5 & 0,875 & 1,377 & 3,462 & 0,992 \\
\hline 6 vs $4 y 5$ & 0,875 & 1,377 & 3,462 & 0,992 \\
\hline 6 vs $3,4,5,6$ y 7 & 0,875 & 1,377 & 3,462 & 0,992 \\
\hline 6 vs 5,6 y 7 & 0,875 & 1,377 & 3,462 & 0,992 \\
\hline 6 vs 6 y 7 & 0,875 & 1,377 & 3,462 & 0,992 \\
\hline 6 vs 2 & 0,620 & 0,976 & 3,462 & 1,000 \\
\hline 6 vs 5 y 6 & 0,475 & 0,748 & 3,462 & 1,000 \\
\hline 6 vs 7 & 0,475 & 0,748 & 3,462 & 1,000 \\
\hline 6 vs 4,5 y 6 & 0,375 & 0,590 & 3,462 & 1,000 \\
\hline 6 vs 1 & 0,275 & 0,433 & 3,462 & 1,000 \\
\hline 6 vs 4 & 0,042 & 0,066 & 3,462 & 1,000 \\
\hline 4 vs 3,4 y 5 & 0,833 & 1,312 & 3,462 & 0,995 \\
\hline 4 vs $4 y 5$ & 0,833 & 1,312 & 3,462 & 0,995 \\
\hline 4 vs $3,4,5,6$ y 7 & 0,833 & 1,312 & 3,462 & 0,995 \\
\hline 4 vs 5,6 y 7 & 0,833 & 1,312 & 3,462 & 0,995 \\
\hline 4 vs 6 y 7 & 0,833 & 1,312 & 3,462 & 0,995 \\
\hline 4 vs 2 & 0,578 & 0,910 & 3,462 & 1,000 \\
\hline 4 vs 5 y 6 & 0,433 & 0,682 & 3,462 & 1,000 \\
\hline 4 vs 7 & 0,433 & 0,682 & 3,462 & 1,000 \\
\hline 4 vs 4,5 y 6 & 0,333 & 0,525 & 3,462 & 1,000 \\
\hline 4 vs 1 & 0,233 & 0,367 & 3,462 & 1,000 \\
\hline 1 vs 3,4 y 5 & 0,600 & 0,944 & 3,462 & 1,000 \\
\hline 1 vs $4 y 5$ & 0,600 & 0,944 & 3,462 & 1,000 \\
\hline 1 vs $3,4,5,6$ y 7 & 0,600 & 0,944 & 3,462 & 1,000 \\
\hline 1 vs 5,6 y 7 & 0,600 & 0,944 & 3,462 & 1,000 \\
\hline 1 vs 6 y 7 & 0,600 & 0,944 & 3,462 & 1,000 \\
\hline 1 vs 2 & 0,345 & 0,543 & 3,462 & 1,000 \\
\hline 1 vs 5 y 6 & 0,200 & 0,315 & 3,462 & 1,000 \\
\hline 1 vs 7 & 0,200 & 0,315 & 3,462 & 1,000 \\
\hline 1 vs 4,5 y 6 & 0,100 & 0,157 & 3,462 & 1,000 \\
\hline 4,5 y 6 vs 3,4 y 5 & 0,500 & 0,787 & 3,462 & 1,000 \\
\hline 4,5 y 6 vs $4 y 5$ & 0,500 & 0,787 & 3,462 & 1,000 \\
\hline \multicolumn{5}{|l|}{4,5 y 6 vs $3,4,5,6$} \\
\hline y 7 & 0,500 & 0,787 & 3,462 & 1,000 \\
\hline
\end{tabular}




\begin{tabular}{|c|c|c|c|c|c|}
\hline 4,5 y 6 vs 5,6 y 7 & 0,500 & 0,787 & 3,462 & 1,000 & No \\
\hline 4,5 y 6 vs 6 y 7 & 0,500 & 0,787 & 3,462 & 1,000 & No \\
\hline 4,5 y 6 vs 2 & 0,245 & 0,386 & 3,462 & 1,000 & No \\
\hline 4,5 y 6 vs 5 y 6 & 0,100 & 0,157 & 3,462 & 1,000 & No \\
\hline 4,5 y 6 vs 7 & 0,100 & 0,157 & 3,462 & 1,000 & No \\
\hline 7 vs 3,4 y 5 & 0,400 & 0,630 & 3,462 & 1,000 & No \\
\hline 7 vs $4 y 5$ & 0,400 & 0,630 & 3,462 & 1,000 & No \\
\hline 7 vs $3,4,5,6$ y 7 & 0,400 & 0,630 & 3,462 & 1,000 & No \\
\hline 7 vs 5,6 y 7 & 0,400 & 0,630 & 3,462 & 1,000 & No \\
\hline 7 vs 6 y 7 & 0,400 & 0,630 & 3,462 & 1,000 & No \\
\hline 7 vs 2 & 0,145 & 0,228 & 3,462 & 1,000 & No \\
\hline 7 vs 5 y 6 & 0,000 & 0,000 & 3,462 & 1,000 & No \\
\hline 5 y 6 vs 3,4 y 5 & 0,400 & 0,630 & 3,462 & 1,000 & No \\
\hline 5 y 6 vs $4 y 5$ & 0,400 & 0,630 & 3,462 & 1,000 & No \\
\hline 5 y 6 vs $3,4,5,6$ y 7 & 0,400 & 0,630 & 3,462 & 1,000 & No \\
\hline 5 y 6 vs 5,6 y 7 & 0,400 & 0,630 & 3,462 & 1,000 & No \\
\hline 5 y 6 vs 6 y 7 & 0,400 & 0,630 & 3,462 & 1,000 & No \\
\hline 5 y 6 vs 2 & 0,145 & 0,228 & 3,462 & 1,000 & No \\
\hline 2 vs 3,4 y 5 & 0,255 & 0,401 & 3,462 & 1,000 & No \\
\hline 2 vs $4 y 5$ & 0,255 & 0,401 & 3,462 & 1,000 & No \\
\hline 2 vs $3,4,5,6$ y 7 & 0,255 & 0,401 & 3,462 & 1,000 & No \\
\hline 2 vs 5,6 y 7 & 0,255 & 0,401 & 3,462 & 1,000 & No \\
\hline 2 vs 6 y 7 & 0,255 & 0,401 & 3,462 & 1,000 & No \\
\hline 6 y 7 vs 3,4 y 5 & 0,000 & 0,000 & 3,462 & 1,000 & No \\
\hline 6 y 7 vs $4 y 5$ & 0,000 & 0,000 & 3,462 & 1,000 & No \\
\hline 6 y 7 vs $3,4,5,6$ y 7 & 0,000 & 0,000 & 3,462 & 1,000 & No \\
\hline 6 y 7 vs 5,6 y 7 & 0,000 & 0,000 & 3,462 & 1,000 & No \\
\hline 5,6 y 7 vs 3,4 y 5 & 0,000 & 0,000 & 3,462 & 1,000 & No \\
\hline 5,6 y 7 vs 4 y 5 & 0,000 & 0,000 & 3,462 & 1,000 & No \\
\hline \multicolumn{6}{|l|}{5,6 y 7 vs $3,4,5,6$} \\
\hline y 7 & 0,000 & 0,000 & 3,462 & 1,000 & No \\
\hline \multicolumn{6}{|l|}{$3,4,5,6$ y 7 vs 3,4 y } \\
\hline 5 & 0,000 & 0,000 & 3,462 & 1,000 & No \\
\hline $3,4,5,6$ y 7 vs $4 y 5$ & 0,000 & 0,000 & 3,462 & 1,000 & No \\
\hline $4 y 5$ vs 3,4 y 5 & 0,000 & 0,000 & 3,462 & 1,000 & No \\
\hline \multicolumn{3}{|c|}{ Valor crítico del d de Tukey: } & 4,896 & & \\
\hline
\end{tabular}

Fuente: Propia

Como podemos apreciar en la gráfica de medias, todas las categorías se sitúan entre los valores 3,000 y 1,000. Presentando el valor más alto las categorías $(3)$ y $(3,4,5,6)$ y el más bajo las categoría $(3,4,5,6,7),(3,4,5),,(4,5),,(4,5,6),(5,6,7)$ y $(6,7)$.

El análisis del contrate de pares no nos reporta ningún resultado estadísticamente significativo. 


\subsubsection{Análisis de la variable i12 (V5).Definición de recursos, formatos, soportes, y tecnología empleados.}

Estudiamos si existen diferencias significativas en la definición de recursos de los programas atendiendo al ámbito pedagógico al que están destinados.

Tabla 91. Análisis de varianza (i12) (V5)

\begin{tabular}{llllll}
\hline Fuente & GL & $\begin{array}{l}\text { Suma de } \\
\text { cuadrados }\end{array}$ & medios & F & Pr $>$ F \\
\hline Modelo & 15 & 31,517 & 2,101 & 2,782 & $\mathbf{0 , 0 0 1}$ \\
$\begin{array}{l}\text { Error } \\
\text { Total }\end{array}$ & 245 & 185,034 & 0,755 & & \\
corregido & 260 & 216,552 & & & \\
\hline
\end{tabular}

Fuente: Propia

Dado el valor $\mathrm{p}$ asociado al estadístico $\mathrm{F}$ calculado en la tabla ANOVA, y dado el nivel de significación del 5\%, existen diferencias estadísticamente significativas en la variable $\mathrm{i} 12$.

Figura 24. Gráfico de medias. (i12) (V5)

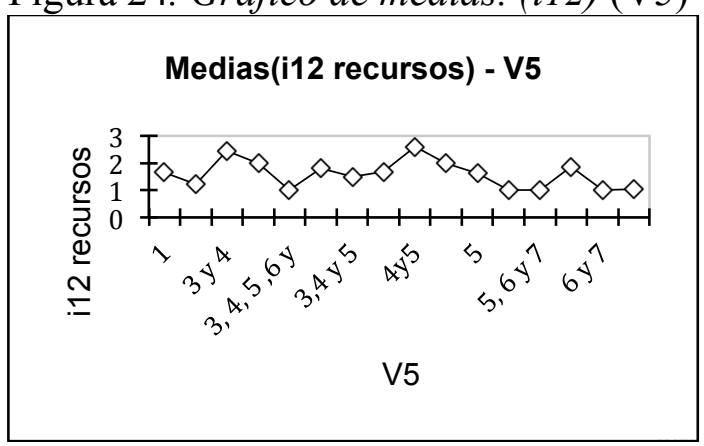

Fuente: Propia

Tabla 92. Análisis de diferencias entre las categorías, (V5)

\begin{tabular}{llllll}
\hline Categoría & Medias LS & $\begin{array}{l}\text { Error } \\
\text { estándar }\end{array}$ & $\begin{array}{l}\text { Límite } \\
\text { inferior } \\
(95 \%)\end{array}$ & $\begin{array}{l}\text { Límite } \\
\text { superior } \\
(95 \%)\end{array}$ & Grupos \\
\hline 4y5 & 2,600 & 0,389 & 1,834 & 3,366 & $\mathrm{~A}$ \\
3 y 4 & 2,444 & 0,290 & 1,874 & 3,015 & $\mathrm{~A}$ \\
4,5 y 6 & 2,000 & 0,615 & 0,790 & 3,210 & $\mathrm{~A}$ \\
3 & 2,000 & 0,389 & 1,234 & 2,766 & $\mathrm{~A}$ \\
6 & 1,875 & 0,307 & 1,270 & 2,480 & $\mathrm{~A}$ \\
$3,4,5,6$ & 1,800 & 0,275 & 1,259 & 2,341 & $\mathrm{~A}$ \\
4 & 1,667 & 0,251 & 1,173 & 2,161 & $\mathrm{~A}$ \\
1 & 1,648 & 0,085 & 1,481 & 1,815 & $\mathrm{~A}$ \\
5 & 1,632 & 0,199 & 1,239 & 2,024 & $\mathrm{~A}$ \\
3,4 y 5 & 1,500 & 0,615 & 0,290 & 2,710 & $\mathrm{~A}$ \\
2 & 1,216 & 0,122 & 0,976 & 1,455 & $\mathrm{~A}$ \\
7 & 1,040 & 0,174 & 0,698 & 1,382 & $\mathrm{~A}$ \\
$3,4,5,6$ y & 1,000 & 0,869 & $-0,712$ & 2,712 & $\mathrm{~A}$
\end{tabular}


7

\begin{tabular}{llllll}
5,6 y 7 & 1,000 & 0,869 & $-0,712$ & 2,712 & $\mathrm{~A}$ \\
6 y 7 & 1,000 & 0,869 & $-0,712$ & 2,712 & $\mathrm{~A}$ \\
5 y 6 & 1,000 & 0,389 & 0,234 & 1,766 & $\mathrm{~A}$ \\
\hline
\end{tabular}

Fuente: Propia

Tabla 93.Ámbito pedagógico / Tukey (HSD) / Análisis de las diferencias entre las categorías con un intervalo de confianza de 95\% (i12 recursos) (V5)

Fuente: Propia

\begin{tabular}{|c|c|c|c|c|c|}
\hline Contraste & Diferencia & $\begin{array}{c}\text { Diferencia } \\
\text { estandarizada }\end{array}$ & $\begin{array}{l}\text { Valor } \\
\text { crítico }\end{array}$ & $\operatorname{Pr}>$ Dif & Significativo \\
\hline $4 y 5$ vs 5 y 6 & 1,600 & 2,297 & 3,462 & 0,627 & No \\
\hline $4 y 5$ vs $3,4,5,6$ y 7 & 1,600 & 2,297 & 3,462 & 0,627 & No \\
\hline $4 y 5$ vs 5,6 y 7 & 1,600 & 2,297 & 3,462 & 0,627 & No \\
\hline $4 y 5$ vs 6 y 7 & 1,600 & 2,297 & 3,462 & 0,627 & No \\
\hline $4 y 5$ vs 7 & 1,560 & 2,239 & 3,462 & 0,668 & No \\
\hline $4 y 5$ vs 2 & 1,384 & 1,987 & 3,462 & 0,830 & No \\
\hline $4 y 5$ vs 3,4 y 5 & 1,100 & 1,579 & 3,462 & 0,971 & No \\
\hline $4 y 5$ vs 5 & 0,968 & 1,390 & 3,462 & 0,991 & No \\
\hline $4 y 5$ vs 1 & 0,952 & 1,367 & 3,462 & 0,993 & No \\
\hline $4 y 5$ vs 4 & 0,933 & 1,340 & 3,462 & 0,994 & No \\
\hline $4 y 5$ vs $3,4,5,6$ & 0,800 & 1,148 & 3,462 & 0,999 & No \\
\hline $4 y 5$ vs 6 & 0,725 & 1,041 & 3,462 & 1,000 & No \\
\hline $4 y 5$ vs 3 & 0,600 & 0,861 & 3,462 & 1,000 & No \\
\hline $4 y 5$ vs 4,5 y 6 & 0,600 & 0,861 & 3,462 & 1,000 & No \\
\hline $4 y 5$ vs 3 y 4 & 0,156 & 0,223 & 3,462 & 1,000 & No \\
\hline 3 y 4 vs 5 y 6 & 1,444 & 2,073 & 3,462 & 0,780 & No \\
\hline 3 y 4 vs $3,4,5,6$ y 7 & 1,444 & 2,073 & 3,462 & 0,780 & No \\
\hline 3 y 4 vs 5,6 y 7 & 1,444 & 2,073 & 3,462 & 0,780 & No \\
\hline 3 y 4 vs 6 y 7 & 1,444 & 2,073 & 3,462 & 0,780 & No \\
\hline 3 y 4 vs 7 & 1,404 & 2,016 & 3,462 & 0,814 & No \\
\hline 3 y 4 vs 2 & 1,229 & 1,764 & 3,462 & 0,927 & No \\
\hline 3 y 4 vs 3,4 y 5 & 0,944 & 1,356 & 3,462 & 0,993 & No \\
\hline 3 y 4 vs 5 & 0,813 & 1,167 & 3,462 & 0,999 & No \\
\hline 3 y 4 vs 1 & 0,797 & 1,144 & 3,462 & 0,999 & No \\
\hline 3 y 4 vs 4 & 0,778 & 1,116 & 3,462 & 0,999 & No \\
\hline 3 y 4 vs $3,4,5,6$ & 0,644 & 0,925 & 3,462 & 1,000 & No \\
\hline 3 y 4 vs 6 & 0,569 & 0,817 & 3,462 & 1,000 & No \\
\hline 3 y 4 vs 3 & 0,444 & 0,638 & 3,462 & 1,000 & No \\
\hline 3 y 4 vs 4,5 y 6 & 0,444 & 0,638 & 3,462 & 1,000 & No \\
\hline 4,5 y 6 vs 5 y 6 & 1,000 & 1,435 & 3,462 & 0,988 & No \\
\hline \multicolumn{6}{|l|}{4,5 y 6 vs $3,4,5,6$} \\
\hline y 7 & 1,000 & 1,435 & 3,462 & 0,988 & No \\
\hline 4,5 y 6 vs 5,6 y 7 & 1,000 & 1,435 & 3,462 & 0,988 & No \\
\hline
\end{tabular}




\begin{tabular}{|c|c|c|c|c|}
\hline 4,5 y 6 vs 6 y 7 & 1,000 & 1,435 & 3,462 & 0,988 \\
\hline 4,5 y 6 vs 7 & 0,960 & 1,378 & 3,462 & 0,992 \\
\hline 4,5 y 6 vs 2 & 0,784 & 1,126 & 3,462 & 0,999 \\
\hline 4,5 y 6 vs 3,4 y 5 & 0,500 & 0,718 & 3,462 & 1,000 \\
\hline 4,5 y 6 vs 5 & 0,368 & 0,529 & 3,462 & 1,000 \\
\hline 4,5 y 6 vs 1 & 0,352 & 0,506 & 3,462 & 1,000 \\
\hline 4,5 y 6 vs 4 & 0,333 & 0,478 & 3,462 & 1,000 \\
\hline 4,5 y 6 vs 3,4,5,6 & 0,200 & 0,287 & 3,462 & 1,000 \\
\hline 4,5 y 6 vs 6 & 0,125 & 0,179 & 3,462 & 1,000 \\
\hline 4,5 y 6 vs 3 & 0,000 & 0,000 & 3,462 & 1,000 \\
\hline 3 vs 5 y 6 & 1,000 & 1,435 & 3,462 & 0,988 \\
\hline 3 vs $3,4,5,6$ y 7 & 1,000 & 1,435 & 3,462 & 0,988 \\
\hline 3 vs 5,6 y 7 & 1,000 & 1,435 & 3,462 & 0,988 \\
\hline 3 vs 6 y 7 & 1,000 & 1,435 & 3,462 & 0,988 \\
\hline 3 vs 7 & 0,960 & 1,378 & 3,462 & 0,992 \\
\hline 3 vs 2 & 0,784 & 1,126 & 3,462 & 0,999 \\
\hline 3 vs 3,4 y 5 & 0,500 & 0,718 & 3,462 & 1,000 \\
\hline 3 vs 5 & 0,368 & 0,529 & 3,462 & 1,000 \\
\hline 3 vs 1 & 0,352 & 0,506 & 3,462 & 1,000 \\
\hline 3 vs 4 & 0,333 & 0,478 & 3,462 & 1,000 \\
\hline 3 vs $3,4,5,6$ & 0,200 & 0,287 & 3,462 & 1,000 \\
\hline 3 vs 6 & 0,125 & 0,179 & 3,462 & 1,000 \\
\hline 6 vs 5 y 6 & 0,875 & 1,256 & 3,462 & 0,997 \\
\hline 6 vs $3,4,5,6$ y 7 & 0,875 & 1,256 & 3,462 & 0,997 \\
\hline 6 vs 5,6 y 7 & 0,875 & 1,256 & 3,462 & 0,997 \\
\hline 6 vs 6 y 7 & 0,875 & 1,256 & 3,462 & 0,997 \\
\hline 6 vs 7 & 0,835 & 1,199 & 3,462 & 0,998 \\
\hline 6 vs 2 & 0,659 & 0,946 & 3,462 & 1,000 \\
\hline 6 vs 3,4 y 5 & 0,375 & 0,538 & 3,462 & 1,000 \\
\hline 6 vs 5 & 0,243 & 0,349 & 3,462 & 1,000 \\
\hline 6 vs 1 & 0,227 & 0,326 & 3,462 & 1,000 \\
\hline 6 vs 4 & 0,208 & 0,299 & 3,462 & 1,000 \\
\hline 6 vs $3,4,5,6$ & 0,075 & 0,108 & 3,462 & 1,000 \\
\hline $3,4,5,6$ vs 5 y 6 & 0,800 & 1,148 & 3,462 & 0,999 \\
\hline \multicolumn{5}{|l|}{$3,4,5,6$ vs $3,4,5,6$} \\
\hline y 7 & 0,800 & 1,148 & 3,462 & 0,999 \\
\hline $3,4,5,6$ vs 5,6 y 7 & 0,800 & 1,148 & 3,462 & 0,999 \\
\hline $3,4,5,6$ vs 6 y 7 & 0,800 & 1,148 & 3,462 & 0,999 \\
\hline $3,4,5,6$ vs 7 & 0,760 & 1,091 & 3,462 & 0,999 \\
\hline $3,4,5,6$ vs 2 & 0,584 & 0,839 & 3,462 & 1,000 \\
\hline $3,4,5,6$ vs 3,4 y 5 & 0,300 & 0,431 & 3,462 & 1,000 \\
\hline $3,4,5,6$ vs 5 & 0,168 & 0,242 & 3,462 & 1,000 \\
\hline $3,4,5,6$ vs 1 & 0,152 & 0,219 & 3,462 & 1,000 \\
\hline
\end{tabular}




\begin{tabular}{|c|c|c|c|c|c|}
\hline $3,4,5,6$ vs 4 & 0,133 & 0,191 & 3,462 & 1,000 & No \\
\hline 4 vs 5 y 6 & 0,667 & 0,957 & 3,462 & 1,000 & No \\
\hline 4 vs $3,4,5,6$ y 7 & 0,667 & 0,957 & 3,462 & 1,000 & No \\
\hline 4 vs 5,6 y 7 & 0,667 & 0,957 & 3,462 & 1,000 & No \\
\hline 4 vs 6 y 7 & 0,667 & 0,957 & 3,462 & 1,000 & No \\
\hline 4 vs 7 & 0,627 & 0,900 & 3,462 & 1,000 & No \\
\hline 4 vs 2 & 0,451 & 0,647 & 3,462 & 1,000 & No \\
\hline 4 vs 3,4 y 5 & 0,167 & 0,239 & 3,462 & 1,000 & No \\
\hline 4 vs 5 & 0,035 & 0,050 & 3,462 & 1,000 & No \\
\hline 4 vs 1 & 0,019 & 0,027 & 3,462 & 1,000 & No \\
\hline 1 vs 5 y 6 & 0,648 & 0,930 & 3,462 & 1,000 & No \\
\hline 1 vs $3,4,5,6$ y 7 & 0,648 & 0,930 & 3,462 & 1,000 & No \\
\hline 1 vs 5,6 y 7 & 0,648 & 0,930 & 3,462 & 1,000 & No \\
\hline 1 vs 6 y 7 & 0,648 & 0,930 & 3,462 & 1,000 & No \\
\hline 1 vs 7 & 0,608 & 0,872 & 3,462 & 1,000 & No \\
\hline 1 vs 2 & 0,432 & 0,620 & 3,462 & 1,000 & No \\
\hline 1 vs 3,4 y 5 & 0,148 & 0,212 & 3,462 & 1,000 & No \\
\hline 1 vs 5 & 0,016 & 0,023 & 3,462 & 1,000 & No \\
\hline 5 vs 5 y 6 & 0,632 & 0,907 & 3,462 & 1,000 & No \\
\hline 5 vs $3,4,5,6$ y 7 & 0,632 & 0,907 & 3,462 & 1,000 & No \\
\hline 5 vs 5,6 y 7 & 0,632 & 0,907 & 3,462 & 1,000 & No \\
\hline 5 vs 6 y 7 & 0,632 & 0,907 & 3,462 & 1,000 & No \\
\hline 5 vs 7 & 0,592 & 0,849 & 3,462 & 1,000 & No \\
\hline 5 vs 2 & 0,416 & 0,597 & 3,462 & 1,000 & No \\
\hline 5 vs 3,4 y 5 & 0,132 & 0,189 & 3,462 & 1,000 & No \\
\hline $\begin{array}{l}3,4 \text { y } 5 \text { vs } 5 \text { y } 6 \\
3,4 \text { y } 5 \text { vs } 3,4,5,6 \text { y }\end{array}$ & 0,500 & 0,718 & 3,462 & 1,000 & No \\
\hline 7 & 0,500 & 0,718 & 3,462 & 1,000 & No \\
\hline 3,4 y 5 vs 5,6 y 7 & 0,500 & 0,718 & 3,462 & 1,000 & No \\
\hline 3,4 y 5 vs 6 y 7 & 0,500 & 0,718 & 3,462 & 1,000 & No \\
\hline 3,4 y 5 vs 7 & 0,460 & 0,660 & 3,462 & 1,000 & No \\
\hline 3,4 y 5 vs 2 & 0,284 & 0,408 & 3,462 & 1,000 & No \\
\hline 2 vs 5 y 6 & 0,216 & 0,310 & 3,462 & 1,000 & No \\
\hline 2 vs $3,4,5,6$ y 7 & 0,216 & 0,310 & 3,462 & 1,000 & No \\
\hline 2 vs 5,6 y 7 & 0,216 & 0,310 & 3,462 & 1,000 & No \\
\hline 2 vs 6 y 7 & 0,216 & 0,310 & 3,462 & 1,000 & No \\
\hline 2 vs 7 & 0,176 & 0,252 & 3,462 & 1,000 & No \\
\hline 7 vs 5 y 6 & 0,040 & 0,057 & 3,462 & 1,000 & No \\
\hline 7 vs $3,4,5,6$ y 7 & 0,040 & 0,057 & 3,462 & 1,000 & No \\
\hline 7 vs 5,6 y 7 & 0,040 & 0,057 & 3,462 & 1,000 & No \\
\hline 7 vs 6 y 7 & 0,040 & 0,057 & 3,462 & 1,000 & No \\
\hline 6 y 7 vs 5 y 6 & 0,000 & 0,000 & 3,462 & 1,000 & No \\
\hline 6 y 7 vs $3,4,5,6$ y 7 & 0,000 & 0,000 & 3,462 & 1,000 & No \\
\hline
\end{tabular}




\begin{tabular}{lrrrrr}
$\begin{array}{l}6 \text { y } 7 \text { vs } 5,6 \text { y } 7 \\
5,6 \text { y } 7 \text { vs } 5 \text { y } 6\end{array}$ & 0,000 & 0,000 & 3,462 & 1,000 & No \\
$\begin{array}{l}5,6 \text { y } 7 \text { vs } 3,4,5,6 \\
\text { y } 7\end{array}$ & 0,000 & 0,000 & 3,462 & 1,000 & No \\
$3,4,5,6$ y 7 vs 5 y 6 & 0,000 & 0,000 & 3,462 & 1,000 & No \\
\multicolumn{2}{l}{ Valor crítico del d de Tukey: } & 0,000 & 3,462 & 1,000 & No \\
\hline
\end{tabular}

Como podemos apreciar en la gráfica de medias, todas las categorías se sitúan entre los valores 3,000 y 1,000 . Presentando el valor más alto la categorías $(4,5,6)$ y el más bajo las categoría $(3,4,5,6,7),(4,5,6),(5,6),(5,6,7),(6,7)$ y $(7)$.

El análisis del contrate de pares no nos reporta ningún resultado estadísticamente significativo.

\subsubsection{Análisis de la variable i13 (V5). Determinación de los sistemas o herramientas de evaluación.}

Analizamos si existen diferencias significativas en la descripción de las herramientas de evaluación de los programas atendiendo al ámbito pedagógico al que están destinados.

Tabla 94. Análisis de varianza (i13) (V5)

\begin{tabular}{|c|c|c|c|c|c|}
\hline Fuente & GL & $\begin{array}{l}\text { Suma de } \\
\text { cuadrados }\end{array}$ & $\begin{array}{l}\text { Cuadrados } \\
\text { medios }\end{array}$ & $\mathrm{F}$ & $\operatorname{Pr}>F$ \\
\hline Modelo & 18 & 37,501 & 2,083 & 4,321 & $<0,0001$ \\
\hline Error & 243 & 117,160 & 0,482 & & \\
\hline $\begin{array}{l}\text { Total } \\
\text { corregido }\end{array}$ & 261 & 154,660 & & & \\
\hline
\end{tabular}

Dado el valor $\mathrm{p}$ asociado al estadístico $\mathrm{F}$ calculado en la tabla ANOVA, y dado el nivel de significación del 5\%, existen diferencias estadísticamente significativas en la variable $\mathrm{i} 13$.

Figura 25. Gráfico de medias, (i13) (V5)

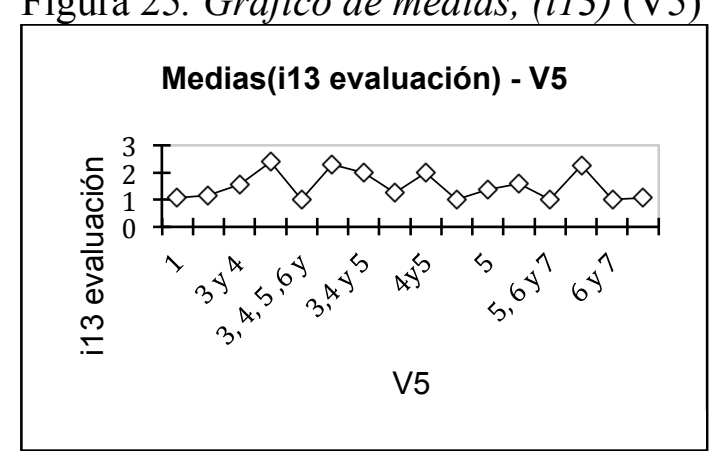

Fuente: Propia 
Tabla 95. Análisis de diferencias entre las categorías (V5)

\begin{tabular}{llllll}
\hline Categoría & Medias LS & $\begin{array}{l}\text { Error } \\
\text { estándar }\end{array}$ & $\begin{array}{l}\text { Límite } \\
\text { inferior } \\
(95 \%)\end{array}$ & $\begin{array}{l}\text { Límite } \\
\text { superior } \\
(95 \%)\end{array}$ & Grupos \\
\hline 3 & 2,400 & 0,312 & 1,786 & 3,014 & $\mathrm{~A}$ \\
$3,4,5,6$ & 2,300 & 0,220 & 1,866 & 2,734 & $\mathrm{~A}$ \\
6 & 2,250 & 0,246 & 1,765 & 2,735 & $\mathrm{~A}$ \\
3,4 y 5 & 2,000 & 0,493 & 1,030 & 2,970 & $\mathrm{~A}$ \\
4 y5 & 2,000 & 0,312 & 1,386 & 2,614 & $\mathrm{~A}$ \\
5 y 6 & 1,600 & 0,312 & 0,986 & 2,214 & $\mathrm{~A}$ \\
3 y 4 & 1,556 & 0,232 & 1,098 & 2,013 & $\mathrm{~A}$ \\
5 & 1,368 & 0,160 & 1,054 & 1,683 & $\mathrm{~A}$ \\
4 & 1,250 & 0,201 & 0,854 & 1,646 & $\mathrm{~A}$ \\
2 & 1,157 & 0,098 & 0,965 & 1,349 & $\mathrm{~A}$ \\
7 & 1,080 & 0,139 & 0,806 & 1,354 & $\mathrm{~A}$ \\
1 & 1,076 & 0,068 & 0,942 & 1,210 & $\mathrm{~A}$ \\
$3,4,5,6$ y & & & & & \\
7 & 1,000 & 0,697 & $-0,372$ & 2,372 & $\mathrm{~A}$ \\
4,5 y 6 & 1,000 & 0,493 & 0,030 & 1,970 & $\mathrm{~A}$ \\
5,6 y 7 & 1,000 & 0,697 & $-0,372$ & 2,372 & $\mathrm{~A}$ \\
6 y 7 & 1,000 & 0,697 & $-0,372$ & 2,372 & $\mathrm{~A}$ \\
\hline
\end{tabular}

Fuente: Propia

Tabla 96.Ámbito pedagógico / Tukey (HSD) / Análisis de las diferencias entre las categorías con un intervalo de confianza de 95\% (i13 evaluación) (V5),

\begin{tabular}{lrrrrl}
\hline \multicolumn{1}{c}{ Contraste } & Diferencia & $\begin{array}{c}\text { Diferencia } \\
\text { estandarizada }\end{array}$ & $\begin{array}{c}\text { Valor } \\
\text { crítico }\end{array}$ & $\begin{array}{c}\text { Pr } \\
\text { > Dif }\end{array}$ & Significativo \\
\hline 3 vs $3,4,5,6$ y 7 & 1,400 & 2,507 & 3,462 & 0,470 & No \\
3 vs 4,5 y 6 & 1,400 & 2,507 & 3,462 & 0,470 & No \\
3 vs 5,6 y 7 & 1,400 & 2,507 & 3,462 & 0,470 & No \\
3 vs 6 y 7 & 1,400 & 2,507 & 3,462 & 0,470 & No \\
3 vs 1 & 1,324 & 2,371 & 3,462 & 0,571 & No \\
3 vs 7 & 1,320 & 2,364 & 3,462 & 0,577 & No \\
3 vs 2 & 1,243 & 2,226 & 3,462 & 0,678 & No \\
3 vs 4 & 1,150 & 2,059 & 3,462 & 0,789 & No \\
3 vs 5 & 1,032 & 1,847 & 3,462 & 0,896 & No \\
3 vs 3 y 4 & 0,844 & 1,512 & 3,462 & 0,980 & No \\
3 vs 5 y 6 & 0,800 & 1,433 & 3,462 & 0,988 & No \\
3 vs 4 y5 & 0,400 & 0,716 & 3,462 & 1,000 & No \\
3 vs 3,4 y 5 & 0,400 & 0,716 & 3,462 & 1,000 & No \\
3 vs 6 & 0,150 & 0,269 & 3,462 & 1,000 & No \\
3 vs 3,4,5,6 & 0,100 & 0,179 & 3,462 & 1,000 & No \\
$3,4,5,6$ vs 3, 4, 5 & & & & & \\
6 y 7 & 1,300 & 2,328 & 3,462 & 0,603 & No \\
$3,4,5,6$ vs 4,5 y 6 & 1,300 & 2,328 & 3,462 & 0,603 & No
\end{tabular}




\begin{tabular}{|c|c|c|c|c|}
\hline $3,4,5,6$ vs 5,6 y 7 & 1,300 & 2,328 & 3,462 & 0,603 \\
\hline $3,4,5,6$ vs 6 y 7 & 1,300 & 2,328 & 3,462 & 0,603 \\
\hline $3,4,5,6$ vs 1 & 1,224 & 2,192 & 3,462 & 0,702 \\
\hline $3,4,5,6$ vs 7 & 1,220 & 2,185 & 3,462 & 0,707 \\
\hline $3,4,5,6$ vs 2 & 1,143 & 2,047 & 3,462 & 0,796 \\
\hline $3,4,5,6$ vs 4 & 1,050 & 1,880 & 3,462 & 0,882 \\
\hline $3,4,5,6$ vs 5 & 0,932 & 1,668 & 3,462 & 0,953 \\
\hline $3,4,5,6$ vs 3 y 4 & 0,744 & 1,333 & 3,462 & 0,994 \\
\hline $3,4,5,6$ vs 5 y 6 & 0,700 & 1,254 & 3,462 & 0,997 \\
\hline $3,4,5,6$ vs $4 y 5$ & 0,300 & 0,537 & 3,462 & 1,000 \\
\hline $3,4,5,6$ vs 3,4 y 5 & 0,300 & 0,537 & 3,462 & 1,000 \\
\hline $3,4,5,6$ vs 6 & 0,050 & 0,090 & 3,462 & 1,000 \\
\hline 6 vs $3,4,5,6$ y 7 & 1,250 & 2,239 & 3,462 & 0,669 \\
\hline 6 vs 4,5 y 6 & 1,250 & 2,239 & 3,462 & 0,669 \\
\hline 6 vs 5,6 y 7 & 1,250 & 2,239 & 3,462 & 0,669 \\
\hline 6 vs 6 y 7 & 1,250 & 2,239 & 3,462 & 0,669 \\
\hline 6 vs 1 & 1,174 & 2,102 & 3,462 & 0,762 \\
\hline 6 vs 7 & 1,170 & 2,095 & 3,462 & 0,766 \\
\hline 6 vs 2 & 1,093 & 1,958 & 3,462 & 0,846 \\
\hline 6 vs 4 & 1,000 & 1,791 & 3,462 & 0,917 \\
\hline 6 vs 5 & 0,882 & 1,579 & 3,462 & 0,971 \\
\hline 6 vs 3 y 4 & 0,694 & 1,244 & 3,462 & 0,997 \\
\hline 6 vs 5 y 6 & 0,650 & 1,164 & 3,462 & 0,999 \\
\hline 6 vs $4 y 5$ & 0,250 & 0,448 & 3,462 & 1,000 \\
\hline 6 vs 3,4 y 5 & 0,250 & 0,448 & 3,462 & 1,000 \\
\hline \multicolumn{5}{|l|}{$4 y 5$ vs $3,4,5,6$ y } \\
\hline 7 & 1,000 & 1,791 & 3,462 & 0,917 \\
\hline $4 y 5$ vs 4,5 y 6 & 1,000 & 1,791 & 3,462 & 0,917 \\
\hline $4 y 5$ vs 5,6 y 7 & 1,000 & 1,791 & 3,462 & 0,917 \\
\hline $4 y 5$ vs 6 y 7 & 1,000 & 1,791 & 3,462 & 0,917 \\
\hline $4 y 5$ vs 1 & 0,924 & 1,654 & 3,462 & 0,956 \\
\hline $4 y 5$ vs 7 & 0,920 & 1,648 & 3,462 & 0,958 \\
\hline $4 y 5$ vs 2 & 0,843 & 1,510 & 3,462 & 0,981 \\
\hline $4 y 5$ vs 4 & 0,750 & 1,343 & 3,462 & 0,994 \\
\hline $4 y 5$ vs 5 & 0,632 & 1,131 & 3,462 & 0,999 \\
\hline $4 y 5$ vs 3 y 4 & 0,444 & 0,796 & 3,462 & 1,000 \\
\hline $4 y 5$ vs 5 y 6 & 0,400 & 0,716 & 3,462 & 1,000 \\
\hline $4 y 5$ vs 3,4 y 5 & 0,000 & 0,000 & 3,462 & 1,000 \\
\hline \multicolumn{5}{|l|}{3,4 y 5 vs $3,4,5,6$} \\
\hline y 7 & 1,000 & 1,791 & 3,462 & 0,917 \\
\hline 3,4 y 5 vs 4,5 y 6 & 1,000 & 1,791 & 3,462 & 0,917 \\
\hline 3,4 y 5 vs 5,6 y 7 & 1,000 & 1,791 & 3,462 & 0,917 \\
\hline 3,4 y 5 vs 6 y 7 & 1,000 & 1,791 & 3,462 & 0,917 \\
\hline 3,4 y 5 vs 1 & 0,924 & 1,654 & 3,462 & 0,956 \\
\hline
\end{tabular}




\begin{tabular}{|c|c|c|c|c|}
\hline 3,4 y 5 vs 7 & 0,920 & 1,648 & 3,462 & 0,958 \\
\hline 3,4 y 5 vs 2 & 0,843 & 1,510 & 3,462 & 0,981 \\
\hline 3,4 y 5 vs 4 & 0,750 & 1,343 & 3,462 & 0,994 \\
\hline 3,4 y 5 vs 5 & 0,632 & 1,131 & 3,462 & 0,999 \\
\hline 3,4 y 5 vs 3 y 4 & 0,444 & 0,796 & 3,462 & 1,000 \\
\hline 3,4 y 5 vs 5 y 6 & 0,400 & 0,716 & 3,462 & 1,000 \\
\hline \multicolumn{5}{|l|}{5 y 6 vs $3,4,5,6$ y } \\
\hline 7 & 0,600 & 1,075 & 3,462 & 0,999 \\
\hline 5 y 6 vs 4,5 y 6 & 0,600 & 1,075 & 3,462 & 0,999 \\
\hline 5 y 6 vs 5,6 y 7 & 0,600 & 1,075 & 3,462 & 0,999 \\
\hline 5 y 6 vs 6 y 7 & 0,600 & 1,075 & 3,462 & 0,999 \\
\hline 5 y 6 vs 1 & 0,524 & 0,938 & 3,462 & 1,000 \\
\hline 5 y 6 vs 7 & 0,520 & 0,931 & 3,462 & 1,000 \\
\hline 5 y 6 vs 2 & 0,443 & 0,794 & 3,462 & 1,000 \\
\hline 5 y 6 vs 4 & 0,350 & 0,627 & 3,462 & 1,000 \\
\hline 5 y 6 vs 5 & 0,232 & 0,415 & 3,462 & 1,000 \\
\hline 5 y 6 vs 3 y 4 & 0,044 & 0,080 & 3,462 & 1,000 \\
\hline \multicolumn{5}{|l|}{3 y 4 vs $3,4,5,6$ y } \\
\hline 7 & 0,556 & 0,995 & 3,462 & 1,000 \\
\hline 3 y 4 vs 4,5 y 6 & 0,556 & 0,995 & 3,462 & 1,000 \\
\hline 3 y 4 vs 5,6 y 7 & 0,556 & 0,995 & 3,462 & 1,000 \\
\hline 3 y 4 vs 6 y 7 & 0,556 & 0,995 & 3,462 & 1,000 \\
\hline 3 y 4 vs 1 & 0,479 & 0,858 & 3,462 & 1,000 \\
\hline 3 y 4 vs 7 & 0,476 & 0,852 & 3,462 & 1,000 \\
\hline 3 y 4 vs 2 & 0,399 & 0,714 & 3,462 & 1,000 \\
\hline 3 y 4 vs 4 & 0,306 & 0,547 & 3,462 & 1,000 \\
\hline 3 y 4 vs 5 & 0,187 & 0,335 & 3,462 & 1,000 \\
\hline 5 vs $3,4,5,6$ y 7 & 0,368 & 0,660 & 3,462 & 1,000 \\
\hline 5 vs 4,5 y 6 & 0,368 & 0,660 & 3,462 & 1,000 \\
\hline 5 vs 5,6 y 7 & 0,368 & 0,660 & 3,462 & 1,000 \\
\hline 5 vs 6 y 7 & 0,368 & 0,660 & 3,462 & 1,000 \\
\hline 5 vs 1 & 0,292 & 0,523 & 3,462 & 1,000 \\
\hline 5 vs 7 & 0,288 & 0,517 & 3,462 & 1,000 \\
\hline 5 vs 2 & 0,212 & 0,379 & 3,462 & 1,000 \\
\hline 5 vs 4 & 0,118 & 0,212 & 3,462 & 1,000 \\
\hline 4 vs $3,4,5,6$ y 7 & 0,250 & 0,448 & 3,462 & 1,000 \\
\hline 4 vs 4,5 y 6 & 0,250 & 0,448 & 3,462 & 1,000 \\
\hline 4 vs 5,6 y 7 & 0,250 & 0,448 & 3,462 & 1,000 \\
\hline 4 vs 6 y 7 & 0,250 & 0,448 & 3,462 & 1,000 \\
\hline 4 vs 1 & 0,174 & 0,311 & 3,462 & 1,000 \\
\hline 4 vs 7 & 0,170 & 0,304 & 3,462 & 1,000 \\
\hline 4 vs 2 & 0,093 & 0,167 & 3,462 & 1,000 \\
\hline 2 vs $3,4,5,6$ y 7 & 0,157 & 0,281 & 3,462 & 1,000 \\
\hline 2 vs 4,5 y 6 & 0,157 & 0,281 & 3,462 & 1,000 \\
\hline
\end{tabular}




\begin{tabular}{|c|c|c|c|c|c|}
\hline 2 vs 5,6 y 7 & 0,157 & 0,281 & 3,462 & 1,000 & No \\
\hline 2 vs 6 y 7 & 0,157 & 0,281 & 3,462 & 1,000 & No \\
\hline 2 vs 1 & 0,081 & 0,144 & 3,462 & 1,000 & No \\
\hline 2 vs 7 & 0,077 & 0,138 & 3,462 & 1,000 & No \\
\hline 7 vs 4,5 y 6 & 0,080 & 0,143 & 3,462 & 1,000 & No \\
\hline 7 vs $3,4,5,6$ y 7 & 0,080 & 0,143 & 3,462 & 1,000 & No \\
\hline 7 vs 5,6 y 7 & 0,080 & 0,143 & 3,462 & 1,000 & No \\
\hline 7 vs 6 y 7 & 0,080 & 0,143 & 3,462 & 1,000 & No \\
\hline 7 vs 1 & 0,004 & 0,007 & 3,462 & 1,000 & No \\
\hline 1 vs 4,5 y 6 & 0,076 & 0,136 & 3,462 & 1,000 & No \\
\hline 1 vs $3,4,5,6$ y 7 & 0,076 & 0,136 & 3,462 & 1,000 & No \\
\hline 1 vs 5,6 y 7 & 0,076 & 0,136 & 3,462 & 1,000 & No \\
\hline 1 vs 6 y 7 & 0,076 & 0,136 & 3,462 & 1,000 & No \\
\hline 6 y 7 vs 4,5 y 6 & 0,000 & 0,000 & 3,462 & 1,000 & No \\
\hline \multicolumn{6}{|l|}{6 y 7 vs $3,4,5,6$ y } \\
\hline 7 & 0,000 & 0,000 & 3,462 & 1,000 & No \\
\hline 6 y 7 vs 5,6 y 7 & 0,000 & 0,000 & 3,462 & 1,000 & No \\
\hline 5,6 y 7 vs 4,5 y 6 & 0,000 & 0,000 & 3,462 & 1,000 & No \\
\hline \multicolumn{6}{|l|}{5,6 y 7 vs $3,4,5$} \\
\hline 6 y 7 & 0,000 & 0,000 & 3,462 & 1,000 & No \\
\hline \multicolumn{6}{|l|}{4,5 y 6 vs $3,4,5$} \\
\hline 6 y 7 & 0,000 & 0,000 & 3,462 & 1,000 & No \\
\hline
\end{tabular}

Fuente: Propia

Como podemos apreciar en la gráfica de medias, todas las categorías se sitúan entre los valores 2,600 y 1,000 . Presentando el valor más alto la categoría $(3,4,5,6)$ y el más bajo las categorías $(3,4,5,6,7),(4,5,6),(5,6,7)$ y $(6,7)$.

El análisis del contrate de pares no nos reporta ningún resultado estadísticamente significativo.

\subsubsection{Análisis de la variable i14 (V5). Medición del impacto y repercusión de la propuesta}

Finalmente estudiamos si existen diferencias significativas en la medición del impacto de los programas atendiendo al ámbito pedagógico al que están destinados.

Tabla 97. Análisis de varianza (i14) (V5)

\begin{tabular}{|c|c|c|c|c|c|}
\hline Fuente & GL & $\begin{array}{l}\text { Suma de } \\
\text { cuadrados }\end{array}$ & $\begin{array}{l}\text { Cuadrados } \\
\text { medios }\end{array}$ & $\mathrm{F}$ & $\operatorname{Pr}>F$ \\
\hline Modelo & 15 & 4,264 & 0,284 & 0,974 & 0,483 \\
\hline Error & 245 & 71,490 & 0,292 & & \\
\hline $\begin{array}{l}\text { Total } \\
\text { corregido }\end{array}$ & 260 & 75,755 & & & \\
\hline
\end{tabular}

Fuente: Propia 
Los resultados indican que no existen diferencias estadísticamente significativas $[\mathrm{F}(18,261)=0,885 ; \mathrm{p}=0,598]$ a la hora de comparar las medias de las categorías. 
CUERPO CONCLUSIVO 


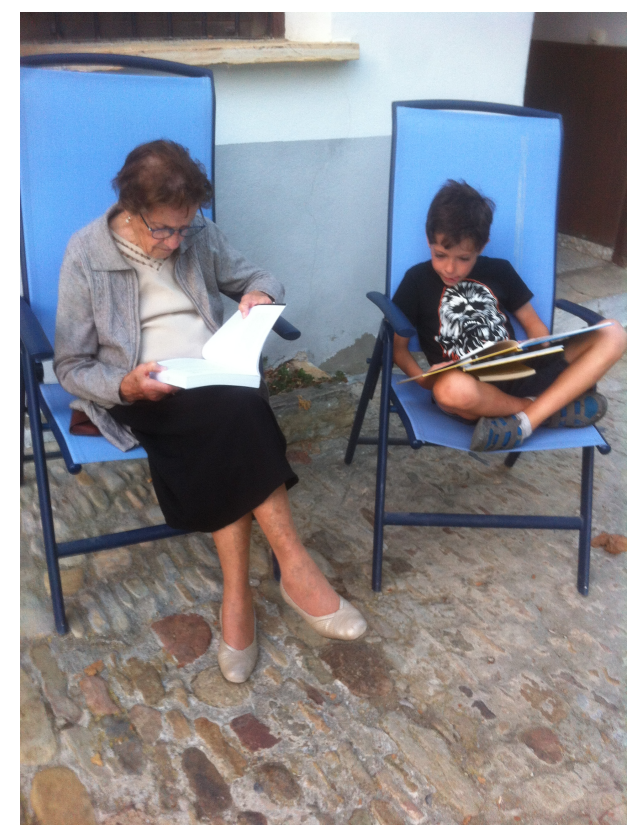

"Todos los días deberíamos oír un poco de música, leer una buena poesía, contemplar un cuadro hermoso y si es posible, decir algunas palabras sensatas".

Johann Wolfgang Von Goehe

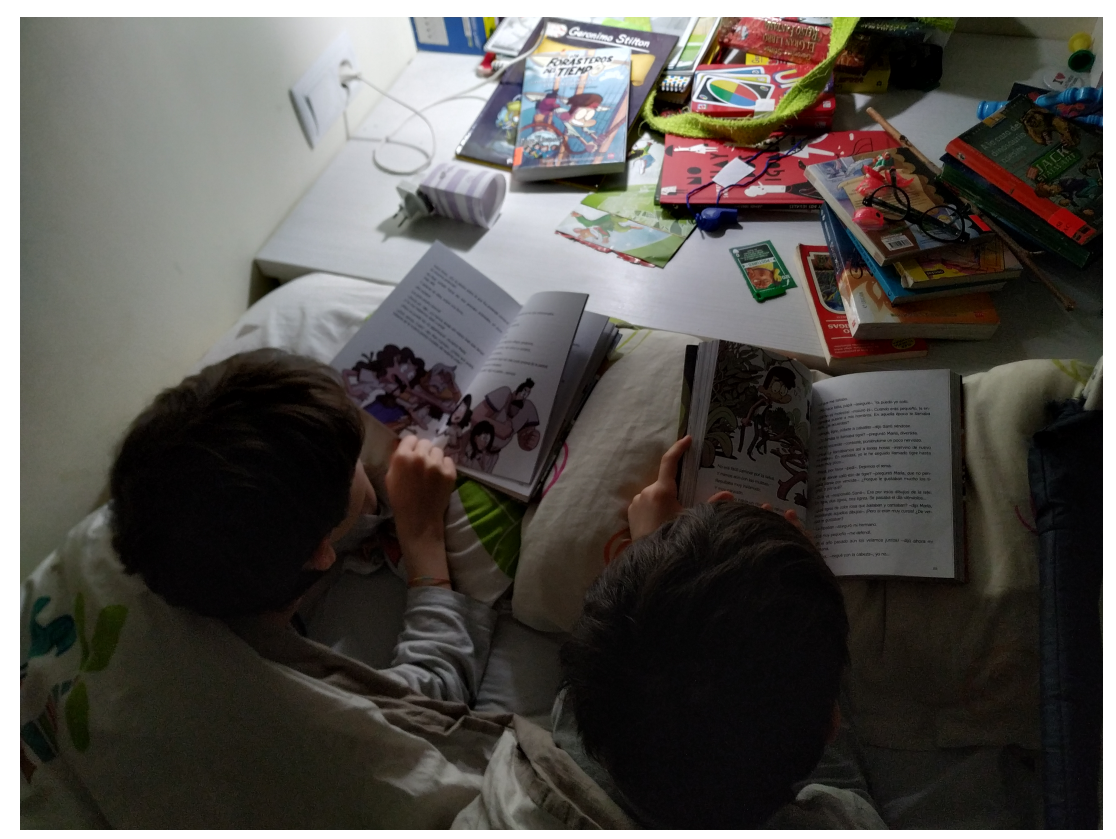




\section{CAPÍTULO 6. CONCLUSIONES}

El cuerpo conclusivo de esta investigación se estructura siguiendo el orden lógico de la misma. En primer lugar volveremos sobre el análisis de la literatura científica y legislativa que relaciona el patrimonio y las emociones a nivel nacional e internacional. Seguidamente abordaremos la relación entre patrimonio y creatividad en las mismas esferas referidas anteriormente. Pretendemos en ambos casos extraer conclusiones sobre la presencia e importancia de los términos objeto de estudio, tal y como nos planteamos en la introducción del trabajo de investigación. Finalizaremos la revisión del marco teórico con el tratamiento de ambos conceptos, emociones y creatividad, bajo el prisma de la educación patrimonial en el ámbito de Primaria. En último lugar tomaremos en consideración el análisis de los datos extraídos del marco empírico, para conocer la calidad con la que descansa en el plano práctico toda la literatura analizada anteriormente.

\subsection{Conclusiones al Marco Teórico.}

\subsubsection{Patrimonio y Emociones.}

La revisión documental tenía como objetivo estudiar la presencia de los ámbitos emocional y creativo, en la documentación emanada de los principales organismos internacionales y nacionales que trabajan con el patrimonio, así como la literatura científica al respecto. Se pretendía por tanto elaborar un amplio estado de la cuestión en torno a los tres ejes señalados: Patrimonio, Emociones y Creatividad.

Encontramos como principales hallazgos en la revisión legislativa internacional, una baja presencia de alusiones emocionales en la documentación patrimonial, y por el contrario una alta frecuencia de referencias creativas. No obstante ambas presentan una escasa incidencia en cuanto a la relación e influencia en la normativa analizada. Esta tendencia la podemos extrapolar a la producción científica, si bien a medida que nos acercamos a la actualidad el número de publicaciones que acogen nuestros temas de análisis va aumentando.

La UNESCO desde su fundación en 1945, actúa a través de cinco grandes programas entre los que se encuentran, la educación, la cultura o las ciencias sociales y humanas. A lo largo de todo este tiempo, y como hemos podido comprobar en el marco teórico, son frecuentes las alusiones a determinados tipos de patrimonio asociados a la emoción. Ya en la Conferencia General de año 1956 al hablar de excavaciones arqueológicas, se aboga por desarrollar el sentimiento de pertenencia como mejor elemento de conservación. Esta misma idea la encontramos en otros textos posteriores (UNESCO, 1968, 1970, 1978).

Sin embargo, es en la Conferencia General de París de 1962, y más concretamente en la Recomendación relativa a la Protección de la Belleza y del carácter de los lugares y paisajes, donde podemos encontrar una referencia explícita al valor de los elementos bellos como un motor de lo emocional. La recomendación hace hincapié en la necesidad de la belleza para la vida de las personas, tanto en el aspecto físico, como moral o espiritual (UNESCO, 1962). Extraemos de aquí un paralelismo con nuestro objetivo de búsqueda emocional, ya que consideramos la gestión emocional personal como componente vital en un desarrollo armónico y pleno de la persona, atisbando un papel relevante al patrimonio, como generador de esa buscada estabilidad personal, bien sea a 
través de la belleza o de la identificación personal, cultural o de proximidad con el elemento patrimonial.

En posteriores alusiones a la emoción desde el ámbito patrimonial, se ligan ambos términos a la consecución de objetivos dispares como el desarrollo identitario (UNESCO, 1980, 2003), o la paz (UNESCO, 2011).

Podemos concluir por tanto, que la relevancia que se da al ámbito emocional dentro de los más de treinta instrumentos normativos analizados y relacionados con el patrimonio, es testimonial. Se nombran tan solo diez veces ligando su valor en la mayoría de los casos, a la utilidad que pudieran presentar como medio de conservación, estimulando la identidad cultural o por medio de acciones (no concretadas en el texto), por parte de los estados miembros. Así mismo, encontramos una sola referencia a la palabra emoción ligada a la experiencia estética (UNESCO, 1976), aunque exclusivamente en el entorno del patrimonio artístico. En este sentido, como ya hemos señalado en el marco teórico, las referencias a la contribución del arte para el desarrollo moral y espiritual entroncan plenamente en nuestra propuesta de una educación patrimonial como herramienta de formación integral de la persona. Cualquier producción humana, bien con objetivos ornamentales, culturales, estéticos, utilitarios, técnicos, etc. puede ser destinada como instrumento didáctico para el desarrollo humano pleno, independientemente de su consideración o no como elemento artístico o bello.

Entendemos que la UNESCO considera necesario estimular los sentimientos de pertenencia de las comunidades locales primero, y de las universales después, como mejor medio de conservación de las diferentes manifestaciones patrimoniales. Pero no otorga relevancia, o al menos no podemos extraer esta idea de sus publicaciones, al papel que el patrimonio puede desempeñar para formar ciudadanos más sensibles y comprometidos. El contexto general de los documentos demanda que la educación ayude a la conservación del patrimonio por medio de su difusión didáctica y desde una visión moral, pero no se contempla la posibilidad de que el patrimonio pueda contribuir a educar en el más amplio sentido de la palabra.

En cuanto a la normativa europea, destacamos la alusión encontrada en la documentación educativa dentro de la Recomendación sobre las competencias clave en el aprendizaje permanente, en ella se menciona la utilidad de las artes como medio de expresión emocional. Estamos ante un punto de vista en el que quizá hay consenso (Gardner, 1994), incluso dentro del ámbito de la educación formal (Calaf y Fontal, 2010). No obstante tal y como hemos argumentado en el marco teórico, entendemos que las posibilidades de las artes van más allá de ser utilizadas como medio de expresión emocional del autor solamente, así y siguiendo a López (2010), concebimos que estas puede servir también como herramienta para el trabajo emocional con los sujetos receptores.

La revisión legislativa europea del ámbito cultural, arroja solamente seis referencias directas sobre emociones y patrimonio dentro de los ocho documentos analizados, un bagaje escaso máxime cuando el enfoque de las alusiones es estrictamente económico. Pese a ello, entendemos que nuestros términos de búsqueda adquieren mayor presencia en la revisión de origen educativo, donde se presentan los elementos patrimoniales como dependientes de la educación para su mantenimiento y renovación y se presentan los elementos emocionales como transversales en el proceso de adquisición de competencias (Unión Europea, 2006). Exceptuando las alusiones competenciales hallamos referencias emocionales en la documentación relativa al desarrollo del sentimiento identitario europeo y en la referida al desarrollo de la creatividad y la innovación. Por ello, este aporte referencial de dos alusiones, sin profundidad teórica ni 
carácter preceptivo hacia el desarrollo emocional, se revela insuficiente para impulsar la puesta en marcha de iniciativas educativas que contengan nuestros ámbitos de interés.

Al adentrarnos en la legislación nacional, observamos que tanto la Ley de Patrimonio Histórico como la Ley de Patrimonio Inmaterial carecen de referencias emocionales. Por otro lado, tan solo 5 de las 19 leyes autonómicas sobre patrimonio revisadas tienen alusiones al respecto y éstas se circunscriben a la creación de un sentimiento identitario regional. Al estudiar El Plan Nacional de Educación y Patrimonio y El Plan Nacional para la Salvaguarda del Patrimonio Cultural Inmaterial, encontramos que el patrimonio cultural inmaterial es el que más alusiones a emociones o sentimientos presenta.

Esta tendencia la corrobora también la literatura científica, donde es más habitual la relación del patrimonio inmaterial con las emociones (Santacana y Llonch 2015; Mock, 2018; Martínez, 2019). Esta predisposición se fundamenta en el carácter marcadamente personal de este tipo de bien, donde muchos de los elementos que lo conforman hunden sus más profundas raíces en las tradiciones personales y sociales de cada comunidad.

Asumimos ese tipo de relación más cercana, personal incluso, con el patrimonio inmaterial próximo, fiestas y tradiciones, donde cada uno ha desarrollado su relación desde la niñez. No obstante, entendemos que tal y como señala la Convención de patrimonio mundial (UNESCO, 1972), existen elementos que pertenecen al patrimonio mundial de la humanidad y estos elementos pueden provocar en cualquier observador distintas emociones (López, 2010) y por tanto, ser utilizados como herramientas educativas. Esta relación entre patrimonio cultural y emociones, desde un punto de vista didáctico, es acometida por multitud autores (Vázquez-Bernal, Pérez y Jiménez-Pérez, 2020; Cuenca-López, Martín-Cáceres y Estepa, 2020; Estepa-Giménez y Martín Cáceres, 2020; Coma, Fuentes y Sánchez, 2020; Ferreras-Listán, Pineda-Alfonso y Hunt-Gómez, 2020; Gómez, López Facal y Castro, 2020; Molina y Riquelme, 2020), concluimos como señalan Santacana y Martínez (2018) que existe una relación clara entre las emociones, el patrimonio y el aprendizaje de la cultura. Así abogamos, en consonancia con López (2017), por la inclusión en los currículos oficiales de los distintos niveles educativos obligatorios, de los contenidos patrimoniales de forma explícita, apelando al disfrute de los mismos por medio de las experiencias vivenciales in situ siempre que sea posible, y no abandonándolos a meros aspectos teóricos de conocimiento y análisis estilístico (Munilla, 2014).

Los resultados obtenidos son acordes en el ámbito institucional y legislativo. Este último presenta las 5 referencias ya mencionadas que hacen que incluso tomando en consideración las dos leyes estatales, el porcentaje de alusiones emocionales esté por debajo del 24\%. El espectro investigador arroja mayor frecuencia referencial, con un total de 68 para el ámbito internacional y 59 para el nacional, aunque existen autores que comparten ambas categorías. Debemos señalar que con la salvedad de cinco hallazgos, el resto han sido escritos en la última década.

Hemos podido ver que en ocasiones ambas áreas aparecen en las publicaciones legislativas e institucionales, por lo que entendemos que son tenidas en cuenta y crean un corpus legal a su alrededor. La literatura científica aumenta la frecuencia de sus referencias a medida que nos acercamos a la actualidad. En cualquier caso ni unos ni otros textos, acometen los dos términos paralelamente de forma que se les otorgue la importancia de vertebrar acciones concretas donde patrimonio y emociones sean los elementos centrales. 


\subsubsection{Patrimonio y Creatividad}

La UNESCO toma en consideración la creatividad en sus textos patrimoniales desde muy temprano. En la Recomendación sobre los medios más eficaces para hacer los museos accesibles a todos (UNESCO, 1958), se habla concretamente de "creaciones del espíritu", en lo que entendemos una referencia a la creatividad nacida de lo más interno del individuo como medio de expresión individual. Este enfoque ha llegado hasta nuestros días (Gardner, 2002), y a día de hoy, nadie discute la creación como medio de expresión personal ni la posibilidad de desarrollarla (De Bono, 2008, 2010).

En la Recomendación relativa a la protección de la Belleza y el Carácter de los Lugares y Paisajes, de la Conferencia General de 1962, se habla de que la creatividad humana se torna tangible al observar los monumentos conservados a lo largo de la historia. Paralelamente se une esta idea a la educación como elemento que sustenta tanto el patrimonio como la creatividad. Así mismo, se señala explícitamente a la Educación Primaria como una etapa en la que se debe infundir en los niños el gusto por la creación (UNESCO, 1962). Por nuestra parte, corroboramos lo recogido en esta recomendación de hace sesenta años y lo hacemos nuestro en la propuesta de desarrollo de capacidades para el alumnado de primaria (Munilla 2016) que está en sintonía con autores que defienden el uso de las potencialidades de cada alumno para la mejora del aprendizaje (Gardner, 1998).

Las alusiones a la educación como medio para desarrollar la creatividad son constantes a lo largo de la documentación patrimonial del organismo internacional (UNESCO, 1964, 1968, 1976, 1978, 1982, 2015), aunque debemos aclarar que las referencias no son nada concretas sobre el modo de hacerlo. Si bien encontramos arengas a su estímulo cuando se insta a los estados a tomar las medidas adecuadas para estimular la creación (UNESCO, 1966), o cuando se señala la importancia de reforzar las actividades que permitan a la juventud acciones creadoras (UNESCO, 1968), en ningún momento se dan pautas para ello más que las referidas a la enseñanza de las bellas artes (UNESCO, $1968,1972)$. En las últimas décadas hemos abandonado esta visión tan reduccionista de la creatividad, circunscrita únicamente a las enseñanzas artísticas. Hoy conocemos que la creatividad tiene múltiples orígenes y que se pueden plasmar no solo en creaciones artísticas, si no en cuestiones diversas como la resolución de problemas, la tecnología, etc. (Elisondo, 2018). Algunos investigadores van más allá, ligando la creatividad a la salud, la autorrealización y el crecimiento personal (Maslow, 1994, 1998; Fromm, 1986). En sentido similar se pronunció posteriormente la UNESCO en varias ocasiones al citar lo religioso (UNESCO, 1976) y lo social (UNESCO, 1989), como naturalezas capaces de desarrollar nuevos elementos, haciendo alusión incluso en la primera de las recomendaciones a la creación no profesional y sin fines artísticos como medio de desarrollo personal.

De la misma manera esta recomendación aborda el tiempo como elemento indispensable para los procesos creativos, buscar el espacio y el tiempo para elaborar. Cuando hablamos de crear, bien de forma artística o funcional, no debemos olvidar que normalmente la producción de elementos nuevos requiere de un proceso de investigación, reflexión, ensayo, etc. y que todo ello requiere tiempo. Esta idea que ya en 1976 se pide para adultos trabajadores, no se ha conseguido a día de hoy con claridad suficiente en el ámbito de la educación obligatoria. Se ha atropellado un estilo de vida nada dado a los horarios estrictos y prisas, como es el de la niñez. En cuanto a los adultos, el ritmo de vida frenético al que estamos sometidos por el torbellino de la inmediatez, nos hace consumir incluso los tiempos de ocio y nos impide disfrutar del 
análisis pausado, las pruebas, la meditación sobre los errores, la búsqueda de nuevas perspectivas...elementos todos ellos generadores de la creatividad (Campos y Palacios, 2018). La UNESCO (1976, 1982) ya señalaba que la escuela, además de la adquisición de conocimientos, debe velar por los comportamientos autodidácticos, el espíritu crítico, las actitudes reflexivas y las capacidades creadoras.

En las Actas de la Conferencia General de la 20 reunión de París 1978, dentro del programa 1979-1980, encontramos la primera propuesta de la UNESCO para estimular la creatividad artística e intelectual a través del desarrollo de acciones sobre temas como: "La creación artística y su desarrollo en las sociedades tradicionales y en las industrializadas", "Desarrollo de los contactos e intercambios al servicio de la creación artística", "El arte y la educación permanente", "Promoción de la condición social del artista". Esta propuesta la hace suya años más tarde la Unión Europea en las Conclusiones del Consejo y de los representantes de los Gobiernos de los Estados miembros, reunidos en el seno del Consejo, sobre la promoción de la diversidad cultural y el diálogo intercultural en las relaciones exteriores de la Unión Europea y de sus Estados miembros (Unión Europea, 2015). En ambos escritos, se insta a la comunidad internacional a fomentar la cooperación en el campo artístico, estimular la participación de todas las categorías sociales, o promover investigaciones destinadas a conocer mejor el proceso creativo. Como podemos comprobar, se pretende estimular el intercambio de experiencias, la promoción de artistas, la investigación y el estudio del papel del arte y sus creadores en la sociedad, como elemento relevante para un desarrollo equilibrado del hombre. Nos parece importante, como hemos argumentado en el marco teórico (Munilla, 2014, 2016a, 2017), que se reconozca este valor en las artes, sin embargo desde nuestra perspectiva didáctica, estamos convencidos de que la función de enriquecimiento interior que se otorga al arte, la puede llevar a cabo de manera más completa el patrimonio. Este es resultado de la creación humana tanto física como inmaterial, lo que nos aporta un abanico de posibilidades didácticas muchísimo más amplio y, lo que es más importante, un espectro más completo a trabajar de la psique humana. Esta idea es refrendada en una Comunicación conjunta al Parlamento Europeo y al Consejo un año más tarde (Unión Europea, 2016), cuando se señala explícitamente que la creatividad es un medio para construir la libertades fundamentales y que la cultura no es solo arte y literatura.

Llegados a este punto, debemos señalar que la documentación cultural europea analizada contiene numerosísimas alusiones a la creatividad. Sin embargo, en la mayoría de las ocasiones las propuestas presentan un cariz marcadamente económico. Es el caso de acciones como: Europeana, Sello de patrimonio europeo, Plan de trabajo en materia de cultura, Capitales europeas de la cultura y Planteamientos locales centrados en las personas del patrimonio cultural. Se otorga al patrimonio, la cultura y la educación un rol de fuente de desarrollo económico, por encima incluso del papel de impulso personal y social que deben tener. No obstante, y aún de forma minoritaria, en ocasiones la creatividad y el patrimonio sí son tenidos en cuenta de manera explícita como motor de la educación formal, no formal e informal (Unión Europea, 2015).

Las revisiones documentales europeas de origen educativo presentan una postura general que aboga por la utilización de la educación como eje de desarrollo de sentimientos identitarios. Se le otorga así mismo el papel de germen de la innovación (Unión Europea, 2017), ampliando el campo de acción de los beneficios creativos más allá de la cultura. Es destacable el papel que se le otorga al profesor y al entorno de aprendizaje, como motor de desarrollo creativo dentro de las Conclusiones del consejo sobre el papel de la educación infantil y primaria en el fomento de la creatividad, la innovación y la competencia digital (Unión Europea, 2015). Deducimos de lo analizado 
en las conclusiones, que se asume en general que el profesorado tiene la capacidad de mediar con cualquier contenido, incluyendo por tanto en este axioma la creatividad y aceptando que existe una pedagogía general que otorga esta capacidad y es válida para cualquier área, algo que se pretende solucionar hablando de la formación del profesorado en la Comunicación sobre desarrollo escolar y docencia excelente (Unión Europea, 2017). En el ámbito escolar, también se ha producido cierta crítica sobre el desarrollo de la creatividad. Algunos autores han llegado a afirmar que la escuela lejos de fomentar la creatividad, la entorpece (Beghetto y Kaufman, 2010; Robinson, 2012).

Las didácticas específicas son esenciales en los procesos de enseñanza-aprendizaje, una formación pedagógica especializada en cualquier área es necesaria para conseguir los objetivos didácticos de forma más plena. Cuando desde el campo de la investigación en educación se habla de conocimiento didáctico del contenido, se alude al conocimiento por parte del docente de la materia a enseñar más el conocimiento pedagógico y didáctico específico de cómo transmitir la misma. Destacamos en éste campo el artículo de Bolivar (2005), donde se analiza de forma exhaustiva, el Programa de desarrollo del conocimiento de la enseñanza de Shulman (1987). En el escrito se contextualiza su enfoque y se describen algunos de sus componentes, al tiempo que se analiza en que medida puede servir para fundamentar las didácticas específicas y sus implicaciones para la formación del profesorado especialista en un ámbito disciplinar. Un trabajo sólido para entender la importancia de una didáctica enfocada al contenido a transmitir, y un profesorado formado específicamente para ello. Abogamos por tanto, por una formación especializada del profesorado en los ámbitos del patrimonio, las emociones y la creatividad, como el mejor medio para poder alcanzar nuestros objetivos de desarrollo emocional y creativo en el aula de primaria, utilizando el patrimonio como elemento puente entre estos elementos y el alumnado.

No obstante, cuando se alude a la formación de los docentes, sin referirse a la formación de los formadores de docentes (Unión Europea, 2008, 2015), estamos dejando de lado los cimientos del problema que pretendemos abordar. No se puede aspirar a mejorar el mundo docente ignorando el germen del mismo, la universidad. A día de hoy aceptamos que el papel del docente de enseñanzas obligatorias debe cambiar, acomodándose a las características que la sociedad presenta (Marcelo y Vaillant, 2018), pero olvidamos hacer alusión a esa misma regeneración y cambio de rol en los docentes de las facultades de educación.

La revisión de la documentación europea de contenido educativo, nos revela que no existe vinculación terminológica directa alguna del patrimonio con la creatividad. La ausencia de referencias conjuntas a nivel europeo, plasma que los ámbitos administrativos y legislativos continentales no valoran como esencial para el ámbito educativo la presencia en él de la creatividad ligada al patrimonio.

La literatura científica por el contrario sí que presenta algunos ejemplos que unen el patrimonio y la creatividad. En estos textos, en gran medida se trata el papel mediador que puede jugar la creatividad entre el patrimonio y el desarrollo económico (Cerisola, 2019a, 2019b; Cilona, 2019; Capello, Cerisola, Perucca, 2020), lo que en ocasiones se concreta en el turismo (Anderson, 2011; Saidi, 2016). Sin embargo, en algunos casos también encontramos alusiones al patrimonio como fuente de desarrollo creativo que permita generar modelos de conservación patrimonial (Tan, Lim, Tan y Kok, 2020), como fuente de desarrollo artístico (Kamel, Shahat, Al-Hashel, 2020) o como elemento educativo (Adetunji, Essien y Owolabi, 2018). En este último argumento encontramos ejemplos interesantes de cómo trabajar la creatividad y el patrimonio en el ámbito educativo no formal (Hayakawa 2018; Álvarez, 2016; Werner, 2002) y también en el formal (Granel, 2012). El trabajo de la educación para estimular la creatividad por 
medio del patrimonio desde múltiples disciplinas académicas ha sido impulsado por esta investigación con resultados visibles en el Congreso Internacional de Educación Patrimonio y Creatividad. Las iniciativas que unen creatividad y patrimonio parten de áreas tan diversas como la literatura, el teatro, la tecnología, los museos, la arqueología, el emprendimiento, la psicología, etc. demostrando que la educación posee una fuerza transdisciplinar enorme en el uso del patrimonio como herramienta didáctica (De la Fuente y Munilla, 2017, 2018, 2019 y 2020).

La revisión documental de la UNESCO nos ha reportado 55 referencias a la creación, entre ellas destacamos por su cantidad las 14 referidas a la creación artística. En ellas se hace referencia a las dos palabras como término, es decir utilizadas de forma indivisible aportando un significado único. De esta manera, asociaríamos la creación solamente a lo artístico y con ello, obviaríamos todas las creaciones humanas que no han tenido una intencionalidad estética. Debemos recordar que muchas de las creaciones del hombre, que hoy consideramos instrumentales y que guardamos en museos, no tenían un origen estético en su momento y el simple paso de los años no las ha convertido en elementos bellos simplemente por su antigüedad. Queremos con ello resaltar, que las creaciones humanas, sean del tipo que sean, son fruto de la creatividad, bien sea estética o práctica, pero han servido a un fin de mejora social en el plano tecnológico, artístico, sentimental, transcendente, utilitario $\mathrm{u}$ otros. Todas ellas como producciones humanas tangibles $\mathrm{o}$ intangibles deben ser consideradas patrimonio. Igualmente, tampoco se hace alusión, más que en una sola ocasión a los elementos intelectuales que posibilitan el acto creativo, por medio de lo que se denomina en el texto "proceso creativo" (UNESCO, 1980, p.23). Una sola alusión que sin embargo nos parece destacable, ya que confirma que la creación no es algo aleatorio surgido de la nada o de la suerte, sino fruto de las interacciones culturales, la reflexión, el análisis, el intercambio de ideas, el resultado de un proceso, etc. (De Bono, 2016). Con ello damos legitimidad a tres cuestiones, por un lado que la educación puede ser una de las bases de la creación, por otro que el pensamiento es vital para el ser humano, y finalmente que es importante tener en cuenta todo lo ya creado para apoyar las nuevas iniciativas creadoras. En este sentido resultan destacables las menciones que hemos podido encontrar con respecto al papel que la UNESCO entiende que debería desempeñar la educación como motor de difusión del gusto por la creación y protección del patrimonio. Dentro de ellas, señalamos la mención a la Educación Primaria por lo inhabitual, ya que como hemos mencionado, cuando la educación y el arte van de la mano con frecuencia se habla de educación superior. La franja de edad que comprende la educación primaria es una etapa madurativa esencial para despertar inquietudes, y por ende para trabajar el desarrollo de la sensibilidad y la educación integral (UNESCO, 1982; Bisquerra, Pérez y García2015; Munilla, 2016a; Munilla 2016b).

La Unión Europea presenta numerosas menciones a la creatividad, aunque como hemos visto en el marco teórico, con un enfoque marcadamente económico. Esto se produce tanto para la documentación patrimonial, como para la cultural o educativa. En esta última las referencias al emprendimiento son continuas, e incluso al mencionar el desarrollo de capacidades, se hace desde un contexto de innovación y creación de empleo. Somos conscientes de que los objetivos de la UE presentan un importante componente económico, ya que de los ocho objetivos fundamentales, tres tienen una clara visión económica. Este aspecto ayuda a entender la temática de los textos analizados, quizá por ello es inevitable que las referencias culturales o educativas estén enfocadas hacia este aspecto. ${ }^{23}$ No obstante, esta visión mercantilista se contrapone con

${ }^{23} \mathrm{https}$ ://europa.eu/european-union/about-eu/eu-in-brief_es 
la acepción del término que defendemos y el enfoque de utilidad del patrimonio que nos interesa.

Al hablar de la legislación nacional, debemos concluir que las considerables referencias creativas halladas en las leyes de patrimonio, tanto nacionales como autonómicas, tienen un cariz accesorio y no presentan menciones que profundicen en el valor per se de la misma.

Como cierre a toda la documentación analizada en el capítulo de ámbito mundial, europeo y español, debemos reseñar que nos aporta abundantes y diferentes referencias a creatividad como parte de textos patrimoniales, educativos o científicos.

$\mathrm{Si}$ atendemos a las producciones de organismos oficiales, vemos una presencia constante del tema creativo a lo largo de la historia de los mismos, aunque analizando el impacto que hayan podido tener en actuaciones concretas, debemos remitirnos a los últimos años. El auge de los medios digitales ha posibilitado algunas acciones que facilitan la realización de experiencias de fomento creativo.

En el ámbito educativo y científico también entendemos, y así podemos corroborarlo por la evidencias ya señaladas, que la importancia otorgada al ámbito creativo es más relevante en las últimas décadas. Si nos atenemos a iniciativas concretas, propuestas prácticas o referencias claras, debemos mirar a las leyes de patrimonio surgidas a partir del año 2010, a las dos últimas leyes de educación o a la literatura científica de las mismas fechas.

Entendemos que, sin ser la creatividad un elemento nuevo en los ámbitos analizados, ha ido tomado progresivamente cierta relevancia de forma paralela a la aparición de los nuevos enfoques educativos en la escuela y del desarrollo económico en el ámbito cultural no formal.

\subsubsection{Patrimonio, emociones y creatividad en la etapa de Primaria.}

La presencia del patrimonio en la Ley Orgánica 8/2013, de 9 de diciembre, para la mejora de la calidad educativa (LOMCE), y su concreción en primaria a través del Real Decreto 126/2014, de 28 de febrero, por el que se establece el currículo básico de la Educación Primaria, está documentada (Fontal, 2016; Fontal, Ibáñez-Echevarría, Martínez, y Rivero, 2017). No obstante, debemos señalar que no aparece en los objetivos generales de la etapa a diferencia de lo que ocurre en secundaria y bachillerato (Reyes y Méndez, 2017).

Las referencias patrimoniales encontradas en el decreto de primaria se concentran en las áreas de Ciencias Sociales, Lengua y Literatura o Educación Artística, olvidando un enfoque transversal de las mismas. Es significativo el hecho de que no se nombre en el contexto de valores sociales y cívicos, lo que choca con toda la legislación internacional referida anteriormente. Todo ello redunda en un reflejo más que previsible y tradicional del área en los libros de texto (Cuenca, Estepa y Martín, 2017).

La presencia de la educación emocional en primaria abarca algunas áreas más que el patrimonio, lo que sin duda le otorga un trabajo más transversal. Su importancia en esta etapa está largamente contrastada (Bisquerra, 2003, 2009; Bisquerra, Pérez y García, 2015) y ha redundado en propuestas de trabajo interesantes (Ozáez 2015; Soler, Aparicio, Díaz, Escolano, Rodríguez 2016), no obstante no podemos decir que sea algo generalizado y estructurado convenientemente. Quizá el hecho de que la LOMCE solo contenga una alusión directa, pueda dar una explicación a este problema.

La creatividad es de los tres elementos analizados el que mayor presencia tiene tanto en la LOMCE, como en el Real Decreto 126/2014. Su inclusión en ambos es más concreta, se explicita que debe ser trabajada transversalmente, trasladando la responsabilidad de 
su desarrollo a todas las áreas. No obstante, en ningún momento se concreta como hacerlo, lo que hace que su tratamiento descanse en la inventiva o buena voluntad del profesorado (De la Torre, 2006, 2007), aunque esto pueda resultar complicado en ocasiones por la propia estructura del sistema educativo (Navarro, 2008).

La investigación en educación propone distintos enfoques para incluir el patrimonio en los currículos de primaria (Gozález-Monfort, 2011; Fontal, 2016; Fontal, IbáñezEchevarría, Martínez y Ribero, 2017), aunque parece que los ámbitos de las Ciencias Sociales, o la Educación Artística son los más nombrados.

Al analizar los libros blancos de ANECA vemos que nuevamente las referencias a la creatividad son mayores que al resto de los otros dos elementos analizados. Las emociones son tomadas en consideración como elementos esenciales del equilibrio emocional profesional del docente y también en otros aspectos que no se recogen de igual manera en los diferentes países. Las referencias pueden variar en su aparición entre los apartados de competencias clave, capacidades técnicas básicas y materias obligatorias, lo que les otorga una importancia distinta. La creatividad tiene una presencia mayor y más definida, ya que aparece en todas las áreas y también en todas las especialidades, confiriéndole un estatus mayor que las dos anteriores, al menos en la jerarquía que se le otorga. Esta predisposición se podría extender al resto de documentación analizada en todo el marco teórico. Desde la óptica de la educación, la creatividad es el ámbito al que más relevancia se le otorga. Esto podemos achacarlo a que, al menos a priori, se le confiere mayor disposición para una utilización transversal en el currículo por su predisposición para desarrollarla desde cualquier materia.

La presencia e importancia del patrimonio a nivel legislativo e investigador no se ha visto reflejada en un tratamiento adecuado dentro de las aulas de primaria. Esto mismo podemos extrapolarlo a la educación emocional donde las propuestas son aisladas y sin la continuidad que requiere el desarrollo cognitivo de los alumnos en la etapa de primaria. La creatividad por su parte, recibe un trato más concreto en lo que a las referencias legislativas se refiere, aunque quizá el resultado en las aulas sea similar en los tres casos.

Las referencias de la Ley o el Decreto no son lo suficientemente especificas para que el reflejo de los tres ámbitos en el aula sea lo bastantemente profundo como para tener un reflejo claro en la formación del alumnado. La inconcreción de la legislación tiene también su influencia en la formación del profesorado de primaria. Si las leyes no inciden suficientemente en estos ámbitos, los libros blancos de los grados de magisterio tampoco lo hacen. Como consecuencia de ello los maestros titulan deficientemente formados en estos ámbitos, por lo que cuando llegan a al aula no poseen los recursos necesarios para trabajar con sus alumnos los elementos patrimoniales, emocionales y creativos.

\subsection{Discusión y conclusiones al Marco Empírico.}

La evaluación de programas ha sido tradicionalmente una asignatura pendiente, tanto en nuestro país como han señalado Fontal e Ibáñez-Etxeberria $(2015,2017)$, como a nivel internacional (Diamond, Horn y Uttal 2016). La escala Q-Edutage (Fontal, García, Arias, y Arias, 2018) (Fontal y García, 2019), es una herramienta que ha intentado solventar este problema creando un instrumento de evaluación de programas breve y preciso. Desde su creación ha sido utilizada para la valoración de programas de educación patrimonial relacionados con diferentes ámbitos (Pablos, 2018; García, 2018; Martínez-Rodríguez, 2019; Sánchez, 2019). Nuestra investigación es la primera que se 
adentra en la estimación de programas de educación patrimonial que atienden a elementos patrimoniales y creativos.

El trabajo realizado en este marco empírico ha cubierto los objetivos específicos propuestos al comienzo de la investigación. Así comenzamos el trabajo por extraer del total de programas recogidos en la base de datos del OEPE, aquellos que incluían en sus propuestas contenidos emocionales y creativos, el número total de programas en el momento de la realización de esta investigación era de 2221. Este primer proceso nos deparó una muestra de $\mathrm{n}=262$. De ellos, los que incluyen exclusivamente emociones son $42(16,031 \%)$, los que incluyen solamente creatividad son $205(78,244 \%)$ y los que trabajan ambos aspectos de forma conjunta son $15(5,725 \%)$. En segundo lugar y respondiendo al objetivo OE2 se extrajeron estos programas y se agruparon y ordenaron en tres listados según los resultados de las búsquedas. Las tablas que analizan estos programas (tablas 15, 16 y 17) contienen información sobre el nombre, la entidad responsable y el país donde se desarrollan. Posteriormente se evaluaron los programas con la escala Q-Edutage y a partir de los resultados se generaron los estadísticos. Finalmente se ha realizado un análisis de los estadísticos descriptivos de las variables sociodemográficas y de resultado, de las correlaciones y de los análisis de varianza.

\subsubsection{Conclusiones del análisis descriptivo de variables y correlaciones.}

Tomamos en consideración seis tipos de variables sociodemográficas. Variable cero (V0) correspondiente al tipo de búsqueda realizada en la base de datos e integrada por tres categorías: emociones, creatividad y emociones + creatividad. La correspondiente al tipo de entidad responsable, variable uno (V1) donde incluimos tres categorías: organismos públicos, entidades privadas y aquellas sostenidas con fondos provenientes de ambas identidades. La variable que determinan el tipo de patrimonio que trabaja cada programa, variable dos (V2) está compuesta por dieciocho categorías. Variable tres (V3) que aglutina los dieciocho tipos de proyecto. Variable cuatro (V4) que determina el tipo de público al que se dirige el programa y que dividimos en cinco categorías. Y variable cinco (V5) que explicita el ámbito pedagógico que acoge el programa: educación formal, educación no formal y educación informal.

La primera de las variables sociodemográfica tenidas en cuenta (V0) presenta un total de programas analizados de $n=262$. De ellos, los correspondientes a las búsquedas de emociones son 42, a creatividad $205 \mathrm{y}$ a ambos aspectos 15. Ello supone que un $78,244 \%$ de los programas de nuestra muestra trabajan la creatividad de forma individual, si a ellos les sumamos los que la trabajan de forma conjunta con emociones, el porcentaje se dispara hasta el $83,969 \%$. Esto nos dejaría un $16,031 \%$ de programas que trabajan exclusivamente emociones.

El análisis descriptivo (Tabla 18) de la variable uno (V1), nos informa de que el tipo de entidad responsable que más promueve programas patrimoniales con elementos emocionales y creativos son las entidades públicas, con una frecuencia de $n=177$ y un porcentaje sobre el total de programas analizados del 67,557\%. Si tenemos en cuenta que los programas considerados como mixtos $(n=48 ; 18,32 \%)$, también tienen participación pública, el global nos sitúa en un porcentaje por encima del $85 \%$ de programas con financiación pública total o parcial.

Al considerar la categoría de patrimonio (Tabla 19), vemos que el patrimonio cultural es el que tiene un mayor porcentaje de trabajo emocional-creativo ( $\mathrm{n}=103 ; 39,31 \%)$, casi duplicando los resultados del patrimonio inmaterial, que se sitúa en el segundo puesto de frecuencia $(n=57 ; 21,75 \%)$. Ninguna de las demás categorías de patrimonio sobrepasa el 6\%, con la excepción de "otros", que como es lógico, aglutina el resto de 
categorías de patrimonio no explicitadas dentro de las 18 que se presentan en esta variable. Entendemos que uno de los factores por los que el patrimonio cultural aparece de forma tan destacada puede deberse, entre otros motivos, a que su denominación sea quizá algo inespecífica. Por ello puede acoger bajo ese apelativo iniciativas de origen más diverso que aquellos tipos de patrimonio más definidos.

La variable tres (V3) acoge dieciocho categorías (Tabla 20). De ellas, son los programas educativos los que presentan una mayor frecuencia $(n=67 ; 25,57 \%)$, seguidos por los proyectos educativos $(n=37 ; 14,12 \%)$, recursos didácticos $(n=31 ; 11,83 \%)$ y diseños didácticos $\mathrm{n}=17,6,489 \%$ ). La única categoría que no presenta resultados es la correspondiente a redes sociales, lo cual resulta destacable, teniendo en cuenta las alusiones a la innovación, nuevas fórmulas de turismo, etc. referidas a lo largo de toda la documentación analizada en el marco teórico.

Por otra parte destacamos que los tipos de proyecto que se definen como educativos o didácticos, acogen en un alto porcentaje iniciativas que abarcan la creatividad o las emociones. Como hemos podido comprobar en el marco teórico la educación formal las tiene en cuenta, por ello cualquier proyecto relacionado con la educación, sea formal o informal, es coherente que los incluya.

Los resultados de la variable cuatro (V4) nos informan de que la categoría a la que más programas emocionales y creativos se destinan es la dirigida a todos los públicos $(n=84$; $32,061 \%)$. Dentro de aquellas dirigidas a una franja de edad concreta, la categoría con mayor frecuencia $(n=63 ; 24,046 \%)$ es infantil, compuesta por personas entre cero $y$ dieciséis años. En segundo lugar la categoría juvenil $(n=37 ; 14,504 \%)$ entre dieciséis y veintidós años. Si tenemos en cuenta las categorías individuales y sumamos aquellas en las que aparece esta categoría asociada a otras, el grupo de edad de infantil acogería 91 propuestas, juvenil 76, sénior 34 y tercera edad 3. Parece evidente por tanto, que en cualquiera de las condiciones de análisis, el grupo de edad al que más iniciativas patrimoniales creativo-emocionales se dirige es al comprendido entre los 0 y 16 años, infantil. Tras él los programas dirigidos a todos los públicos con 84, posteriormente la franja de edad juvenil (16 a 22) con 76 programas, en cuarto lugar la franja sénior (22 a $65)$ con 34 , y finalmente la tercera edad con 3.

Finalizamos la revisión de los resultados de las variables sociodemográficas con la variable cinco (V5). La tabla 22 nos informa de que, tanto la educación formal como no formal, atienden de la misma manera a los elementos emocionales y creativos $(n=105$; $40,076 \%$ ), señalamos que la suma de ambos porcentajes los sitúa por encima del $80 \%$ de los programas analizados. Esto refleja que las iniciativas de educación patrimonial que tienen unos objetivos educativos claros, toman en consideración el valor de la creatividad y las emociones muy por encima de lo que lo hacen los programas que no tiene una vocación educativa exclusiva, como son los de la educación informal. Al poner el foco en la educación formal (Tabla 23), vemos que es la universidad la que presenta una mayor frecuencia $(n=25 ; 9,542 \%)$, seguida por los programas destinados a la Educación Secundaria Obligatoria $(\mathrm{n}=19 ; 7,252 \%)$. Este dato está en consonancia con los registros obtenidos en la tabla 21 , ya que los subtipos de variable infantil y juvenil que son los de mayor frecuencia, abarcan una franja de edad que llega hasta los 22 años, edad de finalización de los estudios universitarios.

En el lado opuesto de las frecuencias, se sitúan los programas destinados a todas las etapas educativas conjuntamente, categoría 3, 4, 5, 6, y $7(\mathrm{n}=1 ; 0,382 \%)$. Este dato nos hacer pensar, que las acciones destinadas a la educación patrimonial que contienen elementos creativo-emocionales, tienen un diseño concreto para una determinada etapa educativa. Esta concreción nos lleva a especular que estos proyectos didácticos están 
muy ajustados en sus objetivos educativos a los desarrollos cognitivos de su público objeto, presuponiéndoles al menos por esta razón cierta calidad en su creación.

Si tomamos en consideración las frecuencias y porcentajes totales de los subtipos de la variable de Educación Formal que incluyen acciones en cada etapa tomados de forma individual o asociados a otros (Tabla 24), observamos que arrojan resultados bastante homogéneos entre todos los subtipos de variable. Concretando más podemos apreciar que la etapa con mayor porcentaje de proyectos es la de secundaria $(n=45 ; 26,627 \%)$, seguida por la de primaria $(n=41 ; 24,260 \%)$, siendo ambas las que aglutinan un porcentaje ligeramente superior al 50\%. Este último dato nos aporta información sobre el interés de las autoridades educativas por que los alumnos tengan cierta formación en estas edades de instrucción forzosa, posibilitando de esta manera la sensibilización al respecto de una parte considerable de la población. Las etapas de infantil, bachillerato y universidad se sitúan todas en un porcentaje alrededor del $28 \%$. El equilibrio de frecuencias general de esta tabla 24, refleja que cualquier etapa educativa tiene en consideración la educación patrimonial asociada a elementos creativo-emocionales como un factor a tener en cuenta en el desarrollo educativo de sus alumnos.

Pasamos a explorar los datos de las variables de resultado. Como podemos observar en la tabla 25, los resultados son bajos para los programas de educación patrimonial que incluyen emociones y creatividad. Tan solo uno de los ítems analizados sobrepasa los tres puntos de media, dos consiguen una valoración entre 2,5 y 3 , y once se sitúan igual o por debajo de 2,5 con una mediana de 2 o 1 . Entendemos por tanto, que no alcanzan la calidad suficiente o lo hacen con condiciones.

Los ítems con más valoración (i1, i4 e i5) entran dentro de lo que se consideran metadatos y que forman parte de la información del programa. Entre los ítems con menor valoración (i7, i12 e i13), el primero de ellos forma parte también de los metadatos y los dos últimos pertenecen al grupo de ítems del grado de concreción del diseño educativo, lo que nos informa de que estos programas no tienen bien especificados estos apartados tan importantes para nosotros. Incidiendo en estos ítems correspondientes a la concreción del diseño educativo, aquellos que se sitúan entre el 8 y el 14, vemos que presentan una media inferior a 2 y una mediana de 2 o 1 . Todo ello nos lleva afirmar que, en la evaluación de los programas que acogen en su diseño elementos creativos o emocionales, muy pocos cumplen con los criterios de calidad exigibles en su diseño didáctico.

Sobre el análisis de las correlaciones, destacamos que las variables que pertenecen a la concreción y descripción del diseño educativo (i09, i10, i11, i12 e i13) resultan significativas entre ellas (Tabla 27). En la figura 8 podemos apreciar la uniformidad cromática que presentan lo que nos informa de una correlación mayor que con el resto de variables. Resulta coherente que estas variables que acogen objetivos, contenidos, metodología, recursos y herramientas de evaluación, todos ellos componentes esenciales de un proyecto didáctico, presenten una correlación destacada sobre el resto de variables, especialmente las referidas a metadatos, que se sitúan en el polo opuesto a una propuesta pedagógica.

\subsubsection{Conclusiones del análisis de varianza.}

Los análisis de las comparativas de las medias de grupos, arrojan algunas conclusiones interesantes con respecto a la muestra de programas analizados. 
Tabla 98. Resumen de significatividad ANOVA.

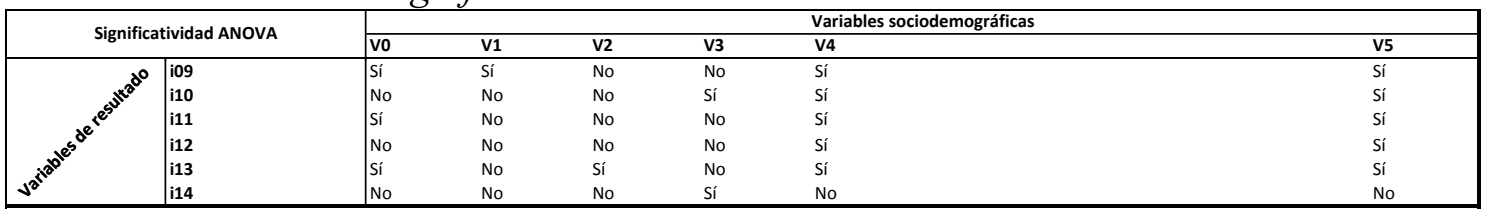

Fuente: Propia

Tabla 99. Resumen de diferencias de medias entre categorías.

\begin{tabular}{|c|c|c|c|c|c|c|}
\hline \multirow{2}{*}{ Diferencia de medias entre categorías } & \multicolumn{6}{|c|}{ Variables sociodemográficas } \\
\hline & vo & V1 & V2 & V3 3 & V4 & V5 \\
\hline 109 & $1<3$ & $1>3,2>3$ & No & No & $1-6>1-4 ; 1-6>2-3-4$ & \\
\hline i10 & & No & No & No & $1-6>1-4 ; 1-6>2-3-4 ; 1-6>3-4$ & No \\
\hline i11 & $1<3,2<3$ & No & No & No & $1-6>1-2-3 ; 1-6>2-3-4 ; 1-6>3-4 ; 1-6>3 ; 1-6>5 ; 1-6>2-3$ & No \\
\hline i12 & No & No & No & No & No & No \\
\hline i13 & $1>2$ & No & $12>$ el resto & No & No & No \\
\hline |i1 & No & No & No & No & No & No \\
\hline
\end{tabular}

Fuente: Propia

Los análisis de varianza de V0 recogen tres categorías de búsqueda: programas emocionales (categoría 1), creativos (categoría 2) y emocionales+creativos (categoría 3). Su estudio nos indica, como vemos en la tabla 98, que de las seis variables de resultado tres resultan significativas (i09, i11 e i13) y otras tres no (i10, i12 e i14). No obstante, i10 presenta un valor muy cercano a 0,05 . Tomando esto en consideración, vemos que las variables de resultado que forman el grueso teórico del diseño educativo (objetivos, contenidos, metodología y evaluación) resultan significativas (con la excepción de i10). En el caso contrario tenemos que los dos parámetros que recogen elementos menos didácticos, como son la definición de los formatos, soportes o tecnología de los recursos y la repercusión de los programas, no resultan significativos (Tabla 98).

Entendemos que estos programas tienen un sólido diseño educativo dentro de las temáticas categóricas que abordan dados los ítems que resultan significativos. Por el contrario, los parámetros menos didácticos parecen más desatendidos o al menos con una concreción mucho menor.

En cuanto a las tres categorías de búsqueda, observamos que al analizar las diferencias entre las categorías de búsquedas o el valor crítico del d de Tukey (tabla 99), aparece como significativo el contraste que contiene la categoría 3 en las tres variables dependientes que consideramos variables imprescindibles de un diseño educativo (i09, i10, i11). Entendemos, que el hecho de acoger estos programas elementos emocionales y creativos de forma conjunta, hace mucho más rico el proyecto patrimonial y por tanto precisa de una mayor concreción de objetivos, contenidos y variedad metodológica. Esto puede determinar su significatividad en contra de aquellos que solo abordan uno de los ámbitos por separado.

Destacamos así mismo, que dentro de la variable i13 de herramientas de evaluación, el contraste significativo ha sido el 1 vs 2 , lo que achacamos a la especificidad necesaria para realizar una buena evaluación concretando al máximo la adquisición de las destrezas analizadas. Esto puede requerir de una especificidad mayor, lo que hace más sencillo evaluar un solo parámetro que dos de forma simultánea, por lo que quizá emociones y creatividad de forma aislada haya sido el contraste significativo.

Finalmente, las dos variables de contenido menos didáctico i12 e i14 no resultan significativas, algo que podemos achacar a que si los programas son diseñados por educadores, presten menos atención a estos aspectos.

El análisis de varianza de la variable V1 analiza los tipos de entidades que promueven los programas patrimoniales, entidades públicas, entidades privadas e iniciativas sostenidas por ambos tipos de agrupaciones de forma conjunta. De las seis variables de 
resultado, solamente una de ellas presenta diferencias de medias significativas entre categorías, concretamente la i09, donde se describen los objetivos a lograr en los desarrollos de los programas. Entendemos que puede resultar positivo para la concreción de objetivos el hecho de que los programas sean promovidos por una sola entidad, bien sea pública o privada. Quizá, el no tener que consensuar los logros que pretende alcanzar el programa con otras entidades, acaso con una visión final diferente, parece que dota de significatividad a la concreción de intenciones atendiendo a las diferentes esferas del aprendizaje, al desarrollo integral y a los pilares que establece la UNESCO tal y como describe esta variable.

Tanto los contenidos, como la metodología, los recursos, la evaluación o la repercusión de los programas, no resultan significativos. No obstante, vemos algunas diferencias entre estas variables: la i10, i12 e i13 presentan medias similares entre las tres categorías, en cambio la i11 e i14 tienen algunas diferencias entre aquellos programas con participación pública y los que son completamente privados. En cuanto a la metodología y estrategias de enseñanza aprendizaje (i11), los programas públicos o con participación pública presentan una media inferior lo cual resulta algo sorprendente, ya que aquí incluimos un número importante de programas de educación formal que deberían ser muy concretos en este aspecto. Las medias de la variable de medición del impacto y repercusión de las propuestas (i14) presentan una figura contrapuesta a la variable anterior, teniendo una media más alta de los programas públicos o con participación pública. Esto último resulta coherente por el interés de estos organismos en publicitar socialmente sus acciones y resultados de las mismas.

La variable V2 correspondiente al tipo de patrimonio se desglosa en dieciséis tipologías diferentes, de las cuales solamente catorce están representadas en la muestra analizada. El análisis ANOVA muestra que solamente una de ellas presenta significatividad estadística, la correspondiente a la variable de resultado i13, sistemas de evaluación. Dentro de esta variable, la diferencia de medias entre categorías, señala que la tipología 12 "monumento obra escultórica" resulta estadísticamente significativa con respecto al resto de categorías. Nos resulta difícil explicar esta última significatividad estadística desde el punto de vista de la investigación, ya que no pensamos que los programas patrimoniales sobre escultura tengan por qué estar evaluados de forma diferente que el resto. Por el contrario, sí nos resulta interesante que destaque la evaluación como significativa, entendiendo que se presta especial atención a este elemento en el diseño de programas.

Así mismo resulta destacable el hecho de que ninguna tipología de patrimonio (V2) destaque estadísticamente por encima de otras. Esto podría informarnos de que todas ellas tienen una misma valoración en la concreción de su diseño educativo, sin destacar un tipo de patrimonio por encima de otros. Es decir, que tendrían un tratamiento educativo similar sin dar más importancia a patrimonios que en principio suelen tener una mayor presencia en las acciones educativas, como pudieran ser el patrimonio artístico o el natural.

Al analizar los tipos de proyecto (V3), la variable se divide en dieciocho categorías de las que en nuestra muestra solamente tenemos representadas 17, quedando excluida la de redes sociales. Así podemos encontrar 1-programa educativo, 2-proyecto educativo, 3-diseño didáctico, 4-recurso didáctico, 5- herramienta didáctica, 6-acción educativa, 7actividad aislada, 8-taller, 9-proyecto de investigación, 10-proyecto de mejora, 11concurso, 12-itinerario didáctico/ruta/visita, 13-plan, 14- red, 15-evento científico, 16curso, 18-otros.

El análisis de ANOVA nos muestra dos variables estadísticamente significativas la i10 y la i14, correspondientes a la presentación de contenidos y a la medición del impacto 
de la propuesta respectivamente. Por el contrario, al analizar las diferencias entre categorías con Tukey, no encontramos significatividad estadística ni en las variables señaladas ni en ninguna otra. En cualquier caso, las dos variables significativas tienen poca relación entre ellas como para sacar alguna conclusión conjunta, más allá de que quizá programas con un buen diseño de contenidos y por tanto con una sólida estructura general, posibiliten de manera más fácil una difusión adecuada por el interés que pudieran despertar.

La variable cuatro V4 analiza el tipo de público al que se dirige el programa: 1- infantil, 2- juvenil, 3- sénior, 4- tercera edad, 5-todos los públicos, 6-colectivos específicos. Al analizar las ANOVA de las variables de resultado, vemos que todas ellas excepto i14, resultan estadísticamente significativas. Este dato nos resulta relevante, ya que como hemos comentado, todas estas variables componen la concreción del diseño educativo, con la salvedad de i14 que se ocupa del impacto del programa. Entendemos que el diseño didáctico de los programas es coherente, independientemente del público al que se dirige. Al acudir al análisis de medias de los pares, observamos que el par 1-6 (infantil-colectivos específicos), resulta estadísticamente significativo hasta en once ocasiones, con otros pares en las variables de resultado i09, i10, e i11. Entendemos que este par aglutina quizá los extremos de los tipos de público, infantil y los colectivos específicos, y estos son los que menos características comunes pueden presentar a la hora de diseñar objetivos (i09), contenidos (i10) y metodología (i11). Los pares con los que resultan estadísticamente significativas sus medias (categoría 2, categoría 3, categoría 4) son aquellos que podrían presentar mayor uniformidad en las variables de resultado, porque pueden compartir objetivos, contenidos y metodologías con menores modificaciones.

La variable que analiza el ámbito pedagógico (V5) se subdivide en siete categorías 1educación no formal, 2- educación informal, 3-educación formal, infantil, 4-educación formal, primaria, 5-educación formal, secundaria, 6-educación formal, bachillerato, y 7educación formal, universidad. En esta variable sociodemográfica, nuevamente resultan estadísticamente significativas todas las variables de resultado, correspondientes al diseño didáctico (exceptuando i14), igual que ocurría en la variable V4. Entendemos que el diseño didáctico de los programas es consistente, independientemente del tipo de ámbito pedagógico que lo ampara. Al analizar la diferencia de medias entre categorías, no encontramos ninguna estadísticamente significativa.

\subsection{Conclusiones del estudio}

Hacemos referencia finalmente al total de los estudios realizados, tanto al análisis documental, como al estadístico.

Los objetivos generales de investigación planteados al comienzo de este trabajo perseguían establecer un estado de la cuestión en torno a la relación entre patrimonio, emociones y creatividad, a nivel legislativo y científico por un lado, y por otro valorar programas de educación patrimonial de OEPE que incluyeran estos ámbitos.

Para conseguir el primero de ellos nos plantemos como objetivos específicos: analizar la presencia de emociones y creatividad en la legislación patrimonial emanada de la UNESCO y el Consejo de Europa, examinar las leyes de patrimonio estatales y autonómicas de España, inspeccionar la ley educativa actual y el decreto de primaria, y finalmente explorar la literatura científica nacional e internacional al respecto.

Para alcanzar el segundo objetivo general nos planteamos los siguientes objetivos específicos: examinar los programas de educación patrimonial existentes en la base de datos de OEPE para determinar cuales incluyen emociones y creatividad en sus 
propuestas, analizar los programas de educación patrimonial inventariados en OEPE y que incluyen elementos emocionales y creativos, evaluar los programas de educación patrimonial inventariados en la base de datos de OEPE que incluyen elementos emocionales, y evaluar los programas de educación patrimonial inventariados en la base de datos de OEPE que incluyen elementos creativos.

El marco teórico de esta investigación da respuesta al primero de los objetivos generales planteados que se concretan en: 33 documentos analizados de la UNESCO entre 1948 y 2015, de los que se han extraído 12 referencias a emociones y 55 a creatividad; 18 documentos del Consejo de Europa donde se han encontrado y referenciado 5 alusiones a emociones y 21 a creatividad; dentro de las leyes autonómicas de patrimonio, encontramos 7 referencias a emociones y 43 a creatividad; dentro de los Planes Nacionales del Instituto del Patrimonio cultural de España, analizamos el Plan Nacional de Educación y Patrimonio que presenta 3 alusiones a emociones y 2 a creatividad, y el Plan Nacional para la Salvaguarda del Patrimonio Cultural Inmaterial que presenta 3 menciones emocionales y 4 creativas; dentro de la legislación educativa se han analizado la Ley Orgánica 8/2013, de 9 de diciembre, para la mejora de la calidad educativa (LOMCE) que contiene 1 referencia a emoción y 3 a creatividad, y Real Decreto 126/2014, de 28 de febrero, por el que se establece el currículo básico de la Educación Primaria que acoge 14 referencias a emociones y 35 a creatividad; la documentación de origen científico se ha concretado en la revisión de un total de 144 textos de origen internacional y 731 de origen nacional de los que se han referenciado 51 internacionales y 77 nacionales, lo que hace un total de 128 reseñas de las que 47 corresponden a temáticas emocionales y 81 a creativas.

Todo este análisis documental da respuesta a los cuatro objetivos específicos iniciales y permite establecer un estado de la cuestión al respecto que se concreta en las siguientes conclusiones:

- Existe una presencia tanto de temática emocional como creativa en la legislación nacional e internacional de origen patrimonial.

- Existe una producción científica importante de origen patrimonial que estudia el valor de la emociones o la creatividad principalmente en la última década.

- La producción científica que contiene referencias emocionales y creativas proviene de áreas patrimoniales, educativas, turísticas o económicas.

- Las referencias creativas casi duplican a las emocionales tanto en el grueso de la documentación analizada, como en cada grupo de textos investigados.

- El patrimonio, las emociones y la creatividad no son tenidos en cuenta de forma conjunta en ninguno de los ámbitos textuales analizados.

El segundo de los objetivos generales que perseguía nuestra investigación se plasma en el marco empírico de la misma. En este apartado se parte de la base de datos de OEPE con un total de 2221 programas inventariados. Respondiendo al objetivo específico número uno extraemos aquellos que trabajan emociones, creatividad o ambos elementos, conformando una muestra de 262 programas que son analizados y evaluados dando respuesta a los objetivos dos, tres y cuatro.

Esta evaluación nos aporta las siguientes conclusiones en relación a los programas de educación patrimonial que tienen en cuenta emociones y creatividad:

- El 83,9\% de los programas patrimoniales analizados tienen en consideración la creatividad de forma individual o asociada a emociones. Solamente el 16\% de los programas analizados consideran las emociones de manera individual. 
- El 85,8\% de los programas patrimoniales que contiene emociones y/o creatividad tienen participación pública.

- El 39,3\% de los programas patrimoniales que contienen emociones y/o creatividad están destinados a patrimonio cultural.

- El 25,5\% de los programas patrimoniales que contienen emociones y/o creatividad son programas educativos.

- El 32\% de los programas patrimoniales que contienen emociones y/o creatividad están destinados a todos los públicos.

- La franja de edad a la que más programas patrimoniales que contienen emociones y/o creatividad se destinan es la de 1 a 16 años con un porcentaje del $24 \%$.

- El ámbito pedagógico al que más programas patrimoniales que contienen emociones y/o creatividad se destina el de la educación formal y no formal con un mismo porcentaje del $40 \%$.

- Las iniciativas de educación patrimonial que poseen objetivos educativos (educación formal y no formal), toman en consideración el valor de la creatividad y las emociones $(80 \%)$ muy por encima de lo que lo hacen los programas que no tiene una vocación educativa exclusiva como son los de la educación informal $(19,8 \%)$.

- Dentro de la educación formal la etapa a la que mayor porcentaje de proyectos patrimoniales que contienen emociones y/o creatividad se destinan es la de educación secundaria con un $26,5 \%$.

- Todas las etapas educativas tienen en consideración la educación patrimonial asociada a elementos creativo-emocionales en un porcentaje entre el $15 \%$ y el $26 \%$ como un factor a tener en cuenta en el desarrollo educativo de sus alumnos.

- La evaluación y el posterior análisis estadístico muestran que los programas patrimoniales que contienen emociones y/o creatividad, no alcanzan niveles de calidad suficientes o los alcanzan con condiciones.

- Los programas analizados presentan un diseño didáctico que no cumple con los criterios de calidad suficientes. No obstante las variables destinadas a la concreción y descripción del diseño presentan cierta coherencia entre ellas como demuestran sus coeficientes de correlación.

Concluimos que tanto la legislación nacional como internacional, en mayor o menor medida, recogen la importancia de los tres elementos analizados: patrimonio, emociones y creatividad. Si bien no de forma conjunta, sino tomados como unidades temáticas individuales o agrupadas de dos en dos. Entendemos que estos textos dan una cobertura legal a cualquier tipo de iniciativa política, investigadora o educativa, aunque no crean las bases suficientes para que de ello surjan iniciativas concretas. El mundo investigador profundiza mucho más en las relaciones paralelas del patrimonio con las emociones y del patrimonio con la creatividad. De ello surgen propuestas interesantes que pueden servir, quizá en un futuro cercano, para entrar directamente en las legislaciones educativas y leyes de patrimonio de forma mucho más sólida. No obstante todo ello no puede revertir directamente en la sociedad si no tomamos en consideración la formación de las personas encargadas de llevarlo a la práctica, bien a través de la educación formal o de la no formal, y ello pasa a su vez por analizar quién y cómo está educando a los futuros trabajadores de estos ámbitos desde la universidad.

En cualquier caso patrimonio, creatividad y emociones, no son tenidos en cuenta de manera conjunta en ninguno de los ámbitos analizados, ni legislativo, ni investigador. 
El total de datos estadísticos extraídos nos informa de que los programas de educación patrimonial analizados trabajan en una proporción mucho mayor la creatividad que las emociones. Esta es una tendencia que también se puede observar en la frecuencia con la que aparecen los términos en las revisiones legislativas. Un porcentaje superior al $85 \%$ de los programas están promovidos total o parcialmente por entidades públicas. Es el patrimonio cultural el que acomete en mayor medida el trabajo emocional y creativo, así como los programas educativos son el tipo de proyecto que más los aborda. En cuanto a la franja de edad a la que más iniciativas se destinan, es la comprendida entre cero y dieciséis años, aunque existe un alto porcentaje destinado a todos los públicos. La educación formal y no formal atienden en igual medida las temáticas que estudiamos, doblando las iniciativas informales. Si atendemos a la educación formal, vemos que hay una especial predilección por proyectos para la universidad, la ESO y primaria, presentado estas dos últimas etapas un porcentaje por encima del 50\%.

En cuanto a la calidad del diseño educativo, los datos nos llevan a afirmar que muy pocos cumplen con los criterios de calidad exigibles, aunque las variables de concreción del diseño educativo presentan un alto grado de correlación entre ellas.

Al analizar las medias entre las distintas categorías de las variables sociodemográficas, vemos que presentan mayor uniformidad las variables de tipo de organismo, tipo de patrimonio y tipo de proyecto, ya que hay poca significatividad con la mayoría de variables de resultado. En cambio, se comportan de manera distinta las variables de tipo de público y ámbito pedagógico, que si resultan significativas para casi todas las variables de resultado.

Entendemos que queda patente en la literatura que patrimonio, emociones y creatividad no se toman en ningún caso de manera conjunta. Dada la importancia otorgada a cada elemento por separado, entendemos que esta puede multiplicarse exponencialmente al utilizarlos conjuntamente, tanto en su consideración educativa como en su valor pedagógico de formación integral. No obstante el descanso teórico en la práctica, deja patente tras el análisis estadístico, que los programas actuales no presentan la calidad suficiente para ello. El diseño de programas no es lo bastante profundo y presenta varias limitaciones, lo que está en consonancia con otras investigaciones anteriores (MartínezRodríguez, 2019).

\subsection{Líneas futuras}

A la luz de los resultados obtenidos deducimos que existe un campo muy interesante y necesario por desarrollar en la atención a los ámbitos patrimonial, emocional y creativo de forma paralela. Por ello como futuras líneas de investigación planteamos las siguientes:

- Proseguir con la evaluación de programas de educación patrimonial que incluyan emociones y creatividad con una muestra más representativa, utilizando la escala Q-Edutage (Fontal, García, Arias, y Arias, 2018; Fontal y García, 2019).

- Crear un diseño didáctico sistemático dentro del área de Ciencias Sociales en los cursos de quinto y sexto de educación primaria, para trabajar emociones y creatividad por medio del patrimonio y analizar los resultados del desarrollo de estas áreas en los alumnos.

- Analizar la formación de los alumnos del grado de magisterio en las universidades españolas y proponer un programa de estudios que tenga en consideración la educación patrimonial, emocional y creativa de forma consistente (Fontal, Ibáñez-Echevarría, Martínez, y Rivero, 2017). 


\subsection{Limitaciones de la investigación.}

El estudio se ha prolongado más de lo que hubiera sido deseable por parte del investigador, pero circunstancias personales así lo han determinado. Esto mismo ha generado que la investigación tuviera que condensarse más de lo planificado en un principio. Esta circunstancia ha provocado que algunas de las iniciativas que se han desarrollado paralelamente a esta investigación, hayan quedado desdibujadas y no formen parte de la misma como debiera haber ocurrido. Es el caso de la creación del Congreso Internacional de Educación, Patrimonio y Creatividad, EPAC ${ }^{24}$, la edición de cuatro libros sobre educación y patrimonio (De la Fuente y Munilla, 2017, 1018, 2019, 2020), o la creación de un aula de trabajo específica sobre patrimonio, creatividad y emociones en un centro de primaria para trabajar estos tres ámbitos desde las Ciencias Sociales (Munilla, 2016). Estas iniciativas habrían sido de ayuda para conocer la evolución de las tres disciplinas analizadas a lo largo de los últimos seis años, como en el caso del congreso y las publicaciones, y para evaluar la validez de una propuesta de trabajo didáctico con el patrimonio, las emociones y la creatividad en el aula de primaria.

En otro orden de cosas, debemos también apuntar las limitaciones del estudio en el ámbito de la muestra de programas patrimoniales analizados, donde en ocasiones los datos que los describen están faltos de profundidad y concreción lo que entorpece la labor del investigador. De la misma manera la representatividad hace difícil realizar relaciones y generalizaciones significativas debido al tamaño de la misma.

Finalmente este investigador debe reconocer sus limitaciones e inexperiencia en el tratamiento y análisis de datos estadísticos, lo que ha ralentizado aún más la finalización de la investigación y ha supuesto un desafío científico y personal.

\footnotetext{
${ }^{24}$ www.epac.es.
} 


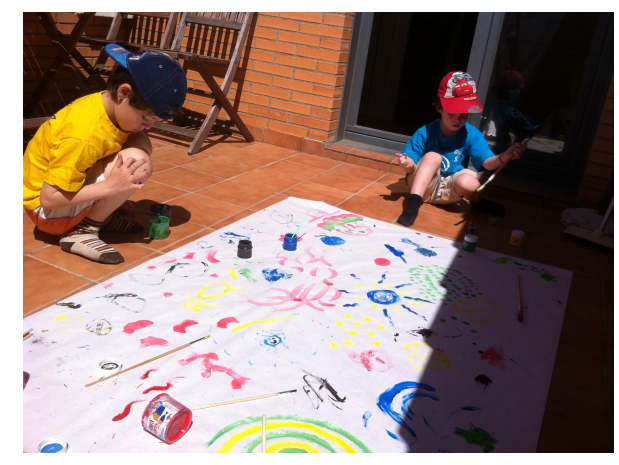

"Un cuadro toma vida ante la presencia de un observador sensible, en cuya conciencia se desarrolla y crece"

Mark Rothko

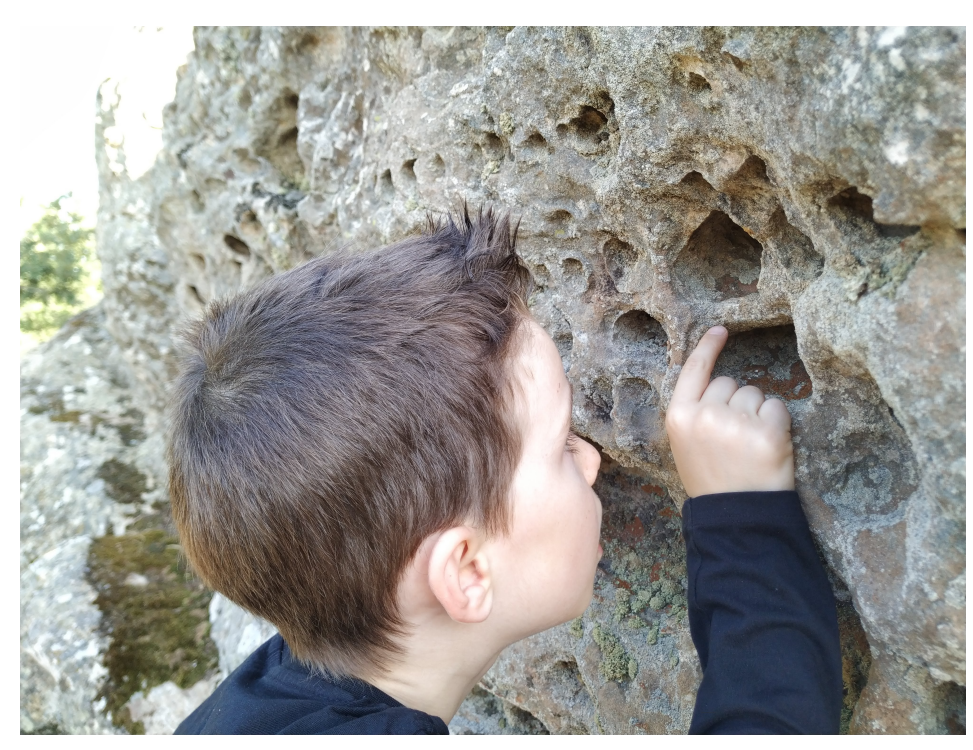




\section{CAPÍTULO 7 - BIBLIOGRAFÍA}

Adetunji, O.S., Essien, C. y Owolabi, O.S. (2018). eDIRICA: Digitizing Cultural Heritage for Learning, Creativity, and Inclusiveness. Lecture Notes in Computer Science. 11196 LNCS, 447-456.

Agencia Nacional de Evaluación de la Calidad y Acreditación, ANECA. (2004). Libro Blanco. Título de grado en magisterio. (Volumen I). Madrid: Omán Impresores.

Agencia Nacional de Evaluación de la Calidad y Acreditación, ANECA. (2004). Libro Blanco. Título de grado en magisterio. (Volumen II). Madrid: Omán Impresores.

Alfaro, E. (30 de noviembre de 2018). La Virgen de la Peña. San Pedro Manrique. Idouveda Etno. Un proyecto etnoarqueológico en Tierras Altas de Soria. Recuperado de http://www.idoubeda.com/2018/11/la-virgen-de-la-penasan-pedro- manrique.html

Álvarez, P. (2007). Educación emocional, desarrollo de la afectividad y museos pedagógicos. En A. Bernal-Guerrero (coord.), Afectividad y educación en la sociedad globalizada: actas de las IV Jornadas Pedagógicas de la Persona, (pp. 14-36). Universidad de Sevilla.

Álvarez, P. (2013). Educar en emociones y transmitir valores éticos: un desafío para los museos de pedagogía, enseñanza y educación. Educació $i$ Història: Revista d'Història de l'Educació, 22, 93-116. DOI:10.2436/20.3009.01.118.

Álvarez, P. (coord.). (2016). Los Museos Pedagógicos en España: entre la memoria y la creatividad. Gijón: Trea; Sevilla: Editorial Universidad de Sevilla.

Andersson, D.E. (ed.). (2011). Handbook of creative cities. Edward Elgar Publishing.

Andre, L., Durksen, T. y Volman, M.L. (2016). Museums as avenues of learning for children: a decade of research. Learning Environments Research, 20(1), 47-76.

Apaydin, V. (2018). The entanglement of the heritage paradigm: values, meanings and uses. International Journal of Heritage Studies, 24(5), 491-507. https://doi.org/10.1080/13527258.2017.1390488.

Aranguren, G. (2020). Mineras de la memoria. la gestión del valor de la memoria oral y el patrimonio inmaterial: el caso de Labrit. [Tesis doctoral, Universidad del País Vasco]. https://www.educacion.gob.es/teseo/mostrarRef.do?ref=459252.

Arias, J. y Savater, F. (1996). El arte de vivir. Barcelona: Planeta.

Arias, N. (2017). Patrimonio y emociones: educando para la sociedad integradora. En R. de la Fuente y C. Munilla (eds.), Patrimonio y creatividad miradas educativas, (pp. 309-319). Valladolid: Verdelis. 
Asiáin. A. (2005). Archivo del patrimonio oral e inmaterial navarro: polifonía de emociones. Cuadernos de etnología y etnografia de Navarra, 37(80), 7-22.

Aznárez, M., \& Santazilia, E. (2016). Un acercamiento a la conceptualización de algunas emociones en el patrimonio fraseológico del euskera y del castellano. Huarte de San Juan. Filología y Didáctica de la Lengua, 16, 13-33. Recuperado de $\quad$ https://hdl.handle.net/2454/22717.

Baecchi, C., Ferracani, A. y Bimbo, A.D. (2020). Automatic emotion recognition for cultural heritage. IOP Conference Series: Materials Science and Engineering, 949(1), art. no. 012043. DOI:10.1088/1757-899X/949/1/012043.

Ballester, P., Ferrándiz, C. y López, O. (2003). Estrategias para favorecer la creatividad. En Ma D. Prieto, O. López y C. Ferrándiz, La creatividad en el contexto escolar. Estrategias para favorecerla, (pp. 97-120). Madrid: Pirámide.

Benetti, A. C., Ozelame, Ângela M. C. C., Pereira, L. A., \& Tricárico, L. T. (2018). Turismo de Experiência em Áreas Patrimoniais: uma análise das emoções a partir dos comentários do Tripadvisor sobre a Estrada Parque TranspantaneiraMT-Brasil. PASOS Revista De Turismo Y Patrimonio Cultural, 16(3), 565-581. https://doi.org/10.25145/j.pasos.2018.16.042.

Bisquerra, R. (2003). Educación emocional y competencias básicas para la vida. Revista De Investigación Educativa, 21(1), 7-43. Recuperado de https://revistas.um.es/rie/article/view/99071.

Bisquerra, R. (2009). Psicopedagogía de las emociones. Madrid: Síntesis.

Bisquerra, R., Pérez, J.C. y García, E. (2015). Inteligencia emocional en la educación. Madrid: Síntesis.

Bolivar, A. (2005). Conocimiento didáctico del contenido y didácticas específicas. Revista de currículum y formación del profesorado, 9, 2. Universidad de Granada. Recuperado de http://www.ugr.es/local/recfpro/Rev92ART6.pdf

Bollini, L., Fazia, I.D. (2020). Situated emotions. the role of the soundscape in a geobased multimodal application in the field of cultural heritage. Lecture Notes in Computer Science (including subseries Lecture Notes in Artificial Intelligence and Lecture Notes in Bioinformatics), 12251 LNCS, (pp. 805-819). DOI: 10.1007/978-3-030-58808-3_58.

Boniolo, P., Dalle, P., \& Elbert, R. (2005). Manual de metodología: construcción del marco teórico, formulación de los objetivos y elección de la metodología. Buenos Aires: Clacso.

Bull, A.C. y De Angeli, D. (2020). Emotions and critical thinking at a dark heritage site: investigating visitors' reactions to a First World War museum in Slovenia. Journal of Heritage Tourism. DOI: 10.1080/1743873X.2020.1804918. 
Burillo, F; Burillo, P; Alfaro, E. (2014). Una propuesta para el origen celtibérico de la hoguera del "paso del fuego" de San Pedro Manrique. VII Simposio sobre los Celtíberos. Nuevos Hallazgos, Nuevas Interpretaciones. 38, (pp.361-369).

Buss, K. (2011). Behavioural Patterns for the Analisis of Creative Behaviour. [Tesis doctoral]. De Montfort Universiti, Software Technology Research Laboratory. Recuperado de https://www.semanticscholar.org/paper/Behavioural-patternsfor-the-analysis- of-creativeBuss/2dcee07d82732fd692723cbd6e4a6399f9302a1c\#citing-papers

Calaf, R., Fontal, O. y Valle, R. E. (Coord.) (2007). Museos de arte y educación. Construir patrimonios desde la diversidad. Gijón: Trea.

Calaf, R. y Fontal, O. (2010). Como enseñar arte en la escuela. Síntesis: Madrid.

Campos, G. y Palacios, A. (2018). La creatividad y sus componentes. Creatividad y Sociedad, (27), 167-183. Recuperado de https://www.academia.edu/36251133/La_creatividad_y_sus_componentes.

Campos, T. (2019). ¿Para qué sirve la arqueología preventiva? una propuesta desde la (re)significación del patrimonio, la práctica arqueológica y la educación. [Tesis doctoral, Universidad del País Vasco]. https://www.educacion.gob.es/teseo/mostrarRef.do?ref=454662.

Carrasco, C. J., Facal, R. L. \& Fernandez, B. M. (2020). Trainee Teachers' Perceptions of History Teaching and the Critical Education of Citizenship. In E. J. DelgadoAlgarra \& J.M. Cuenca-López (Ed.), Handbook of Research on Citizenship and Heritage Education (pp. 239-263). IGI Global. http://doi:10.4018/978-1-7998-1978-3.ch012.

Castillejo, J. L. (1982). El marco sociocultural de la educación. En J.L Castillejo, J. Escamez y R. Marín, Teoría de la educación. Madrid: Anaya.

Castro, B y López, R. (2017). De patrimonio nacional a patrimonio emocional. HER\&MUS monografias. 18, 41-53.

Castro, L. (2020). Modelo de avaliación de programas de educación patrimonial (MAPEP). deseño e avaliación do programa patrimonializarte. [Tesis doctoral, USC]. https://www.educacion.gob.es/teseo/mostrarRef.do?ref=1932762

Castro, L. y López-Facal, R. (2019). Educación patrimonial: necesidades sentidas por el profesorado de infantil, primaria y secundaria. Revista Interuniversitaria de Formación del Profesorado, 94(33.1), 97-114.

Cazau, P. (2006). Introducción a la investigación en ciencias sociales. Lima: Editorial Universidad Ricardo Palma.

Cerisola, S. (2019a). Cultural Heritage, Creativity and Economiclo Devepment.. Milano. Italia: Edward Elgar Publishing. 
Cerisola, S. (2019b). A new perspective on the cultural heritage-development nexus: the role of creativity. Journal of Cultural Economics, 43(1), 21-56. DOI: $10.1007 / \mathrm{s} 10824-018-9328-2$

Cilona, T. (2019). The Creativity of Cultural Heritages and Landscapes. Redevelopment Experiences Compared. In World Heritage and Legacy: culture, creativity, contamination. Le Vie dei Mercanti XVII International Forum, (pp. 674-683). Roma: Gangemi.

Coca, P. (2015). El comisariado educativo como modelo de gestión de espacios expositivos en museos de arte contemporáneo. [Tesis doctoral, Universidad de Valladolid]. https://www.educacion.gob.es/teseo/imprimirFicheroTesis.do

Colom, A.J. (1998). Educación ambiental y la conservación del patrimonio. En J. Sarramona, G. Vázquez y A.J. Colom, Educación no formal, (pp. 127-150). Barcelona: Ariel.

Coma, L., Fuentes, C., \& Sánchez, L. (2020). Heritage Education as an Instrument for the Construction of a Democratic Citizenship in the Social Sciences Classrooms of Secondary Education. In E.J. Delgado-Algarra \& J.M. Cuenca-López (Ed.), Handbook of Research on Citizenship and Heritage Education (pp. $\quad 127-$ 147). IGI Global. http://doi:10.4018/978-1-7998-1978-3.ch007

Cominelli, F. (2012). Intangible cultural heritage: Safeguarding for creativity. City, Culture and Society, 3(4), 245-250. DOI: 10.1016/j.ccs.2012.10.003.

Conde, J. y Armas, X. (2019). Social representations of primary education students on heritage. Study by the word association. Revista Interuniversitaria de Formación del Profesorado-Rifop, 187-201. https://doi.org/10.47553/rifop.v33i2.73266

Cordero, Ma. T. (2017). Creatividad: un mecanismo de empoderamiento comunitario para la conservación del patrimonio. En E. Alicia Isasmendi, F. Quiles García y Z. Ruiz Romero, (eds.), Acervo mexicano. Legado de culturas, (pp. 140-150). Recuperado de http://hdl.handle.net/10433/5175

Crouch D. (2015) Affect, Heritage, Feeling. In: Waterton E., Watson S. (eds), The Palgrave Handbook of Contemporary Heritage Research, (pp. 177-190). London: Palgrave Macmillan. https://doi.org/10.1057/9781137293565 11

Cuenca, J. Ma , y Estepa, J. (2017). Educación patrimonial para la inteligencia territorial y emocional de la ciudadanía, Midas, 8, 1-11. DOI: 10.4000/midas. 1173 .

Cuenca, J.Ma , Estepa, J. y Martín, M.J. (2017). Patrimonio, educación, identidad y ciudadanía. Profesorado y libros de texto en la enseñanza obligatoria. Revista de Educación, (375), 136-159. DOI: 10.4438/1988-592X-RE-2016-375-338. 
Cuenca-López, J.Ma , Martín-Cáceres, M. y Estepa, J. (2020). Good practices in heritage education. Analysis of connections between emotions, territory and citizenship. Aula abierta, 49(1), 45-54. DOI:10.17811/rifie.49.1.2020.45-54

De Bono, E. (2008). Creatividad. Barcelona: Paidós.

De Bono, E. (2010). Seis sombreros para pensar. Barcelona: Paidós.

De Bono, E. (2016). El pensamiento creativo. Barcelona: Paidós.

De Bono, E. (2018). El pensamiento lateral. Barcelona: Paidós.

De Castro, P. (2016). Cartografía autoetnográfica de una genealogía de programas de educación patrimonial desde la perspectiva del aprendizaje basado en proyectos y la investigación-acción. [Tesis doctoral, Universidad de Valladolid]. http://uvadoc.uva.es/handle/10324/16853

De la Fuente, R y Munilla, C. (Ed.). (2017). Patrimonio y Creatividad. Miradas Educativas. Valladolid, España: Verdelis.

De la Fuente, R y Munilla, C. (Ed.). (2018). Visiones transdisciplinares en torno a Patrimonio, Creatividad y Poesía. Valladolid, España: Verdelis.

De la Fuente, R y Munilla, C. (Ed.). (2019). Patrimonio, Creatividad y Teatro. Territorios comunes. Valladolid, España: Verdelis.

De la Fuente, R. y Munilla, C. (Ed.) (2020). Educación, Patrimonio y Creatividad. Valladolid, España: Verdelis.

De la Torre, S. (2006). Creatividad en la Educación Primaria. Una mirada desde la complejidad. En S. de la Torre y V. Violant (Coord.), Comprender y evaluar la creatividad, Vol. I, (pp. 253-266). Málaga: Aljibe.

De la Torre, S. (2007). Creatividad aplicada. Recursos para una formación creativa. Argentina: Magisterio del Río de la Plata.

De Leersnyder, J., Kim, H.S., Mesquita, B. (2020). My emotions belong here and there: extending the phenomenon of emotional acculturation to heritage culture fit. Cognition and Emotion, 34(8), 1573-1590. DOI: 10.1080/02699931.2020.1781063.

Delgado-Algarra, E. J. y Cuenca-López, J. Ma . (Coord.) (2020). Handbook of Research on Citizenship and Heritage Education. Hershey (USA): IGI Global. DOI: 10.4018 / 978-1-7998-1978-3.

Diamond, J., Horn, M., y Uttal, D. H. (2016). Practical Evaluation Guide: Tools for Museums and Other Informal Educational Settings. Lanham MD: Rowman \& Littlefield. 
Díez, J. (2018). Trance y proceso creativo. En R. De la Fuente y C. Munilla (Eds.), Visiones transdisciplinares en torno a Patrimonio, Creatividad y Poesía, (pp. 211-216). Valladolid, España: Verdelis.

Dios, F. (2008). La creatividad musical y el patrimonio artístico en algunas comunidades bolivianas. Creatividad y Sociedad: revista de la Asociación para la Creatividad, (13), 237-256.

Djabarouti, J. (2020). Stories of feelings and things: intangible heritage from within the built heritage paradigm in the UK. International Journal of Heritage Studies, DOI: $10.1080 / 13527258.2020 .1798271$.

Domínguez, A., \& López, R. (2018). Formación de maestros y educación patrimonial. Estudios Pedagógicos, 43(4), 49-68. DOI:10.4067/S0718-07052017000400003.

Domínguez-Almansa, A., Riveiro-Rodríguez, T., Monteagudo-Fernández, J., \& López, R. (2020). Conflictive Memory and Heritage Education in the Initial Training of Primary Teachers. In J.M. Delgado-Algarra \& J.M. Cuenca-López (Ed.), Handbook of Research on Citizenship and Heritage Education, (pp. 472-500). IGI Global. http://doi:10.4018/978-1-7998-1978-3.ch022.

Domínguez-Quintero, A.M., González-Rodríguez, M.R. y Roldán, J.L. (2019). The role of authenticity, experience quality, emotions, and satisfaction in a cultural heritage destination. Journal of Heritage Tourism, 14(5-6), 491-505. DOI:10.1080/1743873X.2018.1554666.

Duran, N. G., Molina, N. L., \& Santacana, J. (2016). Identidades culturales: educando ciudadanos desde la mirada patrimonial. En S. Molina, A. Escribano-Miralles y J. Díaz-Serrano. Patrimonio, identidad y ciudadanía en la enseñanza de las ciencias sociales, (pp. 75-88). Universidad de Murcia. Recuperado de https://www.academia.edu/30565683/Identidades_culturales_educando_ciudada nos desde la mirada patrimonial.

Eley G. (2009) How is the National Past Imagined? National Sentimentality, True Feeling and the "Heritage Film", 1980-1995. In P. Levine \& S.R. Grayzel (eds.), Gender, Labour, War and Empire, (pp. 238-255). London: Palgrave Macmillan. https://doi.org/10.1057/9780230582927 13.

Elisondo, R.C. (2018). Creatividad y educación: llegar con una buena idea. Creatividad y sociedad, 27, 145-166.

Estepa-Giménez, J., \& Martín-Cáceres, M. (2020). Heritage in Conflict: A Way to Educate in a Critical and Participative Citizenship. In E.J. Delgado-Algarra \& J.M. Cuenca-López (Ed.), Handbook of Research on Citizenship and Heritage Education, (pp. 43-55). IGI Global. http://doi:10.4018/978-1-7998-19783.ch003.

Esquivias, M. T. (2004). Creatividad: definiciones, antecedentes y aportaciones. Revista digital interuniversitaria, 5(1). Universidad Nacional Autónoma de México. Recuperado de http://www.revista.unam.mx/vol.5/num1/art4/art4.htm 
Ethro, D. (2017). Transgressive Touch: Ruination, Public Feeling, and the Sunday Times Heritage Project. In K. Miller \& B. Schmahmann (Eds.), Public Art in South Africa: Bronze Warriors and Plastic Presidents, (pp. 166-190). Bloomington, Indiana: Indiana University Press. doi:10.2307/j.ctt20060c0.12.

Falcón, A. (2016). Pedagogía y performance en educación artística en la Enseñanza Secundaria Obligatoria. [Tesis doctoral, Universidad de Valladolid]. http://uvadoc.uva.es/handle/10324/19130

Fernández, A.R. (2021). El patrimonio como medio para la construcción de la diversidad afectivo-sexual: estudio de su grado de desarrollo curricular en la formación de los futuros maestros de educación primaria en Andalucía. [Tesis doctoral, Universidad de Málaga]. https://www.educacion.gob.es/teseo/mostrarRef.do?ref=1945527.

Ferreira, I. (2016). Criatividade nos Museus: Espaços entre e elementos de mediação. Portugal: Caleidoscópico.

Ferreras, M. y Jiménez, R. (2013). ¿Cómo se conceptualiza el patrimonio en los libros de texto de Educación Primaria? Revista de Educación, 361, 591-618. DOI: 10.4438/1988-592X-RE-2013-361-234.

Ferreras-Listán, M., Pineda-Alfonso, J. A., \& Hunt-Gómez, C. I. (2020). Heritage Education as a Tool for Creating Critical Citizens: Analysis of Conceptions of Teachers in Training. In E.J. Delgado-Algarra \& J.M. Cuenca-López (Ed.), Handbook of Research on Citizenship and Heritage Education, (pp. 199-218). IGI Global. http://doi:10.4018/978-1-7998-1978-3.ch010.

Fontal, O. (2003). La educación patrimonial. Teoría y práctica en el aula, el museo e internet. Gijón, España: Trea.

Fontal, O. (2015). The Spanish Heritage Education Observatory / El Observatorio de Educación Patrimonial en España. Cultura y Educación, 28(1), 254-266. http://dx.doi.org/10.1080/11356405.2015.1110374

Fontal, O. (2016). El patrimonio a través de la educación artística en la etapa de primaria. Arte, Individuo y Sociedad, 28(1), 105-120.

Fontal, O. e Ibáñez-Etxeberria, A. (2015). Strategies and Tools for Heritage Education in Spain. Educatio Siglo XXI, 33(1), 15-32.

Fontal, O., y Juanola, R. (2015). La Educación Patrimonial: Una disciplina útil y rentable en el ámbito de la gestión del patrimonio cultural. Cadmo. International Journal of Educational Research, 23(1), 254-266. DOI: 10.3280/CAD2015001002 .

Fontal, O. e Ibáñez-Etxeberria, A. (2017). La investigación en Educación Patrimonial. Evolución y estado actual a través del análisis de indicadores de alto impacto. Revista de Educación, (375), 184-214. 
Fontal, O., Ibáñez-Echevarría, A., Martínez, A. y Rivero, P. (2017). El patrimonio como contenido en la etapa de Primaria: del currículum a la formación de maestros. Revista electrónica interuniversitaria de formación del profesorado, 20(2), 7975. https://doi.org/10.6018/reifop/20.2.286321

Fontal, O., García, S., Arias, B. y Arias, V. (2018). Assessing the Quality of Heritage Education Programs: Construction and Calibration of the Q-Edutage Scale. Revista de Psicodidáctica (english ed.), 24(1), 31-38.

Fontal, O. y García, S. (2019). Evaluación de programas de Educación Patrimonial: estándares de calidad. Ensayos, Revista de la facultad de Educación de Albacete, 34(1). https://doi.org/10.18239/ensayos.v34i1.2039

Fontal, O., García-Ceballos, S. y Aso, B. (2020). Desarrollo de competencias docentes en educación patrimonial mediante plataformas 2.0 y entornos digitales como herramienta de aprendizaje. Investigación en la Escuela, 101(jul. 2020), 1-14. https://doi.org/10.12795/IE.2020.i101.01.

Fontal, O. y Martínez, M. (2020). The Heritage and Education Research Network: Place Value on Cultural Heritage in Europe. En E. Delgado y J.M Cuenca (eds.), Handbook of Research on Citizenship and Heritage Educatión, (pp. 173-196). (USA) IGI Global: Hershey.

Frihammar, M., Silverman, H. (2017) Heritage of Death: Landscapes of Emotion, Memory and Practice. Heritage of Death: Landscapes of Emotion, Memory and Practice, (pp. 1-243). DOI: 10.4324/9781315440200.

Fromm, E. (1986). Ética y psicoanálisis. México: Fondo de Cultura Económica.

Fuentes, C.R., y Torbay, A. (2004). Desarrollar la creatividad desde los contextos educativos: un marco de reflexión sobre la mejora socio-personal. Revista Electrónica Iberoamericana sobre Calidad, Eficacia y Cambio en Educación. 2(1).

Fuertes, C. (2016). Emoción, oralidad e itinerarios didácticos: un estudio de caso en el grado en maestro de Educación Infantil. Revista de Didácticas Específicas, 15, 51-69. Recuperado de https://revistas.uam.es/didacticasespecificas/article/view/4058/7286

Galton, F. (1869). Hereditary Genius: and Inquiry into its Laws and Consequences. London: Mcmillan.

García, C. (2004). Gestión del patrimonio emocional. Organizaciones emocionalmente sostenibles. Boletín de estudios económicos, 59(183), 425-435.

García, J. (2013). La cultura digital para la puesta en valor del Patrimonio: Generación de productos patrimoniales con alcance educativo. [Tesis doctoral, Universidad de Valladolid]. http://uvadoc.uva.es/handle/10324/4322. 
García-Ceballos, S. (2018). Evaluación de programas en educación patrimonial: Indicadores de calidad a través del método SAEPEP-OEPE y su instrumento basado en estándares EBEB-OEPE. [Tesis doctoral, Universidad de Valladolid]. http://uvadoc.uva.es/handle/10324/33112.

García, M. (2007). Patrimonio y creatividad. La música de tradición oral en contextos devocionales. En J. Ruiz y J.P. Vázquez. Religiosidad Popular: V Jornadas. Instituto de Estudios Almerienses. Almería, España.

García, M. (2009). Creatividad y/o patrimonio. Música culta vs música popular. Papeles del festival de Música Española de Cádiz, 4, 341-367.

Gardner, H. (1994). Educación artística y desarrollo humano. Barcelona: Paidós.

Gardner, H. (1995). Mentes creativas. Una anatomía de la creatividad vista a través de las vidas de S. Freud, A. Einstein, P. Picasso, I. Stravinsky, T.S. Elliot, M. Graham, M. Gandhi. Barcelona: Paidós.

Gardner, H. (1998). Inteligencias múltiples. La teoría en la práctica. Barcelona: Paidós.

Gardner, H. (2002). Mentes creativas. Una anatomía de la creatividad. Barcelona: Paidós.

Gillate, I. (2014). Programas de educación patrimonial en contextos informales: análisis y valoración de su influencia en el alum-nado de ESO de la zona minero-industrial de Bizkaia. [Tesis doctoral, Universidad del País Vasco]. https://www.educacion.gob.es/teseo/mostrarRef.do?ref=349464.

Goleman, D. (1996). Inteligencia emocional. Barcelona: Kairós.

Gómez, I. y Cuenca J.M. (2015). Trabajar las emociones desde la educación patrimonial para atender la diversidad del aula. En R. Martínez, R. García-Morís y C.R. García. Investigación en didáctica de las Ciencias Sociales. Retos, preguntas y lineas de investigación, 105, 649-657. Córdoba: Universidad de Córdoba.

Gómez, J.A. (2020). Apropiación y puesta en valor del patrimonio cultural inmaterial en los festivales de folklore: una mirada desde la gestión artística en música danza. [Tesis doctoral, Universidad del País Vasco]. http://hdl.handle.net/10251/152483.

Gómez-Redondo, C. (2013). Procesos de patrimonialización en el arte contemporáneo: diseño de un artefacto educativo para la identización. [Tesis doctoral, Universidad de Valladolid]. http://uvadoc.uva.es/handle/10324/3568.

Gómez Villar, J., Canessa Vicencio, F. (2019). Social emotions, heritage and recognition. The Struggle of Colina Stonemasons in Santiago, Chile. International Journal of Heritage Studies, 25(12), 1263-1278. DOI: 10.1080/13527258.2019.1590448. 
González, G. (2016). Los centros históricos, ¿ciudades creativas? Problemáticas y posibles soluciones en torno a la gestión sostenible del patrimonio. Telos: cuadernos de comunicación e innovación, 105, 23-33.

González, P. (2015). Actualización de un debate patrimonial a través del paisaje histórico y la creatividad urbana. Boletín del Instituto Andaluz de Patrimonio Histórico, 87, 206-215.

González-Monfort, N. (2006). El valor educativo y el uso didáctico del patrimonio cultural. [Tesis Doctoral]. Universitat Autónoma de Barcelona.

González-Monfort, N. (2011). La presencia del patrimonio cultural en los currícula de educación infantil, primaria y secundaria obligatoria en España. Revista de Patrimonio Cultural de España, 5, 59-74.

Granel, R. (2012). El patrimonio como cauce para la creatividad y la sensibilización. [Trabajo Fin de Máster]. Universidad de Zaragoza.

Guilford, J.P. (1968). Intelligence, creativity and their educational implications. San Diego: Knapp.

Hayakawa Casas, J. (2018). V Congreso Educación, Museos y Patrimonio. Creatividad e innovación educativa en museos y espacios patrimoniales. Devenir - Revista De Estudios Sobre Patrimonio Edificado, 2(3), 150. https://doi.org/10.21754/devenir.v2i3.271.

Hoare, J. (2018). Heart on Your Sleeve? Emotion, Wearable Technology and Digital Heritage Proceedings of the 2018 3rd Digital Heritage International Congress. DOI: 10.1109/DigitalHeritage.2018.8810130

Hoare, J. (2020). The practice and potential of heritage emotion research: an experimental mixed-methods approach to investigating affect and emotion in a historic house. International Journal of Heritage Studies, 26(10), 955-974. DOI: $10.1080 / 13527258.2020 .1714696$.

Instituto del Patrimonio Cultural de España (2015). Plan Nacional de Educación y Patrimonio. Madrid: IPCE.

Instituto del Patrimonio Cultural de España (2015). Plan Nacional para la Salvaguarda del Patrimonio Cultural Inmaterial. Madrid: IPCE.

Jagošová, L. (2020). Emotions in museum education. Potential for the development of a relationship to cultural and historical heritage [Article@Emoce v muzejní edukaci. Potenciál pro rozvoj vztahu ke kulturně-historickému dědictví] Museologica Brunensia, 9(2), 10-16. DOI: 10.5817/MuB2020-2-2

Kam, J.A. (2011). The Effects of Language Brokering Frequency and Feelings on Mexican-Heritage Youth's Mental Health and Risky Behaviors. Journal of Communication. 61(3), 455-475. 
Kamel, M.K., Shahat, H.A., Al-Hashel, M.S. (2020). Aesthetics of the gulf architectural heritage in Al Ahsa as a source of artistic creativity. Scientific Journal of King Faisal University, 21(2), 1-10.

Kluczewska-Wójcik, A. (2019). To protect heritage, to inspire emotions. Private museums in France [Article@CHRONIC DZIEDZICTWO, BUDZIC EMOCJE .MUZEA PRYWATNE WE FRANCJI]. Muzealnictwo, 60, 143-153. DOI: 10.5604/01.3001.0013.2973.

Lanza, D. (2012). Estrategias didácticas para el desarrollo de la creatividad en educación primaria. En F. Guerra, R. García-Ruiz, N. González, P. Renés y A. Castro (Coord.), Estilos de aprendizaje. Investigaciones y experiencias. $V$ Congreso Mundial de Estilos de Aprendizaje. Santander: Universidad de Cantabria.

Lauro, G. (2014). Recuperación de la memoria histórica de la lucha por la defensa del patrimonio Cholula a través de las emociones. Puebla, México: Íbero. Recuperado de http://hdl.handle.net/20.500.11777/3409.

Ley 16/1985, de 25 de junio, del Patrimonio Histórico Español. Boletín Oficial del Estado, núm. 155, de 29 de junio de 1985.

Ley 4/1990, de 11 de abril, de medidas de fomento del patrimonio histórico de la Región de Murcia. Boletín Oficial del Estado, núm. 170, de 17 de julio de 1990.

Ley 9/1993, de 30 de septiembre, del Patrimonio Cultural Catalán. Boletín oficial del Estado, núm. 264, de 4 de noviembre de 1993.

Ley 4/1998, de 11 de junio, del Patrimonio Cultural Valenciano. Boletín Oficial del Estado, núm. 174, de 22 de julio de 1998.

Ley 11/1998, de 13 de octubre, de Patrimonio Cultural de Cantabria. Boletín oficial del Estado, núm. 10, de 12 de enero de 1999.

Ley 12/1998, de 21 de diciembre, del Patrimonio Histórico de las Illes Balears. Boletín Oficial del Estado, núm. 31, de 5 de febrero de 1999.

Ley 3/1999, de 10 de marzo, del Patrimonio Cultural Aragonés. Boletín Oficial del Estado, núm. 88, de 13 de abril de 1999.

Ley 4/1999, de 15 de marzo, de Patrimonio Histórico de Canarias. Boletín Oficial del Estado, núm. 85, de 9 de abril de 1999.

Ley 2/1999, de 29 de marzo, de Patrimonio Histórico y Cultural de Extremadura. Boletín Oficial del Estado, núm. 139, de 11 de junio de 1999.

Ley 1/2001, de 6 de marzo, del Patrimonio Cultural del Principado de Asturias. Boletín oficial del Estado, núm. 135, de 6 de junio de 2001. 
Ley 12/2002, de 11 de julio, de Patrimonio Cultural de Castilla y León. Boletín Oficial del Estado, núm. 183, de 1 de agosto de 2002.

Ley 7/2004, de 18 de octubre, de Patrimonio Cultural, Histórico y Artístico de La Rioja. Boletín Oficial del Estado, núm. 272, de 11 de noviembre de 2004.

Ley Foral 14/2005, de 22 de noviembre, del Patrimonio Cultural de Navarra. Boletín Oficial del Estado, núm. 304, de 21 de diciembre de 2005.

Ley 4/2007, de 16 de marzo, de Patrimonio Cultural de la Comunidad Autónoma de la Región de Murcia. Boletín Oficial del Estado, núm. 176, de 22 de julio de 2008.

Ley 14/2007, de 26 de noviembre, del Patrimonio Histórico de Andalucía. Boletín Oficial del Estado, núm. 38, de 13 de febrero de 2008.

Ley 4/2013, de 16 de mayo, de Patrimonio Cultural de Castilla-La Mancha. Boletín Oficial del Estado, núm. 240, de 7 de octubre de 2013.

Ley 3/2013, de 18 de junio, de Patrimonio Histórico de la Comunidad de Madrid. Boletín Oficial del Estado, núm. 247, de 15 de octubre de 2013.

Ley Orgánica 8/2013, de 9 de diciembre, para la Mejora de la Calidad Educativa, Boletín Oficial del Estado, núm. 295, de 1 de diciembre de 2013.

Ley 10/2015, de 26 de mayo, para la salvaguardia del Patrimonio Cultural Inmaterial. Boletín Oficial del Estado, núm. 126, de 27 de mayo de 2015.

Ley 5/2016, de 4 de mayo, del patrimonio cultural de Galicia. Boletín Oficial del Estado, núm. 147, de 18 de junio de 2016.

Ley 18/2019, de 8 de abril, de salvaguardia del patrimonio cultural inmaterial de las Illes Balears. Boletín Oficial del Estado, núm. 109, de 7 de mayo de 2019.

Ley 6/2019, de 9 de mayo, de Patrimonio Cultural Vasco. Boletín oficial del Estado, núm. 128, de 29 de mayo de 2019.

Ley Orgánica 6/2001, de 21 de diciembre, de Universidades. Boletín Oficial del Estado, núm. 307, de 24 de diciembre de 2001.

Liebelt, B.G. (2019). Touching grindstones in archaeological and cultural heritage practice: materiality, affect and emotion in settler-colonial Australia. Australian Archaeology, 85(3), 267-278. DOI: 10.1080/03122417.2019.1751982.

López, A. (2010). La experiencia estética y su poder formativo. Bilbao: Deusto.

López, C.T. (2017). El patrimonio en el contexto escolar: análisis de concepciones como vehículo para el desarrollo profesional docente: experiencia didáctica, "Farmington Junior High y su entorno patrimonial", Utah. [Tesis doctoral, 
Universidad de Huelva]. http://hdl.handle.net/10272/15501.

López, O. y Navarro, J. (2010). Influencia de una metodología creativa en el aula de primaria, European Journal of Education and Psychology, 3(1), 89-102.

Lucas, L. (2018). La enseñanza del patrimonio y de la ciudadanía en las clases de ciencias sociales: un estudio de caso en ESO. [Tesis doctoral, Universidad de Huelva]. http://hdl.handle.net/10272/15597.

Lucas, L. y Estepa, J. (2017). Educación Patrimonial e Inteligencia Emocional. Hablan los alumnos. CLIO. History and History teaching, 41.

Mains, S.P. (2016). From menie to montego bay: Documenting, representing and mobilising emotion in coastal heritage landscapes. Heritage, Affect and Emotion: Politics, Practices and Infrastructures, (pp. 179-200). Londres: Routledge. DOI: 10.4324/9781315586656.

Maldonado, M. S. (2016). Educación Patrimonial y redes sociales. Análisis y evaluación de acciones en los medios de comunicación social para la definición de una cartografia educativa. [Tesis doctoral, Universidad de Valladolid] http://uvadoc.uva.es/handle/10324/16879.

Maldonado, S. y Marañón, R. (2017). ¿Paisajes emocionales? El mapeo colectivo como encuentro patrimonial. En De la Fuente, R y Munilla, C. (Ed.), Patrimonio y creatividad. Miradas Educativas, (pp. 237-253). Valladolid, España: Verdelis.

Marcelo, C. y Vaillant, D. (2018). Desarrollo profesional docente. ¿Cómo se aprende a Enseñar?. Madrid: Narcea.

Marchant, A. \& Nancarrow, J.-H. (2019). Introduction: Practice, performance, and emotions in medieval and early modern heritage. Parergon, 36(2), 1-16. DOI: 10.1353/pgn.2019.0052.

Marín-Cepeda, S. (2014). Educación Patrimonial y diversidad: evaluación de programas y definición de un modelo basado en los procesos de patrimonialización. [Tesis doctoral, Universidad de Valladolid]. http://uvadoc.uva.es/handle/10324/7416.

Martínez, M. (2017). El uso del arte como mediador del aprendizaje en la etapa escolar (Infantil, Primaria, Secundaria y Bachillerato). [Tesis doctoral, Universidad Complutense de Madrid]. https://eprints.ucm.es/id/eprint/48662/1/T40416.pdf.

Martínez, S., Aldecoa, A. y Munilla, C. (2011). The Life Tiermes proyect Experiences: 2003-2011. International Forum UNESCO. Capri, Italia: Universitá de Napoli y Universitá Mediterránea di Regio Calabria.

Martínez, S. y Munilla, C. (2017). Acción cultural y didáctica en yacimientos arqueológicos: el proyecto LIFE Tiermes. En R. De la Fuente y C. Munilla (Ed.), Patrimonio y Creatividad. Miradas Educativas, (pp. 163-176). Valladolid, España: Verdelis. 
Martínez-Rodríguez, M. y Fontal, O. (2016). El binomio educación y patrimonio cultural inmaterial: evaluación de programas educativos. Libro de actas VII Simposio de Didáctica de las Ciencias Sociales en el ámbito Iberoamericano, (pp. 624-637). Santiago de Compostela.

Martínez-Rodríguez, M. (2019). La educación patrimonial inmaterial: análisis del currículo y evaluación de programas. [Tesis doctoral, Universidad de Valladolid]. http://uvadoc.uva.es/handle/10324/39468.

Martínez, T., López, V., Asensio, M. \& Santacana. J. (2018). ¿Entretener o aprender? La evaluación de las tecnologías móviles en la Didáctica del Patrimonio. ENSAYOS, Revista de la Facultad de Educación de Albacete, 33(1). https://doi.org/10.18239/ensayos.v33i1.1738

Masachs, R. C. y Berciano, S. G. (2017). The Thyssen-Bornemisza Museum; evaluating it's educative programs to teach art. Arte, Individuo y Sociedad. 29(1), 39-56.

Masachs, R.C., Maroto, J.L., y Berciano, S. G. (2017). Evaluación de programas educativos en museos: Una nueva perspectiva. Bordón, 69(1), 45-65.

Maslow, A. (1994). La personalidad creadora. Barcelona: Kairós.

Maslow, A. (1998). El hombre autorrealizado. Barcelona: Kairós.

McMillan, J. H. \& Schumacher, S. (2005). Investigación educativa. Madrid: Pearson Educación, S. A.

Mendoza, R. (2019). Framework para la educación patrimonial apoyada en realidad aumentada. [Tesis doctoral, Universitat de Girona]. http://hdl.handle.net/10803/668354.

Mikolajczak, M. (2009). Going Beyond the Ability-Trait Debate: The Three-Level Model of Emotional Intelligence. Electronic Journal of Applied Psychology. 5(2), 25-31. DOI: 10.7790/ejap.v5i2.175.

Mock, S.J. (2018). Mapping authenticity: Cognition and emotion in public heritage. The Oxford Handbook of Public Heritage Theory and Practice, (pp. 371-385). DOI: 10.1093/oxfordhb/9780190676315.013.15.

Molina, N. L., Piñol, C. M., \& Santacana, J. (2017). Una experiencia de formación del profesorado basada en las inteligencias múltiples y la Educación Artística. Educatio Siglo XXI, 35(2 Julio), 317-340. 
Molina Puche, S. \& Riquelme Adán, M. D. (2020). Future Citizens: Analysis of the Knowledge and Attitudes on Citizenship of Elementary Education Pupils of Murcia, Spain From an Inquiry Based on the ICCS. In E.J. Delgado-Algarra, E \& J.M. Cuenca-López (Ed.), Handbook of Research on Citizenship and Heritage Education, (pp. 352-376). IGI Global. Recuperado de https://doi.org/10.4018/978-1-7998-1978-3.ch010.

Munilla, C. (2007). Proyecto de difusión del Museo provincial de Segovia. [Trabajo Fin de Máster]. Universidad Nacional de Educación a Distancia. Madrid.

Munilla, C. (2012). Didáctica del patrimonio. Propuestas didácticas sobre patrimonio arqueológico. [Trabajo Fin de Grado]. Universidad internacional de la Rioja. Logroño.

Munilla, C. (2013). Propuesta didáctica para primer curso de ESO. La civilización romana y la romanización del alto Duero. [Trabajo Fin de Máster]. Universidad Internacional Valenciana. Valencia.

Munilla, C. (2014). Educación Patrimonial versus Educación Integral. Polos opuesto o almas gemelas. Segovia Histórica, 1, 287-294. Segovia: JCyL.

Munilla, C. (2016a). El patrimonio como recurso educativo y apuesta pedagógica. En T. Ramiro-Sánchez, M.T. Ramiro-Sánchez, P. Bermúdez. 4th. International Congress of Educational Sciences and Developmen. Acercar el museo al aula, (pp. 330-335). Universidad de Granada. Santiago de Compostela.

Munilla, C. (2016b). Aula CPC Conoce, Piensa, Crea. En O. Fontal, A. IbañezEchevarría, M. Domingo, $\mathrm{M}$ y $\mathrm{S}$. Marín. III Congreso Internacional de Educación Patrimonial. Madrid: Plan Nacional de Educación y Patrimonio.

Munilla, C (2017). Prólogo. Heritage Thinking. En R. de la Fuente y C. Munilla. Patrimonio y Creatividad Miradas Educativas, (pp. 7-9). Valladolid, España: Verdelis.

Munilla, C (2018). Prólogo. En R. de la Fuente y C. Munilla. Visiones Transdisciplinares en torno a Patrimonio, Creatividad y Poesía, (pp. 7-8). Valladolid, España: Verdelis.

Munilla, C. y Marín-Cepeda, S. (2020). Patrimonio y emociones. Estado de la cuestión desde las perspectivas internacional y nacional. Revista Interuniversitaria de Formación del Profesorado, 34(1), 177-196.

Munilla, C. y Martínez, S. (2005a). Del yacimiento a la exposición. Taller de arqueología. Proyecto Life Tiermes. Soria.

Munilla, C. y Martínez, S. (2005b). Taller de arqueología, medio ambiente e historia. Comarca de Tiermes-Caracena. Proyecto Life Tiermes. Soria

Munilla, C. y Martínez, S. (2005c). Iniciación a la arqueología para alumnos de Bachillerato. Proyecto Life Tiermes. Soria. 
Munilla, C. y Martínez, S. (2006). Yacimiento de Tiermes y su entorno. Cuaderno de campo. Proyecto Life Tiermes. Soria.

Navarro, J. (2008). Mejora de la creatividad en el aula de primaria. [Tesis doctoral, Universidad de Murcia]. https://digitum.um.es/digitum/handle/10201/3049.

Ndlovu, J. (2016). 4. Narrative and Emotions: Interpreting Tourists' Experiences of Cultural Heritage Sites in KwaZulu-Natal. In H. Manwa, N. Moswete \& J. Saarinen (Ed.), Cultural Tourism in Southern Africa, (pp. 47-57). Bristol, Blue Ridge Summit: Channel View Publications. https://doi.org/10.21832/9781845415532-009.

Oliver, M.C. (2010). El patrimonio intelectual y creativo. Revista General de Derecho Romano, 15.

Oren, G., Shani, A. y Poria, Y. (2021). Dialectical emotions in a dark heritage site: A study at the Auschwitz Death Camp. Tourism Management, Volume 82. https://doi.org/10.1016/j.tourman.2020.104194.

Ozáez, M. T. (2018). Inteligencia emocional en Educación Primaria. Revista Internacional De Apoyo a La inclusión, Logopedia, Sociedad Y Multiculturalidad, $\quad 1(3), \quad 51-60 \quad$ Recuperado de https://revistaselectronicas.ujaen.es/index.php/riai/article/view/4165.

Pablos, L. (2018). Evaluación de programas de educación patrimonial para personas con Trastorno del Espectro Autista (TEA) en museos. [Tesis doctoral, Universidad de Valladolid]. http://uvadoc.uva.es/handle/10324/35103.

Padró, J. (2003). Hacia una gestión creativa del patrimonio. PH: Boletín del Instituto Andaluz de Patrimonio Histórico, 42, 48-49.

Pérez, S. (2014). Educación Artística y Patrimonial para la percepción, comprensión y reflexión del colectivo sordo en el ámbito museal. Estudio de casos evaluativo. [Tesis doctoral, Universidad de Valladolid]. http://uvadoc.uva.es/handle/10324/6998.

Petrides, K.V. y Furnham, A. (2001). Trait emotional intelligence: Psycometric investigation with reference to established trait taxonomies. European Journal of Personality, 15(6), 425-448.

Prayag, G. y Del Chiappa, G. (2021). Nostalgic feelings: motivation, positive and negative emotions, and authenticity at heritage sites. Journal of Heritage Tourism. DOI: 10.1080/1743873X.2021.1874000.

Prlic, D. (2019). Vier Jahre Sharing a World of Inclusion, Creativity and Heritage (SWICH). Archiv Weltmuseum Wien, 68, 4-19. 
Rana, J., Willemsen, M., Dibbits, H.C. (2017). Moved by the tears of others: emotion networking in the heritage sphere. International Journal of Heritage Studies, 23 (10), 977-988. DOI: 10.1080/13527258.2017.1362581.

Real Decreto 126/2014, de 28 de febrero, por el que se establece el currículo básico de la Educación Primaria, Boletín Oficinal del Estado, núm. 52, del 1 de marzo de 2014.

Renom, A. (Coord.) (2003). Educación emocional. Programa para educación primaria (6-12 años). Barcelona: Wolters Kluwer.

Reyes J.L. y Méndez, R. (2016). La función educativa de las ciencias sociales en la LOMCE. El ejemplo de la educación patrimonial en la enseñanza primaria. Revista Educación, Política y Sociedad, 1(2), 125-144.

Riera, C. (2016). En defensa del patrimonio creativo. Revista de occidente, 241, 5-7.

Rivero, T. López, M. y López, R. (2015). La compresión del paisaje partiendo de las emociones. En R. Martínez, R. García-Morís y C.R. García. Investigación en didáctica de las Ciencias Sociales. Retos, preguntas y líneas de investigación, (pp. 751-761). Córdoba, España: Universidad de Córdoba.

Robinson, K. (2012). El elemento. Descubrir tu pasión lo cambia todo. Barcelona: Conecta.

Roma, M‥F, Rosati, F. L., Gutierrez, N.J \& Maragliano, Mª.G. (2015). Interpretación del patrimonio y creatividad. II Congreso Internacional de Investigación y Docencia de la Creatividad. Argentina. Recuperado de https://cetripunco.org/wp- content/uploads/2015/09/CREATIVIDAD-YTURISMO.pdf

Ruiz, J.A. y Corchuelo, C. (2015). Una aproximación a la educación emocional desde el marco legislativo. En J. Clare, I. Wilmer y A. Benavides (Coord.), Expresión y comunicación emocional: prevención de dificultades socioeducativas: actas del I Congreso Internacional de Expresión y Comunicación Emocional, (pp. 192-199). Sevilla: Universidad de Sevilla. Recuperado de http://congreso.us.es/ciece/Publicacion_CIECE_2015.pdf.

Rusillo, M. (2017). El patrimonio cultural despierta nuestras emociones: un proyecto educativo para la educación infantil. [Trabajo Fin de Grado]. Universidad de Granada.

Saidi, H. (2016). Créativité et médiation en tourisme et en patrimoine : modalités, acteurs et enjeux / Creativity and Mediation in Tourism and in Heritage: Approaches, Stakeholders and Issues. Ethnologies, 38(1-2), 3-29. https://doi.org/10.7202/1041584ar.

Salovey, P. y Mayer, J.D. (1990). Emotional Intelligence. Imagination, Cognition, and Personality, 9(3), 185-211. 
Sánchez, A. (2016). Memoria, identidad y comunidad: evaluación de programas de educación patrimonial en la Comunidad de Madrid. [Tesis doctoral, Universidad de Valladolid]. http://uvadoc.uva.es/handle/10324/16789.

Sánchez, I.C. (2019). La educación patrimonial en Castilla y León: evaluación de programas y evaluación de aprendizajes en Secundaria y Bachillerato. [Tesis doctoral, Universidad de Valladolid]. http://uvadoc.uva.es/handle/10324/40580.

Sanders, V.R., Friedlmeier, W., Sanchez Gonzalez, M.L. (2018). Emotion Norms in Media: Acculturation in Hispanic Children's Storybooks Compared to Heritage and Mainstream Cultures. SAGE Open, 8(3). DOI: 10.1177/2158244018788607.

Sanjo, L. (2004). Patrimonio, educación y ciudadanía creativa: el programa de Educación Patrimonial. En F. Morales. (Coord.) XVI Coloquio de Historia Canario-Americana, (pp. 293-310).

Santacana, J. (2012). Arqueología, museología y comunicación. En C. Ferrer García y J. Vives-Ferrándiz Sánchez (coords.), Construcciones y usos del pasado: patrimonio arqueológico, territorio y museo: Jornadas de debate del Museu de Prehistória de València, (pp. 137-151). Museu de Prehistória de València.

Santacana, J. (25 de noviembre, 2014). El patrimonio, la educación y el factor emocional. Didàctica del patrimoni cultural. Recuperado de https://didcticadelpatrimonicultural.blogspot.com/2014/11/el-patrimonio-laeducacion-y-el-factor.html

Santacana, J. (2017). Reflexión sobre el patrimonio cultural, la educación y las identidades, RUNAE, (1), 67-82. Recuperado de https://revistas.unae.edu.ec/index.php/runae/article/view/20

Santacana, J. Llonch, N. y Martínez, T. (2015). Las emociones y el patrimonio inmaterial. En J. Santacana, J. y N. Llonch. (eds.), El patrimonio cultural inmaterial y su didáctica, (pp. 104-108). Gijón, España: Trea.

Santacana, J. Martínez, T. y Asensio, M. (2016). Investigando en Educación Patrimonial: los museos y la inclusión cultural en la educación secundaria. HERMUS Heritage \& Museography, (17), 15-23. Recuperado de http://diposit.ub.edu/dspace/bitstream/2445/121413/1/672470.pdf.

Santacana, J. y Martínez, T. (2018). El patrimonio cultural y el sistema emocional: un estado de la cuestión desde la didáctica. Arbor, 194(788), a446. https://doi.org/10.3989/arbor.2018.788n2006.

Senft, N., Campos, B., Shiota, M. N. \& Chentsova-Dutton, Y. E. (2020). Who emphasizes positivity? An exploration of emotion values in people of Latino, Asian, and European heritage living in the United States. Emotion. Advance online publication. https://doi.org/10.1037/emo0000737. 
Serradela L.I.; Leo Neto N.A. (2016). Dinâmica das emoções através da educação patrimonial pautada na arteleducação. Recuperado de http://portal.iphan.gov.br/.

Sevdalis, N., Petrides, K. V., \& Harvey, N. (2007). Trait emotional intelligence and decision-related emotions. Personality and Individual Differences, 42(7), 13471358. https://doi.org/10.1016/j.paid.2006.10.012

Sieverts, T. (2017). The Principle of Heritage-Preservation and its Generalisation in the Anthropocene: Counteracting Acceleration and Abstraction, Fostering Emotion and Handling Uncertainties by Experiments. DISP, 53(1), 99-105. DOI: 10.1080/02513625.2017.1316576.

Smith, L. (2014). Visitor Emotion, Affect and Registers of Engagement at Museums and Heritage Sites. Conservation Science in Cultural Heritage, 14(2), 125131.

Soler, J.L., Aparicio, L., Díaz, O., Escolano, E. y Rodríguez. A. (Coords.). (2016). Inteligencia emocional y bienestar. Reflexiones, experiencias personales $e$ investigaciones. Zaragoza: Universidad de San Jorge.

Song, K.Y. (2016). Emotion culture as a resource of sensemaking: Transforming an arson case of a Korean national heritage to citizens' responsibility. Poetics, 55, 46-59. DOI: 10.1016/j.poetic.2015.12.001.

Stake, R. (2006). Evaluación comprensiva y evaluación basada en estándares. Barcelona: Graó.

Sternberg, R.J. (1997). Inteligencia exitosa. Barcelona: Paidós.

Sternberg, R.J. (2006). Creativity is an habit. Education Week, 25(24), 47-64.

Stenhouse, L. (2007). Investigación como base de la enseñanza. Madrid: Morata.

Shulman, L. (1987). Knowledge and teaching: Foundations of the New Reform. Harvard Educational Review, 57(1), 1-23. https://doi.org/10.17763/haer.57.1.j463w79r56455411.

Su, L.J. \& Hsu, M.K. (2013). Service Fairness, Consumption Emotions, Satisfaction, and Behavioral Intentions: The Experience of Chinese Heritage Tourists. Journal of Travel and Tourism Marketing, 30(8), 786-805. DOI: $10.1080 / 10548408.2013 .835228$.

Tan, S.-K., Lim, H.-H., Tan, S.-H. \& Kok, Y.-S. (2020). A Cultural Creativity Framework for the Sustainability of Intangible Cultural Heritage. Journal of Hospitality and Tourism Research, 44(3), 439-471. DOI: $10.1177 / 1096348019886929$.

Tolia-Kelly, D.P., Waterton, E. \& Watson, S. (Ed.). (2016). Heritage, affect and emotion: Politics, practices and infrastructures. London: Taylor and Francis. 
Touriñán, J.M. (1983). Análisis teórico del carácter formal, no formal e informal de la educación. Papers d'Educació, 1, 105-127.

Touriñán, J.M. (1996). Análisis conceptual de los procesos educativos formales, no formales e informales. Teoría de la Educación. Revista Interuniversitaria, 8, 5580. Recuperado de http://hdl.handle.net/10366/71784.

Trabajo, M. y Cuenca, J.Ma. (2017). La educación patrimonial para la adquisición de competencias emocionales y territoriales del alumnado de enseñanza secundaria. Pulso. Revista de Educación, 40, 159-174.

UNESCO. Recomendación que define los Principios Internacionales que deberían aplicarse a las Excavaciones Arqueológicas. Conferencia General de la Organización de las Naciones Unidas para la Educación, la Ciencia y la Cultura, Nueva Delhi (India) 5 de diciembre de 1956.

UNESCO. Recomendación sobre canje internacional de publicaciones. Conferencia General de la Organización de las Naciones Unidas para la Educación, la Ciencia y la Cultura, Paris (Francia) 3 de diciembre de 1958.

UNESCO. Recomendación sobre los medios más eficaces para hacer los museos accesibles a todos. Conferencia General de la Organización de las Naciones Unidas para la Educación, la Ciencia y la Cultura, Paris (Francia) 14 de diciembre de 1960.

UNESCO. Recomendación relativa a la protección de la Belleza y el Carácter de los Lugares y Paisajes. Conferencia General de la Organización de las Naciones Unidas para la Educación, la Ciencia y la Cultura, Paris (Francia) 9-12 de diciembre de 1962.

UNESCO. Recomendación sobre las Medidas Encaminadas a Prohibir e Impedir la Exportación, Importación y Transferencia de Propiedades Ilícitas de Bienes Culturales. Conferencia General de la Organización de las Naciones Unidas para la Educación, la Ciencia y la Cultura, Paris (Francia) 20 octubre al 20 noviembre de 1964.

UNESCO. Declaración de los principios de la cooperación cultural internacional. Conferencia General de la Organización de las Naciones Unidas para la Educación, la Ciencia y la Cultura, Paris (Francia) 4 noviembre de 1966.

UNESCO. Recomendación sobre la Conservación de los Bienes Culturales que la Ejecución de Obras Públicas o privadas pueda poner en peligro. Conferencia General de la Organización de las Naciones Unidas para la Educación, la Ciencia y la Cultura, Paris (Francia) 19 de noviembre de 1968. 
UNESCO. Convención sobre las Medidas que Deben Adoptarse para Prohibir e Impedir la Importación, la Exportación y la Transferencia de Propiedad Ilícitas de Bienes Culturales. Conferencia General de la Organización de las Naciones Unidas para la Educación, la Ciencia y la Cultura, Paris (Francia) 12-14 de noviembre de 1970.

UNESCO. Convención sobre la protección del patrimonio mundial, cultural y natural. Conferencia General de la Organización de las Naciones Unidas para la Educación, la Ciencia y la Cultura, Paris (Francia) 17 de octubre al 21 de noviembre de 1972.

UNESCO. Recomendación relativa a la Salvaguarda de los Conjuntos Históricos o Tradicionales y su Función en la vida Contemporánea. Conferencia General de la Organización de las Naciones Unidas para la Educación, la Ciencia y la Cultura, Nairobi (Kenia) 26 de octubre-30 de noviembre de 1976.

UNESCO. Declaración sobre los principios fundamentales relativos a la contribución de los medios de comunicación de masas al fortalecimiento de la paz y la comprensión internacional, a la promoción de los derecho humanos y la lucha contra el racismo, el apartheid y la incitación a la guerra. Conferencia General de la Organización de las Naciones Unidas para la Educación, la Ciencia y la Cultura, Paris (Francia) 24 octubre-28 de noviembre de 1978.

UNESCO. Recomendación sobre la Salvaguardia y la Conservación de las Imágenes en Movimiento. Conferencia General de la Organización de las Naciones Unidas para la Educación, la Ciencia y la Cultura, Belgrado (Serbia) 23 de septiembre 28 de octubre de 1980 .

UNESCO. Declaración de México sobre las políticas culturales. Conferencia mundial sobre las políticas culturales de la Organización de las Naciones Unidas para la Educación, la Ciencia y la Cultura, México D.F (México) 26 de julio - 6 de agosto de 1982.

UNESCO. Recomendación sobre la salvaguardia de la cultura tradicional y popular. Conferencia General de la Organización de las Naciones Unidas para la Educación, la Ciencia y la Cultura. París (Francia) 17 de octubre- 16 de noviembre de 1989.

UNESCO. Declaración universal sobre diversidad cultural. Conferencia General de la Organización de las Naciones Unidas para la Educación, la Ciencia y la Cultura. París (Francia) 15 de octubre- 3 de noviembre de 2001.

UNESCO. Convención para la salvaguarda del patrimonio cultural inmaterial. Conferencia General de la Organización de las Naciones Unidas para la Educación, la Ciencia y la Cultura. París (Francia) 29 de septiembre- 17 de octubre de 2003.

UNESCO. Convención sobre la protección y la promoción de la diversidad de las expresiones culturales. Textos fundamentales edición 2013. Paris (Francia) 20 de Octubre de 2005. 
UNESCO. Recomendación sobre el paisaje urbano histórico. Conferencia General de la Organización de las Naciones Unidas para la Educación, la Ciencia y la Cultura. París (Francia) 25 de octubre- 10 de noviembre de 2011.

UNESCO. Recomendación relativa a la protección y promoción de los museos y colecciones, su diversidad y su función en la sociedad Conferencia General de la Organización de las Naciones Unidas para la Educación, la Ciencia, y la Cultura. París (Francia) 17 de noviembre de 2015.

UNIÓN EUROPEA. Decisión n. ${ }^{\circ}$ 1622/2006/CE del Parlamento Europeo y del Consejo, de 24 de octubre de 2006, por la que se establece una acción comunitaria en favor de la manifestación «Capital Europea de la Cultural» para los años 2007 a 2019 (DO L 304 de 3.11.2006, pp. 1-6). Diario oficial de la Unión Europea.

UNIÓN EUROPEA. Recomendación 2006/962/CE del Parlamento Europeo y del Consejo, de 18 de diciembre de 2006, sobre las competencias clave para el aprendizaje permanente (DO L 394 de 30.12.2006, pp. 10-18). Diario oficial de la Unión Europea.

UNIÓN EUROPEA. Comunicación de la Comisión al Consejo y al Parlamento Europeo. Mejorar la calidad de la formación del profesorado [COM(2007) 392 final de 3.8.2007].

UNIÓN EUROPEA. Versión consolidada del Tratado de Funcionamiento de la Unión Europea. Diario oficial de la Unión Europea. Tratado de Lisboa 13 de diciembre de 2007. C 202 de 7.6.2016.

UNIÓN EUROPEA. Conclusiones del Consejo y de los Representantes de los Estados miembros, reunidos en el seno del Consejo, de 22 de mayo de 2008, sobre el fomento de la creatividad y la innovación en la educación y la formación. Diario oficial de la Unión Europea.

UNIÓN EUROPEA. Conclusiones del Consejo y de los representantes de los Gobiernos de los Estados miembros, sobre la promoción de la diversidad cultural y el diálogo intercultural en las relaciones exteriores de la Unión Europea y de sus Estados miembros. Diario oficial de la Unión Europea. DO C 320 de 16.12.2008, pp. 10-12.

UNIÓN EUROPEA. Reglamento (CE) no 116/2009 del Consejo, de 18 de diciembre de 2008, relativo a la exportación de bienes culturales. DO L 39 de 10.2.2009, pp. $1-7$.

UNIÓN EUROPEA. Decisión no 1194/2011/UE del Parlamento Europeo y del Consejo, de 16 de noviembre de 2011, por la que se establece una acción de la Unión Europea relativa al Sello de Patrimonio Europeo (DO L 303 de 22.11.2011, pp. 1-9). Diario oficial de la Unión Europea. 
UNIÓN EUROPEA. Reglamento (UE) no1295/2013 del Parlamento Europeo y del Consejo, de 11 de diciembre de 2012, por el que se establece el Programa Europa Creativa (2014 a 2020). Diario oficial de la Unión Europea.

UNIÓN EUROPEA. Decisión no 445/2014/UE del Parlamento Europeo y del Consejo, de 16 de abril de 2014, por la que se establece una acción de la Unión relativa a las Capitales Europeas de la Cultura para los años 2020-2033. Diario oficial de la Unión Europea.

UNIÓN EUROPEA. Conclusiones del Consejo sobre la gobernanza participativa del patrimonio cultural (DO C 463 de 23.12.2014, pp. 1-3). Diario oficial de la Unión Europea.

UNIÓN EUROPEA. Conclusiones del Consejo y de los Representantes de los Gobiernos de los Estados miembros, reunidos en el seno del Consejo, sobre el Plan de trabajo en materia de cultura (2015-2018) (DO C 463 de 23.12.2014, pp. 4-14). Diario oficial de la Unión Europea.

UNIÓN EUROPEA. Conclusiones del Consejo sobre pasarelas en el ámbito cultural y creativo para estimular la innovación, la sostenibilidad económica y la inclusión social (DO C 172 de 27.5.2015, pp. 13-16). Diario oficial de la Unión Europea.

UNIÓN EUROPEA. Conclusiones del Consejo sobre el papel de la educación infantil y primaria en el fomento de la creatividad, la innovación y la competencia digital (DO C 172 de 27.5.2015, pp. 17-21). Diario oficial de la Unión Europea.

UNIÓN EUROPEA. Conclusiones del Consejo sobre la cultura en las relaciones exteriores de la UE, con énfasis en la cultura en la cooperación para el desarrollo. Diario oficial de la unión europea. DO C 417 de 15.12.2015, pp. 4143.

UNIÓN EUROPEA. Comunicación conjunta al Parlamento europeo y al Consejo. Hacia una estrategia de la UE para las relaciones culturales internacionales. JOIN de 8.6.2016, 29 final.

UNIÓN EUROPEA. Conclusiones del Consejo sobre la función de Europeana en el acceso, la visibilidad y el uso digitales del patrimonio cultural europeo (DO C 212 de 14.6.2016, pp. 9-13). Diario oficial de la Unión Europea.

UNIÓN EUROPEA. Comunicación de la Comisión al Parlamento Europeo, al Consejo, al Comité Económico y Social Europeo y al Comité de las Regiones: desarrollo escolar y docencia excelente para un gran comienzo en la vida [COM(2017) 248 final, 30.5.2017].

UNIÓN EUROPEA. Comunicación de la Comisión al Parlamento Europeo, al Consejo, al Comité Económico y Social Europeo y al Comité de las Regiones: Reforzar la identidad europea mediante la Educación y la Cultura. La contribución de la Comisión Europea a la reunión de dirigentes en Gotemburgo, 17 de noviembre de 2017 [COM(2017) 673 final, 14.11.2017]. 
Vázquez-Bernal, B.; Perez, M.A. y Jiménez-Pérez, R. (2020). Heritage identity, emotions and teaching of EXperimental Sciences. Didáctica de las Ciencias Experimentales y Sociale, 38, 153-170. DOI: 10.7203/DCES.38.15688.

Vicent, N. (2013). Evaluación de un programa de educación patrimonial basado en tecnología móvil. [Tesis doctoral, Universidad Autónoma de Madrid]. https://repositorio.uam.es/handle/10486/14321.

Vietze, J., Juang, L., Schachner, M.K., Werneck, H. (2018). Feeling Half-Half? Exploring Relational Variation of Turkish-Heritage Young Adults' Cultural Identity Compatibility and Conflict in Austria. Identity, 18(1), 60-76. DOI: 10.1080/15283488.2017.1410159.

Waty, B. (2016). Émotions patrimoniales: Quand le patrimoine devient l'affaire detous. Bulletin des Biblioteques de France, (7), 9-22.

Werner, J. P. (2002). Territorio y gestión creativa del patrimonio cultural y natural. Ábaco: Revista de cultura y ciencias sociales, (34), 55-60.

Zeidner, M.; Matthews, G.; Roberts, R. Y MacCann, C. (2003). Development of Emotional Intelligence: Towards a Multi-Level Investment Model. Human Development, 46, 69-96. https://doi.org/10.1159/000068580.

Zhao, X., Wang, X., Ji, L. (2020). Evaluating the effect of anticipated emotion on forming environmentally responsible behavior in heritage tourism: developing an extended model of norm activation theory. Asia Pacific Journal of Tourism Research, 25(11), 1185-1198. DOI: 10.1080/10941665.2020.1837892.

Zheng, D., Liang, Z. \& Ritchie, B.W. (2020). Residents' social dilemma in sustainable heritage tourism: the role of social emotion, efficacy beliefs and temporal concerns. Journal of Sustainable Tourism, 28(11), 1782-1804. DOI: 10.1080/09669582.2020.1760288. 


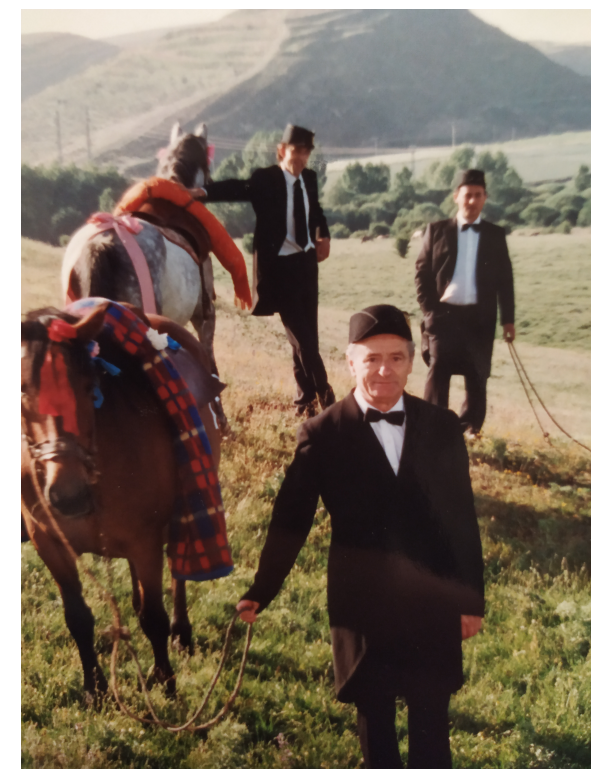

"Para crear debes ser consciente de las tradiciones, pero para mantener las tradiciones debes de crear algo nuevo".

Carlos Fuentes

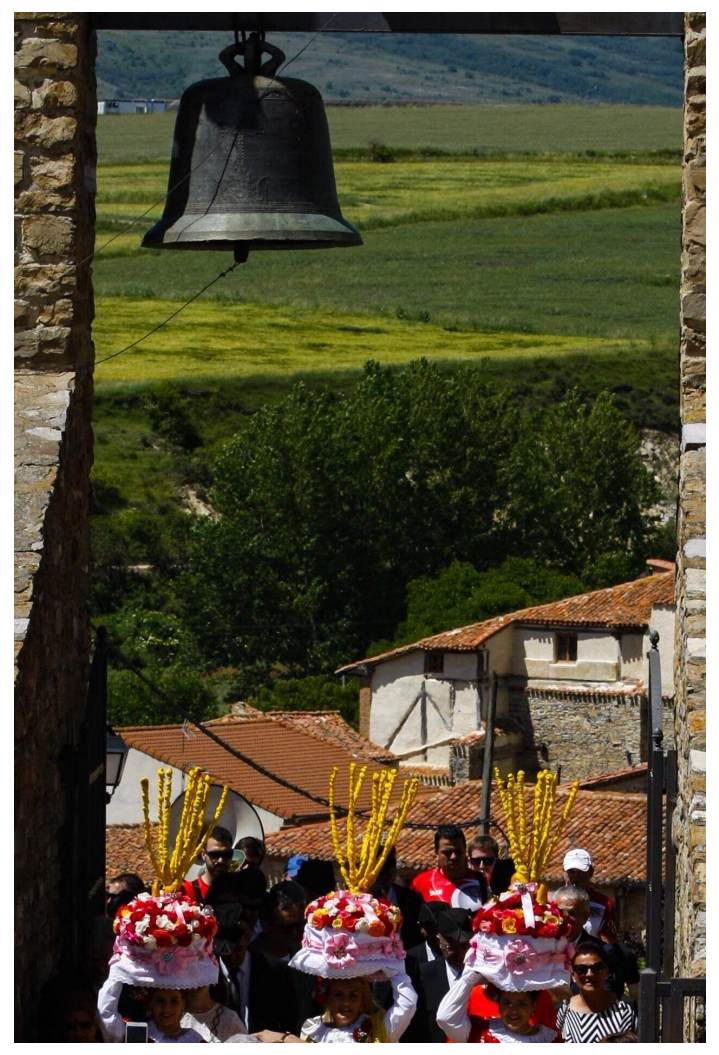


